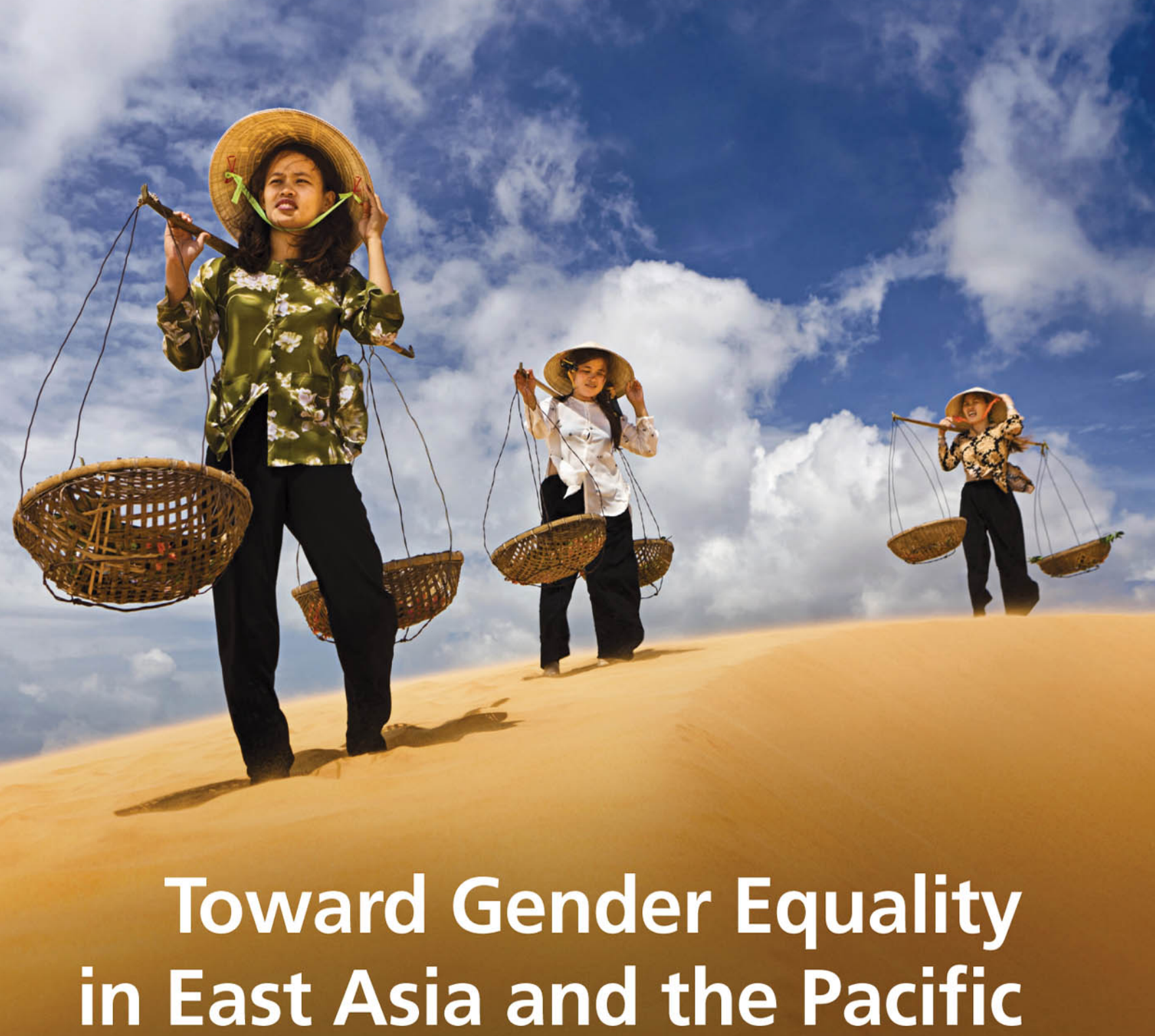

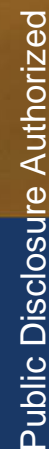

\author{
A Companion to the \\ World Development Report
}

WORLD BANK EAST ASIA AND PACIFIC REGIONAL REPORT 

Toward Gender Equality in East Asia and the Pacific

\section{A Companion to the World Development Report}




\section{WORLD BANK EAST ASIA AND PACIFIC REGIONAL REPORTS}

Well known for their economic success and dynamism, countries in the East Asia and Pacific region must tackle an increasingly complex set of challenges to continue on a path of sustainable development. Learning from others within the region and beyond can help identify what works, what doesn't, and why, in the search for practical solutions to these challenges. This regional report series presents analyses of issues relevant to the region, drawing on the global knowledge and experience of the World Bank and its partners. The series aims to inform public discussion, policy formulation, and development practitioners' actions to turn challenges into opportunities. 
World Bank East Asia and Pacific Regional Report

\title{
Toward Gender Equality in East Asia and the Pacific
}

\author{
A Companion to the \\ World Development Report
}


(C) 2012 International Bank for Reconstruction and Development / The World Bank

1818 H Street NW, Washington DC 20433

Telephone: 202-473-1000; Internet: www.worldbank.org

Some rights reserved

123415141312

This work is a product of the staff of The World Bank with external contributions. Note that The World Bank does not necessarily own each component of the content included in the work. The World Bank therefore does not warrant that the use of the content contained in the work will not infringe on the rights of third parties. The risk of claims resulting from such infringement rests solely with you.

The findings, interpretations, and conclusions expressed in this work do not necessarily reflect the views of The World Bank, its Board of Executive Directors, or the governments they represent. The World Bank does not guarantee the accuracy of the data included in this work. The boundaries, colors, denominations, and other information shown on any map in this work do not imply any judgment on the part of The World Bank concerning the legal status of any territory or the endorsement or acceptance of such boundaries.

Nothing herein shall constitute or be considered to be a limitation upon or waiver of the privileges and immunities of The World Bank, all of which are specifically reserved.

Rights and Permissions

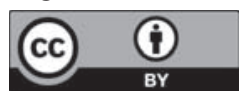

This work is available under the Creative Commons Attribution 3.0 Unported license (CC BY 3.0) http:// creativecommons.org/licenses/by/3.0. Under the Creative Commons Attribution license, you are free to copy, distribute, transmit, and adapt this work, including for commercial purposes, under the following conditions:

Attribution-Please cite the work as follows: World Bank. 2012. Toward Gender Equality in East Asia and the Pacific: A Companion to the World Development Report. Washington, DC: World Bank. doi: 10.1596/978-0-8213-9623-0 License: Creative Commons Attribution CC BY 3.0

Translations-If you create a translation of this work, please add the following disclaimer along with the attribution: This translation was not created by The World Bank and should not be considered an official World Bank translation. The World Bank shall not be liable for any content or error in this translation.

All queries on rights and licenses should be addressed to the Office of the Publisher, The World Bank, 1818 H Street NW, Washington, DC 20433, USA; fax: 202-522-2625; e-mail: pubrights@worldbank.org.

ISBN (paper): 978-0-8213-9623-0

ISBN (electronic): 978-0-8213-9626-1

DOI: $10.1596 / 978-0-8213-9623-0$

Cover photo: () www.istockphoto.com / Bartosz Hadyniak

\section{Library of Congress Cataloging-in-Publication Data}

Toward gender equality in East Asia and the Pacific.

p. cm. - (World Bank East Asia and Pacific regional report)

"A companion to the World development report."

Includes bibliographical references.

ISBN 978-0-8213-9623-0 - ISBN 978-0-8213-9626-1 (electronic)

1. Women's rights-Asia. 2. Women's rights-Pacific Area. 3. Women in development-Asia. 4. Women in development-Pacific Area. 5. Sex discrimination against women-Asia. 6. Sex discrimination against women-Pacific Area. I. World Bank. II. World development report. III. Series: World Bank East Asia and Pacific regional report.

HQ1236.5.A78T69 2012

323.3 ' $4095-\mathrm{dc} 23$ 


\section{Contents}

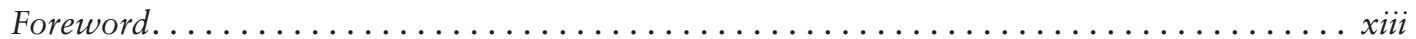

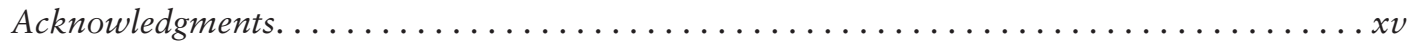

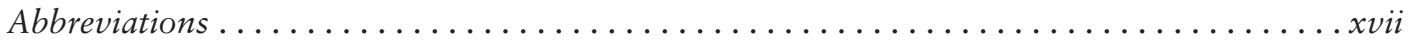

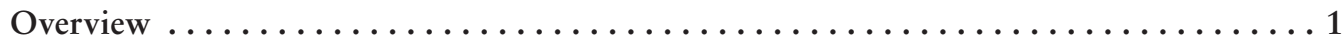

Why does gender equality matter for development? . $\ldots \ldots \ldots \ldots \ldots \ldots \ldots \ldots \ldots$

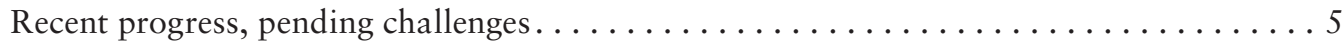

Why do many gender inequalities persist? . . . . . . . . . . . . . . . . 12

Emerging opportunities and risks in an increasingly integrated world $\ldots \ldots \ldots \ldots \ldots$

Toward gender equality in East Asia and the Pacific: Directions for policy . . . . . . 18

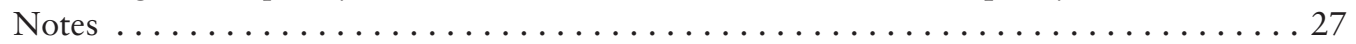

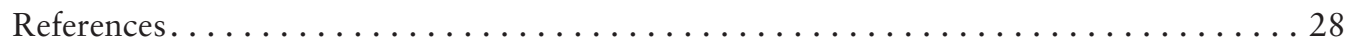

1. The State of Gender Equality in East Asia and the Pacific .............. 33

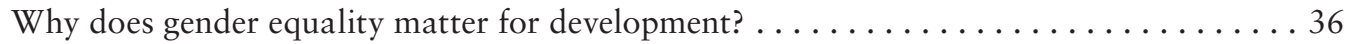

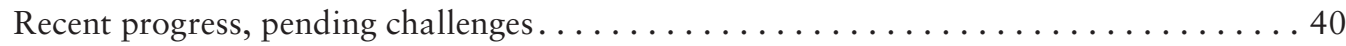

Fostering new opportunities, managing emerging risks $\ldots \ldots \ldots \ldots \ldots \ldots \ldots \ldots \ldots \ldots \ldots \ldots \ldots$

Gender equality in East Asia and the Pacific: A roadmap to the report . . . . . . . . 53

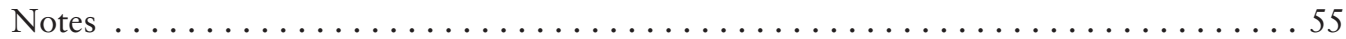

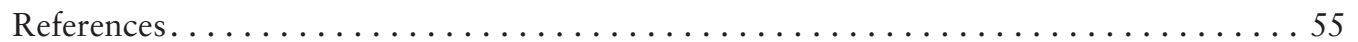

2. Gender and Endowments: Access to Human Capital and Productive Assets ........61

Substantial progress toward gender equality in education $\ldots \ldots \ldots \ldots \ldots \ldots \ldots \ldots \ldots \ldots \ldots$

Improvements and remaining gender issues in health $\ldots \ldots \ldots \ldots \ldots \ldots \ldots \ldots$

Gender equality in productive assets: An unfinished agenda $\ldots \ldots \ldots \ldots \ldots \ldots \ldots 5$

Policies to promote gender equality in endowments $\ldots \ldots \ldots \ldots \ldots \ldots \ldots \ldots \ldots \ldots \ldots \ldots$

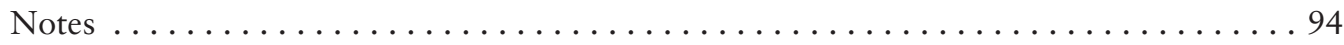

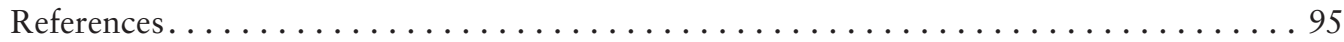




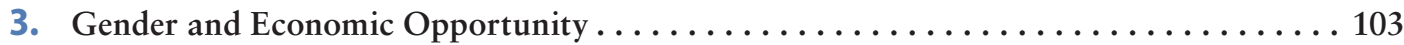

Limited effects of growth on gender gaps in economic opportunity . . . . . . . . . . 105

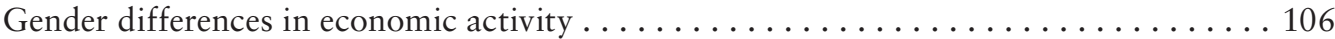

What determines gender inequality in economic opportunities? . . . . . . . . . . . . 114

Policies to promote gender equality in economic opportunity . . . . . . . . . . . . . 130

Notes ........................................... 133

References............................................ 135

4. Agency: Voice and Influence within the Home and in Society . . . . . . . . . . 145

Agency_important for gender equality and development . . . . . . . . . . . 145

The state of women's agency in East Asia and the Pacific . . . . . . . . . . . . . . . 147

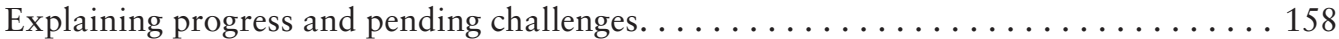

Policy approaches to promote gender equality in agency . . . . . . . . . . . . 169

Notes ............................................ 172

References ........................................ 173

5. Gender and the Region's Emerging Development Challenges. . . . . . . . . . . 179

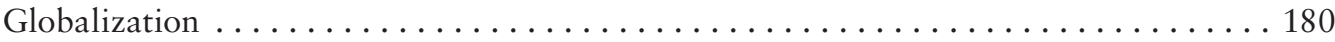

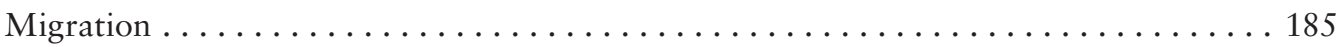

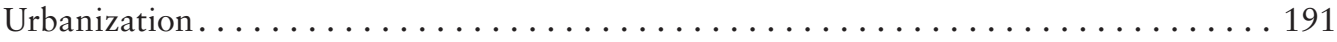

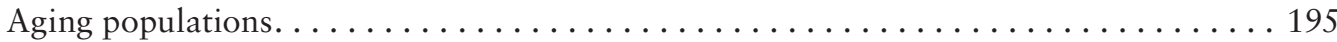

Information and communication technologies . . . . . . . . . . . . . . . . . . . . 199

Notes .............................................. 203

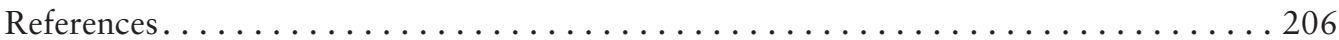

6. Promoting Gender Equality in East Asia and the Pacific: Directions for Policy . . . . . 213

Promoting gender equality in human development . . . . . . . . . . . . 215

Taking active measures to promote gender equality in economic opportunity . . . . . 221

Taking measures to strengthen women's voice and influence $\ldots \ldots \ldots \ldots \ldots \ldots \ldots 234$

Fostering new opportunities, managing emerging risks $\ldots \ldots \ldots \ldots \ldots \ldots \ldots \ldots \ldots$

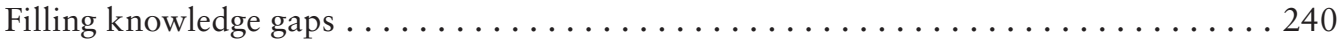

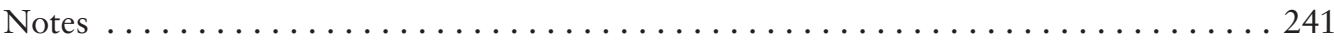

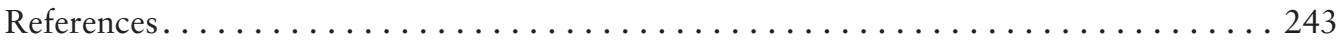

\section{Boxes}

$1.1 \quad$ Defining and measuring gender equality $\ldots \ldots \ldots \ldots \ldots \ldots \ldots \ldots \ldots \ldots \ldots \ldots \ldots$

1.2 Defining and measuring agency: Women's voice, influence, and participation. . . . . 48

$2.1 \quad$ Various parts of the world experience reverse gender gaps in education . . . . . . 64

2.2 Recent improvement in the sex ratio at birth in the Republic of Korea . . . . . . 8 82

3.1 Is higher female labor force participation always a good thing? . . . . . . . . 107

3.2 Gender-related beliefs on appropriate employment in Fiji, Papua

New Guinea, Indonesia, and Vietnam . . . . . . . . . . . . . . . . . 130

4.1 Gender and land tenure in a plural legal environment: The case of the Solomon

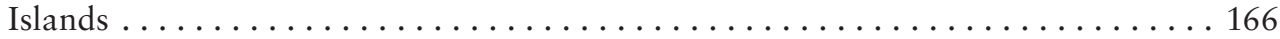

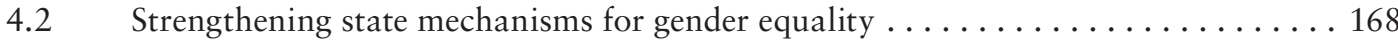

6.1 Reducing maternal mortality rates through improved staffing and quality of service delivery. . . . . . . . . . . . . . . . . . . . . . . . . . . . 217

6.2 The design of infrastructure projects has important gender dimensions . . . . . . 223

6.3 Leveling the playing field in access to resources: Lessons from Papua

New Guinea and Mongolia . . . . . . . . . . . . . . . . . . . . . . . . . 227 
6.4 The impact of active labor market policies on female employment: Evidence

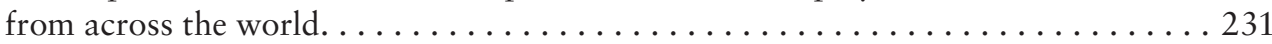

\section{Figures}

O.1 The East Asia and Pacific region has experienced rapid economic growth........2

O.2 Poverty reduction in the East Asia and Pacific region has been impressive. . . . . . . 2

O.3 Girls' secondary school enrollments have converged to those of boys . . . . . . . . 6

O.4 Maternal mortality rates have declined in most countries in the region. . . . . . . . 7

O.5 Female labor force participation is high by global standards but also varies

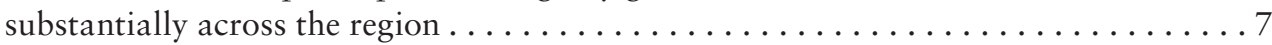

O.6 Across the region, female-headed households own less land than male-headed

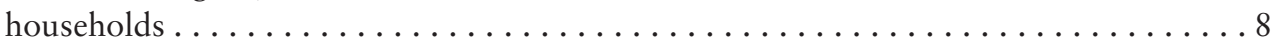

O.7 Women in East Asia and the Pacific still earn less than men $\ldots \ldots \ldots \ldots \ldots \ldots$

O.8 In urban China and Indonesia, gender wage gaps are largest among low

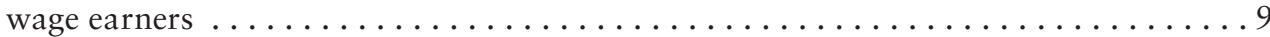

O.9 Enterprises with female managers tend to be smaller. . . . . . . . . . . . . 9

O.10 Who decides how wives' cash earnings are used varies widely across the region . . . . 10

O.11 Women's representation in parliament is low, especially in the Pacific. . . . . . . 11

O.12 Violence against women is high in the region $\ldots \ldots \ldots \ldots \ldots \ldots \ldots \ldots \ldots \ldots \ldots$

O.13 Women are concentrated in certain fields of study, such as education and medicine, but are underrepresented in law and engineering. . . . . . . . . . 12

O.14 In Lao PDR, women-particularly those with young children-must balance household and market work. ........................... 14

O.15 In Indonesia, female-led enterprises are clustered in lower-productivity and less capital-intensive industries. . . . . . . . . . . . . . . . . . 15

O.16 Male- and female-led firms report similar constraints in Indonesia . . . . . . . . . 15

O.17 Men and, in some cases, women believe that men make better political leaders

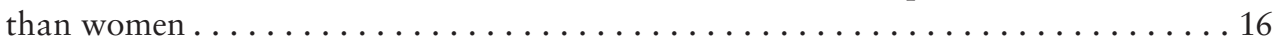

O.18 The share of female workers in export-oriented firms is relatively high . . . . . 17

O.19 China has seen remarkable growth in Internet use since 2000, but women's

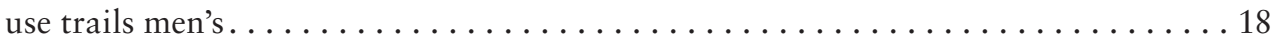

O.20 The old-age dependency ratio is increasing in most East Asian countries . . . . . . 19

1.1 The East Asia and Pacific region has experienced rapid economic growth. . . . . . . 34

1.2 Poverty reduction in the East Asia and Pacific region has been impressive. . . . . . . 34

1.3 Girls' secondary school enrollments have converged to those of boys . . . . . . . 38

1.4 Tertiary school enrollments of females have converged to those of males in East Asia and the Pacific . . . . . . . . . . . . . . . . . . 38

1.5 Gender gaps in secondary school enrollment vary substantially across countries . . . 39

1.6 Gender gaps in education have reversed in several countries, particularly at the tertiary level. .............................. 39

1.7 Minority populations in Vietnam often experience lower educational enrollments . . 40

1.8 In Indonesia, gender gaps in enrollment do not vary substantially

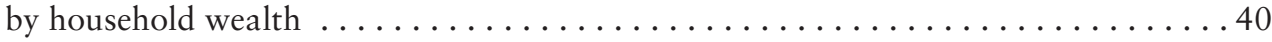

$1.9 \quad$ Fertility rates have declined across the world $\ldots \ldots \ldots \ldots \ldots \ldots \ldots \ldots \ldots \ldots$

1.10 Under-five mortality rates have declined sharply for both boys and girls. . . . . . .4 41

1.11 Maternal mortality rates have declined across the world . . . . . . . . . . 42

1.12 Maternal mortality rate has declined in most countries in the region . . . . . . . 42

1.13 East Asia has a highly skewed male-to-female ratio at birth . . . . . . . . . 44

1.14 The East Asia and Pacific region has high female labor force participation rates. . . . . 44 
1.15 Female labor force participation varies substantially across countries $\ldots \ldots \ldots 45$

1.16 The fraction of the workforce employed in agriculture has declined

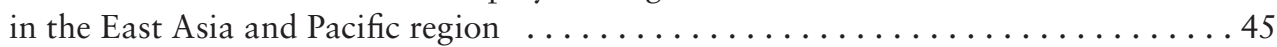

1.17 The evolution of sectoral composition by gender varies across countries . . . . . . 46

1.18 Women are more likely than men to be temporary workers. . . . . . . . . 46

1.19 Enterprises with female management tend to be smaller . . . . . . . . . 47

1.20 In Lao PDR, women—particularly those with young children—must balance household work commitments with market work . . . . . . . . . . . . . . 47

1.21 Women in East Asia still earn less than men . . . . . . . . . . . . . . . . . 48

1.22 Women in East Asia and the Pacific have more control over earnings and household decisions across all wealth quintiles than women from

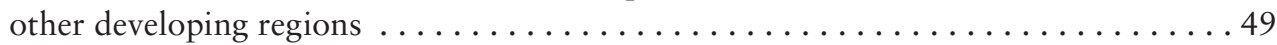

1.23 Female representation in parliament in East Asian and Pacific countries has hardly changed since the 1990 s . . . . . . . . . . . . . . . . . . . . . . . . . . 49

1.24 Women's representation in parliament is low, especially in the Pacific . . . . . . . 50

1.25 Men, and in some cases women, believe that men make better political

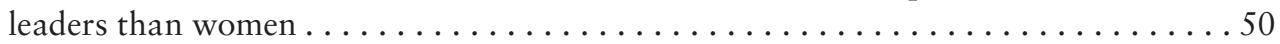

1.26 More women hold top management positions in East Asia and the Pacific

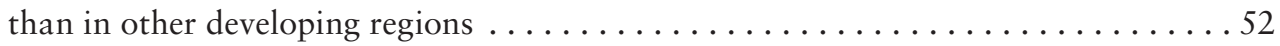

1.27 Violence against women is high in East Asia and the Pacific . . . . . . . . . 52

1.28 The dependency ratio is increasing in most East Asian countries . . . . . . . . 53

2.1 Enrollment for both genders has been converging even among the

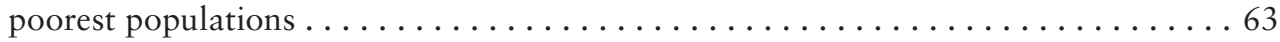

2.2 Gender gaps in youth literacy are smaller than gender gaps in adult literacy . . . . 63

B2.1.1 The biggest enrollment disadvantage for boys in the Phillippines

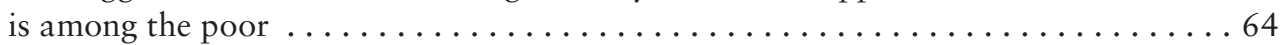

2.3 Girls in some ethnic minority groups in Lao PDR lag even further in enrollment . . 65

2.4 Girls in some ethnic minority groups in Vietnam lag even further in enrollment . . 665

2.5 Even girls in wealthier households in Cambodia and Lao PDR lag behind boys . . . . 67

2.6 Women are concentrated in certain fields of study, such as education and health, but are underrepresented in law and engineering. . . . . . . . . . . . . 69

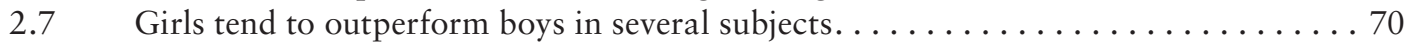

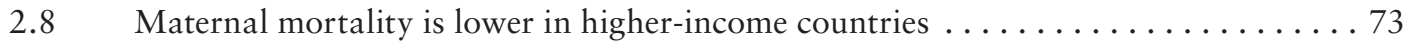

2.9 Female infant mortality is lower in higher-income countries . . . . . . . . . . 73

2.10 Most East Asia and Pacific region countries do not have female-skewed under-five mortality and infant mortality, except China . . . . . . . . 74

2.11 Women in wealthier households are more likely to have births assisted by trained medical staff . . . . . . . . . . . . . . . . . . 76

2.12 Contraceptive prevalence varies across East Asian and Pacific countries . . . . . . . 77

2.13 The percentage of births attended by skilled professionals varies across East Asian and Pacific countries . . . . . . . . . . . . . . . . . . . 77

2.14 Women in rural areas are less likely to have births assisted by trained medical staff. .............................. 78

2.15 Sex ratios at higher order births are still of concern, even though the overall sex ratio at birth has approached the normal range in the Republic of Korea . . . . . 79

2.16 Men are more likely to smoke than women $\ldots \ldots \ldots \ldots \ldots \ldots \ldots \ldots \ldots$

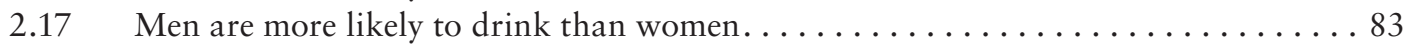

2.18 Tobacco use is positively correlated with mortality due to lung cancer . . . . . . 8 84

2.19 Alcohol consumption is positively correlated with mortality due to alcohol

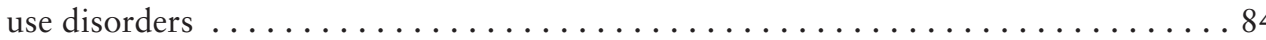


2.20 The poor are slightly more likely to engage in smoking $\ldots \ldots \ldots \ldots \ldots \ldots$

2.21 The probability of owning land is not substantially lower for female-headed households than for male-headed households . . . . . . . . . . . . 87

2.22 Female-headed households own less land in terms of land size $\ldots \ldots \ldots \ldots \ldots 87$

2.23 Vietnamese men owned more agricultural land plots than did women in 2008. . . .88

2.24 Female-headed households are less likely to own livestock $\ldots \ldots \ldots \ldots \ldots \ldots . \ldots 8$

2.25 Female-headed households are slightly less likely to borrow from a financial institution. . . . . . . . . . . . . . . . . . . . . . . . . . . 89

2.26 Women are slightly less likely than men to report having an account at a formal financial institution. . . . . . . . . . . . . . . . . . . . 89

3.1 Female labor force participation in the Republic of Korea rose for women of

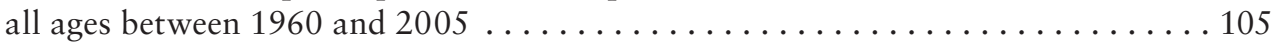

3.2 Labor force participation is greater in rural areas than in urban areas for both

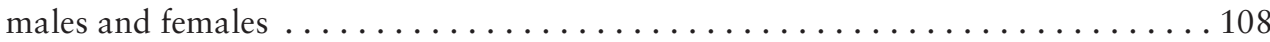

3.3 Female labor force participation rates in Malaysia have risen over time among 20- to 55-year-olds, but continue to decline during child-bearing years. . . . 109

3.4 Women in rural Vietnam with children under age 2 are substantially less likely to participate in the labor market than those without young children . . . . . 110

3.5 Women earn less than men in the majority of East Asian and Pacific countries

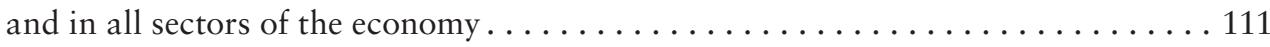

3.6 Male- and female-owned firms in the formal sector do not display substantial differences in productivity . . . . . . . . . . . . . . . . . 111

3.7 In the informal sector, gender-based differences in productivity are more pronounced than in the formal sector . . . . . . . . . . . . . . . . . 112

3.8 Women are more likely than men to work as unpaid family workers. . . . . . . . 112

3.9 Women are slightly more likely to be employed in the informal sector than men. Rural-urban differences in informality are greater than gender differences within rural or urban areas . . . . . . . . . . . . . . . . . . 113

3.10 Men and women work in different sectors throughout the East Asia and Pacific region . . . . . . . . . . . . . . . . . . . . . . 114

3.11 The pattern of female ownership by firm size varies across countries $\ldots \ldots \ldots 115$

3.12 In Indonesia, female-led enterprises are clustered in lower-productivity and

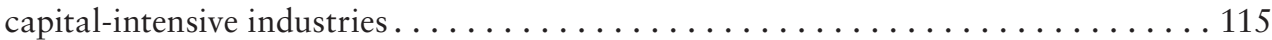

3.13 Female labor force participation is high by global standards but also varies

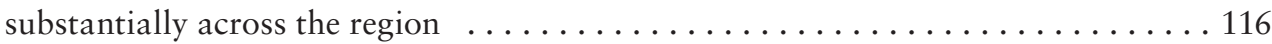

3.14 The fraction of the gender wage gap explained by differences in characteristics is smaller than the fraction of the wage gap attributable to differences in

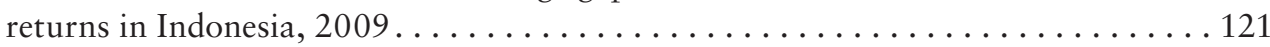

3.15 Differences in productivity across informal and formal firms in Vietnam are larger than differences across male- and female-led enterprises. . . . . . . . . 123

3.16 Self-reporting shows little difference in access to finance between male- and female-run firms, with the exception of Timor-Leste and Tonga . . . . . . . . . 123

3.17 Male- and female-led informal firms report similar constraints in Indonesia . . . . 124

3.18 In Cambodia, women-particularly those with young children-balance household work commitment with market work . . . . . . . . . . . . . 127

3.19 Women in Timor-Leste spend more time on domestic activities than men, and these differences are found among richer as well as poorer

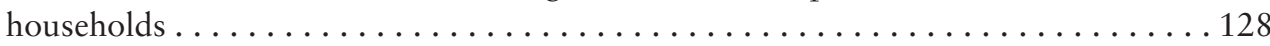

4.1 There is a positive relationship between economic development and

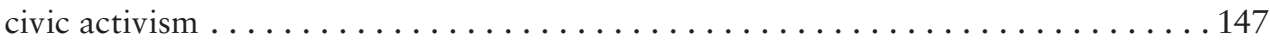


4.2 There is no clear relationship between economic development and women's representation in parliament ........................ 147

4.3 Who decides how wives' cash earnings are used varies across

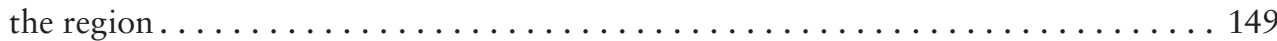

4.4 A majority of wives control decisions regarding their own health care and

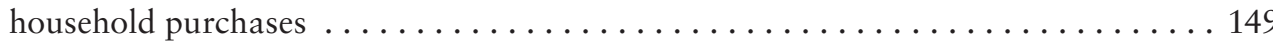

4.5 Women in East Asia have greater control over decisions than

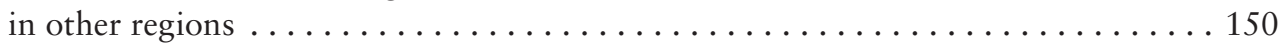

4.6 Fertility rates in the region have declined over the past three decades . . . . . . 151

4.7 Adolescent fertility is especially high in the Pacific . . . . . . . . . . . 151

4.8 The rate of unwanted and mistimed pregnancies is especially high in the Pacific . . 152

4.9 Many firms have female participation in ownership, but fewer have a female

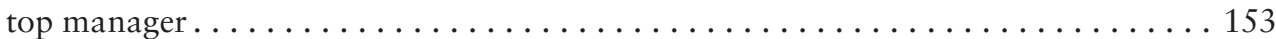

4.10 Civic activism has grown in the low- and middle-income countries in the region . . . 153

4.11 Women's representation in parliament has grown in much of East Asia but has experienced little change in the Pacific Islands . . . . . . . . . . . 155

4.12 Women's representation in parliament is low, especially in the Pacific . . . . . . 155

4.13 Violence against women is high in the region. . . . . . . . . . . . 156

4.14 The incidence of sexual intimate-partner violence is significantly higher in the Pacific . . . . . . . . . . . . . . . . . . . . . 157

4.15 Gender-based violence can have inter-generational consequences . . . . . . . . 157

4.16 Many men and women in the region believe that men make better

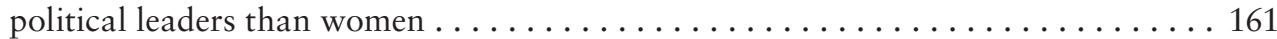

5.1 Women are more likely to work in export-oriented firms than in non-export-oriented firms . . . . . . . . . . . . . . . . . . . . . 181

5.2 Employment in textile and apparel in Vietnam grew substantially

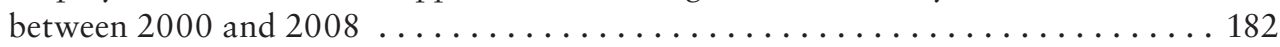

5.3 Women predominate in the garment sector in four East Asian countries. . . . . . 182

5.4 The share of international female migrants has increased over time in

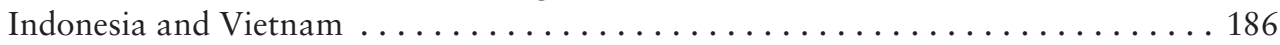

5.5 The urban population now accounts for more than 50 percent of the world's population . . . . . . . . . . . . . . . . . . . . . . . . . 191

5.6 Urbanization is expected to be rapid in East Asia . . . . . . . . . . . . . . . 192

5.7 The rates of urban growth are predicted to vary substantially across countries in the Pacific . . . . . . . . . . . . . . . . . . . . . . . . . . . . . . 192

5.8 In most East Asian and Pacific countries, urban areas have better access to improved sanitation . . . . . . . . . . . . . . . . . . . 193

5.9 Rural areas have lower access to improved water sources than urban areas in the majority of countries in the region . . . . . . . . . . . . . . . 193

5.10 The old age dependency ratio is expected to increase for both men and women in the next two decades; the female ratio will exceed the male ratio in the future. . . . . . . . . . . . . . . . . . . . . . . . . . . . 195

5.11 The gender gap in life expectancy at birth is lower in the East Asia and Pacific region than in many other regions . . . . . . . . . . . . . . 196

5.12 Life expectancy at birth in the region has improved for both men and women since 1990, although gender gaps have widened in some countries . . . . . . . . 196

5.13 Women ages 65 and above are far more likely to be widowed than men . . . . . 197

5.14 Women's time devoted to housework and caregiving activities is not significantly greater in households with elderly members. . . . . . . . . . . . . . . 199 
5.15 Internet use has increased substantially in the East Asia and Pacific region

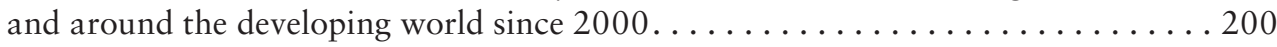

5.16 The number of cell phone subscribers per 100 people in the East Asia and Pacific region has grown substantially since $2000 \ldots \ldots \ldots \ldots \ldots \ldots \ldots \ldots . \ldots \ldots 20 \ldots$

5.17 Internet use has grown quickly in many countries in the region but has grown slowly in others. . . . . . . . . . . . . . . . . . . . . 201

5.18 The number of cell phone subscribers in the population has grown across most of East Asia but has remained limited in some Pacific countries . . . . . . . . . . 201

5.19 Women in the region are less likely to be mobile phone subscribers than men. . . . 202

5.20 Internet use has grown for both men and women in China, although a persistent gender gap in access remains . . . . . . . . . . . . . 202

\section{Tables}

2.1 Labor market returns to studying engineering are high relative to

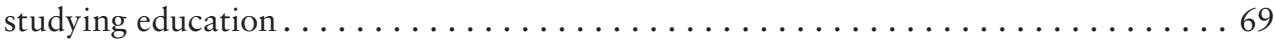

2.2 School curricula in a number of East Asian countries have gender stereotyping . . . . 71

2.3 The East Asia and Pacific region, mainly driven by China, is characterized by its

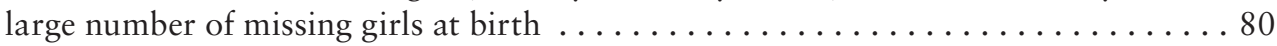

2.4 Most East Asian and Pacific countries do not differentiate by gender in inheritance and property laws . . . . . . . . . . . . . . . . 91

3.1 Legal retirement ages in the East Asia and Pacific region. . . . . . . . . . . . 119

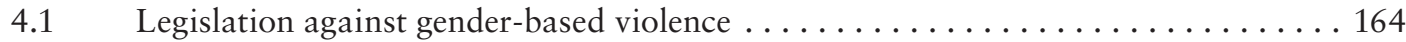

4.2 Political affirmative action in East Asia and the Pacific . . . . . . . . . . . 167

5.1 Evidence shows no systematic gender differences in consumption poverty among the elderly, regardless of family status . . . . . . . . . . . . . . . 197

6.1 Selected policy approaches to tackle excessive tobacco and alcohol use. . . . . . . 221 



\section{Foreword}

ver the past few decades, the East Asia and Pacific region has been the most economically dynamic region in the world. In most countries in the region, incomes have grown dramatically, and with that growth, absolute poverty has declined rapidly. Most of the region's economies have also shifted away from agriculture and toward manufacturing and services. Rapid growth, structural transformation, and poverty reduction have been accompanied by progress toward gender equality in several key areas. Economic development has led to the closing of gender gaps in school enrollments and a decline in maternal mortality rates: girls in the region as a whole now enroll in secondary schools at a higher rate than boys, and maternal mortality has fallen by half over the past 20 years. Access to economic opportunities has also increased, particularly among younger, better educated women. In many ways, women in East Asian and Pacific countries are better positioned than ever before to participate in, contribute to, and benefit from development.

Yet, the experience of the region illustrates also how growth and economic development are not enough to attain gender equality in all its dimensions. Women still have less access than men to a range of productive assets and services, including land, financial capital, agricultural extension services, and new information technologies. Substantial employment segregation by gender remains. Women are less likely than men to work in formal sector jobs and more likely to work in poorly remunerated occupations and enterprises. Despite the closing of education gaps, women still earn less than men for similar work all across the region. Women in East Asian and Pacific countries still have a weaker voice and less influence than men, whether within the household, in the private sector, in civil society, or in politics. And women across the region remain vulnerable to gender-based violence, often at the hand of an intimate partner.

The main message of this book, Toward Gender Equality in East Asia and the Pacific - a regional companion to the World Development Report 2012: Gender Equality and Development-is that policy makers in the region need to understand why progress in closing gender gaps has been mixed and to implement corrective policies where gaps remain persistent. The reason is that gender equality is both an important development objective in its own right as well as good development policy. A growing body of 
evidence shows that promoting gender equality in access to productive resources, economic opportunity, and voice can contribute to higher economic productivity, improve the economic prospects and wellbeing of the next generation, and lead to more effective development policy making. Yet, gender equality in many areas does not happen automatically. Thus, gender-aware public policy is required if countries are to achieve both gender equality and more rapid development.

As a regional report, Toward Gender Equality in East Asia and the Pacific focuses on issues that are particularly pertinent to the region. Among other things, the report examines the gender dimensions of several emerging trends in the region-increased global economic integration, the rising use of information and communication technologies, migration, urbanization, and rapid population aging-all of which are generating new opportunities, but also new risks, for promoting gender equality. The report also contributes to the development of new data and evidence on gender and development, significantly strengthening the ability of countries to formulate evidence-based policy in this area.

Drawing on this evidence base, the report identifies four priority areas for public action in the countries of East Asia and the Pacific. First, promoting gender equality in human development remains important where gender gaps in education and health outcomes remain large. Second, policies to close gender gaps in economic opportunity have a critical role. Such measures are often warranted on both equity and efficiency grounds. Third, initiatives to strengthen women's voice and influenceand to protect them from violence-are also called for across the region. Strengthening women's agency will enhance the quality of development decision making and, thus, development broadly. And, finally, public policy can foster the opportunities and manage the risks associated with emerging trends in the region; taking a gender-aware approach to policy making in this area will lead to better genderand development-outcomes.

This report shows that in East Asia and the Pacific, as in other parts of the world, gender equality is both the right development objective as well as good development policy.

Pamela Cox

Vice President

East Asia and Pacific Region The World Bank 


\section{Acknowledgments}

This study has been prepared by a multisectoral, multidisciplinary team led by Andrew Mason under the guidance of Bert Hofman and Sudhir Shetty. The report was written by a core team comprising Reena Badiani, Trang Van Nguyen, Katherine Patrick, Ximena Del Carpio, and Andrew Mason, with significant contributions from Jennifer Golan. Patricia Fernandes, Anne Kuriakose, Rea Chiongson, and Daniel Mont also provided substantive inputs. New data analysis for the report was carried out by Juan Feng, Reno Dewina, and Flora Nankhuni, using the East Asia and Pacific Region's Poverty Monitoring Database. Background papers for the report were written by Sarah Iqbal, Nayda Almodovar Reteguis, Yasmin Klaudia bin Humam, Josefina Posadas, Reena Badiani, John Rang, Benedikte Bjerge, Chris Sakellariou, and Dongxiao Liu. Qualitative studies on women's economic decision making in Fiji, Indonesia, Papua New Guinea, and Vietnam were coordinated by Carolyn Turk and Patti L. Petesch as part of a 22-country research effort carried out under the auspices of the World Development Report 2012 on gender equality and development. Production support was provided by Lynn Yeargin, Cathryn Summers, and Mildred Gonsalvez.
The team is grateful for the ongoing support and guidance provided by members of the East Asia and Pacific Region's management, including James Adams, Pamela Cox, Vikram Nehru, John Roome, Emmanuel Jimenez, Linda Van Gelder, Magda Lovei, Xiaoqing Yu, Annette Dixon, Victoria Kwakwa, and Coralie Gevers. The team also appreciates the support of the members of the Region's Gender Practice Group, past and present, including Nina Bhatt, Helene Carlsson Rex, Markus Kostner, Eduardo Velez, and Lester Dally. Furthermore, the team benefitted from the ongoing interaction, coordination, and support of the World Development Report 2012 team, namely Ana Revenga, Sudhir Shetty, Ana Maria Munoz, Carolina Sanchez-Paramo, Luis Benveniste, Markus Goldstein, Jishnu Das, and Aline Coudouel.

During the report's preparation, the team received helpful comments from four peer reviewers: Gillian Brown, Jeni Klugman, Pierella Paci, and Martin Rama. Several country teams, represented by their Country Gender Coordinators (including Laura Bailey, Edith Bowles, Yulia Immajati, Vanna Nil, Solvita Klapare, Erdene Ochir Badarch, and Pamornrat Tansanguanwong), also provided valuable feedback at various stages. 
In addition, the team received constructive comments and inputs from Keith Bell, Shubham Chaudhury, Qimiao Fan, Mary Hallward Dreimeier, Mathew Verghis, Robert Jauncey, Gladys Lopez-Acevedo, David Newhouse, Carmen Niethammer, Bob Rijkers, Sevi Simavi, Monica das Gupta, Isabella Micali Drossos, Thuy Thi Thu Nguyen, Tehmina Khan, and Carlos Sobrado. Mark Ingebretsen, Patricia Katayama, and Andrés Meneses, from the Office of the Publisher, provided excellent support in the design and publication of the report. Mohamad Al-Arief and Carl Hanlon provided invaluable guidance on a dissemination and communication strategy.

The team benefited from early consultations with policy makers, civil society representatives, academics, and development partners in Indonesia, Mongolia, Thailand, and Vietnam. It also gained from feedback on preliminary findings and messages from the participants of the International Association for Feminist Economics, held in June 2011 in Hangzhou, China; from country team colleagues in Cambodia, the Lao People's Democratic Republic, and Thailand who participated in a video seminar in September 2011; from participants in the Asia-Pacific Economic Cooperation (APEC) Women and the Economy Summit held in San Francisco in September 2011; and from colleagues, counterparts, and other stakeholders who participated in events in Australia and New Zealand in November 2011; Japan, Indonesia, and Vietnam in December 2011; and in Papua New Guinea, the Solomon Islands, and Fiji in March 2012.

Generous financial support for the preparation and dissemination of this report was provided by AusAID. 


\section{Abbreviations}

ADAPT

ADB

AED

AGI

ALMPs

ASEAN

AusAID

BFC

BMI

BPS

BREAD

CAPWIP

CAREM-Asia

CCT

CDD

CEDAW

CGA

CIDA

CWCC

CWDI

DFID

DHS

EAP

EC

ECA

ECPAT

EFA

EPZ

FAO

FCND
An Giang Dong Thap Alliance for the Prevention against Trafficking

Asian Development Bank

Academy for Education Development

Adolescent Girls Initiative

active labor market policies

Association of South East Asian Nationals

Australian Agency for International Development

Better Factories Cambodia

body mass index

Badan Pusat Statistik

Bureau for Research and Economic Analysis of Development

Center for Asia-Pacific Women in Politics

Coordination of Action Research on AIDS, Mobility-Asia

conditional cash transfers

community-driven development

Convention on the Elimination of All Forms of Discrimination against

Women

Country Gender Assessment

Canadian International Development Agency

Cambodian Women's Crisis Centre

Corporate Women Directors International

Department for International Development (United Kingdom)

Demographic and Health Surveys

East Asia and Pacific

European Commission

Europe and Central Asia

End Child Prostitution in Asian Tourism

education for all

Export Processing Zone

Food and Agriculture Organization of the United Nations

Food Consumption and Nutrition Division 


\begin{tabular}{|c|c|}
\hline FODE & Flexible Open and Distance Education \\
\hline GBV & gender-based violence \\
\hline GDC & Gender and Development for Cambodia \\
\hline GDP & gross domestic product \\
\hline GEM & gender equity model \\
\hline GNP & Grand National Party \\
\hline G-PSF & Government-Private Sector Forum \\
\hline GRID & Global Resource Information Data Base \\
\hline $\mathrm{HEF}$ & Health Equity Fund \\
\hline HNP & Health Nutrition and Population \\
\hline HSI & Hang Seng Index \\
\hline ICT & information and communication technology \\
\hline ICRW & International Center for Research on Women \\
\hline IDEA & International Development Evaluation Association \\
\hline IFC & International Finance Corporation \\
\hline ILO & International Labour Office \\
\hline INSTRAW & $\begin{array}{l}\text { United Nations International Research and Training Institute for the } \\
\text { Advancement of Women }\end{array}$ \\
\hline $\mathrm{IOM}$ & International Organization for Migration \\
\hline ISCO & International Standard Classification of Occupations \\
\hline ISD & Indices of Social Development \\
\hline KDP & Kecamantan Development Program \\
\hline KILM & Key Indicators of the Labour Market \\
\hline LAC & Latin America and the Caribbean \\
\hline Lao PDR & Lao People's Democratic Republic \\
\hline MDGs & Millennium Development Goals \\
\hline MENA & Middle East and North Africa \\
\hline $\mathrm{MIC}$ & middle income countries \\
\hline MMR & maternal mortality rate \\
\hline MPDF & Mekong Project Development Facility \\
\hline MSMEs & micro, small, and medium enterprises \\
\hline NCRFW & National Commission on the Role of Filipino Women \\
\hline NGOs & nongovernmental organizations \\
\hline NIPH & National Institute of Public Health \\
\hline NIS & National Institute of Statistics \\
\hline NSD & National Statistics Directorate \\
\hline NSO & National Statistics Office \\
\hline OECD & Organisation for Economic Co-operation and Development \\
\hline ORC & Opinion Research Corporation \\
\hline PEKKA & Indonesia Women Headed Household Program \\
\hline PISA & Programme for International Student Assessment \\
\hline PPP & purchasing power parity \\
\hline SAR & special administrative region \\
\hline SciCon & Science Connections \\
\hline SEZ & Special Economic Zone \\
\hline SHG & self-help group \\
\hline SIGI & Social Institutional and Gender Index \\
\hline SMEs & small and medium enterprises \\
\hline SPC & Secretariat of the Pacific Community \\
\hline SRB & sex ratios at birth \\
\hline STI & sexually-transmitted infections \\
\hline SUSI & Survey of Cottage and Small-Scale Firms (Survei Usaha Terintegrasi) \\
\hline
\end{tabular}


ThaiHealth

TIMSS

UN

UNDP

UNESCO

UNFPA

UNICEF

UNIFEM

VCCI

WBL

WDR

WHO
Thai Health Promotion Foundation

Trends in International Mathematics and Science Study

United Nations

United Nation Development Programme

United Nations Educational, Scientific and Cultural Organization

United Nations Fund for Population Activities

United Nations Children's Fund

United Nations Development Fund for Women

Vietnam Chamber of Commerce and Industry

Women, Business, and the Law

World Development Report

World Health Organization

ISO 3166 country name abbreviations

$\begin{array}{ll}\text { AUS } & \text { Australia } \\ \text { CHN } & \text { China } \\ \text { FJI } & \text { Fiji } \\ \text { FSM } & \text { Federated States of Micronesia } \\ \text { HKG } & \text { Hong Kong SAR, China } \\ \text { IDN } & \text { Indonesia } \\ \text { JPN } & \text { Japan } \\ \text { KHM } & \text { Cambodia } \\ \text { KIR } & \text { Kiribati } \\ \text { KOR } & \text { Republic of Korea } \\ \text { LAO } & \text { Lao People's Democratic Republic } \\ \text { MHL } & \text { Marshall Islands } \\ \text { MMR } & \text { Myanmar } \\ \text { MNG } & \text { Mongolia } \\ \text { MYS } & \text { Malaysia } \\ \text { NZL } & \text { New Zealand } \\ \text { PHL } & \text { Philippines } \\ \text { PLW } & \text { Palau } \\ \text { PNG } & \text { Papua New Guinea } \\ \text { PRK } & \text { Democratic Republic of Korea } \\ \text { PYF } & \text { French Polynesia } \\ \text { SGP } & \text { Singapore } \\ \text { SLB } & \text { Solomon Islands } \\ \text { THA } & \text { Thailand } \\ \text { TMP } & \text { Timor-Leste } \\ \text { TON } & \text { Tonga } \\ \text { TUV } & \text { Tuvalu } \\ \text { TWN } & \text { Taiwan, China } \\ \text { VNM } & \text { Vietnam } \\ \text { VUT } & \text { Vanuatu } \\ \text { WSM } & \text { Samoa } \\ \end{array}$





\section{Overview}

I

$n$ recent decades, women across the globe have made positive strides toward gender equality. Literacy rates for young women and girls are higher than ever before, while gender gaps in primary education have closed in almost all countries. In the last three decades, over half a billion women have joined the world's labor force (World Bank 2011c). Progress toward gender equality in East Asia and the Pacific has been similarly noteworthy. Most countries in the region have either reached or surpassed gender parity in education enrollments. Health outcomes for both women and men have improved significantly. Female labor force participation rates in the region are relatively high. Yet, despite considerable progress in this economically dynamic region, gender disparities persist in a number of important areas-particularly in access to economic opportunity and in voice and influence in society. For policy makers in East Asian and Pacific countries, closing these gender gaps represents an important challenge to achieving more inclusive and effective development.

The East Asia and Pacific Region's significant economic growth, structural transformation, and poverty reduction in the last few decades have been associated with reduced gender inequalities in several dimensions. The region grew at 7 percent on average between 2000 and 2008 (figure O.1), the structure of the region's economies has shifted away from agriculture toward manufacturing and services, and extreme poverty has fallen dramatically. Indeed, the share of the region's population living on less than US\$1.25 a day has declined by more than 50 percent since 1990-from among the highest rates of poverty in the world to among the lowest (figure O.2). Growth, structural transformation, and poverty reduction have been accompanied by considerable progress toward gender equality in several key areas, particularly education and health. Many countries in the region have experienced closing gender gaps in school enrollments and declining maternal and child mortality rates.

But growth and development have not been enough to attain gender equality in all its dimensions. Women still have less access than men to a range of productive assets and services, including land, financial capital, agricultural extension services, and new information technologies. Substantial employment segregation by gender remains. Women are less likely than men to work in 


\section{FIGURE 0.1 The East Asia and Pacific region has experienced rapid economic growth}

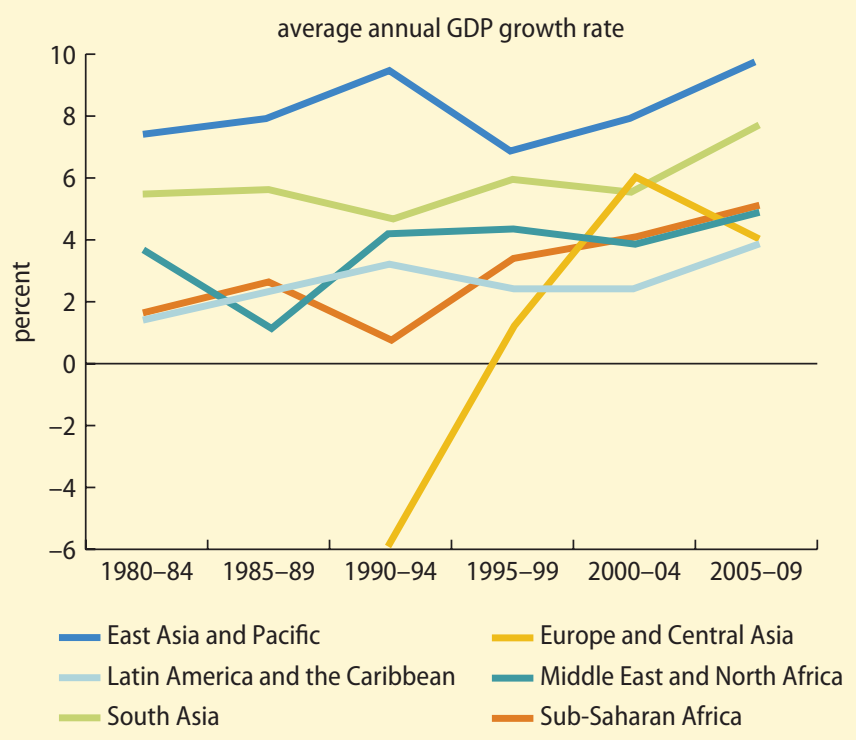

Source: World Development Indicators (WDI) database

\section{FIGURE 0.2 Poverty reduction in the East Asia and Pacific region has been impressive}

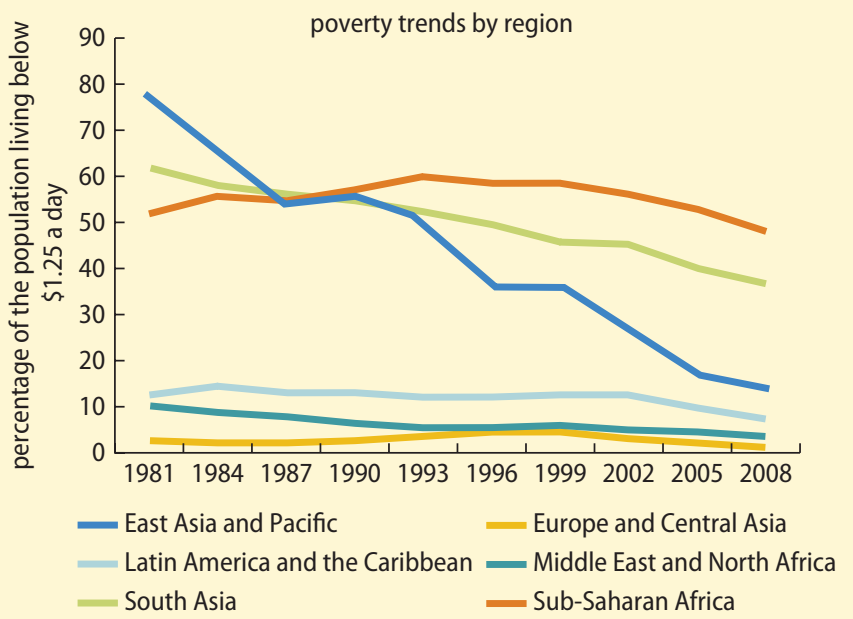

Source: PovcalNet.

formal sector jobs and more likely to work in poorly remunerated occupations and enterprises. And despite closing of education gaps, women continue to be paid less than men for similar work. Women in East Asian and
Pacific countries still have a weaker voice and less influence than men, whether in household decision making, in the private sector, in civil society, or in politics. Moreover, women across the region remain vulnerable to gender-based violence, often at the hand of an intimate partner.

This report clarifies empirically the relationship between gender and development and outlines an agenda for public action to promote gender equality in East Asian and Pacific countries. The report was written as a companion to the World Development Report 2012: Gender Equality and Development (World Bank 2011c) and is intended as a tool to help policy makers in the region promote both gender equality and more effective development. Following the World Development Report 2012, this report focuses on gender outcomes in three domains: (a) endowments-human and productive capital; (b) economic opportunity-participation and returns in the economy; and (c) agency-women's voice and influence in all facets of society.

The report makes several distinct contributions to policy makers' understanding of gender, development, and public policy in East Asian and Pacific countries.

- First, the analysis focuses on issues that are particularly relevant to the region. Compared with other developing regions, for example, female access to basic education is no longer a first-order concern in most East Asian and Pacific countries. Gender stereotyping and gender "streaming" in education still represent critical challenges, however, and thus receive particular emphasis in the report.

- Second, the report examines the gender dimensions of several emerging trends that are important to the region's development: increased global economic integration, rising use of information and communication technologies (ICTs), migration, urbanization, and rapid population aging. These trends have gender dimensions that 
are not commonly accounted for by policy makers but that will generate a distinct set of challenges for promoting gender equality going forward.

- Third, the East Asia and Pacific region is vast and diverse, with important differences in economic and social characteristics that affect progress toward gender equality. The report accounts for intraregional diversity in a way that is not possible in a global report. Particular emphasis is placed, where possible, on the challenges faced by countries in the Pacific as distinct from those in East Asia.

- Finally, the report has undertaken extensive empirical analysis of gender equality using a newly created database of household surveys for the region. In doing so, the report has contributed significantly to the development of indicators and evidence on gender, development, and public policy that were not available previously.

\section{Why does gender equality matter for development?}

Gender equality matters intrinsically. Nobel prize-winning economist Amartya Sen transformed the discourse on development when he argued that development not only is about raising people's incomes or reducing poverty but rather involves a process of expanding freedoms equally for all people (Sen 1999). ${ }^{1}$ Viewed from this perspective, gender equality is intrinsically valued. The near-universal ratification and adoption of the Convention on the Elimination of All Forms of Discrimination against Women (CEDAW) ${ }^{2}$ - and the subsequent commitment of the international community to Millennium Development Goals 3 and 5-underscores a near-global consensus that gender equality and women's empowerment are development objectives in their own right.

Gender equality also matters for development. A growing body of empirical literature from around the world demonstrates that promoting gender equality is also good development policy, or as stated in the World
Development Report 2012 (World Bank 2011c, 3), "Gender equality is smart economics." Indeed, the literature shows that greater gender equality in endowments, access to economic opportunities, and agency can (a) contribute to higher productivity, income growth, and poverty reduction; (b) improve the opportunities and outcomes of the next generation; and (c) enhance development decision making. This section explores the evidence on these three pathways, in turn.

\section{Gender equality can contribute to higher productivity and income growth}

For households and economies to function at their full potential, resources, skills, and talent should be put to their most productive use. If societies allocate resources on the basis of one's gender, as opposed to one's skills and abilities, this allocation comes at a cost. Indeed, the economic costs of gender inequalities-whether caused by the persistence of traditional norms or by overt discrimination-can be considerable. A recent study commissioned for the World Development Report 2012 found that in the East Asia and Pacific region, output per worker could be 7 to 18 percent higher across a range of countries if female entrepreneurs and workers were to work in the same sectors, types of jobs, and activities as men and to have the same access to productive resources (Cuberes and TeignierBaqué 2011).

Evidence suggests that misallocation of female skills and talent commonly begins before women enter the labor force, when families and societies underinvest in girls' schooling. A number of cross-country studies have found a robust inverse relationship between the size of the gender gap in education and gross domestic product (GDP) growth, controlling for average education levels and other factors associated with economic growth (see, for example, Klasen 2002; Knowles, Lorgelly, and Owen 2002). ${ }^{3}$ Moreover, to the extent that young women (or men) choose fields of study on the basis of their gender rather than their abilities, 
this too will exact costs not only on individuals' employment and earnings, but also on a country's economic productivity more broadly.

Gender inequalities in access to productive assets also have costs in terms of productivity and income. Microeconomic studies from a number of countries across developing regions show that female farmers and entrepreneurs are inherently no less productive than male farmers and entrepreneurs; rather, they tend to have less access to productive inputs. ${ }^{4}$ A recent study by the Food and Agriculture Organization of the United Nations estimates that equalizing access to productive resources between female and male farmers could increase agricultural output in developing countries by 2.5 to 4.0 percent (FAO/Sida Partnership Cooperation 2010).

A number of studies show that genderbased violence also imposes significant costs on the economies of developing countries through lower worker productivity and incomes, lower human capital investments, and weaker accumulation of social capital (Morrison, Ellsberg, and Bott 2007). In addition to indirect costs, gender-based violence has large direct economic costs on society. A study in the United States found that the direct health care costs of intimate partner violence against adult women were more than $\$ 4$ billion USD in 1995 (USCDC 2003). Reducing gender-based violence would thus have significant positive effects on the region's economies by reducing health care costs and increasing investments in women's human capital, female worker productivity, and women's accumulation of social capital.

As the global economy becomes more integrated, the productivity effects associated with greater gender equality are likely to be increasingly important to East Asian and Pacific countries. Recent studies on the relationship between gender and trade suggest that gender inequalities have become financially detrimental for countries in a world of open trade (Do, Levchenko, and Raddatz 2011). To participate effectively in an increasingly competitive world, countries will need to harness their resources efficiently by improving opportunities for all and allocating labor on the basis of skill instead of gender. Gender inequality, whether in endowments, economic opportunities, or agency, reduces a country's ability to compete in this increasingly globalized economic environment (World Bank 2011c).

\section{Promoting gender equality is also an investment in the next generation}

A large body of cross-country and countryspecific literature shows that healthier, better educated mothers have healthier, better educated children, which can be expected to positively affect children's future productivity and economic prospects. The effects begin even before childbirth. In Timor-Leste, highly educated mothers and those in the wealthiest households are more likely to have their babies delivered by skilled attendants than less educated mothers and those from poorer households (NSD, Ministry of Finance, and ICF Macro 2010). Similarly, Demographic and Health Survey data show that Cambodian women with little education are relatively less likely to receive prenatal care and assistance from trained health personnel during birth deliveries than women with more education (Johnson, Sao, and Hor 2000). A mother's health and nutrition status is also found to strongly affect children's physical health as well as cognitive and noncognitive abilities, which can have long-lasting developmental and societal consequences (Naudeau et al. 2011).

Higher labor force participation as well as income earned and assets held by women have also been shown to have positive effects on the next generation. In Indonesia, for example, women with a higher share of household assets before marriage tend to use more prenatal care and are more likely to have their births attended by skilled health care providers (Beegle, Frankenberg, and Thomas 2001). Similarly, in China, 
increasing adult female income by 10 percent of the average household income raised the fraction of surviving girls by 1 percentage point and increased years of schooling for both boys and girls. In contrast, a similar increase in male income reduced survival rates and educational attainment for girls with no impact on boys (Qian 2008). Studies from across developing and developed regions (for example, from places as diverse as Brazil, Ghana, South Africa, and the United States) show that income in the hands of women positively affects their female children's health (Duflo 2003; Thomas 1995); commonly, the marginal effects of income and assets in the hands of mothers are larger than effects of similar income and assets in the hands of fathers.

Reductions in gender-based violence through greater female agency can also have important intergenerational benefits. Several studies show that experiencing domestic violence between parents as a child contributes to a higher risk of both women experiencing domestic violence as adults and of men perpetrating violence against their spouses (Fehringer and Hindin 2009). In Timor-Leste, 56.4 percent of women who were victims of spousal violence had a father who beat their mother (NSD, Ministry of Finance, and ICF Macro 2010). In Cambodia, women who reported that their mothers experienced domestic violence were more likely to experience physical and psychological domestic violence as well (NIPH, NIS, and ORC Macro 2006). Efforts that increase women's safety and security and that reduce domestic violence can thus lead to lower intergenerational transmission of violence within families.

\section{Strengthening women's voice can enhance the quality of development decision making}

Several studies show that women and men have different policy preferences (Edlund and Pande 2001; Lott and Kenny 1999). Despite perceptions in some East Asian and Pacific countries that women do not make as good leaders as men, studies suggest that capturing these gender-based differences in perspective can lead to not only more representative but also better decision making. Evidence from South Asia suggests that development policy making can benefit from greater gender equality in voice. As an example, a study of women elected to local government in India found that female leadership positively affected the provision of public goods at the local level in ways that better reflected both women's and men's preferences (Chattopadhyay and Duflo 2004). Similarly, studies from rural India and Nepal found that when women who were previously excluded from decisions about local natural resource management gained greater voice and influence, local conservation outcomes improved significantly (Agarwal 2010a, 2010b).

Women's collective agency can also be transformative, both for individuals and for society as a whole. For example, for a group of ethnic minority women in rural China, information sharing among them has helped empower them and raise their social standing in the Han-majority communities into which they married (Judd 2010). In a more formal setting, over the last 15 years, migrant domestic workers in Hong Kong SAR, China, have been engaged in civic action focused on local migrant workers' rights as well as international human rights (Constable 2009). These efforts have contributed to the enactment of laws that now provide migrant domestic workers in Hong Kong SAR, China, with some of the most comprehensive legal protections in the world.

\section{Recent progress, pending challenges}

Over the last few decades, most East Asian and Pacific countries made considerable progress toward gender equality in several dimensions. In other dimensions, gender disparities have been more persistent. This section reviews recent progress and pending challenges in the region, noting where economic growth and development have 
contributed to advances and where they have been insufficient.

\section{Growth and development have been accompanied by reduced gender inequalities in several dimensions}

Many gender gaps in education have closed. Over the last few decades, boys' and girls' schooling outcomes have converged at levels that are high by international standards. East Asia and the Pacific has performed better than other developing regions, in terms of both increasing female and male educational enrollments and raising the female-to-male enrollment ratio. In 2010, the region had the highest primary school ratio of female-to-male enrollments among all developing regions; at the secondary level, only Latin America and the Caribbean had a higher female-to-male enrollment ratio (figure O.3).

Key health outcomes have improved. During the past half century, the region has experienced significant advances in several health indicators. Fertility rates have

FIGURE 0.3 Girls' secondary school enrollments have converged to those of boys

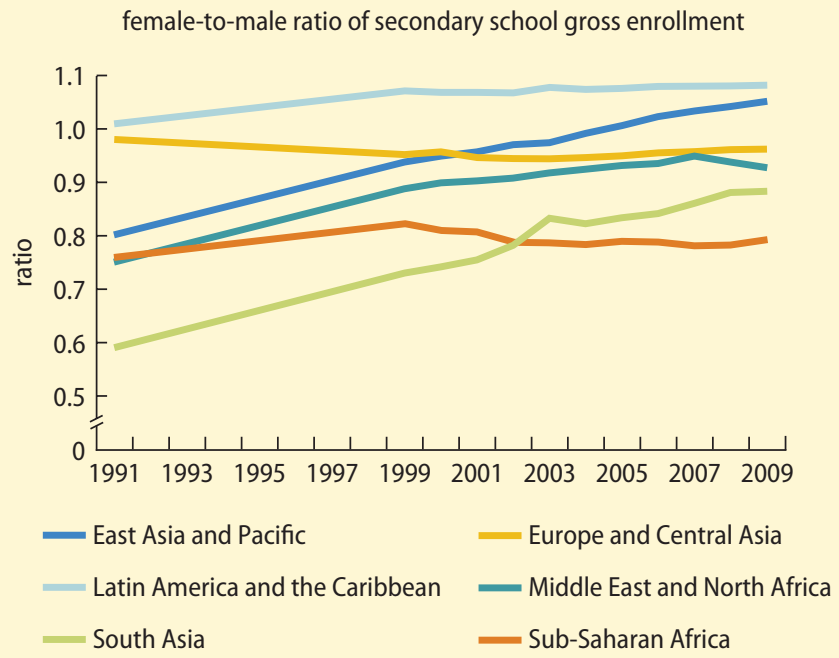

Source: WDI database, 2011 data. sharply declined, and under-five mortality rates have halved since 1990 for both boys and girls. Noteworthy gains have been made in birth attendance by health professionals. In addition, the East Asia and Pacific region has seen substantial declines in the maternal mortality rate, from approximately 200 deaths per 100,000 live births in 1990 to 100 in 2008 (figure O.4).

Gender gaps in labor force participation have narrowed. Female labor force participation in East Asian and Pacific countries is high by international standards (figure O.5), and among younger cohorts, female labor force participation has tended to rise over time. Moreover, as countries grow and develop, women are increasingly moving into jobs in the nonagricultural sector and are migrating to urban areas in search of better employment opportunities. Trends and patterns of labor force participation look similar to those observed in the United States and other countries of the Organisation for Economic Co-operation and Development (OECD) during their economic transformations.

In many ways, women in East Asia and the Pacific are better positioned today than ever before to participate in and contribute to their countries' development.

\section{Despite progress, important challenges to promoting gender equality remain}

Progress has been uneven across the region. Substantial variation remains across countries, both in overall enrollment rates and in female-to-male enrollment ratios. Countries such as Cambodia, the Lao People's Democratic Republic (Lao PDR), and Papua New Guinea still have relatively low enrollment levels and low female-tomale enrollment ratios, particularly at the secondary school level. Furthermore, although countries have experienced convergence in enrollment among the young, substantial gaps still remain in the educational endowments of adult populations. 
Maternal mortality remains high in lower-income countries and in several Pacific countries (figure O.4). In Lao PDR, for example, maternal mortality rates were still more than 500 deaths per 100,000 births in 2008, among the highest rates in the world. Indonesia's maternal mortality rate remains high compared to other countries in the region at similar levels of development.

Substantial differences in labor force participation occur across countries in the region, even among countries with similar income levels. Relative to their income levels, countries such as China and Vietnam have substantially higher rates of female labor force participation than the world average, whereas participation is near the world average in countries such as Indonesia and the Philippines, and below average in countries such as Fiji and Malaysia (figure O.5).

Within countries, interactions between gender and other socioeconomic characteristics can often exacerbate disparities. Economically disadvantaged and minority populations often experience lower educational enrollments, for example. In Vietnam, school participation among 15- to 17-year-olds is substantially higher among the Kinh and Hoa (Chinese) majorities than among many of the 52 ethnic minority populations. Among the more economically disadvantaged and less well integrated Hmong, Dao, and Khmer minorities, far fewer girls attend school than boys (Baulch et al. 2002). ${ }^{5}$ Geographic distance, or remoteness, can also serve to compound gender disadvantage. Women in remote rural areas commonly have limited access to health care, significantly raising the risks associated with pregnancy and childbirth. While Vietnam has experienced noteworthy declines in maternal mortality, on average, over the last decade, progress has been much slower in remote and ethnic minority regions (World Bank 2011b).

\section{Some gender disparities fail to close- or close very slowly-with development}

More than a million girls and women per year are "missing" in East Asia. Among
FIGURE 0.4 Maternal mortality rates have declined in most countries in the region

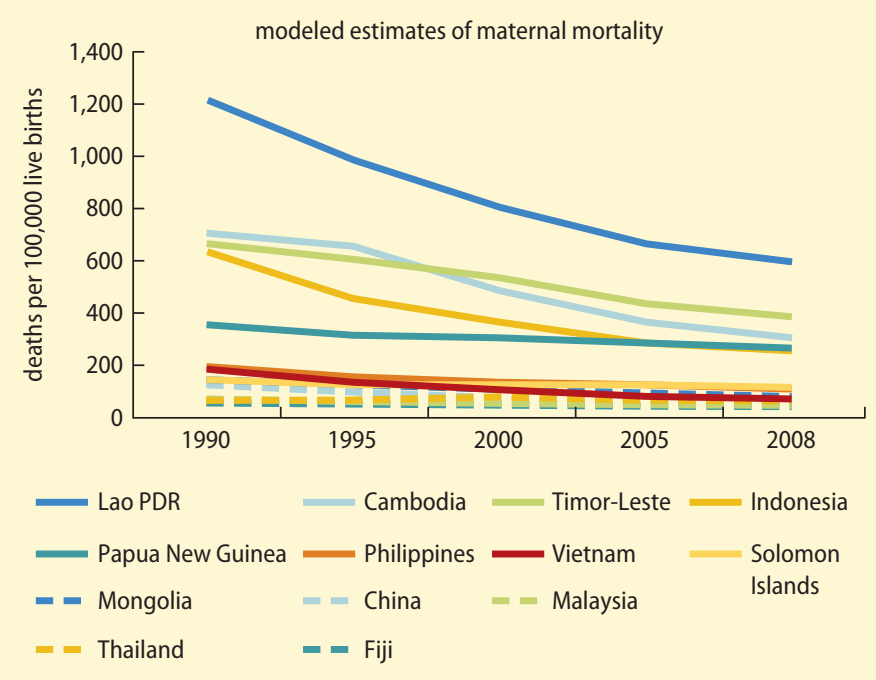

Source: WDI database, Gender Statistics, 2010 data.

\section{FIGURE 0.5 Female labor force participation is high by global} standards but also varies substantially across the region

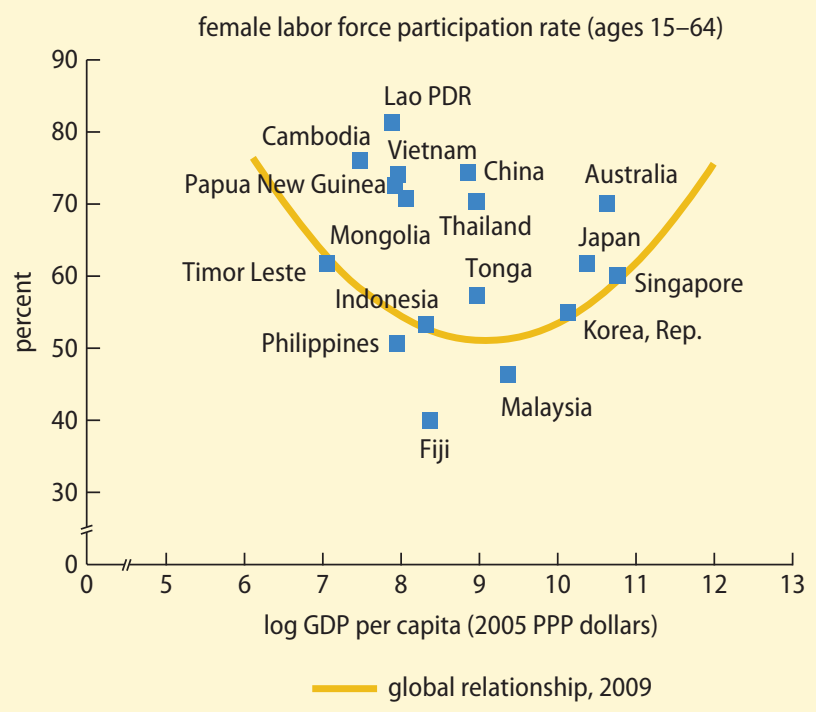

Sources: World Bank staff estimates using Key Indicators of Labour Market (KILM) labor force data (International Labour Organization) and purchasing power parity adjusted GDP per capita (in logs and at 2005 prices) from the Penn World Tables.

Note: GDP = gross domestic product, PPP = purchasing power parity. The data shown for each country are from 2009 and the estimated U-shaped relationship uses data from across the world.

the most concerning issues is that despite growth and development, the problem of missing girls remains significant. The term "missing women" was first coined 


\section{FIGURE 0.6 Across the region, female-headed households own less land than male-headed households}

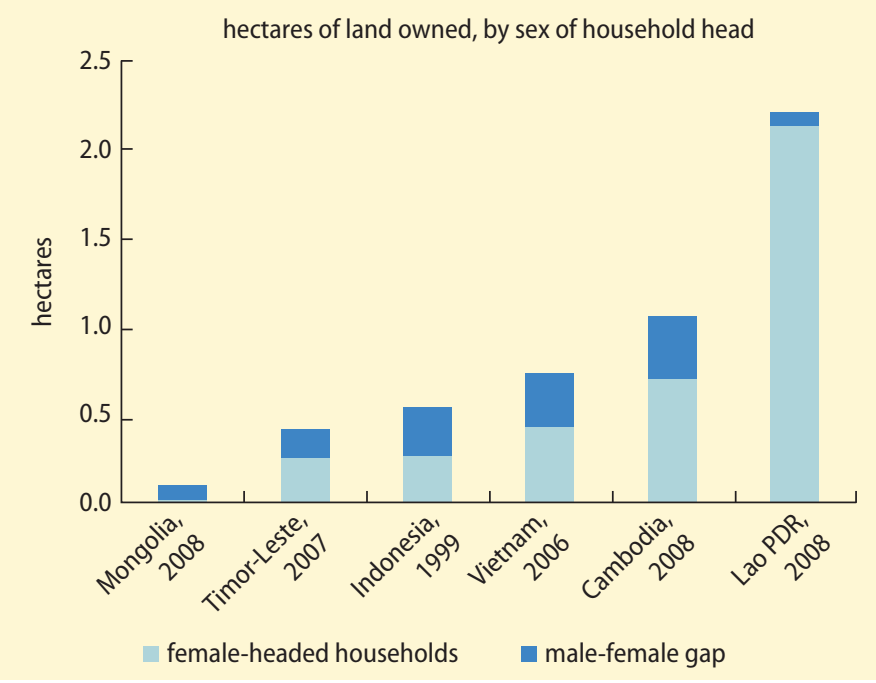

Source: World Bank staff estimates using household income and expenditure surveys.

\section{FIGURE 0.7 Women in East Asia and the Pacific still earn less}

\section{than men}

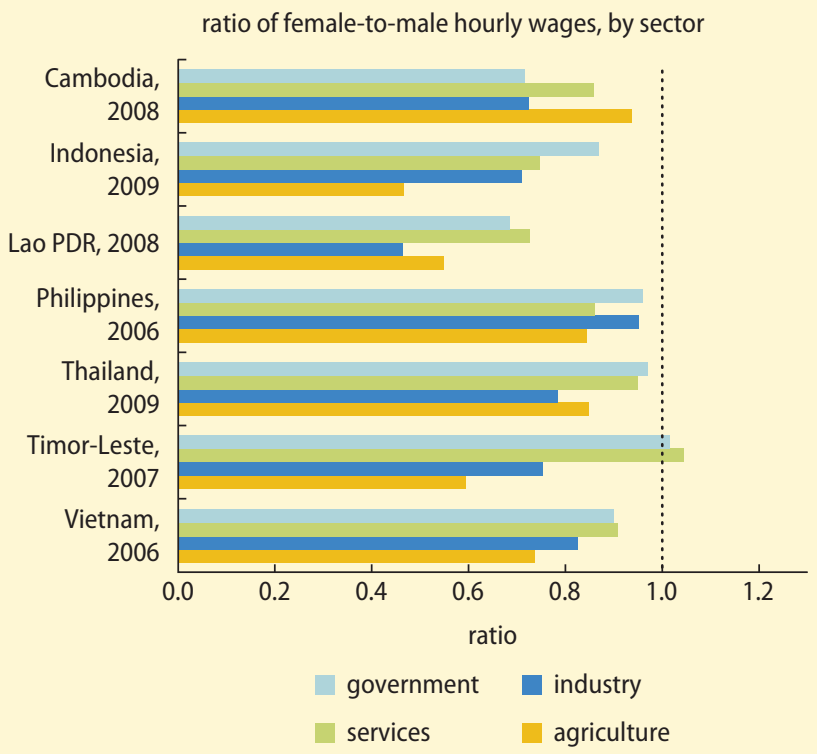

Source: World Bank staff estimates using household income and expenditure surveys.

by Amartya Sen (1999) to refer to the phenomenon that many low-income countries have far fewer women than men relative to what is observed in developed countries. Sen argued that this imbalance in sex ratios reflected severe forms of gender bias in affected societies. Biological differences between males and females imply that approximately 105 boys are born for every 100 girls. Nonetheless, China, Vietnam, and until recently, the Republic of Korea have experienced substantial deviations from the biological norm, and the trend over time, particularly in China, has been alarming. In China, the number of girls who are missing per year at birth increased from 890,000 in 1990 to 1,092,000 in 2008. Missing girls as a fraction of the total number of female births increased from 8.6 percent in 1990 to 13.3 percent in 2008 (World Bank 2011c).

Gender disparities still exist in access to and control of productive resources. Gender disparities in access to and control of land and farm inputs are pervasive in the region despite growth and development. Women remain less likely to own land than men. And when women, or specifically, femaleheaded households, do own land, they typically have smaller holdings (figure O.6). ${ }^{6}$ Female-headed households also tend to have poorer access to other productive inputs and support services, including livestock holdings and access to agricultural extension services.

Despite high labor force participation, important gender inequalities in economic opportunity remain. Women still earn less than men in nearly all sectors in all countries in the region (figure O.7). Gender wage gaps increase with age, reflecting in part lower levels of experience among women caused by workforce interruptions and reduced working hours during childbearing years, as well as gender disparities in education among older cohorts. Gender wage gaps in the region are also strongly influenced by occupational and sectoral segregation, mirroring patterns seen in the United States and other 
OECD countries. Together, differences in education endowments, experience, and industrial and occupational segregation explain up to 30 percent of observed gender wage disparities in East Asian countries (Sakellariou 2011).

Gender wage gaps in the region are often greatest among men and women with relatively low education and skill levels. Several studies from East Asian and Pacific countries point toward "sticky floors," that is, wider wage gaps at the bottom than at the top of the earnings distribution (figure O.8). The finding of sticky floors contrasts with studies from OECD countries, which more commonly find "glass ceilings," that is, larger wage gaps among higher-earning men and women.

Women are more likely to work in small firms, to work in the informal sector, and to be concentrated in lower-paid occupations and sectors. Within firms, women are more likely than men to be temporary workers. Such employment segregation affects a number of economic outcomes by gender, including earnings, returns to education and experience, social security coverage, and exposure to shocks. Substantial gender-based occupational and sectoral segregation is seen in all countries and does not decline with development. In fact, employment segregation tends to increase as economies become more diverse with development. Economic growth and, in particular, urbanization appear to make occupational and sectoral segregation by gender more pronounced, particularly during the early stages of economic structural change.

Similarly, female-led enterprises tend to be smaller and more precarious than male-led enterprises (figure O.9). The micro, small, and medium firm sectors are important segments of most East Asian and Pacific economies and contribute a substantial fraction of GDP. Female-led enterprises across the region, particularly in the informal sector, have lower profits, are less likely than male-led enterprises to be registered,
FIGURE 0.8 In urban China and Indonesia, gender wage gaps are largest among low wage earners

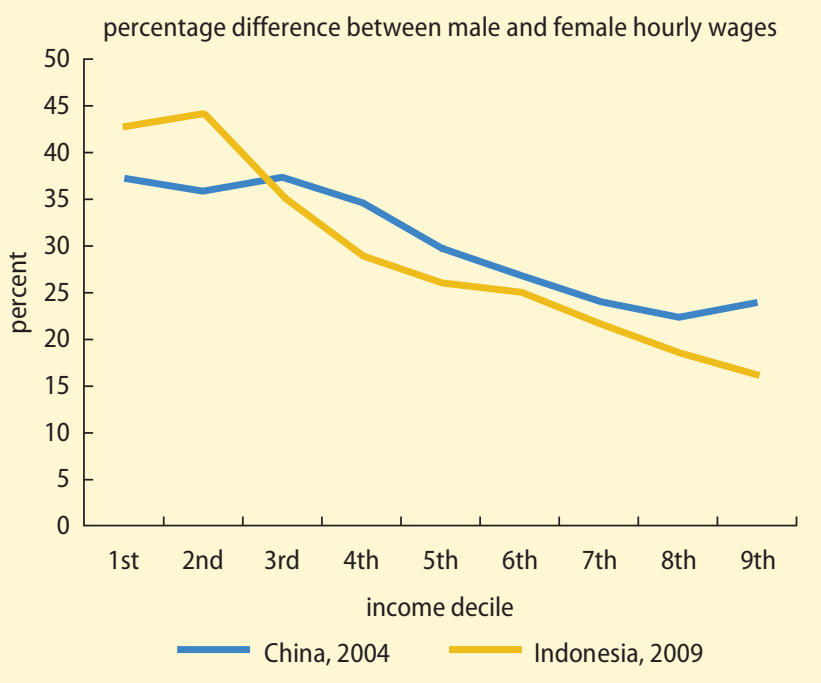

Sources: Chi and Li 2007; Sakellariou 2011.

\section{FIGURE 0.9 Enterprises with female managers tend to be smaller}

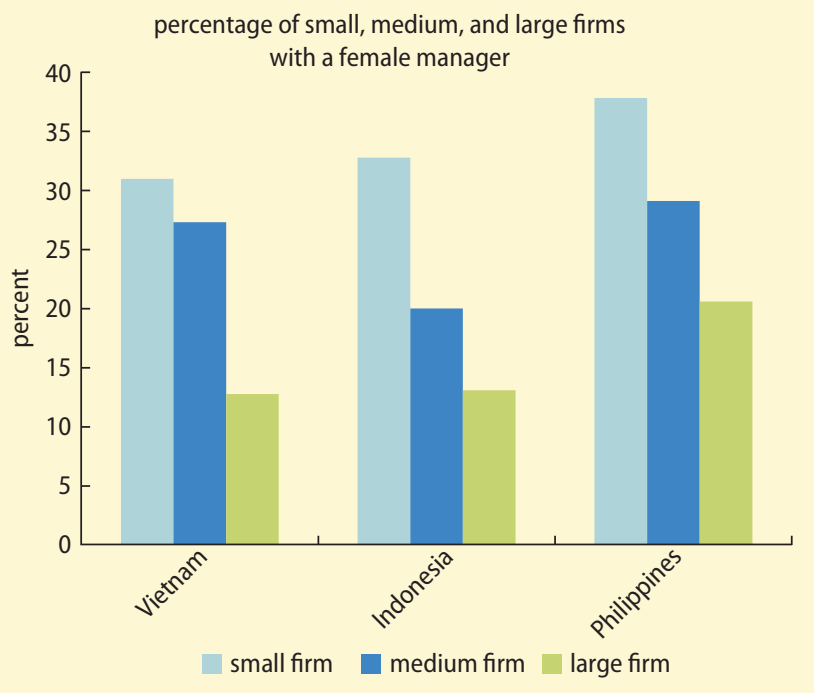

Source: World Bank staff estimates using Enterprise Surveys database for 2006-11.

have fewer employees and assets, and are more likely to be home based or to operate out of nonpermanent premises. Although 
female-owned and -managed enterprises are not inherently less productive, they tend to be smaller, less capitalized, and located in less remunerative sectors.

Women in the region still have less voice and influence than men. Women's household decision-making power in East Asia and the Pacific is relatively high, but levels of autonomy vary across the region. Women's autonomy in the household can be measured in several ways, including control of assets, freedom of physical mobility, and voice in decision making. By several of these measures, including control over large household purchases and visiting family and relatives, women in East Asian countries appear to have relatively high autonomy compared with women in other developing regions (World Bank 2011c). Women in the Pacific have relatively less control over their own earnings, however. Over 15 percent of women in the Marshall Islands, 15 percent in Samoa, and 13 percent in Tuvalu report that their husbands control their cash earnings (figure O.10). Moreover, 58 percent of partnered women in the

\section{FIGURE 0.10 Who decides how wives' cash earnings are used varies widely across the region}

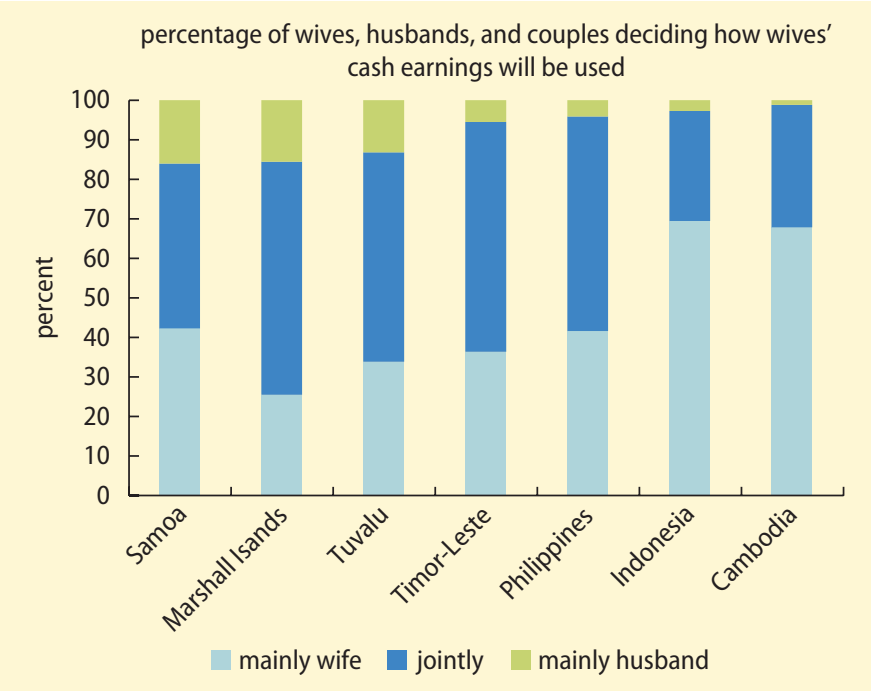

Sources: Demographic and Health Surveys, various years.
Solomon Islands and 69 percent of partnered women in Vanuatu report that they have experienced some sort of controlling behavior by their partners. This includes preventing them from seeing family, wanting to know where they are at all times, forbidding contact with other men, and controlling their access to health care (SPC and NSO 2009; VWC 2011).

Women's voice and influence in the public domain-as measured by representation in national and local political assemblies-remains low. The share of female parliamentarians in East Asian and Pacific countries is just below the global average, at approximately 18 percent in 2011. Despite economic growth and development in the region, this figure has barely changed since 1990. Although the share of women in national assemblies varies considerably across the region, it is systematically lower in the Pacific than in East Asia (figure O.11). Indeed, in no country in the Pacific does the share of parliamentarians who are female exceed 10 percent, and four countries-the Federated States of Micronesia, Nauru, Palau, and the Solomon Islands-have no female parliamentarians.

The prevalence of gender-based violence is high in the region, and particularly so in the Pacific where the prevalence of domestic violence is among the highest in the world. As can be seen in figure O.12, 68 percent of ever-married women 15-49 years of age in Kiribati, 64 percent in the Solomon Islands, and 60 percent in Vanuatu have experienced physical or sexual violence at the hands of an intimate partner (SPC, Ministry of Internal and Social Affairs, and Statistics Division 2010; SPC and NSO 2009; VWC 2011). Although no nationally representative data exist for Papua New Guinea, studies conducted at the subnational level suggest that domestic violence is just as prevalent (Ganster-Breidler 2010; Lewis, Maruia, and Walker 2008). This violence is a linchpin to a bigger story; violence against women represents the extreme deprivation of voice and freedom among 
FIGURE 0.11 Women's representation in parliament is low, especially in the Pacific

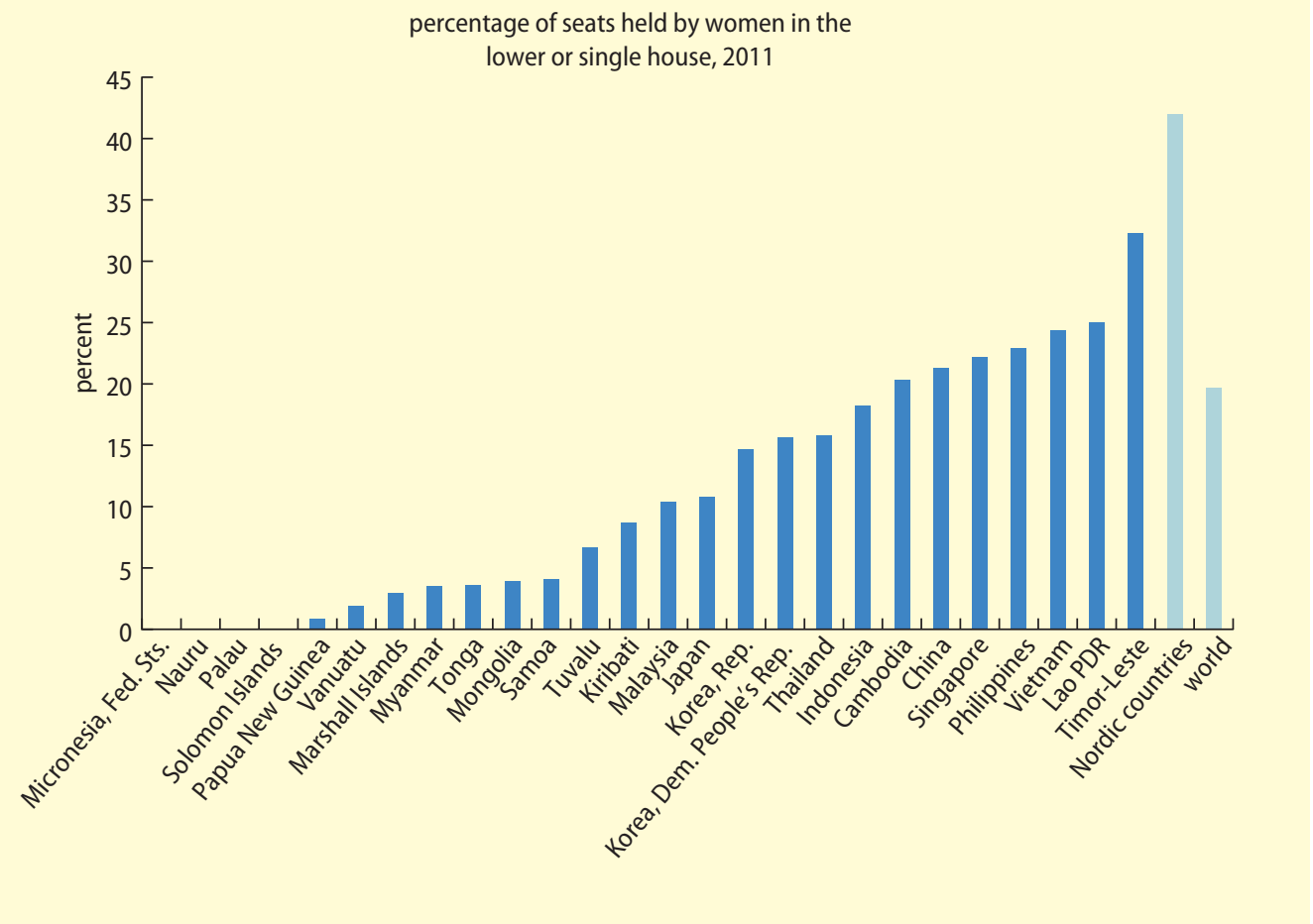

women and, as such, is often associated with a lack of agency in other dimensions.

Awareness is increasing that men and boysnot just women and girls-face genderspecific risks. Some countries in the region have started to experience a reverse gender gap in education; girls' secondary school enrollment now exceeds that of boys in China, Fiji, Malaysia, Mongolia, the Philippines, Samoa, and Thailand. Reverse gender gaps at the tertiary level are sometimes even starker: in Thailand, 122.4 females were enrolled for every 100 males in 2008. In addition, men across the region experience higher levels of morbidity and premature mortality related to substance abuse. The prevalence of smoking and drinking among males in East Asian and Pacific countries is much higher than the prevalence among females.

\section{FIGURE 0.12 Violence against women is high in the region}

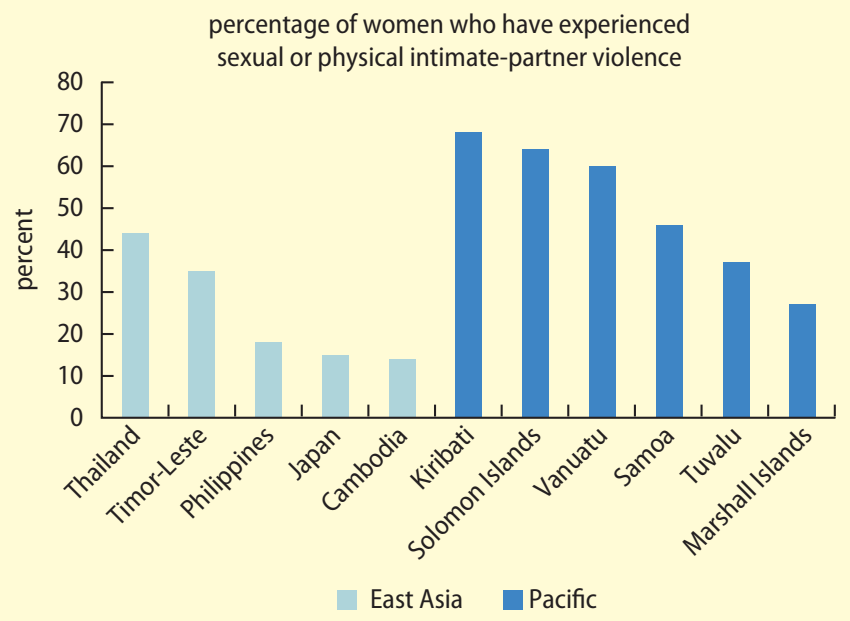

Sources: Demographic and Health Surveys, various years, and government surveys. Note: Data for Thailand are for Bangkok and Nakhonsawan only, and data for Japan are for Yokohama only. 


\section{Why do many gender inequalities persist?}

\section{Low household incomes, weak service delivery, and traditional norms can impede gender equality in education and health}

Where gender gaps in education are still observed, low income coupled with high costs of education can limit household demand for schooling. Traditional gender norms and practices also strongly influence household schooling decisions. Participants of focus group discussions in a qualitative research exercise in Papua New Guinea report, for example, that parents value boys' education over girls' education. The reason is that males will carry the family name and become household heads whereas females are expected to submit to their husbands and be caregivers and homemakers.

Weak systems of service delivery also constrain progress in education-overall as well as for girls. In Cambodia, Lao PDR, and Papua New Guinea, for example, school enrollments are low overall, and gender gaps persist. Low enrollment rates in Papua New Guinea also reflect limited physical access to schools and high dropout rates. Poor and sparse school infrastructure, poor teacher attitudes and attendance, lack of teachers in remote areas, and negative pupil behavior all contribute to low overall enrollments. Long distances to schools have been observed to make school attendance costly in both Cambodia and Lao PDR, particularly for girls, because long travel distances raise safety

FIGURE 0.13 Women are concentrated in certain fields of study, such as education and medicine, but are underrepresented in law and engineering

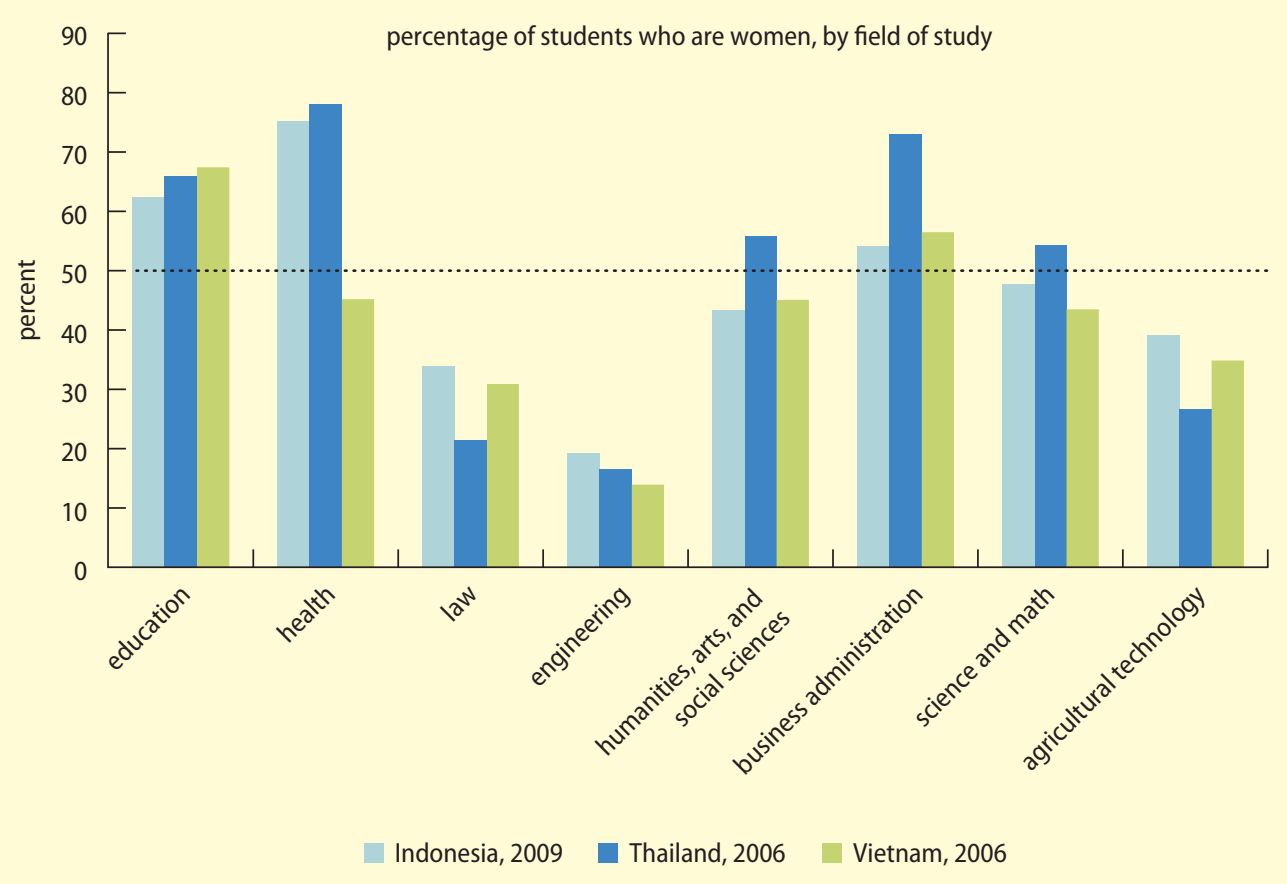


concerns among parents. The lack of toilets at many schools makes attendance more difficult for girls than boys.

Gender streaming in education largely reflects societal norms and expectations and has implications for gender inequalities in job placement and earnings. Substantial differences remain in the composition of education between men and women in the region (figure O.13). Economic returns or comparative advantage of females and males in different fields of study do not appear to explain education streaming. Social norms about appropriate work for women and men, role models in the labor market, and gender stereotyping in school curricula play important roles. In East Asia and the Pacific, teaching materials more frequently portray males than females in active and leadership roles. Women are often depicted as secretaries, assistants, nurses, and teachers whereas men are portrayed as doctors, politicians, or police officers. Gender streaming in education ultimately affects the type of work that women and men do and, importantly, affects their respective abilities to take advantage of existing and emerging economic opportunities.

Poor service delivery and cultural norms about birthing practices contribute in large part to high maternal mortality in several East Asian and Pacific countries. Poor access to quality obstetric health services, particularly in remote rural areas, places women at higher risk for maternal death. Rural areas tend to be less well served by the health system, and rural residents have much lower access to birth deliveries attended by trained staff than do urban residents. Evidence shows that poor health infrastructure and long distances to the nearest health center are both important barriers to reducing maternal mortality in Cambodia and Lao PDR. In addition, culture and tradition play an important role in the choice of health practices, such as the location of childbirth, the use of skilled birth attendants, and sterilization practices. Preferences can vary from birth deliveries at home to deliveries in the forest, including beliefs that women do not need prenatal care or delivery supported by skilled attendants. These factors take a heavy toll on women during pregnancy and pose higher risks of mortality related to birth complications.

Strong son preference, intensified by declining fertility and the availability of prenatal sex-identification technology, underlies the observed skewed sex ratios at birth in a few East Asian countries (China, Vietnam, and to a lesser extent now, Korea). Parents' choices to keep and care for boys over girls can depend on social norms and values, different economic opportunities by gender, and the benefits parents expect from a son compared to a daughter, including material support in old age. Although many societies have some mild degree of preference for sons, the interplay of culture, state, and political processes can generate extreme patrilineality and highly skewed child sex ratios. In addition, the manifestation of son preference is influenced by public policies-for example, China's one-child policy and Vietnam's twochild policy-and the spread of prenatal sex-determination technology since the early 1980s. For these reasons, economic growth and development alone do not necessarily reduce son preference and sex ratios at birth in East Asia.

Gender norms about masculinity play a strong role in influencing the excessive tobacco and alcohol consumption observed among men in many parts of the region. Smoking and drinking are commonly viewed as masculine behaviors. Men and boys feel substantial pressure to accept gender stereotypes that they should be strong and tough. In contrast, social disapproval of women who smoke keeps the smoking prevalence among women very low in Vietnam, for example. Survey data indicate that the primary reason why most Vietnamese women do not use tobacco is the expectation that "women shouldn't smoke." Survey respondents consider this factor more influential in affecting smoking behaviors than health concerns. 


\section{Norms regarding women's household roles and disparities in productive resources constrain economic opportunity}

Gender norms related to the allocation of time to household work affect women's opportunities in the labor market because they are expected to take primary responsibility for home and family in addition to any market role. Responsibility in the household fundamentally affects all outcomes in the market sphere-from where women work and what they do to how much they earn. Women work longer total hours than men and devote significantly more time to domestic and caregiving activities (figure O.14), particularly in households with small children. Many women temporarily leave the labor force when they must care for small children or the elderly. Trade-offs between household and market work can be particularly stark in rural areas, where women can spend long hours on domestic chores because of poor infrastructure and a lack of alternative childcare options. Indeed, differences in the types of work that women and men do, along with higher rates of female presence in the informal sector, are in part caused by

FIGURE 0.14 In Lao PDR, women-particularly those with young children-must balance household and market work

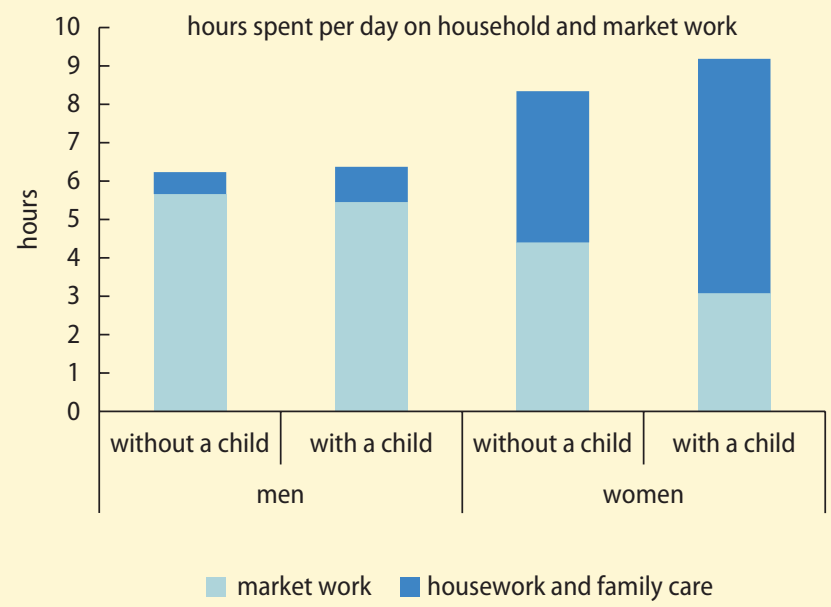

Source: World Bank staff estimates using Lao Socio-economic Survey, 2008. women's greater need for workplace flexibility to facilitate management of their dual household and market roles.

Female-headed households in the region tend to have less access to land because of the interaction of complex legal, social, and economic factors. In the majority of countries in East Asia, statutory law does not differentiate property inheritance by gender. However, parallel statutory and customary legal systems in a number of East Asian and Pacific Island countries mean that women are not treated equally to men in the implementation of the law. Gender inequalities persist also in access to other productive inputs and support services-from livestock holdings to agricultural extension services. Although evidence on access to credit is mixed across the region, female entrepreneurs in several countries, including TimorLeste and Tonga, report greater difficulty than their male counterparts in accessing credit. Such disparities in access to productive resources continue to impede gender equality in access to economic opportunity.

A substantial share of the gaps in productivity and profits between female- and male-led firms can be accounted for by gender-based segregation of enterprises by sector, firm size, and firm characteristics. This "sorting" of firms is found among both formal and informal enterprises and reflects both gender norms regarding time allocation to household and market work and differential access to productive inputs. In Indonesia, for example, the food, retail, and garment manufacturing sectors-where female entrepreneurs are most likely to locate-are among the least capital-intensive and productive sectors (figure O.15). By contrast, the transport sector-where male entrepreneurs are most likely to locate-has higher productivity and capital intensity.

Broader constraints to business development, such as cumbersome registration procedures, affect both female- and male-led enterprises (figure O.16). The most important issues vary by country, but, within any given country, both male and female entrepreneurs often identify similar challengescompetition, difficulty in accessing finance, 
and lack of electricity-and in comparable magnitudes. Evidence suggests that such constraints may be more onerous among small and informal firms than among larger firms, however, so to the extent that female-led firms are smaller and more likely to be informal, they are likely to be more adversely affected.

\section{Gender inequalities in endowments and economic opportunity limit women's agency...}

A woman's agency is affected in fundamental ways by her endowments and access to economic opportunities. Gender inequalities in educational attainment, economic assets, and own earnings can hinder women's abilities to influence their circumstances in the home, to enter and participate effectively in politics, or to leave bad or dangerous household situations. In Indonesia, for example, women with little or no education are less likely to participate in decisions involving their own health care, to make household purchases, or to engage regularly in social activities than women with at least a secondary education (BPS and ORC Macro 2003). In China and Cambodia, women with less education are less likely to enter politics-for reasons of norms or statute-than women with higher levels of education (Maffii and Hong 2010; Wang and Dai 2010). Moreover, worldwide evidence suggests that a woman's ownership and control of her own assets and income is associated with a decreased risk of intimate-partner violence (Agarwal and Panda 2007; ICRW 2006; Pronyk et al. 2006; Swaminathan, Walker, and Rugadya 2008). Women's income can also positively affect their accumulation of assets, which in turn positively affects their ability to leave an abusive partner, to cope with shocks, and to invest and expand their earnings and economic opportunities (World Bank 2011c).

\section{... as do traditional norms regarding women's roles...}

Social norms and practices can limit women's voice and influence in the home or in
FIGURE 0.15 In Indonesia, female-led enterprises are clustered in lower-productivity and less capital-intensive industries

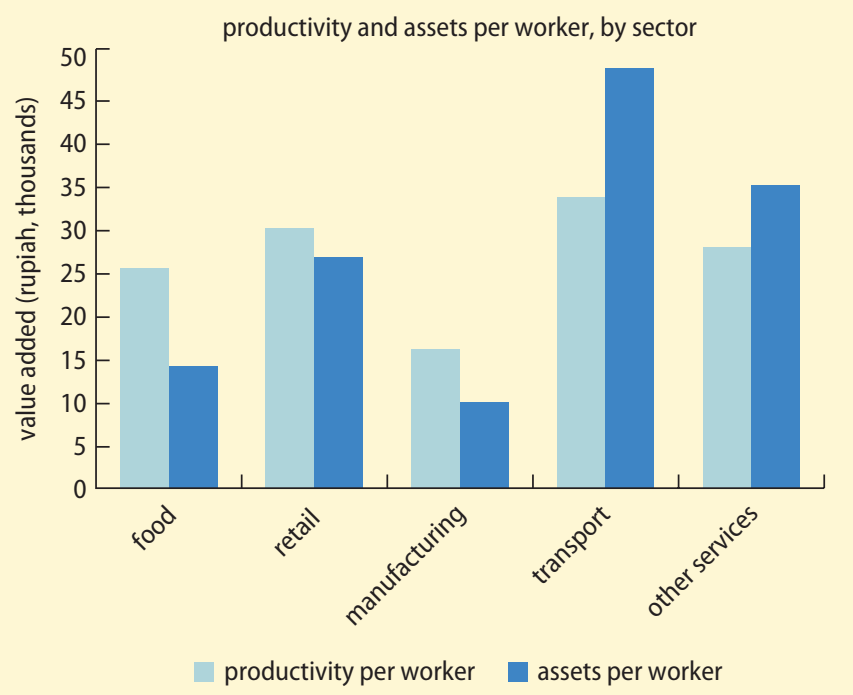

Source: World Bank staff estimates using Indonesia Family Life Survey 2007/2008.

Note: The graph shows productivity and assets per worker in five industries for firms with fewer than five workers. Productivity is measured by value added.

FIGURE 0.16 Male- and female-led firms report similar constraints in Indonesia

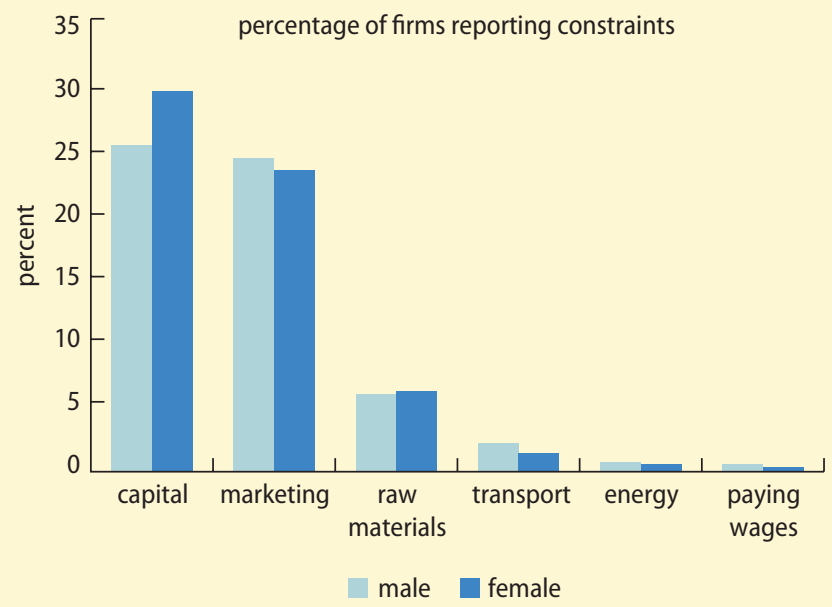

Source: World Bank staff estimates using Survey of Cottage and Small-Scale Firms (SUSI) 2002.

society. As previously noted, traditional norms about women's roles within the home constrain their economic opportunities and thus their decision-making power within the home. Traditional gender norms 


\section{FIGURE 0.17 Men and, in some cases, women believe that men make better political leaders than women}

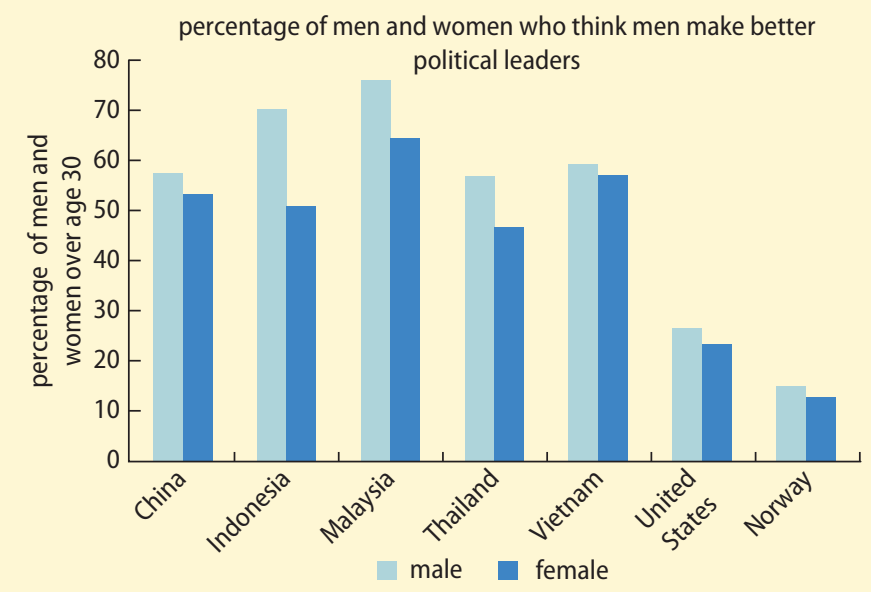

Source: World Values Survey database, 2005-2009 data.

Note: Data for Indonesia, Malaysia, the United States, and Vietnam are for 2006; data for China and Thailand are for 2007; data for Norway are for 2008.

and social expectations also shape people's views about women's roles in the public sphere. Surveys conducted in several East Asian countries indicate, for example, that a majority of men-and sometimes a majority of women-think that men make better political leaders than women (figure O.17). Similarly, in parts of rural China, many people still think of women as less capable (disuzhi), and local norms dictate that they should confine their activities to the domestic settings (Wang and Dai 2010).

\section{... and complex legal environments and, often, weak access to justice}

The legal setting, along with people's access to justice, establishes the underlying environment in which women (and men) can exercise agency in the home and in society. Whether women and men are equally supported under the law, and whether their rights are protected in practice thus critically affect their voice and influence in society. Laws and access to justice also create the environment in which women and men can (or cannot) access resources and economic opportunity and accumulate assets, which also affects their agency. In several countries in the region, the legal environment is affected by not only statutory but also customary law.

Plural legal environments, where both statutory and customary laws are practiced, can create important challenges to promoting gender equality in voice and influence. Statutory laws, customary (and sometimes religious) laws and practices can affect women's voice and influence in different ways when they bestow different rights by gender. Moreover, in practice, the interaction between statute and custom can mean that women's legal status varies substantially across ethnic (and religious) groups, even within a single country. This interaction can affect women's rights in marriage and divorce, reproductive health, education, asset ownership, inheritance, and freedom of mobility, among other things, which in turn can fundamentally affect the extent of women's agency.

In some countries, inadequate legal protection, weak implementation and enforcement, and social tolerance enable gender-based violence. Although more than three-quarters of countries in East Asia have strengthened legislation on domestic abuse in recent years (including, for example, Indonesia, Korea, Lao PDR, Thailand, and Vietnam), in the Pacific, more than 60 percent of countries still lack sufficient legislation on domestic violence (UNDP 2010). Even when countries have appropriate legislation in place, women remain unprotected by the legal system because the laws remain largely unenforced. A recent study found, for example, that officers in the Fiji Police Force Sexual Offences Unit often have unwelcoming attitudes when dealing with female victims (UNFPA 2008). The same is true in some areas in Cambodia, where many local officials still believe that a husband can threaten his wife despite the laws in place (UNDP Cambodia and VBNK 2010).

\section{Emerging opportunities and risks in an increasingly integrated world}

Several emerging trends in the region will present both new opportunities and new 
risks to achieving gender equality. East Asia and the Pacific are at the forefront of several global trends: increasing global economic integration, rising availability and use of ICTs, increased domestic and cross-border migration, rapid urbanization, and population aging. Because these trends have gender dimensions, they will affect the evolution of gender equality in the region. In many ways, these trends will bring with them new opportunities for gender equality. For example, increased economic integration, greater access to ICTs, and increased migration will likely all contribute to increased income earning opportunities for women. Along with new opportunities, however, these emerging trends will bring new risks.

Increasing global integration will likely continue to be an important source of nonagricultural employment growth for women, who are already highly represented in export-oriented sectors (figure O.18). And greater employment and earnings in exportorientated industries can contribute to greater female independence and autonomy in decision making. At the same time, increasing global integration can increase economic risk and uncertainty, as shocks are quickly transmitted across integrated markets. A number of studies find that while shocks do not necessarily have more adverse impacts on women than men, they do have gender-differentiated effects on outcomes as diverse as employment, earnings, labor force participation, education, health, and nutrition (see, for example, Bruni et al. 2011; Rodgers and Menon forthcoming).

Advances in ICTs are opening up opportunities for both men and women throughout the region. New and emerging technologies, if accessible, can help increase women's welfare through a number of channels by opening new economic opportunities, empowering women by breaking down information barriers, facilitating engagement of women in isolated communities in distance learning, and enabling them to take collective action. In Malaysia, for example, female entrepreneurs have created self-help cyber communities to
FIGURE 0.18 The share of female workers in export-oriented firms is relatively high

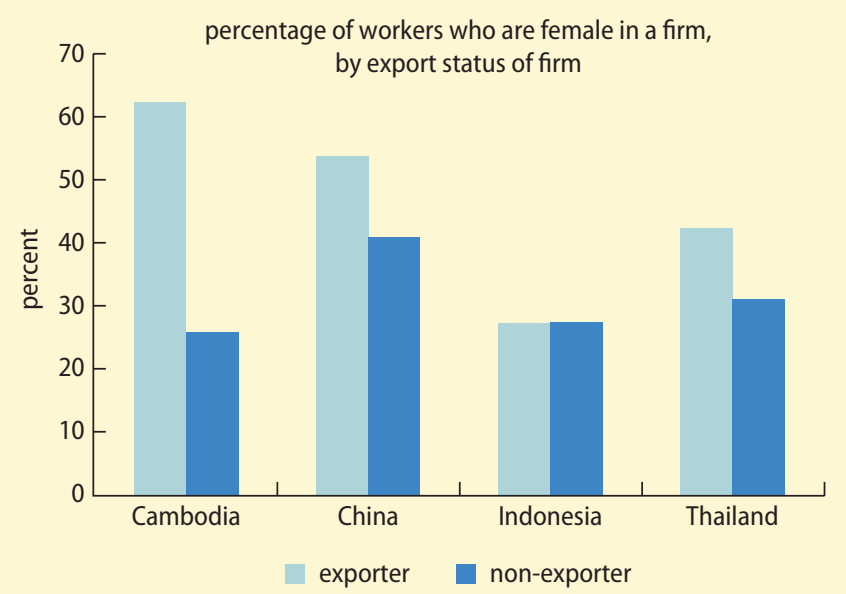

Source: World Bank staff estimates using Enterprise Surveys database for 2002-06. Note: Share of female workers = female workers/total workers.

network and share information about starting and running a business. Limited evidence suggests that women in the region may still have lower access to information technologies than men, however. Although data from China show rapid growth in access to ICT services, Chinese women are still less likely to use the Internet or to subscribe to mobile phone services (figure O.19). Widening gender gaps in access to ICTs raise the risk of rising disparities in economic opportunity and voice going forward.

High economic growth and increased economic integration over the past three decades have spurred significant migration across the region. Women constitute nearly half of all migrants in East Asia and the Pacific and are increasingly migrating in search of better economic opportunity. Female migrants dominate a number of occupations and sectors, including labor-intensive manufacturing and export-oriented industries, and domestic work. Migration can provide women with increased economic opportunity, give them the chance to improve their knowledge and skills, and increase their agency through raising their contributions to family income. 

FIGURE 0.19 China has seen remarkable growth in Internet use
since 2000, but women's use trails men's

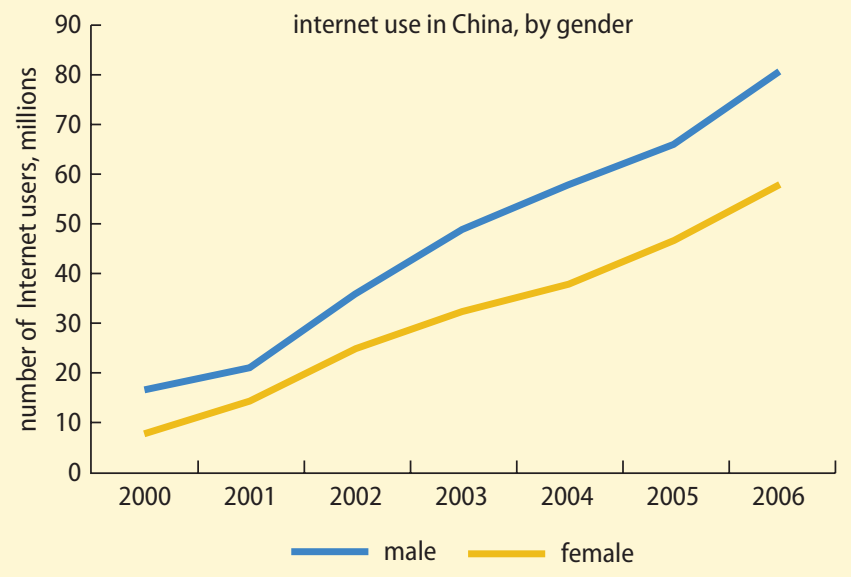

Source: CNNIC (China Internet Network Information Center) Internet Statistics.

At the same time, migration brings with it important gender-specific risks. For example, many female migrants work as domestic workers, an occupation with particularly weak worker protections in most countries. Female migrants are also disproportionately susceptible to human trafficking.

Many East Asian and Pacific countries are experiencing unprecedented levels of urbanization as migrants move to urban areas in search of economic opportunity. Between 2000 and 2015, Indonesia, China, and Cambodia are predicted to see an increase of the population residing in urban areas by 17,13 , and 9 percentage points, respectively (UN 2010). Urbanization affects all aspects of life, from the nature of employment to the availability of services to one's ability to rely on extended family and community networks for support. These changes almost certainly have gender-specific impacts. While urban areas can open up a wider range of economic opportunities for both men and women, women's ability to take advantage of new opportunities is likely to depend more fundamentally on the nature and availability of urban services-for example, whether transportation systems facilitate their safe travel to job sites or affordable child care can compensate for the loss of extended family networks.

Finally, the high-income economies in East Asia are experiencing rapid population aging. Most emerging countries in the region have also begun this process; dependency ratios are already increasing in many middleincome countries in East Asia and the Pacific. Old-age dependency is expected to increase even more quickly in the coming decades (figure O.20). Population aging is likely to have gender-differentiated effects at all age levels. Gender differences in time devoted to caring for the elderly imply that in the absence of institutionalized care services, women are likely to bear the brunt of the increased demand for elder care (Dwyer and Coward 1992; Ofstedal, Knodel, and Chayovan 1999). In addition, while women tend to live longer than men, gender differences in education and labor force participation imply that women are less likely to be vested in formal pension systems and may have fewer assets to ensure a basic level of well-being in old age.

At present, these emerging trends have gender dimensions that are not commonly accounted for by policy makers. Nonetheless, these trends will generate a distinct set of challenges for promoting gender equality going forward. An important role for public policy, therefore, will be to support women (and men) in taking advantage of emerging opportunities while protecting them against the emerging risks.

\section{Toward gender equality in East Asia and the Pacific: Directions for policy}

The collection of evidence points to four priority areas where public policy can contribute to greater gender equality and more effective development in East Asian and Pacific countries:

- First, promoting gender equality in human development remains a priority where gender gaps in education are large or health outcomes are poor; closing gaps in human 
development, where they persist, is likely to yield high returns.

- Second, taking active measures to close gender gaps in economic opportunity is often warranted on both equity and efficiency grounds. Which policy levers will yield the highest returns depends on the structure of the country's economy and which specific constraints are most binding.

- Third, taking measures to strengthen women's agency-and to protect them from violence-is also called for across the region; strengthening women's voice and influence will contribute to the quality of development decision making and thus to development more broadly.

- Fourth, public policy has a critical role in fostering new opportunities and managing emerging risks associated with increasing global economic integration, the rising role of ICTs, increasing migration, rapid urbanization, and population aging.

The following sections examine policy approaches to promoting gender equality in East Asia and the Pacific in these four priority areas, drawing on recent experience from the region and beyond.

\section{Promoting gender equality in human development}

\section{Closing persistent gender gaps in human development}

In countries with unequal gender outcomes in education and health, the priority remains improving these outcomes. In East Asia and the Pacific, gender gaps in human development at the national level tend to persist where overall outcomes are low. In such cases, public action to strengthen countries' education and health systems will be called for to improve gender (as well as overall) outcomes. For countries with more localized gender disparities, for example, among specific ethnic groups or in remote, rural regions, more targeted interventions may be warranted. The exact constraints
FIGURE 0.20 The old-age dependency ratio is increasing in most East Asian countries

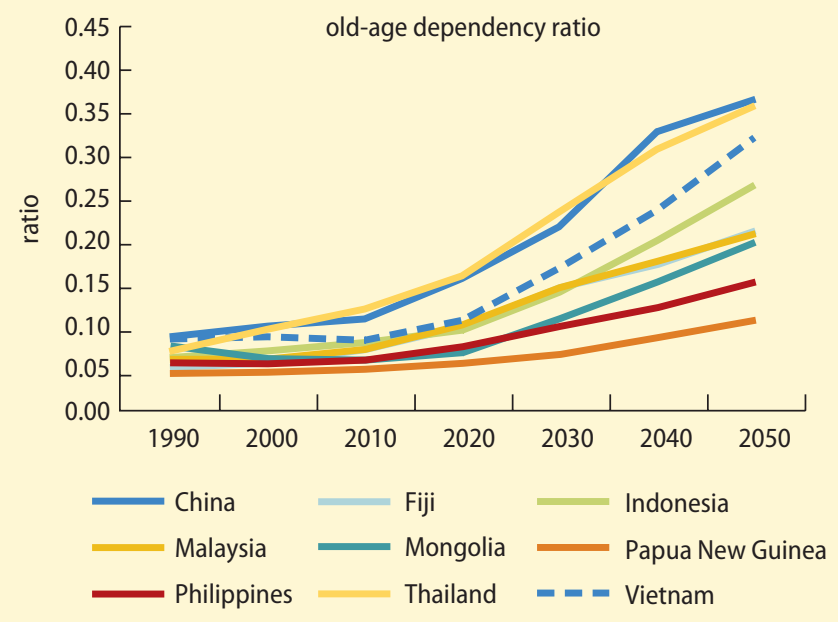

Sources: Data for 1990-2010: World Bank 2010; data for 2020-50: HNPStats Population Projections database.

Note: The old age dependency ratio is defined as the ratio of the elderly (ages 65 and above) to the working age population (ages 15-64).

vary by country context, but the evidence makes clear that both demand-side and supply-side factors are responsible for these poor human capital outcomes.

Policies can thus have an impact by improving service delivery (for example, through infrastructure, staffing, incentives, and use of ICTs) and implementing demand-side interventions (for instance, through cash transfers to poor households, information campaigns, and improved accountability). For example, Indonesia's school construction program in the 1970s significantly increased education attainment and future earnings (Duflo 2000). In Cambodia, a scholarship program targeted at girls and a related program targeted at boys and girls from low-income households led to an increase in school enrollment of at least 20 percentage points (Filmer and Schady 2008, 2009). Evidence indicates that to reduce maternal mortality, interventions that ensure basic infrastructure and improve accountability for service delivery are important. Approaches to providing services that take into account traditional norms and practices also show promise. For example, Malaysia 
has adopted programs that provide guidance that traditional birth attendants on hygiene practices, diagnosis of complicated cases, and information on the importance of prenatal care.

\section{Reducing gender streaming in education}

For East Asian and Pacific countries where gender equality in access to human capital is no longer the dominant concern, addressing education quality-specifically, gender streaming in education-will have high returns. Although concerted efforts in both education and the labor market will be needed to break gender "silos" in education and, consequently, in the economy, significant steps can be taken within the education system. One important step involves reform of school curricula to address the transmission of gender stereotypes through the education system. Cambodia, Lao PDR, and Vietnam have reviewed curricula and revised learning materials or encouraged better practice without gender stereotyping. Other active interventions may be warranted, including information campaigns, financial or nonfinancial incentives, and efforts to create gender-friendly environments in higher education. Providing information on wages and career paths in these programs before individuals choose their courses may help reduce gender streaming in training. In the United States, for example, the Science Connections program offered monthly science workshops for girls plus a summer science weekend for families to increase girls' knowledge about and interest in nontraditional careers in science. Scholarships that support women (and men) in entering nontraditional fields may provide another avenue for breaking down gender silos in education.

\section{Promoting balanced sex ratios at birth}

In the few countries with "missing girls" at birth, rooted in the prevalence of son preference, active measures are needed to address the issue. Even where laws against sex-selective abortion have been enacted, strong incentives to select the preferred gender still induce expectant parents to bypass the law, and enforcement of such laws is difficult. Existing evidence suggests a more promising approach is to adopt policies that aim to enhance family perceptions of the value of daughters. While general policies to promote economic development may play a role, Korea's recent experience suggests that introducing interventions to influence norms and facilitate the spread of new social values may also be important, rather than relying on efforts to raise female education and labor force participation alone. Information campaigns, financial incentives, and improved social security for the elderly can all contribute to changing societal preferences and behaviors. China has been adopting several of these types of programs. For example, the National Population and Family Planning Commission scaled up the Chaohu pilot through the national Care for Girls campaign in 24 counties with severe gender imbalance. This campaign went beyond advocacy and media publicity alone; direct financial incentives for parents to raise daughters have also been introduced. Preliminary evidence suggests that these programs have had some impact on reducing imbalances in the sex ratio at birth.

\section{Addressing male-specific gender issues}

Paying attention to male- as well as femalespecific gender issues is appropriate for reasons of basic welfare as well as for development effectiveness. In this context, initial signs of reverse gender gaps in education in several countries should be monitored closely. While the long-term implications of male disadvantage in education are still to be understood, depending on the underlying causes, it could have both economic and social consequences. Moreover, excessive tobacco and alcohol consumption among males in many parts of the region deserves policy attention; the social costs are usually higher than private costs because of the negative effects of these behaviors on other members of the society. Possible measures to tackle this challenge include providing information about the health risks of excessive tobacco and alcohol consumption, enacting 
or increasing taxes on tobacco and alcohol, imposing regulatory measures on advertising, and restricting smoking in public sites. The Thai Health Promotion Foundation, for example, uses alcohol excise tax revenues to support the operation of an alcohol control center and a research center on alcohol consumption, to support advertising campaigns to reduce alcohol-related traffic accidents, and to promote abstinence and increase knowledge about the links between alcohol use and domestic violence.

\section{Taking active measures to close gender gaps in economic opportunity}

\section{Mitigating trade-offs between women's} household and market roles

Women often face stark time trade-offs between household and market work, particularly in rural areas. In such contexts, programs targeted at reducing women's time on household work-for example, through investment in infrastructure-are likely to increase women's ability to engage in market-based income-earning opportunities. In Lao PDR, for example, evidence indicates that having access to electricity extends the hours available for both productive and leisure activities, particularly for women and girls (World Bank 2011a).

Policies that support women in balancing their caregiving and market roles are also important in strengthening their access to economic opportunity. Access to affordable and accessible child care can be critical in this regard. Community child care centers, particularly those targeted at low-income neighborhoods, have been found to increase maternal employment in a number of Latin American countries. The importance of affordable child care, particularly as urban areas expand, can be seen from recent experience in the region. In Mongolia and China, reductions in subsidized child care in the 1990s and 2000s have significantly and negatively affected female labor force participation in urban areas.

Parental and paternity leave can promote greater parity between the sexes by facilitating a more equitable division of childrearing responsibilities and allowing women to have the same opportunities as men for advancing their careers in the formal sector. Within the region, only Cambodia, Indonesia, and the Philippines currently have provisions for paternity leave. While the principles behind paternity (and parental) leave are appealing, evidence from the OECD on the take-up of paternity leave is mixed, suggesting that providing paternity leave alone is not sufficient to change the current gender division of child-rearing responsibilities within households; rather, such leave policies need to be combined with other approaches to breaking down gender norms regarding household caregiving.

\section{Breaking down gender silos in the labor market}

A key element of breaking down gender silos in the labor market involves supporting young women and men to invest in skills on the basis of their productivity rather than on the basis of gender norms and perceptions regarding "appropriate" occupations. Beyond efforts to reduce gender streaming in education, programs that help both women and men understand employment options outside of gender silos will likely improve the allocation of talent toward jobs in ways that improve both equality of economic opportunity and productivity. In Kenya, for example, a micro and small enterprise voucher program, called Jua Kali, provided its female beneficiaries information about wages in a range of occupations. Preliminary evaluation of the program suggests that 5 percent of women who received the information switched to more lucrative (often "male") jobs as compared to those who did not receive the information (Hicks et al. 2011).

Breaking down social norms and perceptions about gender roles in the workplace is an area where the public sector can lead by example, particularly with respect to enabling women as leaders and managers. The public sector is in a unique position to establish good practice in this regard by encouraging women's professional advancement, either 
through direct measures such as targets or quotas or through specialized training programs. In this context, the government of Malaysia has put in place a system of quotas for female managers in the public sector. In Mexico, the government initiated a system of grants to firms to address gender-related employment issues in the workplace, including fostering greater female participation in management.

Eliminating resource constraints on femaleled farms and enterprises

Despite progress, women continue to have less access to a range of productive resources than do men as a function of their gender rather than because of their innate productive capabilities. Public policies thus have an important role to play in promoting gender equality in the control of productive inputswhether land, agricultural extension, technology, or financial capital. Improving women's access to productive assets can play an important role in raising enterprise productivity in both the farm and nonfarm sectors. Following are some examples.

- Several countries in the region have made headway in recent years in increasing ownership and control of land. In response to concerns about persistent gender inequalities in land, several countries-including Indonesia, Lao PDR, and Vietnam-have recently adopted gender-sensitive reforms in land titling. Since the 2004 Land Law in Vietnam, all new land tenure certificates must include the names of both spouses. Qualitative assessment of the reform's effects in three provinces suggests that joint titling improves opportunities for women to access loans, empowers women in case of disputes, and leads to more mutual decision making (World Bank 2008). Because the reasons for women's lower access to land differ across the region-from unfavorable legal frameworks to cultural norms and practices that deem land to be a "male asset"-effective policies to increase female land holdings need to account for context-specific constraints.
- Gender inequalities in access to information and training, extension services, and other productive inputs constrain the productivity of female-led enterprises, both within and outside agriculture. In Papua New Guinea, where training and extension services are more likely to reach male than female farmers, a recently launched agriculture training program includes several components focused on closing the gap between rural women's economic needs and the inputs and services provided. Similarly, in Cambodia, the Cambodia-Australia Agricultural Extension Project has addressed two key constraints that have limited female farmers' access to agricultural support: the project has increased by 80 percent the number of female extension workers and undertakes special initiatives that account for female farmers' relatively lower levels of literacy.

- While evidence on access to finance in East Asian and Pacific countries is mixed, women do face particular challenges in accessing credit, especially given their poorer access to land, an important source of collateral. Beyond financial constraints, training programs that improve business skills may be implemented to address gender differences in entrepreneurial capital. In this context, an impact assessment of a women's entrepreneurship training program in Aceh, Indonesia, found that business planning and management training helped promote greater confidence among women trainees, create or strengthen social networks, and identify ways to improve the business environment for female entrepreneurs (ILO 2008).

As in the case of education and health, broad systemic weaknesses-whether in the form of cumbersome registration procedures, weak systems of financial intermediation, or lack of electricity-affect both femaleand male-led enterprises. Evidence suggests that such constraints may be more onerous among small and informal firms than among larger firms and, therefore, may constrain 
female-led enterprises disproportionately. As a result, interventions that focus on improving the overall investment climate and particularly on promoting small business development will be important. Addressing systemic as well as gender-specific constraints will thus be critical to promoting gender equality in economic opportunity.

\section{Creating an enabling environment for gender equality in employment}

Public policy can strengthen the enabling environment for gender equality in formal employment. An important element of this is to ensure that women and men face a level legal playing field with respect to jobs and sectors. Labor regulations that result in asymmetries in the employability and costs of hiring male and female workers can be found across the region. Ostensibly protective legislation, in the form of restrictions on women working at night, working overtime, and working in so-called dangerous sectors, serves in practice to inhibit women's economic participation. Priority should be given to reducing labor market restrictions that limit women's employment options. Where the original concerns motivating these policies are still valid-for example, health and safety issues-measures should be taken to ensure that these concerns are addressed more directly through workplace safety codes, provision of safe and reliable transport infrastructure, and so on.

Active labor market policies are another means of overcoming gender differences in access for formal employment. For example, wage subsidies may induce employers to hire female workers whom they may not have otherwise considered, due to lack of information about their workplace productivity. This intervention thus provides the opportunity to reduce gender stereotypes by enabling employers to observe women's skills directly, and it can facilitate women gaining valuable labor market experience. Skills training programs may also enable women and men to move into professions outside of gender silos, particularly when paired with apprenticeship opportunities. Although evidence on the effect of active labor market policies in East Asia and the Pacific is limited, studies from Latin America and the Middle East suggest that well-designed active labor market policies can help improve women's employment outcomes.

Affirmative action policies have also been used to overcome gender-specific barriers to employment, whether caused by implicit or overt discrimination in hiring and promotion. The literature reflects some debate regarding the benefits and costs of affirmative action, but the collection of evidence (largely from high-income countries) suggests that carefully designed policies can help break down barriers to female employment with little or no adverse effects on firm productivity (World Bank 2011c). Affirmative action in hiring and promotion in the public sector can have important demonstration effects. In 2004, the government of Malaysia introduced a quota for the public sector of 30 percent female representation across all decision-making levels, including positions such as department heads or secretary-general (ASEAN 2008). Whereas in 2006, women held 24.6 percent of top positions in the public sector, by 2010 , the figure had risen to 32.0 percent. More recently, the Malaysian government set a target for 30 percent of corporate board positions to be held by women by 2016 .

\section{Taking measures to strengthen women's voice and influence}

Measures to increase women's endowments and economic opportunity, such as those described previously, contribute to strengthening their voice within the household and in society. Educated women in good health, with assets and income, are better able to act on their preferences and influence outcomes that affect themselves and others in society. In addition, several other policy approaches can directly promote women's agency and reduce gender-based violence.

\section{Supporting initiatives to transform gender} norms and practices

While gender norms may be persistent, they are far from static. Individual experiences 
as well as large-scale political and economic processes are capable of bringing about dramatic, and often rapid, social change. In East Asia, increasing economic integration and rising access to ICTs are not only transforming the economic landscape but also increasing flows of information in ways that may serve to transform gender norms in the region. Similarly, migration and rapid urbanization across the region are bringing with them the possibility of newly defined roles for men and women, as women and men alike are exposed to new ideas and production modalities.

The education system can be a vital source to change social norms that perpetuate gender inequality. The integration of gender equality principles into the school and professional curricula can address the value system of children early on and, over time, transform social norms (Utomo et al. 2009). Evidence of the positive effects of changing the curriculum is available for adults in Thailand where gender sensitivity was integrated into the curriculum in the Chulalangkorn medical school. Evaluation of the program showed that respondents were more aware of gender issues and tended to apply gender concepts and concerns in their work and personal lives (WHO GWH 2007).

Provision of information through television programming can also play a critical role in changing social norms, especially with respect to fertility and gender-based violence. Evidence shows that people can be prompted to rethink gender roles in society when they are exposed to new information and experiences that challenge existing norms. In Brazil, despite strong traditional norms in favor of having many children, increased exposure to the opposite behavior by popular women in soap operas led to a measurable decline in fertility (Chong and La Ferrara 2009; La Ferrara, Chong, and Duryea 2008). In India, increased exposure to television contributed to decreased acceptance of wife beating, lower fertility rates, and noticeable shifts away from son preference (Jensen and Oster 2008).

\section{Strengthening the legal and institutional environment}

Nearly all countries in the region have acceded to CEDAW, signaling commitment to adhering to internationally agreedupon norms regarding gender equality. ${ }^{7}$ An important pending agenda is to ensure that domestic legislation and the institutions of implementation and enforcement are aligned with countries' commitments. Where comprehensive legal reform is not possible, governments should identify priorities for action. For example, in contexts where women's agency within the home remains weak, a case exists for reforms to focus on rights in marriage and divorce, inheritance and maintenance laws, and protection of women from gender-based violence, which can strengthen the enabling environment for greater voice and influence in the household. As part of the process of monitoring progress toward gender equality, governments should undertake regular assessments to ensure that legal gaps are being filled and that relevant laws are being enforced. In countries where multiple systems of law coexist, assessing customary practices to ascertain whether they limit women's agency and then developing strategies to address these limiting factors will be important.

Strengthening the capacities of institutions to enforce the law and increasing knowledge of the law are also critical. Both financial and human investments need to be made to ensure that public sector personnel, such as judges and police, have the knowledge and capacity to actively enforce laws intended to protect women and to promote gender equality. Concerns have been raised that police forces in several countries in the region, including Indonesia, Malaysia, and Thailand, have been too passive in investigating trafficking and enforcing antitrafficking laws (U.S. Department of State 2011). The Cambodian Women's Crisis Center began a community program that increases the awareness of violence against women and of the legal rights of women, including the law on domestic violence 
and protection that was implemented in 2005. The program promotes initiatives to strengthen enforcement of the law by providing information and training to local authorities and developing community support networks.

\section{Increasing women's access to justice}

Financial costs and travel distances often are de facto barriers to women accessing justice, even when the appropriate laws and institutions are in place. In that context, developing and implementing innovative methods to improve access to the judicial system can help women exercise their agency in the courts when needed. The use of mobile courts, for example, such as those in rural areas of China and Indonesia, provides a solution to the problem of accessibility and security for women who wish to exercise their rights in the legal system but who are unable to travel to the court. Technology, such as telephone hotlines and websites, can be used to undertake basic legal transactions. For women with few economic resources, waiving or subsidizing the costs of legal aid can help reduce financial barriers to accessing the judicial system.

\section{Enabling women's participation in politics and policy making}

Active measures to promote women's participation in policy making can be effective in increasing female representation in local and national assemblies in many contexts. A range of affirmative action mechanisms have been used in developing countries. Quotas have been used in several countries, sometimes in the form of constitutional changes to reserve a specified number of posts for women and sometimes through legislative and political party quotas. Quotas can be informal (and voluntary) or mandated formally at the subnational or national level (Dahlerup 2006). The idea is to provide temporary measures to break down barriers to the entry of women into politics. The suitability and impact of different forms of quotas or targets differ depending on the specific context. Data suggest that these measures can be effective in increasing female representation in elected bodies. They can also help transform people's views about the efficacy of female political leaders (Beaman et al. 2009). At the same time, electoral quotas do impose constraints on the democratic process. It is thus important to keep this-as well as the expected benefits of increasing female participation in politics - in mind when determining when and how to enact such measures.

\section{Pursuing a multipronged approach to reducing gender-based violence}

Reducing gender-based violence requires action on a number of fronts: efforts to increase women's voice within the household; enactment and enforcement of appropriate legislation and strengthening of women's access to justice; provision of adequate support services for victims of violence; and use of the media to provide information on women's rights, to increase social awareness, and to shift social norms with respect to violence.

Countries that take a strong stance on gender-based violence legislation and enforcement can make positive strides against such violence in short periods of time. Cambodia saw a significant decrease in the incidence of domestic violence between 2000 and 2005 , largely attributed to strong efforts by the country's Ministry of Women's Affairs, which introduced draft domestic violence legislation in 2001. Four years later, in October 2005, the National Assembly adopted the legislation. The new law criminalized acts of domestic violence, provided for the protection of victims, and enabled neighbors or local organizations to intervene if they witnessed domestic violence. As a complement to the law, women's organizations and other nongovernmental organizations carried out information campaigns to disseminate information on people's basic rights and responsibilities under the law.

Governments also need to provide adequate support services for victims when violence does occur. This support can include a range of services, from police and judiciary to 
health and social services. In Malaysia, the government established integrated one-stop crisis centers in hospitals that provide easy access to medical care and social services, and facilitate reporting of violence to specially trained police officers (World Bank 2011c).

\section{Creating space for women's collective agency}

While promoting women's individual agency is important, supporting women's collective agency can be an effective way to empower women to advocate for and promote effective public action toward gender equality. Experience from around the region highlights the potential of enabling women's collective agency. For example, during the debate in Cambodia leading to the 2005 Law on Prevention of Domestic Violence and Protection of Victims, the Cambodia Committee of Women, a coalition of 32 nongovernmental organizations, persistently lobbied the government and the Ministry of Women's Affairs to secure the legislation's passage. Similarly, in Fiji, the Fiji Women's Crisis Center campaigned successfully for the implementation of a nationally representative quantitative survey on violence against women; the results of this survey are scheduled to be released in 2012. Partnerships with the private sector, including women's business associations, can provide an important space for women to interact, learn, and advocate for gender equality. A recent initiative to increase women's participation in the private sector's dialogue with government in Cambodia, through the Government Private Sector Forum, has induced policy makers to undertake new initiatives addressing the needs of female entrepreneurs.

\section{Fostering new opportunities, managing emerging risks}

A new and important challenge for policy makers will be to belp foster emerging opportunities and, in particular, to manage emerging risks associated with increasing economic integration, increasing access to ICTs, migration, rapid urbanization, and population aging. Many of the emerging opportunities can be fostered through the types of efforts to promote greater gender equality in endowments, economic opportunity, and agency discussed in this report. For example, where gender gaps in ICT use are growing, ensuring that women have access to these new technologies may require active measures similar to those discussed earlier to ensure equal access to other types of productive resources. Managing emerging risks, however, may require additional policy approaches, such as the following.

Greater economic integration will bring with it increased exposure to employment shocks that will have gender-differentiated effects. Adequately addressing the risks associated with economic integration will require designing social protection programs that take into account the different risks faced by female and male workers. Building on the lessons from recent economic crises, several developing countries, including some from East Asia and the Pacific, have begun to recognize the gender dimensions of risk and shocks in the design of programs. In Indonesia, for example, a conditional cash transfer program, Keluarga Harapan, targets households with members who are particularly vulnerable during times of crisis, such as pregnant and lactating women.

As female migration across the region increases economic opportunities for women, it creates new concerns about female migrants' welfare. Protecting female migrants from exploitative situations, including sex work and human trafficking, will also require a gender-aware approach. Greater protection through better laws, enforcement, and monitoring; improved information flows; and safety nets will better address the vulnerabilities specific to women traveling abroad. Specific areas for action include improving legal protections for female migrants, strengthening the monitoring and credibility of recruitment agencies, and developing and providing welfare and support services to assist female migrants. Governments in both sending and receiving countries will need to actively address the 
issue of human trafficking through prevention, protection, and prosecution. Genderawareness training for people involved in the migration process will improve their ability to identify and assist abused female migrants, including those trafficked or at risk of being trafficked.

Growing urbanization in the East Asia and Pacific region has presented women not only with increased economic opportunities but also with particular challenges, such as limited access to child care and higher security risks in urban areas. Thus, policy makers need to ensure that child care, education, infrastructure, transportation, and water and sanitation policies take into account women's specific social and cultural needs. Rigorous laws and policies to protect women in urban areas from the risk of violence and exploitation are also warranted.

Rapid population aging in the region is likely to have important gender-differentiated effects, among other things, because older women may increasingly find themselves living as widows. Along with risks from urbanization and the breakdown of extended family support networks, these women are likely to find themselves at increased economic risk, having accumulated relatively few assets and mostly lacking access to formal social security. In this context, designing old-age income security programs that can protect women from destitution in old age will have an increasingly important role. In addition, policy makers should consider ways to strengthen care for the elderly to ensure that women do not bear an undue burden of caregiving as the region's population ages.

\section{Filling knowledge gaps}

Finally, while much has been learned from recent global and regional evidence on gender equality and development, much remains to be understood empirically to help inform effective public action. Continuing to close data and analytical gaps will thus be important to better understand policy priorities, the effects of specific interventions, and the costs and benefits of different policy options. To fill knowledge gaps, additional gender-disaggregated data need to be collected. Moreover, additional empirical analysis, both on long-standing gender issues and the gender implications of emerging trends in the region, will enable policy makers to better promote both gender equality and more effective development.

\section{Notes}

1. Sen (1999) defines freedoms and "unfreedoms" in five categories: (a) political freedoms, (b) economic facilities, (c) social opportunities, (d) transparency guarantees, and (e) protective security.

2. Adopted in 1979 by the United Nations General Assembly, CEDAW is often referred to as the international bill of rights for women. The convention defines what constitutes discrimination against women and provides an agenda for national action to end such discrimination. To date, it has been ratified by 187 countries worldwide (http://www.un.org/ womenwatch/daw/cedaw/).

3. It is important to interpret these studies with caution, given the difficulty in establishing a causal relationship between gender equality in education and growth in cross-country studies.

4. Evidence from Africa and Latin America, for example, suggests that ensuring equal access to productive assets and technologies could significantly raise agricultural production and household income (Goldstein and Udry 2008; Quisumbing 1995; Udry 1996).

5. Globally, poverty and gender often interact to compound gender inequalities (World Bank 2011c). In East Asia and the Pacific, poverty does not appear to be as important a contributor to gender disadvantage in education as elsewhere, however. Survey data from several countries in the region indicate that gender gaps in enrollment do not vary substantially or systematically across income quintiles.

6. For data on land holdings, by gender, in China, see de Brauw et al. (2011). Data on other countries are based on World Bank staff calculations, using household survey data.

7. As of the end of 2011 , only six countries in the world had not ratified CEDAW. Two of those countries are in the Pacific: Palau and Tonga (CEDAW, http://www.un.org/womenwatch/daw/cedaw/). 


\section{References}

Agarwal, Bina. 2010a. "Does Women's Proportional Strength Affect Their Participation? Governing Local Forests in South Asia.” World Development 38 (1): 98-112.

- - . 2010b. Gender and Green Governance: The Political Economy of Women's Presence Within and Beyond Community Forestry. New York: Oxford University Press.

Agarwal, Bina, and Pradeep Panda. 2007. "Toward Freedom from Domestic Violence: The Neglected Obvious." Journal of Human Development 8 (3): 359-88.

ASEAN (Association of Southeast Asian Nations). 2008. "ASEAN Continues to Empower Women". http://www.aseansec.org/BulletinFeb-08.htm\#Article-2.

Baulch, Bob, Truong Thi Kim Chuyen, Dominique Haughton, and Jonathan Haughton. 2002. "Ethnic Minority Development in Vietnam: A Socioeconomic Perspective." Policy Research Working Paper 2836, World Bank, Washington DC.

Beaman, Lori, Raghabendra Chattopadhyay, Esther Duflo, Rohini Pande, and Petia Topalova. 2009. "Powerful Women: Does Exposure Reduce Bias?" Quarterly Journal of Economics 124 (4): 1497-540.

Beegle, Kathleen, Elizabeth Frankenberg, and Duncan Thomas. 2001. "Bargaining Power within Couples and Use of Prenatal and Delivery Care in Indonesia." Studies in Family Planning 32 (2): 130-46.

BPS (Badan Pusat Statistik-Statistics Indonesia) and ORC Macro. 2003. Indonesia Demographic and Health Survey 2002-2003. Calverton, MD: BPS and ORC Macro.

Bruni, Lucilla, Andrew D. Mason, Laura Pabon, and Carrie Turk. 2011. "Gender Impacts of the Global Financial Crisis in Cambodia.” World Bank, Washington, DC.

Chattopadhyay, Raghabendra, and Esther Duflo. 2004. "Women as Policy Makers: Evidence from a Randomized Policy Experiment in India." Econometrica 72 (5): 1409-43

Chi, Wei, and Bo Li. 2007. "Glass Ceiling or Sticky Floor? Examining the Gender Pay Gap across the Wage Distribution in Urban China, 1987-2004.” MPRA Paper 3544, University Library of Munich, Germany.

Chong, Alberto, and Eliana La Ferrara. 2009. "Television and Divorce: Evidence from Brazilian Novelas." Journal of the European Economic Association 7 (2-3): 458-68.
CNNIC (China Internet Network Information Center) Internet Statistics. Beijing, China. http:// www1.cnnic.net.cn/en/index/0O/index.htm.

Constable, Nicole. 2009. "Migrant Workers and the Many States of Protest in Hong Kong." Critical Asian Studies 41 (1): 143-64.

Cuberes, David, and Marc Teignier-Baqué. 2011. "Gender Inequality and Economic Growth." Background paper for the World Development Report 2012, World Bank, Washington, DC.

Dahlerup, Drude. 2006. "Introduction." In Women, Quotas and Politics, edited by Drude Dahlerup, 3-31. London and New York: Routledge.

de Brauw, Alan, Jikun Huang, Linxiu Zhang, and Scott Rozelle. 2011. "The Feminization of Agriculture with Chinese Characteristics.” Background paper for the World Development Report 2012, World Bank, Washington, DC.

Do, Quy-Toan, Andrei Levchenko, and Claudio Raddatz. 2011. "Engendering Trade.” Policy Research Working Paper 5777, World Bank, Washington, DC.

Duflo, Esther. 2000. "Child Health and Household Resources in South Africa: Evidence from the Old Age Pension Program." American Economic Review 90 (2): 393-98.

_. 2003. "Grandmothers and Granddaughters: Old-Age Pensions and Intrahousehold Allocation in South Africa." World Bank Economic Review 17 (1): 1-25.

Dwyer, Jeffrey, and Raymond Coward. 1992. "Gender and Family Care of the Elderly: Research Gaps and Opportunities.” In Gender, Families, and Elder Care, edited by Jeffrey W. Dwyer and Raymond T. Coward, 151-62. London: Sage.

Edlund, Lena, and Rohini Pande. 2001. "Why Have Women Become Left-Wing? The Political Gender Gap and the Decline in Marriage.” Quarterly Journal of Economics 117 (3): 917-61.

Enterprise Surveys database. World Bank/ International Finance Corporation, Washington, DC. http://www.enterprisesurveys.org/.

FAO (Food and Agriculture Organization)/Sida Partnership Cooperation. 2010. National Gender Profile of Agricultural Households, 2010: Report Based on the Lao Expenditure and Consumption Surveys, National Agricultural Census and Population Census. Vientiane, Lao PDR: FAO.

Fehringer, Jessica, and Michelle J. Hindin. 2009. "Like Parent, Like Child: Intergenerational Transmission of Partner Violence in Cebu, the 
Philippines." Journal of Adolescent Health 44 (4): 363-71.

Filmer, Deon, and Norbert Schady. 2008. "Getting Girls into School: Evidence from a Scholarship Program in Cambodia." Economic Development and Cultural Change 56 (3): 581-617.

- 2009. "School Enrollment, Selection and Test Scores.” Policy Research Working Paper Series 4998, World Bank, Washington, DC.

Ganster-Breidler, Margit. 2010. "Gender-Based Violence and the Impact on Women's Health and Well-Being in Papua New Guinea." DWU Research Journal 13.

Goldstein, Markus, and Christopher Udry. 2008. "The Profits of Power: Land Rights and Agricultural Investment in Ghana." Journal of Political Economy 116 (6): 981-1022.

Hicks, Joan, Hamory Hicks, Michael Kremer, Isaac Mbiti, and Edward Miguel. "Vocational Education Voucher Delivery and Labor Market Returns: A Randomized Evaluation Among Kenyan Youth," Report for Spanish Impact Evaluation Fund (SIEF) Phase II, World Bank, Washington, DC.

HNPStats Population Projections database. World Bank, Washington, DC. http://go.worldbank. org/H4UN4D5KI0

ICRW (International Center for Research on Women). 2006. Property Ownership and Inheritance Rights of Women for Social Protection: The South Asia Experience. Washington, DC: ICRW.

ILO (International Labour Organization). 2008. Women's Entrepreneurship Development Aceh: Gender and Entrepreneurship Together (GET Abead) Training Implementation: Impact Assessment. Jakarta, Indonesia: ILO Jakarta Office.

- Key Indicators of the Labour Market (KILM) database. International Labour Organization, Geneva, Switzerland. http://kilm.ilo .org/kilmnet/.

Indonesia Family Life Survey. 2007/2008. RAND Family Life Surveys, IFLS-4. http://www.rand .org/labor/FLS/IFLS/ifls4.html.

Jensen, Robert, and Emily Oster. 2008. "The Power of TV: Cable Television and Women's Status in India." University of Chicago, IL. http://home.uchicago.edu/eoster/tvwomen .pdf.

Johnson, Kiersten, Sovanratnak Sao, and Darith Hor. 2000. Cambodia 2000 Demographic and Health Survey: Key Findings. Calverton, MD: ORC Macro.
Judd, Ellen R. 2010. "Family Strategies: Fluidities of Gender, Community and Mobility in Rural West China." China Quarterly 204: 921-38.

Klasen, Stephan. 2002. "Low Schooling for Girls, Slower Growth for All? Cross-Country Evidence on the Effect of Gender Inequality in Education on Economic Development." World Bank Economic Review 16 (3): 345-73.

Knowles, Stephen, A. K. Lorgelly, and Dorian Owen. 2002. "Are Educational Gender Gaps a Brake on Economic Development? Some Cross-Country Empirical Evidence." Oxford Economic Papers 54 (1): 118-49.

La Ferrara, Eliana, Alberto Chong, and Suzanne Duryea. 2008. "Soap Operas and Fertility: Evidence from Brazil.” BREAD Working Paper 172, Bureau for Research and Economic Analysis of Development, Duke University, Durham, NC.

Lewis, Ione, Bessie Maruia, and Sharon Walker. 2008. "Violence against Women in Papua New Guinea." Journal of Family Studies 14: 183-97.

Lott, John R., and Lawrence W. Kenny. 1999. "Did Women's Suffrage Change the Size and Scope of Government?" Journal of Political Economy 107 (6): 1163-98.

Maffii, Margherita, and Sineath Hong. 2010. "Political Participation of Indigenous Women in Cambodia." Asien 114-15 (April): 16-32.

Morrison, Andrew, Mary Ellsberg, and Sarah Bott. 2007. "Addressing Gender-Based Violence: A Critical Review of Interventions." World Bank Observer 22 (1): 25-51.

Naudeau, Sophie, Naoko Kataoka, Alexandria Valerio, Michelle Neuman, and Leslie Elder. 2011. Investing in Young Children: An Early Childhood Development Guide for Policy Dialogue and Project Preparation. Washington, DC: World Bank.

National Center for Injury Prevention and Control. 2003. Costs of Intimate Partner Violence against Women in the United States. Atlanta, GA: Centers for Disease Control and Prevention.

NIPH (National Institute of Public Health [Cambodia]), NIS (National Institute of Statistics [Cambodia]) and ORC Macro. 2006. Cambodia Demographic and Health Survey 2005. Phnom Penh, Cambodia, and Calverton, Maryland, USA: NIPH, NIS, and ORC Macro.

NSD (National Statistics Directorate [TimorLeste]), Ministry of Finance [Timor-Leste], and ICF Macro. 2010. Timor-Leste Demographic 
and Health Survey 2009-10. Dili, TimorLeste: NSD and ICF Macro.

Ofstedal, Mary Beth, John E. Knodel, and Napaporn Chayovan. 1999. "Intergenerational Support and Gender: A Comparison of Four Asian Countries." Southeast Asian Journal of Social Sciences 27 (2): 21-41.

PARLINE database on national parliaments. Inter-Parliamentary Union, Geneva. http:// www.ipu.org/parline-e/parlinesearch.asp and http://www.ipu.org/wmn-e/world.htm.

PovcalNet (online poverty analysis tool). Development Research Group, World Bank, Washington, DC. http://iresearch.worldbank .org/PovcalNet/index.htm.

Pronyk, Paul M., James R. Hargreaves, Julia C. Kim, Linda A. Morison, Godfrey Phetla, Charlotte Watts, Joanna Busza, and John D. H. Porter. 2006. "Effect of a Structural Intervention for the Prevention of Intimatepartner Violence and HIV in Rural South Africa: A Cluster Randomized Trial." Lancet 2368 (9551): 1973-83.

Qian, Nancy. 2008. "Missing Women and the Price of Tea in China: The Effect of Sex-Specific Earnings on Sex Imbalance." Quarterly Journal of Economics 123 (3): 1251-85.

Quisumbing, Agnes. 1995. "Gender Differences in Agricultural Productivity: A Survey of Empirical Evidence." FCND Discussion Paper No. 5, Food Consumption and Nutrition Division, International Food Policy Research Institute, Washington, DC.

Rodgers, Yana, and Nidhiya Menon. Forthcoming. "Impact of the 2008-2009 Twin Economic Crises on the Philippine Labor Market." World Development.

Sakellariou, Chris. 2011. "Determinants of the Gender Wage Gap and Female Labor Force Participation in EAP." Paper commissioned for Toward Gender Equality in East Asia and the Pacific: A Companion to the World Development Report, Washington, DC: World Bank.

Sen, Amartya. 1999. Development as Freedom. Oxford, U.K.: Oxford University Press.

SPC (Secretariat of the Pacific Community), Ministry of Internal and Social Affairs [Republic of Kiribati], and Statistics Division [Republic of Kiribati]. 2010. Kiribati Family Health and Support Study: A Study on Violence against Women and Children. Nouméa, New Caledonia: SPC.

SPC (Secretariat of the Pacific Community) and NSO (National Statistics Office) [Solomon
Islands]. 2009. Solomon Islands Family Health and Safety Study: A Study on Violence against Women and Children. Nouméa, New Caledonia: SPC.

SUSI (Survei Usaha Terintegrasi). 2002. Integrated Survey of Cottage and Small-Scale Firms, Indonesia. BPS. http://dds.bps.go.id.

Swaminathan, Hema, Cherryl Walker, and Margaret A. Rugadya, eds. 2008. Women's Property Rights, HIV and AIDS, and Domestic Violence: Research Findings from Two Rural Districts in South Africa and Uganda. Cape Town: HSRC Press.

Thomas, Duncan. 1995. "Like Father, Like Son, Like Mother, Like Daughter, Parental Resources and Child Height." Papers 95-01, RAND Reprint Series, Rand Corporation, Santa Monica, CA.

Udry, Christopher. 1996. "Gender, Agricultural Production, and the Theory of the Household." Journal of Political Economy 104 (5): 1010-14.

UN (United Nations Department of Economic and Social Affairs, Population Division). 2010. World Urbanization Prospects: The 2009 Revision. New York: United Nations. http:// esa.un.org/unpd/wup/index.html.

UNDP (United Nations Development Programme). 2010. Asia-Pacific Human Development Report. Power, Voice and Rights: A Turning Point for Gender Equality in Asia and the Pacific. Colombo, Sri Lanka: Macmillan Publishers India Ltd. for UNDP.

UNDP (United Nations Development Program) Cambodia and VBNK. 2010. Talking About Domestic Violence: A Handbook for Village Facilitators. Phnom Penh: UNDP Cambodia and the Agencia Española de Cooperación para el Desarrollo.

UNFPA (United Nations Population Fund). 2008. An Assessment of the State of Violence against Women in Fiji. Suva, Fiji.

USCDC (United States Centers for Disease Control and Prevention). 2003. "Costs of Intimate Partner Violence against Women in the United States." USCDC, National Center for Injury Prevention and Control, Atlanta, Georgia.

U.S. Department of State 2011. Trafficking in Persons Report 2011. Washington, DC: U.S. Department of State.

Utomo, Iwu, Peter McDonald, Terence Hull, Ida Rosyidah, Tati Hattimah, Nurul Idrus, Saparinah Sadli, and Jamhari Makruj. 2009. "Gender Depiction in Indonesian School Text Books: Progress or Deterioration.” Australian 
Demographic and Social Research Institute, Australian National University.

VWC (Vanuatu Women's Centre) in partnership with the Vanuatu National Statistics Office. 2011. Vanuatu National Survey on Women's Lives and Family Relationships. Port Vila, Vanuatu: VWC.

Wang, Zhengxu, and Weina Dai. 2010. “Women's Participation in Rural China's Self-Governance: Institutional, Socioeconomic, and Cultural Factors in a Jiangsu County." Discussion Paper 69, China Policy Institute, University of Nottingham, U.K.

WHO GWH (World Health Organization, Department of Gender, Women and Health). 2007. Integrating Gender into the Curricula for Health Professionals, Meeting Report, 4-6 December 2006. Geneva: WHO.
World Bank. 2008. Vietnam: Analysis of the Impact of Land Tenure Certificates with Both Names of Wife and Husband: Final Report. Washington, DC: World Bank.

- 2010. World Development Indicators 2010. Washington, DC: World Bank.

—_. 2011a. "Lao PDR Country Gender Assessment." World Bank, Washington, DC.

. 2011b. "Vietnam Country Gender Assessment." World Bank, Washington, DC.

. 2011c. World Development Report 2012: Gender Equality and Development. Washington, DC: World Bank.

World Values Survey database. World Values Survey Association, Stockholm, Sweden. http:// www.worldvaluessurvey.org/. 



\section{The State of Gender Equality in East Asia and the Pacific}

I

$n$ recent decades, women across the globe have made advances toward gender equality. Literacy rates for young women and girls are higher than ever before, and gender gaps in primary education have closed in almost all countries across the world. In the past three decades, over half a billion women have joined the world's labor force (World Bank 2011b).

Strides toward gender equality in East Asia and the Pacific have been similarly noteworthy. Most countries in the region have either reached or surpassed gender parity in education enrollments. Health outcomes for both women and men have improved significantly. Female labor force participation rates in the region are relatively high. Yet despite considerable progress in this economically dynamic region, gender disparities persist in a number of important areas-particularly in access to economic opportunity and in voice and influence in society. For policy makers in East Asian and Pacific countries, closing these gender gaps represents an important challenge to achieving more inclusive and effective development.

The East Asia and Pacific region's significant economic growth, structural transformation, and poverty reduction in the past few decades have been associated with reduced gender inequalities in several dimensions. The region grew at 7 percent on average between 2000 and 2008 (figure 1.1), the structure of the region's economies has shifted away from agriculture toward manufacturing and services, and extreme poverty has fallen dramatically. Indeed, the share of the region's population living on less than US\$1.25 a day has declined by more than 50 percent since 1990-from the highest poverty head count rate in the world to among the lowest (figure 1.2). Growth, structural transformation, and poverty reduction have been accompanied by considerable progress toward gender equality in several key areas, particularly education and health. Many countries in the region have experienced closing gender gaps in school enrollments and declining maternal and child mortality rates.

But growth and development have not been enough to attain gender equality in all its dimensions. Women still have less access than men to a range of productive assets and services, including land, financial capital, agricultural extension services, and new information technologies. Substantial employment segregation, or sorting, by gender still remains an issue. Women are less likely than 


\section{FIGURE 1.1 The East Asia and Pacific region has experienced rapid economic growth}

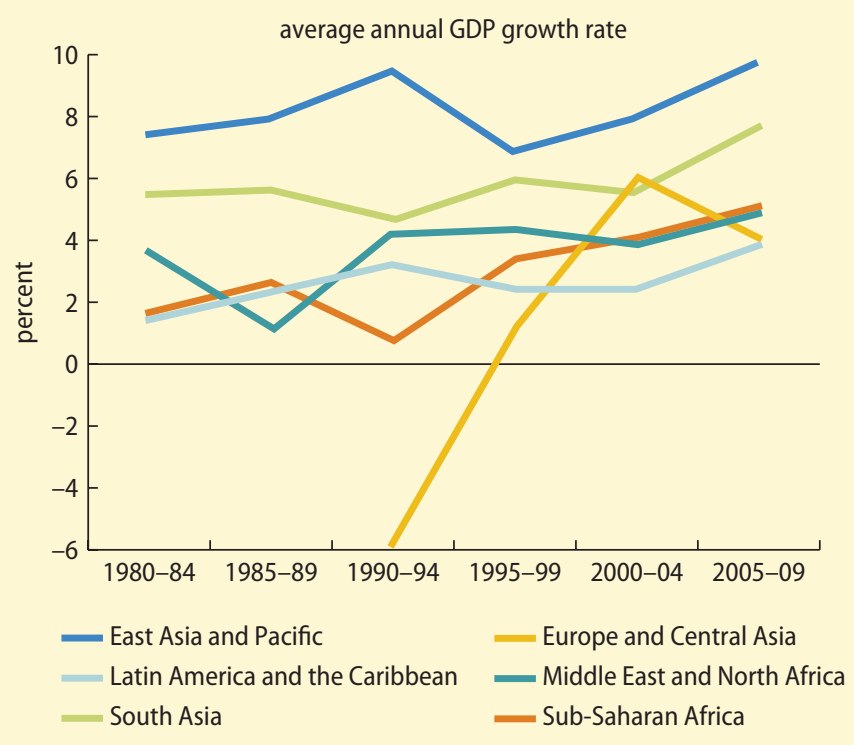

Source:World Bank 2010b

\section{FIGURE 1.2 Poverty reduction in the East Asia and Pacific} region has been impressive

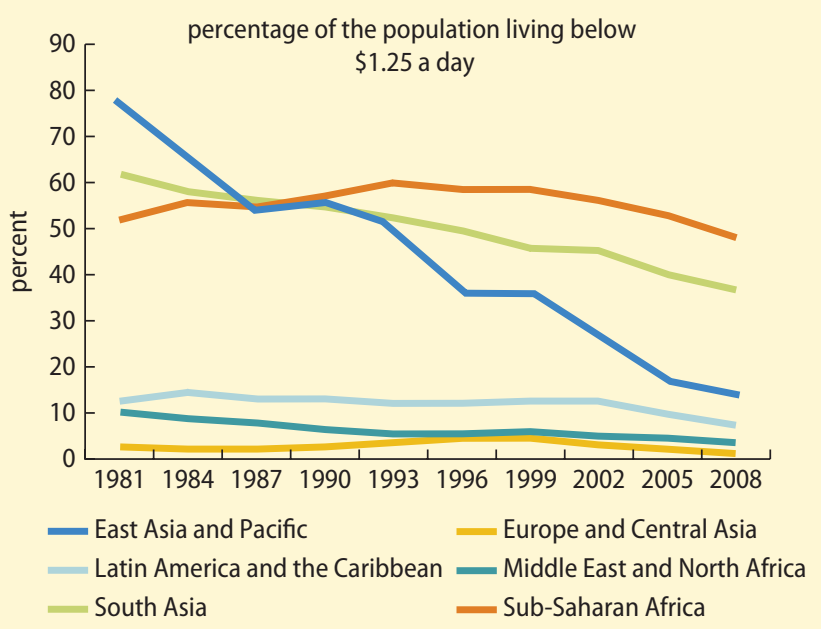

Source: PovcalNet.

men to work in formal sector jobs and more likely to work in poorly remunerated occupations and enterprises. And despite the closing of education gaps, women continue to be paid less than men for similar work. Women in East Asian and Pacific countries still have a weaker voice and less influence than men, whether in household decision making, in the private sector, in civil society, or in politics. Moreover, women across the region remain vulnerable to gender-based violence, often at the hand of an intimate partner.

The East Asia and Pacific region is vast and diverse, with large differences in economic and social progress, including toward gender equality. Achievements in growth and development have not been uniform across the region. Although average annual gross domestic product (GDP) growth during the first decade of the 2000s neared 10 percent in China, it was close to zero in several small Pacific Island countries. By the end of the decade, levels of GDP per capita among the low- and middle-income countries of the region also varied widely, from US\$623 in Timor-Leste to US\$8,373 in Malaysia (WDI database). Nor has progress toward gender equality been uniform. Despite widespread progress toward gender equality in schooling, a few (mostly low-income) countries continue to face challenges in closing gender gaps in basic education. In spite of broad improvements in health outcomes, China-and, to a lesser extent, Vietnam-face significant imbalances in the ratio of boys to girls at birth, a function of prenatal sex selection stemming from the strong preference for sons in those societies. As a result, the region has more than a million "missing" girls at birth per year.

A number of Pacific Island countries face particular challenges with respect to promoting women's voice, influence, and empowerment-in both the private and public spheres. For example, although gender-based violence remains pervasive in the region, its prevalence in the Pacific is among the highest in the world. Data from Solomon Islands, Kiribati, and Vanuatu indicate that more than 60 percent of adult women have experienced physical or sexual violence during their lifetime, often at the hands of an intimate partner (SPC, Ministry of Internal and Social Affairs, and Statistics Division 2010; SPC and NSO 2009; VWC 2011). 
Moreover, female representation in politics in the Pacific is among the lowest in the world. Although female political participation is relatively low worldwide-only 19.6 percent of the world's parliamentarians were women in December 2011—four of the eight countries in the world with no female parliamentarians were located in the Pacific (PARLINE database, 2011 data).

A growing body of literature also suggests that patterns of growth-not just levels-can affect gender equality by affecting incentives to invest in and to create opportunities for women and girls. Cross-country evidence indicates that gender gaps-in education and labor force participation, for example-tend to be smaller in countries that export more in relatively female labor-intensive sectors (Do, Levchenko, and Raddatz 2011). Recent studies have found that natural resource extraction, namely oil, reduces and discourages female labor force participation, which in turn reduces their political influence (Ross 2008; World Bank 2012a). Such distinctions in economic structure are relevant to the East Asia and Pacific context. East and Southeast Asian economies rely heavily on export-oriented manufacturing growth, whereas economies of the Pacific Islands are dominated by natural resource extraction, tourism, and remittances. These differences in economic incentives generated by distinct patterns of development may help to explain, at least in part, differences in progress toward gender equality in East Asian and Pacific countries, particularly with respect to voice and influence in society.

Several emerging trends in East Asian and Pacific countries will present both new opportunities and new risks to achieving gender equality. Much of the region is characterized by high levels of openness and economic integration with the rest of the world. Much of the region is also characterized by migration and rapid urbanization as the center of economic activities has moved from rural to urban areas. Increasing numbers of the region's citizens cross national boundaries in search of better economic opportunities. Swift declines in fertility and mortality are dramatically changing the demographic profile of the region, and many countries will face rapid population aging in the coming years. The region also experiences rising adoption of new information and communication technologies (ICTs), which are breaking down information barriers, opening up new economic opportunities, and enabling collective action in many contexts.

These trends are likely to have important gender dimensions, generating both new opportunities and new risks for gender equality. For instance, while increased economic integration has contributed to higher demand for female labor in several East Asian countries, it has also increased workers' vulnerability to external shocks, with different effects on females and males. Similarly, while increased migration has opened up new economic opportunities in the region, it has also been accompanied by new risks-among the most severe is the risk of human trafficking.

This report clarifies empirically the relationship between gender equality and development and outlines an agenda for public action to promote gender equality in East Asian and Pacific countries. Written as a companion to the World Development Report 2012: Gender Equality and Development (World Bank 2011b), the report makes several distinct contributions to policy makers' understanding of gender, development, and public policy in the region. First, the analysis focuses on those issues and policy challenges that are particularly relevant to East Asian and Pacific countries. For example, compared with other developing regions, female access to basic education is no longer a firstorder issue in many parts of the region. At the same time, gender stereotyping and gender "streaming" in education still represent critical challenges. These factors affect women's and men's aspirations and behaviors and contribute to persistent employment segregation. Second, the report examines the gender implications of several key emerging trends in the region: increased global economic integration, migration, urbanization, rapid population aging, and rising use of ICTs. 
These trends have important gender dimensions that are not commonly accounted for by policy makers but that will generate a distinct set of challenges for promoting gender equality going forward. Third, the report accounts for intraregional diversity in a way that is not possible in a global report. Particular emphasis is placed, where possible, on the challenges faced by countries in the Pacific as distinct from those in East Asia. Finally, the report has undertaken extensive empirical analysis of gender equality using a newly created database of household surveys for the region. In doing so, the report has contributed significantly to the development of indicators and evidence on gender, development, and public policy that were not available previously.

This chapter examines the state of gender equality in the East Asia and Pacific region, highlighting both recent progress and pending challenges. Following the World Development Report 2012, the discussion focuses on gender equality in three domains: (a) endowments, (b) economic opportunity, and (c) agency (see box 1.1). Endowments are defined here as human capital and other productive assets that allow individuals to live healthy and productive lives. To analyze gender equality in endowments, the discussion focuses on education and health as well as other productive assets, such as land. Economic opportunity pertains to an individual's ability to fully and freely participate in and receive returns from their work in the economy. The report focuses on a range of economic indicators, including labor force participation, earnings, and employment segregation, whether in the labor market or in self-employment. Agency is defined as the ability of women and men to express themselves (exercise voice) in accordance with their preferences and to take actions on their own behalf to influence their surroundings. Since people exercise agency in all aspects of life, the report focuses on multiple dimensions: agency within a household and in several aspects of the public domain, including civil society, the private sector, and politics. The report also focuses on safety and security as a dimension of agency, defining violence against women as the extreme deprivation of agency.

\section{Why does gender equality matter for development?}

Gender equality matters intrinsically. Nobel prize-winning economist Amartya Sen transformed the discourse on development when he argued that development is not only about raising people's incomes or reducing poverty, but rather involves a process of expanding freedoms equally for all people (Sen 1999). ${ }^{1}$ Viewed from this perspective, gender equality is intrinsically valued. The near-universal ratification and adoption of the Convention on the Elimination of All Forms of Discrimination against Women (CEDAW) ${ }^{2}$ - and the subsequent commitment of the international community to Millennium Development Goals 3 and 5-underscores a near-global consensus that gender equality and women's empowerment are development objectives in their own right.

Gender equality also matters for development. A growing body of empirical literature from around the world demonstrates that promoting gender equality is also good development policy, or as stated in the World Development Report 2012 (2011b, 3), "Gender equality ... is smart economics." Indeed, the literature shows that greater gender equality in endowments, access to economic opportunities, and agency can (a) contribute to higher productivity, income growth, and poverty reduction; (b) improve the opportunities and outcomes of the next generation; and (c) enhance development decision making. This section explores the evidence on these three pathways, in turn.

\section{Gender equality can contribute to higher productivity and income growth}

For households and economies to function at their full potential, resources, skills, and talent should be put to their most productive use. If societies allocate resources on 


\section{BOX 1.1 Defining and measuring gender equality}

Gender refers to the social, behavioral, and cultural attributes, expectations, and norms that distinguish men and women. Gender equality refers to the extent to which men's and women's opportunities and outcomes are constrained-or enhanced-solely on the basis of their gender. This book focuses on gender equality in three domains: (a) endowments-human and productive capital; (b) economic opportunityparticipation and returns in the economy; and (c) agency - the voice and influence of women in multiple dimensions in the private and public domains.

Gender equality can be conceptualized in two ways: in terms of equality of opportunities and equality of outcomes. Equality of opportunities measures inequalities that arise from circumstances beyond the control of individuals. Equality of outcomes measures equality of results (World Bank 2011b). Both concepts can be useful, depending on the domain.

In some domains, such as in health and education, where gender equality in outcomes may be inherently valued, it is reasonable to focus on equality of outcomes. In contrast, equality of opportunities may be the more relevant conception of gender equality in the economic sphere, where people's preferences may lead to different outcomes, even if their opportunities are equal. Despite these distinctions, it is often difficult to distinguish opportunities from outcomes empirically. As such, though the book will rely on both conceptions of gender equality in its analysis, data limitations often necessitate that the evidence focuses on measuring outcomes. the basis of one's gender, as opposed to one's skills and abilities, this comes at a cost. Indeed, the economic costs of gender inequalities-whether caused by the persistence of traditional norms or by overt discrimination-can be considerable. A recent study commissioned for the World Development Report 2012 found that in the East Asia and Pacific region, output per worker could be 7 to 18 percent higher across a range of countries if female entrepreneurs and workers were to work in the same sectors, types of jobs, and activities as men, and have the same access to productive resources (Cuberes and Teignier-Baqué 2011).

Evidence suggests that misallocation of female skills and talent commonly begins before women enter the labor force, when families and societies underinvest in girls' schooling. A number of cross-country studies have found a robust inverse relationship between the size of the gender gap in education and GDP growth, controlling for average education levels and other factors associated with economic growth (see, for example, Klasen 2002; Knowles, Lorgelly, and Owen 2002). ${ }^{3}$ Moreover, to the extent that young women (or men) choose fields of study on the basis of their gender rather than their abilities, this too will exact costs not only on individuals' employment and earnings, but also on a country's economic productivity more broadly.

Gender inequalities in access to productive assets also have costs in terms of productivity and income. Microeconomic studies from a number of countries across developing regions show that female farmers and entrepreneurs are inherently no less productive than male farmers and entrepreneurs; rather, they tend to have less access to productive inputs. ${ }^{4}$ A recent study by the Food and Agriculture Organization of the United Nations estimates that equalizing access to productive resources between female and male farmers could increase agricultural output in developing countries by 2.5 to 4.0 percent (FAO/Sida Partnership Cooperation 2010).

A number of studies show that genderbased violence also imposes significant costs on the economies of developing countries through lower worker productivity and incomes, lower human capital investments, and weaker accumulation of social capital 


\section{FIGURE 1.3 Girls' secondary school enrollments have converged to those of boys}

female-to-male ratio of secondary school gross enrollment

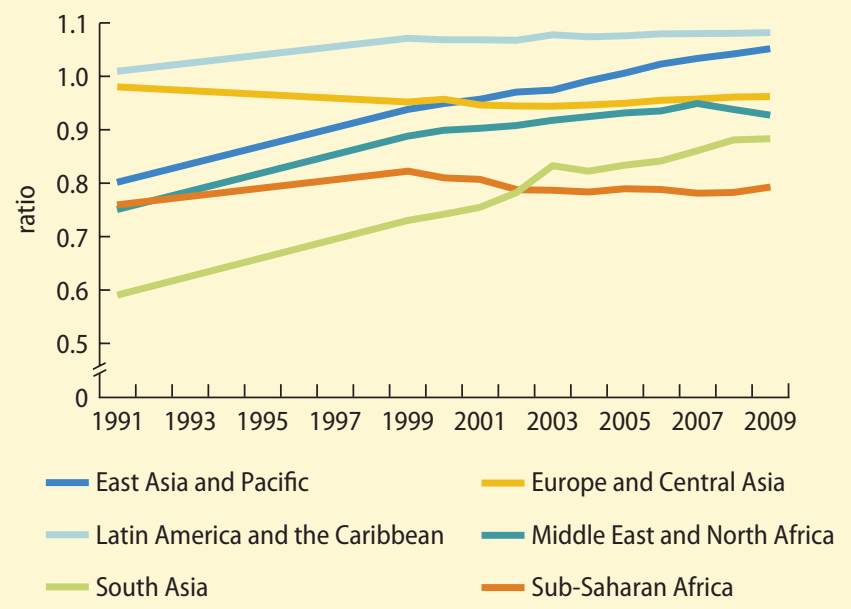

Source: World Bank 2011c

FIGURE 1.4 Tertiary school enrollments of females have converged to those of males in East Asia and the Pacific

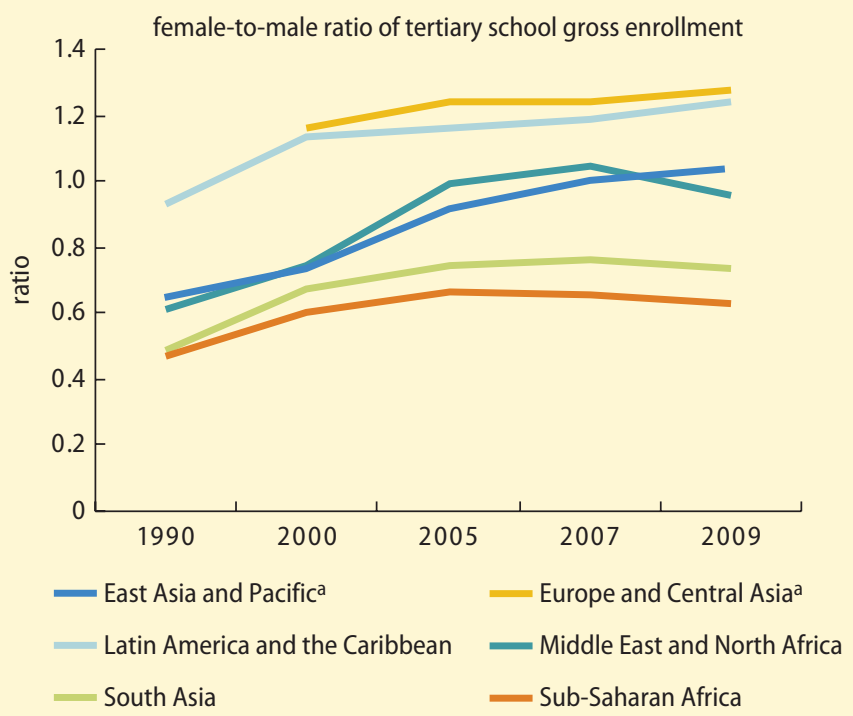

Source: UNESCO Institute for Statistics (UIS) Data Centre, 2009, 2011 data.

a. East Asia and Pacific includes developed countries. In this figure, Mongolia is included in Europe and Central Asia, not in East Asia and the Pacific.

(Morrison, Ellsberg, and Bott 2007). In addition to indirect costs, gender-based violence has large direct economic costs on society. A study in the United States found that the direct health care costs of intimate partner violence against adult women were more than $\$ 4$ billion USD in 1995 (USCDC 2003). Reducing gender-based violence would thus have significant positive effects on the region's economies by reducing health care costs and increasing investments in women's human capital, female worker productivity, and women's accumulation of social capital.

As the global economy becomes more integrated, the productivity effects associated with greater gender equality are likely to be increasingly important to East Asian and Pacific countries. A recent study on the relationship between gender and trade suggest that gender inequalities have become financially detrimental for countries in a world of open trade (Do, Levchenko, and Raddatz 2011). To participate effectively in an increasingly competitive world, countries will need to harness their resources efficiently by improving opportunities for all and allocating labor based on skill rather than by gender. Gender inequality, whether in endowments, economic opportunities, or in agency (voice), reduces a country's ability to compete in this increasingly globalized economic environment (World Bank 2011b).

\section{Promoting gender equality is also an investment in the next generation}

A large body of cross-country and countryspecific literature shows that healthier, better educated mothers have healthier, better educated children, which can be expected to positively affect children's future productivity and economic prospects. The effects begin even before childbirth. In Timor-Leste, highly educated mothers and those in the wealthiest households are more likely to have their babies delivered by skilled birth attendants than less educated mothers and those from poorer households (NSD, Ministry of Finance, and ICF Macro 2010). Similarly, Demographic and Health Survey data show that Cambodian women with little education are relatively less likely to receive prenatal care and assistance from trained health personnel during birth deliveries than women with higher education (Johnson, Sao, and Hor 2000). A mother's 
health and nutrition status is also found to strongly affect children's physical health as well as cognitive and noncognitive abilities, which can have long-lasting developmental and societal consequences (Nadeau et al. 2011).

Higher labor force participation, greater income earned, and more assets held by women have also been shown to have positive effects on the next generation. In Indonesia, for example, women with a higher share of household assets before marriage tend to use more prenatal care and are more likely to have their births attended by skilled health care providers (Beegle, Frankenberg, and Thomas 2001). Similarly, in China, increasing adult female income by 10 percent of the average household income raised the fraction of surviving girls by 1 percentage point and increased years of schooling for both boys and girls. In contrast, a similar increase in male income reduced survival rates and educational attainment for girls with no impact on boys (Qian 2008). Studies from across developing and developed regions (for example, from places as diverse as Brazil, Ghana, South Africa, and the United States) show that income in the hands of women positively affects their female children's health (Duflo 2003; Thomas 1995); commonly, the marginal effects of income and assets in the hands of mothers are larger than the effects of similar income and assets in the hands of fathers.

Reductions in gender-based violence through greater female agency can also have important intergenerational benefits. Several studies show that experiencing domestic violence between parents as a child contributes to a higher risk of both women experiencing domestic violence as adults and of men perpetrating violence against their spouses (Fehringer and Hindin 2009). In TimorLeste, 56.4 percent of women who were victims of spousal violence had a father who beat their mother (NSD, Ministry of Finance, and ICF Macro 2010). In Cambodia, women who reported that their mothers experienced domestic violence were more likely to experience physical and psychological domestic violence as well (NIPH, NIS, and ORC

\section{FIGURE 1.5 Gender gaps in secondary school enrollment vary substantially across countries}

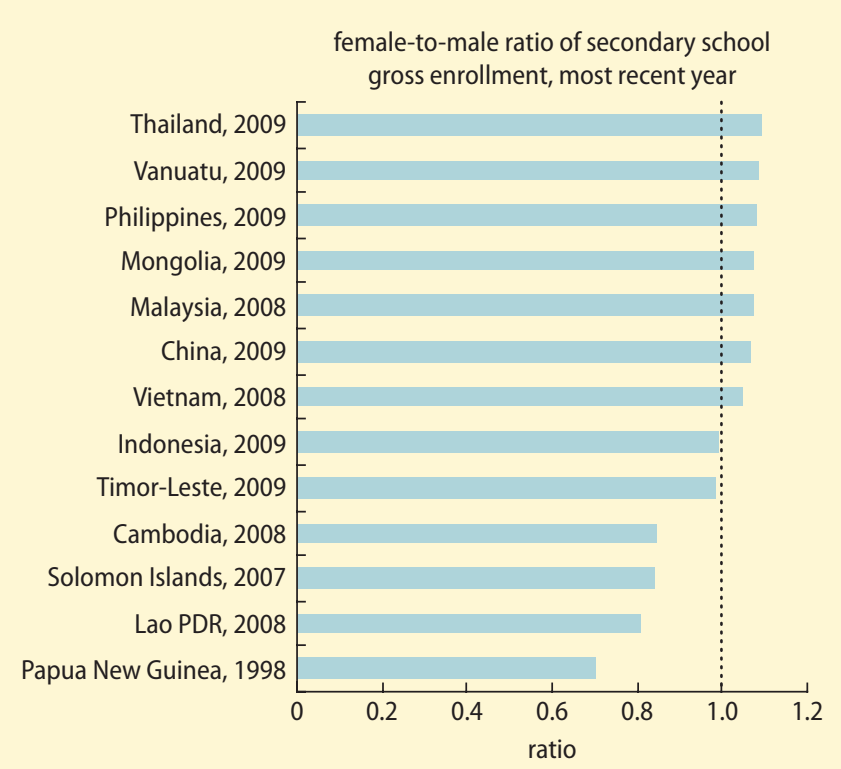

Source: World Bank 2011c

FIGURE 1.6 Gender gaps in education have reversed in several countries, particularly at the tertiary level

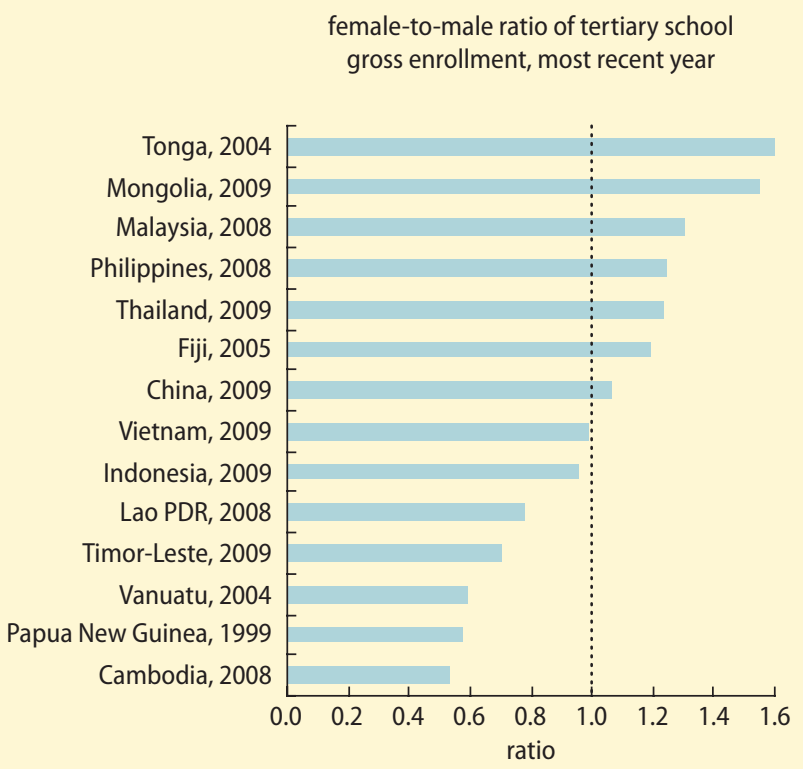

Source: UIS Data Centre, 2009, 2011 data. 


\section{FIGURE 1.7 Minority populations in Vietnam often experience} lower educational enrollments

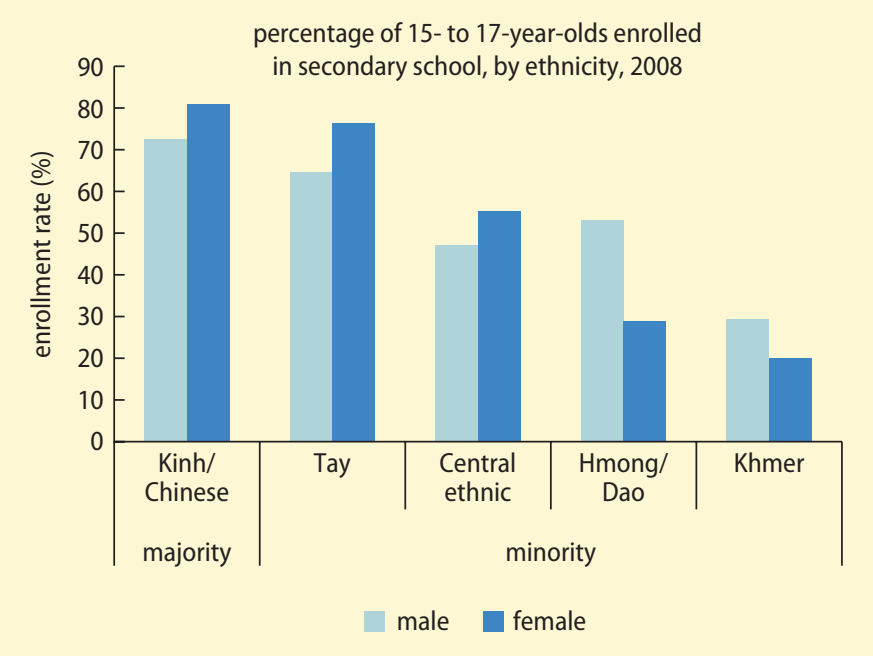

Source: World Bank 2011a.

FIGURE 1.8 In Indonesia, gender gaps in enrollment do not vary substantially by household wealth

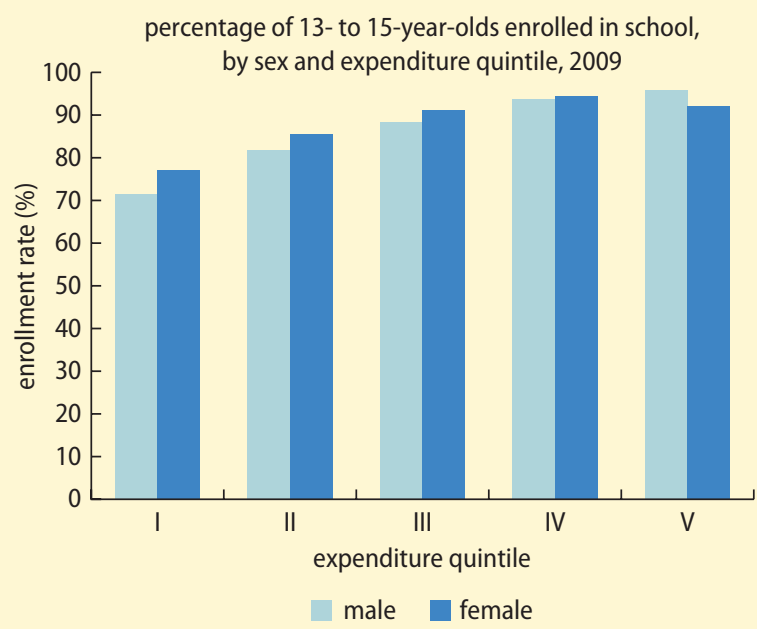

Source: World Bank estimates using Indonesia National Socioeconomic Survey 2009.

Macro 2006). Efforts that increase women's safety and security and that reduce domestic violence can thus lead to lower intergenerational transmission of violence within families. ${ }^{5}$

\section{Strengthening women's voice can enhance the quality of development decision making}

Several studies have shown that women and men have different policy preferences (Edlund and Pande 2001; Lott and Kenny 1999). Capturing these gender-based differences in perspective can lead to not only more representative but also better decision making. Evidence from India indicates that private firms can benefit from greater gender equality among the ranks of senior management. Other evidence from South Asia suggests the same is true with respect to development policy making. As an example, a study of women elected to local government in India found that female leadership positively affected the provision of public goods at the local level in ways that better reflected both women's and men's preferences (Chattopadhyay and Duflo 2004). Similarly, studies from rural India and Nepal found that when women who were previously excluded from decisions about local natural resource management had greater voice and influence, local conservation outcomes improved significantly (Agarwal 2010a, 2010b).

Women's collective agency can also be transformative, both for individuals and for society as a whole. For example, for a group of ethnic minority women in rural China, information sharing among them has helped empower them and raise their social standing in the Han-majority communities into which they married (Judd 2010). Migrant domestic workers in Hong Kong SAR, China, have been engaged in civic action focused on local migrant workers' rights as well as international human rights over the last 15 years (Constable 2009). These efforts have contributed to the enactment of laws that now provide migrant domestic workers in Hong Kong SAR, China, with some of the most comprehensive legal protections in the world.

\section{Recent progress, pending challenges}

Over the past few decades, many East Asian and Pacific countries have experienced 
considerable progress toward gender equality, at least in some dimensions. In others, gender disparities have been more persistent. This section reviews recent progress and pending challenges in achieving gender equality in endowments, economic opportunity, and agency in the region. It emphasizes where growth and development have contributed to advances in promoting gender equality and where this has not been sufficient. The section also highlights the considerable diversity of experience within the region as well as within countries. The basic gender profile developed here provides the foundation for the deeper analysis of gender, development, and public policy presented in subsequent chapters.

\section{Endowments: Human and productive capital}

Economic growth and poverty reduction in the region have been associated with rapid increases in female enrollment and convergence in the rates of school enrollment, across both genders and at all levels of education. In 2010, the region had the highest female-to-male enrollment ratio of all developing regions at the primary level. At the secondary enrollment level, only Latin America and the Caribbean had a higher ratio (figure 1.3). Although the female-tomale enrollment ratio in the East Asia and Pacific region is still below 1 at the tertiary level, it has been rising consistently over the past two decades (figure 1.4).

However, both overall enrollment rates and female-to-male enrollment ratios vary substantially across countries. Countries such as Cambodia, the Lao People's Democratic Republic, and Papua New Guinea still have relatively low enrollment levels and low female-to-male enrollment ratios, particularly at the secondary school level. Despite convergence in enrollment among the young, substantial gaps still remain in the educational endowments of adult populations. At the same time, the gender gap in education has reversed in several countries; girls' secondary enrollment rates now exceed those of boys in

\section{FIGURE 1.9 Fertility rates have declined across the world}

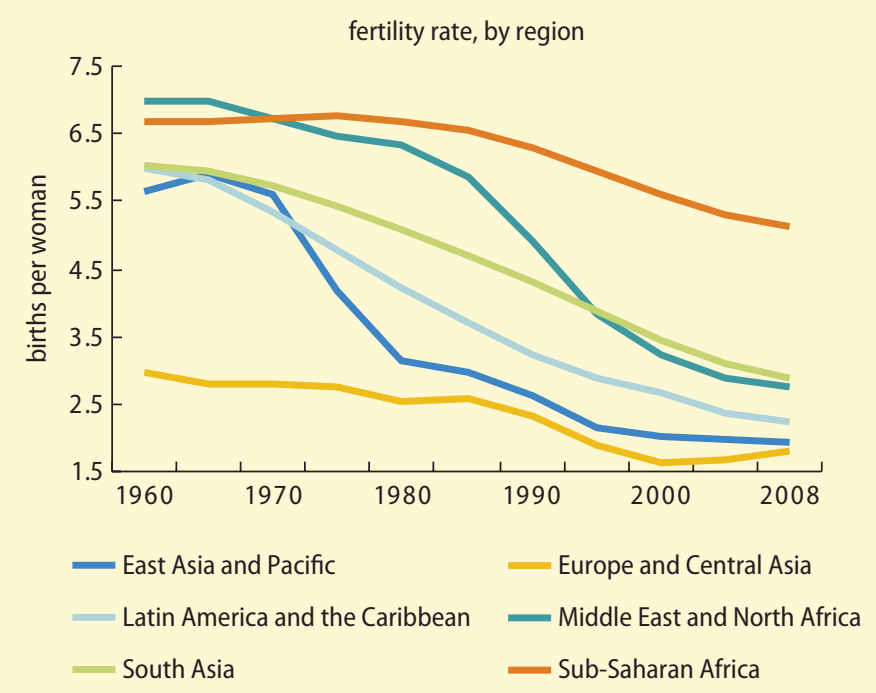

Source: World Bank 2010b.

FIGURE 1.10 Under-five mortality rates have declined sharply for both boys and girls

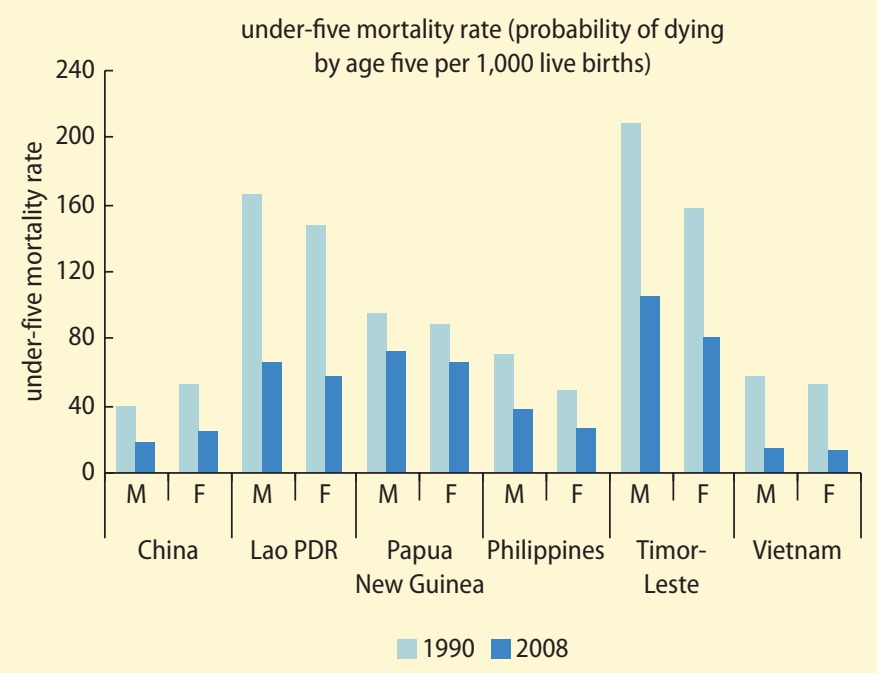

Source: World Health Organization (WHO) Global Health Observatory Data Repository. Note: $\mathrm{M}=$ male, $\mathrm{F}=$ female. The under-five mortality rate is defined as the probability of death derived from a life table and expressed as the rate per 1,000 live births.

countries such as China, Malaysia, Mongolia, the Philippines, Thailand, Vanuatu, and Vietnam (figure 1.5). Reverse gender gaps at the tertiary level are sometimes even starker (figure 1.6). 


\section{FIGURE 1.11 Maternal mortality rates have declined across the world}

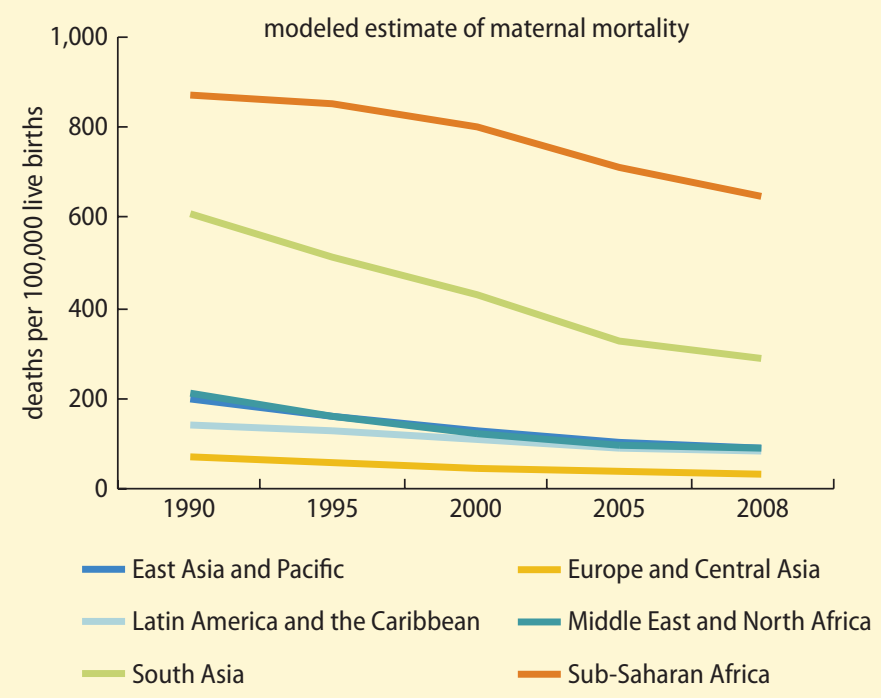

Source: World Bank 2010b.

FIGURE 1.12 Maternal mortality rate has declined in most countries in the region

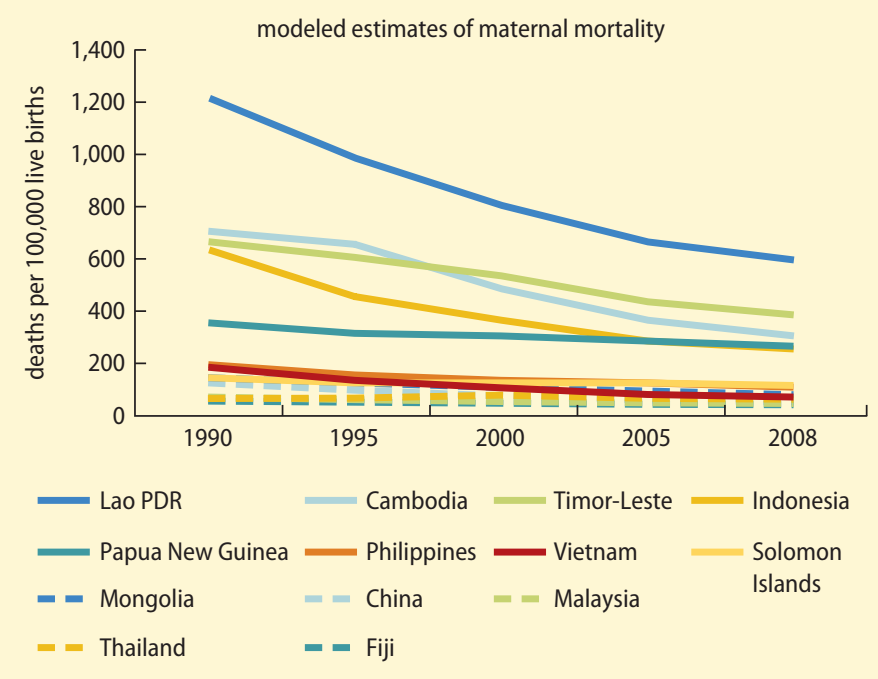

Source:World Bank 2010b.

Within countries, interactions between gender and other socioeconomic characteristics tend to exacerbate disparities in education. For example, economically disadvantaged and minority populations often experience lower educational enrollments. In Vietnam, school participation among 15- to 17-year-olds is substantially higher among the Kinh and Hoa (Chinese) majorities than among many of the 52 ethnic minority populations. Among the more economically disadvantaged and less well integrated Hmong, Dao, and Khmer minorities, far fewer girls attend school than boys (figure 1.7, and Baulch et al. 2002).

Globally, poverty and gender often interact to compound gender inequalities. Data suggest that, in East Asia and the Pacific, poverty is not as important a contributor to gender disadvantage in education as elsewhere in the world, however. Household survey data from several countries indicate that gender gaps in enrollment do not vary substantially or systematically across income quintiles. Indonesia, for example, actually shows a slight female advantage in enrollments among 13- to 15 -year-olds from poorer households, but a slight female disadvantage exists among the wealthiest households (figure 1.8). Overall, data from the region suggest that gender gaps in enrollment tend to be smaller than enrollment gaps across income or wealth groups.

Although gender disparities in enrollment have closed, education streaming persists. Males and females differ in the types of education obtained. Data from Indonesia, Thailand, and Vietnam indicate that the fields of engineering and law are dominated by males, whereas the fields of education, health, and business administration are dominated by females. ${ }^{6}$ This "gender streaming" in education contributes to persistent inequalities between women and men in access to economic opportunities.

Growth and development in the region during the past half century have also been associated with substantial improvements in key health indicators. Fertility rates have sharply declined, both in the region as well as across the world (figure 1.9). Underfive mortality rates have more than halved since 1990 for both boys and girls (figure 1.10). Noteworthy gains have been made in birth attendance by health professionals. In 2006, 87 percent of births were attended by 
physicians, compared to 47 percent in 1992. Gains of this magnitude were not witnessed in any other region. In addition, the East Asia and Pacific region has also seen declines in the maternal mortality rate, from approximately 200 deaths per 100,000 births in 1990 to 100 in 2008 (figure 1.11). The region has experienced consistent increases in both male and female life expectancy at birth since 1960. Female life expectancy in the region has increased from 48 to 74 , and male life expectancy has increased from 45 to 70 .

As with education, progress in health has been uneven across the region. Maternal mortality remains high in lower-income countries and in parts of the Pacific, especially in Cambodia, Lao PDR, Papua New Guinea, and Timor-Leste (figure 1.12). In Lao PDR, for example, maternal mortality rates were approximately 580 deaths per 100,000 births $^{7}$ in 2008, among the highest in the world. Indonesia's maternal mortality rate remains high compared to other countries in the region at similar levels of development. Women in remote rural areas commonly have limited access to health care, which significantly raises the risks associated with pregnancy and childbirth. Although Vietnam has, on average, experienced noteworthy declines in maternal mortality over the past decade, progress has been much slower in remote and ethnic minority regions (World Bank 2011a).

Moreover, more than a million girls and women per year are "missing" in East Asia. Despite growth and development, the problem of missing girls remains. The term missing women was first coined by Sen (1992) to refer to the phenomenon that many low-income countries have far fewer women than men, relative to what is observed in developed countries. Sen argued that this imbalance in sex ratios reflected severe forms of gender bias in affected societies. At birth, biological differences between males and females imply that approximately 105 boys are born for every 100 girls. Nonetheless, China, Vietnam, and, until recently, the Republic of Korea have experienced substantial deviations from the biological norm. Moreover, the trend over time in China has been alarming (figure 1.13). The number of missing girls at birth per year in China, calculated by comparing the sex ratio at birth in China to those in high-income countries, increased from 890,000 in 1990 to 1,092,000 in 2008 (World Bank 2011b).

Men face gender-specific health risks as well. For example, men are more likely to experience higher morbidity and premature mortality related to substance abuse, war and conflict, and violence. Cambodia experienced considerable declines in the male population during the Khmer Rouge regime of Pol Pot; so did Vietnam during its war era. Moreover, differences between men and women in the incidence of tobacco use are higher in East Asia and the Pacific than in other regions of the world; the gender differential in heavy episodic alcohol consumption is also particularly stark. Male abuse of tobacco and alcohol in the region has important effects on men's health and mortality rates, which in turn can impose significant costs on economic productivity and growth.

Gender disparities still exist in access to and control of productive resources. Gender disparities in access to and control of land or farm inputs are pervasive around the world and remain issues in the region, despite significant growth and development. Women remain less likely to own land (or hold formal land titles) than men. Moreover, data from Cambodia, China, Indonesia, Lao PDR, Mongolia, Timor-Leste, and Vietnam indicate that when women-or, specifically, female-headed households-do own land, they typically have smaller holdings. ${ }^{8} \mathrm{~A}$ recent study of women's land holdings in posttsunami Aceh similarly found that women's land holdings were considerably lower than men's (World Bank 2010). ${ }^{9}$ Female-headed households in the region also tend to have poorer access to other productive inputs and support services, including livestock holdings and access to agricultural extension services.

Despite improvements in women's access to microcredit, important challenges remain in accessing enterprise finance. Women also have traditionally had less access to capital than men. This disparity has been compounded by their poorer access to land, an 


\section{FIGURE 1.13 East Asia has a highly skewed male-to-female ratio at birth}

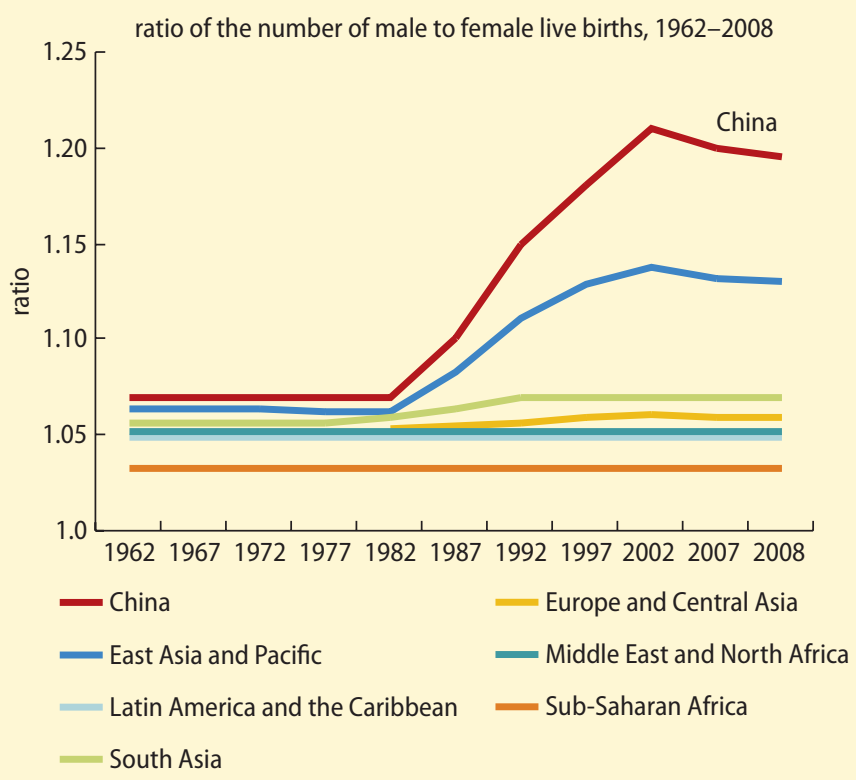

Source: HNP Stats (Health Nutrition Population Statistics) database, 2010 data.

\section{FIGURE 1.14 The East Asia and Pacific region has high female labor force participation rates}

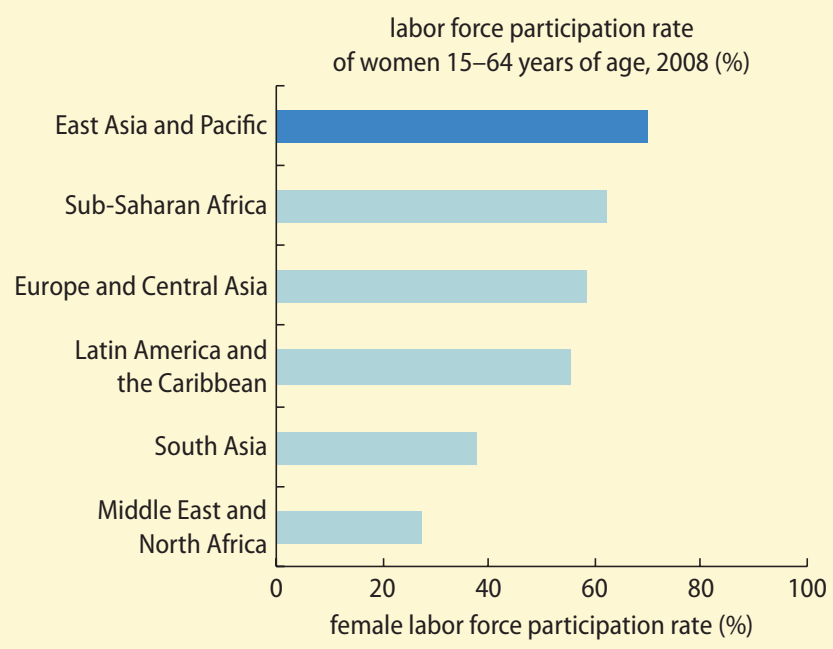

Source:World Bank 2010b. important source of collateral. In response to gender disparities in access to credit, the microfinance movement has focused on increasing women's access to capital across the world. Of the 106.6 million poorest clients worldwide who have been reached by microcredit initiatives by the end of 2007, 83.2 percent were women (Daley-Harris 2009). Evidence on access to credit among female and male entrepreneurs tells a more nuanced story. Among micro- and small firms in Indonesia, both female-and malerun enterprises cite access to finance as their most significant business constraint, with the share of female-run firms reporting this constraint only slightly higher than the share of male-run firms (30 versus 25 percent, respectively). Among small and medium enterprises in nine East Asian and Pacific countries, only in Timor-Leste and Tonga do a greater share of female-led enterprises report access to credit as a significantly more important constraint than reported by their male counterparts. ${ }^{10}$

\section{Economic opportunity: Participation and returns in the economy}

The East Asia and Pacific region has the highest average female labor force participation rate and highest ratio of female-to-male labor force participation in the developing world. In 2008, 70.1 percent of females were participating in labor market activities (figure 1.14) and the gender gap in labor force participation was approximately 15 percentage points. In comparison, the average female labor force participation rate in Latin America and the Caribbean was 55 percent in 2008, and in Europe and Central Asia it was 58 percent. Gender gaps in labor force participation were 27 and 16 percentage points, respectively.

Both the levels of female participation and their trends over time vary substantially in the region. In Cambodia, China, Lao PDR, Thailand, and Vietnam, for example, female labor force participation was over 75 percent in 1980. Between 1980 and 2008, these countries witnessed declines in female 
participation of 5 to 10 percentage points despite strong economic growth. Except for China, these declines were mirrored in similar drops in male participation, leaving the ratio of female-to-male participation rates unchanged. Participation rates in Korea, Indonesia, and Malaysia were significantly lower than the regional average: in 1980, only 45 percent of working-age females participated in the labor market. Female participation rates have increased over time in Korea and Indonesia, while they have remained stagnant in Malaysia despite strong economic growth. Female labor force participation varies substantially in the Pacific, ranging from over 75 percent in Vanuatu to 40 percent in Fiji in 2008 (figure 1.15). Although time series data for these countries are limited, female participation rates appear to have risen over time in countries with lower initial rates. In Fiji, female participation rates rose from 25 percent in 1980 to 40 percent in 2008 , and in Tonga they rose from 45 percent to 57 percent over the same period.

Structural transformation in the region's economies has changed the type of work conducted. The region has seen a significant decline in the fraction of the workforce in the agricultural sector over the past half century, from approximately 60 percent in 1991 to just over 40 percent in 2008 (figure 1.16). Between 1960 and 2000, agriculture's share of total employment declined from over 80 percent to under 50 percent in Thailand, while in Indonesia the share declined from 70 percent to approximately 45 percent (Butzer, Mundlak, and Larson 2003). Nonetheless, agriculture remains important: in 2008, it was still the largest sector of employment in the region (figure 1.16).

Women's labor market responses to structural transformation have, in part, reflected country-specific patterns of development. Thailand, for example, moved from a heavy concentration of workers in agriculture in 1980 to a rising employment share in the industrial and service sectors (figure 1.19). The early 1990s saw a substantial movement of females away from agriculture and out of the workforce. Similar patterns were

\section{FIGURE 1.15 Female labor force participation varies substantially across countries}

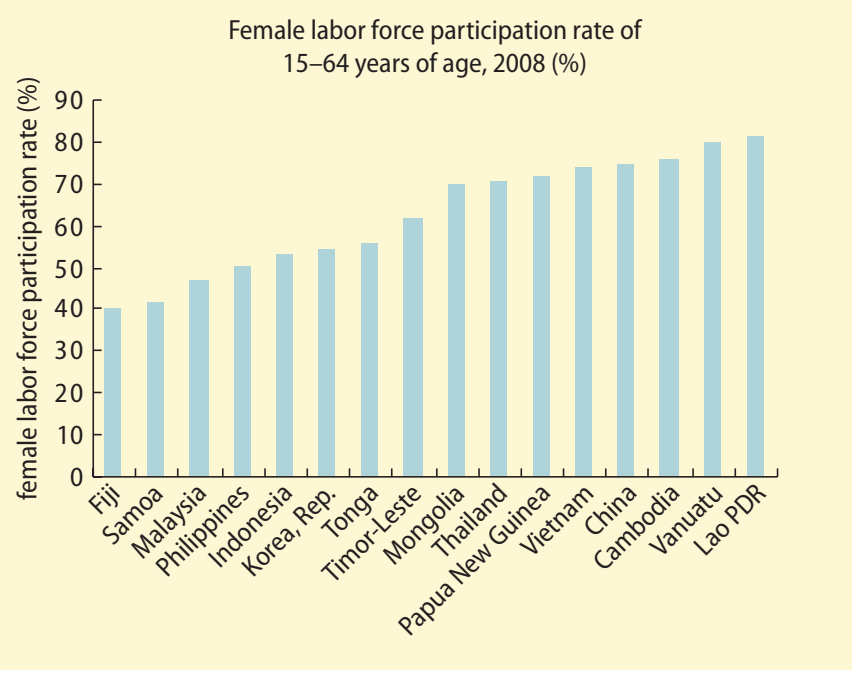

Source: World Bank 2010b

FIGURE 1.16 The fraction of the workforce employed in agriculture has declined in the East Asia and Pacific region

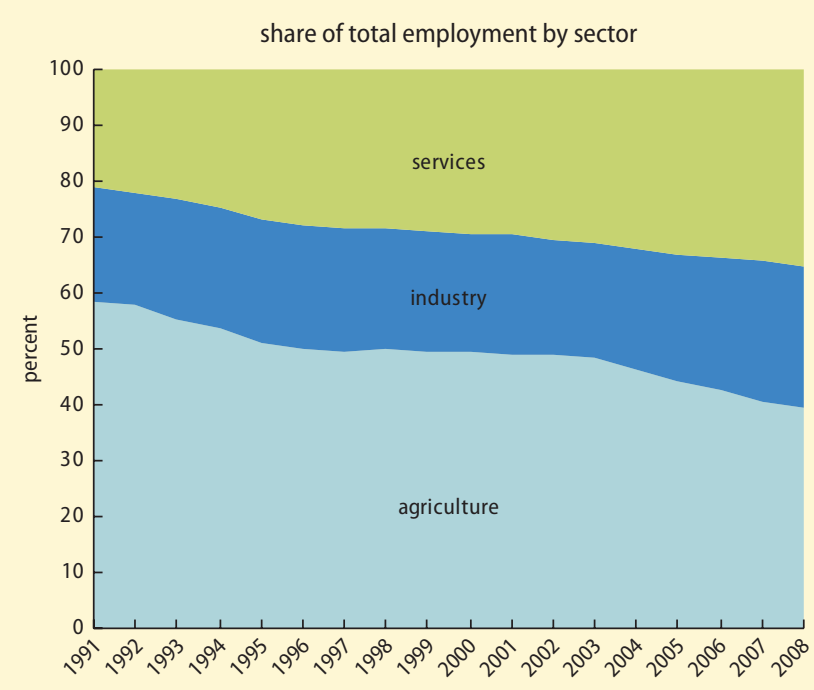

Source: World Bank 2010b

seen in the United States during the early stages of the transition away from agriculture (Goldin 1995; Mammen and Paxson 2000). In Indonesia, by contrast, female labor force participation increased by 9 percentage points between 1980 and 2007, 


\section{FIGURE 1.17 The evolution of sectoral composition by gender varies across countries}

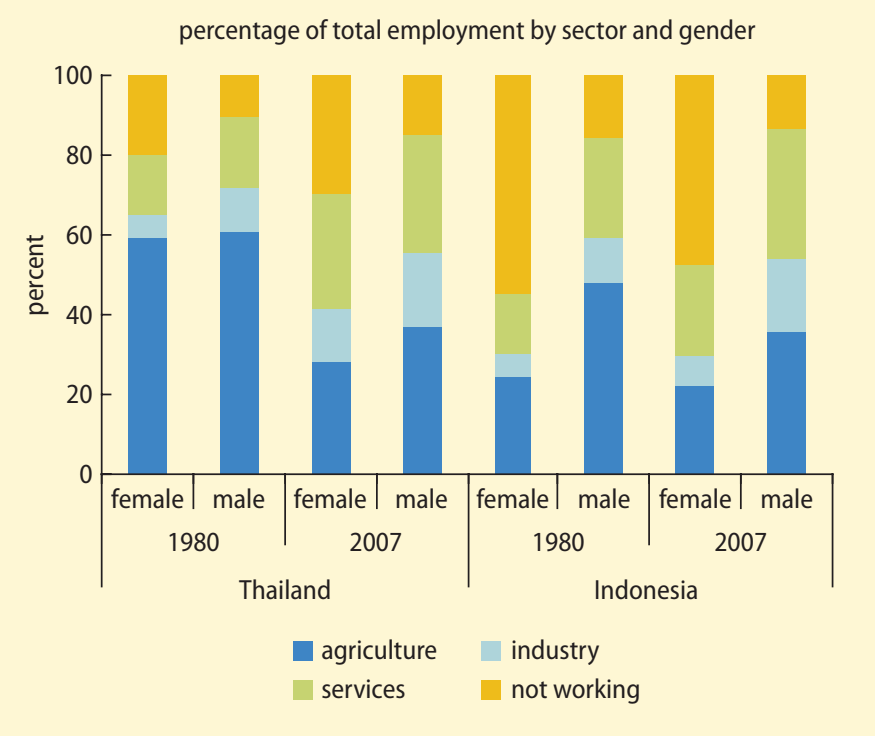

Source: World Bank 2010b

\section{FIGURE 1.18 Women are more likely than men to be temporary workers}

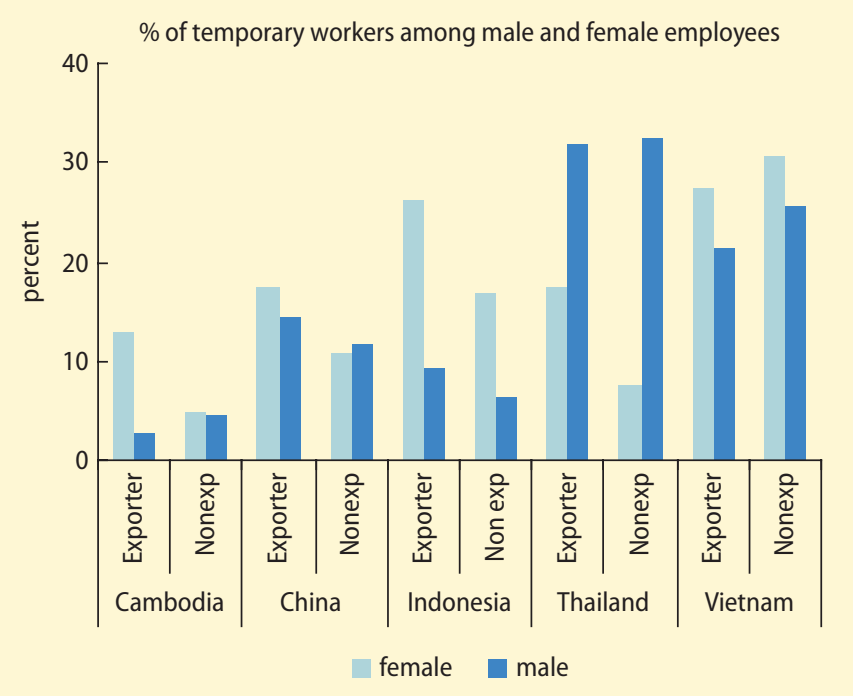

Source: World Bank estimates using Enterprise Surveys database, 2002-06 data.

Note: Nonexp = nonexporter. The percentage of temporary workers is calculated as a ratio of female temporary workers to female total workers. The analysis includes only manufacturing firms. with the bulk of the increase coming from the service sector (figure 1.17). Participation in industry and agriculture was fairly similar in 1980 and 2007.

Labor market "sorting"-or employment segregation-along gender lines is pervasive, by industry, occupation, formality, and flexibility of employment. Such sorting affects a number of economic outcomes, by gender, including earnings, social security coverage, the intensity of work conducted, returns to education and experience, and exposure to shocks. In many countries in the region, women are more likely than men to conduct unpaid family labor in agriculture and in the informal sector (Asia Foundation et al. 2006; Asian Development Bank and World Bank 2005; World Bank 2011a). In addition, women are more likely to be found in some occupations-such as teaching and nursing-and are less likely to be found in others, such as mining. Within the manufacturing sector, women are more likely to be found in industries such as textiles and food processing, and are also found in large and export-oriented firms. Within firms, women are more likely than men to be temporary workers (figure 1.18).

Female- and male-led enterprises also tend to have distinct characteristics. Female-led enterprises across the region tend to be smaller than male-led enterprises (figure 1.19). They are more likely to operate in the informal sector (less likely to be registered) and to be home based or operate out of nonpermanent premises. In general, female-led enterprises across the region have fewer employees and assets and command lower profits. Although female-owned and -managed enterprises are not inherently less productive, they tend to be less capitalized and located in lessremunerative sectors. For instance, in Indonesia, female-led enterprises are more likely to locate in the food and garment manufacturing sectors. These sectors are among the least capital intensive and least productive; male-led enterprises are more likely to locate in sectors such as transportation and other services, which are among the most capital intensive, most productive sectors. 
Women in East Asian and Pacific countries continue to undertake the majority of household work, in addition to market work, a function of longstanding gender norms regarding the division of labor within households. In many contexts, this tradition constrains women's economic opportunities, affecting their labor force participation, choice of sectors and occupations, time worked, and, ultimately, earnings. Global evidence indicates that women tend to work longer hours than men once both market and nonmarket work are taken into account (Ilahi 2000; World Bank 2001, 2011b). The composition of work also varies substantially by gender. Men devote relatively more time to market work, while women devote more time to domestic activities. Evidence from East Asia is consistent with global patterns. Recent data from Lao PDR indicate that both gender differences in hours worked and in the division of labor between market and nonmarket work are exacerbated once families have children (figure 1.20).

Cross-country evidence on wages indicates that in the low- and middle-income countries of East Asia, women earn between 70 and 80 percent of what men earn for similar work (figure 1.21). These gender wage gaps are partially attributable to differences in education, experience, and industrial choice across men and women. Differences in education endowments, experience, and industrial and occupational segregation explain up to 30 percent of the gender wage gap in East Asian countries (Sakellariou 2011).

While gender wage gaps have evolved over time, they have not always narrowed with growth and development. In Vietnam, the process of economic transition from a centrally planned to a market-based economy has been associated with a sharp reduction in the gender pay gap among salaried employees. The average gender pay gap halved between 1993 and 2008, with the majority of the contraction evident by 1998 (Pham and Reilly 2007; Sakellariou 2011). Pay gaps still persist between men and women, however, with women earning on average 75 percent of the male wage in 2009 (Pierre 2012). By

\section{FIGURE 1.19 Enterprises with female management tend to be smaller}

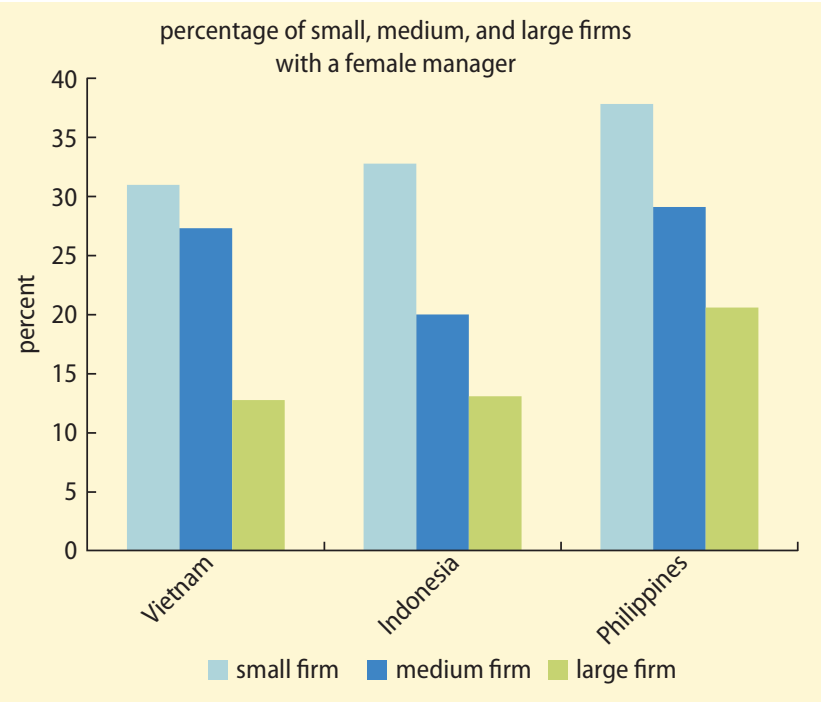

Source: World Bank estimates using Enterprise Surveys database, 2006-11 data.

FIGURE 1.20 In Lao PDR, women-particularly those with young children-must balance household work commitments with market work

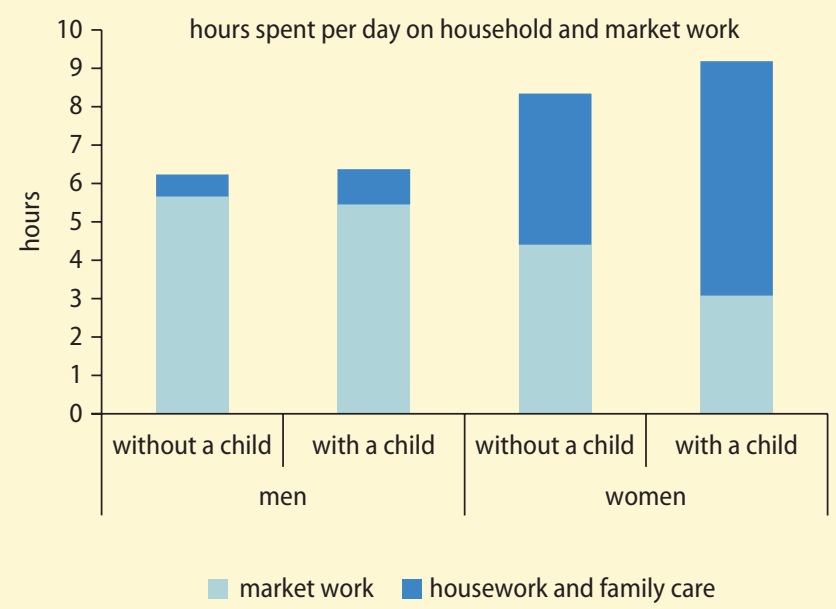

Source: World Bank estimates using the Lao Expenditure and Consumption Survey (LECS) (LSB Lao PDR 2008).

contrast, in the Philippines, the wage gap widened between 2000 and 2009, a change that has been partly attributed to growing differences between men and women in terms of their returns to education and other 
characteristics (Sakellariou 2011). In Indonesia, the average wage gap and the gap by age cohorts widened between 1976 and 1999 (Dhanani and Islam 2004), although more

\section{FIGURE 1.21 Women in East Asia still earn less than men}

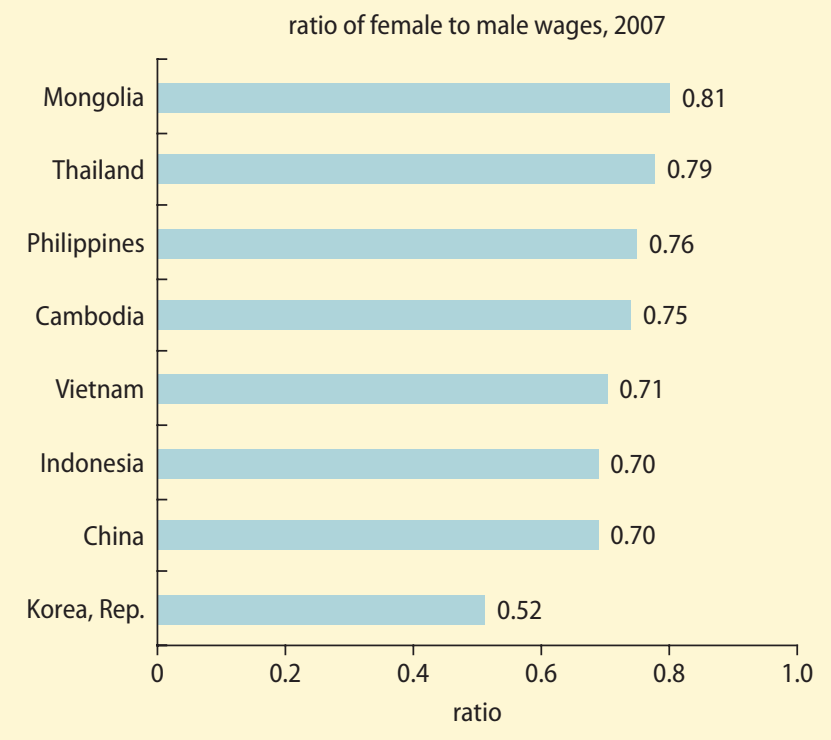

Source: World Bank 2010b. recent evidence suggests that the gender gap declined between 1997 and 2009 (Sakellariou 2011). This complex relationship between growth, development, and the gender wage gap reflects a number of factors at the country level, including changes in the structure of the economy and in labor demand; the gender composition of the labor force; changes in the relative education, skill, and experience among male and female workers; and labor market institutions and policies, each of which affect how remuneration is evolving by gender.

\section{Agency: Women's voice and influence}

East Asian and Pacific countries have experienced progress and pending challenges in achieving gender equality in agencywomen's voice and influence-as with endowments and economic opportunity discussed above. Agency refers to the ability of women and men to take action on their own behalf, in accordance with their preferences, and to influence outcomes that affect them in both private and public domains (box 1.2). The ability to influence

\section{BOX 1.2 Defining and measuring agency: Women's voice, influence, and participation}

All individuals in a society have ideas and preferences on how to use scarce resources and live their lives. The ability of women and men to express and act on their preferences is affected by-and also affects-their ownership and control over endowments and their access to economic opportunities (Kabeer 1999). This ability to act on one's preferences and influence outcomes is referred to as agency. Changes in individuals' characteristics in a household, community, or society will affect the strength of their voices relative to others, and may also influence their preferences. This influence, in turn, will affect choices made at the household, community, and societal levels. For example, an increase in the education of a woman will affect investments in the education and health of her children through its effect on both her relative bargaining power within the household (the extent to which her voice is heard) and, potentially, her preferences.

The concept of agency has multiple dimensions that have been measured empirically. The form of agency that is most frequently measured is the decision-making power of men and women (Mason 2005; McElroy 1990). Agency may be more explicitly measured by examining women's mobility in the public domain, their participation in public action, and the incidence of gender-based violence (Kabeer 1999). Finally, gender differences in bargaining power within a household have been assessed by examining the extent to which people's choices change when factors affecting their bargaining power, such as education, relative earnings, or asset holdings, also change (Duflo 2003; Quisumbing and Maluccio 2003; Thomas 1990, 1995). 
one's life by making choices and taking action is also a key dimension of well-being in and of itself (Sen 1999). This report focuses on agency in three domains: (a) agency in the household and individual decisions, examined through household decision making, control of resources, and reproductive decisions; (b) agency in the public sphere, examined through genderbased participation and representation in the private sector, civil society, politics, and public institutions; and (c) safety and security as an expression of agency, examined through the prevalence of genderbased violence. Although the East Asia and Pacific region has made progress in several domains of agency, progress has been uneven across countries, and many challenges still remain.

Women in East Asia experience relatively high levels of agency at the household level compared with other developing regions. Cross-country data suggest that women across the wealth distribution in East Asia have a greater say in decisions regarding large household purchases and also experience greater freedom to visit family and relatives without husbands' permission than do women in other developing regions. Women in East Asia also have as great as or greater control over their own earnings compared with women in other developing regions (figure 1.22). Reductions in fertility rates and unwanted fertility, defined as gaps between actual and desired fertility, observed in most East Asian and Pacific countries suggest that women may have gained greater control over their reproductive decisions.

Women's voice in the public domain remains weak despite economic development. Women have relatively low levels of representation in political assemblies, whether at the national or local levels. For example, women make up only one-fifth of national parliamentarians worldwide. The share of female parliamentarians in East Asian and Pacific countries is just below the global average, at approximately 18 percent in 2011 (figure 1.23). Female representation in the region has not increased over time with economic
FIGURE 1.22 Women in East Asia and the Pacific have more control over earnings and household decisions across all wealth quintiles than women from other developing regions

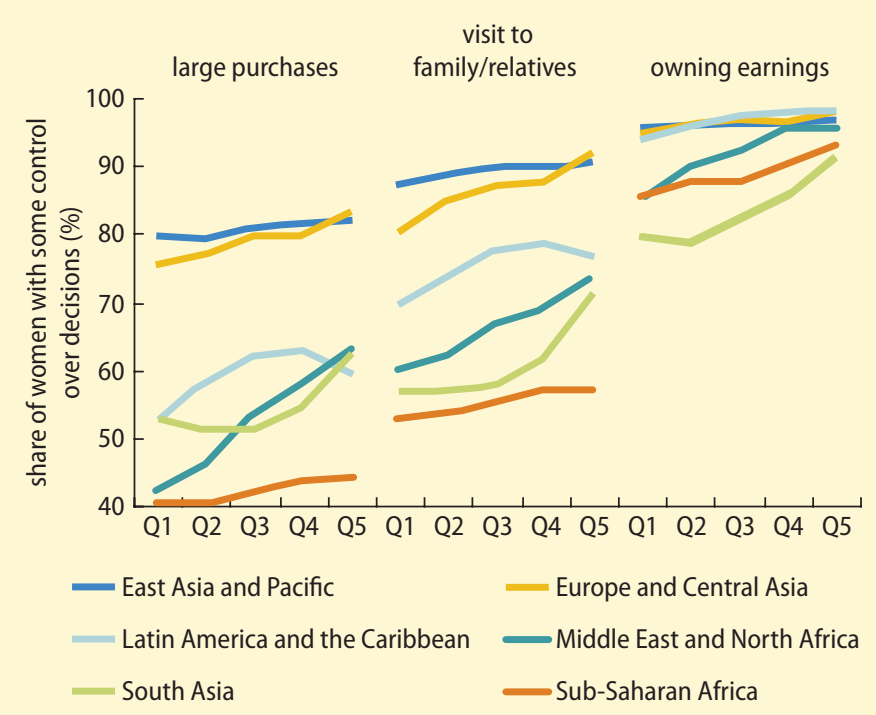

Source: World Development Report 2012 team estimates based on Demographic and Health Surveys of 40 countries, 2003-09.

FIGURE 1.23 Female representation in parliament in East Asian and Pacific countries has hardly changed since the 1990s

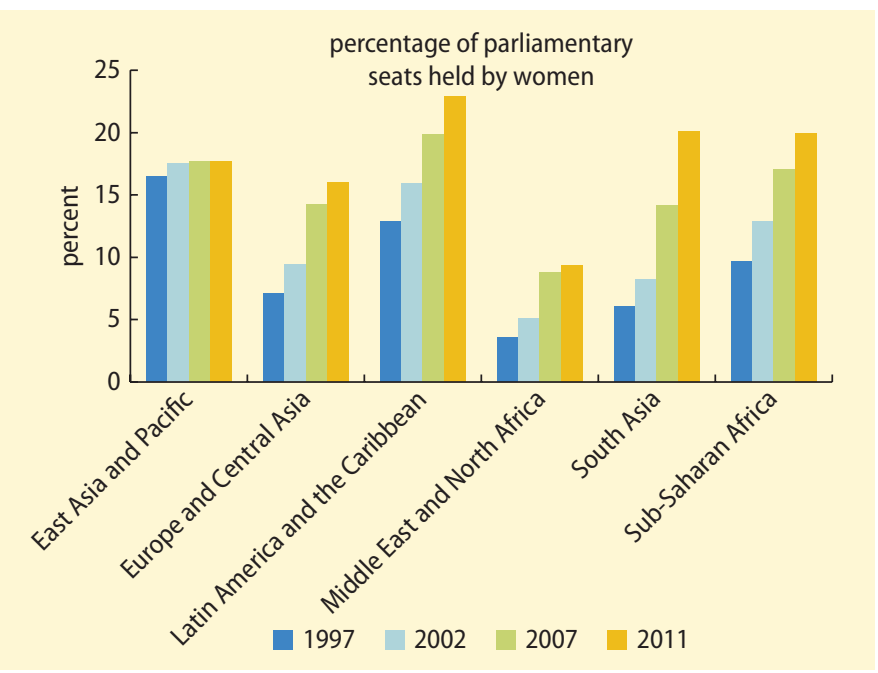

Source: Inter-Parliamentary Union data extracted from World Bank 2011c. 


\section{FIGURE 1.24 Women's representation in parliament is low, especially in the Pacific}

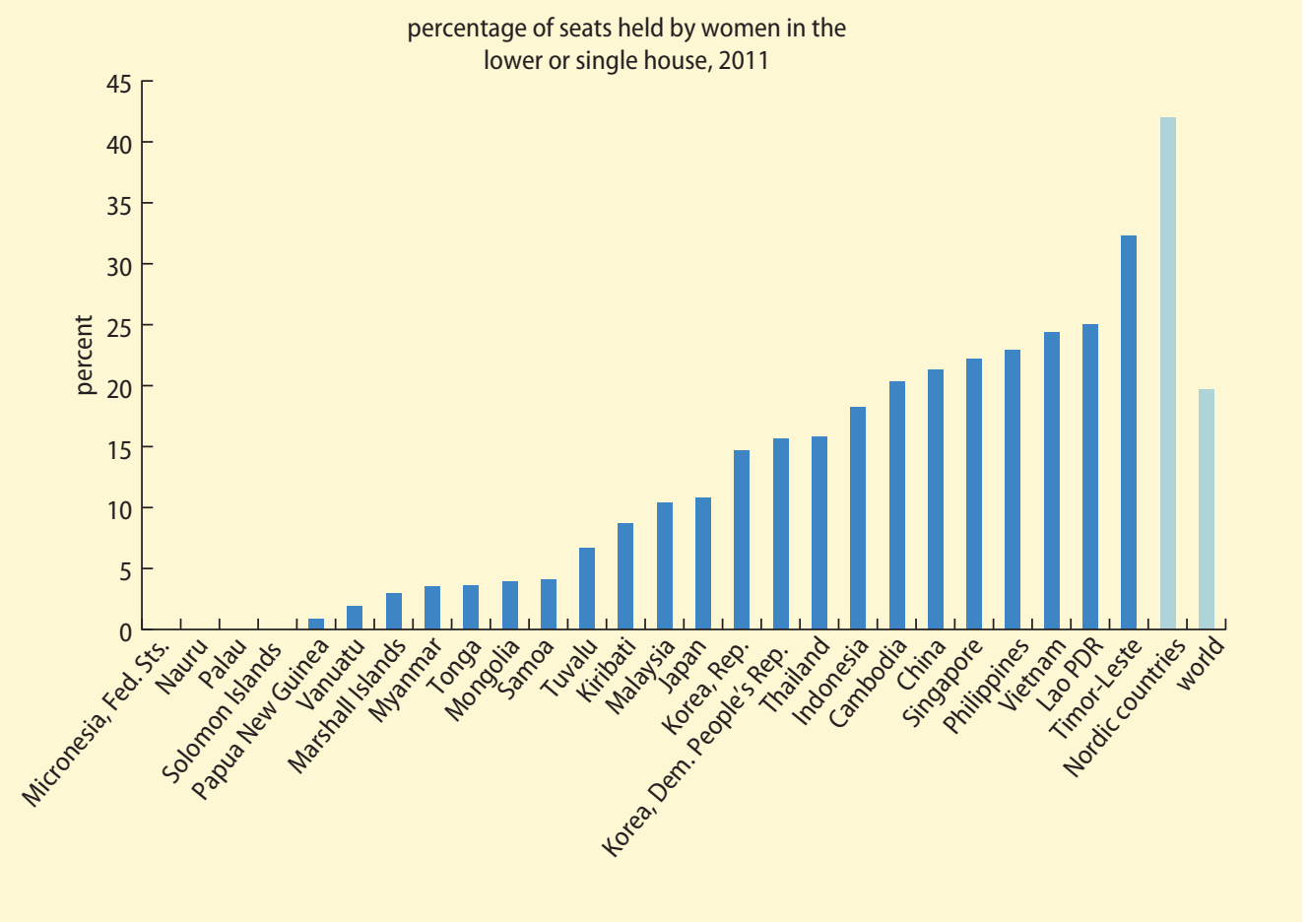

Source: PARLINE database, 2011 data.

\section{FIGURE 1.25 Men, and in some cases women, believe that men make better political leaders than women}

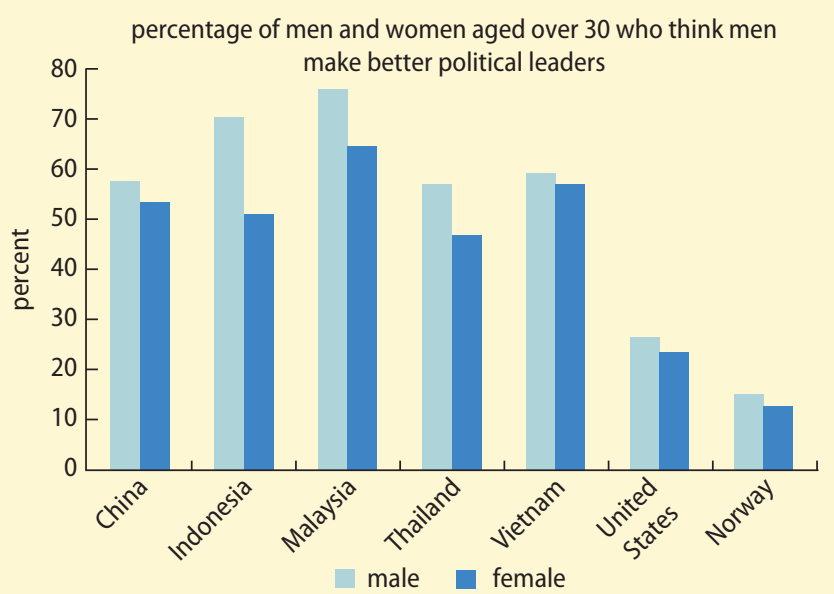

Source: World Values Survey, 2006 and 2007 data. growth and development; the overall share of female parliamentarians in East Asian and Pacific countries has barely changed since the late 1990s. This trend stands in contrast to other developing regions, where levels of female political representation have tended to increase, at least since $2000 .^{11}$

The share of women in national parliaments varies tremendously across the region. In December 2011, the highest levels of female representation were found in TimorLeste (32.3 percent), Lao PDR (25.2 percent), Vietnam (24.4 percent), the Philippines (22.9 percent), and China (21.3 percent) (figure 1.24). Female parliamentary representation in the Pacific is systematically lower. Four countries in the Pacific-the Federated States of Micronesia, Nauru, Palau, and the Solomon Islands-do not have female representation in parliament (PARLINE database, 2011 data). Countries that have enacted temporary special measures to 
promote female participation in political leadership have achieved higher levels of female representation in parliament, with an average of 27 percent in 2009, compared with 14 percent for those countries without temporary special measures.

Barriers to political representation in the region are likely to reflect perceptions held by both men and women that female politicians make less competent political leaders than their male counterparts (figure 1.25). Evidence from India suggests that people's perceptions of women as political leaders improve with exposure to elected female officials (Beaman et al. 2009). However, these perceptions may take time to evolve, reinforcing the case for concerted action to support increased political participation on the part of women. Ensuring that women are represented, whether at the local or national level, is a first step to ensuring that their views and preferences are expressed in public policies.

Women from East Asian and Pacific countries have experienced improvements in their voice and ability to actively participate in civil society and grassroots movements. Civil rights groups tackle a variety of issues to improve gender equality in their community, country, and region. PEKKA, a program in Indonesia, was created to address the needs of widows of conflict in Aceh and now provides training for village paralegals that focuses on domestic violence and family law. The program also holds district forums to bring together judges, prosecutors, police, nongovernmental organizations, and government officials to raise awareness of gender issues (PEKKA 2012; World Bank 2011b). As another example, the Fiji Women's Crisis Center lobbied for a nationally representative quantitative survey on violence against women, to be released in 2012 .

Women's representation in top management and participation in ownership is high relative to other developing regions and the world average. In the East Asia and Pacific region, women are represented among the owners in over 50 percent of small, medium, and large firms, higher than in any other developing region (figure 1.26). Female participation in management in the region and all other regions is lower than participation in ownership, however, indicating that women have a more limited voice in running a firm and making decisions, despite being represented in the ownership of the firm.

The incidence of physical, sexual, psychological, and emotional violence against women is high throughout the region, particularly in the Pacific, where the prevalence of domestic violence is among the highest in the world (figure 1.27). Human trafficking is also a growing concern throughout the region. An increase in female migration in the past decade has brought about increased economic opportunities as well as increased risk of being trafficked. The ILO estimates that Asia and the Pacific account for over half of all trafficked victims worldwide, with an estimated 1.36 million victims, most of whom are women and girls (ILO 2008).

Gender-based violence and human trafficking of women and girls are often enabled by the lack of and weak enforcement of relevant legislation. Although the factors that enable gender-based violence are multiple and complex, the phenomenon is exacerbated by a lack of adequate legal protections in many countries, most notably in the Pacific islands. A recent United Nations Development Programme study (UNDP 2010) found that although more than three-quarters of the countries in East Asia have strengthened legislation on domestic abuse in recent years, more than 60 percent of countries in the Pacific still lacked relevant legislation on domestic violence. Police forces in several countries in the region-including Indonesia, Malaysia, and Thailand-have been criticized for limited commitment in investigating trafficking and enforcing antitrafficking laws (U.S. Department of State 2011).

\section{Fostering new opportunities, managing emerging risks}

As the region continues to develop, several emerging trends will present both new opportunities and new risks to achieving gender equality. As noted earlier, East Asian 


\section{FIGURE 1.26 More women hold top management positions in East Asia and the Pacific than in other developing regions}

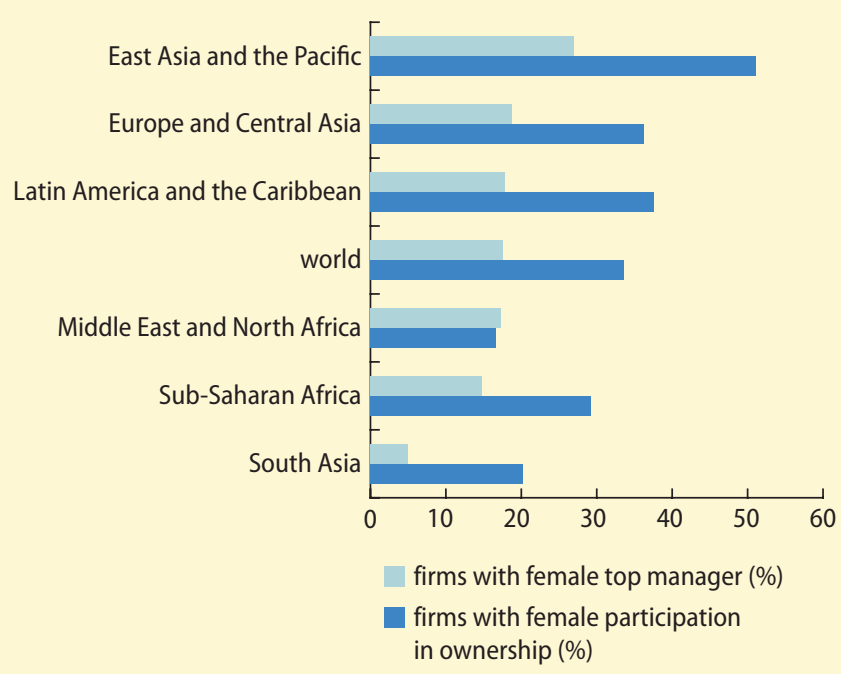

Source: Enterprise Surveys database, World Bank.

\section{FIGURE 1.27 Violence against women is high in East Asia and the Pacific}

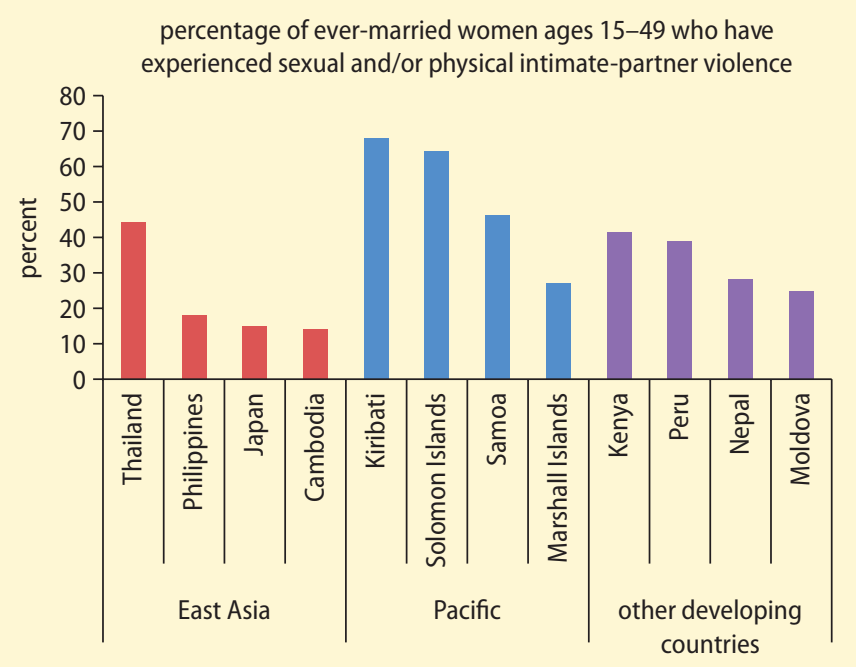

Source: Demographic and health surveys, various countries and years, and government surveys.

and Pacific countries are at the forefront of several global trends: (a) increasing global economic integration, (b) increasing domestic and cross-border migration, (c) rapid urbanization, (d) population aging, and (e) rising availability and use of information and communication technologies (ICTs). Though not commonly accounted for by policy makers, these trends are likely to have important gender dimensions and, thus, affect the evolution of gender equality in the region. They will create new challenges for public policy, in terms of fostering new opportunities and managing new risks to gender equality.

Greater global economic integration brings with it substantial economic opportunities for women, but also potentially greater exposure to economic shocks. For example, evidence indicates that greater global economic integration can contribute to greater access to economic opportunities for women and reduce gender wage gaps by raising demand for female workers in export-oriented enterprises (Boserup 1970; Schultz 2006). At the same time, increasing global integration also increases risk and uncertainty, as shocks are more quickly transmitted across integrated markets. A number of studies find that although shocks do not necessarily have more adverse effects on women than men, they do have gender-differentiated effects on outcomes as diverse as employment, earnings, labor force participation, education investment, health, and nutrition (see, for example, Bruni et al. 2011; Rodgers and Menon forthcoming).

Opportunities gained by migration are balanced by new risks. High economic growth and increased economic integration in the region over the past three decades has spurred significant migration across the region. Women make up nearly half of all migrants in East Asia and the Pacific and in some countries represent the majority of new migrants. Migration can provide both women and men with access to new economic opportunities, which commonly differ by gender because of employment segregation in receiving areas' labor markets. At the same time, migration brings with it important gender-specific risks. For example, many female migrants find employment as domestic workers, a sector with particularly weak worker protection in most countries. Female migrants are also disproportionately susceptible to risks associated with human trafficking. 
Unprecedented levels of urbanization are affecting all aspects of life: from the nature of employment to the availability of services to individuals' ability to rely on extended family and community networks. Many East Asian and Pacific countries are experiencing unprecedented levels of urbanization as migrants move to urban areas in search of economic opportunity. Between 2000 and 2015, Indonesia, China, and Cambodia are predicted to see an increase in the percentage of the population residing in urban areas by 17,13 , and 9 percentage points respectively (World Bank 2009). These changes almost certainly have gender-specific impacts. Although urban residence can open up a wide range of economic opportunities for both men and women, women's ability to take advantage of new opportunities is likely to depend fundamentally on the nature and availability of urban services-for example, whether transport systems facilitate safe travel of women to job sites or if affordable child care can compensate for the loss of extended family networks.

Aging populations will represent another challenge for women. The high-income economies in East Asia are experiencing rapid population aging. ${ }^{12}$ Most emerging countries in the region have also begun this process; dependency ratios are already increasing in many middle-income countries in East Asia and the Pacific. Old-age dependency is expected to increase even more quickly in the coming decades (figure 1.28). Population aging is likely to have gender-differentiated impacts at all age levels. Gender differences in the time devoted to caring for the elderly imply that in the absence of institutionalized care services, women are likely to bear the brunt of the increased demand for elder care (Dwyer and Coward 1992; Ofstedal, Knodel, and Chayovan 1999). Moreover, while women tend to live longer than men, gender differences in education and labor force participation imply that women are less likely to be vested in formal pension systems and may have fewer assets to ensure a basic level of well-being in old age.
Advances in ICTs are revolutionizing the ways in which both men and women in the region are exposed to ideas, share knowledge, and networks. Existing evidence suggests, however, that women in the region still have lower access to information technologies than men. New and emerging technologies, if accessible, can help to empower women by opening new economic opportunities, breaking down information barriers, helping women in isolated communities engage in distance learning or commerce, or enabling women to take collective action. As in the case of other productive resources, such as land, machinery, or credit, growing gender gaps in access to ICTs could lead to widening gaps in access to economic opportunities as well as in voice and influence in society.

\section{Gender equality in East Asia and the Pacific: A roadmap to the report}

This chapter has provided a basic profile on the status of gender equality in East Asia

\section{FIGURE 1.28 The dependency ratio is increasing in most East Asian countries}

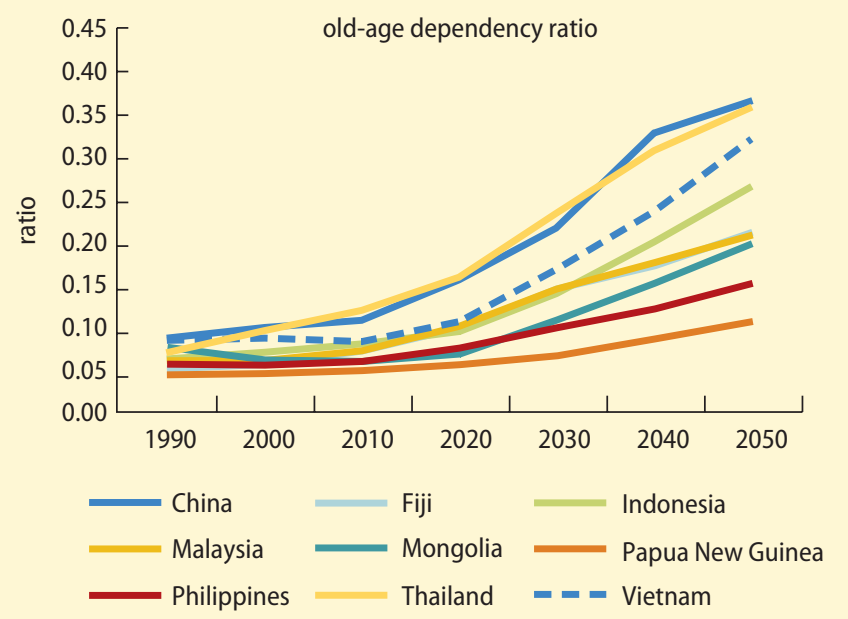

Sources: World Bank 2010b (1990-2010 data); HNP Stats—Population Projection (projections for 2020-50).

Note: Old-age dependency ratio is defined as the ratio of the population 65 years of age and older over working-age population (15-64 years of age). 
and Pacific countries, taking into account several important factors that have characterized development in the region. Specifically, the region has experienced significant growth, poverty reduction, and economic structural transformation over the past several decades. The chapter has shown that rapid growth and development have been accompanied by reduced gender inequalities in several key dimensions, most notably in education and several key aspects of health. In East Asian countries, women's voice and influence, whether in the home or in the economy, are relatively strong. In many ways, women in the region are better positioned than ever before to participate in, contribute to, and benefit from their economies and societies.

At the same time, the evidence demonstrates clearly that economic growth and development alone are not enough to attain gender equality in all its dimensions. While gender outcomes in education and health have been responsive to growth, other areas have proved "stickier"; significant gender inequalities persist in a number of important areas despite development. Women still have less access than men to a range of productive assets and services. There remains substantial employment segregation, by gender. And despite closing of education gaps, women continue to earn less than men. Moreover, women in the region still have weaker voice and influence than men, whether in household decision making, in the private sector, in civil society, or in politics. And women across the region remain vulnerable to gender-based violence.

Progress toward gender equality has been uneven across and within countries. Despite widespread progress, a few, mostly low-income, countries have yet to close gender gaps in basic education. In China (and to a lesser extent Vietnam), significant imbalances occur in the sex ratio at birth, reflecting strong son preference in those societies. At the same time, a number of Pacific island countries face particular challenges with respect to promoting women's voice and influence. Specifically, women in Pacific countries experience among the highest rates of violence against women in the world; they also have among the lowest levels of female representation in politics. Within countries, gender frequently interacts with other socioeconomic characteristics, such as ethnicity or geographic remoteness, resulting in specific subgroups of countries' populations facing a double disadvantage.

Because many aspects of gender inequality do not disappear automatically with growth and development, and because persistent gender inequalities impose high costs on women and girls and on societies more broadly, a case can be made for public policy to promote gender equality. In this context, an important contribution of this report will be to (a) clarify empirically the relationship between gender equality and development, (b) analyze the factors that contribute to or impede gender equality in its different dimensions, and (c) identify effective avenues for public action to promote gender equality and, thus, more effective development in East Asian and Pacific countries.

To achieve these objectives, the three chapters that follow focus on providing a deeper understanding of the factors affecting gender equality in endowments, economic opportunity, and agency. Specifically, chapter 2 examines in more depth the evidence on gender dimensions of human and physical capital accumulation. Chapter 3 analyzes access to economic opportunity, including the factors affecting female labor force participation, employment segregation across occupations and industries, and persistent gender gaps in wages and earnings. And chapter 4 focuses on factors that enhance or constrain women's voice and influence in society, both in the private and public domains. In carrying out their analyses, each of these chapters seeks to frame an agenda for effective public action moving forward.

The report also analyzes the gender dimensions of several important emerging trends in the region. Specifically, chapter 5 examines globalization and economic integration, increasing migration, rapid urbanization, 
population aging, and enhanced access to ICTs, while identifying both the emerging opportunities and the emerging risks to gender equality that these phenomena entail. Building on the in-depth analyses presented in chapters 2 through 5 , chapter 6 then outlines directions for public policy to promote gender equality and, thus, more effective development in East Asian and Pacific countries. The report concludes by framing a forward-looking agenda for analysis and action-to continue to fill knowledge gaps and strengthen public policy responses to promoting gender equality in the region.

\section{Notes}

1. Sen (1999) defines freedoms and "unfreedoms" in five categories: (a) political freedoms, (b) economic facilities, (c) social opportunities, (d) transparency guarantees, and (e) protective security.

2. Adopted in 1979 by the United Nations General Assembly, CEDAW is often referred to as the international bill of rights for women. The convention defines what constitutes discrimination against women and provides an agenda for national action to end such discrimination. To date, it has been ratified by 187 countries worldwide (http://www .un.org/womenwatch/daw/cedaw/).

3. These studies must be interpreted with caution, given the difficulty of establishing a causal relationship between gender equality in education and growth in cross-country studies.

4. Evidence from Africa and Latin America, for example, suggests that ensuring equal access to productive assets and technologies could significantly raise agricultural production and household income (Goldstein and Udry 2008; Quisumbing 1995; Udry 1996).

5. A number of studies show that gender-based violence itself imposes significant costs on the economies of developing countries, for example, through lower worker productivity and incomes, lower human capital investments, and weaker accumulation of social capital (see Morrison, Ellsberg, and Bott 2007, for a review of key findings). For related evidence from the United States, see National Center for Injury Prevention and Control 2003.

6. Similarly, in Organisation for Economic Cooperation and Development (OECD) countries, men are more likely to be found among mathematics and computer science graduates than women and have also been found to outperform women in mathematics (Schleicher 2008).

7. The maternal mortality ratio (MMR) in Lao PDR is a modeled estimate, to make it comparable to MMR estimates in other countries. Lao PDR's national estimate in 2005 was lower, at 405 deaths per 100,000 births (WDI database).

8. For data on land holdings by gender in China, see de Brauw et al. (2011). Data on other countries are based on World Bank staff calculations, using household survey data.

9. Evidence from other parts of Indonesia suggests that land ownership patterns, by gender, can differ in important ways, depending on local norms and customs. In the matrilineal region of West Sumatra, Indonesia, for example, at the time of marriage, husbands commonly own more forest land than their wives, and wives commonly own more paddy land (Quisumbing and Maluccio 2003).

10. Self-reported information on credit constraints, by gender, should be interpreted with caution. As discussed below, female-led enterprises are smaller, use less capital, and operate in difference sectors than male-led enterprises, making direct comparisons of self-reported credit constraints, by gender, difficult.

11. In the Europe and Central Asia region, female representation in national assemblies fell substantially following the dissolution of the Soviet Union, although levels increased again between 2000 and 2008.

12. For example, the share of the elderly (age 65 or above) in Hong Kong SAR, China; Japan; Korea; Singapore; and Taiwan, China, is above 10 percent and is expected to increase substantially in the next two decades.

\section{References}

Agarwal, Bina. 2010a. “Does Women's Proportional Strength Affect Their Participation? Governing Local Forests in South Asia." World Development 38 (1): 98-112.

2010b. Gender and Green Governance: The Political Economy of Women's Presence Within and Beyond Community Forestry. New York: Oxford University Press.

Asia Foundation, ADB (Asian Development Bank), CIDA (Canadian International Development Agency), NDI (National Democratic Institute), 
and World Bank. 2006. Indonesia: Country Gender Assessment. Manila, Philippines: Asia Foundation, ADB, CIDA, NDI, and World Bank.

Asian Development Bank and World Bank. 2005. "Mongolia: Country Gender Assessment." Country Planning Document, Asian Development Bank, Manila, Philippines.

AusAID. 2008. Making Land Work: Vol. 1. Reconciling Customary Land and Development in the Pacific. Canberra: Australian Agency for International Development.

Baulch, Bob, Truong Thi Kim Chuyen, Dominique Haughton, and Jonathan Haughton. 2002. "Ethnic Minority Development in Vietnam: A Socioeconomic Perspective." Policy Research Working Paper 2836, World Bank, Washington, DC.

Beaman, Lori, Raghabendra Chattopadhyay, Esther Duflo, Rohini Pande, and Petia Topalova. 2009. "Powerful Women: Does Exposure Reduce Bias?” Quarterly Journal of Economics 124 (4): 1497-540.

Beegle, Kathleen, Elizabeth Frankenberg, and Duncan Thomas. 2001. "Bargaining Power within Couples and Use of Prenatal and Delivery Care in Indonesia." Studies in Family Planning 32 (2): 130-46.

Boserup, Ester. 1970. Woman's Role in Economic Development. London: Earthscan.

Bruni, Lucilla, Andrew Mason, Laura Pabon, and Carrie Turk. 2011. "Gender Impacts of the Global Financial Crisis in Cambodia." World Bank, Washington, DC.

Butzer, Rita, Yair Mundlak, and Donald Larson. 2003. "Intersectoral Migration in Southeast Asia: Evidence from Indonesia, Thailand and the Philippines." Policy Research Working Paper 2949, World Bank, Washington, DC.

Chattopadhyay, Raghabendra, and Esther Duflo. 2004. "Women as Policy Makers: Evidence from a Randomized Policy Experiment in India." Econometrica 72 (5): 1409-43.

Constable, Nicole. 2009. "Migrant Workers and the Many States of Protest in Hong Kong." Critical Asian Studies 41 (1): 143-64.

Cuberes, David, and Marc Teignier-Baqué. 2011. "Gender Inequality and Economic Growth." Background paper for World Development Report 2012, World Bank, Washington, DC.

Daley-Harris, Sam. 2009. "State of the Microcredit Summit Campaign Report 2009.” Microcredit Summit Campaign, Washington, DC.

de Brauw, Alan, Jikun Huang, Linxiu Zhang, and Scott Rozelle. 2011. "The Feminization of Agriculture with Chinese Characteristics.” Background paper for World Development Report 2012, World Bank, Washington, DC.

Dhanani, Shafiq, and Iyanatul Islam. 2004. Indonesian Wage Structure and Trends, 19762000. International Labour Organization: Geneva.

Do, Quy-Toan, Andrei Levchenko, and Claudio Raddatz. 2011. "Engendering Trade." Policy Research Working Paper 5777, World Bank, Washington, DC.

Duflo, Esther. 2003. "Grandmothers and Granddaughters: Old-Age Pensions and Intrahousehold Allocation in South Africa." World Bank Economic Review 17 (1): 1-25.

Dwyer, Jeffrey, and Raymond Coward. 1992. "Gender and Family Care of the Elderly: Research Gaps and Opportunities." In Gender, Families, and Elder Care, edited by Jeffrey W. Dwyer and Raymond T. Coward, 151-62. London: Sage.

Edlund, Lena, and Rohini Pande. 2001. "Why Have Women Become Left-Wing? The Political Gender Gap and the Decline in Marriage." Quarterly Journal of Economics 117 (3): 917-61.

Enterprise Surveys (database). International Finance Corporation and the World Bank. http://www.enterprisesurveys.org/.

Esteve-Volart, Berta. 2004. "Gender Discrimination and Growth: Theory and Evidence from India." Development Economics Discussion Paper Series 42, Suntory and Toyota International Centres for Economics and Related Disciplines, London School of Economics and Political Science, London.

FAO (Food and Agriculture Organization)/Sida Partnership Cooperation. 2010. National Gender Profile of Agricultural Households, 2010: Report Based on the Lao Expenditure and Consumption Surveys, National Agricultural Census and Population Census. Vientiane, Lao PDR: FAO.

Fehringer, Jessica, and Michelle J. Hindin. 2009. "Like Parent, Like Child: Intergenerational Transmission of Partner Violence in Cebu, the Philippines." Journal of Adolescent Health 44 (4): 363-71.

Goldin, Claudia. 1995. "The U-Shaped Female Labor Force Function in Economic Development and Economic History." In Investment in Women's Human Capital, edited by T. Paul Schultz. Chicago: University of Chicago Press.

Goldstein, Markus, and Christopher Udry. 2008. "The Profits of Power: Land Rights and 
Agricultural Investment in Ghana." Journal of Political Economy 116 (6): 981-1022.

General Statistics Office of Vietnam. 2009. Result of the Survey on Housebold Living Standards 2008. Hanoi: Statistical Publishing House. http://www.gso.gov.vn /default_en. aspx? tabid=515\&idmid=5\&Item ID $=9647$.

HNP Stats (Health Nutrition Population Statistics) database. World Bank, Washington, DC. http://data.worldbank.org/data-catalog/ health-nutrition-population-statistics.

Ilahi, Nadeem. 2000. "The Intra-household Allocation of Time and Tasks: What Have We Learnt from the Empirical Literature?” Working Paper 13, World Bank Development Research Group, World Bank, Washington, DC.

ILO (International Labour Organization). 2008. Women's Entrepreneurship Development Aceh: Gender and Entrepreneurship Together (GET Abead) Training Implementation. Impact Assessment. Jakarta, Indonesia: ILO Jakarta Office.

Indonesia National Socioeconomic Survey (SUSENAS). 2009. Badan Pusat Statistik, Jakarta, Indonesia. http://dds.bps.go.id/eng/ aboutus.php?id_subyek=29\&tabel=1\&fl=3 .

Johnson, Kiersten, Sovanratnak Sao, and Darith Hor. 2000. Cambodia 2000 Demographic and Health Survey: Key Findings. Calverton, MD: ORC Macro.

Judd, Ellen R. 2010. "Family Strategies: Fluidities of Gender, Community and Mobility in Rural West China." China Quarterly 204: 921-38.

Kabeer, Naila. 1999. "Resources, Agency, Achievements: Reflections on the Measurement of Women's Empowerment." Development and Change 30 (3): 435-64.

Klasen, Stephan. 2002. "Low Schooling for Girls, Slower Growth for All? Cross-Country Evidence on the Effect of Gender Inequality in Education on Economic Development." World Bank Economic Review 16 (3): 345-73.

Knowles, Stephen, A. K. Lorgelly, and Dorian Owen. 2002. "Are Educational Gender Gaps a Brake on Economic Development? Some Cross-Country Empirical Evidence." Oxford Economic Papers 54 (1): 118-49.

Lao Statistics Bureau. 2008. Lao Expenditure and Consumption Survey. Vientane, Lao PDR. http://www.nsc.gov.la/index.php?option=com content $\&$ view $=$ article $\&$ id $=50 \&$ Itemid $=73 \&$ lang=.

Lott, John R., and Lawrence W. Kenny. 1999. “Did Women's Suffrage Change the Size and
Scope of Government?" Journal of Political Economy 107 (6): 1163-98.

Mammen, Kristin, and Christina Paxson. 2000. "Women's Work and Economic Development." Journal of Economic Perspectives 14 (4): 141-64.

Mason, Karen Oppenheim. 2005. "Measuring Women's Empowerment: Learning from Cross-National Research." In Measuring Empowerment: Cross-Disciplinary Perspectives, edited by D. Narayan, 89-102. Washington, DC: World Bank.

McElroy, Marjorie. 1990. "The Empirical Content of Nash-Bargained Household Behavior." Journal of Human Resources 25 (4): 559-83.

Morrison, Andrew, Mary Ellsberg, and Sarah Bott. 2007. "Addressing Gender-Based Violence: A Critical Review of Interventions." World Bank Observer 22 (1): 25-51.

Naudeau, Sophie, Naoko Kataoka, Alexandria Valerio, Michelle Neuman, and Leslie Elder. 2011. Investing in Young Children: An Early Childhood Development Guide for Policy Dialogue and Project Preparation. Washington, DC: World Bank.

National Center for Injury Prevention and Control. 2003. Costs of Intimate Partner Violence against Women in the United States. Atlanta, GA: Centers for Disease Control and Prevention.

NIPH (National Institute of Public Health [Cambodia]), NIS (National Institute of Statistics [Cambodia]), and ORC Macro. 2006. Cambodia Demographic and Health Survey 2005. Phnom Penh, Cambodia, and Calverton, Maryland, U.S.: National Institute of Public Health, National Institute of Statistics, and ORC Macro.

NSD (National Statistics Directorate [TimorLeste]), Ministry of Finance [Timor-Leste], and ICF Macro. 2010. Timor-Leste Demographic and Health Survey 2009-10. Dili, TimorLeste: NSD and ICF Macro.

Ofstedal, Mary Beth, John E. Knodel, and Napaporn Chayovan. 1999. "Intergenerational Support and Gender: A Comparison of Four Asian Countries." Southeast Asian Journal of Social Sciences 27 (2): 21-41.

PARLINE database on national parliaments. Inter-Parliamentary Union, Geneva. http:// www.ipu.org/parline-e/parlinesearch.asp and http://www.ipu.org/wmn-e/world.htm.

PEKKA (Perempuan Kepala Keluarga [Women Headed Household Empowerment Program]). 
Accessed 2012. http://www.pekka.or.id/8/ index.php.

Pham, Hung T., and Barry Reilly. 2007. "The Gender Pay Gap in Vietnam, 1993-2002: A Quantile Regression Approach.” Journal of Asian Economics 18 (5): 775-808.

Pierre, Gaelle. 2012. "Recent Labor Market Performance in Vietnam through a Gender Lens.” Policy Research Working Paper 6056, World Bank, Washington, DC.

PovcalNet: An Online Poverty Analysis Tool. World Bank, Washington, DC. http://iresearch .worldbank.org/PovcalNet/index.htm.

Qian, Nancy. 2008. "Missing Women and the Price of Tea in China: The Effect of Sex-Specific Earnings on Sex Imbalance." Quarterly Journal of Economics 123 (3): 1251-85.

Quisumbing, Agnes. 1995. "Gender Differences in Agricultural Productivity: A Survey of Empirical Evidence.” FCND Discussion Paper No. 5, International Food Policy Research Institute, Washington, DC.

Quisumbing, Agnes R., and John A. Maluccio. 2003. "Resources at Marriage and Intrahousehold Allocation: Evidence from Bangladesh, Ethiopia, Indonesia, and South Africa." Oxford Bulletin of Economics and Statistics 65: 283-327.

Quota Project: Global Database of Quotas for Women. Institute for Democracy and Electoral Assistance and Stockholm University. "About Quotas.” http://www.quotaproject.org/ aboutQuotas.cfm.

Rand, John, and Finn Tarp. 2011. "Does Gender Influence the Provision of Fringe Benefits? Evidence from Vietnamese SMEs." Feminist Economics 17 (1): 59-87.

Rodgers, Yana, and Nidhiya Menon. Forthcoming. "Impact of the 2008-2009 Twin Economic Crises on the Philippine Labor Market." World Development.

Ross, Michael. 2008. "Oil, Islam and Women." American Political Science Review 102 (1): 107-23.

Rozelle, Scott, Xiao-yuan Dong, Linxiu Zhang, and Amelia Hughart. 2002. "Opportunities and Barriers in Reform China: Gender, Work, and Wages in the Rural Economy." Pacific Economic Review 7 (1).

Sakellariou, Chris. 2011. "Determinants of the Gender Wage Gap and Female Labor Force Participation in EAP." Paper commissioned for Toward Gender Equality in East Asia and the Pacific: A Companion to the World
Development Report. Washington, DC: World Bank.

Schleicher, Andreas. 2008. "Student Learning Outcomes in Mathematics from a Gender Perspective: What Does the International PISA Assessment Tell Us?" In Girls' Education in the 21st Century, edited by M. Tembon and L. Fort. Washington, DC: World Bank.

Schultz, Paul. 2006. "Does the Liberalization of Trade Advance Gender Equality in Schooling and Health?" Discussion Paper 935, Economic Growth Center, Yale University, New Haven, CT.

Sen, Amartya. 1992. "Missing Women.” British Medical Journal 304: 587-88.

- 1999. Development as Freedom. Oxford, U.K.: Oxford University Press.

SPC (Secretariat of the Pacific Community), Ministry of Internal and Social Affairs [Republic of Kiribati], and Statistics Division [Republic of Kiribati]. 2010. Kiribati Family Health and Support Study: A Study on Violence against Women and Children. Nouméa, New Caledonia: SPC.

SPC (Secretariat of the Pacific Community) and NSO (National Statistics Office) [Solomon Islands]. 2009. Solomon Islands Family Health and Safety Study: A Study on Violence against Women and Children. Nouméa, New Caledonia: SPC.

Thomas, Duncan. 1990. "Intra-household Resource Allocation: An Inferential Approach.” Journal of Human Resources 25 (4): 635-64.

- 1995. "Like Father, Like Son, Like Mother, Like Daughter, Parental Resources and Child Height." Papers 95-01, RAND Reprint Series. Santa Monica, CA: RAND Corporation.

Udry, Christopher. 1996. "Gender, Agricultural Production, and the Theory of the Household." Journal of Political Economy 104 (5): 1010-14.

UIS (UNESCO Institute for Statistics) Data Centre. Montreal, Canada. http://www.uis .unesco.org/Pages/default.aspx.

UNDP (United Nations Development Programme). 2010. Asia-Pacific Human Development Report. Power, Voice and Rights: A Turning Point for Gender Equality in Asia and the Pacific. Colombo, Sri Lanka: Macmillan Publishers India Ltd. for UNDP.

UNESCAP (United Nations Economic and Social Commission for Asia and the Pacific), Statistics Division. 2003. Integrating Unpaid Work into 
National Economics. Bangkok, Thailand: UNESCAP.

UNESCO (United Nations Educational, Scientific and Cultural Organization) Institute for Statistics (UIS). 2009. Global Education Digest. Montreal, Quebec: UIS.

—. 2011. Global Education Digest. Montreal, Quebec: UIS.

USCDC (United States Centers for Disease Control and Prevention). 2003. "Costs of Intimate Partner Violence against Women in the United States." USCDC, National Center for Injury Prevention and Control, Atlanta, Georgia.

U.S. Department of State. 2011. Trafficking in Persons Report 2011. Washington, DC: U.S. Department of State.

VWC (Vanuatu Women's Centre) in partnership with the Vanuatu National Statistics Office. 2011. Vanuatu National Survey on Women's Lives and Family Relationships. Port Vila, Vanuatu: VWC.

WDI (World Development Indicators) database. World Bank, Washington, DC. http:// data.worldbank.org/data-catalog/worlddevelopment-indicators.

WHO (World Health Organization) Global Health Observatory Data Repository. WHO, Geneva, Switzerland. http://apps.who.int/ghodata/.
World Bank. 2001. Engendering Development: through Gender Equality in Rights, Resources, and Voice. Washington, DC: World Bank.

- 2009. "Gender Equality in East Asia: Progress and the Challenges of Economic Growth and Political Change, East Asia Update.” World Bank, Washington, DC.

- 2010a. "Indonesia-Reconstruction of Aceh Land Administration System Project." World Bank, Washington, DC.

- 2010b. World Development Indicators 2010. Washington, DC: World Bank.

—. 2011a. "Vietnam Country Gender Assessment." World Bank, Washington, DC. http://documents.worldbank.org/curated/en/ 2011/11/15470188/vietnam-country-genderassessment.

- 2011b. World Development Report 2012: Gender Equality and Development. Washington, DC: World Bank.

- 2011c. World Development Indicators 2011. Washington, DC: World Bank.

—. 2012a. Capabilities, Opportunities and Participation: Gender Equality and Development in the Middle East and North Africa Region. Washington, DC: World Bank.

World Values Survey. World Values Survey Association, Stockholm, Sweden. http://www .worldvaluessurvey.org/. 



\section{Gender and Endowments: Access to Human Capital and Productive Assets}

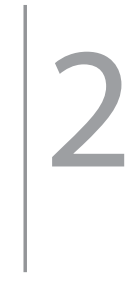

A ccess to human capital and productive assets allows individuals to live healthy and productive lives. Imbalances between such opportunities for men and women are costly to individual welfare, to society, and to development. The East Asia and Pacific region has experienced remarkable economic growth and poverty reduction, combined with the spread of education and progress in health, from the latter half of the 20th century to the first decade of the 21st century. Therefore, East Asian and Pacific countries are well placed to promote strong improvements in access to human capital and productive assets for many men and women in those countries.

This chapter analyzes gender differences in endowments-defined here as the human and productive capital that enables opportunities to improve welfare-in the region and lays the foundations for discussing countries' policy priorities in chapter 6 . It examines factors underlying those gender differences and identifies what drives progress toward gender equality or impedes it. The analysis relies on the framework of the interactions among households, markets, and institutions to understand gender outcomes in endowments. The chapter also acknowledges the links among the different types of endowments—specifically, education, health, and assets-and their ties with economic opportunities and agency.

Education and health are areas in which gender equality has generally been the most responsive to growth and development in the region.

- Girls' enrollment has recently caught up with that of boys, except in several countries and subpopulations experiencing slower progress in education overall.

- Health indicators such as infant and maternal mortality have also had impressive gains, except in several places with slower economic progress.

- However, the region has a large number of "missing girls," a persistent issue that appears not to be mitigated by growth and development.

- Gender equality in assets has been less responsive to development than that in education and health and is constrained by complex legal, social, and economic factors.

These messages, stemming from the analysis in this chapter, help shape thinking about policies to promote gender equality in endowments. The end of the chapter sets the stage for that purpose, and a policy discussion 
placing priorities in the endowment domain in the broader development context will follow in chapter 6 .

\section{Substantial progress toward gender equality in education}

Closing gender gaps in education is beneficial. ${ }^{1}$ Several cross-country analyses find a positive relationship between female education and growth in gross domestic product (GDP) (Klasen and Lamanna 2009; Knowles, Lorgelly, and Owen 2002). Looking at households within countries, an extensive literature has found clear evidence of correlation between mothers' education and children's education and health, particularly children's health and nutrition status (Schultz 1993; Thomas and Strauss 1992). ${ }^{2}$ Women are usually the primary child rearers, and a mother with more education is likely to provide better child care. In East Asian and Pacific countries, analyses of national demographic and health surveys (DHS) show that Cambodian women with little education are less likely than educated women to receive antenatal care and assistance from trained health personnel during birth deliveries (Johnson, Sao, and Hor 2000). Similarly, in Timor-Leste, highly educated mothers are most likely to have their births delivered by skilled attendants ( 88 percent), as are mothers in the wealthiest households (69 percent) (NSD, Ministry of Finance, and ICF Macro 2010).

Gender equality in endowments can feed into development indirectly through links to gender equality in economic opportunities and agency. Promoting equal access to education through investing in girls' education can broaden girls' economic opportunities and raise their income. Better economic opportunities and higher income, in turn, have positive intergenerational effects: income in women's hands is likely to improve children's health (Duflo 2003; Fiszbein and Schady 2009; Thomas 1995). More education and more income also empower women and provide them with more bargaining power, voice, and representation, as discussed in chapter 4 .
Recognizing the importance of educating girls, many East Asian and Pacific countries have made great strides toward equal enrollment between girls and boys, as highlighted in chapter 1 . The discussion on education in this chapter will analyze these patterns in more depth to understand their dynamics and their determinants. These gains in enrollment have responded to changes in both supply-side and demand-side factors that enable better education outcomes. Where the education system as a whole is lagging, progress on the gender front has also been limited. However, even with equal enrollment, quality of education and choice of education streams still affect girls and boys differently and have strong implications for young people's school-to-work transition.

\section{Closing gender gaps in enrollment}

Most countries in the East Asia and Pacific region have seen narrowing gender gaps in school enrollment and completion over the past two decades. Girls' and boys' enrollment rates are now roughly on par at all levels, including tertiary education. The female-tomale enrollment ratio in secondary school has approached parity in most countries. Tertiary enrollment ratios between females and males are more dispersed, but mostly on an upward trend. The East Asia and Pacific region has performed better than any other region at increasing both enrollment levels and the female-to-male enrollment ratio. In 2010, the region had the highest primary school female-to-male ratio of enrollment among the developing regions and the second highest secondary school ratio. ${ }^{3}$

The narrowing of the gender gap in education since the 1990s is observed not only at the aggregate level, but also for the poor and nonpoor alike. Figure 2.1 shows the ratio of female-to-male enrollment rates in upper secondary schools for children in the poorest quintile. In most of the countries depicted, female and male enrollment rates have been converging among the poor. Similar patterns are also observed for primary and lower secondary education. 
Another way to see the significant progress in education is through the smaller gender gaps in youth literacy compared to gaps in adult literacy. Figure 2.2 shows Indonesia and Cambodia as illustrative examples, but the observations are similar in many East Asian and Pacific countries. Younger generations are more likely to be literate. Although the gender gaps in adult literacy can be stark, such as in the case of Cambodia, youth literacy tends to be more equal across genders in both urban and rural areas, as well as across income quintiles. The gender gaps in literacy continue to close over time.

Given this trend, some countries are even starting to experience a reverse gender gap in education: girls' secondary enrollment exceeds that of boys in China, Fiji, Malaysia, Mongolia, the Philippines, Samoa, and Thailand. The reverse gender gaps at the tertiary level are often even starker: in Thailand, 122 females were enrolled for every 100 males in 2008. In Samoa, for example, boys underperform relative to girls in both enrollment and academic achievement. Secondary education enrollment rates have consistently been higher for girls, by a large margin that is widening over time. In tests taken in year 4 and year 6 (the first year of education starts at age 5), girls significantly outperform boys in all three tested subjects: English, Samoan, and numeracy. A significantly higher proportion of boys than girls have been at risk of not achieving minimum competencies in these years. In year 8 , girls still outshine their male counterparts in all subjects, including science and mathematics, but the gender gap is smaller than it was in the earlier years (Jha and Kelleher 2006). Box 2.1 discusses the reverse gender gap in education in further detail.

\section{Persistent gender gaps in some countries and subpopulations}

Despite progress in narrowing the enrollment gaps between genders, several countries and disadvantaged populations within countries still experience more visible gender disparities than elsewhere in the region. ${ }^{4}$ Girls' enrollment has not caught up with that of boys in

\section{FIGURE 2.1 Enrollment for both genders has been converging} even among the poorest populations

\section{female-to-male gross upper-secondary enrollment ratios in the poorest expenditure quintile}

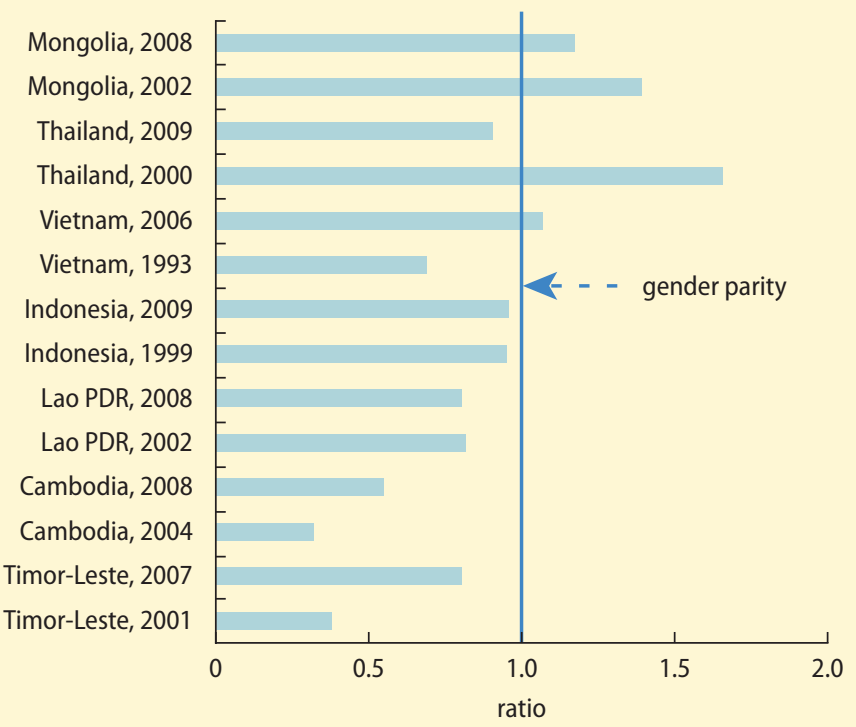

Sources: World Bank estimates using country household income and expenditure surveys: Cambodia Socio-Economic Survey (CSES) (NIS Cambodia), 2004, 2008 data; Indonesia National Socioeconomic Survey (SUSENAS) (BPS Indonesia), 1999, 2009 data; Lao Expenditure and Consumption Survey (LECS) (LSB Lao PDR), 2002, 2008 data; Living Standards Measurement Survey (LSMS) (NSO Mongolia), 2002, 2007-08 data; Thailand Socio-Economic Survey (SES) (NSO Thailand), 2000, 2009 data; Timor-Leste Demographic and Health Survey (DHS) (NSD Timor-Leste), 2001, 2007 data; Vietnam Household Living Standards Surveys (VHLSS) (GSO Vietnam), 1993, 2006 data.

\section{FIGURE 2.2 Gender gaps in youth literacy are smaller than} gender gaps in adult literacy

youth (ages 15-24) versus adult (ages 25+) literacy rates, by gender

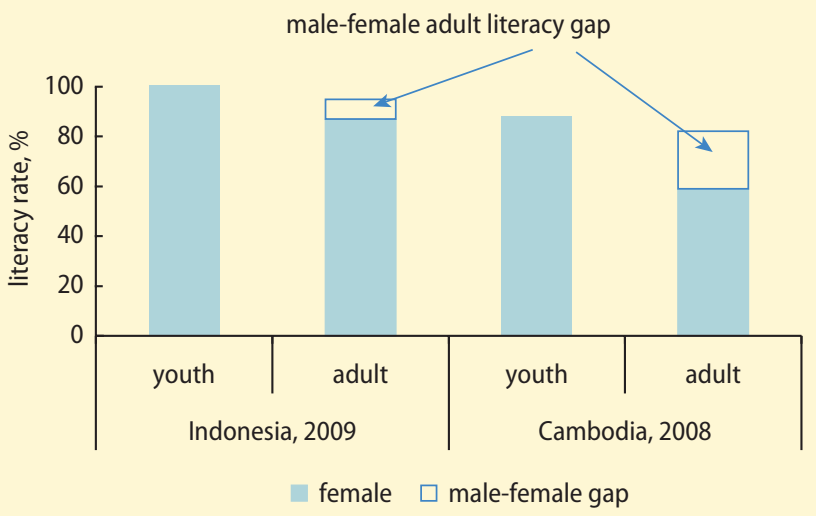

Source: World Bank estimates using CSES (NIS Cambodia), 2008 data; SUSENAS (BPS Indonesia), 2009 data. 


\section{BOX 2.1 Various parts of the world experience reverse gender gaps in education}

Although the phenomenon of reverse gender gaps in education is relatively new in the East Asia and Pacific region, it has long been documented in parts of Europe and Central Asia, Latin America and the Caribbean, and Organisation for Economic Co-operation and Development (OECD) countries. The range of possible reasons varies, including returns in the labor market, norms and gender identity, and the school environment itself. Interactions between households, markets, and institutions influence households' decisions about education investments; therefore, explanations for gender gaps in education are also context-specific. Given the differential payoffs in the labor market, by which men tend to earn more (discussed further in chapter 3), men have an incentive to drop out earlier to join the labor force. Social norms perceiving men as the breadwinner and stressing masculinity values may reinforce this incentive. In many cases, such as Mongolia or the Philippines, male underachievement in education is most stark among the poor. The figure below shows the biggest enrollment disadvantage for boys in the poorest quintile. A U.K. Department for International Development study in Botswana and Ghana also shows a similar relationship between economic disadvantages and boys' underperformance (Dunne and Leach 2005). The study identifies reasons for boys dropping out in the studied areas of Ghana as related to employment opportunities.

The school environment itself may perpetuate this set of norms and gendered identity. Gender stereotyping and how masculinity values within society are reflected in the classroom have been argued to contribute to high dropout rates among boys in the Caribbean (Bailey and Bernard 2003; Davis 2002; Figueroa 2000). Marks (2001) shows that, by age 14, girls in the United Kingdom start to substantially outperform boys in English. Boys' lower performance in the United Kingdom has been attributed to the use of more "female-oriented" reading materials, with suggestions that the inclusion of more factual, male-oriented works could increase male performance. Other authors argue that teachers have low expectations of boys' behavior and academic effectiveness, which contributes to the levels of boys' underachievement in Latin America and the Caribbean (Davis 2002; Figueroa 2000; Martino and Berrill 2003). The experimental literature on test grading suggests that there can be gender bias, but it is context-specific. For example, Lavy (2008) finds that male high school students in Israel face discrimination in teachers' test grading, but Hanna and Linden (2009) do not find such bias in their study in India. The United Nations Children's Fund (UNICEF 2004) outlines the role that poverty has to play in boys' underachievement in the Caribbean and Latin America, where governments have become increasingly aware that boys and young men are more likely to be alienated from school if they come from poor socioeconomic backgrounds.

\section{BOX FIGURE 2.1.1 The biggest enrollment disadvantage for boys in the Phillippines is among the poor}

Gross enrollment rates in secondary schools, by expenditure quintile, gender, and region, Philippines, 2006

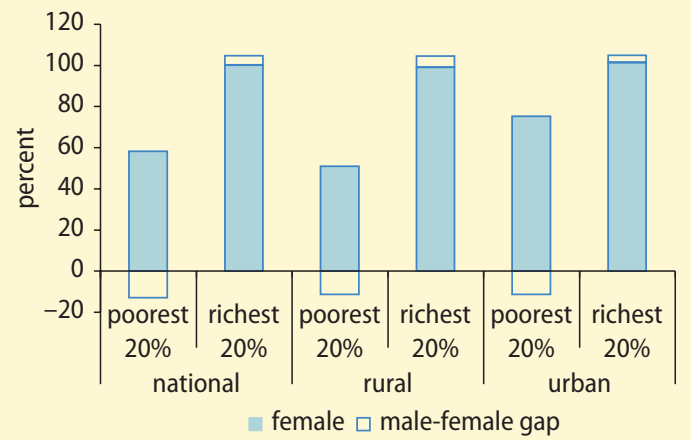

Source: World Bank estimates using Family Income and Expenditures Survey 2006 (NSCB Philippines 2006). 
those places where the overall education level, regardless of gender, is also low.

Gender gaps in enrollment are still high in Papua New Guinea and low-income countries such as Cambodia and the Lao People's Democratic Republic. Papua New Guinea's education enrollment rates are among the lowest in the region, although they have been rising moderately in recent years. In 2007, primary education (elementary preparation through grade 8) gross enrollment rates were 73 percent for males and 66 percent for females (Papua New Guinea Department of Education 2009). Cambodia and Lao PDR have notable gender gaps in enrollment at the secondary level, and more extreme gaps at the tertiary level. The secondary education enrollment ratio is about 8 females to 10 males in Cambodia and Lao PDR. Household survey data from 2008 indicate that although the ratio in enrollment between girls and boys is about equal up to around age 14 in Cambodia, it diverges significantly above that age. In 2008, at the tertiary level, 40 percent of urban males in Cambodia were enrolled, whereas only about 20 percent of urban females were. Enrollment rates in these countries are relatively low regardless of gender. Cambodia's adult literacy rates are also among the lowest in the region, with the biggest gender gaps. About 60 percent of Lao women are literate, as opposed to 80 percent of Lao men and more than 90 percent of people in most other countries in the region.

In some cases, girls in disadvantaged populations have the lowest education outcomes when gender interacts with other forms of vulnerability, such as poverty and ethnicity. Household survey data indicate that girls in the poorest quintile in rural areas in Cambodia and Lao PDR have the lowest secondary school enrollment rates in these countries. ${ }^{5}$ In Lao PDR, gender gaps in school enrollment can be particularly stark among the Hmong population. Girls in the Hmong and Mon-Khmer groups have a lower chance of being in school than boys of the same ethnicity, a disparity that has been slow to change over the past decade. They are only half as likely to be enrolled in lower-secondary school as Lao-Tai (ethnic majority) boys and girls (figure 2.3). Even in Vietnam, where girls do not lag boys at the aggregate level, the Hmong and Dao populations have stark gender gaps in secondary school enrollment: about one girl to two boys is enrolled in secondary school (figure 2.4).

FIGURE 2.3 Girls in some ethnic minority groups in Lao PDR lag even further in enrollment

gross enrollment rates in lower-secondary school, by ethnicity and gender, Lao PDR, 2002 and 2008

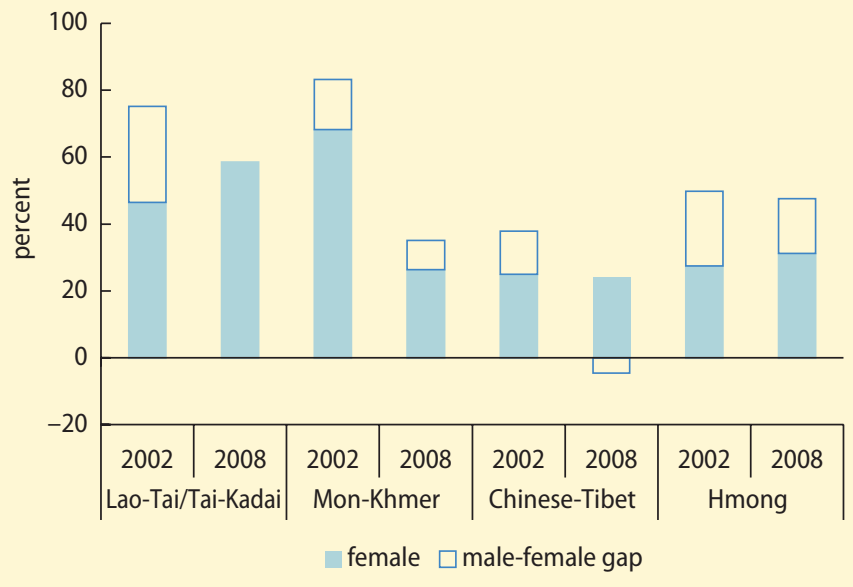

Source: World Bank estimates using LECS (LSB Lao PDR), 2002, 2008 data.

FIGURE 2.4 Girls in some ethnic minority groups in Vietnam lag even further in enrollment

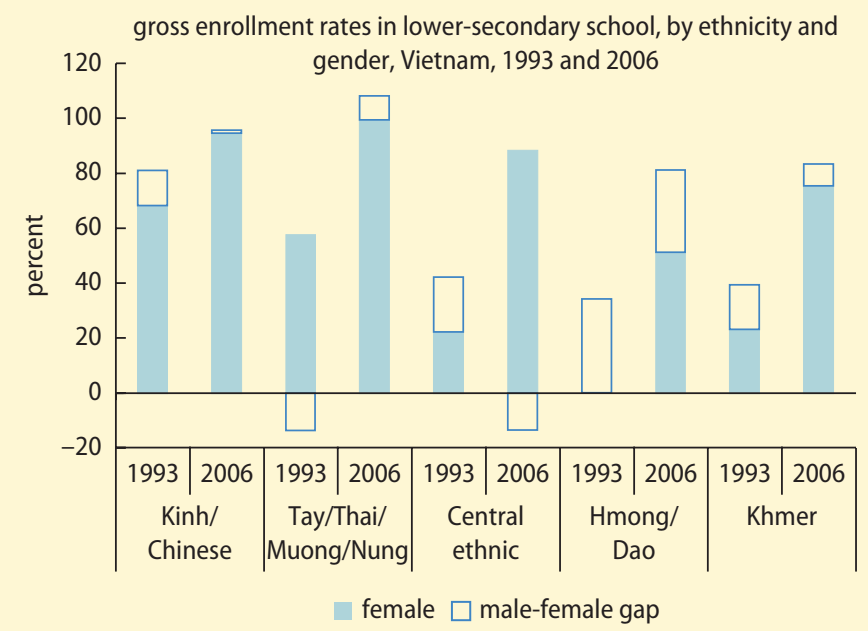

Source: World Bank estimates using VHLSS (GSO Vietnam), 1993, 2006 data. 


\section{Explaining progress and pending challenges in education}

The observed gains in enrollment in East Asian and Pacific countries have been a result of changes in supply-side and demand-side factors that enable better education outcomes. Explanations for progress (or lack of progress) in reducing gender gaps in education are context-specific because interactions between households, markets, and institutions influence households' decisions regarding education investments. Responding to market returns, or payoff, to investment choices, household decisions reflect individual preferences, constraints, and the relative bargaining power of members. The returns to education, as determined in the labor market, play a role. Costs or prices in the form of direct costs (fees and uniforms), indirect costs (distance to schools), and opportunity costs (wages earned outside of school) also matter and can be shaped by markets and institutions. Households have preferences, which may be influenced by cultural norms. They face budget and possible credit constraints. With this framework in mind, the following discusses how changing demandside constraints for households (for example, household income), institutional factors that affect the supply side (for example, reducing the cost/prices of education), and returns to educating girls each and together have led to more gender equality in school enrollment in most East Asian and Pacific countries.

First, factors affecting households' demand for education matter. Household survey data in East Asian and Pacific countries indicate that enrollment is always higher for children in richer families. Poor households in developing countries tend to face borrowing constraints, and, under limited budgets, they tend to invest more in sons than in daughters. Income gains are thus likely to raise school participation relatively more for girls than for boys, as empirically documented in various countries (World Bank 2001). Behrman and Knowles (1999) showed that, in Vietnam, the income elasticity of demand for education was 6 percent lower for boys than for girls in terms of passing grades per year of schooling. Cash transfers that alleviate households' budget constraints have also been shown in many developing countries to increase children's school enrollment. In the East Asia and Pacific region, a program providing scholarships to poor girls in lower secondary schools in Cambodia had large effects on girls' enrollment, an increase of 20 percentage points. A related program for both boys and girls had similar positive impacts on enrollment and attendance for boys and girls (Filmer and Schady 2008, 2009). Economic development in the region, which brings more stable income to households, also helps protect girls' education. In times of income shocks, families with girls are more likely to reduce education expenditure, as shown, for example, in the case of Indonesia (Cameron and Worswick 2001).

In addition, norms and preferences also affect households' demand for schooling by gender. Changing norms in some contexts have led to changing girls' status relative to boys. Qualitative research through focus group discussions in six communities in Fiji suggests that parents value girls' education more now than in previous generations (Chattier 2011). In Indonesia today, compared to a few decades ago, women exhibit a stronger preference for fewer children and stronger emphasis on children's health and education. Evidence suggests that this preference change is associated with decreased preference for sons over daughters compared to the past (Niehof 2003). Indonesian parents now appear to intrinsically value daughters no less than sons (Kevane and Levine 2003).

Second, changes in formal institutions, such as better service delivery and easier access to schools, have improved the supply of education services and lowered the cost of education. Economic development in East Asian and Pacific countries has been associated with better infrastructure and service delivery, either through the public or private sector. The massive school construction program in Indonesia in the 1970s led to significant increases in education attainment and earnings, presumably through reducing costs in terms of distance to schools (Duflo 2000). 
Although expanded service delivery might not specifically target girls, the benefits to them may be disproportionately high because distance and safety tend to be larger barriers for girls than for boys.

Third, in some cases, better employment opportunities and returns to education for females could have encouraged parents to educate girls. Cross-country evidence shows that trade liberalization, which has led to the expansion of nonagricultural jobs for women, is positively linked to greater human capital and more gender equality in human capital investment (Schultz 2006). The literature also shows that education investments do respond to expected returns as long as information on these returns is available (Jensen 2010; Oster and Millet 2010). Longer expected durations of receiving payoff from daughters, as a result of declining maternal mortality, can also induce parents to invest more in girls' education (Jayachandran and Lleras-Muney 2009). However, this component might have played a relatively small role in the East Asia and Pacific region, because the gender wage gaps and gender gaps in expected returns to education are still large, as discussed in chapter $3 .^{6}$

What constrains progress? Where the education system as a whole is lagging, progress on the gender front has also been limited. Although the explanations can be very context-specific, factors related to both the supply and demand sides of education in certain places constrain progress in education outcomes in general as well as outcomes for girls.

Low household income coupled with high costs of education can limit the demand for schooling, but income is usually not the whole story. Families in Cambodia have raised concerns about bearing the high direct cost of education (Velasco 2001). However, in both Cambodia and Lao PDR, gender gaps in secondary school enrollment exist even in the top quintile, as shown in figure 2.5, even though gaps across quintiles are still much larger. Aside from income, norms also have a strong influence on household decisions. Participants of focus group discussions in a qualitative research exercise in Papua New Guinea report that males will carry the family name

\section{FIGURE 2.5 Even girls in wealthier households in Cambodia and Lao PDR lag behind boys}

gross enrollment rates in upper-secondary schools of the poorest $20 \%$ and richest $20 \%$ of population, by gender, 2008

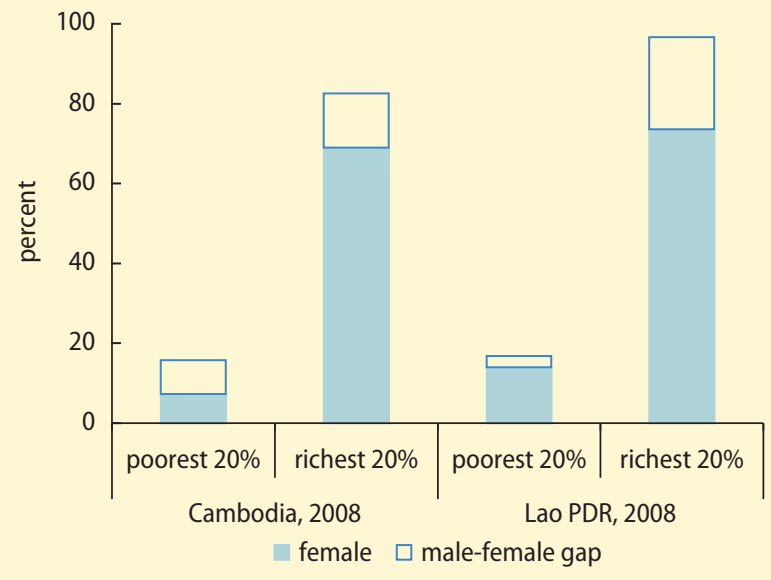

Source: World Bank estimates using CSES (NIS Cambodia), 2008 data; LECS (LSB Lao PDR), 2008 data.

and become household heads. Females are expected to submit to their husbands and be caregivers and homemakers; therefore, parents value boys' education over girls' (Tararia 2011). In Lao PDR, social norms about gender roles within the family may mean that girls face higher opportunity costs of schooling as a result of their socially defined value in home production. Poor rural girls spend the fewest hours in school but spend almost three hours a day fetching water, collecting firewood, and caring for other household members (King and van der Walle 2007). Families' perception of lower benefits from educating girls is also expected to impede girls' enrollment in Cambodia, particularly after puberty (Velasco 2001).

The supply side of service delivery also matters for the overall school enrollment as well as for girls' enrollment. Low enrollment rates in Papua New Guinea are the result of limited access and high dropout rates. Apart from demand-side factors such as affordability of school fees and low perceived value of education, elementary schools have not been established in many communities. Even urban areas may have inadequate capacity to admit all children wanting to enroll. Poor learning 
environments (often due to lack of education materials), poor school infrastructure, poor teacher attitude and attendance, lack of teachers in remote areas, and negative pupil behavior all contribute to poor enrollment overall (Papua New Guinea Department of Education 2009). In Cambodia and Lao PDR, distance to schools is an important barrier. The unequal provision of schools in Lao PDR makes schooling more costly for girls than for boys (King and van der Walle 2007). In Cambodia, given the long distance to schools, boys can live in wats (temples) while attending secondary school, but girls have no comparable system of accommodation. Anecdotal evidence suggests that the lack of toilets at school also makes it more difficult for girls than boys to attend (Velasco 2001).

Limitations of the education system in catering to the rural poor and ethnic minorities mean that the gender disadvantage can interact with these forms of vulnerability. In East Asian and Pacific countries, gender gaps within a subpopulation are usually smaller than the enrollment gaps across income quintiles or between major and minor ethnicities. In Vietnam, though the ethnicity gap in primary enrollment had almost closed between 1993 and 2006, enrollment at the secondary level among the Kinh/Chinese majorities is still substantially higher than that among ethnic minority populations. With the exception of the Hmong and Dao, the gender gaps within an ethnicity in Vietnam are smaller than the gaps across ethnicities (figure 2.4). In Cambodia, the gap in secondary school enrollment across quintiles also exceeds gender gaps within any given quintile. Similar patterns occur in many other East Asian and Pacific countries. These large enrollment gaps across subpopulations suggest that making general improvements in the education system to reach vulnerable subpopulations could contribute to closing the gender gap as well.

\section{Gender streaming in education}

Education investment does not end at enrollment. In middle-income countries in the East
Asia and Pacific region, despite the closing of gaps in enrollment and attainment, male and female students still differ in their choice of education streams. Factors that influence gender streaming in education are important because such streaming affects the occupations and sectors that men and women engage in and the income that they subsequently earn. The persistence of these patterns implies a gender-differentiated school-towork behavior and ultimately sustains gender inequalities in job placement and earnings. Earning gaps across genders largely reflect differences across occupations and sectors of employment. Chapter 3 discusses further the importance of education and labor market streaming to labor market outcomes.

Evidence from the East Asia and Pacific region shows clear patterns of specialization by field among men and women, implying differences in skill profiles when they enter the labor market. Figure 2.6 shows the fraction of females in each field of study in Indonesia, Thailand, and Vietnam. The fields of engineering and law are heavily dominated by males, whereas the fields of education, health, and business administration are dominated by females. These gender differences in the choice of field are larger than the gender differences in enrollment or completion rate in secondary or tertiary education in these countries. The positive relationship between being male and choosing science, engineering, or law is statistically significant in multinomial logit analysis that also accounts for characteristics such as parental education and area of residence (Sakellariou 2011). Education streaming can be slow to change over time and is less responsive to economic growth than enrollments, at least as evidence indicates for Indonesia from 1997 to 2009. Such gender streaming in education is not unique to East Asian and Pacific countries, but is evident in many Organisation for Economic Co-operation and Development (OECD) countries as well. Flabbi (2011) documents that in many OECD countries, relatively more women enter the social sciences and business, whereas more men enter the fields of engineering and architecture. 
There could be multiple reasons for men and women's choice of education streams. The relative payoff of the different streamsthe expected returns from labor markets-is likely to influence this decision. However, evidence shows that women do not necessarily take up fields with the highest premiums in the labor market wage. Table 2.1 shows the estimated returns to selected fields of study in Indonesia. The returns to studying engineering are high for females and are much higher than the returns to studying education. For example, among the female adults surveyed in 2009, the premium for having studied engineering (rather than religion) was 72 percent higher earnings, whereas the premium for having studied education was 17 percent. This phenomenon has been the case for over a decade, since the late 1990s. Still, females prefer education to engineering. As a note of caution, the data available here do not account for differences in unobservable characteristics, such as ability, among those choosing the different fields. They capture only monetary returns, whereas nonmonetary aspects-such as values, attitudes, and social expectations about women as mothers and homemakers or caregivers - also play an important role in influencing the decisions. Nonetheless, the statistics indicate what appear to be persistent patterns that also translate into patterns in the labor market, as discussed in chapter 3 .

An alternative explanation for the gender pattern of subject choice might be that females and males have different comparative advantages in a particular field based on their academic performance. The available evidence from the East Asia and Pacific region does not support this hypothesis. Female students do not systematically perform worse than males in key subjects related to male-dominant fields of study. As shown in figure 2.7 , results of the Trends in International Mathematics and Science Study (TIMSS) indicate no evident female disadvantage in math and science scores in Indonesia, Malaysia, the Philippines, and Thailand, unlike the findings for OECD countries that men tend to outperform
FIGURE 2.6 Women are concentrated in certain fields of study, such as education and health, but are underrepresented in law and engineering

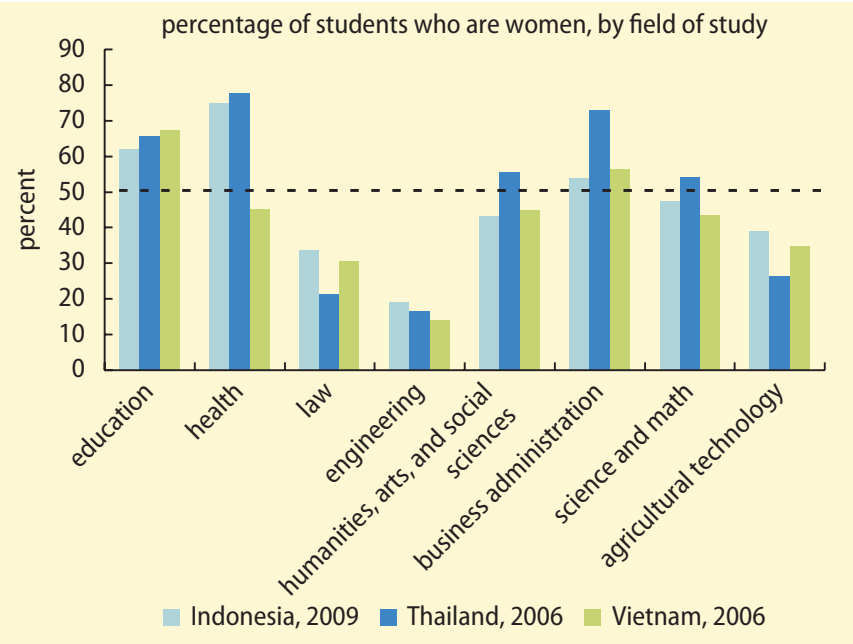

Source: Sakellariou 2011

TABLE 2.1 Labor market returns to studying engineering are high relative to studying education

Indonesia: Estimated return to field of study within tertiary education, \% change in wage

\begin{tabular}{|c|c|c|c|c|c|c|}
\hline \multirow{2}{*}{$\begin{array}{l}\text { Field of study } \\
\text { (compare to } \\
\text { field: Religion) }\end{array}$} & \multicolumn{2}{|c|}{1997} & \multicolumn{2}{|c|}{2006} & \multicolumn{2}{|c|}{2009} \\
\hline & Males & Females & Males & Females & Males & Females \\
\hline Law & 19.7 & 20.9 & 32.3 & 28.4 & 47.7 & 23.4 \\
\hline Health & 39.1 & 10.5 & 32.3 & 20.9 & 56.8 & 39.1 \\
\hline Engineering & 58.4 & 78.6 & 44.8 & 68.2 & 60.0 & 71.6 \\
\hline Education & 13.9 & 10.5 & 13.9 & 15.0 & 23.4 & 17.4 \\
\hline
\end{tabular}

Source: Sakellariou 2011.

Note: The estimates were based on a log wage regression, accounting for characteristics such as experience and experience squared, marital status, and urban/rural residence.

All coefficients were significant at the 5 percent level.

women in math and computer science (Schleicher 2008). Moreover, female students outperform their male counterparts in reading assessments, according to the Programme for International Student Assessment (PISA) test scores.

In addition, norms and expectations may influence preferences and, therefore, the choice of education streams. They can do so, for example, through shaping parental expectations, shaping role models in the labor market, or shaping how gender roles are portrayed in school curricula. Social norms 


\section{FIGURE 2.7 Girls tend to outperform boys in several subjects}

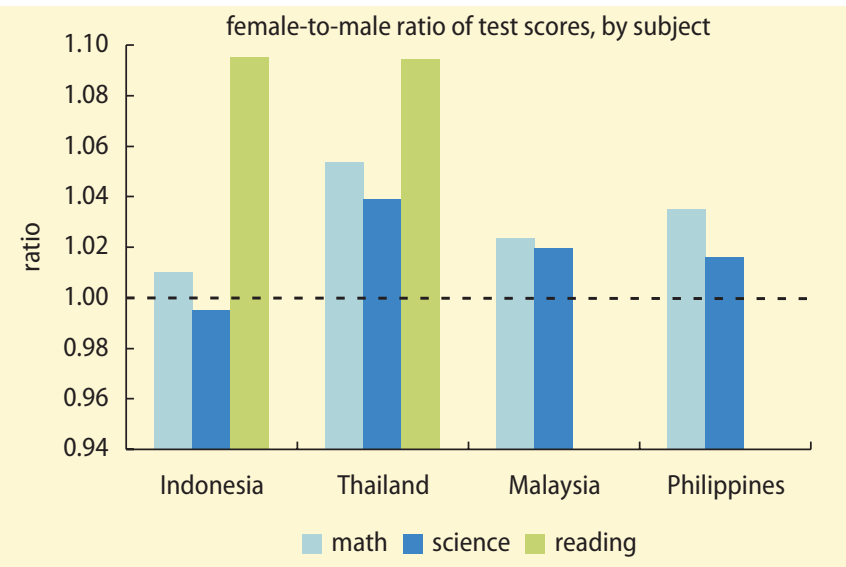

Source: World Bank staff calculations based on TIMSS and PISA data.

Note: Mathematics and science scales for eighth graders are from Trends in International Mathematics and Science Study (TIMSS). The most recent year of data is 2003 for the Philippines and 2007 for all other countries. The reading scale is from the Programme for International Student Assessment (PISA). in school. Gender stereotyping also appears to affect school performance of boys and girls in key subjects (science, mathematics, and computer science), ultimately contributing to varying occupational choices (Blumberg 2007; Eccles and Blumenfeld 1985; Shel 2007). This literature also explores the importance of the gender roles conveyed through teaching materials in shaping boys' and girls' aspirations. School, in particular primary school, is believed to be a key element of socialization for children and a site where key social values are transmitted. Teaching materials and teachers' feedback are the key instruments through which ideas about what are appropriate areas of study and acceptable professions for men and women are conveyed to children (Blumberg 2007; Nielsen and Davies 2010).

In East Asia and the Pacific, the results of a 2008 review of the Education for All (EFA) initiative indicated that teaching materials in the region included stereotypical portrayals of boys and girls (UNICEF 2009). The findings, in line with those of other regions, stress that boys appear more than girls in the learning materials, that they are portrayed as more active (and girls as more passive), and that they are shown more frequently in leadership roles. ${ }^{7}$ The report also found a lack of female role models in teaching materials. Women in the school textbooks reviewed were portrayed as secretaries, assistants, nurses, and teachers more frequently than men, who often appeared as doctors, politicians, or police officers.

Qualitative research involving both the review of teaching materials and classroom observation, which allows for an analysis of teacher-student interaction, has highlighted how gender stereotyping frequently exists in curricula in a number of East Asian countries. Table 2.2 provides selected examples of the types of issues typically encountered in curriculum analysis. Male characters tend to be portrayed as dominant in the public sphere. Similar stereotyping is also observed in other countries throughout the region. The depiction of women in China's history and social sciences manuals illustrates this point. Guo 
TABLE 2.2 School curricula in a number of East Asian countries have gender stereotyping

\begin{tabular}{|c|c|c|c|}
\hline & China & Vietnam & Korea, Rep. \\
\hline $\begin{array}{l}\text { Overall } \\
\text { visibility } \\
\text { of male } \\
\text { and female } \\
\text { characters } \\
\text { or authors } \\
\text { in teaching } \\
\text { materials }\end{array}$ & $\begin{array}{l}\text { The proportion of male characters } \\
\text { rises from } 48 \text { percent in books for } \\
\text { four-year-olds to } 61 \text { percent in books } \\
\text { for six-year-olds. Female characters } \\
\text { appear most commonly in reading } \\
\text { materials for very young children. }\end{array}$ & $\begin{array}{l}\text { In grade } 4 \text { and grade } 5 \text { texts analyzed, } \\
\text { most authors mentioned and quoted } \\
\text { were men ( } 74 \text { of } 85 \text { and } 77 \text { of } 84 \text {, } \\
\text { respectively). } \\
\text { In mathematics textbooks analyzed, } \\
\text { female characters were found to } \\
\text { appear in illustrations more often than } \\
\text { men (some grade levels); however, } \\
\text { they were associated with less } \\
\text { challenging activities. }\end{array}$ & \\
\hline $\begin{array}{l}\text { Stereotypical } \\
\text { portrayals } \\
\text { of men and } \\
\text { women in } \\
\text { textbooks }\end{array}$ & $\begin{array}{l}\text { Portrayal of male and female } \\
\text { characters follows gender role } \\
\text { stereotypes in both mathematics and } \\
\text { social sciences manuals. An analysis of } \\
\text { mathematics texts indicated that male } \\
\text { characters were } 74 \text { percent of those } \\
\text { in stimulating activities, and female } \\
\text { characters represented } 70 \text { percent } \\
\text { of those in passive roles. Men and } \\
\text { boys are therefore typically portrayed } \\
\text { as courageous, independent, and } \\
\text { ambitious, in contrast to "passive, } \\
\text { obedient, neat, cooperative girls." }\end{array}$ & $\begin{array}{l}\text { Stereotypical depictions of men/ } \\
\text { boys and women/girls are present } \\
\text { in a range of textbook illustrations } \\
\text { and exercises. A detailed analysis } \\
\text { of materials used in grades } 1 \text { to } 5 \\
\text { highlights the following depictions of } \\
\text { men and boys: (a) heroes/courageous; } \\
\text { (b) strong/able to do complicated } \\
\text { and physically challenging jobs; (c) } \\
\text { knowledgeable/smart; (d) naughty; (e) } \\
\text { creative; and (f) leaders. } \\
\text { In contrast, women and girls are } \\
\text { typical portrayed as (a) "nice and } \\
\text { lovely"; (b) caring (as teachers, nurses); } \\
\text { (c) clean and ordered; and (d) weak/ } \\
\text { emotional. } \\
\text { Interestingly, men and boys were } \\
\text { also more frequently associated with } \\
\text { "forbidden" or dangerous activities. }\end{array}$ & $\begin{array}{l}\text { Curricular materials presented traditional } \\
\text { gender roles with women depicted } \\
\text { doing housework versus office work for } \\
\text { men, male characters leading activities } \\
\text { and female characters assisting. }\end{array}$ \\
\hline
\end{tabular}

Sources: Jung and Chung 2005 (Korea); Ross and Shi 2003; Shi and Ross 2002 (China); UNESCO/Vietnam Ministry of Education and Training 2011 (Vietnam).

and Zhao's (2002) analysis of elementary language textbooks highlights that only about a fifth of the historical characters portrayed are female. When they are depicted, they also tend to be portrayed in stereotypical roles. For example, an influential female leader of the Chinese Communist Party is depicted twice: once mending Premier Zhou Enlai's clothes, and another time bringing an umbrella to a guard on a rainy day.

\section{Improvements and remaining gender issues in health}

Promoting better health is important for enhancing welfare. Most societies recognize that girls and boys should have equal access to the elements of a healthy life and that maternal health is important. Mothers' health and nutrition affect their children's physical health as well as cognitive abilities. 
Research shows that delays in cognitive and overall development from the time a child is conceived up to age six, a sensitive period for brain formation, have long-lasting consequences that are difficult to compensate for later on in life (Naudeau et al. 2011). In addition, improved maternal health has been shown to enable women to reconcile work and motherhood, playing a role in raising married women's labor force participation in the United States (Albanesi and Olivetti 2009). Research has also shown that with declining maternal mortality-that is, longer life expectancy for women-parents can expect a longer duration of payoff from daughters. In Sri Lanka, for example, parents respond with more investment in girls' education (Jayachandran and Lleras-Muney 2009).

To explain progress or the lack thereof in gender equality in health in East Asian and Pacific countries, this section focuses on several key indicators, such as fertility, child and maternal mortality, and sex ratios at birth. The chapter argues that many, but not all, health outcomes for males and females in the East Asia and Pacific region have improved with development. Fertility and child and maternal mortality have had impressive gains, except in a few places with slower economic progress, such as Cambodia, Lao PDR, and Timor-Leste. However, the region still has a large number of missing girls, a persistent issue not easily mitigated by growth and development. The chapter also sheds light on two behavioral health issues associated with high adult mortality risks for men in all East Asian and Pacific countries: excessive smoking and drinking.

\section{Declines in fertility and child and maternal mortality rates}

Gender differences in health outcomes reflect biological differences as well as genderdifferential behaviors, which are difficult to separate in what we observe. As a result of biological factors determining life expectancy, for example, women tend to live longer than men (Eskes and Haanen 2006). Male mortality is naturally higher than female mortality for the first six months of life (Waldron 1998). Men and women are also susceptible to different diseases, such as different types of cancer. Aside from biological differences, health outcomes are also affected by differences in behaviors and health investments that could disadvantage one particular gender. Thus, many unobservable factors affect morbidity and mortality for men and women.

This chapter focuses on mortality risks throughout the life cycle. For early childhood and childbearing periods, most East Asian and Pacific countries have experienced impressive progress in narrowing the gender gaps in the infant mortality rate and reducing maternal mortality. However, as discussed later, the period before birth is a concern, with male-skewed sex ratios at birth in several parts of the region.

Many East Asian and Pacific countries have significantly improved several health outcomes during the past two decades. Fertility rates went down sharply. Infant and child mortality rates for both boys and girls have declined substantially since 1990 , closing the gender gaps in the infant mortality rate. The maternal mortality rate (MMR) has also been declining, and, along with the female infant mortality rate in most of East Asia and the Pacific, is now low relative to the region's income level. Figures 2.8 and 2.9 illustrate this point: in the cross-country graphs of these health indicators and income measured in terms of purchasing power parity, most East Asian and Pacific countries lie below the downward-sloping curve representing this relationship.

As in the case of education, progress has not been uniform across the region. First, China differs from other East Asian and Pacific countries in having a high rate of female child mortality relative to that of males. Figure 2.10 graphs the ratio of femaleto-male child mortality as well as the ratio for infant mortality against GDP per capita. Although in most countries, male infant and child mortality rates are slightly higher than female rates, consistent with biological 


\section{FIGURE 2.8 Maternal mortality is lower in higher-income countries}

maternal mortality rate (modeled estimate, per 100,000 live births) against income levels, 2008

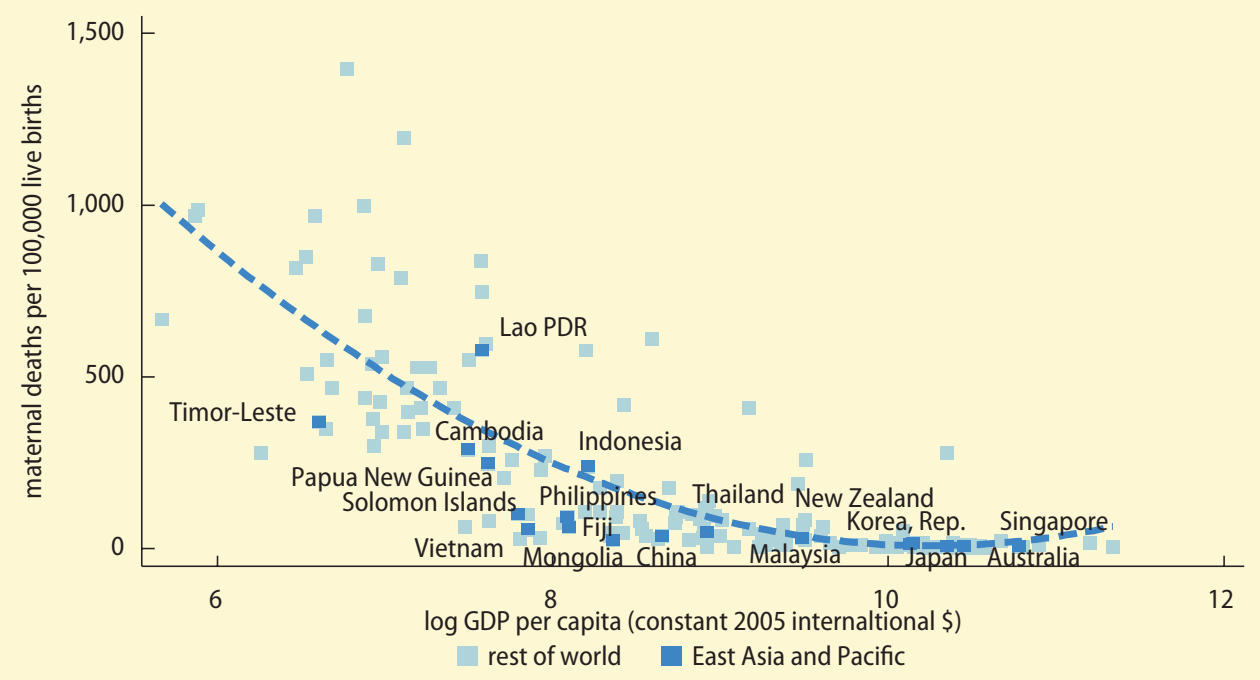

Source: World Bank estimates using World Development Indicators (WDI) database, 2011 data.

\section{FIGURE 2.9 Female infant mortality is lower in higher-income countries}

female infant mortality rate (number of deaths between birth and age one, per 1,000 live births) against income levels, 2009

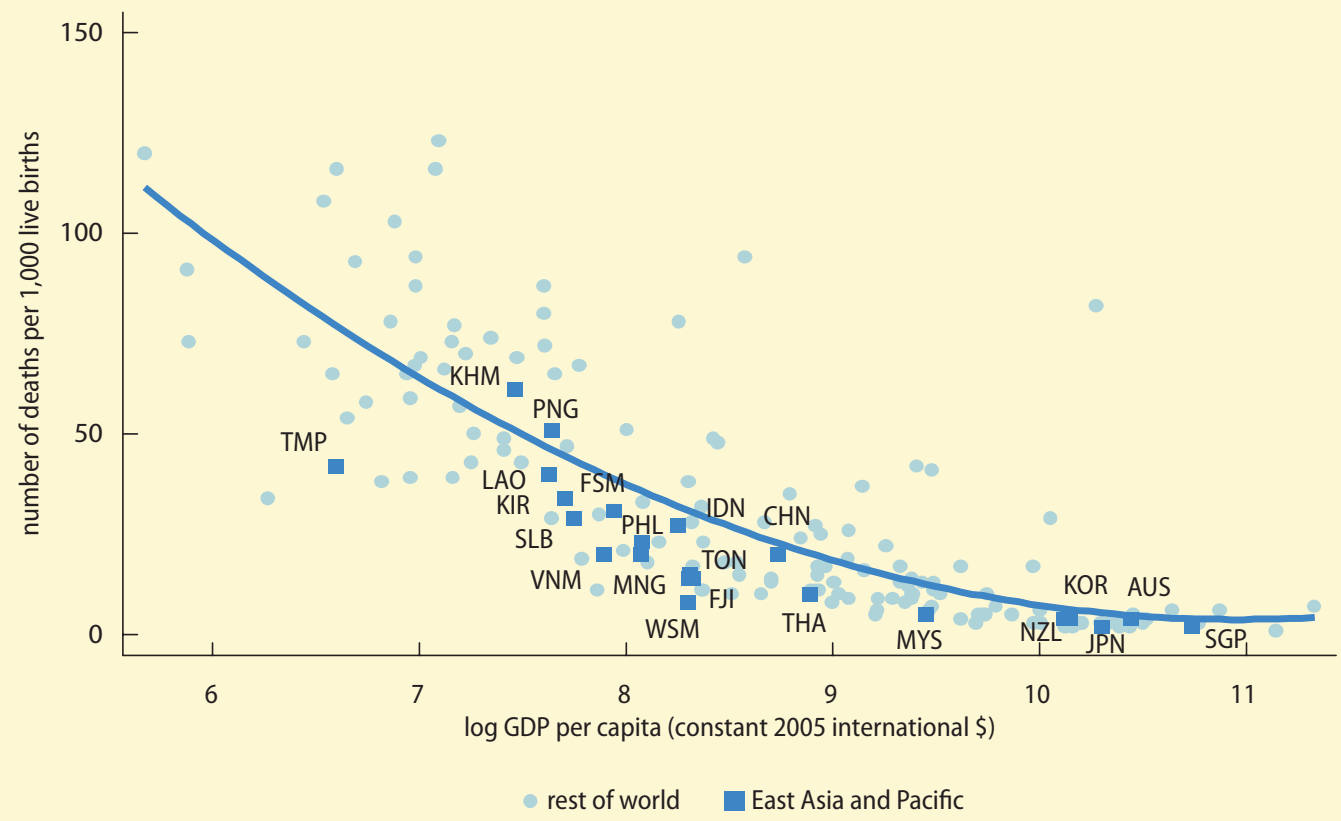


factors, China experiences the opposite patterns. Females face higher mortality risks during infancy than males, and even more so before birth, which is related to the "missing girls at birth" topic, discussed later.
Second, the maternal mortality rate is still a serious concern in a number of places in the region. As shown in figure 2.8, Lao PDR experienced more than 500 maternal deaths per 100,000 births in 2008 , a rate

\section{FIGURE 2.10 Most East Asia and Pacific region countries do not have female-skewed under-five mortality and infant mortality, except China}

a. female-to-male ratio of under-five mortality, 2009

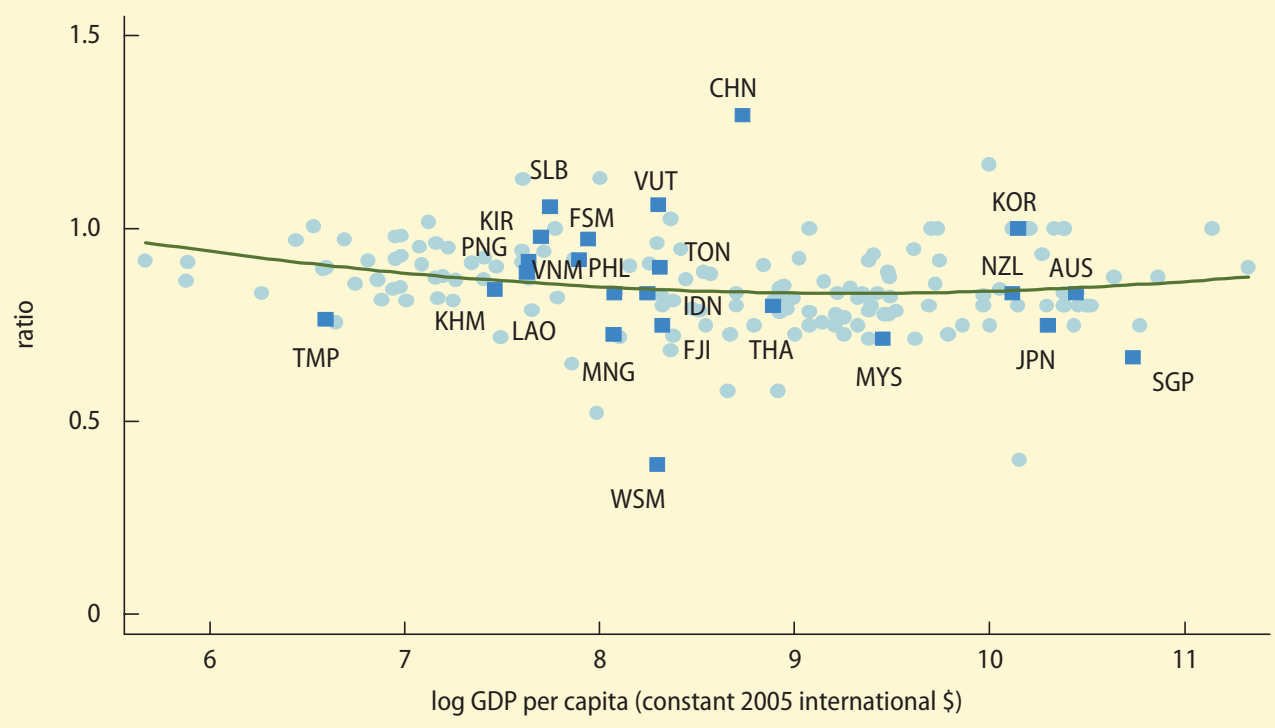

b. female-to-male ratio of infant mortality, 2009

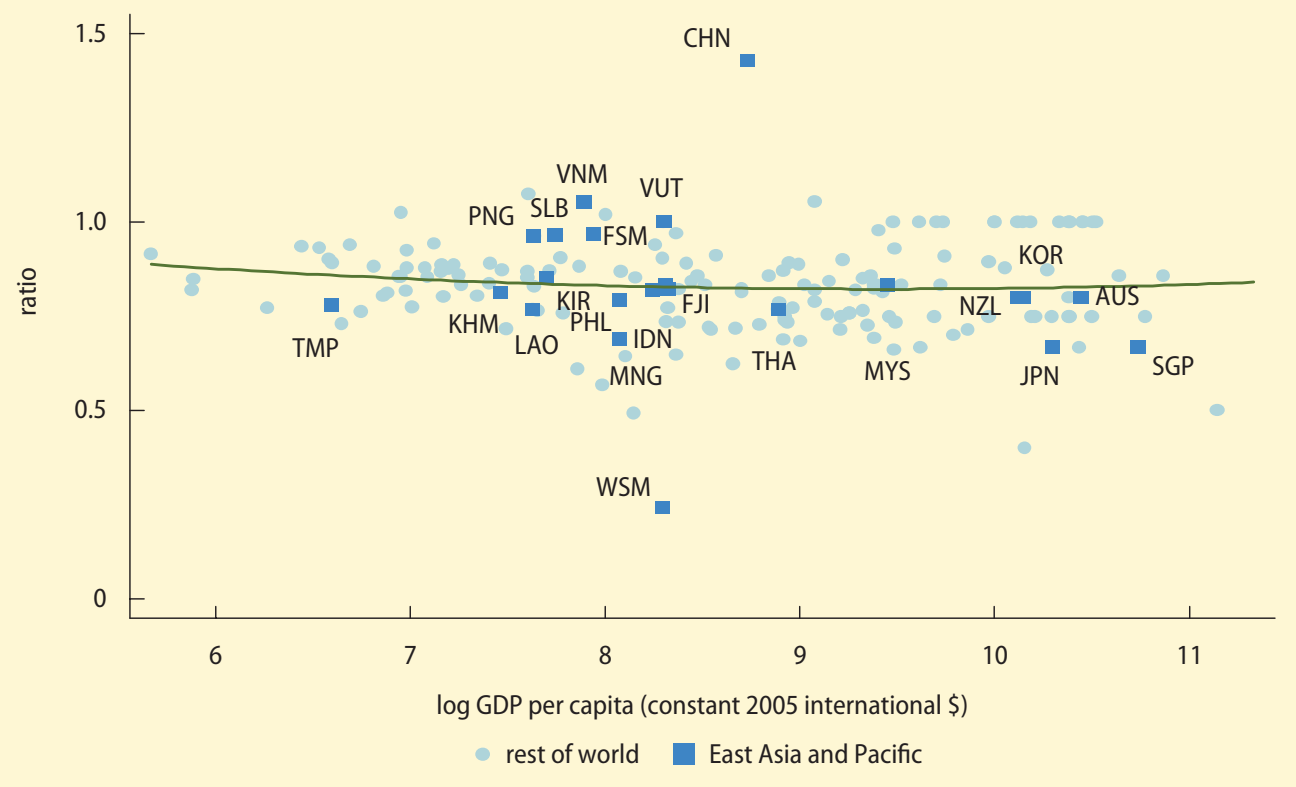


much higher than other countries of similar income level. The maternal mortality rate remains high-above 240 maternal deaths per 100,000 births-in several other countries, such as Cambodia, Papua New Guinea, and Timor-Leste, despite progress over the past two decades. Indonesia's maternal mortality rate remains high compared to other countries in the region at similar levels of development. Even for Vietnam, a country that has successfully reduced this rate at the national level, maternal health outcomes still lag in rural areas and among ethnic minority groups (World Bank 2011b).

\section{Growth, development, and improvements in health outcomes}

Maternal health and child health outcomes are a result of many factors, including service delivery related to the public and private health systems, prices and the availability of insurance mechanisms, and the demand side of households' fertility and health-seeking behavior. Social norms regarding childbirth practices also have an important influence in many contexts.

The East Asia and Pacific region has experienced a substantial reduction in total fertility, and this decline has reduced the risk of maternal health complications and death. The share of women using modern contraception, and thus are presumably more able to control fertility, has been on the rise in many East Asian and Pacific countries. Government policies such as family planning programs and China's one-child policy were expected to control fertility. Schultz and Yi (1997) argued that institutional reforms, such as the replacement of the collective production team with the household responsibility system starting in 1979 in China, may have contributed to the decline in fertility in the long term for a variety of reasons. For example, the intensified market competition encouraged parents to educate children and focus on the "quality" rather than quantity of children. Increased mobility and migration for better economic opportunities were also linked to delayed childbearing. The declining fertility in Thailand before 1980 has been attributed to government subsidies to public and private family planning systems and to the rapid increase in female education (Schultz 1997). Breierova and Duflo (2004) showed that higher education among females in Indonesia led them to have fewer children early on, and the increased education of mothers and fathers led to lower child mortality. As mentioned earlier, in Indonesia today, compared to a few decades ago, women exhibit a stronger preference for fewer children and for more per-child investment in health and education. This preference change is attributed to decreased preference for sons over daughters and to other social changes (Niehof 2003).

Growth and development in the East Asia and Pacific region have contributed to the region's progress in improving maternal and reducing child mortality through a combination of demand-side and supply-side factors. In fact, living in a high-income country is generally associated with lower risk of maternal death and of female infant death (as well as male infant death, not shown). Figures 2.8 and 2.9 show a negative relationship between a country's maternal mortality rate or female infant mortality rate with its GDP per capita level.

For the household, rising income in the region appears to have positive impacts on health outcomes. A rise in income may loosen the incentives to differentiate health investments across boys and girls. Evidence from a large data set of developing countries shows that, on average, a one-unit increase in log GDP per capita is associated with a decrease in mortality of between 18 and 44 infants per 1,000 births. This negative relationship holds true even when various factors-such as the mother's characteristics, weather shocks, conflicts, and the quality of institutionsare accounted for. Female infant mortality is more sensitive to changes in economic conditions than male mortality (Baird, Friedman, and Schady 2007). ${ }^{8}$ In addition, households with higher income can afford more health services, such as the use of prenatal care and hospitals during births. Figure 2.11 shows that in every East Asian and Pacific country 


\section{FIGURE 2.11 Women in wealthier households are more likely to have births assisted by trained medical staff}

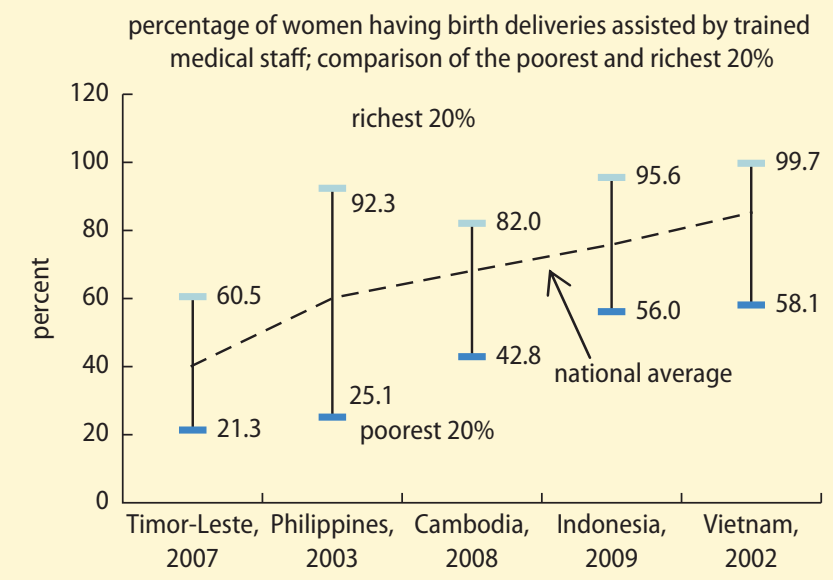

Sources: World Bank staff estimates using household income and expenditure surveys of various countries and years; World Bank Health, Nutrition, and Population Statistics (HNPStats) database.

examined, women living in richer households are more likely to have birth deliveries assisted by trained health professionals. In some cases, such as Cambodia, Indonesia, and the Philippines, the gap between the richest quintile and the bottom one can be fourfold. Over time, as the economy grows, the rate of professional birth attendance increases. Lastly, the availability of insurance mechanisms has also made health care more affordable. The expansion of health insurance coverage in Vietnam, from 25 percent of the population in 2004 to 40 percent in 2006, and serious efforts by the government to extend health insurance to the poor and ethnic minorities in recent years have had positive impacts on access to health services (World Bank 2011b).

Rising women's income, in particular, is likely to have contributed to this progress in health outcomes. Many countries in the East Asia and Pacific region have experienced recent increases in female labor force participation. Evidence shows that income in the hands of women positively affects children's health, particularly girls' (Thomas 1995 for Brazil, Ghana, and the United States; Duflo 2003 for South Africa). Higher female labor force participation has been shown to improve their bargaining power and to increase the height of children in Mexico (Atkin 2010). In Indonesia, women with a higher share of household assets tend to use more prenatal and delivery care (Beegle, Frankenberg, and Thomas 2001).

Improvements in health technologies as well as improvements in the institutions supplying health care have led to lower costs of health services and better health outcomes. Medical progress with the medicalization and hospitalization of childbirth contributed to the substantial decline in maternal mortality in the United States in the first half of the 20th century (Albanesi and Olivetti 2009). These technologies, when adopted in developing countries in the region, were likely to have similar effects. In addition, the share of women using modern contraception has been on the rise in many East Asian and Pacific countries. Contraception use allows families to control fertility and avoid extremely short periods between pregnancies, which tend to pose higher health risks. Countries shown in figure 2.12 with a high rate of contraceptive use (for example, the high and increasing rate in Vietnam) are also those with a low maternal mortality rate.

The functioning of the health system, including infrastructure, medical facilities, and equipment and staffing, is also key to improving health outcomes. Experience in the United States illustrates the importance of public health investments: two-thirds of the decline in overall infant mortality and the entire decline in excess female infant mortality in the early 20th century were attributable to clean water and sanitation (Cutler and Miller 2005). Vietnam's remarkable achievements in bringing down child and maternal mortality have been attributed to a general strengthening of the health system (World Bank 2011b). The gains in the share of births attended by professionals from 2000 to 2008 were very impressive in the East Asia and Pacific region, larger than any other developing region. Bringing better services closer to women can change their patterns of use, and positively affects health outcomes. Frankenberg and Thomas (2001) analyzed the Indonesia Family Life Survey panel data using 
community-level fixed effects to measure the impacts of a major expansion in midwifery services between 1990 and 1998 on health and pregnancy outcomes for women of reproductive age. The authors showed that the addition of a village midwife to communities between 1993 and 1997 was associated with a significant increase in body mass index (BMI) for women of reproductive age, as well as an increase in birthweight of newborns. Frankenberg et al. (2009) further investigated the reasons behind this impact on outcomes. The presence of village midwives appears to have increased women's receipt of iron tablets and influenced their choice of childbirth practice away from reliance on traditional birth attendants toward delivery attended by skilled professionals.

\section{Ongoing challenges: Poor service delivery and social norms}

East Asian and Pacific countries with high maternal mortality rates-Cambodia, Indonesia, Lao PDR, Papua New Guinea, and Timor-Leste-are precisely those with low rates of contraceptive use and low rates of births delivered by professionals (figure 2.12 and figure 2.13). As shown in figure 2.12, Pacific Island countries tend to have low contraceptive prevalence compared to East Asia. In Timor-Leste, for example, only 20 percent of women ages 15-49 use contraception, leading to high fertility rates and very short periods between pregnancies. Less than 20 percent of the births in Timor-Leste are assisted by professionals. Delivery at home without professional help and without easy access to a functioning referral center poses high risks, particularly in case of complications. The absence of the factors that explain progress elsewhere is at play in these countries. Demand-side constraints from households, including social norms about pregnancy and birthing practices, and poor supply-side provision of care explain the poor health outcomes in these countries. The exact reasons can vary from context to context.

On the supply side, poor access to quality obstetric health services, particularly among
FIGURE 2.12 Contraceptive prevalence varies across East Asian and Pacific countries

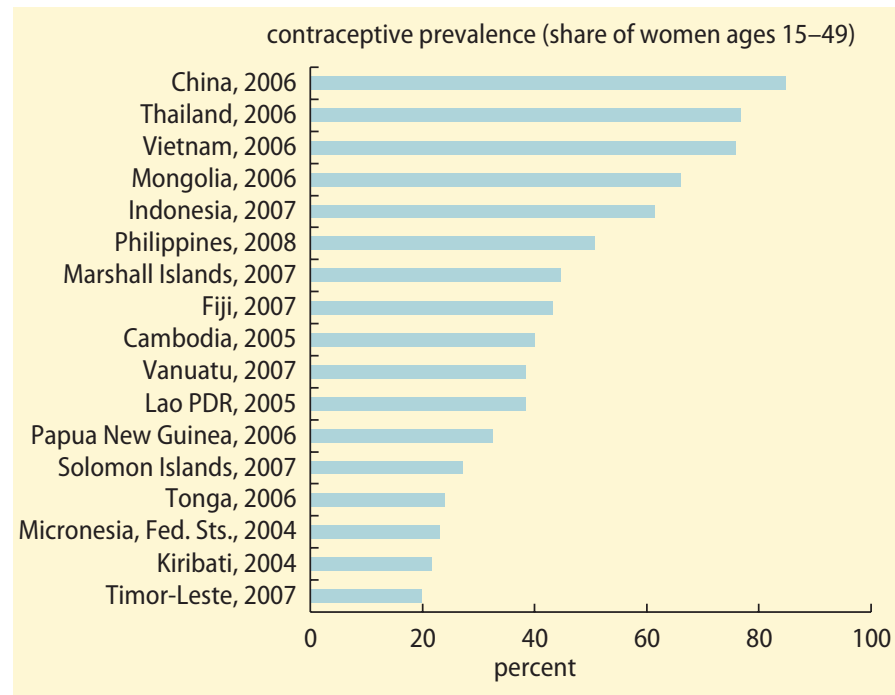

Source: WDI database, Gender Statistics.

FIGURE 2.13 The percentage of births attended by skilled professionals varies across East Asian and Pacific countries

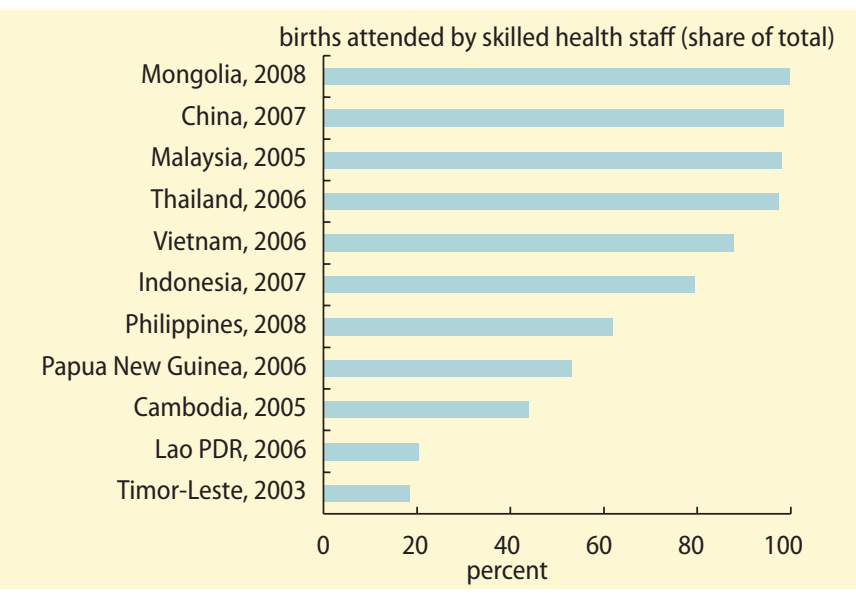

Source: WDI database, Gender Statistics.

rural and remote areas, places women at a high risk for maternal death. Rural areas tend to be less well served by the health system; figure 2.14 shows that rural residents have substantially less access to birth deliveries attended by trained staff than urban residents. Delivery in the home is of particular concern for poor, rural women because they 


\section{FIGURE 2.14 Women in rural areas are less likely to have births} assisted by trained medical staff

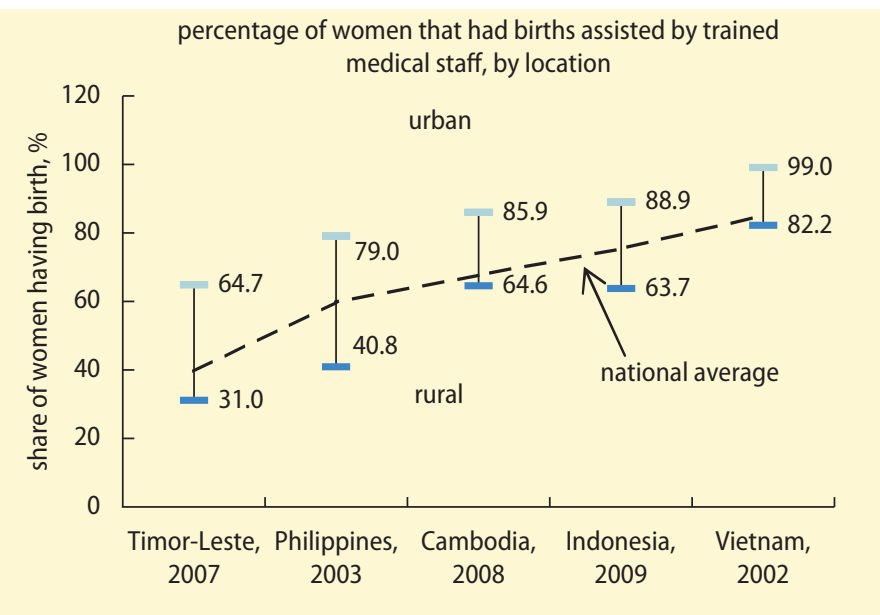

Source: World Bank estimates using household income and expenditure surveys of various countries and years, and the HNPStats database (see figure 2.1 country sources).

lack the basic sanitary conditions needed for a safe delivery. In Lao PDR, almost 90 percent of rural women deliver at home, compared to approximately a quarter of urban women. As a result, a large disparity in maternal mortality rates exists between urban and rural areas in Lao PDR: 170 versus 580 maternal deaths per 100,000 births, respectively (GRID 2005). In Timor-Leste, 59 percent of urban births are assisted by skilled providers, compared with 21 percent of births in rural areas. This rate is 69 percent in the capital city, Dili, but less than 10 percent in the Oecussi region (NSD, Ministry of Finance, and ICF Macro 2010). Moreover, the quality of prenatal care in Timor-Leste, is limited: in 2001-02, only 41 percent of those giving birth were protected against neonatal tetanus, a major cause of neonatal death (ADB 2005). Substantial disparities also exist across provinces in Indonesia: Jakarta has 97 percent of births attended by a skilled provider, whereas Maluku has only 33 percent (World Bank 2010).

Long distance to the nearest health center and the poor infrastructure available can both impose high costs of access. Although high in all rural areas, the rate of deliveries at home is highest among highland women in Lao PDR for whom both distance and infrastructure are of concern (GRID 2005). Chine-Tibet women appear to be most at risk during childbirth since they are very likely to give birth outside of a hospital, and a large majority of Chine-Tibet villages (76 percent) lack safe water, let alone access to other sanitary measures (GRID 2005). In Cambodia, low quality health care, the poor state of rural roads, lack of transport, and poor access to a clean water supply have all been shown to impede progress in bringing down maternal mortality (UNIFEM, World Bank, ADB, UNDP, and DFID/UK 2004).

On the demand side, tight household budgets can constrain the use of health care services. Women from poor families may not be able to afford health costs, which are the major barrier to seeking health care in many developing countries. As shown earlier in figure 2.12, in every country examined, women living in poor households are less likely to have birth deliveries assisted by trained health professionals. In Indonesia, the community health insurance scheme, Jamkesmas, has had little effect on facility-based deliveries because some delivery costs such as transport and costs for family members were not covered (World Bank 2010). Even in a country with health insurance subsidies for the poor, only 60 percent of Vietnamese women in the poorest quintile had births attended by trained medical staff in 2002 (figure 2.11).

Women's access to reproductive health care could be constrained by norms. Culture and tradition play an important role in the choice of health practices, such as the location of childbirth, the use of birth attendants, and sterilization practices. For instance, following a traditional practice, a number of MonKhmer women in Lao PDR deliver neither in the home nor in a medical center, but rather in the forest (GRID 2005). In Cambodia, cultural beliefs that pregnancy and childbirth are part of the natural process lead families to perceive that women do not need prenatal care or delivery supported by skilled attendants. Thus, many women continue heavy physical labor and long work hours during pregnancy and immediately after childbirth 
(UNIFEM, World Bank, ADB, UNDP, and DFID/UK 2004).

The evidence suggests that improving service delivery is key to reducing gender disparities and improving health outcomes. Given the central influence of social norms in birthing practice, service delivery could and should be strengthened by providing services in a culturally acceptable way. Policy implications and recommendations are discussed at the end of this chapter and in chapter 6.

\section{Missing girls at birth}

One concerning issue that persists in the East Asia and Pacific region despite tremendous growth and development is the phenomenon of missing girls, particularly at birth. The term "missing women" was first coined by Sen (1992) to refer to the phenomenon that many low-income countries have far fewer women than men, relative to what is observed in developed countries. At birth, the biological norm is approximately 105 boys born for every 100 girls. Yet, the male-female ratio at birth in East Asian and Pacific countries far exceeds that of other regions, mainly driven by China's ratio.

The United Nations Department of Economic and Social Affairs, Population Division, database provides estimates of cross-country sex ratios at birth over time. These estimates are based on projections from national census data and a fertility modeling exercise. Estimates from national statistical offices can sometimes stem from more recent data and, as a result, differ from the United Nations (UN) projections. According to the UN projections, over the 2005-10 period, 120 boys in China were born for every 100 girls. Outside of China, new concerns are emerging regarding Vietnam's rising sex ratio at birth. According to the Vietnam General Statistical Office's Annual Population Change Surveys, the sex ratio at birth increased regularly from 2004 and crossed the 110 threshold in 2005 (UNFPA 2009). Yet, trends in sex ratios in the East Asia and Pacific region are not all bad news. Korea has seen declining sex ratios at birth, from 110.2 in 1998 to
106.4 in 2008 , now close to the biological ratio (figure 2.15). ${ }^{9}$

Sex ratios at higher order births (that is, second children or above) are usually worse than the average ratios. In China, although the sex ratio at birth in the 1980s was within the normal range for the first birth, it became unbalanced at higher orders -1.3 for the fourth or later child in 1989. The sex ratios for higher order births, conditional on earlier female births, were even more starkly skewed toward males (Zeng et al. 1993). Chung and Das Gupta (2007) used data from Korea's 2003 fertility survey to show that the sex ratio at birth after the first birth was 129 if all the previous births were girls, and it is 112 if at least one previous birth was a boy. This difference was even starker among those women who stated that having a son was imperative. More recently in Korea, even though the average sex ratio at birth is close to the normal range, the ratios for the third birth and for the fourth or higher births were still 116 and 124, respectively, in 2008 (figure 2.15). In Vietnam, the pattern is unusual in that the sex ratio for the first birth is already higher than that for the second birth and similar to that for the third or later births. However, according to Vietnam's 2006 population survey, the sex ratio at birth for third-order

FIGURE 2.15 Sex ratios at higher order births are still of concern, even though the overall sex ratio at birth has approached the normal range in the Republic of Korea

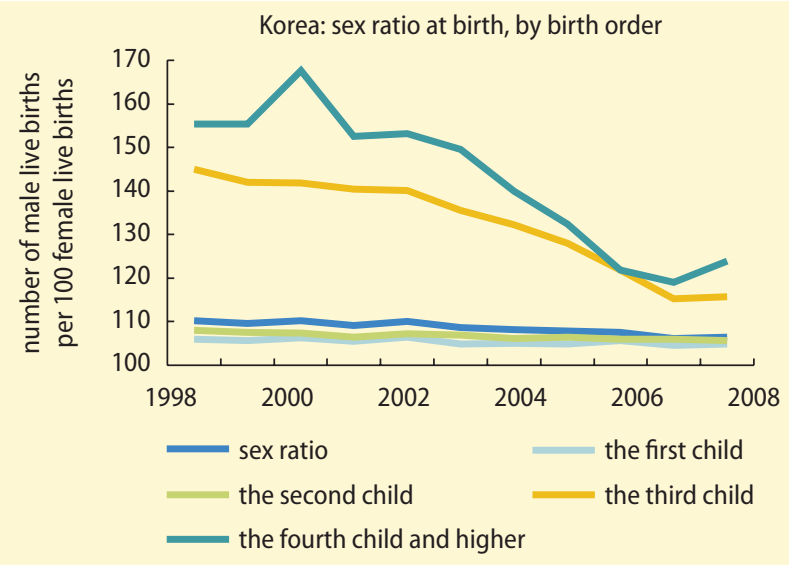

Source: Korea National Statistical Office. http://kostat.go.kr. 
births decreases with the previous number of sons born between 2000 and 2006: 110.3 for no sons, 103.5 for one son, and 102.2 for two sons (UNFPA 2009).

As a consequence, in comparison to other developing regions, the number of missing girls at birth in the East Asia and Pacific region, particularly in China, dominates the excess mortality risks for females after birth. The World Development Report 2012 uses the following methodology to calculate the number of missing girls at birth and excess female deaths in other parts of the life cycle. The number of missing girls at birth is calculated by comparing the sex ratio at birth in a particular country to the ratio in highincome countries (105.9 boys for 100 girls). Throughout the age distribution, excess female mortality is calculated by comparing the mortality risks of females relative to males in a particular age group in a country with the mortality risks in a reference group of high-income countries. ${ }^{10}$ Table 2.3 shows the number of missing girls at birth and excess female deaths per year, calculated using this methodology. Excess female mortality in infancy and during the reproductive years have substantially decreased in China. An estimated 71,000 girls under age five were missing in China in 2008, consistent with figure 2.10, which shows China's high female-to-male child mortality ratio. However, the most worrisome period of missing girls in China is at birth. The number of missing girls at birth increased from 890,000 in 1990 to $1,092,000$ in 2008. Missing girls as a fraction of the total number of female births increased from 8.6 percent in 1990 to 13.3 percent in 2008 .

The reason for the missing girls phenomenon has been attributed to son preference (Das Gupta 2005). Parents' preferential choices to keep and care for boys over girls can depend on social norms and values, different economic opportunities by gender, and what benefits parents expect from a son or a daughter. As an example of how economic opportunities influence parental choice over the gender of their child, Qian (2008) showed that the sex ratio at birth is responsive to returns in the labor markets for women in rural China. An increase in women's income relative to men's led to higher survival rates for girls. Another example of how parental choice responds to changing economic conditions is the rise of marriage migration-cross-border marriages between women from Southeast Asia and men from East Asia. Through a 2007 survey of three migrant-sending communities in southern Vietnam, Bélanger and Tran (2011) documented an enhanced status of emigrating daughters sending remittances

TABLE 2.3 The East Asia and Pacific region, mainly driven by China, is characterized by its large number of missing girls at birth

Missing girls at birth and excess female deaths throughout the age distribution (1,000s per year)

\begin{tabular}{|c|c|c|c|c|c|c|c|c|c|c|c|c|}
\hline & \multicolumn{2}{|c|}{ At birth } & \multicolumn{2}{|c|}{ Under 5} & \multicolumn{2}{|c|}{ 5-14 } & \multicolumn{2}{|c|}{$15-49$} & \multicolumn{2}{|c|}{ 50-59 } & \multicolumn{2}{|c|}{ Total (under 60) } \\
\hline China & 890 & 1,092 & 259 & 71 & 21 & 5 & 208 & 56 & 92 & 30 & 1,470 & 1,254 \\
\hline Sub-Saharan Africa & 42 & 53 & 183 & 203 & 61 & 77 & 302 & 751 & 50 & 99 & 639 & 1,182 \\
\hline South Asia (excluding India) & 0 & 1 & 99 & 72 & 32 & 20 & 176 & 161 & 37 & 51 & 346 & 305 \\
\hline East Asia and Pacific (excluding China) & 3 & 4 & 14 & 7 & 14 & 9 & 137 & 113 & 48 & 46 & 216 & 179 \\
\hline East and Central Asia & 7 & 14 & 3 & 1 & 0 & 0 & 12 & 4 & 4 & 3 & 27 & 23 \\
\hline Latin America and the Caribbean & 0 & 0 & 11 & 5 & 3 & 1 & 20 & 10 & 17 & 17 & 51 & 33 \\
\hline Total & 1,212 & 1,427 & 1,010 & 617 & 230 & 158 & 1,286 & 1,347 & 343 & 334 & 4,082 & 3,882 \\
\hline
\end{tabular}

Source: World Bank 2011c.

Note: Estimates are based on data from World Health Organization (WHO) 2010 and United Nations Department of Economics and Social Affairs, Population Division (UN DESA 2009). 
back home, and, consequently, a change in families' preference for having girls.

Most societies have some mild degree of preference for sons (Williamson 1976), but the manifestation of extreme sex ratios comes from rather extreme son preferences. The interplay of culture, the state, and political processes appears to generate extreme patrilineality and highly skewed child sex ratios such as in the case of China, northwest India, and Korea (Das Gupta 2009). Chung and Das Gupta (2007) argued that son preference in Korea is correlated with factors such as lower socioeconomic status, rural area residence, higher parental control in terms of arranged marriage and co-residence with the parents, and lower education of the woman.

In addition, the manifestation of son preference is also influenced by public policies and the availability of technology. China's one-child policy and Vietnam's two-child policy, though intended to reduce fertility, may have put additional pressure on the incentives to have a son and intensify the skewed sex ratios. In fact, Ebenstein (2010) showed evidence of a positive correlation between the fines imposed by China's one-child policy and the sex ratio. With development and the introduction of prenatal sex determination technology (ultrasound) in the early 1980 s, male-tofemale sex ratios became unnaturally very high in a few East Asian countries. Li and Zheng (2009) found a strong impact of the B-ultrasound technology on the sex ratio of second-order births for rural mothers in Fujian province, China, but no effect among first-born children. The recent increase in Vietnam's sex ratio at birth may be related to supply-side factors, that is, access to quality sex determination technology, rather than to an increasing preference for sons. Ultrasound technology first started to appear in major hospitals in Vietnam during the mid-1990s and was subsequently offered through the private sector (Bélanger et al. 2003), but the quality and availability of medical equipment have improved during the past 10 years. Thus, the proportion of mothers with prior knowledge of the sex of their fetus rose from 60 percent in 2003 to 73 percent in 2007 (UNFPA 2009).

With prior knowledge of the sex of the fetus, families can discriminate through less prenatal investment or even through abortion. In China, as well as other countries with prevalent son preference, mothers are 5 percent more likely to acquire prenatal care and visit an antenatal clinic 10 percent more frequently when pregnant with a boy (Bharadwaj and Nelson 2010). Bélanger and Khuat (2009) examined the timing of abortion among 885 married women in an obstetric hospital in Hanoi, Vietnam, in 2003 to study sex-selective abortions, which generally happen during the second trimester of pregnancy. They found that women with more daughters and without a son were more likely to have a second-trimester than a first-trimester abortion. Their estimates suggest that 2 percent of all abortions by women with at least one prior child were intended to avoid a female birth.

Given the factors discussed earlier, the literature shows mixed evidence on whether development mitigates or worsens son preference and sex ratios at birth in Asia (Chung and Das Gupta 2007). Development can bring about substantial normative changes within the entire society together with improvements in individuals' socioeconomic situations, as argued in the case of Korea by Chung and Das Gupta (2007). However, cross-country evidence shows that modernization does not appear to bring down son preference. In South Asia, son preference is greater for women with more education and is increasing over time (Filmer, Friedman, and Schady 2008). Unbalanced sex ratios at birth could be worsened by economic development, as sometimes argued in the literature, since highly educated and wealthier women tend to have better access to technologies. Vietnam's 2006 population survey shows that the sex ratio at birth is high for women who have a graduate education (113), have highest grade of 10 and above (111), work in a foreign organization (117), and have previous knowledge of the baby's sex (111). Of women with a graduate degree, 87 percent 
knew the gender of their child, whereas no more than 28 percent of illiterate women had prior knowledge of the sex of their child. The sex ratio at birth increases with the level of education, rising from 103 for illiterate women to 113 for women with a graduate education (UNFPA 2009).

The collection of evidence has several implications for approaches to address the unbalanced sex ratios at birth, and China has taken active measures in this direction. General policies to promote economic development might play a role, but Korea's recent experience suggests that active measures to influence social norms and facilitate the spread of new values may be very important, in addition to relying on raising female education and labor force participation alone (box 2.2).

\section{Risky behaviors in men}

Men, as well as women, experience genderspecific health risks. Men tend to bear the burden of higher morbidity and premature mortality related to substance abuse, war and conflict, and violence. The latter tends to be

\section{BOX 2.2 Recent improvement in the sex ratio at birth in the Republic of Korea}

Since the 1970s, Korea has experienced significant industrialization and urbanization, coupled with increases in women's education and labor force participation. It is also the first Asian country to register a decline in the proportion of missing girls, from the most male-skewed sex ratios at birth in the mid1990 s to ratios within the normal range by 2008 . As the sex ratios at birth are usually argued to be a manifestation of son preference, Chung and Das Gupta (2007) used data from fertility surveys to measure trends in son preference directly. They documented a continuous decline from 1985 to 2003 in the fraction of Korean women who reported that they must have a son, from almost 50 percent to less than 20 percent. Women with similar characteristics demonstrated lower son preference over time.

Both the process of development and public policies since the 1950s have influenced the factors underlying son preference in Korea. First, the impacts of development were expected to work in many ways, as argued by Chung and Das Gupta (2007): (a) higher earning prospects increased individuals' independence of family lineage; (b) retirement savings reduced financial dependence on children in old age; (c) urban life setting reduced the focus on traditional filial duty and promoted femaleinclusive social networks; (d) females' greater economic and physical mobility enhanced the value of daughters; and (e) urban life, with assets associated with nonfarm activities and less pressure from customary laws, facilitated gender equity in inheritance. Through a decomposition exercise, the authors attributed the observed reduction in son preference in larger part to changing social norms (changes in son preference within all education and urban/rural population groups) and in smaller part to increased urbanization and education (changes due to movements between education and urban/rural population groups). Another methodological approach using simulations of an economic model also implies the impact of development: as the Korean society becomes richer, households that initially selected boys will select girls because of increasing bride price and declining marginal benefits from unmarried sons (Edlund and Lee 2009).

Second, though the role of Korean public policies in this process is a mixed story, its experience suggests that interventions to influence social norms and facilitate the spread of new values may be very important, as opposed to reliance on raising female education and labor force participation alone. Active policies to promote rapid economic development in Korea played a role early on in breaking down previous norms of son preference as well as raising female education and labor force participation. And changing social norms contributed relatively more to the decrease in son preference. Reforms to policies that directly constrain women's status, such as the Family Law established in 1958, which stipulated male family headship and inheritance only through the male line, were slow to follow. With several women's movements demanding greater gender equity since the establishment of democracy in 1987, this law went through major reforms in 1990, but the system of male household headship was not officially abolished until 2005 (Chung and Das Gupta 2007). 
context-specific rather than an issue that prevails in the region. However, two behavioral health issues-smoking and drinking-are more concerning among men than women in all East Asian and Pacific countries, as well as globally. ${ }^{11}$ Figures 2.16 and 2.17 show the prevalence of smoking and drinking among males compared with the prevalence among females. All East Asian and Pacific countries lie above the 45-degree line, implying a much higher rate among males than females.

The gender difference in the incidence of tobacco use is higher in the East Asia and Pacific region than in other developing regions, even though male dominance in smoking and drinking is a global phenomenon. The data for China in 2006 show that tobacco use is 60 percent for men and 4 percent for women. Similar gender gaps exist throughout the region. Indonesia (62 percent versus 5 percent), Korea (53 percent versus 6 percent), Lao PDR (64 percent versus 15 percent), and Tonga (62 percent versus 15 percent) lead the region in the largest gender differentials in tobacco prevalence (figure 2.16).

Alcohol consumption can vary from occasional drinking to heavy episodic drinking, and the gender differential in the latter is particularly stark. Although women are less likely to report drinking at all in many countries in the East Asia and Pacific region, they do come close to men in places such as Japan and Mongolia (figure 2.17). In terms of heavy episodic drinking (binge drinking) and chronic heavy drinking, data show a large gender gap: overall in the region, men are more than twice as likely to be heavy episodic drinkers. According to the World Health Organization 2011 Global InfoBase database, the countries in the region with the largest gender gaps in heavy drinking are Kiribati (22 percent among males versus 1 percent among females), Samoa (22 percent versus 1 percent), Lao PDR (22 percent versus 5 percent), Japan (18 percent versus 3 percent), Mongolia (14 percent versus 0 percent), and Micronesia (13 percent versus 1 percent). The level of annual per capita consumption of pure alcohol is especially high for males
FIGURE 2.16 Men are more likely to smoke than women

prevalence of currently smoking any tobacco product among adults ( $\geq 15$ years) (\%), male vs. female, 2006

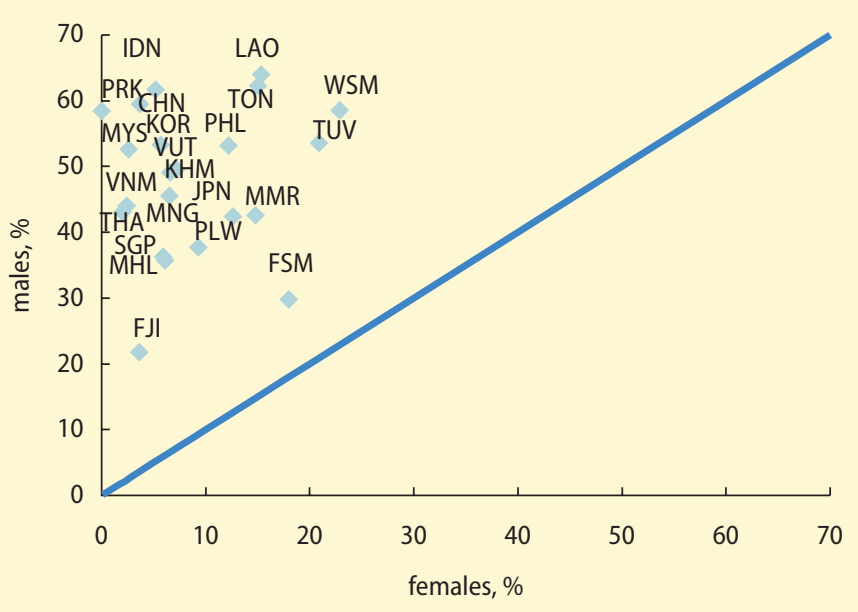

Source: World Health Organization (WHO) Global InfoBase.

\section{FIGURE 2.17 Men are more likely to drink than women}

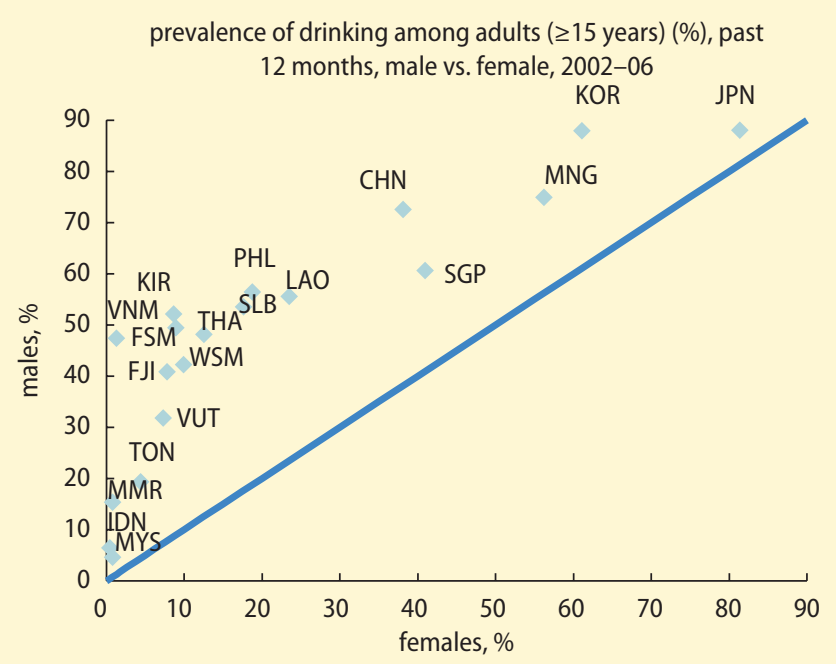

Source: WHO Global InfoBase.

in Tonga (38 liters per capita consumption), Malaysia (32 liters), Thailand (29 liters), and Korea (29 liters).

These behaviors pose substantial risks to men's health and can translate into high costs for productivity and economic growth. Globally, 6 percent of all male deaths are related 
to alcohol, compared to 1 percent of female deaths (WHO 2011a). Half of today's smokers are likely to die from tobacco-related causes. A simple cross-country relationship (shown in figures 2.18 and 2.19) between these behaviors and morbidity and premature mortality related to smoking and alcohol use also indicates positive correlations (other

\section{FIGURE 2.18 Tobacco use is positively correlated with mortality due to lung cancer}

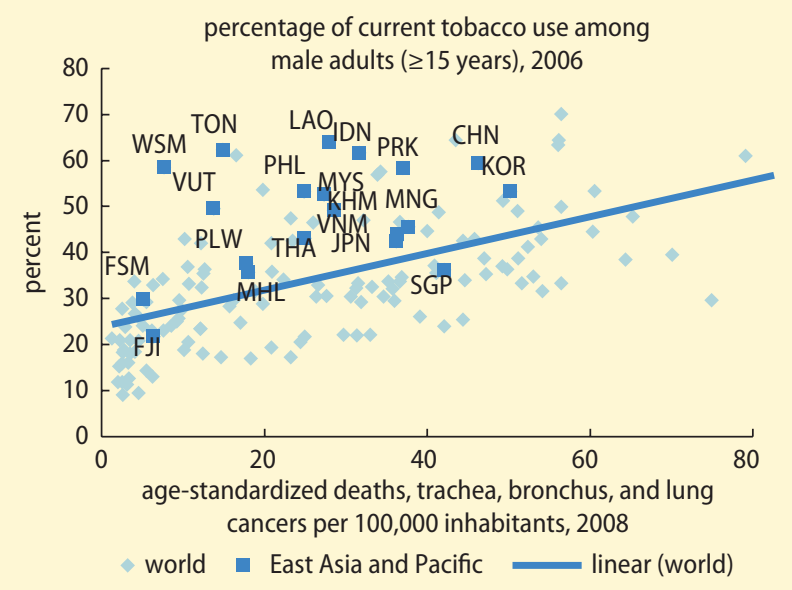

Source: WHO Global InfoBase.

\section{FIGURE 2.19 Alcohol consumption is positively correlated with mortality due to alcohol use disorders}

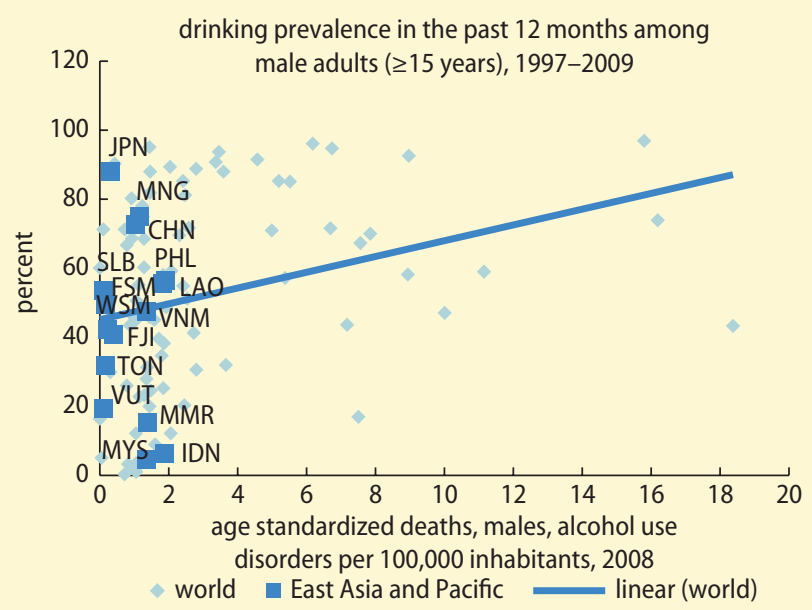

factors may also play a role, such as obesity and heart conditions, which are particularly high in the Pacific countries). In China, the rising risks of noncommunicable diseases, partly linked to men's smoking and drinking behaviors, put greater pressure on the size of the working-age population, already a concern because of its aging population (World Bank 2011a).

These behaviors are influenced by norms about masculinity, cultural beliefs about health, and the surrounding environment, and they can be slow to change. For men, smoking and drinking alcohol are commonly viewed as masculine behaviors, and studies show that men and boys feel substantial pressure to accept gender stereotypes that they should be strong and tough, and the opposite for women. A recent national survey in Vietnam found that the primary reason women did not use tobacco was the belief that women should not smoke. In a country where 50 percent of men but just over 3 percent of women smoke, 76 percent of the 2,020 young urban Vietnamese women surveyed said that this low female prevalence could be attributed to gender norms (that is, social disapproval of women who smoke). Only 20 percent said that the low prevalence was due to health concerns (WHO 2003). In addition, these patterns of smoking behaviors stayed very stable in Vietnam over the period from 1993 to 2006.

The poor tend to be slightly more likely to report "ever smoking," but the relationship is not strong among those countries where such data is available, except in Cambodia. As shown in figure 2.20, individuals ages 15 and above in the poorest quintile in Cambodia were almost twice as likely to engage in smoking cigarettes or chewing tobacco as those in the richest quintile. Among those who smoke, the intensity can vary because of the affordability of cigarettes. In Cambodia, particularly in rural areas, the richer smokers consume more cigarettes per day than the poorer smokers. However, no clear pattern between income and the intensity of smoking is observed in Mongolia and Vietnam. 


\section{Gender equality in productive assets: An unfinished agenda}

Promoting gender equality in the control of productive assets (such as land, financial capital, social capital, and information and technology) is likely to enhance development, through both economic and empowerment benefits. Asset ownership can influence men's and women's income and their voice and influence within the household and within society. This effect can happen through strengthening their ability to take advantage of economic opportunities; for example, evidence shows that clear land-ownership rights have positive effects on agricultural productivity and access to credit (Deininger 2003). In the agricultural sector, evidence from Africa and Latin America suggests that ensuring equal access to productive assets and technologies raises agricultural production (Goldstein and Udry 2008; Quisumbing 1995; Udry 1996). As discussed throughout this report, income in the hands of women has been shown to positively affect children's education and health outcomes (Duflo 2003; Lundberg, Pollak, and Wales 1997). Women's assets prior to marriage have been shown to have positive effects on education expenditures on children in Indonesia and other countries (Quisumbing and Maluccio 2003). Beegle et al. (2001) showed that, in Indonesia, women with a higher share of household assets made more use of prenatal care. Asset ownership can lead to women's empowerment, such as reducing vulnerability to domestic violence in India (Panda and Agarwal 2005).

Gender equality in assets has been less responsive to growth and development than has equality in education and health. Over time, economic growth can promote access to financing that benefits women and men as well as improves economic opportunities and women's income. However, development impacts on gender equality in this domain are constrained by the complex legal, social, and economic factors that shape the control of productive assets. Gender disparities in access to and control of productive assets
FIGURE 2.20 The poor are slightly more likely to engage in smoking

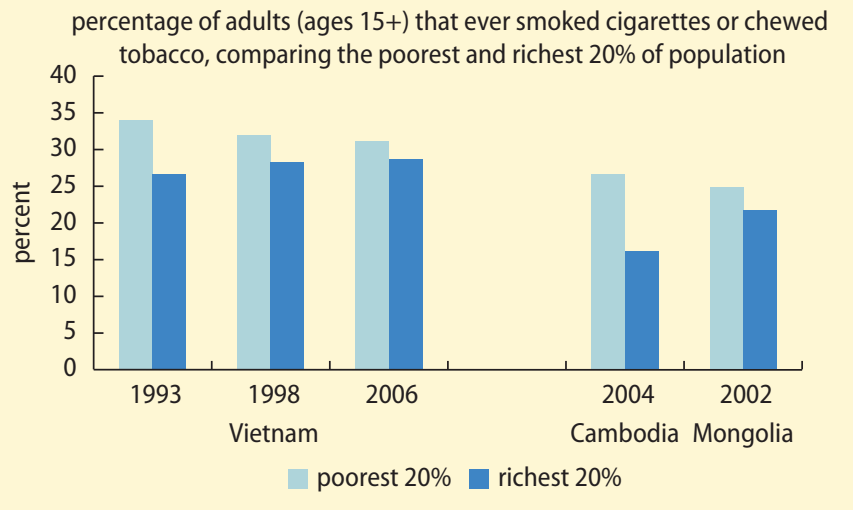

Source: World Bank estimates using household income and expenditure surveys of various countries and years.

still persist around the world and in some parts of the East Asia and Pacific region. For example, household surveys in Bangladesh, Ethiopia, Indonesia, and South Africa indicate that women bring fewer assets into marriage (Quisumbing and Maluccio 2003). Evidence from the Philippines and other developing countries shows that the husband-wife asset difference at the time of marriage has not changed over time and favors the husband, even though gaps in age and education have been closing (Quisumbing and Hallman 2005).

This section focuses mainly on land and credit for the following two reasons. First, they are the major types of assets that strongly influence well-being. Land and property are usually the most valuable assets for a poor person. Aside from itself being a productive asset, land can be used as collateral to acquire credit. Access to financing is also very important because it usually presents a major barrier to realizing economic opportunities in developing countries. Second, data and rigorous quantitative evidence on gender and assets in the East Asia and Pacific region are very limited, particularly for assets other than land and credit. Individual-level data of asset ownership are sometimes available for land 
holdings but rarely for household durables, since many are considered jointly owned. In the face of scarce individual-level data on asset ownership, this section often resorts to comparing female-headed households and male-headed ones. ${ }^{12}$ This section also draws on qualitative evidence and research from outside the region to help complement the limited quantitative evidence from East Asian and Pacific countries.

\section{Persistent gender disparities in access to productive assets}

Analysis of the East Asian and Pacific countries shows persistent gender disparities in productive assets that result in women having lower rates of ownership of and access to land, fewer agricultural inputs such as livestock and less access to extension services, and limited access to credit in some countries and subregions.

\section{Gender-differentiated ownership of land}

Female-headed households tend to own less land than male-headed households. Even though the probability of owning land is not substantially lower among femaleheaded households (figure 2.21), figure 2.22 indicates that male-headed households own much more land in terms of land size. This gap exists even among richer households. Over time, there have been small improvements in women's land ownership as well as men's, although the gender gap has not necessarily narrowed or disappeared except for the case of Vietnam in 2006. Similarly in China, most male-headed and femaleheaded households had access to rural land in 2008, but the amount of land per capita in female-headed households was roughly 70 percent of that in male-headed households (de Brauw et al. 2011). The pattern that female-headed households tend to own less land is similar to other developing countries (Agarwal 1994; Deere and Leon 2003; FAO 2011). Exact comparisons of the gender gaps across regions are difficult, however, since the incidence of land ownership varies drastically across countries, even within the same region, and data are available for only a few countries in each region.

Evidence on individual land ownership suggests different ownership rates and different ownership composition by gender, depending on the context. In post-tsunami Aceh, Indonesia, women have fewer land holdings than men (Bell 2010). Vietnamese men owned more agricultural land plots than women in 2008. Figure 2.23 demonstrates the gender composition of ownership among the agricultural land plots with identified owners on long-term user right certificates. Overall, and among those plots owned by rural households, less than 17 percent of the plots are owned by a woman, but more than 65 percent are owned by a man. Plots jointly owned by a male and a female represent a nonnegligible share, in part because of Vietnam's recent land reform (discussed later in the chapter). However, women are still clearly at a disadvantage in terms of having their name on the land title. The same 2008 household survey data suggest that the gender gap is even starker among ethnic minorities. In some contexts, the allocation of land assets between men and women can depend on the type of land. For example, in matrilineal parts of West Sumatra, Indonesia, wives own more paddy land, and husbands own more forest land (Quisumbing and Maluccio 2003).

\section{Gender disparities in agricultural inputs}

Female-headed households tend to own less livestock, and female-run farms tend to have less access to extension services. In many countries, at least among rural households, livestock is one of the most valuable agricultural assets. It represents a source of income, wealth accumulation, and buffer against shocks. Yet, female-headed households tend to own less livestock across developing regions (FAO 2011). Figure 2.24 shows livestock ownership of femaleheaded and male-headed households in five countries in the region, for households of different wealth quintiles. The gender gap in Lao PDR appears irrespective of income, 
but this observation does not apply in other contexts. In places such as Vietnam or Timor-Leste, gender gaps are more visible among poorer households. In many countries, this same pattern is observed in urban areas as well as rural areas. The data show that gaps also persist over time.

Extension service provision remains low in developing countries, and women tend to have less access to extension services than men (FAO 2011). In Cambodia, few women benefit from agricultural extension services or credit made available to rural people, despite the fact that they make up the majority of farmers and informal sector workers. Agricultural research and extension efforts usually do not consider women's activities-seed preparation and planting - or take into account the fact that men and women tend to specialize in different rural tasks. Distance to the point of service provision, lack of female agents, and insensitivity to illiterate customers (the majority of whom are often women) are other reasons for this lower access of female farmers to extension services (UNIFEM, World Bank, ADB, UNDP, and DFID/UK 2004).

\section{Gender gaps in access to credit}

Evidence on gender differentials in access to credit is mixed. Female-headed households are slightly less likely to borrow from financial institutions, as illustrated by figure 2.25. In most of the East Asian and Pacific countries for which data are available, the gap between households headed by females and males varies widely both across and within countries. The most recent data available indicate that gaps have been small except for Timor-Leste, rural Lao PDR, rural Cambodia, and urban Mongolia. Using survey data from 2000, de Brauw et al. (2011) found no difference between female-managed farms and male-managed farms in China in terms of access to credit. As discussed in chapter 3, female-run and female-owned firms in East Asia, at least those in the formal sector, do not appear to be systematically more constrained in accessing finance than male-run firms. However, a joint study by FAO/UNDP (2002) in Vietnam revealed that female-
FIGURE 2.21 The probability of owning land is not substantially lower for female-headed households than for male-headed households

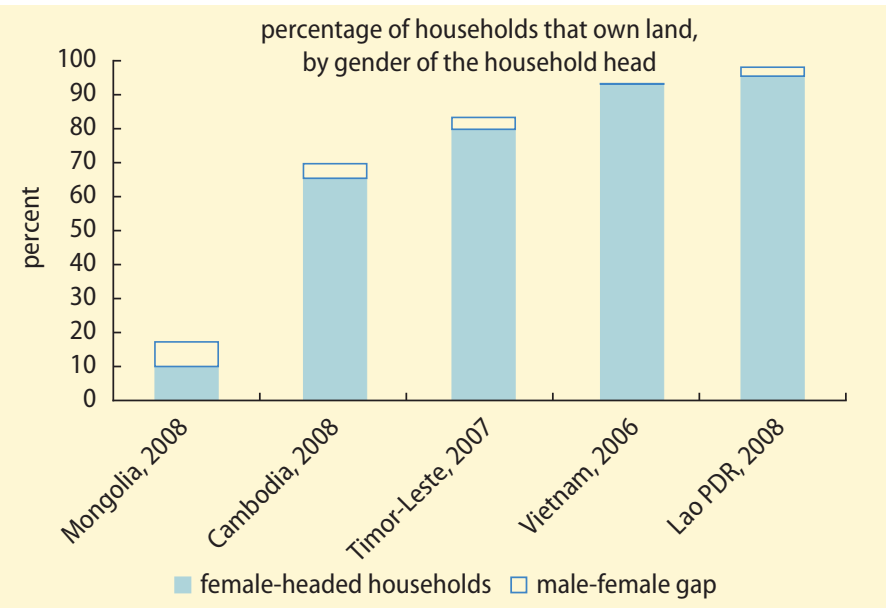

Source: World Bank estimates using household income and expenditure surveys of various countries and years.

FIGURE 2.22 Female-headed households own less land in terms of land size

average size of land among households that own land, comparing the poorest and richest $20 \%$

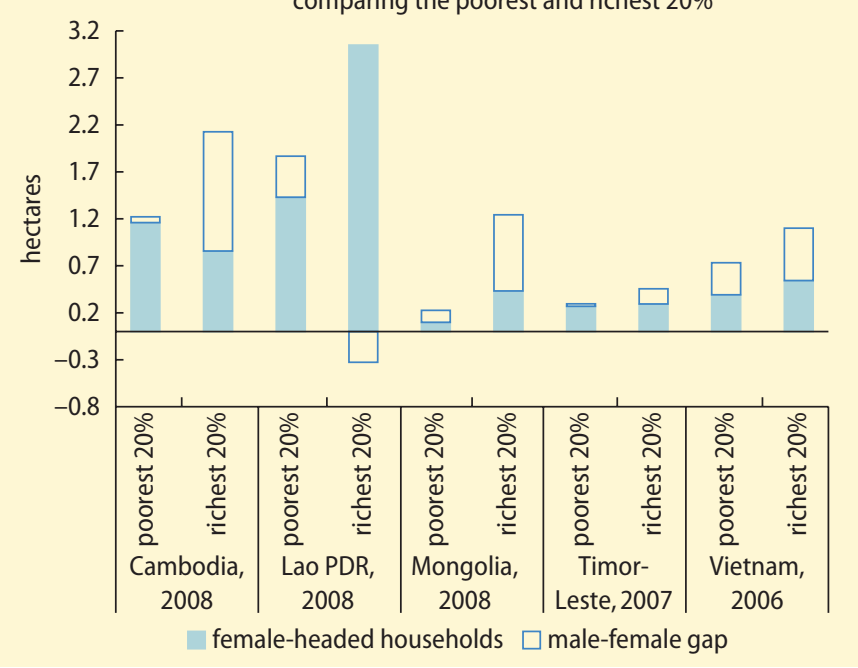

Source: World Bank estimates using household income and expenditure surveys of various countries and years.

headed households borrowed less, had less access to formal credit, and paid higher interest on loans than male-headed households.

Individual-level data on access to financing, by gender, suggest that the gender gap 
FIGURE 2.23 Vietnamese men owned more agricultural land plots than did women in 2008

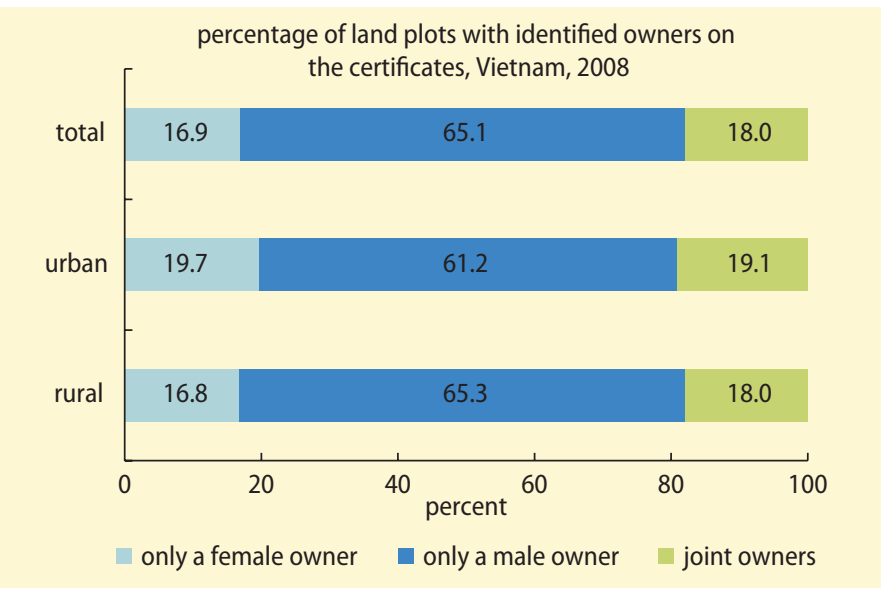

Source: World Bank estimates using VHLSS (GSO Vietnam), 2008 data.

\section{FIGURE 2.24 Female-headed households are less likely to own livestock}

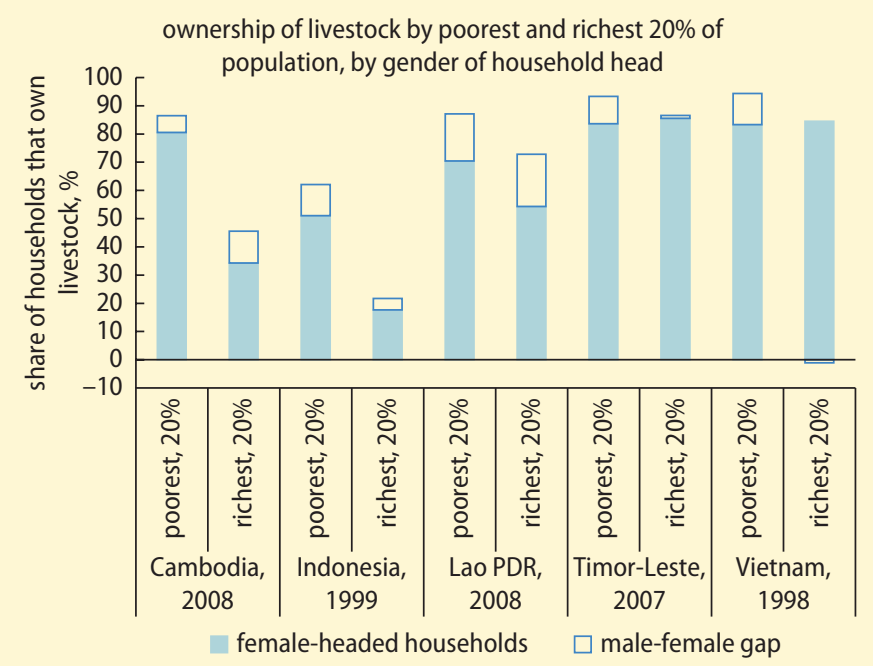

Source: World Bank estimates using household income and expenditure surveys of various countries and years. countries surveyed, women were as likely as men to report having an account in a formal financial institution in Cambodia and Thailand; less likely to have an account in China, Indonesia, Lao PDR, Malaysia, and Vietnam (although the difference is statistically significant only in Malaysia and Vietnam); and more likely to have an account in Mongolia and the Philippines. A small-scale study of Vietnam's rural credit market in 2002 indicated that credit rationing depended on education and credit history, but found no evidence of bias against women (Barslund and Tarp 2003). The Thailand 2005 Household Socio-Economic Panel data show a similar rate between men and women holding a savings account in a financial institution (46 percent and 49 percent, respectively). Although this similarity is observed in Thailand's urban as well as rural areas, the situation may vary between rural and urban areas of other countries and might be very different in the Pacific, for which individual data are lacking.

\section{Limited effects of economic growth on gender gaps in assets}

Economic growth could, in principle, increase women's asset holdings by increasing income, but this factor alone is insufficient to close the gender gap in asset holdings. Market transactions are an important way to accumulate assets, and evidence from Latin America and the Caribbean suggests that, after inheritance, markets are the second most important channel for women in that region to acquire land. In that sense, income plays an important role. However, as shown in chapter 3, substantial gender gaps in income still persist in the East Asia and Pacific region, despite economic growth. Other complex legal and social factors also make it very challenging to close the gender gap in asset holdings with economic growth alone. Evidence from South Asia indicates that better employment opportunities and progressive legislation do not necessarily lead to gender equality in access to and control of land, because of social factors 
(Agarwal 1994). Actually, wealthier households with more valuable assets are not necessarily willing to give women more ownership rights. Analysis of the Vietnam 2008 household survey data by World Bank staff shows that richer households are less likely to have a female name in the title of their agricultural land plots, accounting for factors such as land size and basic household characteristics.

As part of the development process, the expansion of microfinance coverage has been argued to improve women's access to credit. In terms of coverage, microfinance has greatly expanded all over the world, reaching many poor clients (Daley-Harris 2009). In China, microcredit has been used in various instances to support women. The Tianjin Women's Association for Business Development and Promotion, the Guangxi Provincial Women's Federation, and Liuzhou Municipal Women's Federation are examples of microcredit schemes that target poor, laid-off, and unemployed women (ADB 2006a). Not all countries provide such targeted support. In Indonesia, although women are considered to be an important market for microfinance, the Indonesian microfinance industry has never made targeting of women a hallmark of their business. The average proportion of female clients in Indonesia served by major microfinance institutions has remained fairly constant over the past 20 years (Asia Foundation, ADB, CIDA, NDI, and World Bank 2006).

However, rapid expansion of microfinance does not necessarily imply a de facto control of resources. Goetz and Gupta (1996) show that women's access to microcredit has not been matched by an increase in their control of these funds. Microcredit facilities have been established for women in Lao PDR, but women's role in decision making has not improved (GRID 2005). Although women make up a high proportion of membership in credit schemes in Cambodia, they tend to be excluded from the decision-making processes and receive smaller amounts of credit than men (UNIFEM, World Bank, ADB, UNDP, and DFID/UK 2004).
FIGURE 2.25 Female-headed households are slightly less likely to borrow from a financial institution

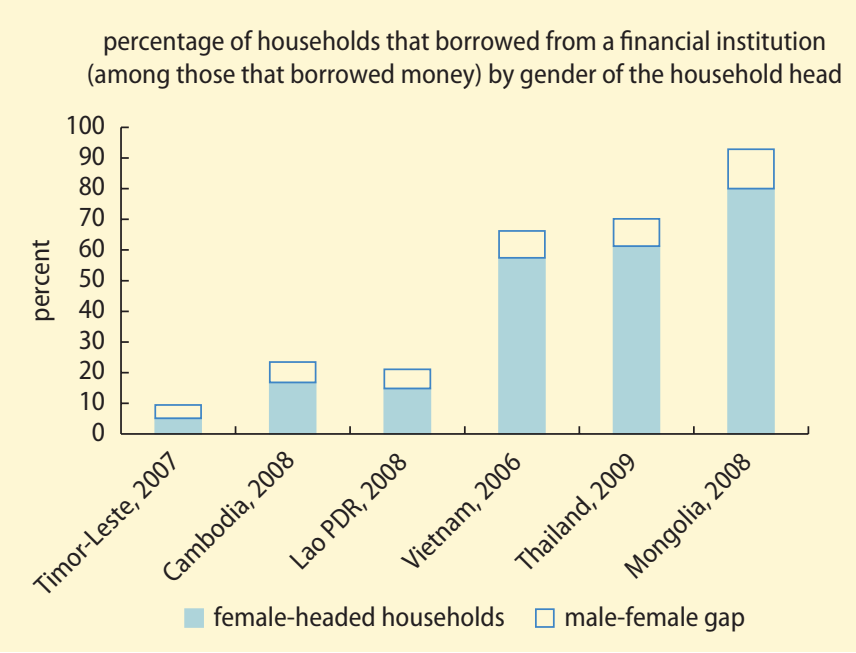

Source: World Bank estimates using household income and expenditure surveys of various countries and years.

FIGURE 2.26 Women are slightly less likely than men to report having an account at a formal financial institution

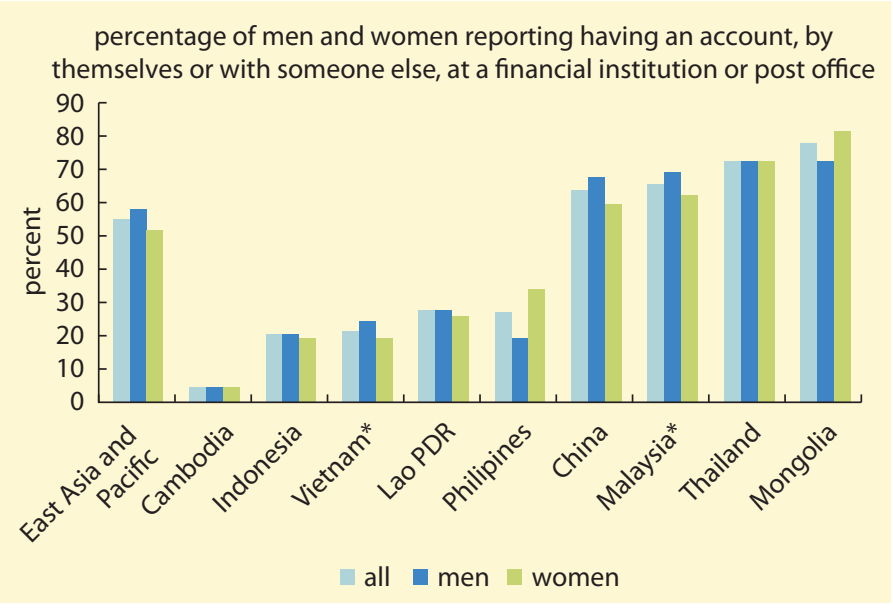

Sources: World Bank Global Financial Inclusion (Global Findex) database; Demirgüç-Kunt and Klapper 2012.

* Denotes a statistically significant difference between men and women at the 1 percent level.

\section{Legal and social constraints to equalizing access to assets}

To understand the observed gender disparities in asset holdings, one must understand how assets are accumulated and the factors determining asset accumulation. Individuals 
can accumulate, or lose, assets in several ways. First, individuals can make market transactions-such as buying land or livestock, or acquiring a bank loan. Second, assets are acquired through inheritance or through allocation or acquisition by the state, for example, through land redistribution. Inheritance is one of the main mechanisms for asset accumulation (Deere and Doss 2006), and equality in asset endowments can be limited by differences in the right to inherit property. Third, life-cycle events such as marriage, including marriage payments, or separation also alter asset holdings.

Complex legal, social, and economic factors determine or constrain asset accumulation: (a) formal institutions-particularly the legal framework for property and inheritance rights, family laws, and law enforcement; (b) informal institutions-social norms and customary laws affecting women's preferences and ability to acquire and accumulate assets; and (c) human capital and other economic factors, such as income and the rate of returns on productive assets. The impact of economic growth on promoting more equal asset holdings is limited, as discussed earlier, because legal and social barriers often act as binding constraints. Despite positive changes in the legal framework in the East Asia and Pacific region, the interactions between formal and informal institutions still leave women at a disadvantage with respect to the control of assets. ${ }^{13}$ The discussion below first describes the legal framework and then highlights the challenges in practice due to weak implementation and the influence of norms and customary laws.

\section{The legal framework}

The majority of countries in East Asia no longer differentiate by gender in statutory law. In that respect, the East Asia and Pacific region differs from some other regions: inheritance rights are still unequal in the Middle East and North African countries and half of the countries in South Asia (World Bank 2011c). As shown in table 2.4, most East Asian countries have legislation for property and inheritance rights with no discrimination against women.
These countries-Cambodia, China, Lao PDR, Mongolia, Thailand, and Vietnamdo not have plural legal systems (for example, customary or religious laws), which means that all citizens adhere to civil law. For example, in China, many advances toward ensuring equal treatment and the protection of the rights of women under the law occurred as early as the 1950s. Women's property and inheritance rights were protected through the enactment of the 1982 constitution, which protects the right of citizens to inherit private property (Article 13), ${ }^{14}$ and the 1985 Law of Succession of the People's Republic of China, which states that males and females are equal in their right to inheritance (Article 9). ${ }^{15}$ The 1992 Law of the People's Republic of China on the Protection of Rights and Interests of Women further promotes gender equality; Article 28 declares that the state shall guarantee that women enjoy the equal right, with men, to property. ${ }^{16}$

In several of the countries examined, males and females are not treated equally, mostly under inheritance laws. Plural legal systems exist in Indonesia, Malaysia, the Philippines, and Singapore. Muslim laws govern the majority of the populations in Indonesia and Malaysia and a small minority of the population in the Philippines and Singapore. For example, according to the Islamic Law Compilation in Indonesia, when a married person dies, each son is entitled to receive a share twice as large as each daughter (Asia Foundation, ADB, CIDA, NDI, and World Bank 2006). The autonomous Muslim region of Mindanao in the Philippines can independently promulgate its own legislation following Islamic law (as allowed in the constitution). Although the Philippines is a community property regime, ${ }^{17}$ the Muslim family code reflects the husband having the final say concerning the handling of joint property. ${ }^{18}$ Among Pacific Island countries, Kiribati and Tuvalu have unequal statutory legislation. Equal inheritance laws exist in Fiji, Papua New Guinea, Samoa, the Solomon Islands, and Vanuatu; however, customary law in relation to land has constitutional status in these countries and may lawfully 
TABLE 2.4 Most East Asian and Pacific countries do not differentiate by gender in inheritance and property laws

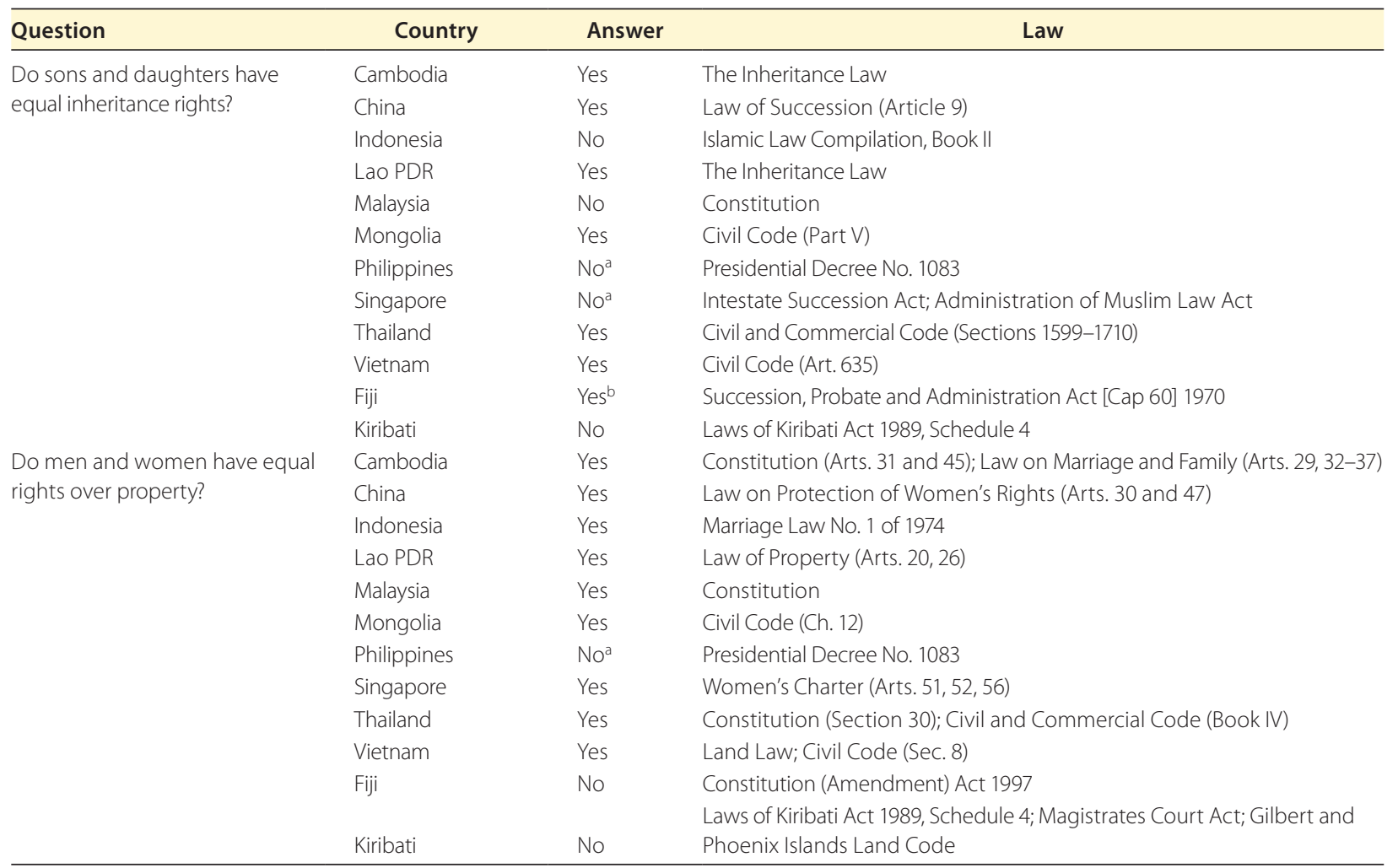

Sources: Women, Business and the Law database; Jivan and Forster 2007. a. Implies that unequal legal systems apply only to a minority population.

b. Denotes that despite equal inheritance in legislation, Fijian custom in relation to land has constitutional status and may lawfully discriminate against women.

discriminate against women (Jivan and Forster 2007).

Beyond the protection of equal inheritance rights, several countries in the region have recently adopted legal changes that actively promote better gender equality in access to land. Since concerns have been raised about promoting gender equity in land titling programs, places such as Indonesia, Lao PDR, and Vietnam have recently adopted gendersensitive reforms in land titling. Since the 2004 Land Law in Vietnam, all new land tenure certificates must include the names of both spouses, a provision intended to reduce gender inequality in access to land, protect families against unilateral decisions by one spouse, and protect women in case of divorce or disputes. Qualitative analysis of impacts in three provinces suggests that joint titling improves procedures and opportunities for women to access loans, empowers women in case of disputes, and leads to higher mutual decision making (World Bank 2008).

\section{Weak implementation and enforcement} of the law

Although women and men may be equal under the law, these legal rights do not always translate into equal access to land in practice. Progress toward gender equality in assets is still limited because of weak implementation and enforcement of the law.

Implementation of the laws may be imperfect and ineffective as a result of challenges in incorporating existing cultural norms and practices. Even where the legal system supports equal access to land, traditional values and norms create difficulty with respect to enforcing the legislation. After the 2004 Land Law requiring joint titling was introduced in 
Vietnam, the results have been varied across ethnic majority and minority groups. Analysis of the Vietnam Household Living Standards Survey 2008 shows that ethnic minority households are much less likely to have a female name in the title of their agricultural land plots, even when accounting for factors such as land size and basic household characteristics. Studies of existing kinship systems in China and Vietnam show resistance to endowing daughters with land, as land is considered lost when daughters get married (Bélanger and Li 2009). In Northern Liaoning, China, women are more likely to become landless at marriage because the population control and land tenure policies reinforce traditional forms of gender bias: a daughter is expected to marry out, whereas a son is expected to reside with or near his parents (Chen and Summerfield 2007). Therefore, during the redistribution of farmland to households based on household size, township and village officials allocated a larger share of land for each son in the household than for each daughter.

The Lao PDR land titling program 1997-2010 offered useful implementation lessons to account for context-specific social norms. An early assessment during the first phase of the program noted that traditional family roles dedicated the man to handling taxes and, thus, to having only his name on land-related tax documents. Mostly men interacted with government officials and participated in information meetings and titling activities. As a response to this assessment, Lao PDR introduced a stronger gender inclusion program, engaging the Lao Women's Union, to raise community awareness of land titling, to include special training for women on their rights, and to ensure their participation during titling. Following this active engagement, a higher number of titles went to women than to men (Lao Land Titling Project II ICR 2010).

Qualitative research, more broadly, has stressed that a lack of information about legal entitlement is a key barrier to enforcing women's land rights throughout the region. Women are generally less aware of the laws governing land ownership. They are also less likely to know about land registration requirements (including whether the land owned by their households is registered and whether their names are included in land titling documents). Dissemination activities on rights and entitlements can exclude women, especially in rural areas. ${ }^{19}$ Even if they have information about their legal land rights, women tend not to pursue formal complaints in cases of land grabbing or disputes regarding inheritance or division of property. A 2008 AusAID report on land tenure in the Pacific region stresses the following factors constraining women's access to the formal legal system to resolve disputes regarding land ownership and use: (a) the system was culturally unfamiliar and based on "adversarial" methods rather than on the consensus building usually preferred by communities; (b) women also faced more "practical" obstacles to accessing courts (limited access to transport, lack of time, income); (c) the "technical nature" of the procedures and inadequate support from court staff were also noted as important barriers (AusAID 2008).

\section{Social norms and practices}

In some contexts, customary practices, rather than statutory laws, directly govern land ownership and land use. Most land in the Pacific region is under customary authority (approximately 80 percent of total land area) (AusAID 2008). Although the rules vary widely within the Pacific region, usually in customary systems, (a) land can only be transferred within networks of social/political relationships, (b) land use is governed by reciprocal relations within the kinship or customary land groups, and (c) social hierarchies and status are important factors determining one's rights to land. In these customary systems, women have access to land primarily through their kinship relations with men. Women also have less voice in public decisions about the use of land (AusAID 2008). For example, Fijian women in most parts of the Fiji Islands are excluded from inheritance rights in customary land and have no rights to land other than those permitted by their fathers or husbands. 
Nor do they normally receive land rents. Most Indo-Fijians with land also practice fatherto-son inheritance (ADB 2006b).

Practices within the region and within countries vary considerably. Inheritance practices based on norms can be patrilineal, matrilineal, or bilateral and, as such, are not always tilted against women. In the matrilineal society of Sumatra, Indonesia, together with the shift from communal to individual tenure, the inheritance system became more egalitarian in that sons and daughters inherit the type of land that is most intensive in their own work effort, and gender bias in land inheritance is either nonexistent or small (Quisumbing and Otsuka 2001). In the Philippines, sons are preferred in land inheritance but daughters are favored in education investments (Estudillo, Quisumbing and Otsuka 2001). In Lao PDR, land inheritance and ownership are important elements of women's autonomy in lowland areas, with daughters customarily inheriting land. However, women in the midlands and highlands, such as those in the Khmu and Hmong ethnic groups, face important barriers to controlling land (Ireson-Doolittle 1999). Understanding the specifics of a particular context is thus important for designing appropriate policies and interventions.

In summary, given the limited evidence in the East Asia and Pacific region, understanding gender inequality in assets is an important research agenda. Gender disparities in access to productive assets can hinder women's ability to participate and benefit from economic opportunities as well as constrain women's voice and representation in the society. Further research and better data are called for to disentangle the complex mechanisms influencing men's and women's control of assets and to shed light on policies.

\section{Policies to promote gender equality in endowments}

The analysis thus far has identified the factors influencing or constraining gender equality in endowments. This analysis also sheds light on where policies may be used and can have an impact. What follows is an initial discussion about policy priorities for promoting gender equality in human capital: (a) closing persistent gender gaps in human development, (b) reducing gender streaming in education, (c) promoting balanced sex ratios at birth, and (d) addressing male-specific gender issues. Policy approaches to close gender gaps in assets are important for gender equality in endowments, and they also enable more equal economic opportunity and agency. These policies are discussed within the general framework of policies to promote gender equality in economic opportunity, which is discussed in chapter 3 and chapter 6 . A more detailed discussion will follow in chapter 6 on policies to promote overall gender equality and more effective development.

\section{Closing persistent gender gaps in human development}

For countries with overall low and unequal gender outcomes in education and health, the priority remains to improve these outcomes. Actions to strengthen the education and health systems are called for to improve overall outcomes, in addition to any focus on gender. Interventions may be needed at the national level and may yield high economic and social returns. For countries with localized gender disparities among certain ethnic groups or low-income regions, interventions may be targeted to these groups. Though the exact constraints vary by country context, the analysis in this chapter has shown that both demand-side and supply-side factors are responsible for these poor human capital outcomes. Policies can have an impact through improving service delivery (infrastructure, staffing, incentives, use of information and communication technology) and demand-side interventions (conditional cash transfers, information campaigns, accountability). For education, policies to improve education outcomes in general are expected to also improve gender equality. For health, the slow improvements in health outcomes in several East Asian and Pacific countries underscore the importance of improving 
service delivery in general, including efforts to account for gender norms that affect service utilization and effectiveness.

\section{Reducing gender streaming in education}

For many countries in the East Asia and Pacific region, addressing education quality—specifically, gender streaming in education-requires policy attention. Many aspects of gender issues regarding basic access in education and health have abated with growth and development. However, concerted efforts in education and labor market policies are needed to break the traditional patterns of females going into certain fields of study and, consequently, jobs in lowerpaying occupations and sectors. Within the education system, possible approaches in this agenda include both curriculum reforms to reduce gender stereotyping and active interventions-financial and nonfinancial incentives as well as information campaigns-to promote entrance into nontraditional fields.

\section{Promoting balanced sex ratios at birth}

In the few countries with "missing girls" at birth, rooted in the prevalence of son preference, continuing efforts are needed. A promising strategy is to adopt policy approaches that aim to enhance the relative value of daughters as perceived by families. General policies to promote economic development may play a role, but Korea's recent experience suggests that interventions to influence social norms and facilitate the spread of new values may be very important, rather than simply relying on raising female education and labor force participation. Information campaigns, financial incentives, and improved social security for the elderly are worthwhile efforts. China has been adopting many of these programs, and they can be expected to reduce the imbalance in the sex ratio at birth.

\section{Addressing male-specific gender issues}

Attention to male gender issues is crucial in many country contexts since they may also hamper growth and development. First, the initial signs of the reversed gender gap in education need to be monitored closely where applicable. Second, the excessive tobacco and alcohol consumption among males in many parts of the East Asia and Pacific region deserves policy attention because the social costs, passed on as externalities to other members of the society, are usually higher than private costs. Possible measures to tackle this challenge include providing information about the health risks of excessive tobacco and alcohol consumption, taxation, regulatory measures on advertisement, and restrictions on smoking in public sites.

\section{Notes}

1. See Malhotra, Pande, and Grown (2003) on impacts of investments in female education on gender equality.

2. See Engendering Development (World Bank 2001) and World Development Report 2012 (World Bank 2011c) for similar literature. However, few studies rigorously identify the causal effects as opposed to simple correlation. And female education or income might not always have dominant, widespread benefits over male education as commonly perceived. For example, controlling for household average education, Breierova and Duflo (2004) found no impact of female education on infant mortality in Indonesia. Edmonds (2006) found that in South Africa, pension money going to grandmothers improved children's health while that going to grandfathers improved children's schooling.

3. Enrollment in different types of education also shows gender differences that vary across countries in the region. Females' completion rate in vocational training has been increasing in Thailand and Vietnam. In recent years, this rate among females is still lower than that among males in Indonesia, Thailand, Vietnam, and Mongolia, even though the reverse tends to be true for completion of general secondary education. Cambodia experiences the opposite patterns, that is, women have lower general secondary completion rates but higher vocational completion rates than men (Sakellariou 2011). 
4. Conflict and postconflict areas also suffer poor education outcomes for both boys and girls, for different reasons, such as the risk for boys of being taken out of school to join the military and the risk of safety for girls at the school.

5. Girls do not always lag boys in poor rural areas. Evidence from China's Gansu province shows no significant gender disadvantage (Hannum and Adams 2002).

6. The returns to education for women have not increased uniformly: the returns for women increased relative to those of men in Vietnam but decreased in Indonesia and Thailand since the late 1990s (Sakellariou 2011).

7. See Kobia (2009) and Lloyd, Mensch, and Clark (1998), for example, for analysis of similar gender stereotyping in Kenya.

8. Prior empirical evidence on the extent to which income causally affects health status has been controversial, partly owing to methodological challenges such as possible omitted variables and the reversed feedback from health to income (Deaton 2006; Filmer and Pritchett 1999; Pritchett and Summers 1996).

9. Das Gupta, Chung, and Shuzhuo (2009) argue that the recent provincial sex ratios in China suggest an incipient turnaround of the "missing girls" phenomenon in East Asia. However, the concern is far from over because child sex ratios in China are still high.

10. See World Bank 2011c, World Development Report 2012, chapter 3 technical annex for detailed methodology.

11. Prevalence estimates of current smoking of any tobacco product result from the latest adult tobacco use surveys, which have been adjusted according to the WHO regression method for standardizing described in the Method of Estimation. "Tobacco smoking" includes cigarettes, cigars, pipes, or any other smoked tobacco products. "Current smoking” includes both daily and nondaily or occasional smoking.

12. Households headed by women and those headed by men may be very different as a result of unobserved factors. The observation that female-headed households have fewer assets does not necessarily mean that women have less access to assets in general (many are widows or single-parent families that face economic difficulties anyway).
Looking at gender of the household head as an approximate measure presumes that females in female-headed households own and control most of the assets while females in male-headed households control and own relatively few assets. This measure could be misleading in cases where male heads of households are temporarily absent.

13. Recent analysis of women and land in Association of Southeast Asian Nations (ASEAN) countries identifies the following supply constraints to women's equal access to land in the region: unfavorable legal framework, pro-male customs, limited opportunities, and lack of data (ASEAN 2008).

14. http://english.people.com.cn/constitution/ constitution.html.

15. http://www.chinaembassycanada.org/eng/ lsfw/Relevant \%20Chinese \%20Laws \% 20 and\%20Regulations/t37737.htm.

16. http://www.womenofchina.cn/html/ report/515-1.htm.

17. In a community property jurisdiction, most property acquired during the marriage (except for gifts or inheritances) is owned jointly by both spouses and is divided upon divorce, annulment, or death.

18. http://www.law.emory.edu/ifl/legal/ philippines.htm.

19. In China, for example, it is a common practice for new policies, regulations, and programs to be discussed in village meetings in which heads of households (primarily men) participate. Information on changes to land laws, for example, might reach women later (or partially, as they may rely on other household members to convey the information) (Liaw 2008). In Indonesia, land acquired during marriage tends to be registered primarily under the name of the male head of household because most landowners are not aware of the possibility of registering land in more than one person's name (Brown 2003).

\section{References}

ADB (Asian Development Bank). 2005. Country Gender Assessment Timor-Leste. Pacific Regional Department and Regional and Sustainable Development Department, Asian Development Bank East and South East Asia Regional Office United Nations Development Fund for Women. Manila, Philippines: ADB. 
- 2006a. ADB Country Gender Assessment: People's Republic of China. Manila, Philippines: ADB.

- 2006b. Republic of the Fiji Islands: Country Gender Assessment. Manila, Philippines: ADB.

Agarwal, Bina. 1994. A Field of One's Own: Gender and Land Rights in South Asia. Cambridge, U.K.: Cambridge University Press.

Albanesi, Stephania, and Claudia Olivetti. 2009. "Production, Market Production and the Gender Wage Gap: Incentives and Expectations." Review of Economic Dynamics 12 (1): 80-107.

ASEAN (Association of Southeast Asian Nations) 2008. "ASEAN Continues to Empower Women.” http://www.aseansec.org/BulletinFeb-08.htm\#Article-2.

Asia Foundation, ADB (Asian Development Bank), CIDA (Canadian International Development Agency), NDI (National Democratic Institute), and World Bank. 2006. Indonesia: Country Gender Assessment. Manila, Philippines: Asia Foundation, ADB, CIDA, NDI, and World Bank.

Atkin, David. 2010. "Endogenous Skill Acquisition and Manufacturing in Mexico." Yale University, Department of Economics, New Haven, CT. http://www.econ.yale.edu/ da334/ Endogenous_Skill_Acquisition_Mexico.pdf.

AusAID. 2008. Making Land Work: Vol. 1. Reconciling Customary Land and Development in the Pacific. Canberra: Australian Agency for International Development.

Bailey, B., and M. Bernard. 2003. "Establishing a Database of Gender Differentials in Enrolment and Performance at the Secondary and Tertiary Levels of the Caribbean Education Systems." Canada-Caribbean Gender Equality Fund Programme II (CARICOM), Georgetown, Guyana.

Baird, Sarah, Jed Friedman, and Norbert Schady. 2007. "Aggregate Income Shocks and Infant Mortality in the Developing World." Policy Research Working Paper 4346, World Bank, Washington, DC.

Barslund, Mikkel, and Finn Tarp. 2003. "Rural Credit in Vietnam.” Discussion Paper, University of Copenhagen, Denmark.

Beegle, Kathleen, Elizabeth Frankenberg, and Duncan Thomas. 2001. "Bargaining Power within Couples and Use of Prenatal and Delivery Care in Indonesia." Studies in Family Planning 32 (2): 130-46.
Behrman, Jere Richard, and James C. Knowles. 1999. "Household Income and Child Schooling in Vietnam." World Bank Economic Review 13: 211-56.

Bélanger, Danièle, and T. H. Oanh Khuat. 2009. Second-Trimester Abortions and Sex-Selection of Children in Hanoi, Vietnam. Population Studies 63 (2): 163-71.

Bélanger, Danièle, and Xu Li. 2009. "Agricultural Land, Gender and Kinship in Rural China and Vietnam: A Comparison of Two Villages." Journal of Agrarian Change 9 (2): 204-30.

Bélanger, Danièle, and Giang Linh Tran. 2011. "The Impact of Transnational Migration of Gender and Marriage in Sendign Communities of Vietnam." Current Sociology 59 (1): 59-77.

Bélanger, Danièle, Thi Hai Oanh Khuat, Jianye Liu, Thanh Thuy Le, and Viet Thanh Pham. 2003. "Are Sex Ratios at Birth Increasing in Vietnam?” Population (English Edition) 58 (2): 231-50.

Bell, Keith Clifford. 2010. "Study on Gender Impacts of Land Titling in Post-Tsunami Aceh, Indonesia." Photocopy, World Bank, Washington, DC.

Bharadwaj, Prashant, and Leah K. Nelson. 2010. "Discrimination Begins in the Womb: Evidence of Sex-Selective Prenatal Investments." Photocopy, University of California, San Diego.

Blumberg, Rae Lesser. 2007. "Gender Bias in Textbooks: A Hidden Obstacle on the Road to Gender Equality in Education." Paper commissioned for the Education for All Global Monitoring Report 2008, Education for All by 2015: Will We Make It? http://unesdoc .unesco.org/images/0015/001555/155509e.pdf.

BPS (Badan Pusat Statistik). Indonesia National Socioeconomic Survey (SUSENAS). Jakarta, Indonesia.

Breierova, Lucia, and Esther Duflo. 2004. "The Impact of Education on Fertility and Child Mortality: Do Fathers Really Matter Less Than Mothers?” NBER Working Paper 10513, National Bureau of Economic Research, Cambridge, MA.

Brown, Jennifer. 2003. "Rural Women's Rights in Java, Indonesia: Strengthened by Family Law but Weakened by Land Registration." Pacific Rim Law and Policy Journal 12 (631): 51.

Cambodia Development Resource Institute. 2001. "Social Assessment of Land in Cambodia-A Field Study." Cambodia Development Resource Institute, Phnom Penh, Cambodia. 
Cameron, L., and C. Worswick. 2001. "Education Expenditure Responses to Crop Loss in Indonesia: A Gender Bias." Economic Development and Cultural Change 49 (2): 351-63.

Chattier, Priya. 2011. "Gender and Economic Choice." Background paper for the World Development Report 2012. University of the South Pacific Laucala Campus, Suva, Fiji.

Chen, Junjie, and Gale Summerfield. 2007. "Gender and Rural Reforms in China: A Case Study of Population Control and Land Rights Policies in Northern Liaoning." Feminist Economics 13: 63-92.

Chung, W., and Monica Das Gupta. 2007. "The Decline of Son Preference in South Korea: The Roles of Development and Public Policy." Population and Development Review 33 (4): 757-83.

Cutler, D., and G. Miller. 2005. "The Role of Public Health Improvements in Health Advances: The Twentieth Century United States." Demography 42 (1): 1-2.

Daley-Harris, Sam. 2009. State of the Microcredit Summit Campaign Report 2009. Washington, DC: Microcredit Summit Campaign.

Das Gupta, Monica. 2005. Explaining Asia's "Missing Women": A New Look at the Data. Population and Development Review 31 (3): 529-35.

-. 2009. "Family Systems, Political Systems, and Asia's 'Missing Girls." Policy Research Working Paper 5148, World Bank, Washington, DC.

Das Gupta, Monica, W. Chung, and L. Shuzhuo. 2009. "Is There an Incipient Turnaround in Asia's 'Missing Girls' Phenomenon?” Policy Research Working Paper 4846, World Bank, Washington, DC.

Davis, James. 2002. "Boys to Men: Masculine Diversity and Schooling." Paper presented at the School Leadership Centre of Trinidad and Tobago, Port of Spain, Trinidad, August 6-8.

Deaton, Angus. 2006. "Global Patterns of Income and Health: Facts, Interpretations, and Policies.” WIDER Annual Lecture, Helsinki, September 29.

de Brauw, Alan, Jikun Huang, Linxiu Zhang, and Scott Rozelle. 2011. "The Feminization of Agriculture with Chinese Characteristics." Background paper for the World Development Report 2012, World Bank, Washington, DC.

Deere, Carmen Diana, and Cheryl Doss. 2006. "The Gender Asset Gap: What Do We
Know and Why Does It Matter?” Feminist Economics 12 (1-2): 1-50.

Deere, Carmen Diana, and Magdalena Leon. 2003. "The Gender Asset Gap: Land in Latin America." World Development 31 (6): 925-47.

Deininger, Klaus. 2003. Land Policies for Growth and Poverty Reduction. Washington, DC: World Bank.

Demirgüç-Kunt, Asli, and Leora Klapper. 2012. "Measuring Financial Inclusion: The Global Findex Database." Policy Research Working Paper 6025, World Bank, Washington, DC.

Duflo, Esther. 2000. "Child Health and Household Resources in South Africa: Evidence from the Old Age Pension Program." American Economic Review 90 (2): 393-98.

-.2003. "Grandmothers and Granddaughters: Old-Age Pensions and Intrahousehold Allocation in South Africa." World Bank Economic Review 17 (1): 1-25.

Dunne, M., and F. Leach. 2005. "Gendered School Experiences: The Impact on Retention and Achievement in Botswana and Ghana." Researching the Issues 56, Department for International Development, London.

Ebenstein, A. 2010. "The Missing Girls of China and the Unintended Consequences of the One Child Policy." Journal of Human Resources 45 (1): 87-115.

Eccles, J. S., and P. Blumenfeld. 1985. Classroom Experiences and Student Gender: Are There Differences and Do They Matter? In Gender Influences in Classroom Interaction, edited by L. C. Wilkinson and C.B. Marrett. Orlando, FL: Academic Press.

Edlund, L., and C. Lee. 2009. "Son Preference, Sex Selection and Economic Development: Theory and Evidence from South Korea." Discussion Paper 0910-04, Columbia University, Department of Economics, Chicago, IL.

Edmonds, E. 2006. "Child Labor and Schooling Responses to Anticipated Income in South Africa." Journal of Development Economics 81 (2): 386-414.

Eskes, T., and C. Haanen. 2006. "Why Do Women Live Longer Than Men?" European Journal of Obstetrics Gynecology and Reproductive Biology 133 (2): 126-33.

Estudillo, J., Agnes Quisumbing, and Keijiro Otsuka. 2001. "Gender Differences in Land Inheritance, Schooling and Lifetime Income: Evidence from the Rural Philippines." Journal of Development Studies 37 (4): 23-48. 
FAO (Food and Agriculture Organization)/UNDP (United Nations Development Programme). 2002. "Gender Differences in the Transitional Economy of Viet Nam.” Hanoi. http://www .fao.org/docrep/005/ac685e/ac685e00.htm.

FAO. 2011. The State of Food and Agriculture 2010-11: Women in Agriculture: Closing the Gender Gap for Development. Food and Agriculture Organization, Rome.

Figueroa, M. 2000. "Making Sense of the Male Experience: The Case of Academic Underachievement in the English-Speaking Caribbean." IDS Bulletin 31 (2).

Filmer, Deon, Jed Friedman, and Norbert Schady. 2008. "Development, Modernization, and Son Preference in Fertility Decisions." Policy Research Working Paper 4716, World Bank, Washington, DC.

Filmer, Deon, and Lant Pritchett. 1999. "The Impact of Public Spending on Health: Does Money Matter?" Social Science and Medicine 49 (10): 1309-23.

Filmer, Deon, and Norbert Schady. 2008. "Getting Girls into School: Evidence from a Scholarship Program in Cambodia." Economic Development and Cultural Change 56 (3): 581-617.

- 2009. "School Enrollment, Selection and Test Scores.” Policy Research Working Paper 4998, World Bank, Washington, DC.

Fiszbein, Ariel, and Norbert Schady. 2009. "Conditional Cash Transfers: Reducing Present and Future Poverty.” Policy Research Series, World Bank, Washington, DC.

Flabbi, Luca. 2011. "Gender Differences In Education, Career Choices and Labor Market Outcomes on a Sample of OECD Countries." OECD Background Paper for World Development Report 2012, World Bank, Washington, DC.

Frankenberg, Elizabeth, A. Buttenheim, B. Sikoki, and W. Suriastini. 2009. "Do Women Increase Their Use of Reproductive Health Care When It Becomes More Available?" Evidence from Indonesia, Studies in Family Planning 40 (1): 27-38.

Frankenberg, Elizabeth, and Duncan Thomas. 2001. "Women's Health and Pregnancy Outcomes: Do Services Make a Difference?” Demography 38 (2): 253-65.

Global Findex (Global Financial Inclusion Database). World Bank, Washington, DC. http://data.worldbank.org/data-catalog/ financial_inclusion.
Goetz, A. M., and R. Gupta. 1996. "Who Takes the Credit? Gender, Power, and Control over Loan Use in Rural Credit Programs in Bangladesh. World Development 24 (1): 45-63.

Goldstein, Markus, and Christopher Udry. 2008. "The Profits of Power: Land Rights and Agricultural Investment in Ghana." Journal of Political Economy 116 (6): 981-1022.

GRID (Gender Resource Information and Development Center). 2005. "Lao PDR Gender Profile." GRID, with support of the World Bank, Washington, DC. http://siteresources .worldbank.org/INTLAOPRD/Resources/ Lao-Gender-Report-2005.pdf.

GSO (General Statistics Office) Vietnam. Household Living Standards Surveys, http:// www.gso.gov.vn.

Guo, L., and Z. Zhao. 2002. "Children, Gender, and Language Teaching Materials." Chinese Education and Society 35 (5): 34-52.

Hanna, Rema, and Leigh Linden. 2009. "Measuring Discrimination in Education." NBER Working Paper 15057, National Bureau of Economic Research, Cambridge, MA.

Hannum, E., and J. Adams. 2002. "Girls in Gansu, China: Expectations and Aspirations for Secondary Schooling." In Exclusion, Gender and Education, edited by M. Lewis and M. Lockheed, 71-96. Washington, DC: Center for Global Development.

HNPStats (Health Nutrition Population Statistics) database. World DataBank, World Bank, Washington, DC. http://data.worldbank.org/ data-catalog/health-nutrition-populationstatistics.

IDN CGA. (2006). "Indonesia: Country Gender Assessment.” Asian Development Bank, Canadian International Development Agency, National Democratic Institute, and the World Bank.

Ireson-Doolittle, C. 1999. "Gender and Changing Property Rights in Laos.” In Women's Rights to House and Land: China, Laos, Vietnam, edited by I. Tinker and G. Summerfield, 14552. Boulder, Colorado: Lynne Rienner.

Jayachandran, S., and A. Lleras-Muney. 2009. "Life Expectancy and Human Capital Investments: Evidence from Maternal Mortality Declines." Quarterly Journal of Economics 124 (1): 349-97.

Jensen, R. 2010. "Economic Opportunities and Gender Differences in Human Capital: Experimental Evidence for India." NBER 
Working Paper 16021, National Bureau of Economic Research, Cambridge, MA.

Jha, Jyotsna, and Fatimah Kelleher. 2006. Boys' Underachievement in Education: An Exploration in Selected Commonwealth Countries. London, U.K.: Commonwealth Secretariat, Gender Section, Social Transformation Programmes Division, and the Commonwealth of Learning.

Jivan, Vedna, and Christine Forster. 2007. Translating CEDAW into Law: CEDAW Legislative Compliance in Nine Pacific Countries. Suva, Fiji: UNDP Pacific Centre and UNIFEM Pacific Regional Office.

Johnson, Kiersten, Sovanratnak Sao, and Darith Hor. 2000. Cambodia 2000 Demographic and Health Survey: Key Findings. Calverton, MD: ORC Macro.

Jung, Kyung, and Haesook Chung. 2005. Gender Equality in Classroom Instruction: Introducing Gender Training for Teachers in the Republic of Korea. Bangkok, Thailand: UNESCO.

Kevane, M., and D. Levine. 2003. "Changing Status of Daughters in Indonesia." Working Paper C03-126, University of California, Berkeley, Center for International Development, Berkeley, CA.

King, E., and D. van der Walle. 2007. Girls in Lao PDR: Ethnic Affiliation, Poverty and Location. In Exclusion, Gender and Education: Case Studies from the Developing World, edited by M. Lewis and M. Lockheed, 31-70. Washington, DC: Center for Global Development.

Klasen, Stephan, and Francesca Lamanna. 2009. "The Impact of Gender Inequality in Education and Employment on Economic Growth: New Evidence for a Panel of Countries." Feminist Economics 15 (3): 91-132.

Knowles, Stephen, A. K. Lorgelly, and Dorian Owen. 2002. "Are Educational Gender Gaps a Brake on Economic Development? Some Cross-Country Empirical Evidence." Oxford Economic Papers 54 (1): 118-49.

Kobia, J. 2009. "Femininity and Masculinity in English Language Textbooks in Kenya." The International Journal of Language Society and Culture, 28: 57-71.

Korea National Statistical Office. Daejeon, Republic of Korea. http://kostat.go.kr.

Lao Land Titling Project II ICR. 2010. "Implementation Completion and Results Report (Ida-38010) on a Credit in the Amount of Sdr 10.8 Million (US\$14.82 Million Equivalent) to the Lao People's Democratic Republic for the Second Land Titling Project." World Bank, Washington, DC.

Lavy, Victor. 2008. "Do Gender Stereotypes Reduce Girls' or Boys' Human Capital Outcomes? Evidence from a Natural Experiment," Journal of Public Economics. 92 (10-11): 2083-2105.

Li, H., and H. Zheng. 2009. "Ultrasonography and Sex Ratios in China." Asian Economic Policy Review 4: 121-37.

Liaw, H. Ray. 2008. “Women's Land Rights in Rural China: Transforming Existing Laws into a Source of Property Rights." Pacific Rim Law and Policy Journal 17 (1): 237-64.

Lloyd, C., B. Mensch, and W. Clark. 1998. "The Effects of Primary School Quality on the Educational Participation and Attainment of Kenyan Girls and Boys.” Population Council Paper 116. http://www.popcouncil.org/pdfs/ wp/16.pdf.

LSB (Lao Statistics Bureau). Expenditure and Consumption Survey, LAO People's Democratic Republic. http://www.nsc .gov.la/.

Lundberg, S. J., R. Pollak, and T. J. Wales. 1997. "Do Husbands and Wives Pool Their Resources? Evidence from the United Kingdom Child Benefit." Journal of Human Resources 32 (3): 463-80.

Malhotra, A., R. Pande, and C. Grown. 2003. "Impact of Investments in Female Education on Gender Equality." Commissioned by the World Bank Gender and Development Group and International Center for Research on Women, Washington, DC.

Marks, J. 2001. "Girls Know Better: Educational Attainment of Boys and Girls." CIVITASThe Institute for the Study of Civil Society, London, U.K.

Martino, W., and D. Berrill. 2003. "Boys, Schooling and Masculinities: Interrogating the 'Right' Way to Educate Boys." Educational Review 55 (2): 99-117.

Naudeau, Sophie, Naoko Kataoka, Alexandria Valerio, Michelle Neuman, and Leslie Elder. 2011. Investing in Young Children: An Early Childhood Development Guide for Policy Dialogue and Project Preparation. Washington, DC: World Bank.

Niehof, A. 2003. "Women and the Social Context of Fertility Under the New Order." In Two is Enough: Family Planning in Indonesia 
Under the New Order 1968-1998, edited by A. Niehof and F. Lubis, 163-183. Leiden: KITLV Press.

Nielsen, Harriet Bjerrum, and Bronwyn Davies. 2010. "Discourse and the Construction of Gendered Identities in Education." In Encyclopedia of Language and Education: Volume 3, Discourse and Education, edited by Marilyn Martin-Jones, Anne-Marie de Mejía, and Nancy H. Hornberger. Berlin: Springer.

NIS (National Institute of Statistics) Cambodia. Cambodia Socio-Economic Survey (CSES). National Institute of Statistics, Phnom Penh, Cambodia. http://www.nis.gov.kh/index.php/ social-statistics/cses.

NSD (National Statistics Directorate) TimorLeste. Timor-Leste Survey of Living Standards. Ministry of Planning and Finance, National Statistics Directorate, Dili, Timor-Leste. http:// dne.mof.gov.tl/TLSLS/AboutTLSLS/index .htm.

NSD (National Statistics Directorate) TimorLeste, Ministry of Finance, and ICF Macro. 2010. Timor-Leste Demographic and Health Survey 2009-10. Dili, Timor-Leste: NSD and ICF Macro.

NSO Mongolia (National Statistical Office of Mongolia). Living Standards Measurement Survey (LSMS). Ulaanbaatar, Mongolia: National Statistical Office. http://www.nso .mn.

NSO Philippines (National Statistics Office, Republic of the Philippines). 2006. Family Income and Expenditure Survey 2006. Manila, the Philippines: National Statistics Office.

NSO Thailand (National Statistical Office Thailand). Thailand Socio-Economic Survey (SES). Bangkok, Thailand: National Statistical Office. http://web.nso.go.th/tnso.htm.

Oster, Emily, and Bryce Millet. 2010. "Do Call Centers Promote School Enrollment? Evidence from India." Draft, University of Chicago Booth School of Business.

Panda, Pradeep, and Bina Agarwal. 2005. "Marital Violence, Human Development and Women's Property Status in India.” World Development 33 (5): 823-50.

Papua New Guinea Department of Education. 2009. "Achieving Universal Education for a Better Future: Universal Basic Education Plan 2010-2019." National Executive Council, Port Moresby, Papua New Guinea.
PISA (Programme for International Student Assessment). Organisation for Economic Co-operation and Development, Paris, France. www.pisa.oecd.org/.

Pritchett, Lant, and Lawrence H. Summers. 1996. "Wealthier Is Healthier." Journal of Human Resources 31 (4): 841-68.

Qian, Nancy. 2008. "Missing Women and the Price of Tea in China: The Effect of Sex-Specific Earnings on Sex Imbalance." Quarterly Journal of Economics 123 (3): 1251-85.

Quisumbing, Agnes. 1995. "Gender Differences in Agricultural Productivity: A Survey of Empirical Evidence." FCND Discussion Paper 5, International Food Policy Research Institute, Washington, DC.

Quisumbing, Agnes, and Kelly Hallman. 2005. "Marriage in Transition: Evidence on Age, Education, and Assets from Six Developing Countries." In The Transition to Adulthood in Developing Countries: Selected Studies, edited by Jere Behrman, Barney Cohen, Cynthia B. Lloyd, Nelly Stromquist. Washington, DC: National Academies Press.

Quisumbing, Agnes R., and John Maluccio. 2003. "Resources at Marriage and Intra-household Allocation: Evidence from Bangladesh, Ethiopia, Indonesia, and South Africa." Oxford Bulletin of Economics and Statistics 65: 283-327.

Quisumbing, Agnes R., and Keijiro Otsuka. 2001. "Land Inheritance and Schooling in Matrilineal Societies: Evidence from Sumatra." World Development 29 (12): 2093-2110.

Ross, Heidi, and Jinghuan Shi, eds. 2003. "Entering the Gendered World of Teaching Materials, Part II." Chinese Education and Society (May-June) 36: 3.

Sakellariou, Chris. 2011. "Determinants of the Gender Wage Gap and Female Labor Force Participation in EAP." Paper commissioned for Toward Gender Equality in East Asia and the Pacific: A Companion to the World Development Report. Washington, DC: World Bank.

Schleicher, A. 2008. "Student Learning Outcomes in Mathematics from a Gender Perspective: What Does the International PISA Assessment Tell Us?" In Girls' Education in the 21st Century, edited by M. Tembon and L. Fort. Washington, DC: World Bank.

Schultz, T. P. 1993. "Returns to Women's Schooling." In Women's Education in Developing Countries: Barriers, Benefits 
and Policy. Baltimore, MD: Johns Hopkins University Press.

- 1997. "The Demand for Children in Low-Income Countries." In Handbook of Population and Family Economics: Vol. 1A, edited by M. R. Rosenzweig and O. Stark. Amsterdam: North-Holland.

- 2006. "Does the Liberalization of Trade Advance Gender Equality in Schooling and Health?" IZA Discussion Papers 2140, Institute for the Study of Labor, Bonn.

Schultz, T. P., and Z. Yi. 1997. "The Impact of Institutional Reform from 1979 to 1987 on Fertility in Rural China." Photocopy. August 29.

Sen, Amartya. 1992. "Missing Women." British Medical Journal 304: 587-88.

Shel, T. A. 2007. "Gender and Inequity in Education Literature Review." Background paper prepared for the Education for All Global Monitoring Report 2008 Education for All by 2015: Will We Make It? http://unesdoc .unsco.org/imagers/0015/001555/155580e. pdf.

Shi, Jinghuan, and Heidi Ross, eds. 2002. "Entering the Gendered World of Teaching Materials, Part I." Chinese Education and Society 35 (5): 3-13.

Tararia, A. 2011. "WDR Rapid Qualitative Assessment on Gender and Economic Choice." Country Synthesis Report, Papua New Guinea. World Bank, Washington, DC.

Thomas, Duncan. 1995. "Like Father, Like Son, Like Mother, Like Daughter, Parental Resources and Child Height." Papers 95-01, RAND Reprint Series, RAND corporation, Santa Marica, CA.

Thomas, Duncan, and John Strauss. 1992. "Prices, Infrastructure, Household Characteristics and Child Height." Journal of Development Economics 39 (2): 301-33.

TIMSS (Trends in International Mathematics and Science Study). International Association for the Evaluation of Educational Achievement, Amsterdam, the Netherlands. http://rms.ieadpc.org/.

Udry, Christopher. 1996. "Gender, Agricultural Production, and the Theory of the Household." Journal of Political Economy 104 (5): 1010-14.

UNESCO (United Nations Educational, Scientific and Cultural Organization) and the Vietnam Ministry of Education and Training. 2011. "National Textbook Review and Analysis from a Gender Perspective: Report of Findings." UNESCO, Hanoi, Vietnam.

UNFPA (United Nations Population Fund). 2009. "Recent Change in the Sex Ratio at Birth in Viet Nam." UNFPA Viet Nam, Hanoi.

UNICEF (United Nations Children's Fund). 2004. "What About the Boys?" In The State of the World's Children 2004, ed. UNICEF, 58-69. New York: UNICEF.

—. 2009. "Education for All Mid-Decade Assessment, East Asia and Pacific." UNICEF East Asia and Pacific Regional Office, Bangkok, Thailand.

UNIFEM, World Bank, ADB, UNDP, and DFID/ UK. 2004. A Fair Share for Women: Cambodia Gender Assessment. UNIFEM, WB, ADB, UNDP, DFID/UK. Phnom Penh.

UN DESA (United Nations Department of Economic and Social Affairs), Population Division. 2009. World Urbanization Prospects: The 2009 Revision. New York: United Nations. http://esa.un.org/unpd/wup/ index.html.

Velasco, E. 2001. "Why Are Girls Not in School: Perceptions, Realities and Contradictions in Changing Cambodia." UNICEF/Cambodia, Phnom Penh.

Waldron, Ingrid. 1998. "Factors Determining the Sex Ratio at Birth." In Too Young to Die: Genes or Gender?, 53-63. New York: United Nations.

WHO (World Health Organization) Global Infobase. World Health Organization, Geneva, Switzerland. https://apps.who.int/infobase/ report.aspx.

—. 2003, November. "Gender, Health and Tobacco." Gender and Health. http:// www.who.int/gender/documents/Gender_ Tobacco_2.pdf.

- 2010. World Health Statistics. Geneva: WHO.

- 2011a. "Action Needed to Reduce Health Impact of Harmful Alcohol Use.” News Release, February 11. http://www .who.int/mediacentre/news/releases/2011/ alcohol_20110211/en/.

- 2011b. Global Status Report on Alcohol and Health. Geneva: WHO. http://www .who.int/substance_abuse/publications/ global_alcohol_report/en/.

Williamson, N. 1976. Sons or Daughters: A Cross-Cultural Survey of Parental Preferences. Beverley Hills, CA: Sage. 
Women, Business and the Law (database). World Bank, Washington, DC. http://wbl.worldbank .org/data.

World Bank. 2001. Engendering Development: through Gender Equality in Rights, Resources, and Voice. Washington, DC: World Bank.

- 2008. "Analysis of the Impact of Land Tenure Certificates with Both the Names of Wife and Husband in Vietnam.” World Bank, Washington, DC. https://openknowledge .worldbank.org/handle/10986/7810.

—. 2010. “... and Then She Died": Indonesia Maternal Health Assessment. Washington, DC: World Bank. https://openknowledge .worldbank.org/handle/10986/2837.

- 2011a. "Toward a Healthy and Harmonious Life in China: Stemming the Rising Tide of Non-Communicable Diseases. Human Development, East Asia and the Pacific.” World Bank, Washington, DC.
- 2011b. Vietnam Country Gender Assessment. Washington, DC: World Bank. http://www-wds.worldbank.org/external/ default/WDSContentServer/WDSP/IB/2011 /11/14/000333038_20111114003420/ Rendered/PDF/655010WP0P12270sessment .0Eng.0Final.pdf.

- 2011c. World Development Report 2012: Gender Equality and Development. Washington, DC: World Bank.

World Development Indicators (WDI) database. World DataBank, World Bank, Washington, DC. http://data.worldbank.org/data-catalog/ world-development-indicators.

Zeng, Yi, Tu Ping, Gu Baochang, Xu Yi, Li Bohua, and Li Yongqing. 1993. "Causes and Implications of the Recent Increase in the Reported Sex Ratio at Birth in China." Population and Development Review 19 (2): 283-302. 


\section{Gender and Economic Opportunity}

I $\mathrm{n}$ the dynamic East Asia and Pacific region, many countries have undergone structural transformations that have shifted the balance of economic opportunities away from rural areas and toward urban areas. These growth processes have opened up nonfarm economic opportunities for men and women in the region, particularly among younger cohorts. The educational attainment and health outcomes of women, particularly younger women, have been catching up to those of men during this period of growth, as discussed in chapter 2 . Along some dimensions of gender equality in economic opportunities, there has been substantial progress over the last two decades. For example, the evidence suggests that the labor market participation decisions of younger women resemble those of their male counterparts in the region. However, many other indicators demonstrate the substantial challenges to be overcome to close the gender gap in access to economic opportunities. The type of work women do remains very different from that of men, and their remuneration for these tasks is lower. Women of all ages are more likely than men to be in poorly remunerated occupations and sectors, women are paid less than men for similar work, and gender norms in the division of labor within the household imply that women work longer hours than men, although fewer of those hours are devoted to remunerated activities.

Reducing gender inequalities in economic opportunities can improve economic outcomes in multiple ways. First, reducing employment segregation (the unequal distribution of male and female workers across occupations and sectors) will reduce efficiency losses associated with the misallocation of talent (Anker 1998; Morrison, Raju, and Sinha 2007). Men and women often choose occupations on the basis of norms, gender stereotypes, and sometimes prejudice, rather than on the basis of earnings or job match (Klasen and Lamanna 2009). Encouraging workers and employers to make labor choices on the basis of their skills, competencies, and inherent ability is likely to raise productivity and may have a positive impact on economic growth by increasing the size of the labor force as well as by expanding the pool of managerial and innovative talent in the economy (Esteve-Volart 2004). As noted in chapter 1, estimates for East Asian and Pacific countries suggest that output per worker could be 7 to 18 percent higher if female entrepreneurs and workers were to work in the same sectors, types of jobs, and activities as men (Cuberes 
and Teignier-Baqué 2011). Second, empirical evidence from other developing regions suggests that reducing gender inequalities in access to productive inputs can increase overall production by increasing the productivity of female-run farms and enterprises (Goldstein and Udry 2008; Quisumbing 1995; Udry 1996).

This chapter examines differences in productive opportunities for men and women within and across countries in the East Asia and Pacific region and explores the economic and institutional factors that have determined how those opportunities have evolved over time. Because education enrollment and attainment are growing and labor markets are changing, this chapter differentiates between the experiences of older and younger generations. It also uses examples from both high-income and low-income countries across the globe to understand these trends.

Gender differences in the economic sphere manifest themselves in several indicators, including differences in labor force participation, in the time spent on productive and reproductive activities, in the sectors in which men and women work, in the tasks and occupations that they do within those sectors, and in the types of firms that employ them. Differences in these indicators contribute to and are themselves determined by gaps in the earnings of men and women. Women are often paid less than men for the same work, and female-run enterprises and farms typically produce less than those of men.

Gender inequalities in economic opportunities are driven by multiple interacting factors. In this chapter we examine how gender differences in access to human and physical capital, technologies, and government services; gender stereotypes; and gender roles explain gender inequality in economic opportunities. These factors are, in themselves, determined by the household, market, and institutional environment in which preferences and gender roles are learned and in which education and time allocation choices are determined.
Three main messages for the East Asia and Pacific region emerge in this chapter:

- In some dimensions, such as labor force participation, gender inequalities in the economic sphere in the region have improved in recent decades and are narrower than those in other regions; however, multiple dimensions of inequalities remain that will require concerted effort to change, such as persistent gender wage and productivity gaps. In several areas, policies and public investment can help to ease the constraints on women and support them in their multiple roles as entrepreneurs, farmers, wage and salaried workers, mothers, and caregivers.

- The constraints faced by women vary across sectors of the economy and also by country according to the institutional environment. Some common themes emerge, however. In the agricultural sector, female farmers' access to productive capital, technologies, and governmental services is lower than that of male farmers; improving access to these inputs is tantamount to increasing productivity. In the nonfarm sector, female-run enterprises are smaller and in different sectors than male-run enterprises. The constraints and productivity differences of female enterprises are predominantly attributable to their small size and to the sectors in which they are found. Constraints in all countries are likely to be greatest at start-up, when access to finance and entrepreneurial skills are likely to be important determinants of sector and initial scale of enterprise. In the labor market, gender-based employment segmentation-or sorting across types of firms, industries and sectors-affects both the wages women earn as well as productivity in the economy, particularly when men and women sort into occupations on the basis of gender rather than skill. Policies that encourage both men and women to think outside of gender-based occupational norms will be productivity enhancing and likely have positive repercussions for female empowerment. 
- As in other parts of the world, women in the region have multiple roles and will require more support to manage competing demands for their time from productive, reproductive, and community management activities as development proceeds and greater nonfarm sector opportunities emerge. Nearly all countries in the region see declines in the female labor force participation of young mothers. Furthermore, to manage their dual roles, women are often obliged to enter into different occupations and work fewer hours than men, both of which are found to have negative implications on their wages and earnings. Policies that support women in juggling the competing demands of home and market work will be required, particularly as women start moving into "male" occupations that have not traditionally allowed them the flexibility to lead their dual lives.

The chapter is structured as follows. The first section explores whether growth is sufficient to reduce gender inequalities in productive activities, drawing upon evidence from high-income countries within and outside the region. The second section describes the current situation with regard to gender inequalities in economic opportunities in East Asian and Pacific countries. The third section examines the determinants of the most persistent gender inequalities, and the fourth section concludes by briefly examining policy directions, a discussion that is taken up again in chapter 6 .

\section{Limited effects of growth on gender gaps in economic opportunity}

The empirical literature suggests that economic development alone is not sufficient to narrow gender differences in earnings (Blau and Kahn 2003; Hertz et al. 2009; Tzannatos 1999). Evidence from East Asian and Pacific countries suggests instead that social, political, and cultural factors are as important as economic development in determining gender wage gaps and, indeed, that these factors interact with the development process to determine the degree to which growth narrows gender inequalities (Meng 1996). ${ }^{1}$

In high-income countries, the age profile of women's economic participation and the sensitivity of their participation to life-cycle factors have changed with development. Between 1950 and 2010, female labor force participation in Hong Kong SAR, China; Japan; the Republic of Korea; and Singapore increased substantially across all age cohorts. For example, in Korea, women's labor force participation has increased monotonically over time (figure 3.1). Similar changes were seen in the United States, particularly among married women (Juhn and Potter 2006). Furthermore, the decline in labor force participation by women in their early 30s has become less severe in these high income countries. Rising female labor force participation with development has been attributed to a number of demographic factors, including later marriage and childbirth and lower fertility rates.

However, income growth in these countries has not been enough to eliminate gender

FIGURE 3.1 Female labor force participation in the Republic of Korea rose for women of all ages between 1960 and 2005

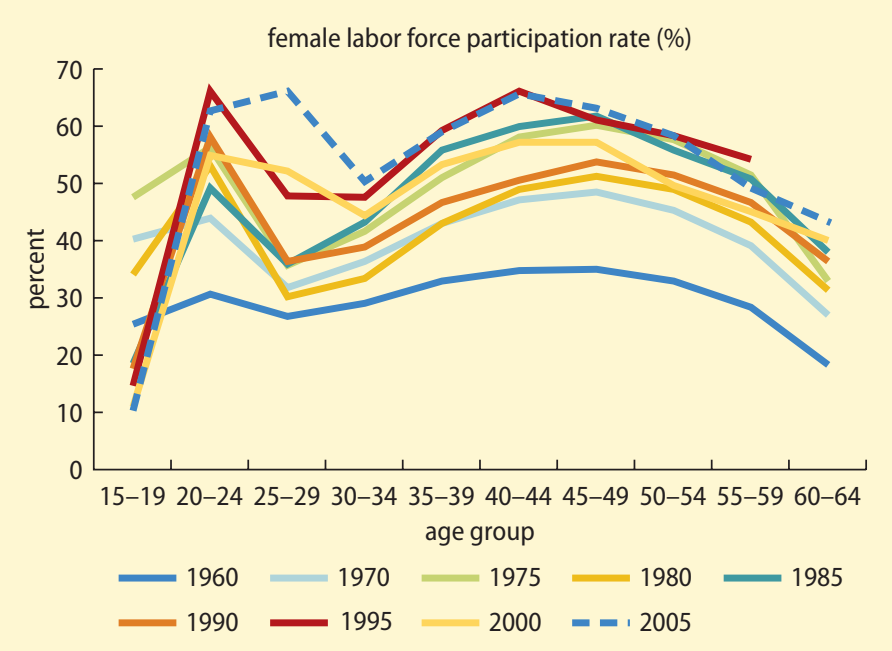

Source: ILO Key Indicators of the Labour Market (KILM) database: Korea Labor Force Survey and Population Census. 
inequalities in all dimensions of economic opportunities. Despite a substantial increase in young women's labor force participation, sharp gender differences in employment status, occupational status, and wage rates continue to exist. In Japan, women are more likely than men to be in nonregular employment, including temporary work, contract work, and part-time work (Hill 1996; Yu 2002). Women continue to leave the workforce in substantial numbers during their childbearing years, even if only temporarily. The greatest drop in female labor force participation rates comes for married women in their mid-20s to early 30 s when they start having children and assuming greater family responsibilities (Hill 1996; Lee, Jang, and Sarkar 2008; Miller 1998, 2003; Sasaki 2002).

Welfare, child care, and tax reforms; legislative changes; and women's movements have helped to narrow gender differences in economic opportunities in high-income countries in the East Asia and Pacific region and across the world. The United States provides a good example of how the combination of economic forces, social changes, and legal reforms has transformed women's labor force participation. Explanations of changes in female labor force participation include demand-side factors that shifted women's market wage as well as supplyside factors that reduced women's opportunity costs of working (Fang and Keane 2004; Galor and Weil 1996; Greenwood, Seshadri, and Yorukoglu 2005; Weinberg 2000). Since the 1980s, Korean labor and family law has sought to improve women's status within marriage and the family and to eliminate gender bias in other areas, including in labor law (Kim 2005). In addition, the Korean government has undertaken several measures to support married women with their child-care responsibilities, such as reforming maternity and paternity leave and expanding expenditures on child-care facilities. Women's and labor organizations have played an important role in advocating for legislation that reduces gender discriminatory practices (Kim 2005). Legislative reforms to level the playing field for women in the labor market have been difficult to enforce in Japan, however (Lam 1992; Liu and Boyle 2001; Miller 2003).

\section{Gender differences in economic activity}

Gender differences in the economic sphere manifest themselves in a number of indicators. This section focuses on examining gender differences in labor force participation, in earnings, and in the labor market segregation of men and women.

\section{Labor force participation}

The East Asia and Pacific region is characterized by high female labor force participation on average, but also by substantial variation across and within countries. Labor force participation is defined as all productive work, whether as wage workers or as unpaid family workers. Female labor force participation in the East Asia and Pacific region is the highest in the developing world-70 percent of females were participating in labor market activities in 2008 (see figure 1.14 in chapter 1). The participation gap (the difference between the participation of men and women in paid or unpaid market-oriented work) was approximately 15 percentage points in the region. In comparison, the female labor force participation rate in the Latin America and the Caribbean region and Europe and Central Asia region was 55 and 58 percent in 2008, respectively, and their gender gaps in labor force participation were 27 and 16 percentage points, respectively. Box 3.1 discusses the ways in which high female labor force participation may, or sometimes may not, be an indicator of enhanced welfare for women.

The average rates of female labor force participation vary substantially within the region (see figure 1.15 in chapter 1). Participation and gender gaps in some parts of the region are among the highest in the world, whereas in others they are among the lowest. For example, in Fiji, Samoa, 


\section{BOX 3.1 Is higher female labor force participation always a good thing?}

Studies from across the world indicate that increased female labor force participation and control by women over household resources are associated with their enhanced well-being and status. For example, a study on India shows that female mortality is lower where female labor force participation rates and earnings are higher (Murthi, Guio, and Drèze 1995). At the same time, although higher household income is associated with higher levels of welfare for household members, the marginal impacts are considerably greater when income is in the hands of the mother. As women gain more control over expenditure decisions, a larger share of household resources tends to be devoted to children's education, health, and nutrition (Thomas 1990; Thomas and Strauss 1997). Women's borrowing from microfinance programs also appears to improve child welfare more substantially than does borrowing by men, including significant improvements in children's nutritional levels and increases in the school enrollment levels of both boys and girls. However, labor force participation is not always empowering and may be a consequence of poverty, which pushes women into low-paying jobs with poor working conditions and job insecurity. Jobs may also be exploitative and may reinforce traditional gender roles (Elson and Pearson 1981). and Malaysia, participation rates in 2008 were an order of magnitude lower than the average for the region, with approximately 55 percent of working-age females in these countries participating in the labor force. Female labor force participation is highest in countries where the state has put a priority on gender equality, for example, in socialist or formerly socialist countries, as well as in agrarian and rural economies where high rates of participation may be a consequence of poverty.

Substantial gender differentials in participation have also been noted within countries in the region. National averages of labor force participation fail to capture important differences in participation across rural and urban areas, as well as regional variation within countries. In all countries within the region, rural labor force participation is higher than urban labor force participation, for both males and females (figure 3.2). Participation gaps in all countries, apart from Mongolia and the Philippines, are substantially greater in urban areas than in rural areas. In Vietnam, higher levels of female participation and lower gender differentials are found in poorer and often low-productivity areas, where female participation in employment to supplement household income is necessary (Pierre 2011).

Even in countries with high overall participation rates, female labor force participation rates decline during childbearing years and old age. Average female labor force participation rates hide important variation over women's life cycles due to factors such as marriage and childbearing, whereas male participation rates remain fairly constant throughout their life cycles. The gaps between men and women in labor force participation, earnings, and job composition increase after marriage and childbearing in many East Asian and Pacific countries, as they do globally. In the United States, for example, young single men and women have more similar labor participation, earnings, and career profiles than do married men and women. In many East Asian and Pacific countries, life-cycle patterns of labor force participation by birth cohorts reveal specific trends that are not apparent in the average rates of participation, especially during periods of rapid growth and structural transformation. Rapid changes in education levels across cohorts, the availability of new economic opportunities in growing sectors, and urbanization mean that young women are more likely than older women to participate in the labor force, and 
FIGURE 3.2 Labor force participation is greater in rural areas than in urban areas for both males and females

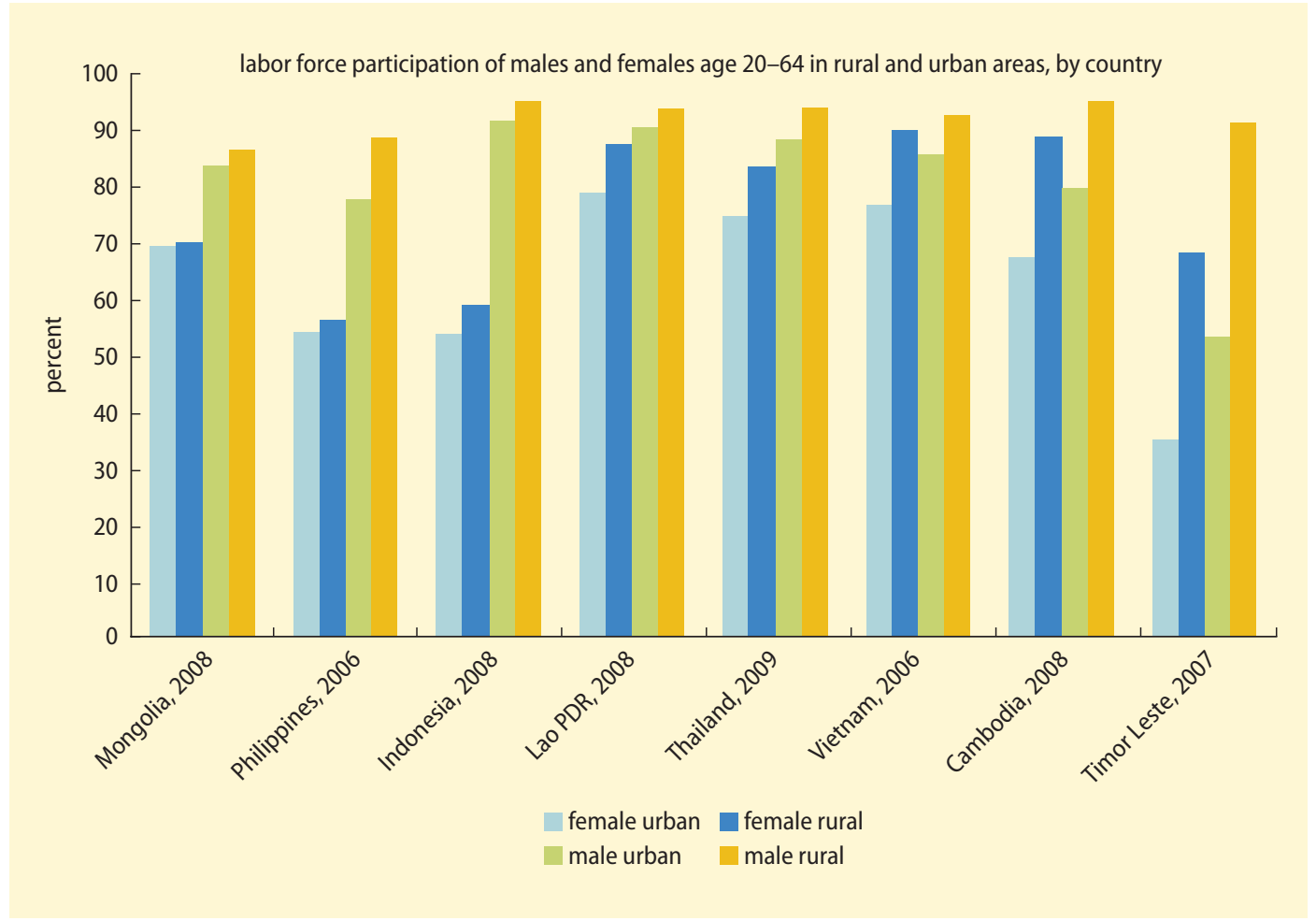

Source: Data generated using country level household data, with the exception of Indonesia which uses labor force data. Note: The countries are sorted by the gap between females in rural and urban areas.

to participate in different sectors (Mammen and Paxson 2000).

Female labor force participation is more sensitive to life-cycle factors, such as marriage and childbearing, in some countries than others. The birth cohort life-cycle participation patterns of women vary substantially within the East Asia and Pacific region and have also exhibited considerable change over time. Three patterns can be distinguished in the region (Horton 1996). ${ }^{2}$ The "plateau" pattern exhibits relatively flat female labor force participation until women reach their early $50 \mathrm{~s}$, and then declines into old age. The "double-peaked" or "M" pattern is generally observed in more industrialized countries: it is characterized by high participation in the labor market prior to marriage and childbearing, with a subsequent return to the labor force once children are older. A "single-peaked" pattern exhibits higher rates of participation at younger ages, which then fall after the peak. This is a more extreme version of the double-peaked pattern and characterizes a labor market in which few women return to work after marriage and childbearing. In the region, this pattern can be seen only in Malaysia, where it continues despite increases in female participation between 1980 and 2010 (figure 3.3). The plateau pattern, in contrast, describes a situation in which female labor force participation is less sensitive to life-cycle effects than in the single- and double-peaked patterns. The plateau pattern can be seen in countries with political regimes that encouraged women's economic independence, such as China, Mongolia, and Vietnam.

Labor force participation decisions of rural and urban women in many countries 
FIGURE 3.3 Female labor force participation rates in Malaysia have risen over time among 20- to 55-yearolds, but continue to decline during child-bearing years

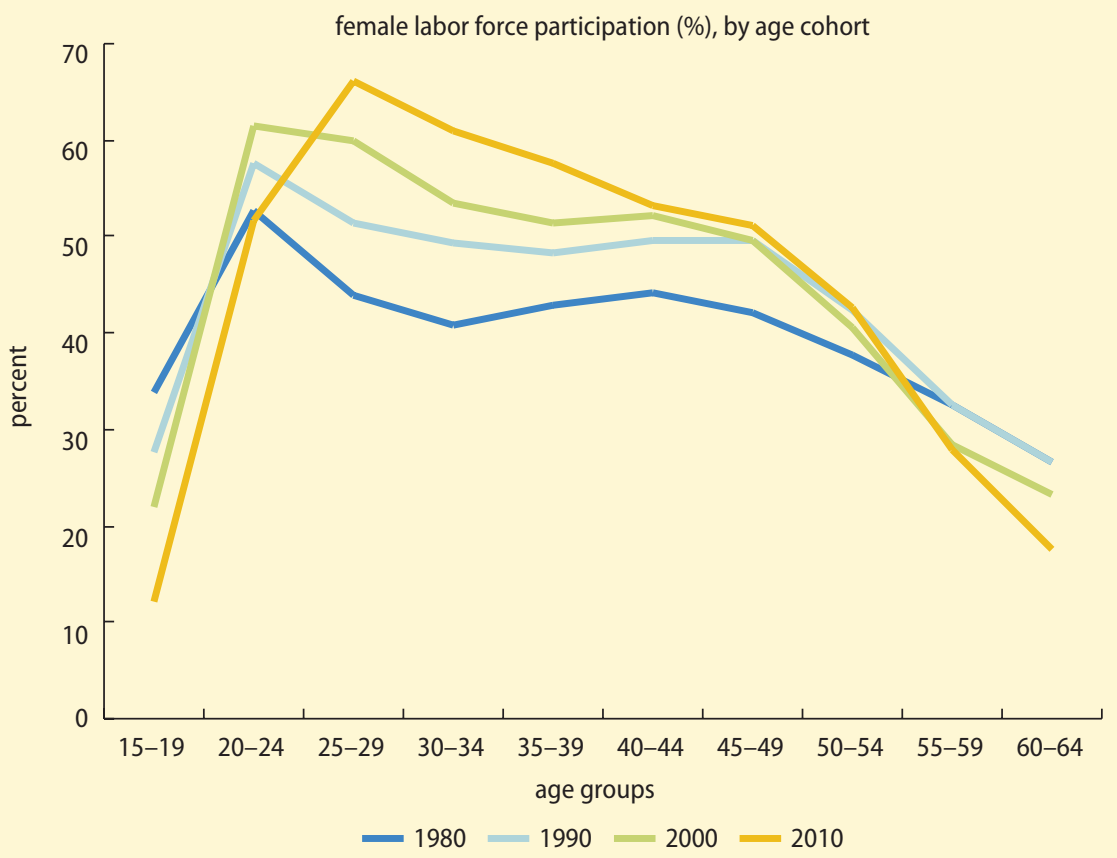

Source: LABORSTA Internet (1980, 1990, and 2000 data), CEIC Data (2010 data).

display different responses to life-cycle changes, and their sensitivity to life-cycle changes may evolve differently over time. In Indonesia, for example, urban women are more likely than rural women to leave the labor force when they have children, and they also leave the labor force for longer. Patterns of participation have changed substantially since 1990 , however, and have evolved differently in rural and urban areas. Although urban women with young children in 2008 are still less likely to work than their rural counterparts, urban women display less sensitivity to childbearing decisions than they did in 1990. In contrast, rural women in 2008 are more likely to reduce their labor supply when having children and to leave the labor force for longer than rural women did in 1990.
East Asian and Pacific countries with higher rates of female labor force participation overall have smaller declines in participation during childbearing years, although predominantly in urban settings. In all countries in the region, women with young children are substantially less likely to participate in the labor market than men with young children and than women without young children. In some countries, such as Mongolia and Vietnam, a reduction in labor market participation is seen in either urban or rural areas alone, whereas in others, such as Indonesia and the Philippines, it is seen in both rural and urban areas. Data from the 2009 Vietnam Labor Force Survey (GSO [Vietnam]) show that rural Vietnamese women between ages 25 and 35 with a child under the age of 2 are a third less likely to 
participate in the labor market than men of the same age with a child. In comparison, the participation of women between ages 25 and 35 without a child is fairly similar to that of men in this age group (figure 3.4). In Vietnam, the effect of children on labor force participation is smaller and of shorter duration than in Mongolia. In Vietnam, the participation gap disappears by the time the child reaches school age, whereas in Mongolia the participation gap continues to be substantial even for older children.

In countries where female labor force participation is low on average, it also tends to be highly sensitive to marriage and childbearing years. Indonesia, Japan, Korea, and Malaysia have historically displayed a single- or double-peaked pattern; that is, women participate in the labor market prior to marriage and childbearing and, in the case of a double-peaked pattern, eventually return to the labor force once the children are older. These countries also have lower average female labor force participation than countries in the region that exhibit a plateau pattern. In Indonesia and

FIGURE 3.4 Women in rural Vietnam with children under age 2 are substantially less likely to participate in the labor market than those without young children

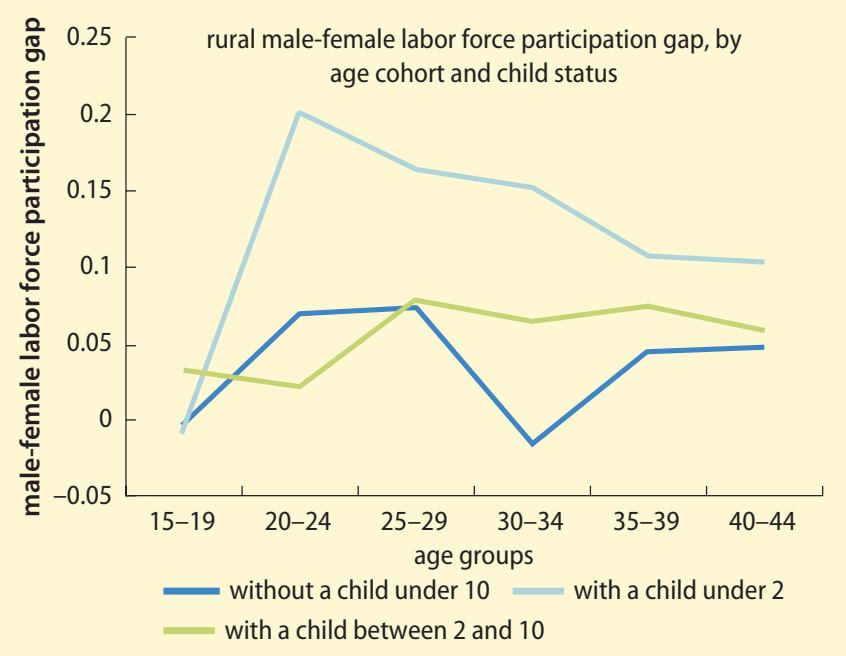

Source: World Bank staff estimates using Vietnam Labor Force Survey (GSO Vietnam), 2009 data. the Philippines, in marked contrast to the examples of Mongolia and Vietnam above, female-male participation gaps are substantial even among women who do not have children, and the gaps widen with age.

\section{Earnings}

Gender gaps in wages and earnings are found in all countries in the region and in all sectors, with rare exceptions. Male and female wages differ in multiple sectors and settings across the region, with female agricultural wage workers earning less than male agricultural wage workers, and female urban wage workers earning less than their male counterparts. ${ }^{3}$ Female entrepreneurs and farmers often display lower revenues and profits than their male counterparts.

A substantial body of evidence has accumulated over the past three decades to suggest that women are paid less for similar work across the world as well as in the region. A cross-country comparison of wages indicates that women earn between 70 and 80 percent of the wages men receive for similar work (Hausmann, Tyson, and Zahidi 2010). ${ }^{4}$ Evidence from across the world suggests that economic development is not sufficient to reduce the gender earnings gaps (Blau and Khan 2003). Even in high-income countries in the East Asia and Pacific regionnotably Japan and Korea-the average woman earns less than half the wage of the average man. Lower-income countries, including Mongolia, Lao People's Democratic Republic, Papua New Guinea, and Vietnam, have lower gender wage gaps, on average, than many richer countries.

Within the agricultural, manufacturing, service, and government sectors, women earn less than men on average (figure 3.5), although the ratio of male-to-female earnings varies substantially across sectors as well as across countries. Female-to-male wage ratios tend to be lower in the agricultural and manufacturing sectors and higher in the service sector and in government, with some exceptions. 
Gender wage gaps in the East Asia and Pacific region are greatest between men and women with the lowest educational endowments and in the lowest paying occupations. Several studies have indicated that the gap is wider at the bottom end of the wage distribution than at the top (Chi and Li 2007; Li and Song 2011; Sakellariou 2011). In contrast, in Organisation for Economic Co-operation and Development (OECD) countries, gender wage gaps tend to be wider at the top than at the bottom of the wage distribution (Albrecht, Björklund, and Vroman 2003; Arulampalam, Booth, and Bryan 2007; de la Rica, Dolado, and Llorens 2005).

In the nonfarm sector, the performance of male and female firms around the world varies substantially, as measured by total factor productivity, labor productivity, profitability, and capital intensity (Sabarwal, Terrell, and Bardasi 2011). In the East Asia and Pacific region, formal sector firms with at least one female owner do not have significantly lower sales than those with no female owners, with the exception of firms in the Philippines (figure 3.6). However, in the informal sector, output per worker in female-owned enterprises is substantially lower than that in male-owned enterprises. Data from Indonesia and Vietnam suggest that in the informal sector, gender earnings gaps are more pronounced than in the formal sector: female-owned enterprises with fewer than five employees generate only approximately 60 to 70 percent of the output per worker generated by male-owned enterprises (figure 3.7).

\section{Labor market segregation}

Multiple studies find that men and women work in different sectors, industries, occupations, and types of firms across the world (Anker 1998; Boserup 1970). As can be seen in figures 3.8 and 3.9, across the region women are overrepresented in unpaid family work, particularly in rural areas, and are slightly more likely to be employed in the informal sector. ${ }^{5,6}$ Within the informal sector, women are more likely to be
FIGURE 3.5 Women earn less than men in the majority of East Asian and Pacific countries and in all sectors of the economy

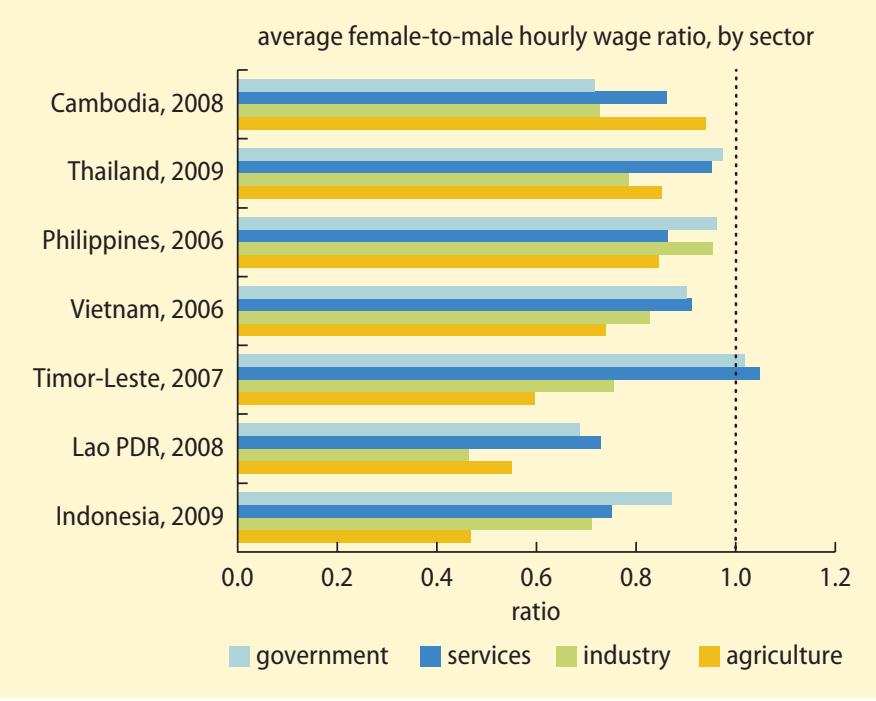

Source: World Bank estimates using household income and expenditure surveys. Cambodia Socio-Economic Survey (CSES) (NIS Cambodia), 2008 data; Indonesia National Socioeconomic Survey (SUSENAS) (BPS Indonesia), 2009 data; Lao Expenditure and Consumption Survey (LSB [Lao PDR]), 2008 data; Philippines Family Income and Expenditures Survey (NSCB 2006); Thailand Socio-Economic Survey (SES) (NSO Thailand), 2009 data; Timor-Leste Survey of Living Standards (NSD Timor-Leste), 2007 data; Vietnam Household Living Standards Surveys (VHLSS) (GSO Vietnam), 2006 data.

FIGURE 3.6 Male- and female-owned firms in the formal sector do not display substantial differences in productivity

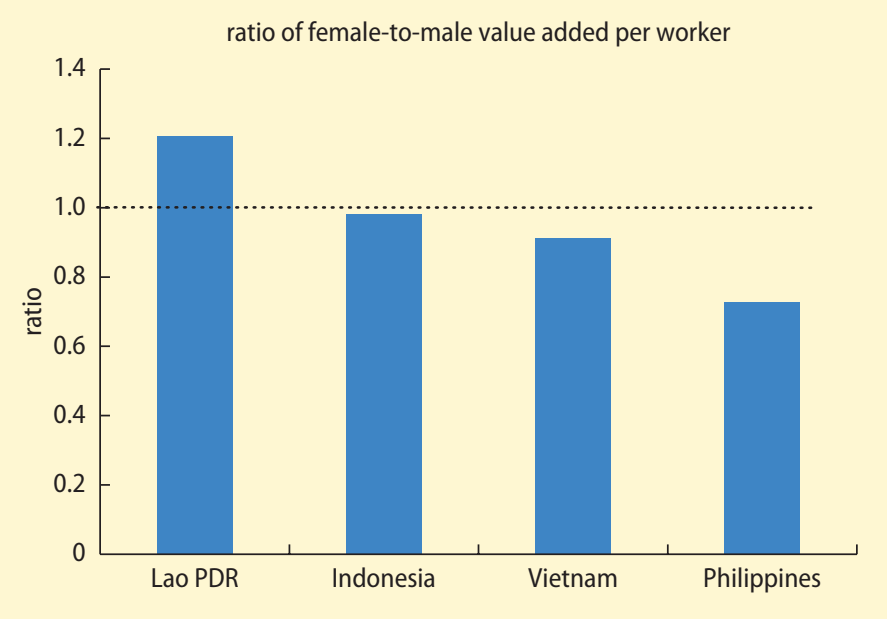

Source: World Bank estimates using Enterprise Surveys, 2006-11 data.

Note: Data are for small (19 employees or less), medium (20-99 employees), and large (100 and more employees) firms in the formal sector. Female-owned firms are defined as those with at least one female owner. Value added is measured as revenues minus material expenses. 
FIGURE 3.7 In the informal sector, gender-based differences in productivity are more pronounced than in the formal sector

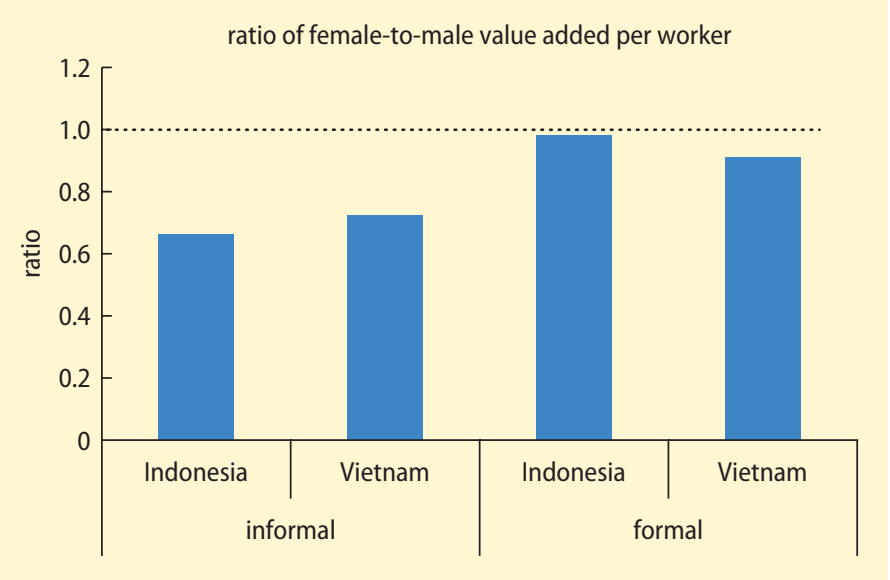

Source: Data for informal firms are based on Indonesia Family Life Survey 2007/2008; VHLSS (GSO Vietnam), 2008 data. Data on formal firms are from Enterprise Surveys.

Note: Based on a sample of firms with fewer than five employees.

\section{FIGURE 3.8 Women are more likely than men to work as unpaid} family workers

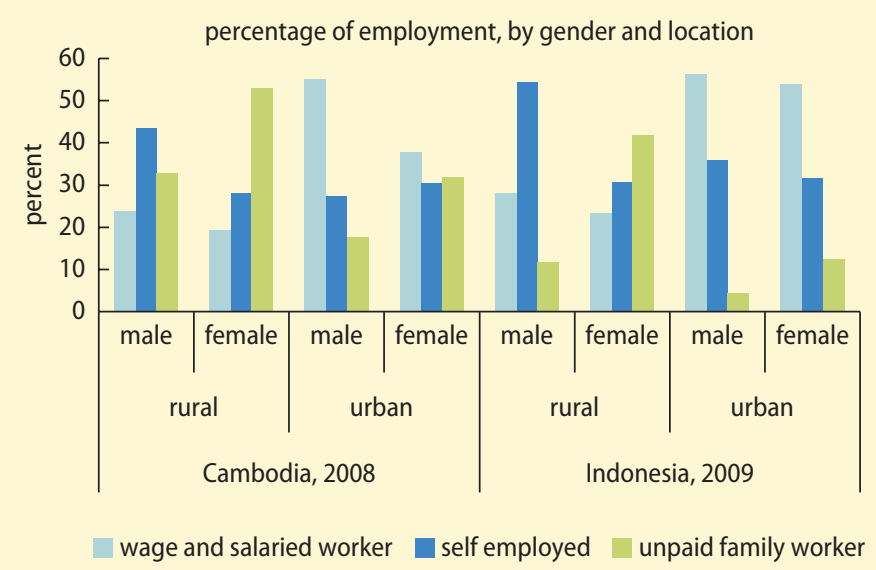

Source: World Bank estimates using socioeconomic surveys: CSES (NIS Cambodia), 2008 data; Indonesia SUSENAS (BPS Indonesia), 2009 data.

own-account workers (self-employed workers working by themselves) and subcontracted workers, whereas men are more likely to be employers or paid employees of informal enterprises (World Bank 2011g). Globally, women are more likely than men to work part-time (ILO 2010).
Across the world, women in the nonagricultural workforce are more likely to work in social and communal services (such as education and health) and in commerce and restaurants, whereas men are more likely to work in transport, construction, public administration, and manufacturing (ILO 2010). Similar trends are found in East Asian and Pacific countries. For example, men in Cambodia and Indonesia are disproportionately found in the manufacturing, transport, construction, and public administration sectors, and women are found in manufacturing, education, health and social services, and commerce (figure 3.10). Estimates from household survey data suggest that, in Fiji and Vietnam, men are more likely to work as professionals and managers and as plant and machine workers, whereas women are more likely to work as technicians, sales workers, and clerks, and in elementary occupations. ${ }^{7}$ Women also make up a smaller fraction of the public sector workforce than men in Cambodia, Thailand, Timor-Leste, and Vietnam. The Philippines, however, displays much higher levels of occupational segregation and also has a higher fraction of women in the public sector than men, a trend that is likely to be related to the relatively high investment in education by Filipino women.

Within the manufacturing sector, women are more likely to be found in industries such as textiles and food processing, and are also found in large and export-oriented firms. Data from country enterprise surveys (2002-05) indicate that, in all developing regions, the fraction of full-time female workers is greater in export-oriented firms. The East Asia and Pacific region has the second-largest fraction of full-time female workers, after Europe and Central Asia. However, within export-oriented firms, women are also more likely than men to be temporary workers in Cambodia, China, and Indonesia, although in Thailand men are more likely to be temporary workers in all firms (see figure 1.18 in chapter 1).

Women are underrepresented in managerial positions and positions of power in all 
sectors, from government to manufacturing (Anker 1998). The East Asia and Pacific region performs relatively well compared to other regions in terms of the fraction of firms with a top female manager (see figure 1.16 in chapter 1$)$. However, women remain less likely than men to serve as managers and directors. The share of female directors ranges from 10 percent in the Philippines and 7 percent in China and Thailand to 5 percent in Indonesia and under 2 percent in Korea and Japan (CWDI 2010). Globally, only one country in the world has succeeded in having more than 30 percent female representation on corporate boards (namely, Norway), and one-third of countries have female board representation over 10 percent (CWDI 2010).

Segregation goes beyond the wage labor market, with smaller female-owned and female-managed firms located in lesscapital-intensive sectors than male-owned and male-managed firms. Female-owned and female-run enterprises are, on average, smaller than male-run enterprises in terms of the number of employees hired, sales, and profits (Aterido and Hallward-Driemeier 2009; Badiani and Posadas 2011; Costa and Rijkers 2011; Sabarwal, Terrell, and Bardasi 2011). Among formal sector firms in the East Asia and Pacific region, enterprise survey data suggest that small firms are more likely than medium and large firms to have a top female manager (see figure 1.19 in chapter 1). Evidence by ownership displays a more mixed picture. In Indonesia, Lao PDR, Mongolia, Timor-Leste, Tonga, and Vanuatu, this pattern still holds, but evidence from the Philippines, Samoa, and Vietnam suggests that female owners are not disproportionately represented among small firms (figure 3.11). ${ }^{8}$ This pattern may be the result of more open cultural norms regarding women's role in business. However, the lower levels of female management relative to ownership suggest that women may still have less control or representation within firms.

Female-run enterprises are also more likely to be found in labor-intensive sectors, such as
FIGURE 3.9 Women are slightly more likely to be employed in the informal sector than men. Rural-urban differences in informality are greater than gender differences within rural or urban areas

percentage of workers in the informal sector, by gender and location

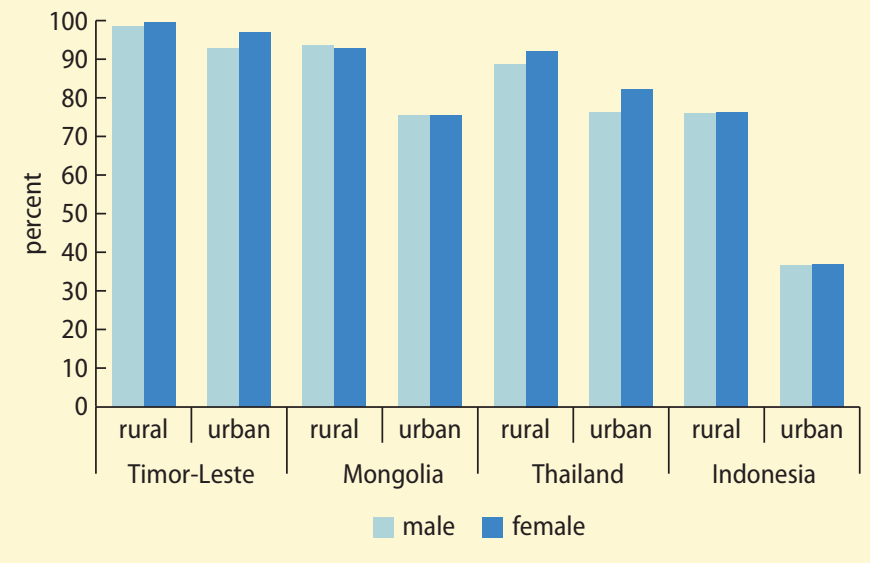

Source: World Bank estimates using Indonesia SUSENAS (BPS Indonesia), 2009 data; Mongolia Living Standards Measurement Survey (LSMS) (NSO Mongolia), 2007-08 data; Thailand SES (NSO Thailand), 2009 data; Timor-Leste Survey of Living Standards (NSD Timor-Leste), 2007 data.

Note: The informal sector is defined using information on an individual's occupation and sector of employment.

services and trade, than in capital-intensive sectors (Klapper and Parker 2010). For example, a study commissioned by this report finds that women are more likely to be found in manufacturing, food sales, and food preparation in Indonesia and less likely to be found in transport, construction, and other services (Badiani and Posadas 2011). Similar patterns have been observed in other countries in the region, including Lao PDR (Davies and Record 2010), Mongolia (World Bank 2011c), and Vietnam (Bjerge and Rand 2011).

The enterprises that women work in are also less productive and capital intensive. In Indonesia, the sectors that women are more likely to be employed in-food and garments production-are among the least capital intensive and productive sectors (figure 3.12). By contrast, the transportation and other service sectors-where male entrepreneurs are most likely to be found-has higher productivity and capital intensity.

Having a female presence in management may have positive implications for workers, however, even if productivity per worker is lower. Female-run firms have been found to 


\section{FIGURE 3.10 Men and women work in different sectors throughout the East Asia and Pacific region}

percentage of workers

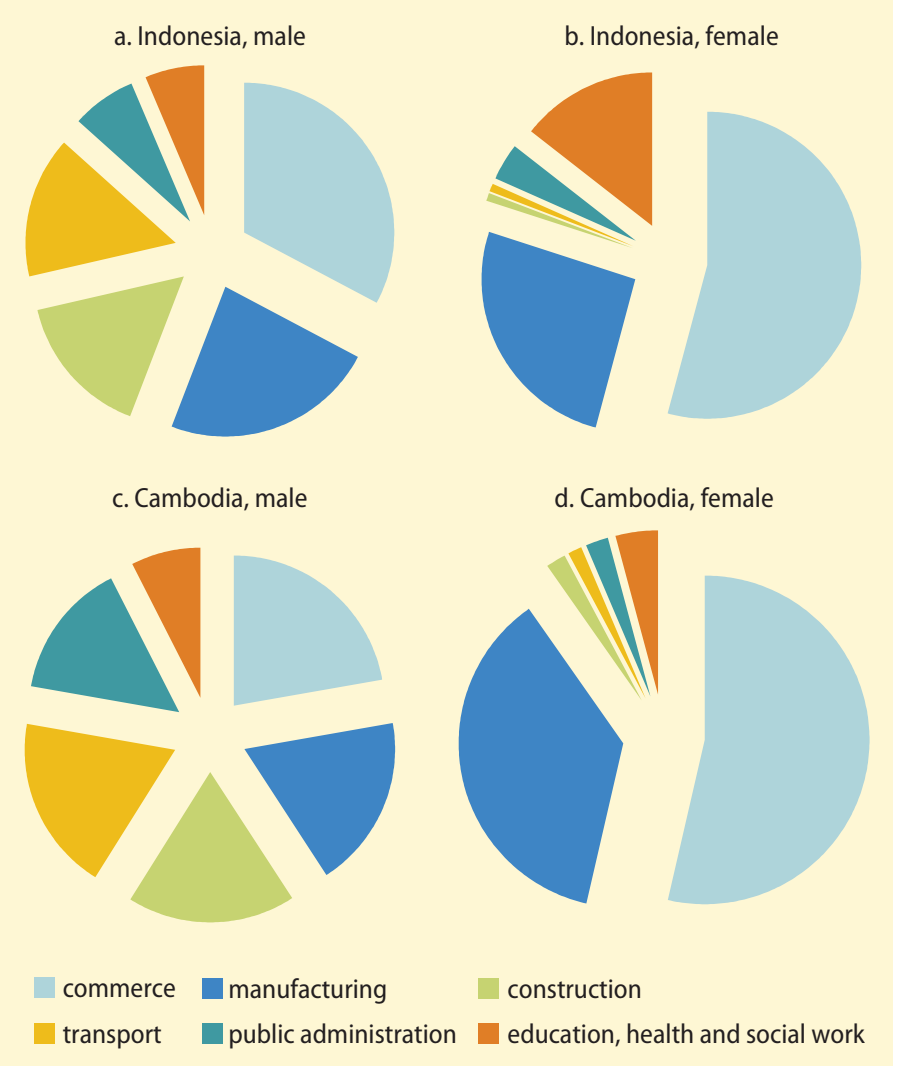

Source: CSES (NIS Cambodia), 2008 data; World Bank estimates using Indonesia SUSENAS (BPS Indonesia), 2009 data. and Ramos 2011; Sakellariou 2011). Among entrepreneurs, differences in industry and size of enterprise have been found to explain a substantial fraction of the raw performance gaps in profits and revenues among male and female firms. ${ }^{11}$

\section{What determines gender inequality in economic opportunities?}

Men and women differ in their economic activities in a number of respects. These differences in activities may represent differences in choices, but they may also represent differences in the constraints that men and women face in their working lives. This section explores the economic, demographic, and cultural factors that determine current gender inequalities in access to economic opportunities in the East Asia and Pacific region.

\section{Determinants of labor market participation}

Female labor force participation is affected by growth processes and development. As development occurs, changes in household income, education, wages, marital, and fertility choices affect participation. The evolution of market opportunities alters the types of jobs present in the economy, as well as the relative demand for skills. The institutional framework of society affects and is affected by the economic participation of women during the process of development; that is, gender norms, expectations, and perceptions within the household and society affect female labor force participation and are also likely to be affected by its evolution.

Female labor force participation and its determinants vary over the life cycle. Early in their careers, women are similar to men in terms of their decisions to join the labor market, but their participation begins to differ as their domestic responsibilities increase. This change is partly due to the increased time that women devote to household activities, such as housework and child rearing, as 
their marital and familial status changes, but it is also a reflection of differences in the roles of and expectations of married and single women. Younger women in the region are investing more in education and hence have delayed their entry into the labor market, in both rural and urban areas. Married women appear to take substantial time out of the workforce for raising children, but the same is not true for men. Furthermore, large labor force participation gaps open up toward the end of women's careers, in part as a result of labor market regulations such as genderdifferentiated retirement policies.

\section{The stage of development of countries and their institutions}

Evidence from across the world suggests that, as countries develop, female labor force participation displays a U-shaped trajectory. ${ }^{12}$ Female labor force participation usually declines as incomes rise and opportunities in the labor market become less attractive to female workers; it then increases again when more attractive employment opportunities emerge (Bloom et al. 2009; Chaudhuri 2009; Goldin 1995; Sinha 1967, cited in Mammen and Paxson 2000; Tam 2011). In poor, agricultural economies, female participation tends to be high because agricultural work and family responsibilities can easily be combined. However, in middle-income countries dominated by the manufacturing and service sectors, female participation declines in part because most new jobs are difficult to combine with family responsibilities. Female participation rates are higher in high-income countries that have large service sectors and a highly educated workforce. This finding holds both across and within countries over time (Fatima and Sultana 2009; Fuwa 2004; Juhn and Ureta 2003; Tansel 2001). ${ }^{13}$

The stylized U-shaped relationship between female labor force participation and economic development holds for countries in the East Asia and Pacific region, as well as globally. Figure 3.13 depicts the relationship between economic development (as captured by income per capita) and female labor force participation across the globe between 1980
FIGURE 3.11 The pattern of female ownership by firm size varies across countries

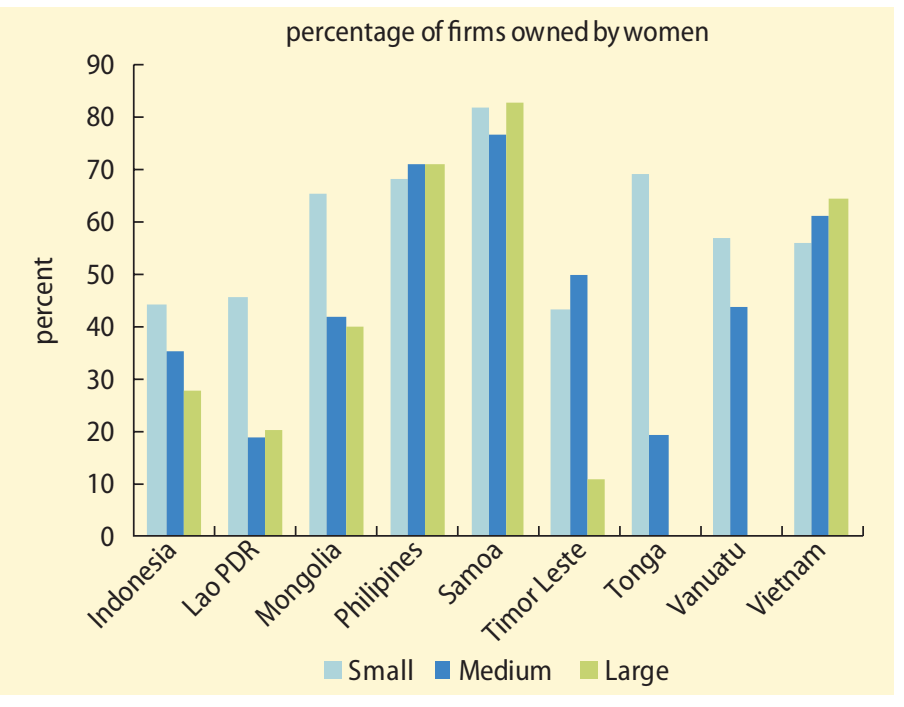

Source: World Bank estimates using Enterprise Surveys (database), 2006-11 data. Note: Survey data are for small (less than 20 employees), medium (20-99 employees), and large (100 and more employees) firms in the formal sector. Female-owned firms are defined as those with females among the owners.

FIGURE 3.12 In Indonesia, female-led enterprises are clustered in lower-productivity and capital-intensive industries

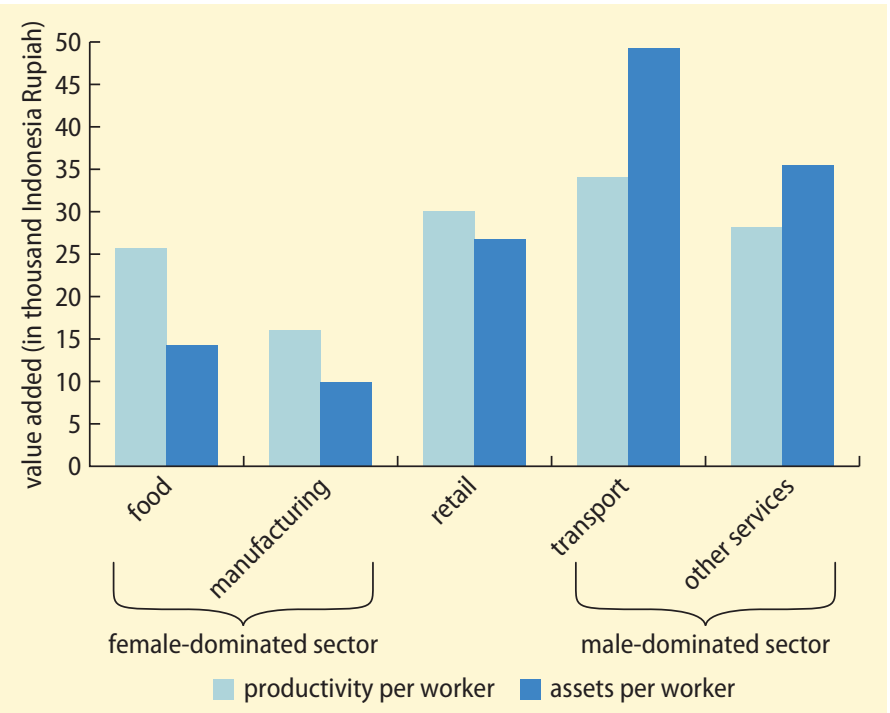

Source: World Bank staff estimates using Indonesia Family Life Survey 2007/2008. Note: The graph shows productivity and assets per worker in five industries for firms with fewer than five workers. Productivity is measured by value added. 
FIGURE 3.13 Female labor force participation is high by global standards but also varies substantially across the region

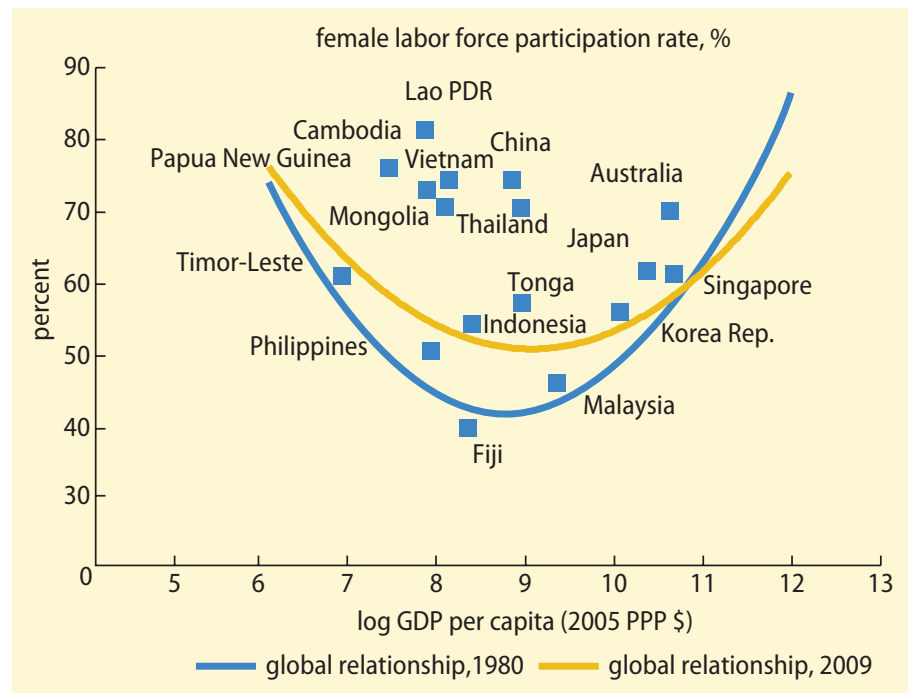

Source: World Bank estimates using labor force data from the ILO KILM database and purchasing power parity (PPP)-adjusted GDP per capita from the Penn World Table.

Note: $\mathrm{GDP}=$ gross domestic product, $\mathrm{PPP}=$ purchasing power parity. The data shown for each country reflect the 2009 data, and the estimated U-shaped relationships use data from across the world.

\section{Gender norms and expectations}

An important question is why labor force participation varies so much between countries with similar per capita income levels, as can be seen in figure 3.13. Gender norms strongly influence labor force participation rates and help to explain the variation in participation across countries that is not explained by the level of economic development. Societal perceptions of women in the workplace and gender norms strongly influence labor force participation decisions (Antecol 2000; Fernández 2010; Fernández and Fogli 2005; Fernández, Fogli, and Olivetti 2004). Countries in which strong socioreligious views exist about women's role in the public sphere, including the workplace, have been found to have lower female labor force participation rates (Psacharopoulos and Tzannatos 1989).

Whether a woman is entitled to make her own choices in the economic sphere, such as entering the workforce or starting a business, varies substantially from country to country. For example, in Vietnam, young single women are increasingly choosing to migrate for employment and to commute long distances (World Bank 2011a). However, in rural Morobe Province in Papua New Guinea, young women are not allowed by their families to migrate out of the village because of the fear of early marriages, which are regarded as taboo (World Bank 2011a).

In countries with large male-female participation gaps throughout the life cycle-such as Indonesia, Malaysia, and the Philippinesfemale labor force participation is considered socially and culturally acceptable as long as it does not interfere with women's primary role as wives and mothers. For example, public gender discourse in Indonesia and Malaysia places particular emphasis on motherhood and child care as a "woman's true vocation" (Blackburn 2001, 2004; Stivens 2006; White 2006). Political and institutional evolution also affects the scope for women's participation in education and in the workplace. Women's labor force participation is substantially higher in socialist and ex-socialist 
countries, such as China, Mongolia, and Vietnam, than in others.

Legislation can codify social norms into discriminatory labor practices. In Korea, marriage bars to private and public employment were common until the 1980s (Hill 1996). In Mongolia, women retire approximately 10 years earlier than men; this practice is, in part, attributable to a lower retirement age for women (World Bank 2011c). In Mongolia, these differences in retirement ages have contributed to the female-male participation gap rising by approximately 20 percentage points between the ages of 50 and 60 .

However, gender roles and relations within households do change over time, particularly in evolving environments. In China, the economic reforms of recent decades have increased the range of opportunities available to both men and women in paid employment, as the structure of the economy has moved away from predominantly agrarian with a capital-intensive heavy industry sector toward labor-intensive light industry and services (Hughes, Maurer-Fazio, and Zhang 2007). However, this transition has been argued to have created new obstacles for women: the state has retreated from its former commitments to gender equality and to strong enforcement of workplace protections for women, thus allowing the reemergence of traditional patriarchal values (Entwisle and Henderson 2000).

\section{Individual and household-level factors: Income, education, marriage and children} Changes in the characteristics of women and households-notably, changes in educational attainment, changes in the demographic profile of the population, and growth in household incomes-do not, for the most part, explain changes in the male-female gap in labor force participation in many countries in the East Asia and Pacific region during the past decade (Sakellariou 2011).

Rising education levels among girls in countries across the region have led to a substantial decline in girls' workforce participation rates. For example, women's participation in rural
Vietnam has declined from almost 89 percent in 1998 (similar to men) to about 81 percent in 2008 (versus 84 percent for men). Most of the decline occurs in rural areas and is accounted for by rising participation in education. Given the corresponding though smaller decline in male participation, the overall male-female participation gap increased from approximately 1.5 percentage points in 1998 to 4.5 percentage points in 2008 (Sakellariou 2011). Similarly, in China, the population census indicates that the labor force participation of 15 - to 22-year-old urban males and females dropped from 70.6 and 72.7 percent, respectively, in 1982 to 43.8 and 46.4 percent, respectively, in 2000, largely because of an increase in educational enrollment (Hughes, Maurer-Fazio, and Zhang 2005). In rural areas, participation of the female population ages 15 to 22 declined from 84.3 percent to 67.3 percent between 1982 and 2000 for the same reason. Where education acquisition varies by gender, a gender gap in participation can be observed.

Although changes in education have not explained a large fraction of changes in participation, variation in education contributes to explaining differences in female labor force participation within a country. In Indonesia, women with higher levels of education are more likely to enter the labor market, particularly in urban areas, which may reflect their higher wage premiums and higher opportunity cost of being inactive (Ogawa and Akter 2007; World Bank 2010a). Literacy in Indonesia is also strongly associated with both participation in the labor market and occupational segregation among women; thus, being illiterate poses a double barrier to labor force outcomes (Gallaway and Bernasek 2004). In Vietnam, women with no educational qualifications are more likely than their male counterparts to be inactive, those with primary or secondary education are slightly less likely than their male counterparts to be working, and those with higher levels of education are more likely than their male counterparts to be working (Pierre 2011).

Declines in fertility have been found to exert a large positive effect on the labor 
force participation rate across the world. The effect is strongest for women ages 20 to 39 , with an additional child being associated with a reduction of approximately four years of paid work over a woman's lifetime (Bloom et al. 2009). In Korea, the reduction in the total fertility rate, from 5.6 children per woman in 1962 to 1.2 in 2002 , has been suggested to have increased per capita income by approximately 36 percent over the period, because of an increase in the size of the workforce and higher female labor force participation as well as a longerterm increase in the capital-to-labor ratio (Bloom et al. 2009).

What will stop us from getting a job is having plenty of children and having nobody to mind them.

\section{Young woman, Indonesia}

(World Bank 2011a)

Child-care costs have a negative impact on female labor force participation, particularly in families without the support of familial networks. ${ }^{14}$ Reductions in child-care provisions in China and Mongolia have had a negative impact on labor force participation. In China, participation of women of childbearing age has declined in urban areas, a trend that is partly attributable to higher child-care costs now that child care is no longer subsidized by the state (Chi and Li 2007; Du and Dong 2010; Li and Song 2011; MaurerFazio et al. 2011). Similar patterns have been observed in Mongolia, where state-funded early child care and education were rolled back in the 1990s (World Bank 2011c; World Bank and ADB 2005).

The labor force participation of older women is also affected by the presence of children, since they are often responsible for caring for younger household members. In Mongolia and rural Vietnam, the evidence suggests that a "grandmother effect" is present. Older women in households with children under the age of 10 have a 15 percentage point larger participation gap than women in households with no children under the age of 10 , a difference that may be attributable to older women staying at home to look after their grandchildren.

\section{Retirement policies}

In nearly all countries in the region, the malefemale participation gap rises after the age of 50 , indicating that women retire earlier than men. These differences can be partly attributed to gender-differentiated retirement policies. In 4 of 12 countries studied in the region (see table 3.1), the statutory age of retirement for women in the private sector is five years earlier than that of men, although only in China is it mandatory to retire at the statutory age. In China, gender differences in mandatory retirement ages influence the prospective value of hiring older men and women, implying that the expected return of hiring an older man is greater than that of hiring an otherwise identical older woman (Giles, Wang, and Cai 2011). Differences in retirement prospects across rural and urban areas also contribute to the explanation of differences in participation across rural and urban areas among older workers. In urban areas, where most long-term residents have had formal wage employment, residents retire at a relatively young age and receive substantial pension support. In contrast, rural residents often lack pension support and hence make their labor supply decisions in the absence of pension availability and the constraint of mandatory retirement (Giles, Wang, and Cai 2011). Since women over 60 in rural areas are less likely to be vested in formal labor markets, they are less likely than other elderly to be covered by the pension system-only 1 percent of rural women over 60 report that pension income is their most significant source of financial support, compared with 8 percent of rural men over 60 (World Bank 2012).

Differences in retirement ages are likely to affect outcomes beyond labor force participation, including educational investment, the number of women in positions of power, and the risk of poverty for elderly women. Because women anticipate having a shorter working life than men, differences in retirement ages affect education and occupation choices. Gender differences in retirement ages also imply that women are less likely to rise to the top of occupational 
ladders, because they have less experience than men toward the end of their careers. Fewer women in Mongolia reach higherlevel managerial positions, despite women having one of the highest levels of education on average in the region. Furthermore, early retirement reduces pension payouts, which depend on the length of tenure. This disadvantage in pension receipt can increase the risk of poverty for low-income households headed by females-women accounted for approximately 70 percent of elderly singleheaded households in Mongolia in 2010 (World Bank 2011c).

\section{Determinants of gender gaps in earnings}

\section{Earnings gaps between male} and female workers

The gender earnings and wage gap may reflect differences between men and women in education and other characteristics, as well as differences in the returns to these characteristics by gender. The literature separates gender gaps into parts that are "explained" by measured factors, such as education, age, experience, and marital status, and those that are "unexplained," often regarded as a measure of discrimination against female workers. Care must be taken in interpreting the remaining component of wages as discrimination, however, since this interpretation assumes that all relevant factors have been considered. ${ }^{15}$

The level and changes in the gender wage gap over time in the East Asia and Pacific region vary by country and across the income distribution, suggesting that the forces that lead to narrowing wage gaps over time are idiosyncratic. A study commissioned for this report found that the evolution of gender wage gaps over time has followed different paths in Cambodia, Indonesia, Mongolia, the Philippines, Thailand, and Vietnam (Sakellariou 2011). In Thailand, gender wage gaps throughout the wage distribution decreased substantially between 1996 and 2006. Changes in experience, education, and return to experience were found to have contributed significantly to this reduction. In
TABLE 3.1 Legal retirement ages in the East Asia and Pacific region

\begin{tabular}{lcc}
\hline \multicolumn{1}{c}{ Retirement age } & Men & Women \\
\hline China & 60 & 55 \\
Hong Kong SAR, China & 65 & 65 \\
Indonesia & 55 & 55 \\
Lao PDR & 60 & 60 \\
Malaysia & 55 & 50 \\
Mongolia & 60 & 55 \\
Papua New Guinea & 55 & 55 \\
Philippines & 65 & 65 \\
Singapore & 67 & 67 \\
Taiwan, China & 65 & 65 \\
Thailand & 55 & 55 \\
Vietnam & 60 & 55 \\
\hline
\end{tabular}

Source: World Bank $2011 f$.

contrast, in the Philippines, the wage gap widened between 2000 and 2009, a change that is partly attributable to growing differences between men and women in terms of their returns to education and other characteristics. Indonesia has the widest earnings gap among the six countries examined, and the study found substantial differences between rural and urban areas, in the size of the wage gap and the factors contributing to it.

Average differences between the characteristics of men and women, such as education, experience, and the sector and occupation of employment, explain up to one-third of the male-female wage differentials across the region and across the world. ${ }^{16}$ Occupational and industrial sorting have been found to contribute more to explaining the gender wage gaps than do differences in human capital across the world, and the same holds true for the East Asia and Pacific region (Nopo, Daza, and Ramos 2011; Sakellariou 2011).

The narrowing of gender wage gaps over time can be partially attributed to the converging of educational attainment of men and women. Between 1985 and 2005, the average characteristics of the female wage and salaried workforce in Thailand improved over time relative to those of males. Nakavachara (2010) finds that the substantial increase in the education of females between 1985 and 2005 was the major source of the narrowing of the gender earnings gap in Thailand 
during this period. Dhanani and Islam (2004) find that, although females earned on average about 30 percent less than men between 1976 and 2000 in Indonesia, overall wage inequality varies with industrial affiliation as well as education and age. The wage gap in Indonesia increases substantially with age, reflecting in part growing differences in education and experience between older men and women.

Since women have higher levels of education on average than men in some countries in the region, estimates suggest that women would have earned more than men had they faced the same returns to their education and other characteristics as men. In the Philippines and Mongolia, women's levels of human capital are higher than those of men on average. In Mongolia, taking into account the different characteristics of men and women, women should have earned 22 percent more than men in 2006 (Pastore 2009). Similarly, in the Philippines, education and other characteristics of women would suggest that, on average, the wages of women should be higher than those of men (Sakellariou 2011).

The bulk of the gender wage gap within the region is due to differences in the labor market value of male and female characteristics. ${ }^{17}$ In the East Asia and Pacific region, the fraction of the gender wage gap explained by differences in characteristics (such as education and experience)-the explained component-is smaller than the fraction of the wage gap attributable to differences in returns-the unexplained component (Sakellariou 2011). Figure 3.14 shows the percentage difference between male and female wages at deciles of the wage distribution in Indonesia in 2009, and the difference in male and female wages that is attributable to differences in characteristics and returns on those characteristics. ${ }^{18}$ Two noteworthy points emerge from figure 3.14. First, the gender wage gap is wider at the bottom than at the top of the wage distribution, pointing toward the phenomenon of "sticky floors." Second, differences in returns to characteristics between men and women are able to account for a greater share of the gender wage gap at all points in the wage distribution-the gender wage gap attributable to returns to characteristics is greater than the gender wage gap attributable to characteristics across the distribution. On average, differences in characteristics explain just over 35 percent of the gross gap in 2009. Differences in labor market experience and returns to labor market experience constituted the major contributor to the characteristics component in both years.

There is substantial variation in the share of gender wage gaps explained by differences in characteristics between men and women. In Vietnam, the fraction of the gap explained by differences in characteristics is only 11 percent in urban areas, whereas in rural areas the characteristics of females would suggest that, on average, the wages of women should be higher than those of men (Sakellariou 2011). In China, the mean gender pay gap increased substantially between 1987 and 2007, from 18 percent in 1995 (Chi and Li 2007) to nearly 30 percent in 2007 (Li and Song 2011). Over this period, the majority of the increase was not attributable to differences in characteristics but rather was due to unexplained differences in the returns to male and female characteristics.

Marriage and childbearing have a larger negative effect on the wages of females than on the wages of males. The trade-off for women between career, earnings growth, and family does not appear to exist for men. For some women, this trade-off is associated with increasingly stark choices. Anecdotal evidence suggests that women in richer parts of East Asia are increasingly less likely to marry and marry later when they do, in part because of the perceived incompatibility of marriage and career (Economist 2011). The negative effect of childbearing on earnings and employment has been found across the world as well as within countries in the East Asia and Pacific region. ${ }^{19}$ In Cebu, in the Philippines, children have a strong negative effect on a woman's likelihood of participating in the labor force and, once in the labor force, on her earnings over time. The negative effect of children on women's earnings represents both a reduction in the number of hours worked and a shift to lower-paying and often less secure 
jobs that are more compatible with childbearing responsibilities (Adair et al. 2002). In China, married women have substantially larger gender wage gaps than their unmarried counterparts, and the wage gap between married men and women grew between 1995 and 2007 while it closed for single men and women (Hughes and Maurer-Fazio 2002; Li and Song 2011). Furthermore, the proportion of the gender wage gap unexplained by differences in the productive characteristics of men and women is greater for married than for single women, although the gap is narrower in the case of more educated married women. These results may be attributable to the greater responsibilities borne by Chinese women for household chores and child care.

Gender wage paths over careers may reflect differences in male and female workplace behavior, as well as differences in the types of characteristics that men and women value in a job. Evidence from the organizational and human resources literature shows females as being less competitive, more risk averse (Croson and Gneezy 2009), less likely to push for pay rises (Babcock and Laschever 2003), and more likely to be content with lower starting salaries. This tendency may be due in part to women having different demands for job characteristics and expectations of labor market outcomes than men. For example, Bender, Donohue, and Heywood (2005) find that flexibility is an important job characteristic that appeals to women and may play a contributing role in gender-based labor market segregation.

In sum, men earn more than women across countries in the East Asia and Pacific region, although the reasons for this vary from country to country. Education differences between men and women are not able to explain the bulk of gender gaps in labor market wages. In some countries, such as Mongolia and the Philippines, education differences in fact imply that women should earn more than men. The most important differences between men and women are those related to occupational choice and family life. Marriage and childbearing are likely to affect men's and women's earnings in different ways, partly
FIGURE 3.14 The fraction of the gender wage gap explained by differences in characteristics is smaller than the fraction of the wage gap attributable to differences in returns in Indonesia, 2009

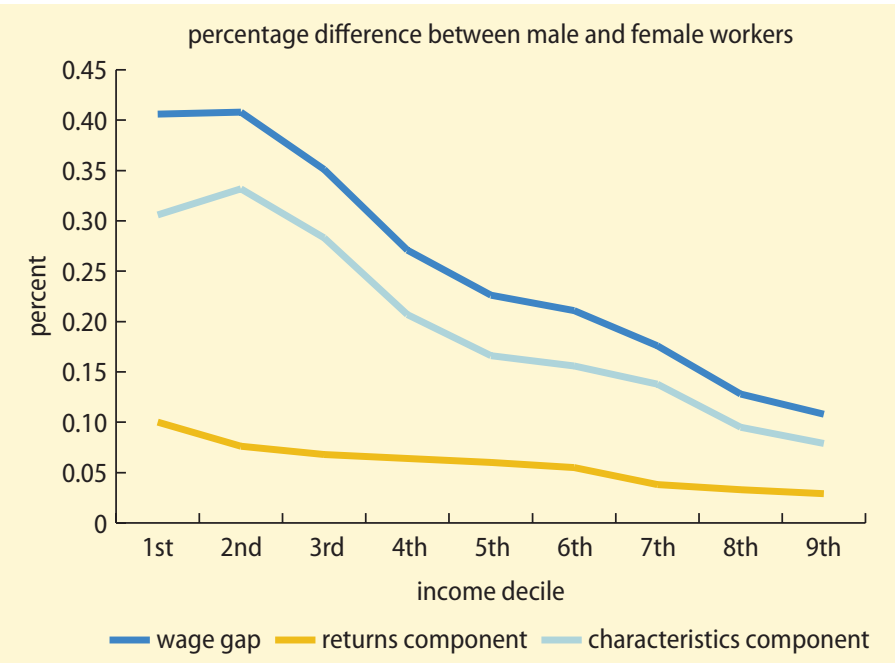

Source: Sakellariou 2011

Note: The graph uses the approach of Firpo, Fortin, and Lemieux (2009), based on Indonesia National Labor Force Survey (BPS Sakernas), 1997 and 2009 data.

reflecting their respective responses to these life-cycle transitions.

\section{Earnings gaps between male and female entrepreneurs}

Female-run firms have fewer employees, lower sales, and lower capital stock than those run by men, as evidence from Europe and Central Asia, Africa, and Latin America and the Caribbean has shown (Amin 2010; Bardasi, Blackden, and Guzman 2007; Bruhn 2009; Costa and Rijkers 2011; Sabarwal and Terell 2008). Various conditions explain why female-run firms produce less per worker than male-run firms and, in particular, why women tend to head smaller firms in less capital-intensive sectors than men. The three predominant explanations examined here are sectoral segregation, skills, and constraints to business development.

Sectoral segregation. Firm size and industrial and occupational sorting along gender lines explain a large part of the differences in returns to capital between firms run by men and those run by women. In a number of studies comparing the productivity of 
male- and female-run enterprises around the world, productivity gaps diminish substantially once the industry or sector of employment is taken into account (Aterido and Hallward-Driemeier 2009; Bruhn 2009; Costa and Rijkers 2011; de Mel, McKenzie, and Woodruff 2009a, 2009b). This finding also holds for the East Asia and Pacific region. In Mongolia, substantial differences in capital and sales exist between maleand female-owned firms. These are largely explained by the sector of employment and firm size (World Bank 2011c). In Lao PDR, differences in the productivity between male- and female-owned firms in the formal sector disappear once differences in sector, capital, size, and other factors that affect productivity are considered (Davies and Record 2010). In Vietnam, a study commissioned for this report found that there were no gender differences in short-term revenue growth or survival probability among in firms in the formal sector between 1997 and 2009 (Bjerge and Rand 2011). ${ }^{20}$ In the informal sector in Indonesia, the sector of operation and the firm's size accounts for almost 90 percent of the observed gender gap in productivity in rural areas (Costa and Rijkers 2011), although they account for substantially less of the gap in urban Indonesia (Badiani and Posadas 2011).

Informality is likely to be a greater determinant of an enterprise's success than the gender of the manager or owner. Evidence from Indonesia and Vietnam suggests that differences in profits between female-headed firms and male-headed firms are substantially smaller than the differences between femaleheaded firms in the formal sector and those in the informal sector (figure 3.15). This mirrors evidence from Africa (Aterido and Hallward-Driemeier 2009).

Evidence on gender constraints in informal enterprises within the East Asia and Pacific region is more limited than evidence from the formal sector, however. More data are urgently needed on the informal sector, as microenterprises constitute a substantial fraction of enterprises and employment in the region. In Indonesia, Vietnam, and the Philippines, microenterprises make up 98.9, 98.2, and 92.3 percent of all micro, small, and medium enterprises (MSMEs), respectively, and they make up 79.3 percent of all enterprises in Malaysia (Kushnir, Mirmulstein, and Ramalho 2010). The East Asia and Pacific region has the highest ratio of MSME employment to total employment of all regions, mainly driven by China, where MSMEs account for 80 percent of total employment.

Skills. Evidence on whether female entrepreneurs have a lower level of managerial skills than male entrepreneurs is limited in the region. However, gender differences in both education and soft skills are likely to affect men's and women's respective decisions to participate in self-employment and in their sector of choice (Brush 1992). Furthermore, differences in entrepreneurial and managerial skills (such as being able to identify market niches and do bookkeeping) between men and women may explain differences in the size of the firms that they establish and earnings gaps (Bruhn, Karlan, and Schoar 2010).

Although evidence from studies of entrepreneurial skills in the region is limited, the evidence from outside the region is mixed with regard to whether a lack of skills is an important constraint for entrepreneurs. A study from Peru suggests that giving business training to female clients of a microcredit program did not lead to higher profits or revenues on average, although the clients did adopt some of the activities taught in the program, including thinking proactively about new markets and profit-making opportunities (Karlan and Valdivia 2011). In Pakistan, business training was found to increase the survival and profitability of male-run firms but had no effect on female-run firms (Giné and Mansuri 2011). However, in India, a two-day training program for female clients of an Indian microfinance institution was found to increase both the amount that they borrowed and the likelihood of the clients' receiving labor income (Field, Jayachandran, and Pande 2010).

Within the region, female entrepreneurs themselves consider that their skill limitations are a barrier to their success. In Vietnam, a 
survey of 500 female owners of enterprises revealed that female entrepreneurs felt the need to improve their skills, particularly in business management and leadership, through training and education (IFC and MPDF 2006). These findings are supported by another survey that indicated that females have lower general training levels than men (VCCI 2006).

Constraints to business development. In the formal sector, the constraints faced by female-run firms do not appear to be uniformly greater than those faced by male-run firms (Davies and Record 2010; IFC 2011; IFC/NORC Indonesia 2010; World Bank 2011b). ${ }^{21}$ In the Philippines, qualitative and quantitative research has found little evidence of gender differentiation in lending or borrowing in small and medium enterprises (IFC 2011). In Indonesia, insufficient finance and financial management were found to be less of a concern for women (IFC/NORC Indonesia 2010).

Data from enterprise surveys carried out in five Pacific and four East and Southeast Asian countries in 2009 show that entrepreneurs, regardless of gender, named competition, finance, and electricity as their top three constraints in five of the nine countries. Male-led and female-led firms reported the same constraints as being the most important in all countries, except Tonga, Vanuatu, and Vietnam. The difference between self-reported access to credit constraints for male- and female-run formal sector firms is small in all countries, with the exception of Timor-Leste and Tonga (figure 3.16).

However, credit constraints are greater in the smallest firms and in the informal sector where female-run firms are concentrated. Constraints to female entrepreneurs may arise in both formal and informal institutional structures, for example, because of difficulties interacting with male officials who adhere to cultural norms of female propriety. In Indonesia, access to capital is the most important constraint reported in both male- and female-run informal firms (figure 3.17), and female-run informal firms appear to have substantially less capital than male-
FIGURE 3.15 Differences in productivity across informal and formal firms in Vietnam are larger than differences across male- and female-led enterprises

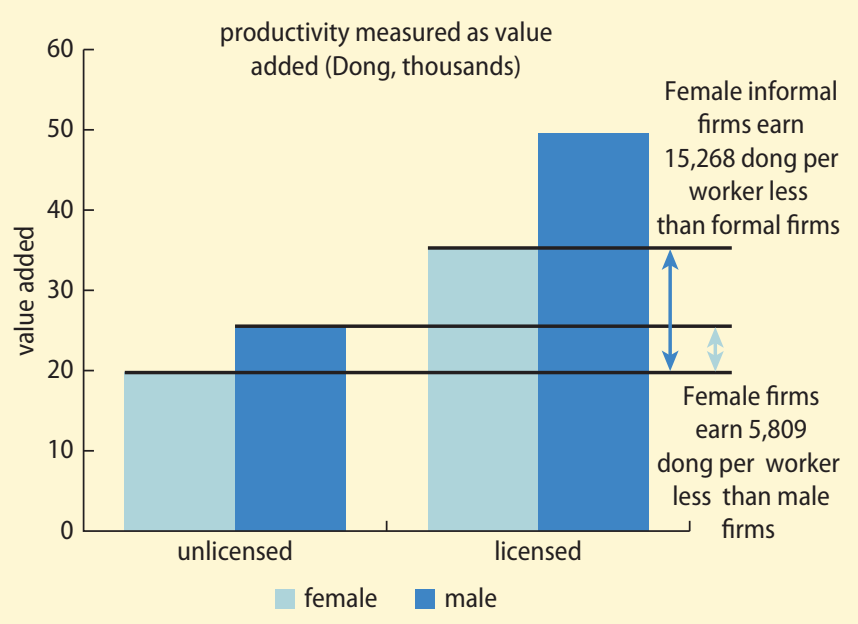

Source: World Bank estimates based on Vietnam Household Living Standards Surveys (VHLSS) (GSO Vietnam), 2009 data.

Note: unlicensed $=$ informal

FIGURE 3.16 Self-reporting shows little difference in access to finance between male- and female-run firms, with the exception of Timor-Leste and Tonga

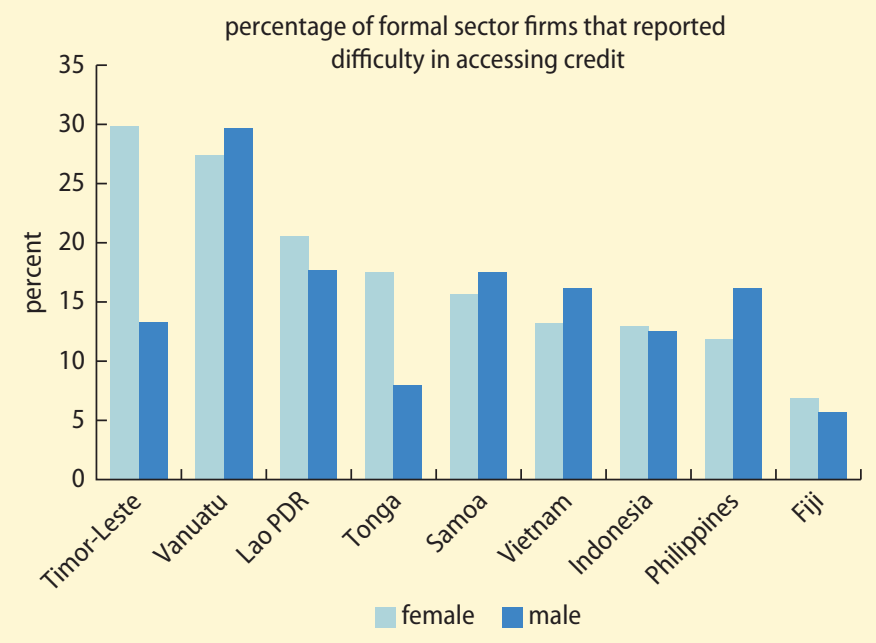

Source: World Bank estimates using Enterprise Surveys (database), 2006-11 data.

Note: Finance is considered to be an obstacle if it is reported as a major or severe constraint.

run informal firms. Female-led microenterprises also have lower levels of start-up capital than male-run microenterprises. ${ }^{22}$

Access to capital may be more limited-and more expensive-for female entrepreneurs 


\section{FIGURE 3.17 Male- and female-led informal firms report similar constraints in Indonesia}

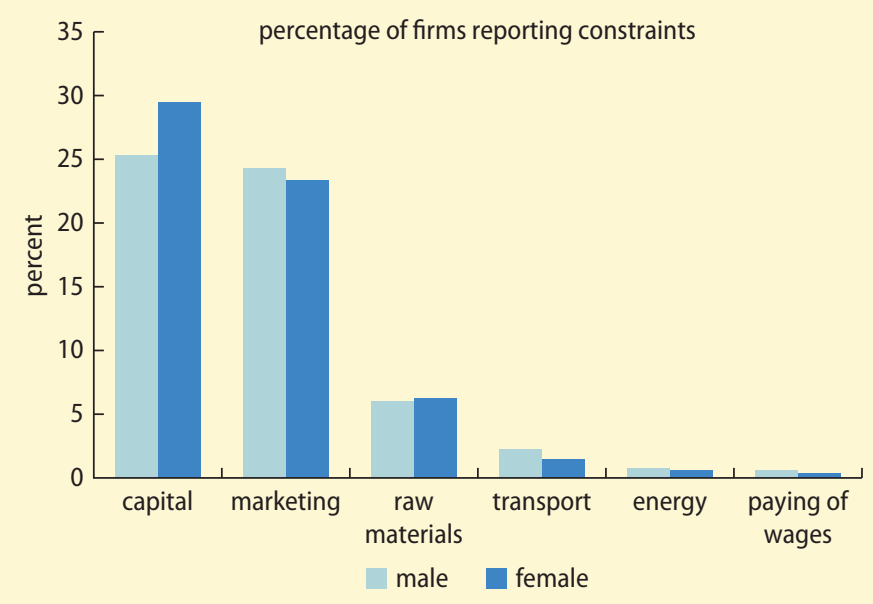

Source: World Bank estimates using SUSI Integrated (Survey of Cottage and Small-Scale Firms) 2002.

because they lack collateral (World Bank 2011g). According to calculations from the World Bank Enterprise Surveys database of 2006-11, in all countries in the region for which data were available, land and buildings were the predominant forms of collateral used to acquire a loan for production purposes. This practice puts female entrepreneurs at a disadvantage since they have fewer of these assets as well as less secure access to land or other immobile assets. However, the most important determinant of access to credit is the size of the firm (Beck et al. 2006). Credit institutions tend to regard small firms as a bigger risk than large firms, and, since women tend to manage smaller firms, this is likely to lead to female-run businesses being more constrained in the credit market than businesses that are run by men (Simavi, Manuel, and Blackden 2010).

\section{Earnings gaps between male and female farmers}

The agricultural sector continues to be the major sector of employment in many countries in the region. In Vanuatu, 80 percent of the population rely upon small-scale agriculture (IFC 2010), and in Cambodia and
Lao PDR over 70 percent of the workforce is employed in agriculture.

As the countries across the world have developed, women have been playing a greater role in agricultural activities as men move to the cities in search of nonfarm work (Deere and Leon 2003; Ganguly 2003; Mu and van de Walle 2009). This "feminization" of agriculture can be seen in multiple countries in the region. In China, the number of households in which women participated in agricultural activities and performed all the farm work rose from 14 percent in 1991 to just under 30 percent in 2009, whereas the fraction of households in which men did all the work remained fairly stable (de Brauw et al. 2011; Rawski and Mead 1998). In Cambodia, women make up the majority of farmers- 1.4 million female farmers compared to 1.2 million male farmers (UNIFEM, World Bank, ADB, UNDP, and DFID/UK 2004). In Vietnam, agriculture accounted for 64 percent of working women in rural areas in 2008 compared to 53 percent of working men (World Bank 2011e).

Despite the important role played in agriculture by women in the region, little evidence is available regarding gender differences in productivity, access to inputs, or agricultural services. Remedying this information gap is likely to become increasingly important if the feminization of agriculture continues within the region.

The evidence from other regions suggests that female farmers earn less than male farmers. ${ }^{23}$ For example, evidence from Africa suggests that, within a household, yields on male-run plots are higher than those on female-run plots, predominantly because of increased male access to fertilizer and labor inputs (Goldstein and Udry 2008; Udry 1996). In comparison, the available evidence from China suggests that female farmers are just as productive and efficient as male farmers, despite differences in mechanization and fertilizer use (de Brauw et al. 2011). Although female farmers are able to produce similar amounts per hectare to men, they do not produce as much overall owing to differences in 
land and nonland inputs between male and female farmers.

Agricultural production varies in part between male and female farmers because of differences in access to land. Female farmers across the world own and operate less land, and often have lower-quality land than male farmers (Deere and Doss 2006; Quisumbing 1998; Quisumbing, Estudillo, and Otsuka 2004). ${ }^{24}$ Evidence from the East Asia and Pacific region suggests that there are substantial differences in access to land between male and female farmers, as discussed in chapter 2. In China, female-headed households own 30 percent less land per capita than male-headed households (de Brauw et al. 2011). In Lao PDR, male-headed agricultural households own approximately 16 percent more land than female-headed households on average, although in the north of the country men have access to 28 percent more land (FAO/Sida Partnership Cooperation 2010). A World Bank study of women's landholdings in post-tsunami Aceh found that women's landholdings were considerably less than men's (World Bank 2010b).

Female farmers have also been found to have less access to technological inputs such as fertilizers and high quality seeds (Peterman, Behrman, and Quisumbing 2010). An important theme in the literature on the use of productivity-enhancing technology is that access to inputs, not the propensity to use inputs or productivity once the inputs have been used, is the key factor for many female farmers. In a review of 24 studies of technological input use, access, and adoption of fertilizer, seed varieties, tools, and pesticides in Africa and South Asia, Peterman, Behrman, and Quisumbing (2010) found that men have greater access to technological resources in the majority of cases. To know whether the same constraints are pertinent in the region requires further evidence on this topic.

Gender differences in access to extension services are also likely to contribute to differences in the adoption of new technologies and farming practices and to perpetuate existing gender inequalities in access to inputs. In Cambodia, access to agricultural extension services was found to be substantially lower for female farmers than for male farmers in the early 2000s, despite the fact that there were more female farmers than male farmers (UNIFEM, World Bank, ADB, UNDP, and DFID/UK 2004). ${ }^{25}$ Reasons for the lower access to extension services among female farmers include the extension services' focus on activities normally conducted by men, the focus on literate farmers, and the need to travel several kilometers to access services (UNIFEM, World Bank, ADB, UNDP, and DFID/UK 2004). Efforts to reduce these constraints in the Cambodian context are discussed in chapter 6 .

Finally, gender-based differences in social and political capital have been found in a number of rural areas, reducing women's access to information on farming techniques and their ability to protect and regulate local resources and their marketing channels. In the Philippines, men and women do not differ in their level of participation in local groups, but they do differ in the types of groups that they join. Men are more likely than women to be members of production-based groups, whereas women are more likely to be members of civic groups, which include women's groups, village youth associations, school committees, and village officials (Godquin and Quisumbing 2008). In Indonesia, men have been found to participate in civil society organizations related to community-level governance, physical infrastructure, environmental improvements, and neighborhood security, whereas women participate in organizations that focus on family welfare, economics, and health (Beard 2005).

\section{Determinants of labor market segregation}

The determinants of persistent gender employment segregation across countries and over time lie at all levels of the economy and society, from gender norms within households and communities to economic signals in the marketplace and ideological predilections at a societal level. Factors that influence labor 
market segregation along gender lines include (a) differences between men and women in the level and composition of their education and experience, (b) differences in their preferences for types of work and job characteristics, (c) their comparative advantages due to their differences in physical endowments, (d) employers' perceptions about male and female employees (sometimes to the extent of discrimination), and (e) labor market institutions that limit or restrict occupational choices. These factors are, in themselves, determined by the economic signals, institutions, and norms facing individuals, households, and communities.

This section examines the effects of three key factors: (a) gender differences in education levels and labor market skills; (b) gender differences in time-use patterns and gender roles within households, both of which affect the characteristics and types of work women are able to do; and (c) labor market and institutional barriers to women's choices.

\section{Education and skills}

Education levels and the type of education acquired (for example, vocational versus general education) affect the skills that individuals bring into the labor market and hence are likely to contribute to their sectoral and occupational choices. ${ }^{26}$ As discussed in chapter 2, male and female education has been converging over the past two decades in the East Asia and Pacific region, and in some countries, such as Mongolia and the Philippines, education acquisition by women has overtaken that of men. At the tertiary level of education (universities, technical training schools, and so forth), a student's field of specialization was likely to be closely related to his or her subsequent sectoral choices. Any gender differences in education choices are therefore likely to be mirrored in sectoral dissimilarities among men and women. If women tend to choose different fields than men, sectoral and occupational segregation is likely to increase as the number of men and women continuing to higher and tertiary education rises.

In the lower- and middle-income countries in the East Asia and Pacific region, only a small fraction of men and women continue to higher education. Therefore, the nexus of education choice and occupational segregation is not currently a primary driving force for labor market segregation in the region. However, it is likely to play a larger role among younger cohorts and future generations as education continues to expand. For example, in Taiwan, China, gender wage gaps declined substantially between 1979 and 1995, a period during which there was a rapid increase in average educational attainment and a shift from academic general-curriculum education toward vocational training. Among university graduates, differences in degree type between men and women are able to explain between 20 percent and 50 percent of the gender wage gap, although the link between occupation and degree type is lower among women than men (Baraka 1999).

\section{Time use and gender roles within housebolds}

Differences in the ways men and women spend their time are informative in illuminating why they may invest differently in human capital, how gender differences in labor market participation may arise, and what their occupational and industry choices will be. Time is a valuable resource that is endowed equally across men and women-everyone has just 24 hours in a day. Time can be devoted to a number of uses: labor market work; unpaid work within the household, such as conducting domestic chores and caring for children and the elderly; and personal activities, including sleeping, eating, and leisure (Becker 1965, 1981).

Women across the world work more than men. This stylized fact holds true in multiple low- and middle-income countries across the world (Berniell and Sanchez-Páramo 2011; World Bank 2011g), as well as in several OECD countries (Burda, Hamermesh, and Weil 2007; Slootmaekers-Miranda 2011). Gender differences in time-use patterns exists at all ages. Whereas men are able to focus predominantly on their single productive role and conduct their other roles sequentially, women 
are more likely to play these roles simultaneously and have to balance competing uses of their time (Blackden and Wodon 2006).

However, time differences in hours worked by men and women diminish when growth in gross domestic product (GDP) is combined with gender-neutral social norms. A study of 25 countries across the world finds that men and women did the same amount of total work in rich northern countries (Burda, Hamermesh, and Weil 2007). The gender difference in total working time is close to zero for countries with relatively high female employment and with more gender-neutral social norms.

In the East Asia and Pacific region, women work more hours and devote more time to caregiving and housework than men, and men specialize in market-oriented activities. Since women's share of unpaid work is higher than that of men, this translates into shorter time in paid work.

Women indeed work harder. We go to the field and return home at the same time as our husband. Afterwards, we still have to cook, do laundry and do other household chores. The men after they return home from the field do not want to work anymore.

Adult woman in rural Batu Palano, Indonesia (World Bank 2011a)

A number of stylized facts emerge from time-use patterns by gender in the region. First, women work more hours than men; this holds true at all ages. In Lao PDR, women work on average 2 hours extra per day than men, and in Cambodia, they work on average 1.2 hours more per day.

Second, gender differences in time-use patterns are starker during the childbearing years. In Cambodia, men and women spend similar amounts of time in market work until they are 20 years old, but after that point, women devote less time to market work than men and more time to domestic activities (CSES [NIS Cambodia], 2004 data). The greatest difference between male and female hours worked is during childbearing years. In households with young children, women work on average 2 hours extra per day in
FIGURE 3.18 In Cambodia, women-particularly those with young children-balance household work commitment with market work

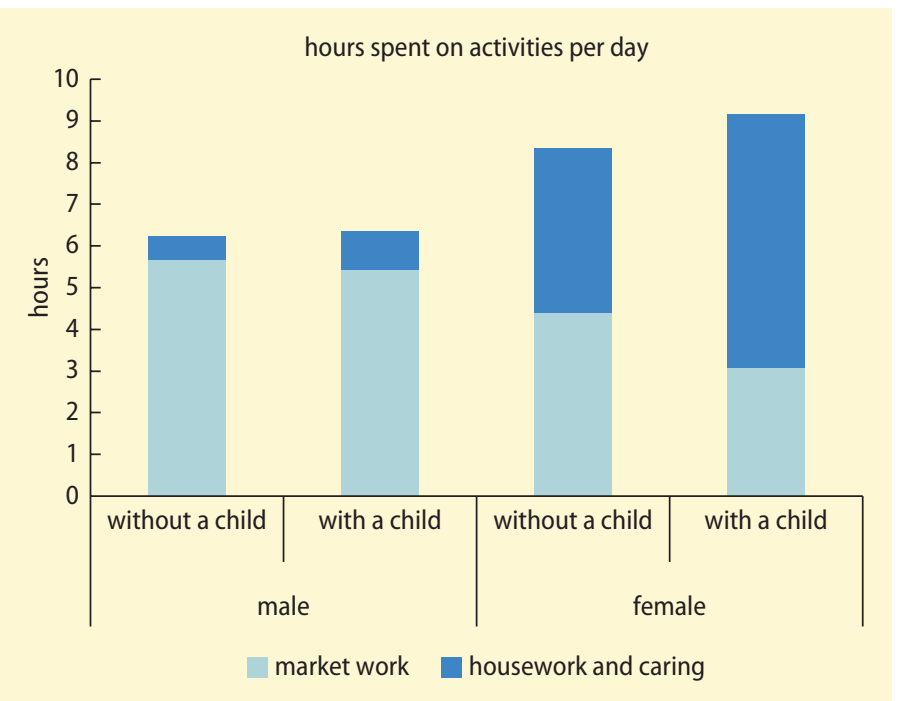

Source: World Bank estimates using CSES (NIS Cambodia), 2004 data.

Cambodia and 1 hour extra per day in Lao PDR (figure 1.20 and 3.18).

Third, gender differences in the time devoted to household activities are smaller in high-income households, although this represents a reduction in female working time rather than an increase in male working time. In Timor-Leste, rural women in the highest income quintile spend more time on domestic activities than men (figure 3.19). The difference between men and women narrows with rising income. The narrowing of time-use differences, however, arises from a reduction in the time devoted by women to these activities, thus reflecting increased access to technologies and household help rather than an increase in male participation.

Finally, gender differences in the time devoted to household activities start at an early age. In the Philippines, Pörtner (2009) studied time use of children between the ages of 7 and 16 and found that, although participation rates and time spent in school by boys and girls were similar, time spent on work and household chores is closely related to the gender of the child. Boys participate in market-related activities more than twice 
FIGURE 3.19 Women in Timor-Leste spend more time on domestic activities than men, and these differences are found among richer as well as poorer households

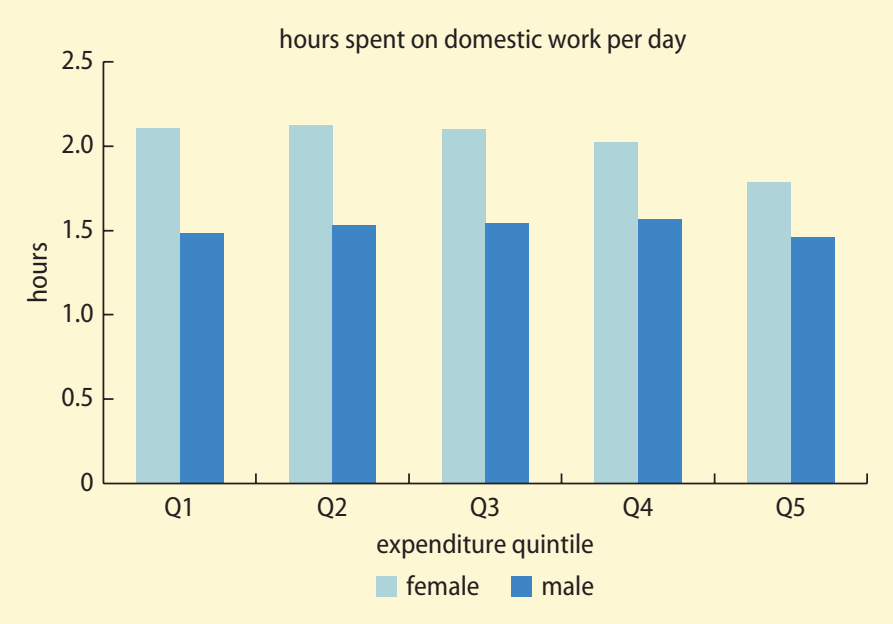

Source: World Bank estimates using Timor-Leste Survey of Living Standards (NSD [Timor-Leste] 2007 data). to be found in the formal sector, whereas married women with children are found in the informal sector, particularly in selfemployment. The evidence suggests that the movement of married women with children into self-employment is a choice rather than an effect of discrimination (Bosch and Maloney 2011).

Differences in the time-use patterns of men and women also reflect society's norms regarding gender roles and "appropriate work." These social norms and customs affect the ability of both men and women to participate in the economic, social, or political domain. In China, despite strong governmental support for gender equality on multiple levels in the workplace, cultural norms have still emphasized the role of women as xianqi liangmu (a good wife and a good mother) and as the bearer of responsibility for household work (Chen 2005; Honig 2000). These norms persist even as development progresses and women's share of income in household economies rises. In Beijing, even when the wife's income represents a larger share of the couple's combined income, women still do the majority of the household work (Zuo and Bian 2001). Both men and women justified this in terms of their gender roles in the household. ${ }^{27}$ Similar patterns are found in Nanjing (Kim et al. 2010).

Social norms may be reinforced at the level of the nation-state, if the role of women as homemakers and mothers and of men as breadwinners is underlined in political discourse. In Malaysia, the Nation of Character project focused on 25 key values important for the development of good character in children. This project very clearly put forward that women's most important tasks were related to the home and to strengthening of the family. The division of labor between men and women in the public and private sphere is further emphasized from an early age in parts of the region (White 2006). In Cambodia, a book of moral codes-the Chba'p srey-emphasizes the "proper" behavior and conduct of women, and limits their opportunities outside the household (Dasgupta and Williams 2010). 


\section{Labor regulations and informal institutions}

Labor laws and regulations can directly affect the demand for female workers and constrain these workers in their choice of occupation. In many countries, restrictions on women's working hours or industries were introduced as measures to protect the health of women (particularly those who are pregnant or lactating) or women in potentially hazardous jobs. However, with improvements in labor market conditions in dangerous industries and with the passing of employment legislation designed to protect the health and safety of workers, many of these restrictions may no longer be relevant and could be changed. Measures that limit women to work only daytime hours or restrict their work to a subset of industries limit their employment options and also drive employers to hire only men for jobs that women might otherwise do.

A study on labor laws commissioned for this report found that protective legislation prohibits women from working in industries and occupations in 9 of the 12 low- and middle-income countries examined in the region (China, Fiji, Kiribati, Korea, Malaysia, Papua New Guinea, the Philippines, Thailand, and Vietnam) (World Bank 2010f). In Thailand, women are prohibited from working in certain occupations, including mining; working on a scaffold more than 10 meters high; and producing or transporting explosives or flammable materials. In Vietnam, the Labor Code prohibits assigning female workers to "heavy or dangerous work, or work requiring contact with toxic substances, which has adverse effects on her ability to bear and raise a child." The code also provides that women, regardless of age, cannot be employed in mines or in deep water. No similar provisions are applicable to men. In Mongolia, until 2008, extensive labor market regulations limited female participation in multiple sectors of the economy, including mining, transport, and construction (World Bank 2011c). Pregnant women are even more limited in their choices: in 6 out of 10 countries in the region, they have more restrictions on industry choices than other men and women (World Bank 2010f).

These protective restrictions may increase the cost of employing women. For example, in Kiribati, Papua New Guinea, and the Philippines, women are not allowed to work the same night hours as men. In the Philippines, the law states that women are unable to work between 10 at night and 6 in the morning of the following day. The restrictions on women's work have been criticized as particularly restrictive by the call center industry, which employs a large proportion of women who are required to work at night (Keitel 2009). Paid maternity leave also increases the cost to employers of hiring female workers rather than male workers, particularly in countries where paternity leave policies are not in place. In contexts where employers bear the burden of this cost, this is particularly likely to raise the cost of hiring female workers.

Discriminatory laws in the area of family and marriage also affect women's economic opportunities. Laws relating to family, marriage, and inheritance play a key role in influencing women's economic rights, including access to land, housing, and other forms of property (Ellis, Kirkwood, and Malhotra 2010). The law of succession in Tonga's constitution, for example, allows only males to inherit. In Indonesia, the civil code prevents women from entering into contracts on their own behalf, whether to sell or buy property, which enables men to influence women's access to collateral. Access to land is dependent on a woman's married status, and her control and ownership can be lost upon divorce, widowhood, migration, or desertion by her husband (IFC 2010).

Women also have less access to information on opportunities and job networks. Personal connections are recognized as facilitating job search, but women's domestic responsibilities make it difficult for them to forge useful social connections (Timberlake 2005). In Nanjing city, China, a case study suggests that women secured less-attractive jobs through their own networks than through those of their husbands. Women 
who have fewer social contacts also were more vulnerable to redundancy and experienced more hardship in finding a new job after having been displaced from their old job (Hiroko, Liu, and Tamashita 2011).

Finally, occupational segregation may be related to persistent stereotypes about what are appropriate occupations for men and women. Stereotypes of women as homemakers and men as breadwinners can translate into perceptions about their skills in the labor market and, therefore, the type of market work they do (Anker 1998). For example, positive stereotypes of womenhaving a caring nature, manual dexterity, skill at conducting household work, and greater honesty-could lead to the hypothesis that women would be better qualified to work as nurses, teachers, clerks, and sales assistants, among other occupations (Anker 1998). In qualitative work undertaken in Fiji, Indonesia, Papua New Guinea, and Vietnam, gendered beliefs about appropriate employment for men and women were remarkably consistent across these countries and among genders (World Bank 2011a). See box 3.2 for more detail.

\section{Policies to promote gender equality in economic opportunity}

The analysis in this chapter has identified several indicators of gender inequalities in the productive sphere where challenges remain and where policy may be able to reduce persistent gender-based differences in economic opportunities and outcomes. A detailed discussion of policy examples and their impacts will follow in chapter 6 .

\section{Mitigating trade-offs between women's household and market roles}

Promoting gender equality in economic opportunity requires policies and investments that address the trade-offs between women's household and market roles. Women often face stark time trade-offs between household chores and market work, particularly in

\section{BOX 3.2 Gender-related beliefs on appropriate employment in Fiji, Papua New Guinea, Indonesia, and Vietnam}

Gender-related beliefs about appropriate employment for men and women were remarkably consistent across East Asian and Pacific countries where qualitative fieldwork was undertaken (Fiji, Papua New Guinea, and Vietnam), and among both men and women, although some change in gender norms was observed among younger cohorts. Comments largely revolved around the concept of "heavy" (physically demanding) versus "light" work, with the former ascribed to men and the latter to women. In Vietnam, an adult man from Hanoi said that "In general, men are better with heavy jobs like taxi driver. Women are better with lighter jobs like sewing, and selling things. ... Men are better with big business because it is hard work-men are more decisive than women. Job[s] like killing pigs, in principle women can do, but it would be strange to see a woman with a knife in her hand." Differing skill levels could be conflated with conceptions of heavy and light work, for example, when one young male respondent said that men do heavy work such as that of an auto mechanic, while women do light work, "such as accounting." A focus group discussion with adult women in the urban National Capital District of Papua New Guinea revealed further gender stereotypes and fears held by these women about what they considered to be gender-specific employment. They said that secretaries should be women (so that they are not "aggressive to their bosses"), and trading stores should be run by men as they have the "ideas, mindset and business knowledge" and would not be "targeted by criminals."

Source: World Bank 2011a. 
rural areas. In such contexts, programs and policies targeted at reducing women's time on chores-for example, through investment in infrastructure-are likely to increase their ability to engage in market-based, incomeearning opportunities. Policies that support women in balancing their caregiving and market roles are also critical to strengthening their access to economic opportunity. Access to affordable and accessible child care can be critical in this regard. Community child-care centers, particularly those targeted at lowincome neighborhoods, have been found to increase maternal employment in a number of Latin American countries.

Parental and paternity leave can promote greater parity between the sexes by facilitating a more equitable division of child-rearing responsibilities, thus allowing women to have the same opportunities as men for advancing their careers in the formal sector. Within the region, only Cambodia, Indonesia, and the Philippines currently have provisions for paternity leave. Evidence from the OECD on the take-up of paternity leave is mixed, however, suggesting that providing paternity leave alone is not sufficient to change the current gender division of child-rearing responsibilities within households. Rather, it needs to be combined with approaches to breaking down gender norms regarding household caregiving roles.

\section{Breaking down gender silos in the labor market}

A critical element of breaking down gender silos in the labor market involves investing in skills on the basis of productivity rather than on gender norms and perceptions of "appropriate" occupations. Beyond efforts to reduce gender streaming in education, discussed above, programs that encourage both women and men to think outside of gender stereotypes in the job market will likely improve the allocation of talent toward jobs in a way that enhances both equality of economic opportunity and productivity.

Breaking down social norms and perceptions is an area where the public sector can also lead by example. Even if women enter more "male" occupations, stereotypes are likely to persist with respect to women as leaders and managers. The public sector is in a unique position to establish good practice in this regard by encouraging women's professional advancement, either through direct measures such as targets or quotas, or through specialized training programs. In this context, the government of Malaysia put in place a system of quotas for female managers in the public sector; the approach has recently been extended to private sector firms to encourage women to assume leadership roles. In Mexico, the government initiated a system of grants to firms to improve genderbased employment issues in their workplace and also to improve the gender distribution in management.

\section{Eliminating resource constraints on female-led farms and enterprises}

Despite progress, the existing evidence suggests that women continue to have less access to a range of productive resources than do men, as a function of their gender as opposed to their innate productive capabilities. Public policies may thus have an important role to play in promoting gender equality in the control of productive inputs-whether land, agricultural extension, technology, or financial capital. Policies aimed at promoting equal access to assets, particularly land, requires careful thought, since complex legal, social, and economic factors are at play and the evidence base is thin. Levelling the legal playing field is usually a good start, but it is even more important to work with the informal institutions and take into account norms and customary practices in order to remove barriers in that domain.

Improving women's access to productive assets can play an important role in raising enterprise productivity, whether in the farm or nonfarm sector, as in the following examples:

- Several countries in the region have made headway in recent years in increasing 
ownership and control of land. In response to concerns about persistent gender inequalities in land, several countries-including Indonesia, Lao PDR, and Vietnamrecently adopted gender-sensitive reforms in land titling. Because the reasons for women's lower access to land differ across the region-from unfavorable legal frameworks to cultural norms and practices that deem land a male asset-effective policies to increase female landholdings need to account for context-specific constraints in developing context-specific solutions.

- Increasing women's access to information and training, extension services, and other productive inputs can also play a key role in enhancing the productivity of femaleled enterprises, both within and outside agriculture.

- Although evidence on access to finance in East Asian and Pacific countries is mixed, women do face particular challenges in accessing credit, given their weaker access to land, which is an important source of collateral.

Where evidence is thin, greater resources should be invested in uncovering the greatest constraints. For example, investments could target the collection of information, by gender, on access to inputs in the agricultural sector in the region, as well as to inputs and productivity in the informal sector.

As in the case of education and health, broader systemic weaknesses-whether in the form of cumbersome registration procedures, weak systems of financial intermediation, or lack of electricity-affect both female- and male-led enterprises. Evidence suggests that such constraints may be more onerous among small and informal firms than among larger firms and, as such, may constrain female-led enterprises disproportionately. Thus, interventions that focus on improving the overall investment climate and, in particular, promoting small business development will be a critical part of a strategy to promote gender equality in access to economic opportunity. In sum, strategies to promote gender equality in economic opportunity should address systemic as well as gender-specific constraints.

\section{Creating an enabling environment for gender equality in employment}

Creating an enabling environment is a key component of efforts to promote gender equality in economic opportunity in the long term in East Asia and the Pacific. An important starting point for promoting equal opportunity in employment is to ensure that women and men face a level legal playing field with respect to jobs and sectors. Labor regulations that result in asymmetries in the costs of hiring male and female workers can be found in countries across the region. Ostensibly protective legislation-in the form of restrictions on women working at night, working overtime, and working in so-called dangerous sectors-in practice inhibits women's economic participation. Priority should be given to reducing labor market restrictions that limit women's employment options. Where the original concerns motivating these policies continue to be valid-for example, health and safety concerns-measures should be taken to ensure that these concerns are addressed more directly and for both men and women, whether through workplace safety codes or through the provision of safe and reliable transport infrastructure.

Although formal sector employment is still small as a share of total employment in most East Asian and Pacific countries, an important role for public policy is to strengthen the enabling environment for gender equality in economic opportunity. Active labor market policies are one means of overcoming gender differences in access for formal employment. For example, wage subsidies may allow individuals, albeit temporarily, to signal their abilities to future employers and make it cheaper for employers to hire female workers whom they may not otherwise have considered. This approach provides the opportunity to reduce stereotypes through directly observing their skills, and also gives women valuable labor market experience. Skills training programs may enable women and men to move into professions outside of gender silos, particularly when paired with apprenticeship opportunities. Although evidence on the impact of active labor market 
policies in East Asia and the Pacific is limited, studies from Latin America and the Middle East suggest that well-designed active labor market policies can help to improve women's employment outcomes.

Affirmative action policies have also been used to overcome gender-specific barriers to employment, whether those barriers are due to implicit or overt discrimination in hiring and promotion. Although the literature continues to debate the benefits and costs of affirmative action, the evidence (largely from high-income countries) suggests that carefully designed policies can help break down barriers to female employment with few or no adverse effects on firm productivity (World Bank 2011g). Affirmative action hiring and promotion in the public sector can also have important demonstration effects. For example, in 2004, the government of Malaysia introduced a public sector gender quota of 30 percent female representation across all decision-making levels, including positions from department head to secretary general (ASEAN 2008).

\section{Notes}

1. Using cross-country data for selected Asian economies, Meng (1996) found no significant relationship between economic development and the relative earnings of men and women. In fact, gender inequality in earnings within the East Asia and Pacific region was worse in high-income countries such as Japan and the Republic of Korea than in the low- and middle-income countries.

2. Unfortunately, data constraints prevent looking at birth age-cohort patterns within the majority of countries in the region.

3. Gender wage gaps do not capture earnings differences among all men and women of working age. First, they miss a large fraction of the workforce, notably those in unpaid work or self-employed workers. Second, since there may be differential selection between males and females into the labor force-and into wage employment rather than entrepreneurship and agriculture-gender wage gaps are also likely to reflect these selection decisions.

4. Aggregate relative wage data should, however, be treated with caution since it confounds differences in human capital and experience, occupational and sectoral selection, underlying ability, selection into the labor market, and discrimination.

5. Household surveys in Thailand and Vietnam corroborate this. In urban areas, women are approximately 10 percentage points less likely to receive benefits than men in Vietnam, whereas they are 3 percentage points less likely to do so in Thailand. In the postreform period in China, a growing number of women and urban workers have been pushed into temporary, part-time, insecure, or low-paying work in the informal sector (Yuan and Cook 2010).

6. Notably, an individual is defined as working in the informal sector if he or she works in agriculture or is self-employed, is working in the household enterprise, or is working as an unpaid family worker. However, an individual is classified as working in the formal sector if he or she works as a legislator or manager, professional, technician or associate professional, or plant machine operator or assembler, or is in the armed forces.

7. Elementary occupations consist of simple and routine tasks that mainly require the use of hand-held tools and often some physical effort. For a more detailed explanation, please refer to the International Standard Classification of Occupations (ISCO) by the International Labour Organization.

8. Care should be taken when interpreting the data from Samoa, Timor-Leste, Tonga, and Vanuatu because of very small sample sizes.

9. Evidence from across the world suggests that firms with greater female representation in management display lower levels of gender inequalities, including wage gaps and inequalities within firms (Cohen and Huffman 2007; Graves and Powell 1995; Huffman, Cohen, and Pearlman 2010).

10. Occupational and industrial segregation by gender is detrimental for labor market efficiency and welfare for four principal reasons (Anker 1998). First, men and women are not working in occupations or industrial sectors to which they are best suited and most productive but are rather choosing their work based on other factors. This trend reduces overall incomes and aggregate productivity. Second, gender-based segregation increases labor market rigidity and reduces the ability of labor markets to respond to economic reforms and labor market shocks, such as those 
related to globalization. Third, segregation reinforces and perpetuates negative gender stereotypes, consequently reducing women's status, income, education, and skills. Finally, segregation of the current generation has negative effects on future generations.

11. In Indonesia, controlling for sector of operation and firm size accounts for 17 percent of differences in profits in rural areas, and 50 percent in urban areas (Badiani and Posades 2011), and industry accounts for 9 to 14 percent of earnings among self-employed individuals in the United States (Hundley 2001).

12. Several hypotheses suggest why female labor force participation first falls before rising with economic development. Boserup (1970) suggests that men's greater access to education and technologies implies that they displace women from the labor force during the early stages of a country's development. As development continues and women gain more access to education and technologies, female labor force participation increases. Another well-established hypothesis for this phenomenon focuses on income and substitution effects (Goldin 1995; Mammen and Paxson 2000). As development occurs, households' unearned incomes rise, reducing the incentive of women to work outside the home. The negative impact of rising incomes on women's labor force participation is termed the "income effect," since greater household income implies that households are able to afford more female leisure time. The substitution effect works in the opposite direction-as female wages rise, more women are enticed to enter the workforce (Goldin 1995; Mammen and Paxson 2000).

13. In the East Asia and Pacific region, evidence of declining female labor force participation as incomes rise has been found in Thailand (Mammen and Paxson 2000).

14. In the OECD, a number of studies find that childcare costs negatively impact rates of female labor force participation and that the provision of subsidized child care raises participation (Anderson and Levine 1999; Blau and Currie 2006; Chevalier and Viitanen 2002; Del Boca 2002; Gelbach 2002; Gustafsson and Stafford 1992).

15. For example, even if differences in average human capital have been considered, the residual is likely to still contain differences between the composition and quality of education of males and females that may help to explain gender earnings gaps, as well as other unobserved characteristics that may vary between males and females, such as the intensity of work conducted, workplace characteristics, and unobserved measures of ability. Furthermore, if the occupation choice or tenure trajectories within a firm reflect the impact of discrimination, then measuring discrimination as the unexplained component of wage gaps will underestimate its true extent.

16. In the OECD, Blau and Kahn (2003) find that 38 percent of the total gender wage gap is unexplained by differences in occupational and sectoral choice, education, and experience. In addition, women have less labor market experience-in OECD countries as well as developing countries (Goldin, Katz, and Kuziemko 2006) —in part because they are more likely both to take time out from the work force and to work part-time.

17. The evidence suggests a similar pattern in the United States. Bertrand, Goldin, and Katz (2010) find that female master of business administration (MBA) graduates earn less, even if they choose similar professional paths as men. Bayard et al. (2003) find that a large portion of the gender wage gap in the United States can be explained by pay differences between males and females within narrowly defined occupations and within establishments.

18. The gender wage gap is decomposed at different points in the earnings distribution using the decomposition method based on unconditional quantile regression as outlined in Firpo, Fortin, and Lemieux (2009). In this method, the estimates from the unconditional quantile regression constitute average partial effects of a small location shift of an independent variable on the unconditional quantile of the dependent variable.

19. Evidence from across the world suggests that marriage and childbearing have a large impact on the gender wage gap. In the United States, marital status and young children account for approximately half the gender wage gap faced by young women. A large component of the gender gap in earnings is attributable to women having more career interruptions and shorter work hours, including more work in part-time positions and self-employment (Becker 1981; Bertrand, Goldin, and Katz 2010; Korenman and Neumark 1992; Mincer and Polachek 1974; Sasser 2005; Wood, Corcoran, and Courant 1993). These estimates may, however, underestimate the effect of parenting and 
gender divisions of household labor on wage gaps, since the demands placed on women at home can influence education, career, and work choices (O’Neill 2003).

20. Indeed, household survey data in Vietnam, which also cover microenterprises, suggest that female-run household enterprises were more likely to survive compared to malerun enterprises between 1993 and 1998 (Vijverberg and Haughton 2004). The higher rates of female-run firms' survival are linked to women's predominance in certain sectors.

21. Evidence from the enterprise surveys conducted in 2009 in Lao PDR suggests that female-run firms consistently report business environment constraints to be less severe than male-run firms (Davies and Record 2010). Similarly, in rural Indonesia, there are no differences in the severity of reported business constraints between female- and male-run household enterprises (Costa and Rijkers 2011).

22. In Indonesia, start-up capital is 3.4 times smaller in female-managed nano- and microenterprises than in male-managed enterprises (Badiani and Posades 2011).

23. Data on female-managed or female-owned plots and on female farmers are extremely limited in the world and, in particular, in the East Asia and Pacific region. Therefore, wherever necessary, this report examines differences between farms run by female-headed households and those run by male-headed households. Because female-headed households are different from male-headed households in a number of respects, this comparison is likely to exaggerate gender differences in agricultural productivity and access to inputs because it will confound differences in socioeconomic characteristics with differences in productivity.

24. In Latin America, women constitute between 13 and 27 percent of landowners in Mexico, Nicaragua, Paraguay, and Peru and own smaller plots of land than men in all of these countries (Deere and Doss 2006).

25. It should be noted that the fraction of farmers overall receiving agricultural extension services is very low.

26. Gender differences in "soft skills," which are acquired within and outside of school, also contribute to gender differences in occupations. Personality traits have wage returns that are both occupation and gender specific (Cobb-Clark and Tan 2011). Women have been found to be employed in safer or lowerrisk jobs, which is consistent with evidence that women are more risk averse than men (Eckel and Grossman 2008).

27. Women tended to consider men's "over engagement" in household chores as "unmanly" and "non ambitious." Women often explained the fact that they carried out most domestic work (while having a full-time job) as fulfilling their obligation to care for their families. In addition, the view was expressed that women with extreme career ambitions-who did not assume much household responsibilities—-would be criticized as "selfish" or "non feminine." Interestingly, wives with higher income and "occupational prestige" than their husbands often retained the primary responsibility for taking care of domestic work. This was seen as a "counter balance" to their violation of cultural values about who should be the primary breadwinner.

\section{References}

Adair, Linda, David Guilkey, Eilene Bisgrove, and Socorro Gultiano. 2002. "Effect of Childbearing on Filipino Women's Work Hours and Earnings." Journal of Population Economics 15 (4): 625-45.

Albrecht, James, Anders Björklund, and Susan Vroman. 2003. "Is There a Glass Ceiling in Sweden?" Journal of Labor Economics 21 (1): 145-77.

Amin, Mohammad. 2010. "Gender and Firm-Size: Evidence from Africa." Economics Bulletin 30 (1): 663-68.

Anderson, Patricia M., and Phillip B. Levine. 1999. "Child Care and Mothers' Employment Decisions.” NBER Working Paper 7058, National Bureau of Economic Research, Cambridge, MA.

Anker, Richard. 1998. Gender and Jobs: Sex Segregation of Occupations in the World. Geneva: International Labour Organization.

Antecol, Heather. 2000. "An Examination of Cross-Country Differences in the Gender Gap in Labor Force Participation Rates." Labour Economics 7: 409-26.

Arulampalam, Wiji, Alison L. Booth, and Mark L. Bryan. 2007. "Is There a Glass Ceiling over Europe? Exploring the Gender Pay Gap across the Wage Distribution." Industrial and Labor Relations Review 60 (2): 163-86.

ASEAN (Association of Southeast Asian Nations). 2008. "ASEAN Continues to Empower Women." ASEAN Bulletin. http://www.aseansec.org/Bulletin-Feb-08 .htm\#Article-2. 
Aterido, Reyes, and Mary Hallward-Driemeier. 2009. "Whose Business Is It Anyway?" Policy Research Working Paper 5571, World Bank, Washington, DC.

Babcock, Linda, and Sara Laschever. 2003. Women Don't Ask: Negotiation and the Gender Divide. Princeton, NJ: Princeton University Press.

Badiani, Reena, and Josefina Posadas. 2011. "Gender and Entrepreneurship in Household Firms in Indonesia: Characteristics and Performance." Paper commissioned for Toward Gender Equality in East Asia and the Pacific: A Companion to the World Development Report. Washington, DC: World Bank.

Baraka, Jessica. 1999. "Does Type of Degree Explain Taiwan's Gender Gap?” Research Program in Development Studies, Princeton University, Princeton, NJ.

Bardasi Elena, Mark Blackden, and Juan Carlos Guzman. 2007. "Gender, Entrepreneurship, and Competitiveness in Africa." Africa Competitiveness Report 2007. Geneva, Switzerland: World Economic Forum.

Bayard, Kimberly, Judith Hellerstein, David Neumark, and Kenneth Troske. 2003. "New Evidence on Sex Segregation and Sex Differences in Wages from Matched EmployeeEmployer Data." Journal of Labor Economics. 21 (4): 887-922.

Beard, Victoria. A. 2005 . "Individual Determinants of Participation in Community Development in Indonesia." Environment and Planning C: Government and Policy 23 (1): 21-39.

Beck, Thorsten., Aslı Demirgüç-Kunt, Luc Laeven, and Vojislav Maksimovic. 2006. "The Determinants of Financing Obstacles.” Journal of International Money and Finance 25 (6): 932-52.

Becker, Gary S. 1965. "A Theory of the Allocation of Time." Economic Journal 75 (299): 493-517.

-1981. A Treatise on the Family. Cambridge, MA: Harvard University Press.

Bender, Keith, Susan Donohue, and John Heywood. 2005. "Job Satisfaction and Gender Segregation." Oxford Economic Papers 57 (3): 479-96.

Berniell, M. I., and Carolina Sanchez-Páramo. 2011. "Closing the Access Gap: Recent Advances in Female Labor Force Participation." Background paper for the World Development Report 2012, World Bank, Washington, DC.
Bertrand, Marianne, Claudia Goldin, and Lawrence F. Katz. 2010. "Dynamics of the Gender Gap for Young Professionals in the Financial and Corporate Sectors." American Economic Journal: Applied Economics 2 (3): 228-55.

Bjerge, Benedikte, and J. Rand. 2011. "Gender Differences in the Vietnamese Business Sector: Evidence from the SME Survey." Paper commissioned for Toward Gender Equality in East Asia and the Pacific: A Companion to the World Development Report. Washington, DC: World Bank.

Blackburn, Susan. 2001. "Gender Relations in Indonesia: What Women Want.” In Indonesia Today, Challenges of History, edited by Grayson Lloyd and Shannon Smith, 270-82. Pasir Panjang, Singapore: Institute of Southeast Asian Studies.

- 2004. Women and the State in Modern Indonesia. Cambridge, U.K.: Cambridge University Press, Cambridge.

Blackden, C. Mark, and Quentin Wodon, eds. 2006. Gender, Time Use, and Poverty in Sub-Saharan Africa. Washington, DC: World Bank.

Blau, David, and Janet Currie. 2006. "Preschool, Day Care, and Afterschool Care: Who's Minding the Kids?" In Handbook of the Economics of Education, Volume 2, edited by Eric A. Hanushek and Finis Welch. Amsterdam: North-Holland.

Blau, Francine, and Lawrence M. Kahn. 2003. "Understanding International Differences in the Gender Pay Gap." Journal of Labor Economics 21 (1): 106-44.

Bloom, David, David Canning, Günther Fink, and Jocelyn Finley. 2009. "Fertility, Female Labor Force Participation and the Demographic Dividend." Journal of Economic Growth 14: 79-101.

Bosch, Mariano, and William Maloney. 2011. "Sectoral Choice and Family Formation: Evidence from Labor Market Transitions in Ghana, Mexico, Serbia, and Thailand." Background paper for the World Development Report 2012 and commissioned for Toward Gender Equality in East Asia and the Pacific: A Companion to the World Development Report. Washington, DC: World Bank.

Boserup, Ester. 1970. Woman's Role in Economic Development. London: Earthscan.

BPS (Badan Pusat Statistik). Indonesia National Labor Force Survey (SAKERNAS). Jakarta, Indonesia. 
.BPS (Badan Pusat Statistik). Indonesia National Socioeconomic Survey (SUSENAS). Jakarta, Indonesia. http://dds.bps.go.id/.

Bruhn, Miriam 2009. "Female-Owned Firms in Latin America. Characteristics, Performance, and Obstacles to Growth." Policy Research Working Paper 5122, World Bank, Washington, DC.

Bruhn, Miriam, Dean Karlan, and Antoinette Schoar. 2010. "What Capital Is Missing in Developing Countries?" American Economic Review: Papers \& Proceedings 100 (2): 629-33.

Brush, Candida G. 1992. "Research on Women: Past Trends, a New Perspective and Future Directions." Entrepreneurship Theory and Practice 16 (4): 5-30.

Burda, Michael, Daniel S. Hamermesh, and Philippe Weil. 2007. "Total Work, Gender and Social Norms." NBER Discussion Paper 2705, National Bureau of Economic Research, Cambridge, MA.

CEIC Data. New York. http://www.ceicdata. $\mathrm{com} /$.

Chaudhuri, Sanjukta. 2009. "Economic Development and Women's Empowerment." Working paper, University of Wisconsin-Eau Claire.

Chen, Feinian. 2005. "Employment Transitions and the Household Division of Labor in China." Social Forces 84 (2): 831-51.

Chevalier, Arnaud, and Tarja Viitanen. 2002. "The Causality between Female Labour Force Participation and the Supply of Childcare." Applied Economics Letters 9: 915-18.

Chi, Wei, and Bo Li. 2007. "Glass Ceiling or Sticky Floor? Examining the Gender Pay Gap across the Wage Distribution in Urban China, 1987-2004.” MPRA Paper 3544, University Library of Munich, Germany.

Cobb-Clark, Deborah A., and Michelle Tan. 2011. "Noncognitive Skills, Occupational Attainment, and Relative Wages." Labour Economics 18 (1): 1-13.

Cohen, Philip, and Matt Huffman. 2007. "Working for the Woman? Female Managers and the Gender Wage Gap." American Sociological Review 72 (5): 681-704.

Costa, Rita, and Bob Rijkers. 2011. "Gender and Rural Non-Farm Entrepreneurship." Background paper for the World Development Report 2012, World Bank, Washington, DC.

Croson, Rachel, and Uri Gneezy. 2009. "Gender Differences in Preferences." Journal of Economic Literature 47(2): 448-74.
Cuberes, D., and Marc Teignier-Baqué. 2011. "Does Gender Inequality Hinder Growth? The Evidence and Its Policy Implications." Background paper for the World Development Report 2012, World Bank, Washington, DC.

CWDI (Corporate Women Directors International). 2010. "CWDI/IFC 2010 Report: Accelerating Board Diversity." CWDI and International Finance Corporation, Washington, DC.

Dasgupta, Sukti, and David Williams. 2010. "Women Facing the Economic Crisis-The Garment Sector in Cambodia." In Poverty and Sustainable Development in Asia: Impact and Responses to the Global Economic Crisis, edited by A. Bauer and M. Thant. Manila: Asian Development Bank.

Davies, Simon, and Richard Record. 2010. "Background Paper for the Second Lao PDR Investment Climate Assessment: Gender and Entrepreneurship in the Lao PDR. Evidence from the 2009 Enterprise Survey.” World Bank., Washington, DC.

de Brauw, Alan, Jikun Huang, Linxiu Zhang, and Scott Rozelle. 2011. "The Feminization of Agriculture with Chinese Characteristics." Background paper for the World Development Report 2012, World Bank, Washington, DC.

Deere, Carmen Diana, and Cheryl Doss. 2006. "The Gender Asset Gap: What Do We Know and Why Does It Matter?" Feminist Economics 12 (1-2): 1-50.

Deere, Carmen Diana, and Magdalena Leon. 2003. "The Gender Asset Gap: Land in Latin America." World Development 31 (6): 925-47.

de la Rica, Sara, Juan J. Dolado, and Vanesa Llorens. 2005. "Ceiling and Floors: Gender Wage Gaps by Education in Spain." IZA Discussion Paper 1483, Institute for the Study of Labor (IZA), Bonn, Germany.

Del Boca, Daniela. 2002. "The Effect of Child Care and Part Time Opportunities on Participation and Fertility Decisions in Italy." Journal of Population Economics 15 (3): 549-73.

de Mel, Suresh, David McKenzie, and Chris Woodruff. 2009a. "Are Women More Credit Constrained? Experimental Evidence on Gender and Microenterprise Returns." American Economic Journal: Applied Economics 1 (3): $1-32$.

- 2009b. "Measuring Microenterprise Profits: Must We Ask How the Sausage Is Made?"Journal of Development Economics 88 (1): 19-31. 
Dhanani, Shafiq, and Iyanatul Islam. 2004. Indonesian Wage Structure and Trends, 1976-2000. Geneva: International Labour Organization.

Du, Fenglian, and Xiao-Yuan Dong. 2010. "Women's Labor Force Participation and Childcare Choices in Urban China During the Economic Transition." World Paper 201004, University of Winnipeg, Department of Economics, Manitoba.

Eckel, Catherine C., and Philip J. Grossman. 2008. "Men, Women and Risk Aversion: Experimental Evidence." In Handbook of Experimental Economic Results, edited by C. Plott and V. Smith. Amsterdam: Elsevier.

Economist. 2011. "Asian Demography: The Flight from Marriage.” August 20.

Ellis, Amanda, Daniel Kirkwood, and Dhruv Malhotra. 2010. Economic Opportunities for Women in the East Asia and Pacific Region. Directions in Development Series. Washington, DC: World Bank.

Elson, Diane, and Ruth Pearson. 1981. "The Subordination of Women and the Internationalisation of Factory Production." In Of Marriage and the Market: Women's Subordination in International Perspective, edited by Kate Young, Carol Wolkowitz, and Roslyn McCullagh. London: CSE Books.

Enterprise Surveys (database). World Bank, Washington, DC. http://data.worldbank.org/ data-catalog/enterprise-surveys

Entwisle, Barbara, and Gail E. Henderson, eds. 2000. Re-Drawing Boundaries: Work, Household, and Gender in China. Berkeley: University of California Press.

Esteve-Volart, Berta. 2004. "Gender Discrimination and Growth: Theory and Evidence from India." Development Economics Discussion Paper Series 42, Suntory and Toyota International Centres for Economics and Related Disciplines, London School of Economics and Political Science, London.

Fang, Hanming, and Michael P. Keane. 2004. "Assessing the Impact of Welfare Reform on Single Mothers." Brookings Papers on Economic Activity 35 (1): 1-116.

FAO (Food and Agricultural Organization)/Sida Partnership Coooperation. 2010. National Gender Profile of Agricultural Households, 2010: Report based on the Lao Expenditure and Consumption Surveys, National Agricultural Census and the National Population Census. Vientiane, Lao PDR: FAO.
Fatima, Ambreen, and Humera Sultana. 2009. "Tracing Out the U-Shape Relationship between Female Labor Force Participation Rate and Economic Development for Pakistan." International Journal of Social Economics 36 (1/2): 182-98.

Fernández, Raquel. 2010. "Does Culture Matter?” NBER Working Paper 16277, National Bureau of Economic Research, Cambridge, MA.

Fernández, Raquel, and Alessandra Fogli. 2005. Fertility: The Role of Culture and Family Experience. NBER Working Paper 11569, National Bureau of Economic Research, Cambridge, MA.

Fernández, Raquel, Alessandra Fogli, and Claudia Olivetti. 2004. "Mothers and Sons: Preference Formation and Female Labor Force Dynamics." Quarterly Journal of Economics 119 (4): 1249-99.

Field, Erica, Seema Jayachandran, and Rohini Pande. 2010. "Do Traditional Institutions Constrain Female Entrepreneurship? A Field Experiment on Business Training in India." American Economic Review Papers and Proceedings 100 (2): 125-29.

Firpo, S., N. M. Fortin, and T. Lemieux. 2009. "Unconditional Quantile Regressions." Econometrica 77 (3): 953-73.

Fuwa, Makiko. 2004. "Macro Level Gender Inequality and the Division of Household Labor in 22 Countries." American Sociological Review 69 (6): 751-67.

Gallaway, Julie H., and Alexandra Bernasek. 2004. "Literacy and Women's Empowerment in Indonesia: Implications for Policy." Journal of Economic Issues 38 (2): 519-25.

Galor, Oded, and David N. Weil. 1996. "The Gender Gap, Fertility, and Growth." American Economic Review 86: 374-87.

Ganguly, Anuradha, and Talwar Swapan. 2003. "Feminization of India's Agricultural Workforce." Labour Education (2-3): 29-33.

Gelbach, Jonah B. 2002. "Public Schooling for Young Children and Maternal Labor Supply." American Economic Review 92 (1): 307-22.

Gender Statistics (database). World DataBank, World Bank, Washington, DC. http://data .worldbank.org/data-catalog/gender-statistics.

Giles, John, and Firman Witoelar Kartaadipoetra. 2011. "Education, Segregation and Labor Markets in Indonesia.” Background paper for the World Development Report 2012, World Bank, Washington, DC. 
Giles, John, Dewen Wang, and Wei Cai. 2011. "The Labor Supply and Retirement Behavior of China's Older Workers and Elderly in Comparative Perspective." Policy Research Working Paper 5853, World Bank, Washington, DC.

Giné, Xavier, and Ghazala Mansuri. 2011. "Money or Ideas? A Field Experiment on Constraints to Entrepreneurship in Rural Pakistan.” Photocopy, Development Economics Research Group, World Bank, Washington, DC.

Godquin, Marie, and Agnes Quisumbing. 2008. "Separate but Equal? The Gendered Nature of Social Capital in Rural Philippine Communities." Journal of International Development 20 (1): 13-33.

Goldin, Claudia. 1995. "The U-Shaped Female Labor Force Function in Economic Development and Economic History." In Investment in Women's Human Capital, edited by T. Paul Schultz. Chicago: University of Chicago Press.

Goldin, Claudia, Lawrence F. Katz, and Ilyana Kuziemko. 2006. "The Homecoming of American College Women: The Reversal of the Gender Gap in College." Journal of Economic Perspectives 20 (Fall): 133-56.

Goldstein, Markus, and Christopher Udry. 2008. "The Profits of Power: Land Rights and Agricultural Investment in Ghana." Journal of Political Economy 116 (6): 981-1022.

Graves, Laura, and Gary Powell. 1995. "The Effect of Sex Similarity on Recruiters' Evaluations of Actual Applicants: A Test of the Similarity-Attraction Paradigm.” Personnel Psychology 48 (1): 85-98.

Greenwood, Jeremy, Ananth Seshadri, and Mehmet Yorukoglu. 2005. "Engines of Liberation." Review of Economic Studies 72 (1): 109-33.

GSO (General Statistics Office) [Vietnam]. Vietnam Household Living Standards Surveys. Hanoi, Vietnam. http://www.gso.gov.vn.

—. Vietnam Labor Force Survey. Hanoi, Vietnam. http://www.gso.gov.vn.

Gustafsson, Siv, and Frank Stafford. 1992. "Child Care Subsidies and Labor Supply in Sweden." Journal of Human Resources 27 (1): 204-30.

Hallward-Driemeier, Mary. 2006. "Improving the Legal Investment Climate for Women in Sub- Saharan Africa." Paper prepared for the NEPAD-OECD Conference, Brazzaville, December 12, 2006.
Hausmann, Ricardo, Laura D. Tyson, and Saadia Zahidi, eds. 2010. The Global Gender Gap Report 2010. Geneva: World Economic Forum.

Hertz, Thomas, Anna P. de la O Campos, Esteban J. Quiñones, Benjamin Davis, Carlo Azzari, and Alberto Zezza. 2009. "Wage Inequality in International Perspective: Effects of Location, Sector, and Gender." Paper presented at the FAO-IFAD-ILO Workshop on "Gaps, Trends and Current Research in Gender Dimensions of Agricultural and Rural Employment: Differentiated Pathways out of Poverty," Rome, March 31-April 2, 2009.

Hill, Anne M. 1996. "Women in the Japanese Economy." In Women and Industrialization in Asia, edited by Susan Horton. London: Routledge.

Hiroko, Takeda, Jieyu Liu, and Junko Tamashita. 2011. "Economic Restructuring and Changing Work/Family Life: The Cases of Japan and China." In New Welfare States in East Asia: Global Challenges and Restructuring, edited by Gyu-Jin Hwang. Cheltenham, U.K.: Edward Elgar.

Honig, Emily. 2000. "Iron Girls Revisited: Gender and the Politics of Work in the Cultural Revolution.” In Re-Drawing the Boundaries of Work, Households, and Gender, edited by Barbara Gutwisle and Gail Henderson. Berkeley: University of California Press.

Horton, Susan. 1996. "Women and Industrialization in Asia: Overview." In Women and Industrialization in Asia, edited by in Susan Horton. London: Routledge.

Huffman, Matt L., Philip Cohen, and Jessica Pearlman. 2010. "Engendering Change: Organizational Dynamics and Workplace Gender Segregation, 1975-2005.” Administrative Science Quarterly 55 (2): 255-77.

Hughes, James, and Margaret Maurer-Fazio. 2002. "The Effects of Market Liberalization on the Relative Earnings of Chinese Women." Journal of Comparative Economics 30 (4): 709-31.

Hughes, James, Margaret Maurer-Fazio, and Dandan Zhang. 2005. "Economic Reform and Changing Patterns of Labor Force Participation in Urban and Rural China." William Davidson Institute Working Paper 787, University of Michigan, Ann Arbor.

- 2007. "An Ocean Formed from One Hundred Rivers: The Effects of Ethnicity, 
Gender, Marriage, and Location on Labor Force Participation in Urban China." Feminist Economics 13 (3-4): 125-53.

Hundley, Greg. 2001. "Why Women Earn Less than Men in Self-Employment." Journal of Labor Research 22 (4): 817-29.

IFC (International Finance Corporation). 2010. "Economic Opportunities for Women in the Pacific." International Financial Corporation, Washington, DC.

- 2011. Women's Entrepreneurship in the Phillippines, Vol. 1, Washington, DC: IFC.

IFC (International Finance Corporation) and MPDF (Mekong Private Sector Development Facility). 2006. "Women Business Owners in Vietnam: A National Survey.” IFC Gender Entrepreneurship Markets Initiative and MPDF, Washington, DC.

IFC (International Finance Corporation)/ NORC Indonesia. 2010. "Indonesia Small and Medium Enterprise Banking Survey." International Financial Corporation, Washington DC; NORC, Chicago. http:// www.norc.org/Research/Projects/Pages/ ifc-indonesia-small-and-medium-enterprisebanking-survey.aspx.

ILO (International Labour Organization). 2010.

"Women in Labor Markets: Measuring Progress and Identifying Challenges." ILO, Geneva.

ILO Key Indicators of the Labour Market (KILM) database. International Labour Office. Korea Labor Force Survey and Population Census. http://kilm.ilo.org/kilmnet/.

Indonesia Family Life Survey. 2007/2008. RAND Family Life Surveys, IFLS-4. http://www.rand .org/labor/FLS/IFLS/ifls4.html.

Juhn, Chinhui, and Simon Potter. 2006. "Changes in Labor Force Participation in the United States." Journal of Economic Perspectives 20 (3): 27-46.

Juhn, Chinhui, and Manuelita Ureta. 2003. "Employment of Married Women and Economic Development: Evidence from Latin American Countries." Society of Labor Economists Meeting, Toronto.

Karlan, Dean, and Martin Valdivia. 2011. "Teaching Entrepreneurship: Impact of Business Training on Microfinance Clients and Institutions." Review of Economics and Statistics 93 (2): 510-27.

Keitel, Robert S. 2009. "Innovation in Borderless Distance Learning of English." Paper presented at the 13th UNESCO-APEID International
Conference World Bank-KERIS High-Level Seminar on ICT in Education.

Kim, Elim. 2005. "Korean Women's Activities for Legislation to Guarantee Gender Equality in Employment. A Symposium: Legal Feminism in Korea." Journal of Korean Law 5 (2): 49-65.

Kim, Sung won, Vanessa Fong, Hirokazu Yoshikawa, Niobe Way, Xinyin Chen, Huihua Deng, and Zuhong Lu. 2010. "Income, Work Preferences and Gender Roles among Parents of Infants in Urban China: A Mixed Method Study from Nanjing." China Quarterly 204: 939-59.

Klapper, Leora F., and Simon C. Parker. 2010. "Gender and the Business Environment for New Firm Creation." World Bank Research Observer 26 (2): 237-57.

Klasen, Stephan, and Francesca Lamanna. 2009. "The Impact of Gender Inequality in Education and Employment on Economic Growth: New Evidence for a Panel of Countries." Feminist Economics 15 (3): 91-132.

Korenman, Sanders, and David Neumark. 1992. "Marriage, Motherhood, and Wages." Journal of Human Resources 27 (2): 233-55.

Kushnir, Khrystyna, Melina Laura Mirmulstein, and Rita Ramalho. 2010. "Micro, Small and Medium Enterprises Around the World: How Many Are There, and What Affects the Count?" MSME Country Indicators, World Bank/IFC, Washington, DC.

LABORSTA Internet (database). International Labour Organization, Geneva, Switzerland. http://laborsta.ilo.org/.

Lam, Alice. 1992. "The Japanese Equal Employment Opportunity Law: Its Effects on Personnel Management and Policies and Women's Attitudes.” MPRA Working Paper 11559, University Library of Munich, Germany.

Lee, Bun Song, Soomyung Jang, and Jayanta Sarkar. 2008. "Women's Labor Force Participation and Marriage: The Case of Korea." Journal of Asian Economics 19 (2): 138-54.

Li, Shi, and Jin Song. 2011. "Changes in Gender Wage Gap in Urban China During 1996-2007.” CIBC Working Paper 2011-20, University of Western Ontario, Department of Economics, London, Ontario.

Liu, Dongxiao, and Elizabeth Heger Boyle. 2001. "Making the Case: The Women's Convention and Gender Discrimination in Japan." International Journal of Comparative Sociology 42: 389-404. 
LSB (Lao Statistics Bureau). Lao Expenditure and Consumption Survey. Vientane, Lao PDR. http://www.nsc.gov.la/index.php? option=com_content $\&$ view $=$ article $\&$ id $=50 \& I$ temid $=73 \&$ lang $=$.

Mammen, Kristin, and Christina Paxson. 2000. "Women's Work and Economic Development." Journal of Economic Perspectives 14 (4): 141-64.

Maurer-Fazio, Margaret, Rachel Connelly, Lan Chen, and Lixin Tang. 2011. "Childcare, Eldercare, and Labor Force Participation of Married Women in Urban China, 19822000." Journal of Human Resources 46 (2): 261-94.

Meng, Xin 1996. "The Economic Position of Women in Asia" Asian-Pacific Economic Literature 10 (1): 23-41.

Miller, Robbie Louise. 1998. "Women's Job Hunting in the 'Ice Age': Frozen Opportunities in Japan." Wisconsin Journal of Law, Gender, and Society 13 (2): 228.

- 2003. "The Quiet Revolution: Japanese Women Working Around the Law." Harvard Journal of Law and Gender 26: 163-215.

Mincer, Jacob, and Solomon Polachek. 1974. "Family Investment in Human Capital: Earnings of Women." Journal of Political Economy 82 (2): S76-S108.

Morrison, Andrew, Dhushyanth Raju, and Nistha Sinha. 2007. "Gender Equality, Poverty, and Economic Growth.” Policy Research Working Paper 4349. World Bank, Washington, DC.

$\mathrm{Mu}$, Ren, and Dominique van de Walle. 2009. "Left Behind to Farm? Women's Labor Re-Allocation in Rural China." Policy Research Working Paper 5107, World Bank, Washington, DC.

Murthi, Mamta, Anne-Catherine Guio, and Jean Drèze. 1995. "Mortality, Fertility, and Gender Bias in India: A District-Level Analysis." Population and Development Review 21 (4): 745-82.

Nakavachara, Voraprapa. 2010. "Superior Female Education: Explaining the Gender Earnings Gap Trend in Thailand." Journal of Asian Economics 21 (2): 198-218.

NIS (National Institute of Statistics) [Cambodia]. Cambodia Socio-Economic Survey (CSES). National Institute of Statistics, Phnom Penh, Cambodia. http://www.nis.gov.kh/index.php/ social-statistics/cses.

Nopo, Hugo, Nancy Daza, and Johanna Ramos. 2011. "Gender Earnings Gaps in the
World." Background paper for the World Development Report 2012, World Bank, Washington, DC.

NSCB (National Statistical Coordination Board) [Philippines]. 2006. Family Income and Expenditures Survey (FIES) 2006. National Statistical Coordination Board, Makati City, Philippines. http://www.nscb.gov.ph/fies/ default.asp.

NSD (National Statistics Directorate) [TimorLeste]. 2007. Timor-Leste Survey of Living Standards. Dili, Timor-Leste: Ministry of Planning and Finance, National Statistics Directorate. http://dne.mof.gov.tl/TLSLS/ AboutTLSLS/index.htm.

NSO Mongolia (National Statistical Office of Mongolia). Living Standards Measurement Survey (LSMS). National Statistical Office, Ulaanbaatar, Mongolia. http://www.nso.mn.

NSO Thailand (National Statistical Office Thailand). Thailand Socio-Economic Survey (SES). Bangkok, Thailand: National Statistical Office. http://web.nso.go.th/tnso.htm.

Ogawa, Keiichi, and Masuma Akter. 2007. "Female Labor Force Participation in Indonesia." Journal of International Cooperation Studies 14 (3): 71-108.

O’Neill, June. 2003. “The Gender Gap in Wages, Circa 2000." American Economic Review May.

Pastore, Fransesco 2009. "The Gender Gap in Early Career in Mongolia." Discussion Paper No. 4480, Institute for the Study of Labor (IZA), Bonn, Germany.

Penn World Table 7.0. Alan Heston, Robert Summers and Bettina Aten, Penn World Table Version 7.0, Center for International Comparisons of Production, Income and Prices at the University of Pennsylvania, May 2011.

Peterman, Amber, Julie Behrman, and Agnes Quisumbing. 2010. "A Review of Empirical Evidence on Gender Differences in Nonland Agricultural Inputs, Technology, and Service in Developing Countries.” IFPRI Discussion Paper 975, International Food Policy Research Institute, Washington, DC.

Pierre, G. 2011. "Recent Labor Market Performance in Vietnam through a Gender Lens." Background paper for the "Vietnam Country Gender Assessment." World Bank, Washington, DC. http://documents.worldbank .org/curated/en/2011/11/15470188/vietnamcountry-gender-assessment.Vietnam Gender Assessment. 
Pörtner, Claus C. 2009. "Children’s Time Allocation, Heterogeneity and Simultaneous Decisions.” Working Paper UWEC-2009-15, University of Washington, Department of Economics, Seattle.

Psacharopoulos, George, and Zafiris Tzannatos. 1989. "Female Labor Force Participation: An International Perspective." World Bank Research Observer 4 (2): 187-201.

Quisumbing, Agnes R. 1995. "Gender Differences in Agricultural Productivity." FCND Discussion Paper 5, International Food Policy Research Institute, Washington, DC.

—_. 1998. "Women in Agricultural Systems." In Women in the Third World: An Encyclopedia of Contemporary Issues, edited by N. Stromquist, 261-72. New York: Garland.

Quisumbing, Agnes R., Jonna P. Estudillo, and Keijiro Otsuka. 2004. Land and Schooling: Transferring Wealth Across Generations. Baltimore, MD: Johns Hopkins University Press.

Rand, John, and Finn Tarp. 2011. "Does Gender Influence the Provision of Fringe Benefits? Evidence from Vietnamese SMEs." Feminist Economics 17 (1): 59-87.

Rawski, Thomas, and Robert W. Mead. 1998. "On the Trail of China's Phantom Farmers." World Development 26 (5): 767-81.

Sabarwal, Shwetlena, and Katherine Terrell. 2008. "Does Gender Matter for Firm Performance? Evidence from Eastern Europe and Central Asia.” Policy Research Working Paper 4705, World Bank, Washington, DC.

Sabarwal, Shwetlena, Katherine Terrell, and Elena Bardasi. 2011. "How Do Female Entrepreneurs Perform? Evidence from Three Developing Regions." Small Business Economics 37 (4): 417-41.

Sakellariou, Chris. 2011. "Determinants of the Gender Wage Gap and Female Labor Force Participation in EAP.” Paper commissioned for Toward Gender Equality in East Asia and the Pacific: A Companion to the World Development Report. Washington, DC: World Bank.

Sasaki, Masaru. 2002. "The Causal Effect of Family Structure on Labor Force Participation among Japanese Married Women.” Journal of Human Resources 37 (2): 429-40.

Sasser, Alicia C. 2005. "Gender Differences in Physician Pay: Tradeoffs Between Career and Family." Journal of Human Resources 40 (2): 477-504.
Simavi, Sevi, Clare Manuel, and Mark Blackden. 2010. Gender Dimensions of Investment Climate Reform: A Guide for Policy Makers and Practitioners. Washington, DC: World Bank.

Sinha, J. N. 1967. "Dynamics of Female Participation in Economic Activity in a Developing Economy." In Proceedings of the World Population Conference, Belgrade, 1965; Vol. 4. Migration, Urbanization, Economic Development, 336-37. New York: United Nations.

Slootmaekers-Miranda, Veerle. 2011. "Cooking, Caring and Volunteering: Unpaid Work around the World." Social, Employment and Migration Working Papers, Organisation for Economic Co-operation and Development, Paris.

Stivens, Maila. 2006. "Family Values and Islamic Revival: Gender, Rights and the State Moral Project." Women's Studies International Forum 29 (4): 354-67.

SUSI (Survei Usaha Terintegrasi). 2002. Integrated Survey of Cottage and Small-Scale Firms. Badan Pusat Statistik, Jakarta, Indonesia.

Tam, Henry. 2011. "U-Shaped Female Labor Force Participation with Economic Development: Some Panel Data Evidence." Economic Letters 110 (2): 140-42.

Tansel, Aysit. 2001. "Economic Development and Female Labor Force Participation in Turkey: Time-Series Evidence and Cross-Province Estimates.” ERC Working Paper 0105, Middle East Technical University, Economic Research Center, Ankara, Turkey.

NSO Thailand (National Statistical Office Thailand). Thailand Socio-Economic Survey (SES). Bangkok, Thailand. http://web.nso.go.th/ tnso.htm.

Thomas, Duncan. 1990. "Intra-household Resource Allocation: An Inferential Approach.” Journal of Human Resources 25 (4): 635-64.

Thomas, Duncan, and John Strauss. 1997. "Health and Wages: Evidence on Men and Women in Urban Brazil." Journal of Econometrics 77 (1): 159-85.

Timberlake, Sharon. 2005. "Social Capital and Gender in the Workplace." Journal of Management Development 24 (1): 34-44.

Tzannatos, Zafris. 1999. "Women and Labor Market Changes in the Global Economy: Growth Helps, Inequalities Hurt and Public Policy Matters." World Development 27 (3): 551-69. 
Udry, Christopher. 1996. "Gender, Agricultural Production, and the Theory of the Household." Journal of Political Economy 104 (5): 1010-46.

UNIFEM, World Bank, ADB, UNDP, and DFID/ UK (United Nations Development Fund for Women, World Bank, Asian Development Bank, United Nations Development Programme, and Department for International Development of the United Kingdom). 2004. "A Fair Share for Women: Cambodia Gender Assessment.” UNIFEM, WB, ADB, UNDP, and DFID/UK, Phnom Penh, Cambodia.

VCCI (Vietnam Chamber of Commerce and Industry). 2006. "Targeted Policies That Support Women's Entrepreneurship Can Boost Vietnam's Economic Growth.” Business Issues Bulletin 13 (16).

Vijverberg, W., and J. Haughton. 2004. "Household Enterprises in Vietnam: Survival, Growth, and Living Standards." In Economic Growth, Poverty, and Household Welfare in Vietnam, edited by David Dollar and Paul Glewwe. Washington, DC: World Bank.

Weinberg, Bruce. 2000. "Computer Use and the Demand for Female Workers." Industrial and Labor Relations Review 53 (January): 290-308.

White, Sally. 2006. "Gender and the Family." In Voices of Islam in Southeast Asia, edited by Greg Fealy and Virginia Hooker, 273-352. Singapore: Institute of Southeast Asian Studies.

Women, Business and the Law (database). World Bank, Washington, DC. http://wbl.worldbank .org/data.

Wood, Robert, Mary Corcoran, and Paul Courant. 1993. "Pay Differences Among the Highly Paid: Male-Female Earnings Gap in Law Salaries." Journal of Labor Economics 11 (3): 417-44.

World Bank. 2010a. "Indonesia Jobs Report: Towards Better Jobs and Security for All." World Bank, Washington, DC.

- 2010b. Indonesia-Reconstruction of Aceh Land Administration System Project. World Bank, Washington, DC.

_—_. 2011a. Defining Gender in the XXI Century: Conversations with Men and Women
Around the World (qualitative assessment dataset). World Bank, Washington, DC. http:// go.worldbank.org/CD8RN24BP0.

—. 2011b. "Female Entrepreneurship in Mongolia." Background paper for the Mongolia Gender Assessment. World Bank, Washington, DC.

—. 2011c. "Gender Disparities in Mongolian Labor Markets and Policy Suggestions.” World Bank, Washington, DC.

—. 2011d. "Gender Equality and Health." Indonesia Policy Brief 2, World Bank, Washington, DC.

—. 2011e. "Vietnam Country Gender Assessment.” World Bank, Washington, DC.

—. 2011f. "Women, Business and the Law in East Asia and Pacific Region." A background paper commissioned for Toward Gender Equality in East Asia and the Pacific: A Companion to the World Development Report. Washington, DC: World Bank.

- 2011g. World Development Report 2012: Gender Equality and Development. Washington, DC: World Bank.

- 2012. The Elderly and Old Age Support in Rural China: Challenges and Prospects. Washington, DC: World Bank.

World Bank and ADB (Asian Development Bank). 2005. "Mongolia, Country Gender Assessment.” World Bank: Washington DC.

World Development Indicators (WDI) database. World DataBank, World Bank, Washington, DC. http://databank.worldbank.org.

Yu, Wei-hsin. 2002. "Jobs for Mothers: Married Women's Labor Force Reentry and Parttime, Temporary Employment in Japan." Sociological Forum 17 (3): 493-523.

Yuan, Ni, and Sarah Cook. 2010. "Gender Patterns of Informal Employment in Urban China." In Gender Equality and China's Economic and Social Transformation: Informal Employment and Care Provision, edited by Xiao-Yuan Dong and Sarah Cook. Beijing: Economic Science Press.

Zuo, Jiping, and Yanjie Bian. 2001. "Gendered Resources, Division of Housework and Perceived Firness: A Case in Urban China." Journal of Marriage and Family 63: 1122-33. 



\section{Agency: Voice and Influence within the Home and in Society

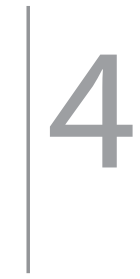

$\mathrm{I}$ n much of the world, women have a more limited voice and influence than men in decision making in their homes, their communities, and society. Women are also more likely to be victims of genderbased violence. The inability of women to voice and act on their preferences negatively affects their own welfare and is detrimental to development.

This chapter analyzes women's agency in East Asian and Pacific countries. The chapter defines agency as the ability of individuals or groups to give voice to and act on their preferences and to influence outcomes that affect them and others in society. Agency is affected by and also affects individuals' ownership of and control over endowments and their access to economic opportunities (Kabeer 1999). The discussion of agency in this chapter also includes the ability of countries to ensure the safety and security of women in their homes and in society, because genderbased violence and trafficking of women reflects the extreme deprivation of women's agency in society.

Within a household or partnership, one's relative power affects the strength of one's voice and influence in household decisions, such as how to spend or invest family resources. Similarly, at the community or societal level, the relative power of individuals and groups affects their ability to act on their preferences and influence outcomes in the economic, social, and political domains. The relative power of different members of society, which often differs systematically by gender, reflects a complex combination of one's personal characteristics, prevailing social norms, and the broader legal and institutional environments.

\section{Agency_important for gender equality and development}

The ability to act on one's preferences, regardless of one's gender, and to translate those preferences into desired outcomes is a development objective in its own right. As discussed in chapter 1 , development not only involves raising incomes or reducing poverty, but also involves a process of expanding freedoms and choices available to all people (Sen 1999). Agency is a measure of a person's well-being, reflecting both the ability to achieve as well as actual achievements (Sen 1992).

Women's agency enhances development. When women are free to make choices, that 
freedom positively affects all levels of society. Increasing women's voice and influence in the home has been found to improve children's education, health, and welfare (Duflo 2003; Fiszbein and Schady 2009; Haddad, Hoddinott, and Alderman 1997; Thomas 1995), as discussed in chapter 2. Increasing women's representation in firm ownership and management, and on corporate boards, also increases gender equality within firms and increases the provision of nonwage benefits to workers (Cohen and Huffman 2007; Ely 1995; Hultin and Szulkin 2003; Rand and Tarp 2011). Increasing women's representation in elected office not only ensures that decisions are more representative of the voting population, but also can lead to increased provision of public goods, better natural resource management, and increased reporting of crimes against women (Agarwal 2009; Ban and Rao 2009; Beaman et al. 2012; Chattopadhyay and Duflo 2004). Global evidence shows that violence against women has lasting negative effects on economic development in addition to causing significant social, psychological, and physical harm to those who experience and witness it (Morrison and Orlando 2004; Morrison, Ellsberg, and Bott 2007). Reducing gender-based violence thus results in healthier workers and higher economic productivity, with dynamic benefits across generations.

Economic growth and development can, in turn, contribute to strengthening women's agency in some areas. As discussed in earlier chapters, growth and development result in better education and health outcomes for women-and better human capital outcomes for women contribute directly to stronger voice and influence, whether in the home, in the economy, or in society. Economic development, as measured by gross domestic product (GDP) per capita, is also associated with higher levels of civic activism, including on issues related to gender equality (figure 4.1). Civic activism is a measure of "collective agency"; that is, it is the space for both male and female citizens to express their voice in the public sphere. ${ }^{1}$ To the extent that development is accompanied by stronger legal and judicial systems, more-developed societies provide women (and men) with better access to justice, which strengthens their voice and protects them against the extreme deprivation of agency.

Growth and development alone are not enough to enhance women's agency in all its dimensions. As shown in previous chapters, women have made positive strides toward gender equality in education and health, yet gender gaps remain in access to assets and economic opportunity. Increasing women's ability to earn and accumulate assets is critical for strengthening their voice and influence in society and making them less vulnerable to domestic violence and other types of abuse. Moreover, the relationship between economic development and women's political representation, an important pathway toward agency in society, is unclear (figure 4.2). Although development can contribute to strengthening women's agency in some dimensions, data show that improvements in a number of other areas are not automatic. Thus, governments need to develop policies that actively raise women's agency if they are to induce meaningful changes toward gender equality in agency.

This chapter aims to strengthen understanding of gender and agency in East Asian and Pacific countries, and to lay the foundation for identifying policy priorities to strengthen women's voice and influence. The analysis in the chapter focuses on agency in the following three domains:

- Agency in the household and in individual decisions is examined through household decision making, control of resources, and reproductive decisions.

- Agency in the public sphere is examined through women's participation and representation in the private sector, civil society, politics, and public institutions.

- Safety and security in expressing one's agency are examined through the prevalence of gender-based violence, an extreme deprivation of agency. 
The form of agency that is most frequently measured is the decision-making power of men and women (Kabeer 1999; Mason 2005; McElroy 1990). Agency may be more explicitly measured by examining women's mobility in the public domain, their participation in public action, and the incidence of gender-based violence (Kabeer 1999). Some researchers have assessed gender differences in bargaining power within a household by examining the extent to which people's choices change when factors affecting their bargaining power, such as education, relative earnings, or asset holdings, change (Duflo 2003; Quisumbing and Maluccio 2003; Thomas 1990, 1992).

Agency at the household level is difficult to measure, since negotiations for decisionmaking power often occur within private spaces in the household. Furthermore, since indicators of agency are of relatively new interest to the international development community, many have not yet been measured over time. Where possible, the chapter will present information on how women's agency has evolved over time in the region. When data on different dimensions of agency are not available over time, however, the chapter will present the most recent evidence available-both qualitative and quantitative.

The remainder of the chapter is structured as follows. The next section analyzes the state of agency in the region. The third section analyzes the factors that influence agency, and the fourth section identifies key policy priorities for promoting gender equality in voice and influence in the region. These directions for policy are discussed in further detail in chapter 6 .

Despite the geographic proximity between East Asian countries and the Pacific Islands, their development experiences and paths toward gender equality have been different, especially with respect to women's voice and influence. For this reason, this chapter distinguishes, where possible, between the progress made and the challenges faced by East Asian and Pacific countries in the different domains of agency.
FIGURE 4.1 There is a positive relationship between economic development and civic activism

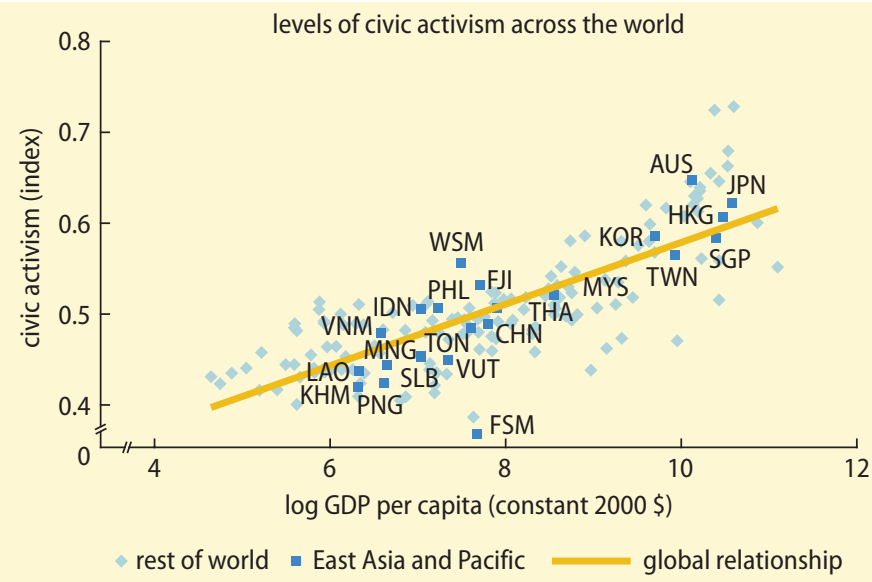

Source: World Development Indicators (WDI) database; Indices of Social Development (ISD) database.

Note: GDP = gross domestic product.

FIGURE 4.2 There is no clear relationship between economic development and women's representation in parliament

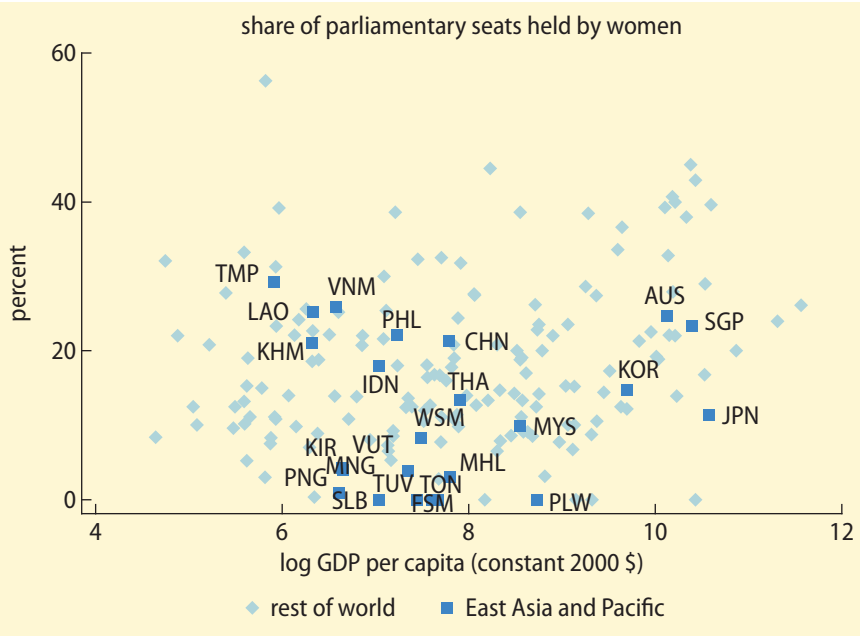

Source: WDI database; ISD database.

Note: $\mathrm{GDP}=$ gross domestic product.

\section{The state of women's agency in East Asia and the Pacific}

The East Asia and Pacific region has experienced uneven gains in women's agency over the past two decades. Although women now have more household decision-making power, more influence and voice in the public sphere, 
and new laws to protect their choices and interests in society, progress has been uneven across countries, and many challenges still remain. Women in East Asia had the highest representation in national parliaments in the developing world in the 1990s; yet, the share of women in parliaments has reached a plateau and fallen behind other regions in the past decade. Women have little representation among parliamentarians in the Pacific. Women's participation in the private sector has increased, but women remain a minority among firm owners and on corporate boards. The sections that follow examine evidence on women's voice and influence in the home and in the public domain, as well as evidence on gender-based violence in the region.

\section{Agency in the household and in personal decisions}

Women's household decision-making power in the region is relatively high. Women from all wealth quintiles in East Asia and the Pacific are more likely to have control over large purchases and over decisions to visit family and relatives than women in other developing regions, and they are among the most likely to have control over their own earnings. However, a higher share of women in East Asia than in the Pacific control their own income and have a say in other household decisions, reflecting a great intraregional variation.

Women in East Asia, in particular, have high levels of autonomy. According to Demographic and Health Survey (DHS) data, nearly 70 percent of married women ages 15 to 49 in Cambodia and Indonesia report that they control their own earnings; 31 and 28 percent, respectively, report joint control of their earnings with their husbands. Only 1 percent of women in Cambodia, and 3 percent of women in Indonesia, report that their husbands decide how their earnings are used (figure 4.3). Women in Cambodia and Timor-Leste report high levels of control not only over their own income, but also over their husband's income (DHS data, various years). ${ }^{2}$
Women in the Pacific have relatively less control over their own earnings. Between 13 and 15 percent of women in Marshall Islands, Samoa, and Tuvalu report that their husbands have control over their wives' cash earnings (figure 4.3). Studies in different countries in the Pacific also find high levels of financial control by men in the household. In Kiribati, for example, 19 percent of women report that their partners do not allow them to make any financial decisions for household expenditures, and 12 percent of women report that they cannot exercise control of their own incomes because their partners take it away. When intimate partner violence occurs, women have an even weaker voice over household financial decisions. Twenty-three percent of women who experience intimate partner violence report that their partners do not allow them to make any financial decisions related to household expenditure, and 22 percent report having no control of their own income.

Most women in the region have the freedom to make other household decisions, whether related to their own health care, household purchases, or visits to family and relatives. Women in the Pacific have slightly less ability to make decisions on their own health care and household purchases, on average, than women in East Asia. In the Philippines, 94 percent of women make their own health care decisions solely or jointly with their spouse, whereas only 70 percent of women in the Marshall Islands do so (figure 4.4). Similar patterns occur in how much say wives have in decisions regarding visits to her family and relatives. However, in some areas in East Asia, women also have relatively little decision-making power with regard to certain choices. For instance, 18 percent of women surveyed in Indonesia report that men have the final say in making decisions on household purchases. Women in Tuvalu and the Marshall Islands report having the lowest control over their own health care decisions and household purchases (figure 4.4; DHS data, various years).

Where DHS data are not available, country surveys from Kiribati, the Solomon Islands, 
and Vanuatu suggests that women have relatively low levels of autonomy with respect to household decision making. This data indicates a high prevalence of controlling behavior by husbands and male partners over household, financial, and mobility decisions. Of partnered women, 58 percent and 69 percent reported the experience of some sort of controlling behavior by their partners in the Solomon Islands and Vanuatu, respectively. This sort of behavior includes preventing her from seeing family, wanting to know where she is at all times, forbidding contact with other men, and controlling access to health care. Controlling behaviors by husbands are often correlated with a lack of agency in other dimensions, as well as with personal characteristics that hinder agency, such as poor endowments and economic opportunities, discussed in more detail below. In both the Solomon Islands and Vanuatu, women with little to no education are more likely to have partners who exhibit controlling behaviors than women with higher educational attainment. Women who have experienced intimate partner violence are also significantly more likely to experience controlling behaviors than women who have not experienced violence (SPC and NSO 2009; VWC and NSO 2011). In that sense, the factors that inhibit women's agency are likely to be mutually reinforcing.

Globally, women living in wealthier households are likely to have more decisionmaking power than women living in poorer households. This pattern bears out in Pacific countries, but less so in East Asia. Evidence from countries in other regions of the world illustrates that women in wealthier households have a wider set of choices and face fewer financial constraints. As a result, they have more freedom to make purchasing decisions and rarely have to forgo human capital investments in their children or to ration their access to goods and services. Available data for East Asia suggest, however, that women in wealthier households do not have substantially more control over decisions than women in households with lower income-levels (figure 4.5). Conversely, data
FIGURE 4.3 Who decides how wives' cash earnings are used varies across the region

person who decides how the wife's cash earnings are used (\%)

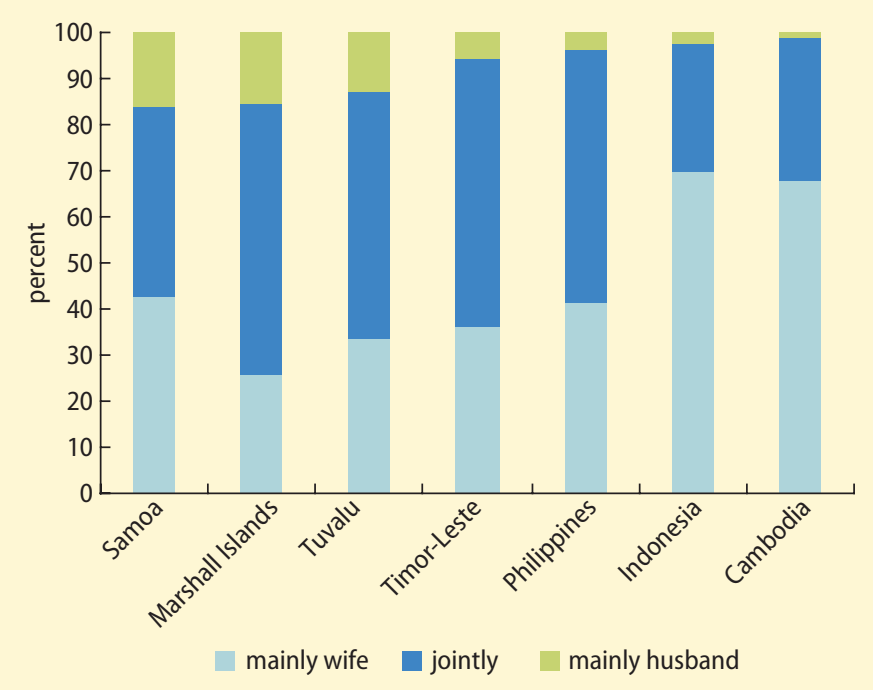

Source: DHS data, various years.

Note: Among currently married women ages 15-49 who receive cash earnings for employment.

FIGURE 4.4 A majority of wives control decisions regarding their own health care and household purchases

percentage of currently married women ages 15-49 who control health care and purchasing decisions solely or with husband

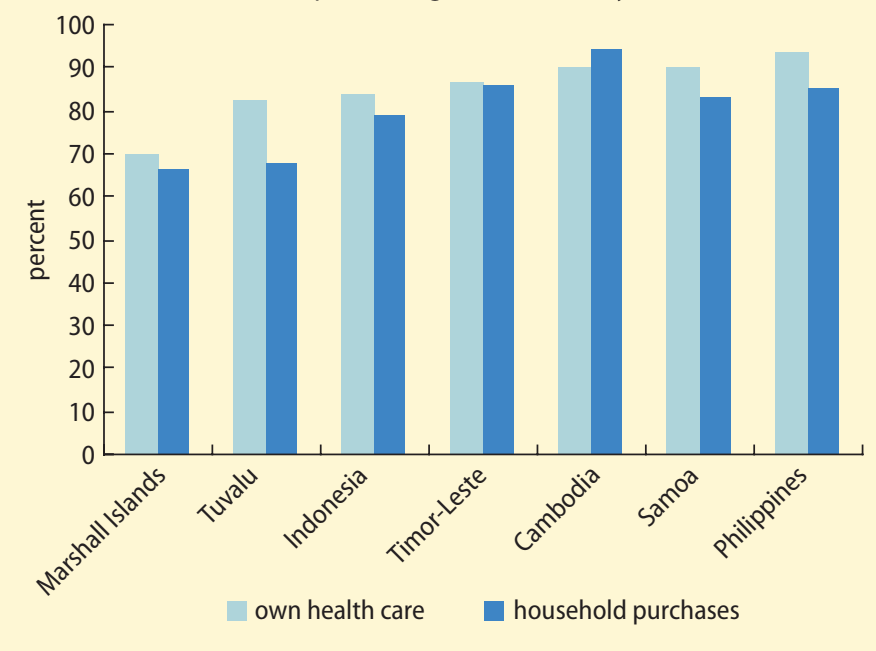

Source: DHS data, various years.

from countries in the Pacific show a different picture. For instance, in Vanuatu, 50 percent of women in households at the bottom of the income distribution have to ask permission 
to visit family or others, while 41 percent of women in wealthier households have to do so (VWC and NSO 2011).

Women have made advances in their ability to make reproductive decisions in nearly all countries in the region. Reductions in fertility rates and fertility gaps-defined as unwanted fertility-are observed across most countries in East Asia, suggesting that women have gained greater control over their reproductive decisions. In many East Asian and Pacific countries, the use of contraceptive methods-whether modern or traditional-has become increasingly more common. For example, in Cambodia, the percentage of married women using modern methods of family planning increased from 19 percent to 35 percent between 2000 and 2010. The percentage of married women using traditional methods increased from 5 percent to 16 percent during the same period (NIS and DGH 2011).

Most countries in both East Asia and the Pacific have seen decreases in the number of births per woman (figure 4.6). In 2009,

\section{FIGURE 4.5 Women in East Asia have greater control over decisions than in other regions \\ (percent)}

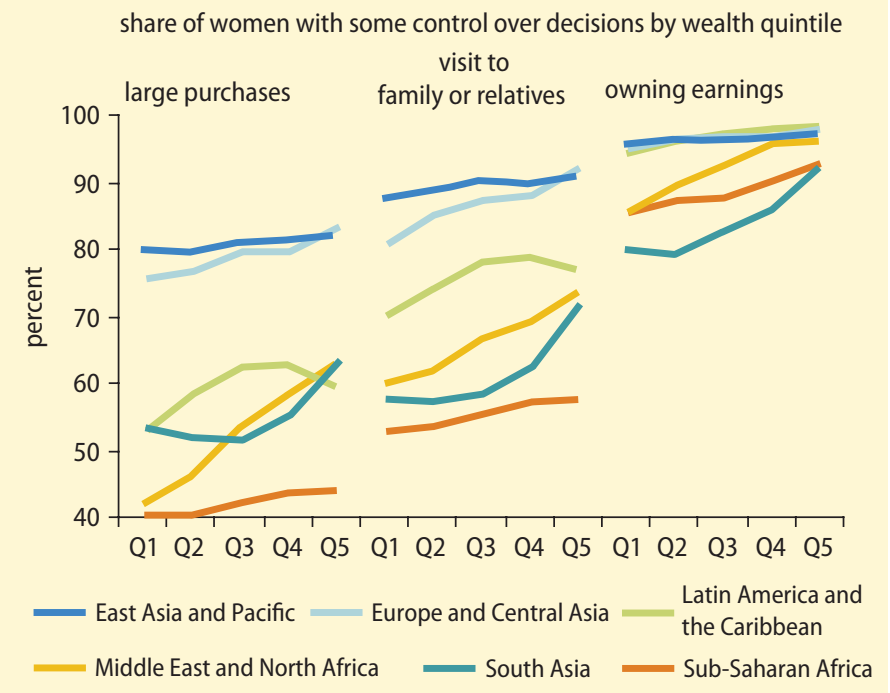

Source: World Bank 2011b

Note: Country coverage for East Asia and Pacific includes Cambodia, Indonesia, and the Philippines.
China, Thailand, and Vietnam had the lowest fertility rate in the region, at less than two births per woman. The Pacific Islands (barring Fiji, at 2.7 births per woman) have the highest fertility rates in the region, at over 3.5 births per woman. While all countries in the region have experienced a decrease in female fertility rates, Timor-Leste experienced a spike of 7.8 births per woman in 2003 before declining to 5.7 births per woman in 200910. Despite progress, fertility remains the highest among the poorest Timorese, at 7.3 births per woman, compared to 4.2 births among the wealthiest. Women with no education have significantly more children than women with more than a secondary education: 6.1 versus 2.9 children per woman. The high fertility observed in Timor-Leste can be partially attributed to weakened health systems due to prolonged political conflict (World Bank 2011d).

Countries with the highest fertility rates also have the highest percentages of adolescent pregnancies. As can be seen in figure 4.6 and figure 4.7, the countries in the region with the highest fertility rates also have the highest percentage of pregnant teenagers ages 15 to 19 . Among young women in the Pacific in this age range, a large number of pregnancies are unwanted or mistimed (figure 4.8). In the Marshall Islands, Solomon Islands, and Nauru, more than half of young women report having had an unwanted pregnancy (Kennedy et al. 2011).

In some countries where fertility rates have decreased, women still have more children than they desire. In the past 50 years in the Philippines, the average number of children per woman decreased from 7.0 children to 3.3 children (Costello and Casterline 2002). However, the fertility gap in the Philippines is still high, with an average number of children per mother of 3.3 and a desired number of children per mother of only 2.4 (NSO [Philippines] and ICF Macro 2009). This may be more the result of norms, or weak service delivery than spousal control. In fact, 65 percent of women who do not use contraceptives mention health concerns, fear of side effects, and inconvenience of use; 18 percent cite 
opposition by women or their partner or religious factors; 23 percent cite issues of access, distance, or cost. Only 2 percent cite lack of knowledge of method or source (NSO [Philippines] and ICF Macro 2009). Women who experience violence also seem more likely to have an unplanned pregnancy. In Kiribati, for example, 22 percent of women who experienced domestic violence had an unplanned pregnancy, compared to 12 percent of those who did not experience domestic violence (SPC, Ministry of Internal and Social Affairs, and Statistics Division 2010).

Advancement toward gender equality in agency in the household in one dimension may not translate into progress in other dimensions. A study of 21 communities in Thailand found that women are relatively free to make fertility-related decisions and participate in the labor market, but they have only moderate levels of freedom of movement and high levels of fear about disagreeing with their husbands on household matters (Mason and Smith 2003). Other studies show even more striking differences in levels of agency across dimensions in countries in the Pacific. For instance, data collected for the international Social Institutions and Gender Index indicate that women in Papua New Guinea face a relatively high level of agency in some public dimensions, such as freedom of movement and freedom of dress, while they experience very low levels of agency in their households, for example, with respect to violence (SIGI, 2010 data).

\section{Agency in the public domain}

Women in East Asia have made dynamic strides in participation and influence in the private sector, civil society, and political institutions. Current levels are still far from equal. In the Pacific, women have experienced little change in many public domains and continue to face large challenges.

\section{The private sector}

Women's participation and leadership in the private sector has made progress in East Asia. In Hong Kong SAR, China, the percentage
FIGURE 4.6 Fertility rates in the region have declined over the past three decades

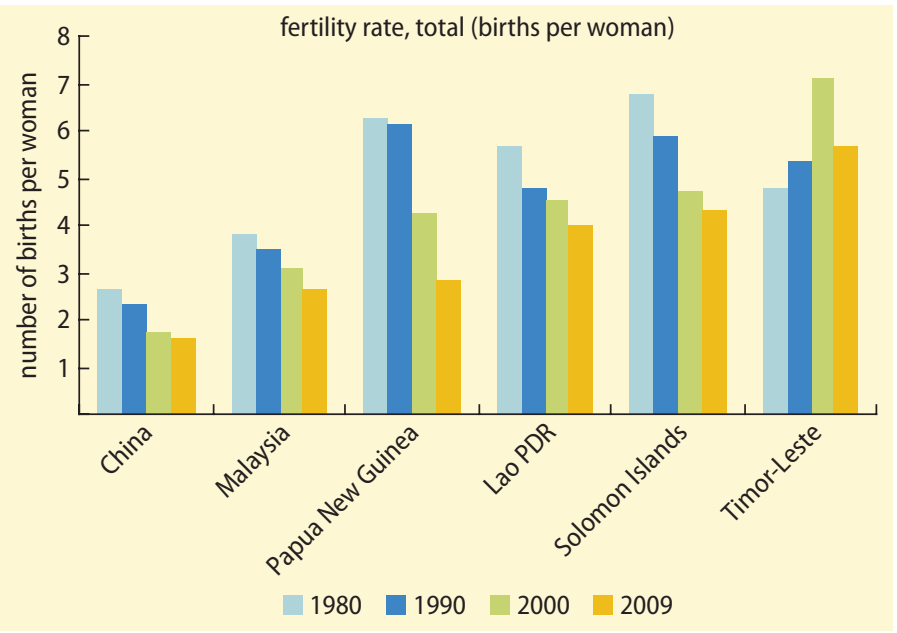

Source: WDI database, 2011 data.

FIGURE 4.7 Adolescent fertility is especially high in the Pacific

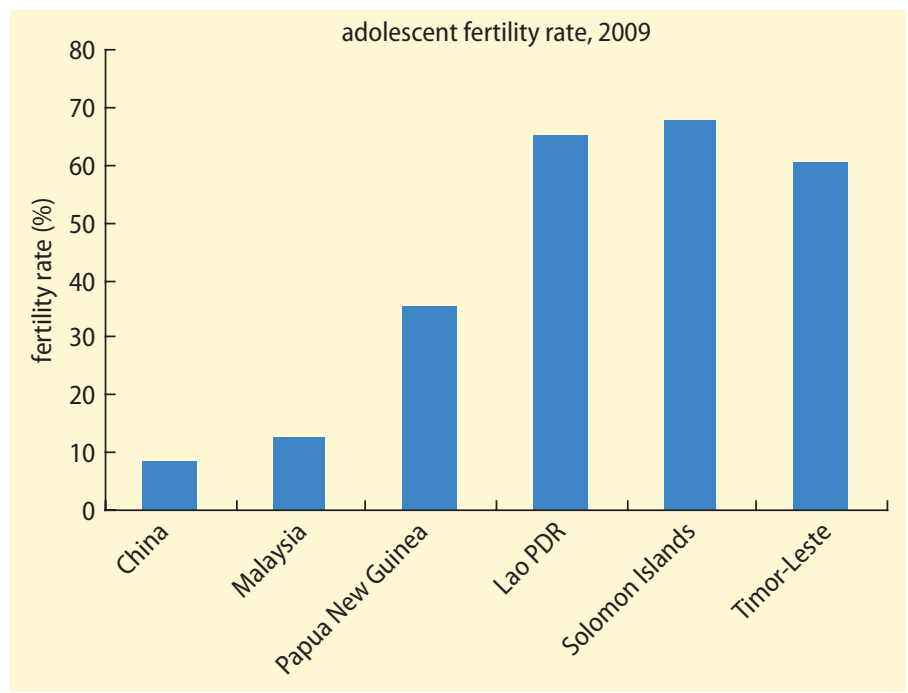

Source: WDI database, 2009 data.

Note: Adolescent fertility rate is the number of births per 1,000 women ages 15-19.

of women on corporate boards increased from less than 5 percent to almost 9 percent over the past decade (Mahtani, Vernon, and Sealy 2009). East Asia has a high percentage of firms owned by women and firms with women in the top management compared to other developing regions. Mongolia, the Philippines, and Vietnam have among the highest levels of female participation in business 


\section{FIGURE 4.8 The rate of unwanted and mistimed pregnancies is especially high in the Pacific}

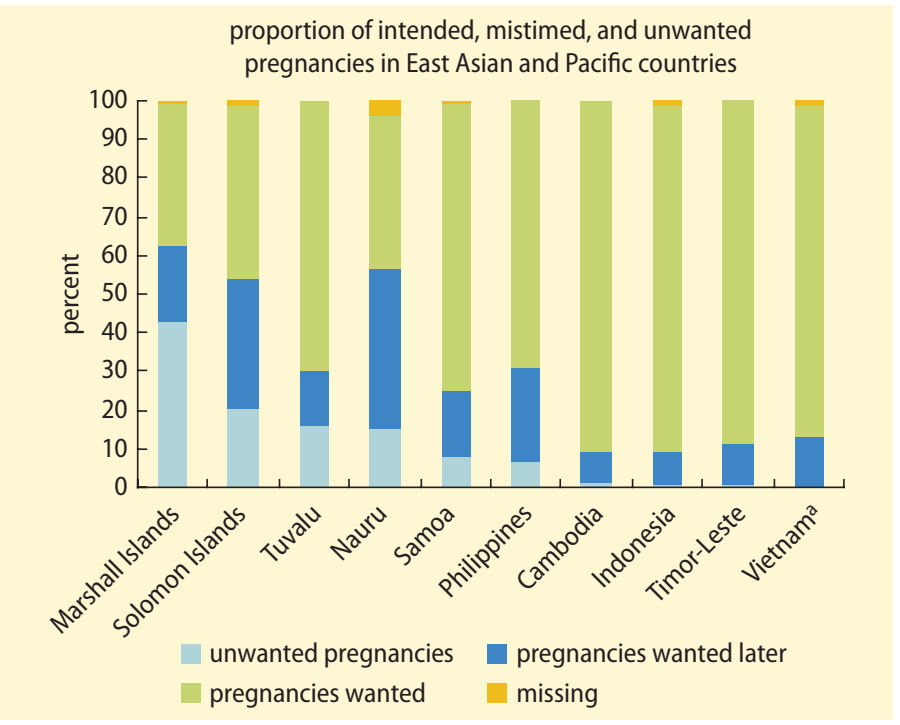

Source: Demographic and Health Surveys, various years.

a. Percent distribution of births to women 15-19 in the five years preceding the survey, except for

Vietnam, where data refer to three years preceding the survey.

ownership (Enterprise Surveys, 2006-09 data).

Still, within companies, women are less likely to be found in management and decision-making positions. The share of female directors ranges from 10 percent in the Philippines and 7 percent in China and Thailand to 5 percent in Indonesia and under 2 percent in the Republic of Korea and Japan (CWDI 2010). Although 67 percent of all publicly traded companies in Hong Kong SAR, China, have at least one woman on the board, only 15 percent of those companies have more than one (Mahtani, Vernon, and Sealy 2009). Globally, only one country in the world, Norway, has succeeded in having more than 30 percent female representation on corporate boards, while only one-third of countries have female board representation of over 10 percent (CWDI 2010).

Despite the presence of women as firm owners in several countries in the region, women make up a much lower share of female top managers and so are less likely to influence firm decisions. Most countries in the region have firms with female participation in ownership. However, owning an asset might be significantly different from having the principal voice in managing and running an enterprise. In the five countries in the region for which data are available-Indonesia, Malaysia, Mongolia, the Philippines, and Vietnam-more firms have female participation in ownership than female top managers (figure 4.9).

\section{Civil society and grassroots movements}

East Asian women have seen some improvements in the strength of their voice and their ability to actively participate in civil society and grassroots movements. Data show a positive relationship between the strength of civil society and gender equality. Civil society groups and women's organizations and movements, in particular, have been important in creating broader space for women to have voice and influence in society. The size and nature of civil society have not been static over the past two decades. Figure 4.10 shows that even though wealthier countries such as Australia and Japan still have a more thriving civil society than poorer countries, over the past two decades there has been an increase in the presence of civil society in poorer countries. As a whole, civil society has been strengthened in the region, which has in part been influenced by increasingly amicable relationships between civil society and governments. ${ }^{3}$

Although most civil society organizations (CSOs) are focused on broad development issues-poverty reduction, education, and health-more organizations now focus on a wider range of gender issues than two decades ago. Of those that currently focus on gender, some operate at the local level while others operate at the national level. In Indonesia, the civil society organization PEKKA (Women-Headed Household Empowerment Program) was created to address the needs of widows who were victims of conflict in Aceh, to improve their access to legal and financial assistance, and to improve their overall welfare. The program provides training for village paralegals who focus on domestic violence and family law, and also holds district 
FIGURE 4.9 Many firms have female participation in ownership, but fewer have a female top manager
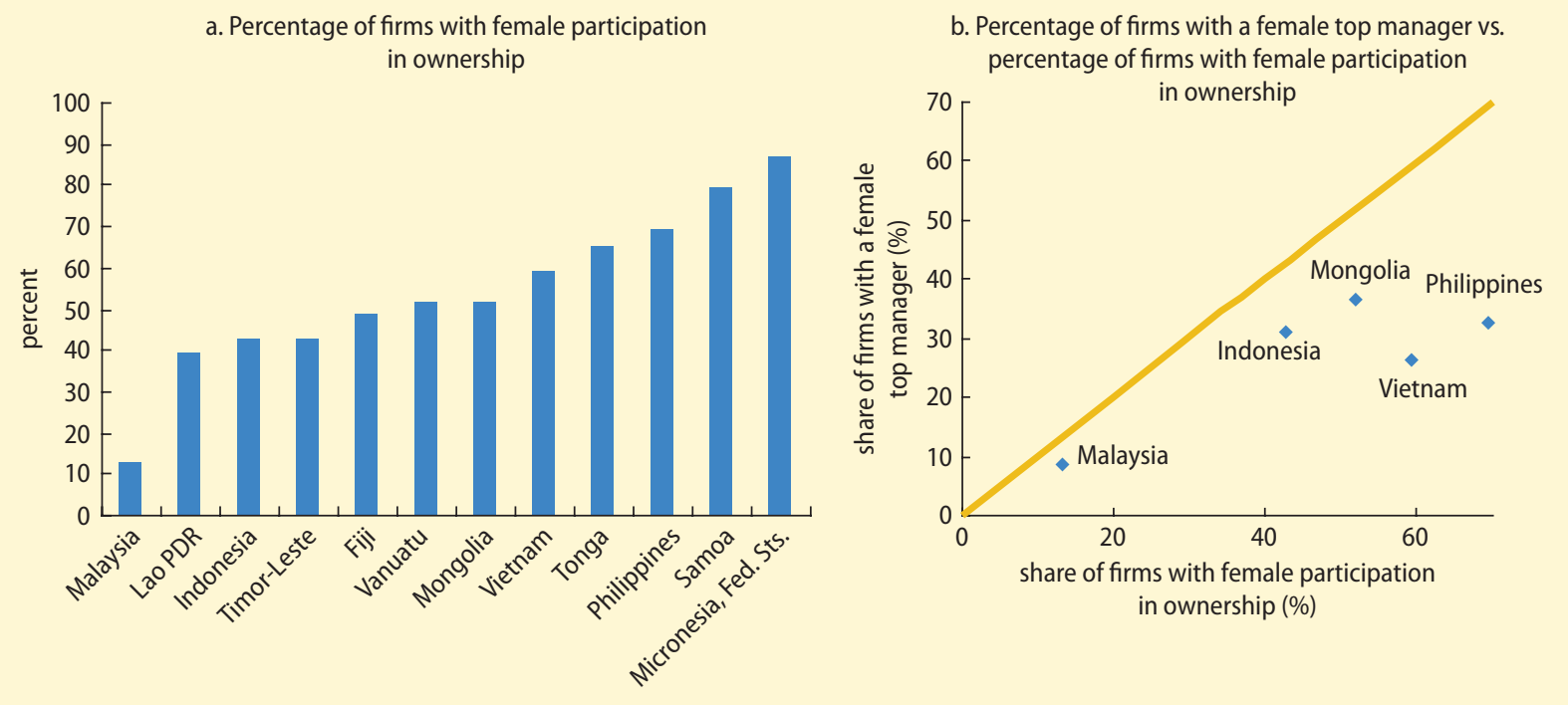

Source: World Bank estimates using Enterprise Surveys database, 2006-09 data.

forums to bring together judges, prosecutors, police, nongovernmental organizations, and government officials to raise awareness of gender issues (PEKKA 2012; World Bank 2011b). In Papua New Guinea, the number of CSOs targeting their assistance to women and enhancing their access to services has expanded. For instance, some provide services such as microcredit and savings to economically empower women. Many Mother's Groups have flourished throughout this period to address local women's needs such as nutrition and health services. Through their services, they enable women to engage actively in their children's health care (Imai and Eklund 2008). Examples of genderfocused activist groups include Gender and Development for Cambodia, the National Council of Women in Thailand (under the patronage of the Queen), and the Liberal Women's Brain Pool in Mongolia. Others that operate at the international level include Save the Children, Coordination of Action Research on AIDS, Mobility Asia (CARAMAsia), and End Child Prostitution in Asian Tourism (ECPAT). CSOs interested in tackling policy issues such as eliminating human trafficking, increasing political representation
FIGURE 4.10 Civic activism has grown in the low- and middleincome countries in the region

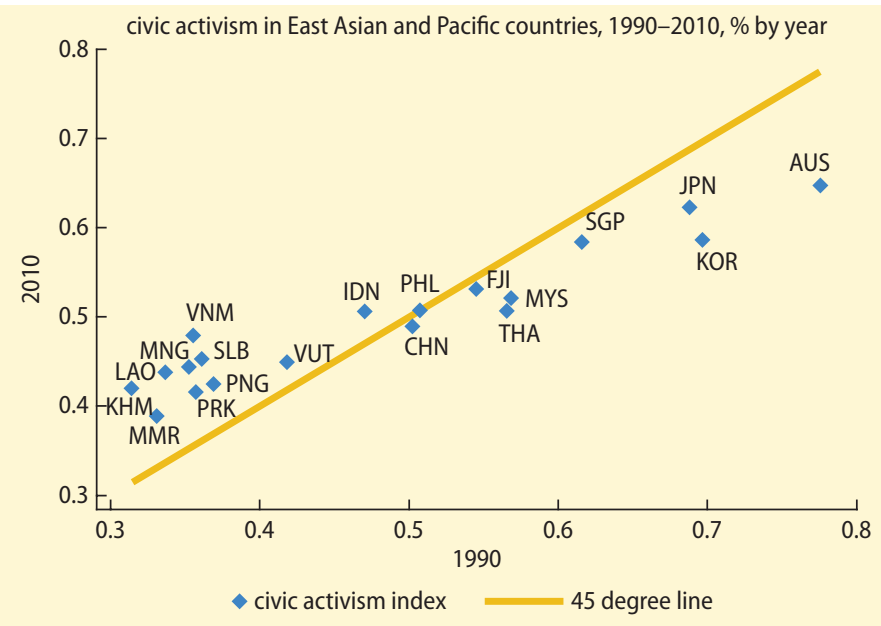

Source: ISD database.

of women, and changing laws to decrease the discrimination of women have also emerged throughout the region.

Pacific countries have seen some progress in the growth of gender-focused CSOs. Civil society continues to be a vital feature of development in the Pacific Island countries, especially in delivering services (Swain 2000). The 
Pacific region has seen an increase of CSOs at the country level as well as multi-island network organizations in the past few decades. Even though only a few organizations focus solely on the promotion of gender equality, an increasing number of organizations are recognizing the importance of taking a more active role in promoting gender equality by giving voice to women.

\section{Politics}

For countries in the region that have experienced growth in female political representation, progress has been slow, and in most countries, levels remain below what is commonly perceived to be an acceptable threshold for women's voice in the political domain: 30 percent of electoral seats at the national and local levels (Agarwal 2010a, 2010b). When women do enter politics or public administration, they tend to be in lowerranked positions and sectors and positions perceived as "female," such as government ministries of women, health, education, or social welfare, and not some more traditionally male ministries, such as finance or planning, where government resource allocations are typically made (World Bank 2011b).

The share of women in national parliaments varies tremendously across the region. Data on female representation in national parliaments provide insight into the level of agency in political decision making. As shown in figure 4.11, many East Asian countries, including Cambodia, Lao PDR, the Philippines, and Singapore, have increased the share of parliamentary seats held by women since 2000. In contrast, Mongolia has experienced a steep decline in female representation during the same period, from about 10 percent in 2000 to less than 4 percent in 2010 (figure 4.11). Figure 4.12 illustrates the variation across the region with respect to parliamentary seats held by women, with Timor-Leste, Lao PDR, and Vietnam having the highest percentage of seats held by women and the Pacific Islands being on the lower end of the spectrum.

Women's voice and participation in politics in the Pacific remains largely absent. Women in Pacific countries have made little progress in terms of political representation in parliament over the past decade. Currently, women represent about 2.5 percent of political leadership roles in the Pacific, and the Federated States of Micronesia, Nauru, Palau, and the Solomon Islands did not have female representation in parliament as of December 2011 (PARLINE database).

Several countries have elected or appointed female heads of state in recent years. Australia, Indonesia, Korea, New Zealand, the Philippines, and, most recently, Thailand have or have had a woman heading their government since 2000. At the ministerial level, Palau and Samoa have the highest percentage of women ministers (at 25 percent and 23 percent, respectively) in the East Asia and Pacific region. These percentages are similar to those found in Australia (23 percent) and slightly below those of New Zealand (29 percent). As of 2010, Nauru, the Solomon Islands, Tuvalu, and Vanuatu had no women ministers appointed to a ministerial position (PARLINE database).

For some countries, the level of female representation at the national level is not necessarily reflected at the local level, and vice versa. In Mongolia, women make up 4 percent of parliament's members at the national level, but they represent 22 percent at the subnational level (UNDP 2010). Overall, local government-level participation in Cambodia was 15 percent in 2007, similar to the national estimate, but elected women at the commune level and people's level was only 11 percent and only 3 percent at the people's chief level (Labani and others 2009).

\section{Protection from gender-based violence and loss of freedom}

Violence and the threat of violence deprive all people of their freedom and undermine their well-being. This section discusses the persistence of domestic violence against women, the intergenerational impacts of violence against children, and rising concerns about human trafficking. 


\section{Gender-based violence}

Countries in the East Asia and Pacific region have among the highest numbers of trafficked people in the world, and the Pacific has the highest incidence of violence against women in the world. Gender-based violence is internationally recognized as "any act of gender-based violence that results in, or is likely to result in, physical, sexual or psychological harm or suffering to women, including threats of such acts, coercion or arbitrary deprivation of liberty, whether occurring in public or in private life" (UN 1993). Violence against women can take the form of physical, sexual, and psychological harm and can take place within the private or the public sphere, or can be in the form of the human trafficking of women and girls, among others. Violence against women is historically underresearched and underreported because of a variety of factors, including the sensitivity of the topic and concerns for the safety of respondents. Despite the lack of easily comparable international statistics over time, the increasing availability of studies shows that violence against women is a major concern for many countries in the region, and particularly in the Pacific.

\section{FIGURE 4.11 Women's representation in parliament has grown in much of East Asia but has experienced little change in the Pacific Islands}

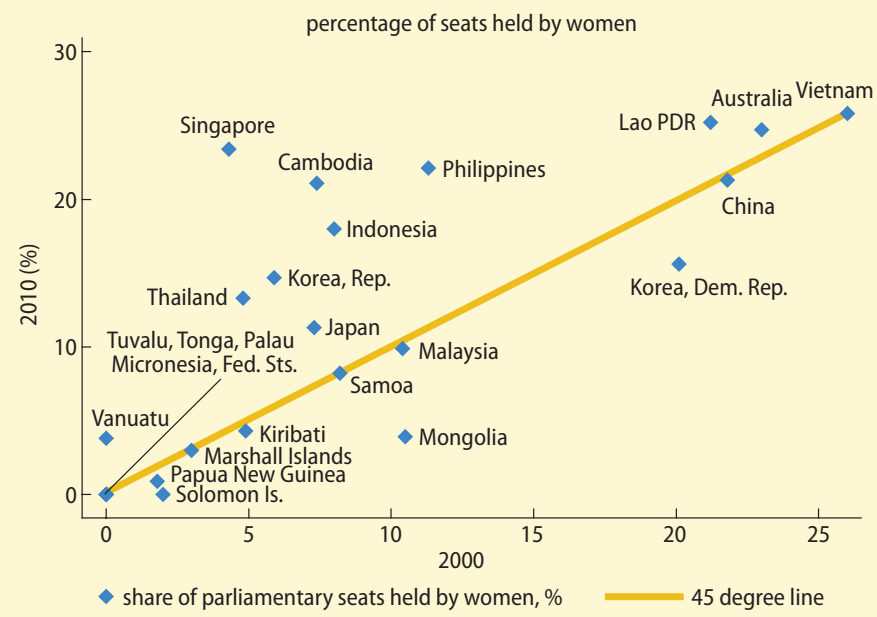

Source: PARLINE database, 2012 data.

\section{FIGURE 4.12 Women's representation in parliament is low, especially in the Pacific}

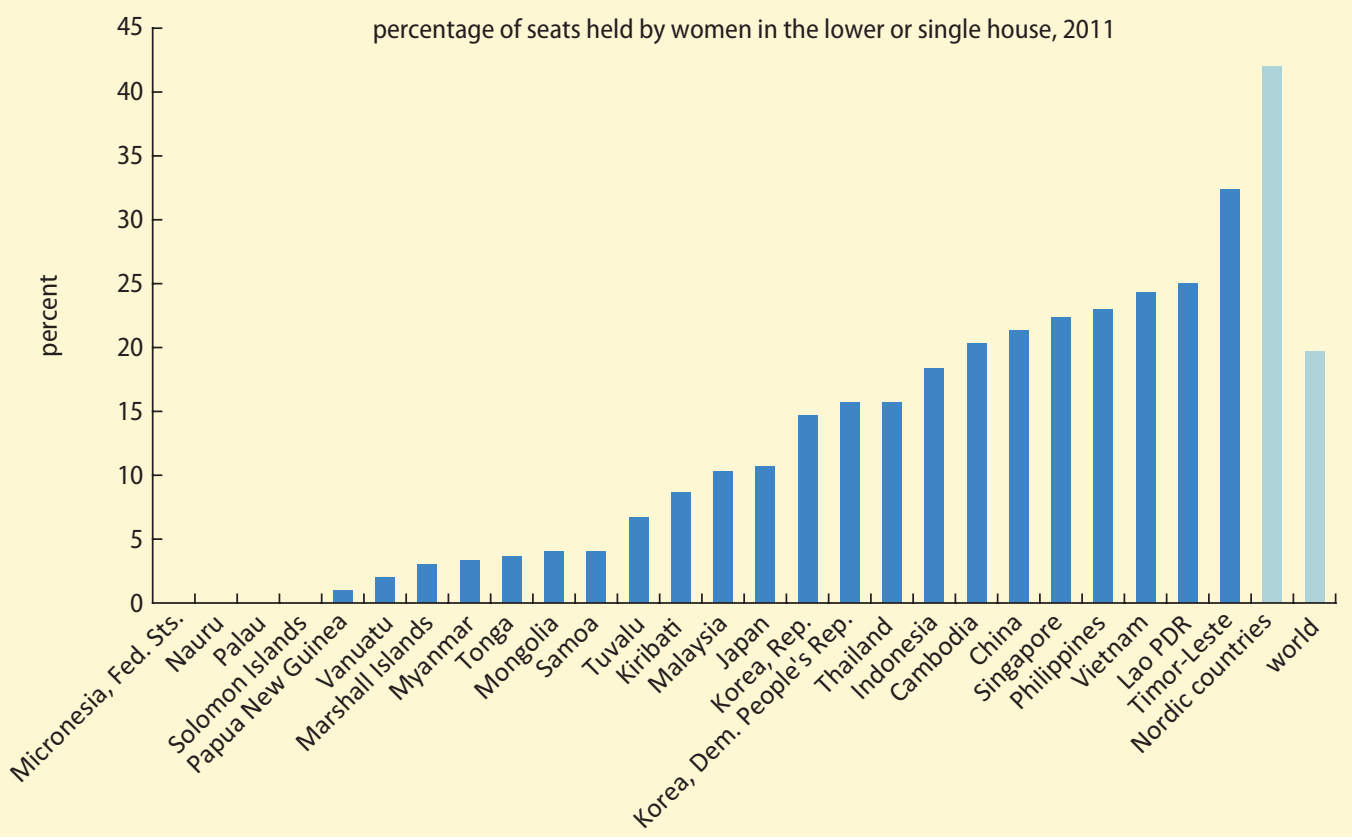


Consistent with international patterns, women in the region are at far greater risk from violence by an intimate partner or somebody they know than from violence by other people. In East Asia and the Pacific, the prevalence of violence by an intimate partner has a wide range (figure 4.13). Some areas in East Asia, including the provinces of Bangkok and Nakhonsawan, Thailand, have a high incidence rate (44 percent). Evidence from the Pacific Islands suggests that violence is endemic. As shown in figure 4.13, 68 percent of ever-married women ages 15 to 49 in Kiribati, 64 percent in the Solomon Islands, and 60 percent in Vanuatu have experienced physical and/or sexual violence by an intimate partner (SPC and NSO 2009; SPC, Ministry of Internal and Social Affairs, and Statistics Division 2010; VWC and NSO 2011). Although no nationally representative data exist for Papua New Guinea, recent regional studies suggest that violence is just as prevalent (Ganster-Breidler 2010; Lewis et al. 2008).

Sexual violence at the hands of an intimate partner is a significant concern in much of the Pacific. In most of East Asia, barring Thailand, physical violence against women far exceeds

\section{FIGURE 4.13 Violence against women is high in the region}

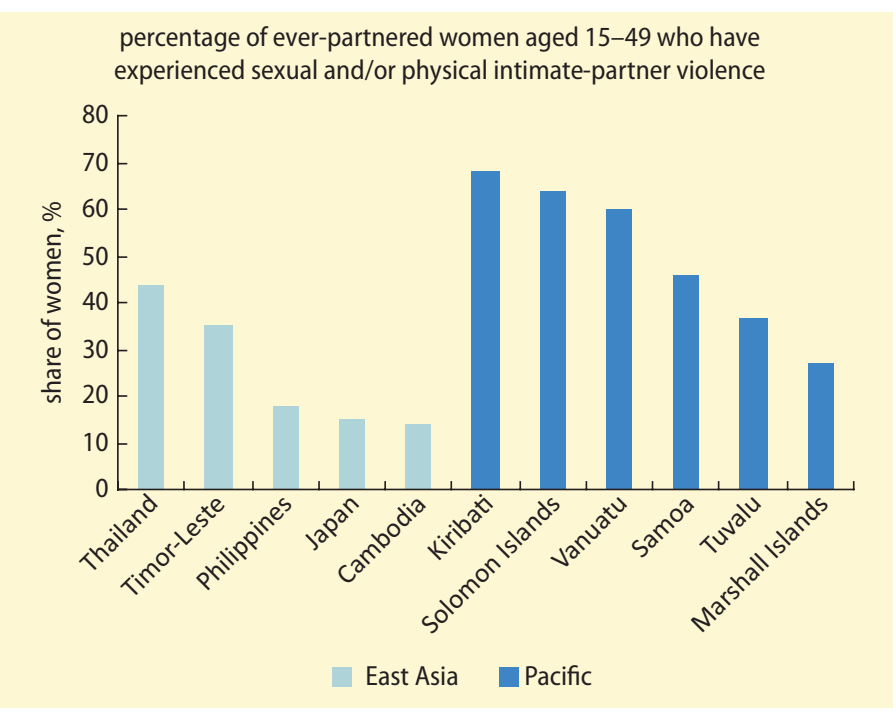

Source: DHS reports, various years.

Note: Data for Thailand are for Bangkok and Nakhonsawan provinces only; data for Japan are for Yokohama only. sexual violence. In the Pacific, however, both physical and sexual violence are extremely high. In the Solomon Islands, sexual violence by an intimate partner is more prevalent than physical violence. Sexual violence by nonpartners is also prevalent, as is childhood sexual abuse (SPC and NSO 2009).

Emotional and psychological violence, as well as harassment, are also common in the region. In 2005, over 30 percent of the region's women in the labor force reported having experienced some form of genderbased harassment-verbal, physical, or sexual (Haspels et al. 2001; UN 2006). Psychological and emotional violence is also pervasive and debilitating, but such violence is often underreported because it is frequently viewed as normal behavior. ${ }^{4}$ In Vietnam, over half of ever-married women reported lifetime emotional abuse from their spouse, with 25 percent reporting abuse in the past 12 months (World Bank 2011a). In Cambodia, the Philippines, and Vietnam, the prevalence of emotional violence far exceeds that of physical and/or sexual violence by an intimate partner. In Kiribati, the Solomon Islands, and Vanuatu, the high prevalence of emotional violence by an intimate partner matches the high incidence of physical and/or sexual violence (World Bank 2011a; SPC and NSO 2009; SPC, Ministry of Internal and Social Affairs, and Statistics Division 2010; VWC 2011). Conversely, women in TimorLeste experience a high prevalence of physical violence, yet very low levels of emotional and sexual violence (NSD [Timor-Leste], Ministry of Finance, and ICF Macro 2010).

\section{Violence against children- Intergenerational impacts}

In some societies in the Pacific there is still have violence against children. One study found that sexual violence has increased, in part because of low access to services and poverty faced by families and the rising prevalence of the logging, mining, and fishing industries, which employ large numbers of single men who seek the services of young women (UNIFEM 2010). The prevalence of sexually related violence against girls under 
the age of 15 in Vanuatu is 30 percent; and for most of these children, assaults are repetitive and carried out by family members (54 and 55 percent, respectively) (VWC and NSO 2011). In Vanuatu, the figure was 40 percent. Child prostitution in Fiji, Papua New Guinea, and the Solomon Islands is an organized venture with formal and informal brothels in urban centers (UNIFEM 2010).

Data also show that effects of violence are transmitted across generations. Domestic violence, and its acceptance, continues to be passed from parent to child (Fehringer and Hindin 2009). In Vanuatu, an estimated 57 percent of children whose mothers experienced violence either saw or heard the violence when it happened. Not only did these children witness the violent episodes, but many (17 percent) also experienced a beating at the same time (VWC and NSO 2011). As shown in figure 4.15, children in Kiribati who witnessed violence between parents while growing up are more likely to experience violence themselves as adults than those who did not witness violence between their parents (SPC, Ministry of Internal and Social Affairs, and Statistics Division 2010). Daughters of violent men have also been shown to be more likely to endure violence from their husbands later in life. In Timor-Leste, women whose fathers beat their mothers are more than twice as likely to experience emotional, physical, or sexual violence from an intimate partner than women whose fathers or mothers were not abusive, at 59 percent versus 24 percent (NSD, Ministry of Finance, and ICF Macro 2010).

The intergenerational consequences of violence also affect child development. In the Solomon Islands, one study shows that children who witness violence are more likely to grow up very timid or withdrawn, to repeat a year or more in school, and, in many cases, to be aggressive and likely to run away from home at an early age (SPC 2009).

\section{Human trafficking}

Human trafficking is also a growing concern throughout the region. An increase in female migration in the past decade has
FIGURE 4.14 The incidence of sexual intimate-partner violence is significantly higher in the Pacific

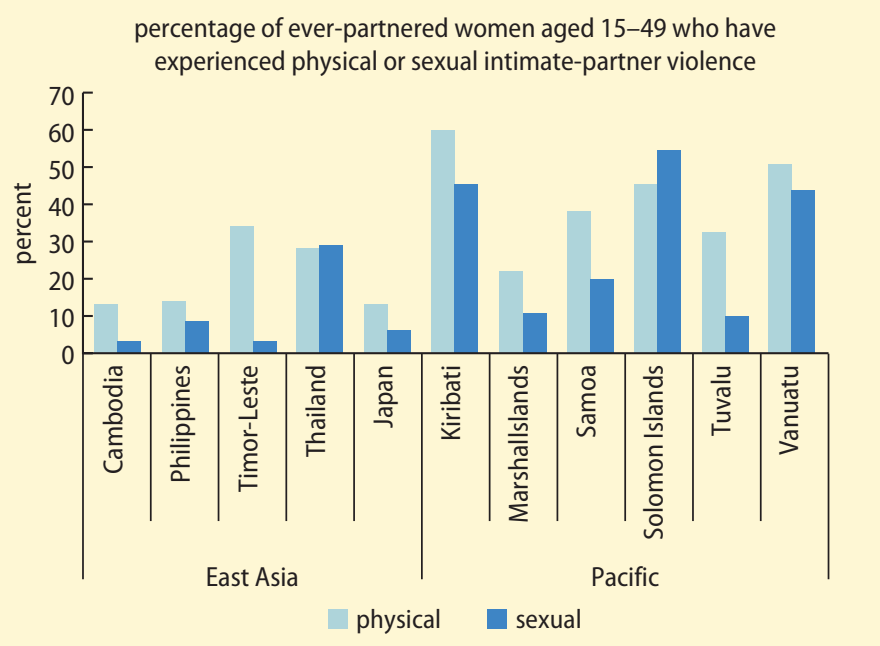

Source: DHS reports, various years.

Note: Data for Thailand are for Bangkok and Nakhonsawan provinces only; data for Japan are for Yokohama only.

\section{FIGURE 4.15 Gender-based violence can have inter-generational consequences}

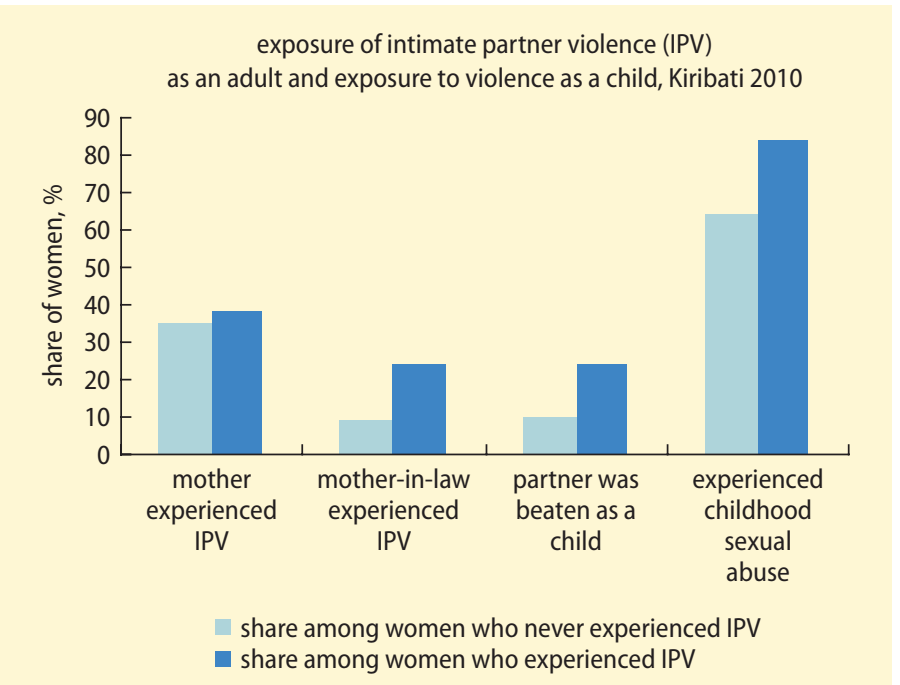

Source: SPC, Ministry of Internal and Social Affairs, and Statistics Division 2010

increased economic opportunities as well as increased the risk of being trafficked (ILO 2009). Human trafficking encompasses forced labor, sex trafficking, bonded labor, debt bondage among migrant laborers, involuntary domestic servitude, forced child labor, sale of children (including bride price), child 
conscription to be soldiers, and child sex trafficking (U.S. Department of State 2011). Although estimates are difficult to generate, the International Labour Organization estimates that Asian and Pacific countries account for over half of all trafficked victims worldwide, at an estimated 1.36 million, most of whom are women and girls (ILO 2008). Studies show that women and girls are the main victims of sexual exploitation in East Asia and the Pacific. Women are also more likely than men to be trafficked for economic exploitation. Although women and children seem to be at higher risk for exploitation, men are also trafficked within and from the region. For instance, in Thailand, women make up the majority of those who are trafficked for commercial sexual exploitation; however, men, women, and children from neighboring countries are also trafficked for labor purposes, for example in fisheries and fishing related industries and domestic work (ILO 2008; UNFPA 2006, U.S. Department of State 2011).

Human trafficking is pervasive throughout the region; however, the nature of the industry varies. The Greater Mekong region and Indonesia are two main hubs for human trafficking. Thailand is both a destination and source country. The country serves as a transit hub to other Asian countries, Australia, the United States, and Western Europe (UNFPA 2006). In two southern counties in Yunnan, China, most women and children are trafficked for forced marriage or adoption. Rural men are willing to pay substantial sums for a trafficked bride who can bear children and extend the family line. Families will pay traffickers for infant boys, whom they will adopt as their own (ILO 2005). Although internal bride trafficking is frequently reported in China, systematic empirical research does not exist. In countries such as Japan and Korea, the majority of human trafficking reported is in the sex trafficking industry. In Cambodia, one study found a strong link between migration from domestic work into commercial sexual exploitation (51 percent of commercially sexually exploited women and girls were previously domestic workers). The same study found that the majority ( 89 percent) of child domestic workers are female (E. Brown 2007).

\section{Explaining progress and pending challenges}

Women's ability to exercise voice in their homes and in society has experienced progress in some areas and challenges in others across East Asia and the Pacific. A complex combination of factors that affect progress includes socioeconomic characteristics, social norms and practices, and a country's legal environment, including women's access to justice. The strength of civil society is an indicator of voice in itself, but it also functions as a means by which individuals can collectively influence decisions that affect gender inequality. Because the extent of women's agency is driven by a combination of factors, this section discusses several influencing factors in turn.

\section{Individual characteristics}

Women's agency is affected in a fundamental way by their endowments and economic opportunities. High educational attainment, good health, economic assets, and their own earnings can enable women to influence their circumstances in accordance with their preferences.

As a woman's education level increases, it expands her knowledge and opportunities and improves her ability to translate her preferences into desired outcomes. Increases in education are positively correlated with women's increased bargaining power (Cochrane 1979; Jejeebhoy 1995). Education creates opportunities for women to connect with the world by removing barriers to knowledge and information. Higher academic achievement can also facilitate better economic opportunities and decrease economic dependency on others. In Indonesia, women who obtain an educational level of secondary school or higher are more likely than less-educated women to participate in decisions involving their own health care, make household purchases, and engage 
more regularly in social activities (DHS 2002-03 data).

Higher education can also facilitate women's entry into politics, whereas little or no formal education can greatly hinder women's participation in politics. In Rudong County in China, women involved in local government had a much higher level of education than average local female villagers; about 68 percent of them had reached senior high school education levels or above (Wang and Dai 2010). Where women have low levels of education-overall, as well as relative to men-they are even less likely to participate in politics. As a result, their voice, which often reflects different preferences than men's, is even less likely to be heard (UNDP 2010). In some contexts, the legal environment can exacerbate this situation. In Cambodia, indigenous women's participation in local politics remains low because they lack the education level and language skills necessary to be active participants. The law in Cambodia mandates that a person must speak, read, and write Khmer in order to run for political office (Maffii and Hong 2010).

Women who are more educated are less likely to experience violence in their household and hold higher perceptions of self-worth with regard to violence against women. Gender-based violence is more prevalent among illiterate women, partly because women are more likely to be economically dependent on their husbands and feel they have to endure an abusive relationship to survive. This situation is evidenced in some countries in the Pacific where bride price, young age of marriage, and lack of education for women perpetuate violence; leaving the marriage would involve having to repay the bride price, and the women commonly have no resources to do so (UNIFEM 2010, SPC and NSO 2009; SPC, Ministry of Internal and Social Affairs [Kiribati], and Statistics Division 2010; VWC and NSO 2011). In Samoa, 48 percent of women with vocational or higher education agree that a husband is justified in hitting or beating his wife, compared with the 69 percent of women with primary or lower levels of education who believe wife beating is legitimate ( $\mathrm{MOH}$ [Samoa], Bureau of Statistics, and ICF Macro 2010).

More educated women have greater economic opportunity, which in turn increases their agency. Women with more education are more equipped to take on skilled occupations and do better in the labor market, on average, than those with little or no education. Moreover, gender gaps in earnings tend to be smaller as females move up the skills ladder. Furthermore, education and skills training is invaluable to entrepreneurship. Low levels of skills and inability to access information have been suggested as hindering women in the Solomon Islands from becoming viable entrepreneurs (Haque and Greig 2011).

Increases in women's educational attainment and relevant training contribute to increasing women's participation in leadership roles in the private sector. However, despite advancements in educational attainment in much of the world, qualitative evidence suggests that the women continue to face genderspecific obstacles in the workplace. Female board members in Hong Kong SAR, China, for instance, argue that in order for companies to appoint qualified-well educated and trained-women to their corporate boards, there needs to be support for women moving up the career ladder to become board members (Mahtani, Vernon, and Sealy 2009).

Women's assets and own income can also increase women's agency within and outside the household in multiple ways. For example, power within the household has been attributed to individual control over economic resources such as individual incomes, assets, and wealth (Quisumbing and Maluccio 2003; Rammohan and Johar 2009; Thomas and Chen 1994). Evidence from the literature on intrahousehold resource allocation shows that increases in women's share of earned income in the household result in an allocation of resources that better reflects the preferences of women, and subsequently leads to improvements in women's overall status in the household and society (Ashraf, Karlan, and Yin 2006; Duflo 2003; Rangel 2005). Evidence also suggests that a woman's ownership and control of her own assets and 
income are associated with a decreased risk of intimate partner violence, at least in the medium term (ICRW 2006; Panda and Agarwal 2005; Pronyk et al. 2006; Swaminathan, Walker, and Rugadya 2008). A woman's income can also positively affect the accumulation of assets, which significantly affects her ability to leave an abusive partner, to cope with shocks, and to invest and expand her earnings and economic opportunities (World Bank 2011b). Women's own health has been found to improve women's relative positions in households, even when households experience adverse shocks (Aizer forthcoming; Dercon and Krishnan 2000).

Economic empowerment in the form of employment can also increase agency by increasing a woman's physical mobility. The ability to move freely means greater ability of women to expand their knowledge, broaden their networks, and create outlets to exercise collective agency through engagements in unions, professional associations, women's groups, and other types of civil society organizations. Civil society has worked to create an environment that enables women to better exercise their agency as well as a vehicle through which women can exercise their collective agency to change rules, regulations, laws, and social norms that positively affect gender equality.

Improvements in women's socioeconomic characteristics may not be sufficient to increase their voice and influence in society, however. Progress in women's economic position can threaten preexisting social norms with regard to women's role in the household and society and lead to undesirable outcomes, at least in the short run, including increased violence against women (Hjort and Villanger 2011; Panda and Agarwal 2005). For instance, in Timor-Leste, the proportion of women who have ever experienced physical violence from an intimate partner is highest among women with more than secondary education (46 percent), women belonging to households in the highest wealth quintile (45 percent), and women who are employed for cash (43 percent) (NSD, Ministry of Finance, and ICF Macro 2010). Evidence suggests that increases in violence may be transitional phenomena, as men and women adjust to new roles. This transition can be aided by a supportive legal and regulatory environment.

Male attributes, attitudes, and behaviors also correlate with gender-based violence. Studies in the Pacific Islands of Kiribati, the Solomon Islands, and Vanuatu found that the most significant risk factors associated with women experiencing physical and/or sexual violence in their lifetime are the characteristics of a woman's husband or partner. A woman is significantly more likely to experience violence if her husband or partner controls her behavior, drinks alcohol or home brews, has affairs with other women, is violent with other men, or is unemployed (SPC and NSO 2009; SPC, Ministry of Internal and Social Affairs, and Statistics Division 2010; VWC and NSO 2011). In the Philippines, husbands from the lowest wealth quintile and with the least educational attainment are the most likely to physically abuse their wives (Philippine Commission on Women 2012). In Vanuatu, the Solomon Islands and Kiribati, a husband's lack of employment and high alcohol consumption and drug use are correlated with a higher likelihood of physical and/or sexual intimate-partner violence (SPC and NSO 2009; SPC, Ministry of Internal and Social Affairs [Kiribati], and Statistics Division 2010; VWC and NSO 2011).

\section{Social norms and practices}

Social norms and practices provide powerful undercurrents that influence preferences, values, and the social behavior that govern gender relations and outcomes. Social norms that perpetuate gender inequality in voice and influence can range from explicit to subtle. They can encourage behavior that on the surface seems to reflect choice but in fact can constrain what is possible for women, whether in the home or in society (Kabeer 1999).

Social norms regarding women's traditional role in the household and in society affect her social bargaining power. In most countries in the region and in the world, housework, child rearing, and care of the 
elderly are normally considered the responsibility of a woman, while men are considered the main financial provider of the family. Qualitative evidence from Fiji and Papua New Guinea shows that girls are expected to work around the house from a very early age, while boys have fewer household responsibilities and are expected to become wage earners (World Bank 2011e). As discussed in chapter 3, these social norms influence the other factors that affect agency, such as earnings capacity and asset accumulation, as well as constrain the choices an individual can make. In other words, traditional social norms may strongly discourage women from pursuing occupations traditionally dominated by men, as well as make it difficult for men to take on traditionally female roles, thus affecting the agency of both genders.

Female expectations in the household often mean that women have less time-and thus fewer networks-to exercise influence outside the home. Other societal expectations, such as having larger families, can increase women's time spent in the household and minimize other activities in society (Freeman 1997; Pritchett 1994). Focus group discussions in Fiji suggest that although men and women may agree in principle on the idea of equal economic opportunity for both genders, in practice, men are the more feasible breadwinners, since women have household responsibilities that family and society expect them to attend to first. Female youth in the community of Baulevu stated that men in the household can hold formal jobs more easily than women because women first have the responsibility to care for and feed the children as well as tend to other household needs before leaving for work (World Bank 2011e).

Gender norms and societal expectations about women's ability to participate in the public sphere hinder participation. Data from the World Values Survey show that many men and women from across the region believe that men make better leaders than women (figure 4.16). Women's participation in voting has sometimes been compromised by their lack of information. One study shows that in rural areas of China, women ask their male family members to write the ballot for them at an election, or they take the opinion of their male family members. In that region of China, many people still think of women as less capable (disuzhi), and norms dictate that they should confine their activities to the domestic settings. This belief, largely based on perceptions that have been transmitted across generations and people, leads people to discourage women from voting or participating in public office (Wang and Dai 2010). Low female representation and participation in politics (as well as in leadership positions in the private sector) can reinforce each other, so that women are less likely to enter politics and other leadership positions because of social beliefs that men are better leaders than women, and women's absence prevents women from demonstrating their ability to lead (World Bank 2011c).

In most countries and in the Pacific Islands in particular, violence against women is perceived as acceptable or justifiable by both men and women. In the Solomon Islands, 73 percent of women believe that a husband is justified in beating his wife under certain

\section{FIGURE 4.16 Many men and women in the region believe that men make better political leaders than women}

$$
\begin{aligned}
& \text { share of men and women over age } 30 \text { who think men } \\
& \text { make better political leaders }
\end{aligned}
$$

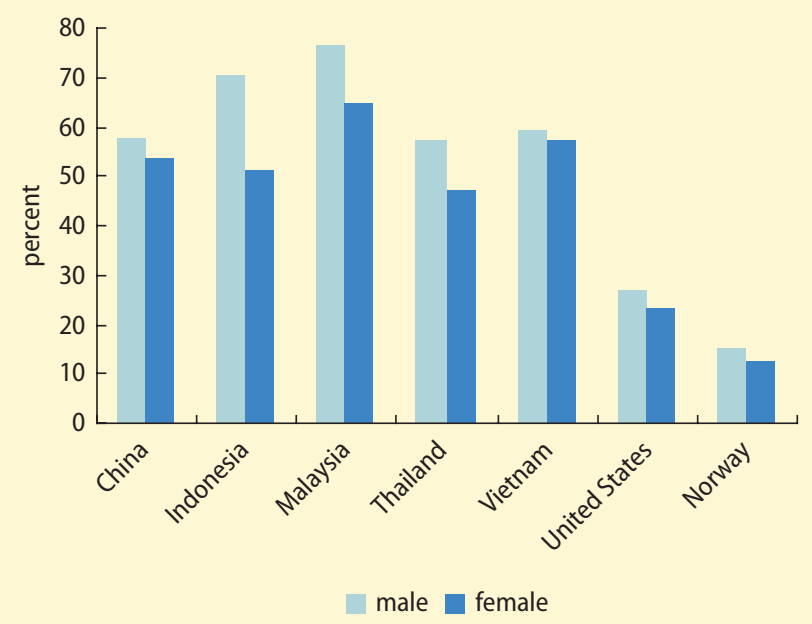

Source: World Values Survey, 2006 and 2007 data. 
circumstances. ${ }^{5}$ In Vietnam, 64 percent of women ages 15 to 49 accept violent treatment from husbands as normal (Vietnam Multiple Indicator Cluster Survey, 2006 data). Men also perpetuate these social norms: 81 percent of men in Timor-Leste believe that beating wives is socially acceptable and justifiable under certain circumstances (NSD, Ministry of Finance, and ICF Macro 2010). These attitudes and acts of violence may be intensified during times of conflict. Violence against women is believed to have reached its height in some areas of the Papua New Guinea Highlands during tribal fighting in 1995-96. During that time, gang rape of women was often considered to be a normal aspect of intervillage conflict (Brouwer, Harris, and Tanaka 1998).

Long-standing cultural practices, such as bride price, affect women's perceptions of their roles within marriage, and therefore their voice. In Vanuatu, about 81 percent of marriages involve a bride price paid to the family of the bride. Over half of women ages 15 to 49 in this country believe that, if a bride price is paid, a wife becomes the husband's property (VWC and NSO 2011). In both Vanuatu and the Solomon Islands, bride price is significantly associated with intimate partner violence (SPC and NSO 2009; VWC and NSO 2011). In East Asia, paying for a bride is a tradition across China, Indonesia, Myanmar, and Thailand (Anderson 2007). Although the practice has become less important in Indonesia, in rural China, where the tradition is still practiced, the groom pays for the rights to the woman's labor and reproductive capabilities (Boomgaard 2003). Similar to what is found in the Solomon Islands and Vanuatu, many young girls in China grow up with the belief that they will eventually become a man's property with little control over their lives (P. Brown 2003; Zhang 1999).

Social expectations of men's roles in society can influence men's actions and harm women's safety and overall agency. The incidence of intimate partner violence is often associated with societal expectations of men's roles in the home and in society, and can be exacerbated by male alcoholism and financial hardship (Heise 2011). In the region, men are subject to a substantial amount of social pressure to be the main provider in the household. Therefore if a man's wife defies traditional social norms and starts earning a higher income than her husband, for instance, this situation may challenge the role of the man as provider of the family, creating stress and resistance.

Deep-seated attitudes that fuel discrimination and enable gender inequality continue to be perpetuated in society by being taught to children. Recent studies show that social attitudes held by both men and women fail to foster an environment conducive to having equality between men and women. In Kiribati and Vanuatu, 56 percent and 50 percent of women, respectively, believe that a good wife must obey her husband at all times. Women in these countries also believe a man should show his wife that he is the boss (61 percent and 40 percent, respectively) (SPC and NSO 2009; SPC, Ministry of Internal and Social Affairs, and Statistics Division 2010). Children grow up absorbing these attitudes and behaviors, accepting them as norms they must follow, and girls internalize their subordinate role in the household and lesser status in society (Bourdieu 1977; Kabeer 1999; see also chapter 2).

\section{The legal and institutional environment}

The legal setting and access to justice form the environment in which men and women can voice and act on their preferences. Whether women and men are equally supported under the law and whether their rights are protected in practice are critical to women's ability to have voice and influence in society directly. This environment also affects voice by affecting the channels through which women build their access to resources and economic opportunity, which, in turn, affects their voice. The law and access to justice are shaped by, but can also shape, the norms that affect women's agency in society.

Equally as important is women's equal access to the judiciary system, which can be influenced by social norms or socioeconomic 
characteristics. For example, a legal court may be a day and a half trip away from home, yet social norms discourage women from sleeping outside the household. Or higher illiteracy rates of elderly women hinder their ability to know their rights. Countries in East Asia and the Pacific have made varying degrees of progress in guaranteeing and enforcing equal rights for men and women. As discussed in the previous section and in chapter 2, several countries in the region have plural legal environments, in which the interaction of customary or religious law and statutory law means that women's legal stature can vary substantially across ethnic groups, even within a country.

\section{International conventions, national laws, and institutions}

Nearly all countries in the East Asia and Pacific region have acceded to and ratified international commitments to reduce genderbased discrimination and promote agency for women as laid out by the Convention on the Elimination of All Forms of Discrimination Against Women (CEDAW), with a few exceptions. The ratification of CEDAW indicates a public commitment by governments to abide by a set of internationally recognized standards regarding gender equality. As of the end of 2011, only six countries in the world have not ratified the CEDAW agreement, including Palau and Tonga in the Pacific (CEDAW 2012).

The signing of CEDAW has served as an instrument to open up space for people to argue for legal and institutional reform to promote women's agency. In several East Asian countries, legal and institutional reforms came about after the ratification of CEDAW, at the behest of CSOs and government agencies arguing for the fulfillment of their countries' international commitments. For instance, individuals, CSOs, and government agencies tasked with women's issues in Cambodia, Indonesia, the Philippines, Thailand, and Vietnam used CEDAW conventions and frameworks as the basis for promoting women's participation in local government and for examining whether existing laws on violence and discrimination against women were aligned with the convention. The organizations then used this information to advocate for an overhaul of existing laws or propose new ones to rectify omissions (UNIFEM 2010).

Beyond CEDAW, many countries in the region have put in place domestic laws to support the advancement of women and gender equality (UNDP 2010). In the past 10 years, gender equality laws such Vietnam's Gender Equality Law (2006), the People's Republic of China Law on the Protection of Rights and Interests of Women (amended in 2005), Lao PDR's Law on the Development and Protection of Women (2004), and the Philippines' Magna Carta of Women (2009) have been adopted with the aim of providing a more comprehensive approach to addressing gender equality. Most countries in the region have also adopted domestic violence legislation over the same period, including Cambodia, China, Indonesia, Korea, Lao PDR, Malaysia, Mongolia, Papua New Guinea, the Philippines, Thailand, Timor-Leste, and Vietnam. Papua New Guinea, for example, reformed its criminal code in 2002 to dramatically change its sexual assault regime by introducing grading of offenses according to the gravity of harm and eliminating marital immunity. Still, many countries (mostly Pacific Island states) lack adequate legislation for gender equality (UNDP 2010).

Most countries in the region have equal rights under inheritance laws, as discussed in chapter 2. Evidence from India suggests that women who own a house or land significantly reduce their risk of marital violence (Agarwal and Panda 2007). The majority of countries in East Asia no longer differentiate by gender in statutory law. Cambodia, China, Lao PDR, Mongolia, Thailand, and Vietnam do not have plural legal systems and have legislation for property and inheritance rights that have no discrimination against women. However, plural legal systems exist in Indonesia, Malaysia, the Philippines, and Singapore, and these laws discriminate against women in inheritance (see chapter 2 for more details). In the Pacific, Kiribati and Tuvalu have unequal statutory 
legislation, and although equal inheritance laws exist in Fiji, Papua New Guinea, Samoa, the Solomon Islands, and Vanuatu, customary law practices regarding land rights are recognized by the constitution and may lawfully discriminate against women (Jivan and Forster 2007). Although many areas of the Pacific region have traditionally had matrilineal land ownership-where land has historically been transmitted through mothers' lines-in practice, men most often make decisions regarding land management (Stege et al. 2008).

In regard to gender-based violence, gaps in the law still remain across the region (UNDP 2010). As illustrated in table 4.1, several countries in the region continue to have legal gaps in the protection of women against genderbased violence. Many of the countries where violence against women is the most prevalent do not have legislation against it, including Kiribati, the Marshall Islands, Papua New Guinea, Samoa, the Solomon Islands, TimorLeste, and Tuvalu.
Important gaps also occur in laws protecting against human trafficking, despite efforts by many countries to pass specific legislative provisions. Between 2005 and 2008 about 10 countries in Asia and the Pacific (including South Asia) introduced new laws or modified old ones (UNODC 2009). However, some countries still lack comprehensive laws to protect men and women vulnerable to trafficking. Thailand and Vietnam, for example, do not have provisions on the exploitation of humans. Some progress has been made on this front in Indonesia, Malaysia, and the Philippines, where mandates against exploitation of women were introduced in the recent past (2007, 2007, and 2003, respectively). In Lao PDR, trafficked humans are treated as victims who have legal immunity from criminal prosecution for prostitution, and they are provided specific services to reunite them with their families, namely legal, medical, and counseling services, all imparted by the Lao Women's Union (U.S. Department of State 2008).

\section{TABLE 4.1 Legislation against gender-based violence}

\begin{tabular}{|c|c|c|c|c|c|}
\hline Region/ Country & $\begin{array}{l}\text { Domestic } \\
\text { violence }\end{array}$ & $\begin{array}{c}\text { Sexual } \\
\text { assault/rape }\end{array}$ & $\begin{array}{c}\text { Sexual harassment } \\
\text { at workplace }\end{array}$ & CEDAW 1979 (c) & $\begin{array}{l}\text { CEDAW optional } \\
\text { protocol } 1999 \text { (d) }\end{array}$ \\
\hline \multicolumn{6}{|l|}{ Pacific } \\
\hline Fiji & Yes & Yes & No & 1995 & Not signed/Not ratified \\
\hline Kiribati & No & Yes & No & 2004 & Not signed/Not ratified \\
\hline Palau & NA & NA & NA & NA & Not signed/Not ratified \\
\hline Papua New Guinea & No & Yes & No & 1995 & Not signed/Not ratified \\
\hline Marshall Islands & No & Yes & No & 2006 & Not signed/Not ratified \\
\hline Micronesia, Fed. Sts. & No & No & No & 2004 & Not signed/Not ratified \\
\hline Samoa & No & Yes & Yes & 1992 & Not signed/Not ratified \\
\hline Solomon Islands & No & Yes & No & 2002 & 2002 \\
\hline Tonga & NA & NA & NA & Not signed/Not ratified & Not signed/Not ratified \\
\hline Tuvalu & No & Yes & No & 1999 & Not signed/Not ratified \\
\hline Vanuatu & Yes & Yes & No & 1995 & 2007 \\
\hline \multicolumn{6}{|l|}{ East Asia } \\
\hline Cambodia & Yes & Yes & Yes & 1992 & Signed \\
\hline China & Yes & Yes & NA & 1980 & Not signed/Not ratified \\
\hline Indonesia & Yes & Yes & No & 1984 & Signed \\
\hline Lao PDR & Yes & Yes & NA & 1981 & Not signed/Not ratified \\
\hline Malaysia & Yes & Yes & No & 1995 & Not signed/Not ratified \\
\hline Mongolia & Yes & Yes & No & 1981 & 2002 \\
\hline Philippines & Yes & Yes & Yes & 1981 & 2003 \\
\hline Thailand & Yes & Yes & Yes & 1985 & 2000 \\
\hline Timor-Leste & No & Yes & Yes & 2003 & 2003 \\
\hline Vietnam & Yes & Yes & No & 1982 & Not signed/Not ratified \\
\hline
\end{tabular}

Source: UNDP 2010. 
Even when countries have appropriate legislation in place, women may be unprotected by the legal system because the laws remain largely unenforced. A recent study highlighted that officers in the Fiji Police Force Sexual Offences Unit, which was set up in 1995, have unwelcoming attitudes when dealing with female victims (UNFPA 2010). The same is true in some areas in Cambodia, where many law enforcement officials are either unaware of the existence of the 2005 Law on the Prevention of Domestic Violence and the Protection of Victims, or continue to believe that domestic violence is an internal family problem (CAMBOW 2007). Even in cases where the police or other formal institutions condemn these acts, they are unable to pursue them further because of inadequate training to respond to the reports or fear of reprisal from the perpetrators, especially in cases in which they are people of influence (U.S. Department of State 2011). In Vanuatu, after a long period of lobbying by various CSOs and by the Vanuatu Women's Center, in 2008, the government passed the Family Protection Act, which focused on advancing women's rights. Implementation and enforcement of the law did not occur in more remote areas, leaving women unprotected and living under the previous legal (or traditional) system (AusAID 2008).

Furthermore, the interaction of customary practice and statutory law means that women's legal stature can vary substantially across ethnic groups, even within a country. Citizens in East Asian and Pacific countries often face a plurality of legal systems within a single country. Statutory laws interactand often compete-with customary (and sometimes religious) laws and practices. In the Pacific Islands, for example, virtually all constitutions state that the constitution is the supreme law, but they simultaneously recognize customary law (UNDP 2010). As a result, inheritance practices vary substantially across the region, from matrilineal systems in most of Micronesia and in parts of Melanesia to patrilineal systems in most other Pacific countries. The interaction between customary and statutory law can even result in discriminatory inheritance practices that vary substantially across subpopulations within a single country (box 4.1).

States that adopt a commitment to revise and develop laws and regulations that promote gender equality create more conducive environments for women to exercise their agency. As women's labor force participation has continued to increase, especially in less traditional occupations, some governments have been proactive and adjusted their protection and antidiscrimination laws. In the Philippines, for example, 85 percent of an estimated 2.5 million domestic workers are women. Despite their number, until recently domestic workers were excluded from enjoying the full range of rights guaranteed to other women in traditional occupations (in industry) under labor law. A bill is presently under way to address the gap and to guarantee women's right to decent working conditions and protection from abuse, trafficking, and exploitation (ADB et al. 2008). ${ }^{6}$

Over the past few decades, several countries in the region have put in place temporary special measures to promote female participation in political leadership. Gender quotas set a fixed goal for having women in decisionmaking positions, with the aim of at least a critical minority of 30 to 40 percent (Agarwal 2010a, 2010b). In the political sphere, quotas can be reserved seats (constitutional and legislative), legal candidate quotas (constitutional and legislative), and political party quotas (voluntary). Although reservation of seats regulates the number of women elected, the latter two types of quotas set a minimum for the share of women on the candidate lists, either as a legal requirement or as a measure written into the statutes of individual political parties. In East Asia, countries including China, Indonesia, Korea, the Philippines, Thailand, and Timor-Leste had reservation systems for the single or lower house, for the upper house, or at the subnational level (The Quota Project, 2012 data). Recently, the revised Pacific Platform for Action 2005-2015 called for governments in the Pacific subregion to put in place affirmative action measures to enhance women's participation in politics. 


\section{BOX 4.1 Gender and land tenure in a plural legal environment: The case of the Solomon Islands}

Land tenure in the Solomon Islands is characterized by multiple, overlapping arenas, norms, and institutions emanating from customary practice, the state, and Christianity. The intersection of customary and state legal systems allows only a small number of individuals, predominantly men, to exert control over customary land. This situation has occurred to the detriment of female landowners, who have often found themselves excluded from both decisionmaking processes and the distribution of financial benefits from the use of land.

In Guadalcanal Island, customs dictate that women be excluded from discussions about landrelated issues that occur in formal and state arenas such as courts or land acquisition hearings. A male child or brother is usually appointed as spokesperson for land-related issues. Women often have less education and, hence, are considered less able to understand the state legal system and manage land transactions. Moreover, some inhabitants of Guadalcanal state that custom dictates that women "no save tok" (cannot/must not talk) about land, and that they must stand behind men when speaking about land in the public arena.

Furthermore, women are limited in their ability to hold land titles. Although people commonly assert that "women are the real landowners," land and court records generally show names of a small number of male leaders as landowners. Though the state legal system requires that the titleholders consult with other landowners before dealing in the land, they often fail to do so, limiting women's roles and participation.

The state legal system also tends to recognize only a small number of individuals with the customary authority to speak about land inside a public arena, thereby turning the customary "right to speak" into effective ownership. A review of court records for West Guadalcanal suggests that the witnesses and parties to a dispute are predominantly senior male leaders. In addition to these individuals having greater authority to speak about the land, these rights are compounded by the court system being based on Western legal principles and an adversarial system. Land disputes are sometimes compared to warfare and are matters for men. Women and children are often advised to stay away from meetings regarding disputes. Hence, as hearings are generally conducted by male chiefs, clerks or judges are also likely to act as a further impediment to women's involvement.

Development of mechanisms for ensuring transparency and accountability is essential for sustained peace and security. Land programming would benefit from being gender sensitive and from paying attention to differential impacts on state legal frameworks and their implementation.

Source: Monson 2010.
Other countries, though not mandating quotas, have taken a strong stance on female representation in government as well as in the private sector. Lao PDR's National Socio-Economic Development Plan (NSEDP) 2011-2015 has stipulated a target to increase the female staff of high-ranking positions in government, political parties, and civil society organizations to at least 15 percent, and to increase women members in the National Assembly to more than 30 percent. Other goals include increasing the number and percentage of women in the paid workforce and in professional careers (Lao PDR Ministry of Planning and Investment 2011). China's Outline for the Development of Chinese Women
2011-2020 states that women's participation should be a 30 percent female-to-male ratio in village-level government committees and a 50 percent ratio in neighbor committees in urban areas, with at least 10 percent of village committee heads being women.

\section{Access to justice}

Providing access to the justice system-by reducing financial costs, bringing services to remote areas, and helping overcome social and psychological constraints-is critical to helping women exercise their agency. Legal reform should not be limited to fixing the laws; it should also extend to ensuring access to the legal system. Women in poorer 
areas can be particularly disadvantaged in this regard because, compared with men, they may have lower education levels, travel outside their communities less often, have fewer resources to pay for the service, and face higher levels of discrimination once they reach places such as police stations and courts. Moreover, when they do have physical access to the justice system, they often face the risk of being treated unequally. In Indonesia, the legal system is vastly underutilized by subsets of women because courts and police stations are not financially or physically accessible. A recent study in Indonesia found, for example, that most female heads of household were unable to access courts to obtain divorce certificates. The average cost of a case filed with the religious courts is about US\$90, or four times the monthly per capita income for those living below the poverty line. In civil court, the cost of divorce with a lawyer is US\$1,100, or 52 times the monthly per capita income (Sumner and Lindsey 2011).

\section{Institutional reforms and opportunities for women}

Strengthening the capacity of institutions to enforce the law can improve the probability of the law being adopted and used. Once legal reform comes about, institutional capacity needs to be reinforced to prevent hindering implementation, access, and enforcement of the law. Moreover, institutions' role as implementers of the law can be hindered further by prevailing social norms. Evidence from many countries shows that government institutions charged with implementing laws related to preventing discrimination against women and enforcing gender equality initiatives lack the human capacity, financial resources, and influence to address gender issues. For

\section{TABLE 4.2 Political affirmative action in East Asia and the Pacific}

\begin{tabular}{|c|c|c|c|c|}
\hline Country & Year & Quota & Quota type & Results \\
\hline China & 2007 & $\begin{array}{l}\text { Legislated quotas for the single } \\
\text { or lower house }\end{array}$ & Reserved seats, $22 \%$ women & $\begin{array}{l}637 \text { of } 2,987 \text { seats }(21 \%) \text { held } \\
\text { by women in } 2008 \text { election }\end{array}$ \\
\hline Indonesia & 2008 & $\begin{array}{l}\text { Legislated quotas for the single } \\
\text { or lower house }\end{array}$ & $\begin{array}{l}\text { Quota of one in three } \\
\text { candidates on a political party } \\
\text { list to be women }\end{array}$ & $\begin{array}{l}101 \text { of } 560 \text { seats }(18 \%) \text { held } \\
\text { by women in } 2009 \text { election }\end{array}$ \\
\hline Korea, Rep. & 2004 & $\begin{array}{l}\text { Legislated quotas for the single } \\
\text { or lower house; legislated quotas } \\
\text { at the subnational level; voluntary } \\
\text { quotas adopted by political } \\
\text { parties }\end{array}$ & $\begin{array}{l}\text { Political party quota of } 50 \% \\
\text { women on candidate lists for } \\
\text { proportional representation } \\
\text { in elections; recommendation } \\
\text { for political parties to include } \\
30 \% \text { women candidates }\end{array}$ & $\begin{array}{l}44 \text { of } 299 \text { seats (15\%) held } \\
\text { by women in } 2008 \text { election }\end{array}$ \\
\hline Philippines & 1991 & $\begin{array}{l}\text { Legislated quotas at the } \\
\text { subnational level; voluntary } \\
\text { quotas adopted by political } \\
\text { parties (Philippine Democratic } \\
\text { Socialist Party, 25\% quota for } \\
\text { women) }\end{array}$ & $\begin{array}{l}\text { Women to be one of three } \\
\text { sectoral representatives that } \\
\text { sits in every municipal, city, } \\
\text { and provincial legislative } \\
\text { council }\end{array}$ & $\begin{array}{l}62 \text { of } 280 \text { seats }(22 \%) \text { held } \\
\text { by women in } 2010 \text { election }\end{array}$ \\
\hline Thailand & n.a. & $\begin{array}{l}\text { Voluntary quotas adopted by } \\
\text { political parties. }\end{array}$ & $\begin{array}{l}\text { The Democratic Party has } \\
\text { a target of 30\% women } \\
\text { candidates for election }\end{array}$ & $\begin{array}{l}79 \text { of } 500 \text { of seats (16\%) } \\
\text { held by women in the } 2011 \\
\text { elections }\end{array}$ \\
\hline Timor-Leste & $\begin{array}{l}2006 \text { and } \\
2011\end{array}$ & $\begin{array}{l}\text { Legislated quotas for the single } \\
\text { or lower house }\end{array}$ & $\begin{array}{l}\text { Modification of the Electoral } \\
\text { Law to require that } 33 \% \text { of } \\
\text { the candidates of each party } \\
\text { be female (from } 25 \% \text { ) }\end{array}$ & $\begin{array}{l}18 \text { of } 65 \text { seats }(28 \%) \text { held by } \\
\text { women in } 2007 \text { election }\end{array}$ \\
\hline
\end{tabular}


instance, in a report to the CEDAW Committee in 2009, the government of Papua New Guinea identified the lack of structures for promoting gender equality as a challenge to carrying out the tasks outlined in international commitments. Similarly, the Lao PDR National Strategy for the Advancement of Women in 2006 and Vietnam National Strategy for the Advancement of Women in 2010 cited low capacity of their national institutions as a problem, and asked for help to strengthen those institutions-through training and more resources-to make them more effective. To address the constraints in institutional capacity, countries such as the Philippines and Vietnam worked on improving their institutional structures and reinforcing mandates already in place to promote women's agency and subsequently promote gender equality (box 4.2).

Several countries use advocacy organizations that are part of government to proactively address women's issues. The Lao Women's Union and the Vietnam Women's Union are two examples of organizations formed to promote information sharing among women, educate women at all levels of society, and promote women's active participation in society. They mobilize women to be active participants in their community (and in political party-related activities) and work to protect women's rights and interests.

\section{Collective agency: Women's organizations and the space for civic action}

Civil society functions both as an indicator of voice and participation and as a lever to create the conditions that enable women to change the legal environment, public priorities, and social norms. It also can facilitate dialogue and cooperation between parties that can influence the other determinants of agency. Collective agency through civil society does not necessarily need to focus on women-specific issues, but instead, it provides a forum in which men and women can exercise voice on any issues they care about.

Civil society organizations, social movements, and civic activists have helped expand women's agency by magnifying their voice in public forums and strengthening women's influence. Having a collective voice, through mass movements, is critical

\section{BOX 4.2 Strengthening state mechanisms for gender equality}

Gender equality laws in the region also focus on the improvement of existing gender equality structures. The Philippine Magna Carta for Women, for example, strengthened the mandate of the Philippine Commission on Women as the primary policymaking and coordinating body on women and gender equality concerns, and emphasized the placement of qualified women in all government departments and their attached agencies. These measures include bringing local government units, government-owned and -controlled corporations, and other government instrumentalities into discussions of how best to ensure a gender balance in their workforce. The Magna Carta for Women strengthened the gender and development focal points by increasing resources and support. The government will evaluate the increased allocation based on the law's influence in making 95 percent of the budget gender-responsive. The law will be subject to an annual audit by the Commission on Audit.

Vietnam's Law on Gender Equality emphasized state responsibility to promote gender equality by identifying a state management agency to unify efforts by all of the government's gender equality entities as well as responsibilities of agencies to mainstream gender in their work. Moreover, Articles 20-22 of the law outline a process for integrating gender into legislation. A designated National Assembly Committee for Social Affairs, together with other parliamentary committees, shall verify the integration of gender equality issues in the draft law and ordinances by drafting agencies.

Source: UNDP 2010. 
in the process of influencing policy, culture, and social environments. Grassroots movements have been instrumental in changing attitudes and behaviors that maintain gender inequalities, such as those that limit women's participation in politics, by promoting new ideas and actively sharing information in the mainstream. In Indonesia, in 1997, a group of women got together to protest policies in response to the crisis that made them unable to afford powdered milk for their children. The group, known as Voice of Concerned Mothers (Suara Ibu Pedulu), was the first group led by women in the country since the beginning of Suharto's New Order (Robinson and Bessell 2002). These protests flourished and evolved into a collective voice representing mothers throughout the country. Its success prompted wider protests against the government, which contributed not only to ending the Suharto regime but also to creating new space for women to participate actively in the post-Suharto period (Rinaldo 2002).

CSOs and citizen movements have often facilitated dialogue and cooperation between ordinary women and those in public office. In Cambodia, CSOs helped promote awareness and political education among women through organizations such as the Women's Media Centre of Cambodia. Party-affiliated organizations, semigovernmental unions, as well as autonomous groups have served as incubators for female leaders to run for office or become appointees in key government positions. These gender grassroots movements worked effectively in promoting the participation of women in local politics through information dissemination campaigns. They concentrated much of their efforts throughout Cambodia producing written and graphic awareness materials-explaining women's rights, responsibilities, and the process for participating-and encouraging women to play an active role in politics. Currently, an increasing number of women organize forums at provincial levels to champion gender-related causes and to pressure politicians into action (Singh 2009).
In matters related to increasing women's role in policy making, intense lobbying efforts by gender-focused CSOs and civic activists have prompted changes in social behavior and engaged the commitment of politicians. Institutional factors such as parliamentary frameworks, coupled with societal norms, continue to hinder women's entrance onto the political stage (UNDP 2010). For instance, the Center for AsiaPacific Women in Politics-based in the Philippines with subregional offices in Fiji, Korea, Mongolia, and Nepal-is an active advocate for increasing the roles of women in politics. This and other similar CSOs actively lobby for expanding the capacity of women in decision-making roles and working toward gender equity in representation. In the Pacific, patterns showed decreasing participation of women in politics, prompting the group Women's Rights and Advocacy in the Pacific (WRAP) to recommit their lobbying efforts to promote women in public office and political leadership (WRAP 2011).

\section{Policy approaches to promote gender equality in agency}

The analysis thus far has focused on the state of agency in the East Asia and Pacific region and identified the factors that advance or constrain gender equality in agency. Knowing those factors can help to identify specific policies and programs to strengthen women's voice and influence in practice. What follows is an initial discussion, based on the evidence presented, about policy priorities for promoting gender equality in agency. Measures to increase women's endowments and economic opportunity, such as those described in previous chapters, contribute to strengthening their voice within the household and in society. Educated women in good health, with assets and income, are better able to act on their preferences and influence outcomes that affect themselves and others in society. In addition, several other policy approaches can directly promote women's agency. 
This section addresses the following factors: (a) supporting initiatives to transform gender norms and practices, (b) strengthening the legal and institutional environment, (c) increasing women's access to justice, (d) enabling women's participation in politics and policy making, (e) pursuing a multipronged approach to reducing gender-based violence, and (f) creating space for women's collective agency.

\section{Supporting initiatives to transform gender norms and practices}

Social norms are not static, and several factors can influence them. The preferences that men and women express at the individual and household level as well as in the public sphere are in part determined by their socially constructed gender roles. Individual experiences as well as large-scale political and economic processes are capable of bringing about dramatic, and often rapid, social change. China's 1949 Communist Revolution, for example, had the effect of reducing gender inequalities to an unprecedented extent (Bian, Logan, and Shu 2000; Whyte and Parish 1984; Wolf 1985). Moments of social change and structural transformation create opportunities for people to rethink their roles and choices. In East Asia, the process of rapid urbanization that is currently under way brings with it the possibility of newly defined roles for men and women. As more women participate in remunerative activities, rigid social norms are challenged. The education system can be a vital source to change gender inequality by promoting social norms from a young age. The integration of gender equality principles into the school and professional curricula can tackle the value system of children early on and challenge discriminatory social norms. In Indonesia, a recent project evaluated the textbooks used in various classes and found that they contained gender-biased material; the researchers identified messages that ignored or condoned sexual harassment, gender-based violence, and gender-based stereotypes (Utomo et al. 2009). Evidence of the positive effects of changing the curriculum is available for adults in Thailand, where gender sensitivity was integrated into the curriculum in the Chulalangkorn medical school. Evaluation of the program showed that respondents were more aware of gender issues and tended to apply gender concepts and concerns to their work and personal lives (WHO GWH 2007).

Provisions of information through television programming can also play a critical role in changing social norms, especially with respect to fertility and gender-based violence. Evidence shows that people can be prompted to rethink gender roles in society when they are exposed to new information and experiences that challenge existing norms. In Brazil, despite strong traditional norms in favor of having many children, increased exposure to the opposite behavior by popular women in soap operas led to a measurable decline in fertility (Chong and La Ferrara 2009; La Ferrara, Chong, and Duryea 2008). In India, increased exposure to television contributed to decreased acceptance of wife beating, lower fertility rates, and noticeable shifts away from son preference (Jenson and Oster 2008).

Policies that promote women's voice and participation in public settings may have positive impacts for future generations. Recent evidence from India shows that the use of political reservation policies improved not only how people view female politicians but also how they view their own children and their future opportunities, as well as how children view their own ambitions (Beaman et al. 2012).

\section{Strengthening the legal and institutional environment}

As discussed earlier, although countries have made some advances, they must continue to improve the legal protections of women to ensure that they have equal rights under the law. Apart from legal reforms, institutions must have the capacity to enforce the law and provide adequate services. This section presents some of the policies and programs 
that countries should continue to pursue. These strategies have contributed to improving the environment for women by enabling them to exercise agency in their own household and community, and have helped to decrease gender-based violence in countries and communities.

Actively participate in international treaties that promote gender equality

The ratification of international treaties such as CEDAW and the Beijing Declaration and Platform for Action signals governments' commitment to gender equality. Through active participation, governments help policy makers, CSOs, individuals, and development agencies strengthen their position, enabling them to call for further reforms of the civil and criminal laws to make them consistent with international standards.

After ratifying international conventions against the discrimination of women, the government's next step is to review the laws and the way institutions function to ensure that they actively promote equality between the genders under the law, actively promote nondiscrimination based on individual characteristics, and legally empower the state to eliminate all discrimination based on gender. In cases in which overall legal reform is not possible, governments should identify priority areas. For instance, in contexts where women's agency in the household is weak, reforms can focus on marriage, divorce, maintenance laws, and the protection of women from gender-based violence. Governments should also commit to undertaking regular assessments to make sure the laws are upheld, fill legal gaps, and monitor progress toward gender equality. In countries where plural systems of law coexist, governments should continuously assess customary practices to ascertain whether they curtail women's agency and develop strategies to address them.

\section{Strengthen the capacities of institutions to enforce the law}

The judicial system fails women when it is reluctant to pursue crimes against them and refuses to uphold judgments in their favor largely on the basis of their gender. Governments must make financial and personnel investments to ensure that public sector personnel have the administrative capacity to enforce the law and are able to follow gender equality principles. Police forces in several countries in the region-including Indonesia, Malaysia, and Thailand-have been criticized for being too passive in investigating trafficking and enforcing antitrafficking laws (U.S. Department of State 2011). Gender training regarding gender-related matters, including human trafficking, should be mandatory for all law enforcement personnel, including judges, lawyers, police officers, mediators, and social workers.

\section{Increasing women's access to justice}

Countries should take steps to make the judicial system more accessible to women so that women can exercise their agency in the courts when needed. For instance, mobile courts, such as those in rural areas of China and Indonesia, provide a solution to the problem of accessibility and security for women who wish to exercise their rights in the legal system but lack transportation. Technology can help extend basic legal services; for instance, basic legal transactions can use telephone hotlines and websites. For women with few economic resources, governments can waive or subsidize the costs of legal aid to ensure access to the judicial system.

\section{Enabling women's participation in politics and policy making}

Countries may adopt affirmative action policies if the context requires it. In both the private and public sectors, voluntary or mandatory affirmative action policies in many countries have increased the representation of women throughout institutions, from entry-level positions to managerial posts. In many countries, private sector companies actively pursue these policies on their own; in other countries, public sector institutions take the lead in promoting 
gender-based temporary special measures to signal to the rest of the labor market. In policies, the range of affirmative action mechanisms also varies. Quotas, for example, can be in the form of constitutional changes to reserve a certain number of government posts for women, both through legislative and (formal or informal) political party quotas. Quotas can be used informally or be formally mandated at the subnational or national levels (Dahlerup 2006). Countries should evaluate the suitability of affirmative action measures well before embarking on their implementation. Affirmative action measures can open doors for women in politics and public office and enable them to move into positions of power. Affirmative action measures can also help to transform people's views about the efficacy of female political leaders by increasing the number of women participating in electoral politics. However, under such measures, the perceptions that women are less qualified may persist and, in some cases women may hesitate to take such positions because of concern they'll be perceived as less capable.

\section{Pursuing a multipronged approach to reducing gender-based violence}

Reducing gender-based violence requires action on a number of fronts: efforts to increase women's voice within the household; enactment and enforcement of appropriate legislation and strengthening of women's access to justice; provision of adequate support services for victims of violence; and use of the media to provide information on women's rights, to increase social awareness and to shift social norms with respect to violence. The Fiji Women's Crisis Centre, for example, provides crisis counseling as well as legal, medical, and other support to women and children who have experienced gender-based violence. The crisis centre encourages male advocacy through programs that train men from police, military, community and religious agencies to more easily recognize and prevent gender-based violence in their communities (Fiji Women's Crisis Centre 2012).

\section{Creating space for women's collective agency}

Collective action has drawn private life into the public arena, identifying and addressing gender bias in statutory, religious, and customary law (UNRISD 2005). It has also reduced the hold of social norms that block greater gender equality. During the debate in Cambodia, which led to passage of the 2005 Law on Prevention of Domestic Violence and Protection of Victims, the draft law was denounced for being antagonistic to Khmer culture. Parliamentarians criticized it for "providing women with too many freedoms and rights, which will cause them to be so happy with their freedom that they do not respect ancient Cambodian customs. ... A cake cannot be bigger than the cake pan (as cited in Frieson 2011)." The Cambodia Committee of Women, a coalition of 32 nongovernmental organizations, persistently lobbied the government and the Ministry of Women's Affairs to secure the legislation's passage (World Bank 2011c) .

\section{Notes}

1. Civic activism is defined as the set of practices among citizens which demand greater involvement and scrutiny of public decisions and outcomes and is often used as a proxy for agency. Examples of civic activism are memberships in civil society organizations, petitions, protests, and peaceful demonstrations.

2. Demographic and health survey data for the countries studied in this chapter are available through MEASURE DHS, ICF International, Calverton, MD. http://www.measuredhs.com/. NSD [Timor-Leste], Ministry of Finance, and ICF Macro 2010; NIS and DGH [Cambodia] 2011; BPS (Statistics Indonesia) and ORC Macro 2003.

3. How individual civil society organizations (CSOs) interact with government varies greatly within countries; distinct paths evolved in the relationship over time among more developed countries in East Asia. In Korea, prior to 1990, 
the relationship between the government and civil society was not close in part because their goals did not seem to be aligned. After 1990, the relationship changed because the government sought to find common ground with CSOs (Kim 1998). The role of civil society in Japan also continues to evolve; it had a limited role in the 1990s because of a cumbersome regulatory framework that made entry of new CSOs and operations of existing ones difficult (Amemiya 1999; Yamaoka 1999). A new legal framework was put forth in 2006, which prompted some positive changes, especially in the relationship between the government and CSOs (Lowry 2008).

4. Psychological and emotional violence is defined by acts or threats of acts, such as shouting, controlling, intimidating, humiliating, and threatening the victim. This type of violence may include coercive tactics.

5. Circumstances include if she does not do her housework to his satisfaction, if she disobeys him, if she refuses to have sex with him, if she asks him whether he has other girlfriends, if he suspects that she is unfaithful, and if he finds out that she has been unfaithful.

6. The Kasambahay bill is still awaiting Senate approval as of mid-June 2012. See http:// www.pia.gov.ph/news/index.php? article $=231339654008$.

\section{References}

ADB (Asian Development Bank), CIDA (Canadian International Development Agency), European Commission, National Commission on the Role of Filipino Women (NCRFW), United Nations Children's Fund (UNICEF), United Nations Development Fund for Women (UNIFEM), and United Nations Population Fund (UNFPA). 2008. Paradox and Promise in the Philippines: A Joint Country Gender Assessment. http:// www.adb.org/documents/paradox-andpromise-philippines-joint-country-genderassessment.

Agarwal, Bina. 2009. "Gender and Forest Conservation: The Impact of Women's Participation in Community Forest Governance." Ecological Economics 68 (11): 2785-99.

- 2010a. "Does Women's Proportional Strength Affect Their Participation? Governing Local Forests in South Asia." World Development 38 (1): 98-112.
- 2010b. Gender and Green Governance: The Political Economy of Women's Presence within and beyond Community Forestry. New York: Oxford University Press.

Agarwal, Bina, and Pradeep Panda. 2007. "Toward Freedom from Domestic Violence: The Neglected Obvious." Journal of Human Development 8 (3): 359-88.

Aizer, Anna. Forthcoming. "The Gender Wage Gap and Domestic Violence." American Economic Review.

Amemiya, Takako. 1999. “Japan.” In Philanthropy and Law in Asia: A Comparative Study of the Nonprofit Legal Systems in Ten Asia Pacific Societies, edited by Thomas Silk, 131-62. San Francisco: Jossey-Bass.

Anderson, Siwan. 2007. "The Economics of Dowry and Brideprice." Journal of Economic Perspectives 21 (4): 151-74.

Ashraf, Nava, Dean Karlan, and Wedley Yin. 2006. "Tying Odysseus to the Mast: Evidence from a Commitment Savings Product in the Philippines." Quarterly Journal of Economics 121 (2): 635-72.

AusAID. 2008. "Vanuatu Country Report." http://www.ausaid.gov.au/Publications /Documents/ResVAW_vanuatu.pdf.

Ban, Radu, and Vijayendra Rao. 2009. "Is Deliberation Equitable? Evidence from Transcripts of Village Meetings in South India.” Policy Research Working Paper 4928, World Bank, Washington, DC.

Beaman, Lori, Esther Duflo, Rohini Pande, and Petia Topalova. 2012. "Female Leadership Raises Aspirations and Educational Attainment for Girls: A Policy Experiment in India." Science 335: 582-86.

Bian, Yanjie, John R. Logan, and Xiaolong Shu. 2000. "Economic Reform and the Gender Wage Gap in China." In Re-Drawing Boundaries: Work, Household, and Gender in China, edited by Barbara Entwisle and Gail E. Henderson, 111-33. Berkeley: University of California Press.

Boomgaard, Peter. 2003. "Bridewealth and Birth Control: Low Fertility in the Indonesian Archipelago, 1500-1900." Population and Development Review 29 (2): 197-214.

Bourdieu, P. 1977. Outline of a Theory of Practice. Cambridge: Cambridge University Press.

BPS (Statistics Indonesia) and ORC Macro. 2003. Indonesia Demographic and Health Survey 2002-2003. Calverton, MD: BPS and ORC Macro. 
Brouwer, Elizabeth C., Bruce M. Harris, and Sonomi Tanaka, eds. 1998. Gender Analysis in Papua New Guinea. Washington, DC: World Bank.

Brown, Eleanor. 2007. Out of Sight, Out of Mind? Child Domestic Workers and Patterns of Trafficking in Cambodia. Geneva, Switzerland: International Organization for Migration.

Brown, Philip. 2003. "Dowry and Intrahousehold Bargaining: Evidence from China." Working Paper 608, William Davidson Institute, University of Michigan, Ann Arbor.

CAMBOW (Cambodian Committee of Women) 2007. Violence Against Women: How Cambodian Laws Discriminate Against Women. Phnom Penh, Cambodia.

CEDAW (Convention on the Elimination of All Forms of Discrimination Against Women). 2012. http://www.un.org/womenwatch/daw/ cedaw/.

Chattopadhyay, Raghabendra, and Esther Duflo. 2004. "Women as Policy Makers: Evidence from a Randomized Policy Experiment in India." Econometrica 72 (5): 1409-43.

Chong, Alberto, and Eliana La Ferrara. 2009. "Television and Divorce: Evidence from Brazilian Novelas." Journal of the European Economic Association 7 (2-3): 458-68.

Cochrane, S. H. 1979. Fertility and Education. What Do We Really Know? Baltimore: Johns Hopkins University Press.

Cohen, Philip, and Matt Huffman. 2007. "Working for the Woman: Female Managers and the Gender Wage Gap." American Sociological Review 72: 681-704.

Costello, Marilou, and John B. Casterline. 2002. "Fertility Decline in the Philippines: Current Status, Future Prospects." Paper prepared for the Expert Group Meeting on Completing the Fertility Transition, Population Division, United Nations, New York, March 11-14.

CWDI (Corporate Women Directors International). 2010. "CWDI/IFC 2010 Report: Accelerating Board Diversity." CWDI and International Finance Corporation (IFC), Washington, DC.

Dahlerup, Drude. 2006. "Introduction." In Women, Quotas and Politics, edited by Drude Dahlerup, 3-31. London and New York: Routledge.

Dercon, Stefan, and Pramila Krishnan. 2000. "In Sickness and in Health: Risk Sharing within Households in Rural Ethiopia." Journal of Political Economy 108 (4): 688-727.
DHS (Demographic and Health Surveys). MEASURE DHS, ICF International, Calverton, MD. http://www.measuredhs.com/.

Duflo, Esther. 2003. "Grandmothers and Granddaughters: Old-Age Pensions and Intrahousehold Allocation in South Africa." World Bank Economic Review 17 (1): 1-25.

Ely, Robin J. 1995. “The Power in Demography: Women's Social Constructions of Gender Identity at Work." Academy of Management Journal 38: 589-634.

Enterprise Surveys (database). World Bank, Washington, DC. http://www.enter prisesurveys.org.

Fehringer, Jaya, and Michelle J. Hindin. 2009. "Like Parent, Like Child: Intergenerational Transmission of Partner Violence in Cebu, Philippines." Journal of Adolescent Health 44 (4): 363-71.

Fiji Women's Crisis Centre. 2012. "Male Advocacy on Women's Human Rights." http://www .fijiwomen.com/index.php?option=com_conte nt\&view $=$ article\&id=94\&Itemid $=115$.

Fiszbein, Ariel, and Norbert Schady. 2009. "Conditional Cash Transfers: Reducing Present and Future Poverty." Policy Research Series, World Bank, Washington, DC.

Freeman, Richard. 1997. "Working for Nothing: The Supply of Volunteer Labor.” Journal of Labor Economics 15 (1): S140-66.

Frieson, Kate 2011. "Cambodia Case Study: Evolution toward Gender Equality." Background paper for the World Development Report 2012, World Bank, Washington, DC.

Ganster-Breidler, Margaret. 2010. "Gender-Based Violence and the Impact on Women's Health and Well-being in Papua New Guinea." DWU Research Journal 13.

Haddad, Lawrence, John Hoddinott, and Harold Alderman, eds. 1997. Intrahousehold Resource Allocation in Developing Countries: Models, Methods, and Policy. Baltimore: International Food Policy Research Institute and Johns Hopkins University Press.

Haque, Tobias, and Froniga Greig. 2011. "Increasing the Participation of Women Entrepreneurs in the Solomon Islands Aid Economy." World Bank, Washington DC. http://documents.worldbank.org/ curated/en/2011/01/13430122/increasingparticipation-women-entrepreneurs-solomonislands-aid-economy.

Haspels, Nelien, Zaitun Mohamed Kasim, Constance Thomas, and Deirdre McCann. 
2001. "Action against Sexual Harassment at Work in Asia and the Pacific." Technical report prepared for the ILO/Japan Regional Tripartite Seminar on Action against Sexual Harassment at Work in Asia and the Pacific, Penang, Malaysia, October 2-4.

Heise, Lori. 2011. "What Works to Prevent Partner Violence? An Evidence Overview.” Department for International Development (DFID) Working Paper, DFID, London.

Hjort, J., and E. Villanger. 2011. "Backlash: Female Employment and Domestic Violence." Technical report, preliminary working paper. World Bank, Washington, DC.

Hultin, Mia, and Ryszard Szulkin. 2003. "Wages and Unequal Access to Organizational Power: An Empirical Test of Gender Discrimination." Administrative Science Quarterly 44: 453-72.

ICRW (International Center for Research on Women). 2006. Property Ownership and Inheritance Rights of Women for Social Protection: The South Asia Experience. Washington, DC: ICRW.

ILO (International Labour Organization). 2005. "The Mekong Challenge. Analysis Report of the Baseline Survey for the TICW Project Phase II in Yunnan Province." The Mekong Sub-regional Project to Combat Trafficking in Children and Women, International Labour Office, Bangkok.

—. 2008. "Women's Entrepreneurship Development in Aceh:Gender and Entrepreneurship Together (GET Ahead) Training Implementation: Impact Assessment." ILO Jakarta Office, Jakarta, Indonesia.

- 2009. "Operational Indicators of Trafficking in Human Beings: Results from a Delphi survey Implemented by the ILO and the European Commission." ILO, Geneva, Switzerland.

Imai, Katsushi, and Per A. Eklund. 2008. "Women's Organizations and Social Capital to Reduce Prevalence of Child Malnutrition in Papua New Guinea." Oxford Development Studies 36 (2): 209-33.

ISD (Indices of Social Development) database. International Institute of Social Studies in The Hague. http://www.indsocdev.org/ home.html.

Jejeebhoy, Shireen. 1995. Women's Education, Autonomy, Reproductive Behavior: Experiences from Developing Countries. Oxford: Clarendon Press.
Jensen, Robert, and Emily Oster. 2009. "The Power of TV: Cable Television and Women's Status in India." Quarterly Journal of Economics 124 (3): 1057-94.

Jivan, Vedna, and Christine Forster. 2007. Translating CEDAW into Law: CEDAW Legislative Compliance in Nine Pacific Countries. Suva, Fiji: UNDP Pacific Centre and UNIFEM Pacific Regional Office.

Kabeer, Naila. 1999. "Resources, Agency, Achievements: Reflections on the Measurement of Women's Empowerment." Development and Change 30 (3): 435-64.

Kennedy, Elissa, Natalie Gray, Peter Azzopardi, and Mike Creati. 2011. "Adolescent Fertility and Family Planning in East Asia and the Pacific: A Review of DHS Reports." Reproductive Health 8: 11. doi:10.1186/1742-4755-8-11.

Kim, H. 1998. Study on the Civil Society and Non-Governmental Organizations in Korea. Seoul: Yonsei University, Dong-Su Yon Ku, Institute of East and West Studies.

Labani, Sepideh, Carla Zabaleta Kaehler, and Paula de Dios Ruiz. 2009. "Gender Analysis of Women's Political Participation in 7 South-East Asian Countries: Bangladesh, Cambodia, the Philippines, Indonesia, Sri Lanka, East Timor and Vietnam." Enjambra Contra la Explotación Sexual. http://www .bantaba.ehu.es/obs/files/view/Gender_ analysis_of_women's_political_participation .pdf?revision_id=79226\&package_id=79202

La Ferrara, Eliana, Alberto Chong, and Suzanne Duryea. 2008. "Soap Operas and Fertility: Evidence from Brazil.” RES Working Paper 4573, Inter-American Development Bank, Washington, DC.

Lao PDR Ministry of Planning and Investment. 2011. "Seventh Five-Year National SocioEconomic Development Plan 2011-2015.” http://www.w pro.who.int/countries/lao/ LAO20112015.pdf.

Lewis, Ione, Bessie Maruia, and Sharon Walker. 2008. "Violence against Women in Papua New Guinea." Journal of Family Studies 14: 183-197.

Lowry, Cameron. 2008. "Civil Society Engagement in Asia: Six Country Profiles." Manuscript prepared for the Asia-Pacific Governance and Democracy Initiative, EastWest Center, Washington, DC.

Maffii, Margherita, and Sineath Hong. 2010. "Political Participation of Indigenous Women in Cambodia." Asien 114-15 (April): 16-32. 
Mahtani, Shalini, Kate Vernon, and Ruth Sealy. 2009. Women on Boards: Hang Seng Index 2009. Community Business and Cranfield School of Management. http:// www.communitybusiness.org/images/cb/ publications/2009/WOB.pdf.

Mason, Karen Oppenheim. 2005. "Measuring Women's Empowerment: Learning from Cross-National Research.” In Measuring Empowerment: Cross-Disciplinary Perspectives, edited by D. Narayan, 89-102. Washington, DC: World Bank.

Mason, Karen Oppenheim, and Herbert L. Smith. 2003. "Women's Empowerment and Social Context: Results from Five Asian Countries." Paper presented at the workshop on "Measuring Empowerment: CrossDisciplinary Perspectives," World Bank, Washington, DC, February 4-5.

McElroy, Marjorie B. 1990. The Empirical Content of Nash-Bargained Household Behavior. Journal of Human Resources 25(4): 559-83.

MOH (Ministry of Health) [Samoa], Samoa Bureau of Statistics, and ICF Macro. 2010. Samoa Demographic and Health Survey 2009. Apia, Samoa: Ministry of Health, Samoa. Available from the MEASURE DHS website http://www.measuredhs.com/publications/ publication-fr240-dhs-final-reports.cfm.

Monson, Rebecca. 2010. "Women, State Law and Land in Peri-Urban Settlements on Guadalcanal, Solomon Islands.” Briefing note. World Bank, Washington, DC.

Morrison, Andrew, Mary Ellsberg, and Sarah Bott. 2007. "Addressing Gender-Based Violence: A Critical Review of Interventions." World Bank Observer 22 (1): 25-51.

Morrison, Andrew, and Maria Beatriz Orlando. 2004. The Costs and Impacts of GenderBased Violence in Developing Countries: Methodological Considerations and New Evidence. Washington, DC: World Bank.

NIS (National Institute of Statistics) [Cambodia Ministry of Planning], and DGH (Directorate General for Health) [Ministry of Health]. 2011. Cambodia: Demographic and Health Survey 2010-Final Report. Calverton, MD: MEASURE DHS.

NSD (National Statistics Directorate) [TimorLeste], Ministry of Finance [Timor-Leste], and ICF Macro. 2010. Timor-Leste Demographic and Health Survey 2009-10. Dili, TimorLeste: NSD and ICF Macro.
NSO (National Statistics Office) [Philippines] and ICF Macro. 2009. Philippines Demographic and Health Survey 2008. Calverton, MD: NSO and ICF Macro.

Panda, Pradeep, and Bina Agarwal. 2005. "Marital Violence, Human Development and Women's Property Status in India." World Development 33 (5): 823-50.

PARLINE database on national parliaments. Inter-Parliamentary Union. http://www.ipu .org/wmn-e/world.htm.

PEKKA (Perempuan Kepala Keluarga [Women Headed Household Empowerment Program]). Accessed 2012. http://www.pekka.or.id/8 /index.php.

Philippine Commission on Women. 2012. http:// pcw.gov.ph/statistics/201205/statisticsviolence-against-filipino-women.

Pritchett, Lant H. 1994. "Desired Fertility and the Impact of Population Policies." Population and Development Review 20 (1): 1-55.

Pronyk, Paul, James Hargreaves, Julia Kim, Linda Morison, Godfrey Phetla, Charlotte Watts, Joanna Busza, and John Porter. 2006. "Effect of a Structural Intervention for the Prevention of Intimate-Partner Violence and HIV in Rural South Africa: A Cluster Randomized Trial." Lancet 2368 (9551): 1973-83.

Quisumbing, Agnes R., and J. Maluccio. 2003. "Resources at Marriage and Intra-household Allocation: Evidence from Bangladesh, Ethiopia, Indonesia, and South Africa." Oxford Bulletin of Economics and Statistics 65: 283-327.

The Quota Project (database). International IDEA, Stockholm University, and Inter-Parliamentary Union. http://www.quotaproject.org/.

Rammohan, Anu, and Meliyanni Johar. 2009. "The Determinants of Married Women's Autonomy in Indonesia." Feminist Economics 15 (4): 31-55.

Rangel, Marcos. A. 2006. "Alimony Rights and Intrahousehold Allocation of Resources: Evidence from Brazil." Economic Journal 116 (July), 627-58.

Rand, John, and Finn Tarp. 2011. "Does Gender Influence the Provision of Fringe Benefits? Evidence from Vietnamese SMEs." Feminist Economics 17 (1): 59-87.

Rinaldo, Rachel. 2002. "Ironic Legacy: The New Order and Indonesian Women's Groups."Outskirts 10. http://www.chloe.uwa .edu.au/outskirts/archive/volume10/rinaldo. 
Robinson, Kathy, and Sharon Bessell. 2002. "Introduction to the Issues." In Women in Indonesia: Gender, Equity and Development, edited by K. Robinson and S. Bessell, 1-12. Singapore: Institute of Southeast Asian Studies.

Sen, Amartya. 1992. "Missing Women.” British Medical Journal 304: 587-88.

- 1999. Development as Freedom. Oxford, U.K.: Oxford University Press.

SIGI (Social Institutions and Gender Index). Poverty Reduction and Social Development Unit, OECD Development Centre. http:// genderindex.org/.

Singh, Umakant. 2009. "Women and Men United to End Violence against Women and Girls: Four Years Impact Evaluation Report 20052009.” Women's Media Centre of Cambodia, Phnom Penh, Cambodia.

SPC (Secretariat of the Pacific Community), Ministry of Internal and Social Affairs [Republic of Kiribati], and Statistics Division [Republic of Kiribati]. 2010. Kiribati Family Health and Support Study: A Study on Violence against Women and Children. Nouméa, New Caledonia: SPC.

SPC (Secretariat of the Pacific Community) and NSO (National Statistics Office) [Solomon Islands]. 2009. Solomon Islands Family Health and Safety Study: A Study on Violence against Women and Children. Nouméa, New Caledonia: SPC.

Stege, Kristina, Ruth Maetala, Anna Naupa, and Joel Simo. 2008. "Land and Women: The Matrilineal Factor: The Cases of the Republic of Marshall Islands, Solomon Islands and Vanuatu.” Pacific Islands Forum Secretariat, Suva, Fiji.

Sumner, Cate, and Tim Lindsey. 2011. "Courting Reform: Indonesia's Islamic Courts and Justice for the Poor." International Journal for Court Administration (December).

Swain, P. 2000. "Development, Globalization, Civil Society and Non-Governmental Organizations in the Pacific." Background paper prepared for the Stakeholders Workshop on NGO Capacity Building, Port Vila, Vanuatu, November 6-8.

Swaminathan, Hema, Cherryl Walker, and Margaret A. Rugadya, eds. 2008. Women's Property Rights, HIV and AIDS and Domestic Violence: Research Findings from Two Districts in South Africa and Uganda. Cape Town, South Africa: HSRC Press.
Thomas, Duncan. 1990. "Intra-household Resource Allocation: An Inferential Approach." Journal of Human Resources 25 (4): 635-64. . 1992. "The Distribution of Income and Expenditures within the Household." Annales d'Economie et de Statistique 29: 109-36.

- 1995. "Like Father, Like Son, Like Mother, Like Daughter, Parental Resources and Child Height." Papers 95-01, RAND Reprint Series.

Thomas, Duncan, and Chien-Liang Chen. 1994. "Income Shares and Shares of Income." Labor and Population Working Paper 94-08, RAND Corporation, Santa Monica, California.

UN (United Nations). 1993. "Declaration on the Elimination of Violence against Women," December 20, http://www.un.org/documents/ ga/res/48/a48r104.htm.

- 2006. "In-Depth Study of All Forms of Violence against Women: Report of the Secretary-General.” A/61/122/Add.1, July 6. UN General Assembly, New York.

UNDP (United Nations Development Programme). 2005. Community Capacity Enhancement Strategy Note. New York: UNDP. http://www .undp.org/content/undp/en/home/librarypage/ hiv-aids/community-capacity-enhancementstrategy-note/.

- 2010. Asia-Pacific Human Development Report: Power, Voice and Rights: A Turning Point for Gender Equality in Asia and the Pacific. Colombo, Sri Lanka: Macmillan.

UNFPA (United Nations Population Fund). 2006. State of the World Population 2006: A Passage to Hope: Women and International Migration. http://www.unfpa.org/swp/2006/ english/introduction.html.

- 2010. "An Assessment of the State of Violence Against Women in Fiji." Suva as cited in CEDAW/C/FIJI/2-4 p. 50, Jan 28, 2010.

UNIFEM (United Nations Development Fund for Women). 2010. "Ending Violence Against Women and Girls: Evidence, Data and Knowledge in the Pacific Island Countries. Literature Review and Annotated Bibliography.” UNIFEM Pacific Regional Office, Suva, Fiji.

UNODC (United Nations Office on Drugs and Crime). 2009. "International Framework for Action to Implement the Trafficking in Persons Protocol," United Nations, New York.

UNRISD (United Nations Research Institute for Social Development). 2005. "Women Mobilizing to Reshape Democracy.” In 
Gender Equality: Striving for Justice in an Unequal World, edited by UNRISD, 167-80. Geneva: United Nations.

U.S. Department of State. 2008. Laos Trafficking in Persons Report 2008. Washington, DC: U.S. Department of State.

. 2011. Trafficking in Persons Report 2011. Washington, DC: U.S. Department of State.

Utomo, Iwu, Peter McDonald, Terence Hull, Ida Rosyidah, Tati Hattimah, Nurul Idrus, Saparinah Sadli, and Jamhari Makruj. 2009. "Gender Depiction in Indonesian School Text Books: Progress or Deterioration." Australian Demographic and Social Research Institute, Australian National University, Canberra.

Vietnam: Multiple Indicator Cluster Survey. 2006. World Bank, Washington, DC. http://microdata .worldbank.org/index.php/catalog/31.

VWC (Vanuatu Women's Center) and NSO (National Statistics Office). 2011. Vanuatu National Survey on Women's Lives and Family Relationships. Port Vila, Vanuatu: VWC.

Wang, Zhengxu, and Weina Dai. 2010. "Women's Participation in Rural China's SelfGovernance: Institutional, Socioeconomic, and Cultural Factors in a Jiangsu Country." Discussion Paper 69, China Policy Institute, University of Nottingham, U.K.

WHO GWH (World Health Organization, Department of Gender, Women and Health). 2007. "Integrating Gender into the Curricula for Health Professionals." Meeting Report, December 4-6. WHO, Geneva.
Whyte, Martin King, and William L. Parish. 1984. Urban Life in Contemporary China. Chicago: University of Chicago Press.

Wolf, Margery. 1985. Revolution Postponed: Women in Contemporary China. Stanford, California: Stanford University Press.

World Bank. 2011a. "Vietnam Country Gender Assessment." World Bank, Washington, DC. http://documents.worldbank.org/curated/ en/2011/11/15470188/vietnam-countrygender-assessment.

- 2011b. Defining Gender in the XXI Century: Conversations with Men and Women Around the World (qualitative assessment dataset). World Bank, Washington, DC. http:// go.worldbank.org/CD8RN24BP0.

- 2011c. World Development Report 2012: Gender Equality and Development. Washington, DC: World Bank.

_. 2011d. "Reproductive Health at a Glance: Timor-Leste.” World Bank, Washington, DC.

WRAP (Women's Rights and Advocacy in the Pacific). 2011. "Promoting Gender Equity in the Pacific: Recommendations for Pacific Island Forum Leaders," WRAP Reports, WRAP, Wellington, New Zealand.

Yamaoka, Yoshinori. 1999. “Japan.” In Philanthropy and Law in Asia, edited by Thomas Silk, 163-98. San Francisco: JosseyBass.

Zhang, Heather. 1999. "Female Migration and Urban Labour Markets in Tianjin." Development and Change 30 (1): 21-41. 


\section{Gender and the Region's Emerging Development Challenges}

he world is more integrated now than it has ever been in its history, bringing regions together economically, socially, and culturally. The East Asia and Pacific region is one of the most dynamic in the world and has been at the forefront of the trend toward greater global integration. Over the course of two decades, many countries in the region have changed the structure of their economies and have gradually opened to greater inflows and outflows of people, goods, and physical capital. Technological advances have changed production processes in all sectors, from better market access in agriculture to mechanization in manufacturing. The region has seen shifts in the geographic patterns of settlement and work as the center of economic activities has moved from rural to urban areas and as international and intranational migration has increased. Rapid declines in fertility and mortality are anticipated to change the region's demographic profile-in some countries, the proportion of the population over age 65 is already larger than the proportion that are 15 and under.

This chapter examines how the following five key trends are affecting the men and women of the East Asia and Pacific region: (a) globalization and integration, (b) migration, (c) urbanization, (d) aging populations, and (e) information and communication technology (ICT). Each of these trends involves a number of gender-related challenges but also presents new and encouraging prospects for women. Policy makers in the region will have to manage these challenges while simultaneously fostering new opportunities:

- Globalization. The trend toward greater global economic integration, which has been particularly marked in the East Asia and Pacific region, has the potential to increase economic opportunities for women and to narrow the gender wage gap. However, globalization also raises the likelihood that shocks will be transmitted from country to country through integrated markets. Many studies, including those from the recent global financial crisis, have found that these shocks have a gender-differentiated effect along a wide range of outcomes, including human capital investment, labor force participation, earnings, and mortality.

- Migration. The economic growth experienced in the region over the past three decades has spurred significant 
movements of people within and across countries in search of better economic opportunities. Women make up nearly half of these migrants in the East Asia and Pacific region. Migration can provide women with more and better economic opportunities, but it can also put them at greater risk for exploitation, abuse, and human trafficking.

- Urbanization. Unprecedented increases in migration to urban areas have taken place in recent decades as men and women move in search of jobs. Urbanization can transform women's lives through improved access to infrastructure, education, and health services and a wider range of economic opportunities. Women's ability to take advantage of these opportunities depends on whether gender-sensitive infrastructure and service delivery have been considered and whether they are able to balance their home and work lives.

- Aging. The population of the East Asia and Pacific region is aging rapidly, in many countries at a faster pace than in the rest of the world. Women, both the elderly and the young, are likely to face particular challenges as a result of this demographic change. Although women tend to live longer than men, they have fewer economic assets and resources and are less likely to be covered by formal social security systems. They are also more likely to be caregivers to the elderly than men.

- Information and communication technology (ICT). Advances in information and communication technologies are revolutionizing the ways in which men and women in the region are exposed to ideas, share knowledge, and network. ICTs can empower women by opening new economic opportunities, breaking down information barriers, changing social norms, and enabling collective action. Evidence suggests that women in the region may still have less access to information technology than men, reducing their ability to harness their transformative potential.

\section{Globalization}

Globalization presents opportunities as well as challenges for reducing gender inequality. The opening up of domestic economies to specialization spurred by international trade may increase economic opportunities and women's empowerment, but this trend also brings with it an increased risk that shocks will be transmitted from country to country through increasingly integrated markets.

\section{Growth in trade and capital flows in East Asia and the Pacific}

Developing countries all over the world are experiencing structural change at a rapid pace. Since 1987, the share of both male and female employment in manufacturing and services in developing countries has grown faster than in developed countries, reflecting changes in the global distribution of production and labor (World Bank 2011b). These trends have been mirrored in the East Asia and Pacific region (chapter 3).

Behind these changes in economic structure lie the powerful global forces of economic and social integration and economic reforms. In many countries in the region, reforms during the 1990s and early 2000s laid the foundation for institutional change and rapid growth. The export of goods and services as a proportion of gross domestic product (GDP) rose from 17 percent in 1980 to 43 percent in 2008 . However, these flows are volatile. The recent financial crisis has caused exports to fall to 35 percent of GDP in the region. Within the region, the ratio of exports to GDP varies widely. For example, in Vietnam, this ratio has increased hugely over time, from 7 percent in 1986 to over 70 percent in the late 2000 s, while in Indonesia, the ratio has remained between 20 and 40 percent over the past three decades. ${ }^{1}$

\section{Globalization and gender}

These trade and capital flows have generated new employment and income-generation 
opportunities within the region, particularly for women. ${ }^{2}$ However, these flows have also been associated with greater economic volatility, because global or regional macroeconomic shocks-such as the Asian financial crisis of 1997-98, the food and fuel crisis of 2004 and 2008, and the global financial crisis-can spread more rapidly throughout the world. This section explores the ways in which globalization has changed the lives of men and women in the region.

\section{Globalization and increased economic opportunities for women}

Women have played an important role in the expansion of export-oriented manufacturing during the process of economic development and structural transformation (Standing 1999; Wood 1991). Increases in trade and mobile capital have expanded job opportunities in the East Asia and Pacific region, particularly for women who make up a large proportion of the labor force in the export-oriented manufacturing sector in the region and around the world (World Bank 2011b).

Export-oriented firms are more likely to hire women than non-export-oriented firms, both across the world and within the region (figure 5.1). The East Asia and Pacific region is second only to Europe and Central Asia in the proportion of female workers working in the export-oriented sector. Within East Asia, the fraction of female workers is substantially higher in export-oriented firms than in non-export-oriented firms, with Indonesia as a key exception in this regard (figure 5.1b).

Female workers predominate in certain export-oriented sectors, such as the garment sector. These sectors have grown substantially and quickly in recent years. Figure 5.2 depicts employment in Vietnam's textile and apparel sectors, which grew significantly between 2000 and 2008. Women are more likely to work in these sectors than men in Cambodia, Indonesia, the Lao People's Democratic Republic, and Vietnam, although overall garments and textiles account for only a small fraction of the female workforce. Among female workers ages 15-34, who are the most likely to be employed in the manufacturing sector, employment in the garment industry is substantial in some countries in the region, from approximately 8 percent of 15- to 34-year-old females in Indonesia to over 15 percent in Vietnam (figure 5.3). Employment patterns have shifted over time

\section{FIGURE 5.1 Women are more likely to work in export-oriented firms than in non-export-oriented firms}

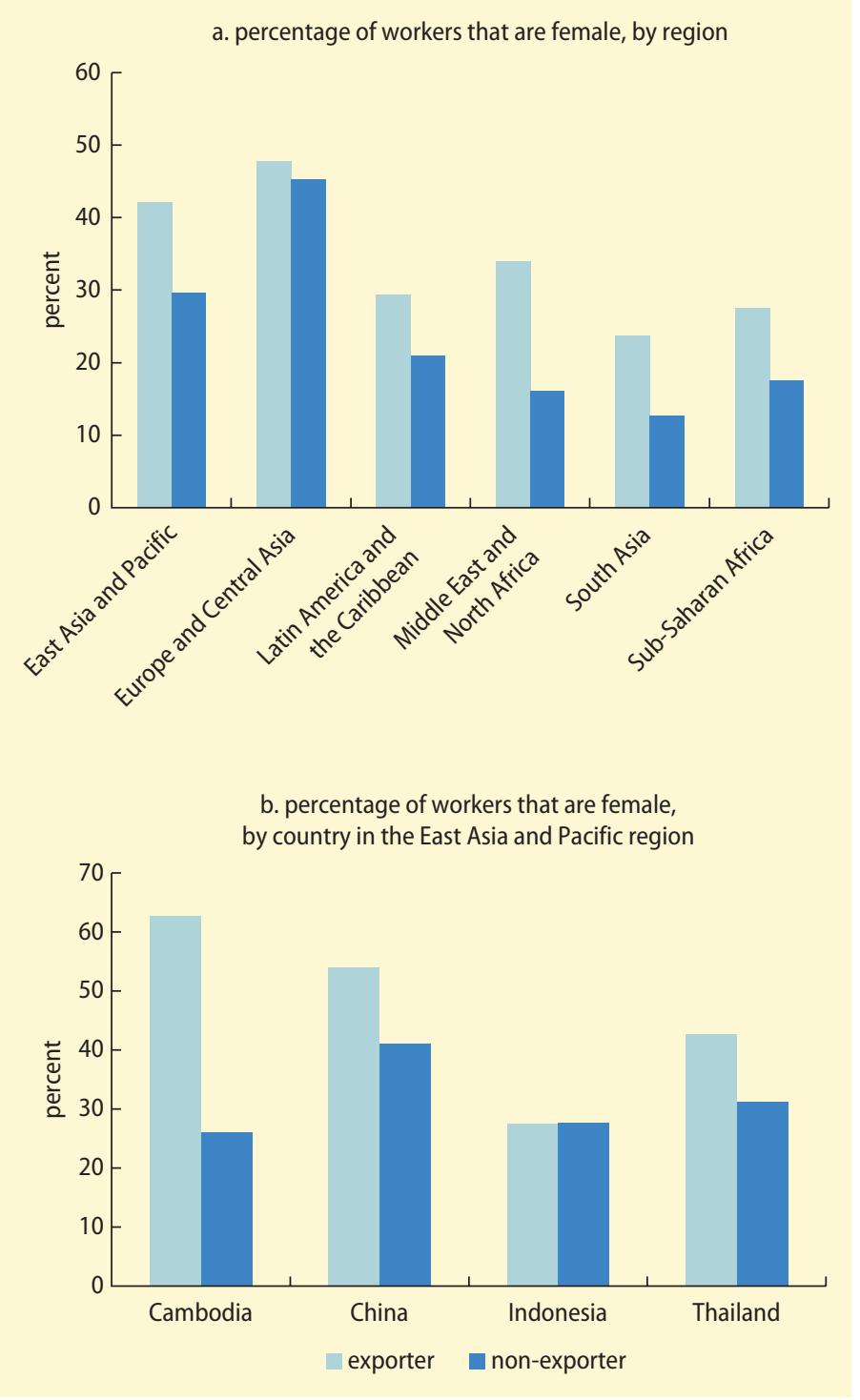

Source: Enterprise Surveys database, 2002-05 data.

Note: The data are not available for examining similar patterns in Pacific countries. 


\section{FIGURE 5.2 Employment in textile and apparel in Vietnam grew substantially between 2000 and 2008}

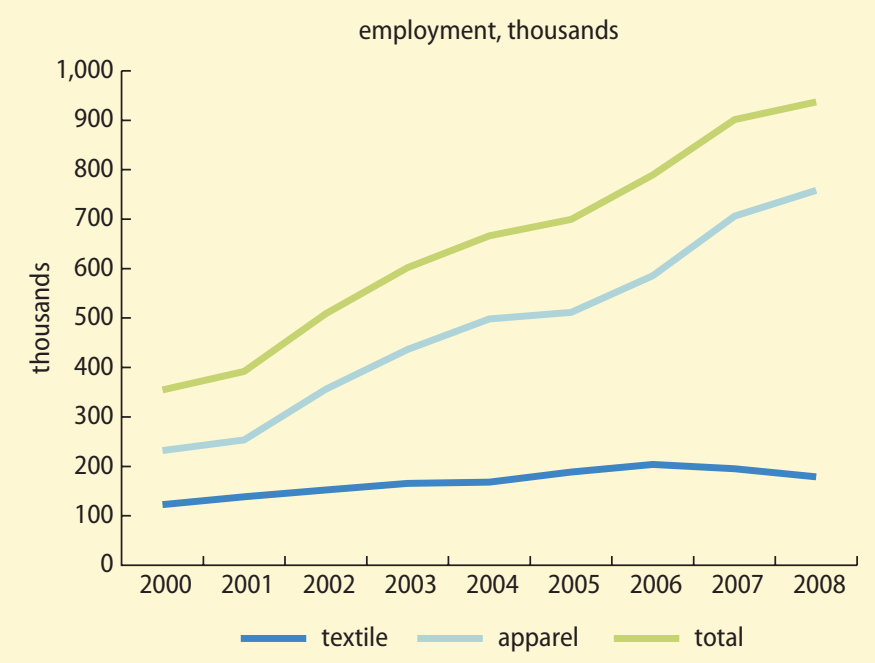

Sources: Frederick and Staritz 2011

FIGURE 5.3 Women predominate in the garment sector in four East Asian countries

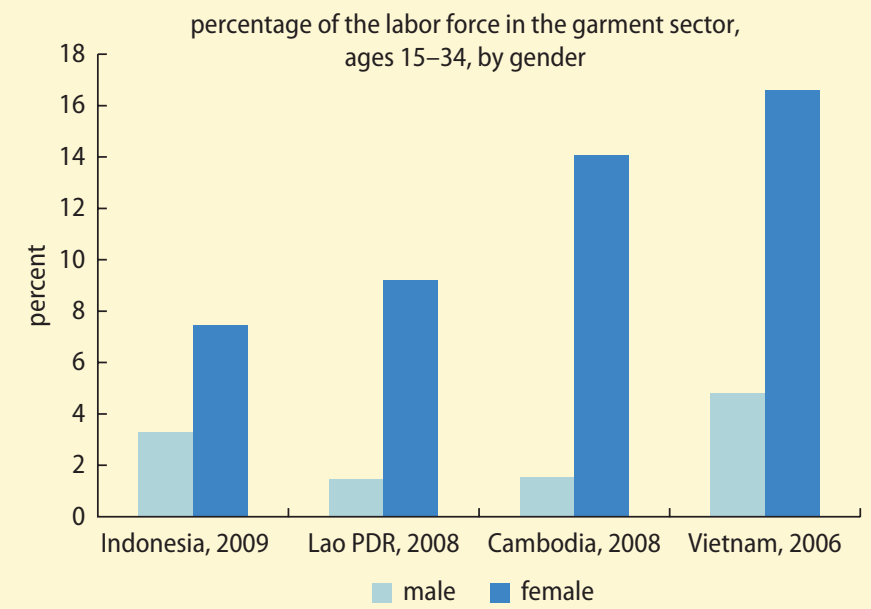

Sources: World Bank staff estimates using Cambodia Socioeconomic Survey (CSES) (NIS Cambodia), 2008 data; Indonesia National Labor Force Surveys (SAKERNAS) (BPS Indonesia), 2009 data; Lao Expenditure and Consumption Survey (LECS) (LSB Lao PDR), 2008 data; VHLSS (GSO Vietnam), 2006 data. from the East Asia and Pacific region suggests that with the exception of Indonesia, electronics production does not appear to be an overwhelmingly female area of work.

The experience of developed countries in the region shows that the demand for female labor in export-oriented industries declines as countries transition from laborintensive to capital-intensive manufacturing. In Korea, women constituted 70 percent of workers in export processing zones in 1990 compared to 42 percent of employees in manufacturing overall (Kusago and Tzannatos 1998), a substantial rise over the 28 percent of women employed in manufacturing in 1972 (Seguino 1997). However, the dominance of females in the exportoriented sector has declined since heavy chemical and manufacturing industries, such as steel, cars, and shipbuilding, began to increasingly replace light manufacturing industries (Kong 2007). In Taiwan, China, a concerted shift toward capital- or technology-intensive exports in the late 1970s and early 1980s was accompanied by a steady decline in the share of female wage workers in the manufacturing sector until the mid1990s (Berik 2000).

Although women are extensively employed in the sectors that are expanding as a result of increased trade opportunities in many East Asian and Pacific countries, as sectors become more technology, skill, and capital intensive, employers may ultimately replace female workers with more highly skilled men (Gamberoni and Reis 2011; Tejani and Milberg 2010). For example, in Malaysia, only 40 percent of the workers in the Special Economic Zones are now female, down from 60 percent two decades ago (IFC 2008). Several possible explanations for this include (a) differences in the level and content of men's and women's education; (b) discrimination and gender segregation in higher skilled jobs; (c) tight female labor markets that can force female wages to rise; and (d) the view that men deserve more secure employment and are less likely to leave paid work to fulfill domestic responsibilities" (Seguino and Grown 2006, 8; Berik

in the electronics industry. In earlier waves of export-orientated growth in Japan, the Republic of Korea and Taiwan, China, the labor force in electronics was predominantly female. Analysis of recent household data 
forthcoming; Gamberoni and Reis 2011; Tejani and Milberg 2010).

The wages of men and women respond differently to trade liberalization and exportoriented growth, depending on (a) the type of growth seen, (b) a country's comparative advantage, and (c) institutional and policy-related factors (Berik, van der Meulen Rodgers, and Zveglich 2004; Black and Brainerd 2002; Oostendorp 2009; Seguino 2000). ${ }^{3}$ During periods of export-oriented growth, gender wage gaps narrowed in Korea while they widened in Taiwan, China (Seguino 2000). The difference in patterns is attributed to increasing capital mobility in Taiwan, China, which moved capital out of labor- and female-intensive industries, whereas regulations in Korea limited the movement of capital (Seguino 2000). Similar evidence from Bangladesh indicates that a movement up the value chain in the Bangladeshi garment industry had negative repercussions for female workers, who are less likely to work in the more skill-intensive occupations (Frederick and Staritz 2011). In Taiwan, China, and in Korea, the wage gap between men and women widened in sectors with strong trade competition between 1980 and 1999 (Berik, van der Meulen Rodgers, and Zveglich 2004). In Taiwan, China, greater export orientation adversely affected both men's and women's wages, but it reduced gender wage inequality because male employees faced a greater wage penalty than female workers did (Berik 2000).

The expansion of labor market opportunities as a result of trade liberalization may also encourage investment in education among young women. For example, the expansion of call centers and other economic opportunities for women linked to globalization have increased female educational investment in India (Munshi and Rosenzweig 2004; Oster and Millet 2010; Shastry 2010). The evidence suggests that the relationship between investment in education and labor market opportunities depends on the skill bias of export-oriented growth and that growth in low-skill intensive opportunities may in fact reduce educational investment. Growth in the unskilled manufacturing sector in Mexico increased the school dropout rate (Atkin 2010).

\section{Gender-related challenges of globalization}

Despite expanding economic opportunities for women, globalization poses challenges in the form of increased exposure to externally driven shocks and in the type and quality of work conducted by women in the export-oriented sector. Externally driven shocks have had a negative effect on women in a number of outcomes related to health, education, and employment.

Men and women work in different occupations and industries, so they tend to be affected differently by economic shocks. In addition, because crises vary in the sectors they affect and in their propagation mechanisms, the employment and wage effects on men and women also vary across crises. For example, in the Philippines, the food and fuel crisis of 2008 affected employment and wages in different ways than the financial crisis of 2009 (Menon and van der Meulen Rodgers forthcoming). Following the food and fuel crisis, more unskilled workers lost their jobs than skilled workers, whereas skilled workers suffered more than unskilled workers during the financial crisis. Women's likelihood of employment dropped more than that of men during both crises but, although most of the decline for men came from falling wage employment, women lost work in both wage employment and self-employment. In Cambodia, analysis showed that the financial crisis resulted in labor market churning, in which high job destruction was followed by an even larger creation of low-quality jobs. Women accounted for the greatest share of job losses but also the largest share of jobs created (Bruni et al. 2012).

Across the world, as well as in the East Asia and Pacific region, both women's employment and the total number of hours that women work tend to increase during periods of economic crisis (Frankenburg, Smith, and Thomas 2000; Lim 2000; Tork and Mason 2009). ${ }^{5}$ Using data from 63 developing and transition countries, Bhalotra and UmanaAponte (2010) found that a 10 percent drop 
in a country's GDP is associated with a 0.74 percentage point increase in women's work participation. ${ }^{4}$ Those authors also found that, in the East Asia and Pacific region, the employment of rural women and married women with a child under the age of five was more sensitive to cyclical variation than other women, possibly because they tend to be closer to their subsistence requirements.

Women's employment in the East Asia and Pacific region may be disproportionately affected by crises because of perceptions that they should leave job opportunities for male workers. In Korea, more women than men dropped out of the labor force and became "discouraged" workers during the 1997-98 crisis (Kim and Voos 2007). The increase in dropouts was concentrated among young, single women and outweighed the increased labor force participation of married women who entered the labor market to maintain their family's income (Kang 1999, cited in Kim and Voos 2007). The majority of employers targeted women workers for voluntary resignation, especially if those women were from double-income families or were married. Anecdotal evidence suggests that women in some sectors in Korea, such as banking, were forced to resign from their permanent positions and were then rehired as temporary employees (Kim and Voos 2007). The disproportionate dismissal of female employees during the crisis occurred partly because of employers' perception that hiring female workers cost them more than hiring male workers (Kong 2007) and partly because employers viewed men as the main family breadwinners and hence believed that women should step aside (Kim and Park 2006).

Female health has been found to be more susceptible to shocks than male health, both in the region and elsewhere (Strauss and Thomas 2008). Females are more likely to suffer from physical and mental health deteriorations during periods of crisis (Dercon and Krishnan 2000; Frankenberg et al. 2008; Friedman and Thomas 2007). Data from 59 developing countries show a large negative association between per capita GDP and infant mortality, with a
1 percent decline in per capita GDP being associated with a 10 to 15 percent increase in infant mortality on average. However, the effect on females is approximately twice the effect on males-a 1 percent decline in per capita GDP increases the mortality rates of boys by 0.27 per thousand born, whereas it raises that of girls by 0.53 per thousand. The quality and quantity of women's and girls' diets are also more likely to have been disproportionately affected by the food and financial crisis than those of men and boys (Jones et al. 2009). In addition, tensions in households increase during periods of economic stress. During the financial crisis of 2009 , both men and women reported an increase in the number of arguments between husbands and wives related to their limited financial resources, which sometimes led to violence (Turk and Mason 2009). ${ }^{6}$

Evidence from macroeconomic crises suggests that, although children's school enrollment declines in response to these shocks, the gender differences are small relative to their overall impacts (Sabarwal, Sinha, and Buvinic 2010). In Indonesia and the Philippines, the 1997-98 crisis was associated with declines in children's school enrollment or increases in child labor (Frankenberg, Beard, and Saputra 1999; Lim 2000; Thomas et al. 2004). In the Philippines, the enrollment of female children declined slightly at the elementary level in 1998-99, whereas male enrollment increased substantially during that year (Lim 2000). At the same time, child labor among boys ages 10 to 14 increased in both urban and rural areas, and labor force participation rates of girls increased only marginally. In Indonesia, real education expenditures as well as the share of the household budget spent on schooling declined between 1997 and 1998 (Thomas et al. 2004). Households spent more on the education of young men (ages 15-19) than young women and mobilized the money to do so by reducing their expenditures on the education of younger male and female children (ages 10-14) and of older females (ages 15-19). 
Finally, globalization poses challenges in the type and quality of work conducted by women in the export-oriented sector. Gender segregation continues to exist. Women are less likely to be employed in managerial or professional positions and are more likely to be in part-time or informal subcontracted jobs (Seguino 2000). ${ }^{7}$ Older female workers also face barriers in these industries. For example, in Shenzhen, the largest of the Special Economic Zones (SEZs) in China, female workers under 25 years of age make up 90 percent of workers in garment and electronics plants (Summerfield 1995, cited in Davin 2004). This bias may be because firms in these zones often use single-sex dormitories to accommodate migrant workers, a situation that is incompatible with marriage and family formation (Davin 2004; Ngai 2004).

Many studies have suggested that employment in Export Processing Zones (EPZs) is characterized by unsafe working conditions and the suppression of labor rights; however, studies do not make clear whether workers in these zones are worse off than their rural and urban counterparts (Murayama and Yokata 2008). Governments set the legal framework for employment practices in SEZs, which may have the same labor standards as those in the country as a whole or may be unique to the SEZs. For example, in the Philippines, all national laws officially apply in EPZs. In practice, however, the Philippines Economic Zone Authority, often allows firms in the EPZ to circumvent these laws (McKay 2006).

\section{Implications for policy related to globalization}

The expansion of employment opportunities in the East Asia and Pacific region due to globalization has been associated with greater female access to income and rising empowerment, particularly among young rural female migrants. However, challenges remain for women working in these sectors. As in the rest of the economy, women are less likely to be employed in managerial positions and more likely to be employed in temporary positions or in the informal sector than men. Furthermore, experience from developed countries in the region suggests that, as economies develop and industries move up the value chain, female employment in the export-oriented sector may decline as so-called male industries emerge.

Policies that reduce gender gaps in economic opportunities, and in particular in labor force participation and gender based occupational and industrial segregation, are necessary to ensure that women are able to fully benefit from the economic opportunities brought about by greater globalization. Since women are disproportionately employed in the export-orientated sector and in special economic zones, there may be scope for policy makers to promote the creation of zone-level social services that are sensitive to women's needs.

Greater economic integration also entails risks, notably an increased exposure to employment shocks, which will have genderdifferentiated impacts. To address these risks, policy makers need to design social protection programs that adequately account for the different risks faced by female and male workers. Recognizing the genderdifferentiated impacts of labor market programs and policies enacted to mitigate crises will lead to better policy making. Evidence from the region suggests that gender blind policies enacted in response to shocks may have gender differentiated impacts.

\section{Migration}

The movement of people, both on a national and international scale, has increased across the world in the past two decades because of improvements in transportation technology and infrastructure (World Bank 2008). Worldwide, women account for almost half of all international migrants, rising from below 47 percent of migrants in 1960 to 49 percent in 2010 (UNPD 2008). Studies have noted a shift in the motive for migration among female migrants. Previously, women 
predominantly migrated for marriage or as dependents of spouses or other male family members who worked abroad. Increasingly, women are migrating independently to improve their economic opportunities and to fulfill the role of primary breadwinner for their families (Sørensen 2005).

\section{Migration and gender}

The economic growth experienced in the East Asia and Pacific region over the past three decades has spurred a significant intraregional movement of people. Evidence of these flows is highly visible within the regionfrom the 200 million people travelling across China to be with their families for the Lunar New Year to the substantial cross-border migration flows seen in the Greater Mekong Subregion (World Bank 2008). Economic booms in East Asian cities have created labor force shortages, which have been met by a growing supply of migrant labor as people have moved to urban areas to improve the well-being of their families and communities. The flow of migrants to several cities in the region has become increasingly female, and women comprise a significant proportion of

FIGURE 5.4 The share of international female migrants has increased over time in Indonesia and Vietnam

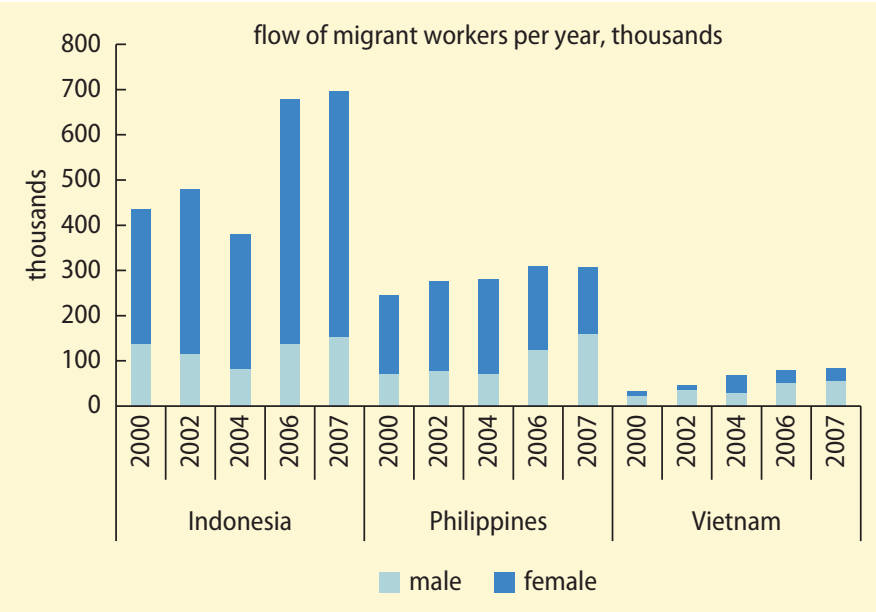

Source: World Bank forthcoming.

Note: Figure is based on data from the Indonesia Ministry of Manpower, the Philippines Overseas Employment Administration, and the Vietnam Ministry of Labor, Invalids and Social Affairs. the international migration from the region as a whole (Guzmán 2006; UN 2001, cited in Hugo 2003).

This section examines the following in the context of the East Asia and Pacific region: (a) emerging migration trends and gender, (b) the socioeconomic characteristics of male and female migrants, (c) factors influencing female migration, (d) the mixed impact of migration on women's status, and (e) the mixed impact of migration on those who stay behind.

\section{Gender-differentiated migration trends in the East Asia and Pacific region}

The often informal and undocumented nature of female migration in the region has resulted in significant information gaps, but three salient facts have emerged in recent years. First, the numbers of women migrating are increasing. At the turn of the 21 st century, the number of female migrants in the region is estimated to have surpassed that of male migrants (Lee 2005). In Fiji and Tonga in 2005, approximately 50 percent of migrants were female (World Bank 2006b). The bulk of female migrants in the region come from Indonesia and the Philippines. Thai women are underrepresented among legal migrants but dominate among irregular migrants or those presumed to be trafficked. Thailand has also been an important destination for irregular migrant women, such as Myanmar and Lao women working as domestic workers (Piper 2009). More than half of the Lao migrants and close to half of the Cambodian migrants to Thailand are women (World Bank 2006c).

Second, the proportion of women in the migrant population is increasing. A study in China covering six provinces found that, between 1995 and 2000, the migration rates for women increased twice as quickly as those for men (de Brauw et al. 2002). The annual proportion of women migrating, of Indonesian workers, reached approximately 80 percent in 2007, an increase from about 70 percent in 2000 (figure 5.4). In Vietnam, women constituted 57 percent of individuals who had migrated internally or who were 
international migrants in the previous five years (Pierre 2011).

Third, female migrants who used to migrate out of the region are increasingly finding opportunities to migrate within the region. Although the most frequent destination for female migrants from Indonesia is Saudi Arabia, more and more of these women are finding employment in other Asian countries such as Hong Kong SAR, China; Malaysia; Singapore; and Taiwan, China. This trend differs from those of Indonesian male migrants. Although the majority of male migrants find work in Malaysia, many are now going to Saudi Arabia (Nguyen and Purnamasari 2011).

\section{Socioeconomic factors characterizing male} and female migrants

The socioeconomic factors that characterize male and female migrants in the region appear to be similar. Migrants, both male and female, are young and relatively lowskilled but are not necessarily among the least educated in their country of origin (Jampaklay et al. 2009; World Bank 2006c; World Bank, forthcoming). ${ }^{8}$ The exception to this trend is the Philippines, where both male and female migrants tend to be older and highly educated (Cabegin and Alba 2011). High-skilled female migration differs from low-skilled migration: the destination countries for this type of migration are usually high-income developed countries in North America and Western Europe. Female migrants participate in all types of migration. They can be found among both internal and international migrants and within temporary and permanent flows; they can be regular or irregular migrants.

\section{Factors influencing female migration}

A combination of factors have influenced the feminization of migrant flows in the region. The perceived comparative advantage of women in growing industries has led to an increase in female labor demand and to the expansion of labor opportunities for women in both the formal and informal sectors in urban areas. Women are more likely than men to work in export-oriented industries, where employers perceive them to have a comparative advantage. ${ }^{9}$ China's Pearl River Delta region is one of the most popular destinations for internal rural migrants. Young rural migrant women constitute 65 to 70 percent of the region's labor force because they are favored by the region's transnational clothing, textile, toy, electronic, and other labor-intensive manufacturing and processing firms (Gaetano and Jacka 2004).

A rapid increase in demand for domestic workers has occurred as a result of urbanization and an expansion of the middle class in many countries in the world. Women migrate to work abroad as domestic workers in response to gender-specific labor demand. Female migrant workers from East Asian and Pacific countries are also employed as domestic workers in other regions, including the Middle East, North America, and Western Europe. Approximately 1 million migrant domestic workers are in Saudi Arabia, with the majority coming from Indonesia, the Philippines, and Sri Lanka. In 2003, an estimated 200,000 migrant domestic workers were found in Hong Kong SAR, China, and 155,000 were found in Malaysia. In Singapore, one of every seven households employs a domestic worker, the majority of whom are migrants (UNFPA 2006).

More women are moving independently for educational and employment reasons. When migration is not restricted, many women choose to migrate to obtain new skills, increase their income, and broaden their education. In Vietnam, approximately 14 percent of male and female migrants migrate to attend school; since females are more likely to migrate, they constitute a larger fraction of those migrating for schooling (Pierre 2011). Women are overrepresented in the brain drain, which may be a consequence of their unequal access to labor markets in developing countries. Econometric estimates show that emigration of highly skilled women is higher the poorer the country of origin (Dumont et al. 2007). Although this can be beneficial to 
the individual in terms of opportunities, the female brain drain can be detrimental to the economic growth of source countries.

The informal sectors of cities have many opportunities for women as well as men, promoting rural to urban migration. The informal labor sector in Cambodia has absorbed female migrants from rural areas in work such as street peddling, manual labor, domestic service, and garbage collection (UNIFEM 2005). Male migrants conduct different, generally brawn-intensive, types of work, including construction, mining, fishing, and logging.

In recent decades, the sex and entertainment industries in Asian cities and in crossborder areas have grown substantially. Almost all women involved in these industries are rural-to-urban migrants with circular, or temporary, patterns of migration (Hugo 2003). Global tourism, which has been promoted as a national policy in countries such as Indonesia, Malaysia, the Philippines, and Thailand for decades, is cited as the primary reason for the rapid growth of the sex and entertainment industry (Hugo 2005). Cambodia and Lao PDR also now face this social challenge.

\section{The mixed impact of migration on women's} position in households and communities

Migration can increase a woman's empowerment, economic opportunity, knowledge, and skills, as well as increase her participation as an active member of society. Through these channels, a woman can contribute to economic growth, increase the wellbeing of her family, and have an intergenerational effect by acting as a role model for other women and girls. ${ }^{10}$ However, female migrants are more likely to be at risk of exploitation, abuse, and human trafficking than male migrants.

Many women become empowered when they move from rural to urban areas and away from familial and rural community social controls. Increased autonomy, access to information, and status can empower women to create new identities for themselves. Rural migrant women in Chinese cities experience more autonomy and independence than they did at home (Zhang 1999). Migrant women who return home may act as role models to other women by transferring or demonstrating newly acquired skills, ideas, attitudes, and knowledge (Hugo 2005; UNFPA 2006). Migrants employed as domestic workers in Chiang Mai and Mae Sot, Thailand, expressed the desire to establish businesses based on the new skills that they've learnt when they return home (Punpuing et al. 2005). The women of rural Anhui and Sichuan, China, who participated in circular migration returned home having adopted the urban norm of desiring only one child; they also experienced lower rates of domestic violence than women who did not migrate. These women also believe that women should be able to choose a marriage partner and that divorce is acceptable (Connelly et al. 2010).

Empowerment may arise in the form of participation in collective organizations, including nongovernmental organizations and labor associations that lobby for gender equality. In the past 15 years, domestic workers in Hong Kong SAR, China, have been active in organizing and participating in political protests that concern not only local migrant workers' rights but also global, transnational, and human rights (Constable 2009).

Migration provides women with increased economic opportunities, which can improve the standard of living of the migrants and their families. For many female rural-tourban migrants in China, their migration is the first time they earn wages and choose how to spend them (Connelly et al. 2010). In Cambodia, the porous border to Thailand allows Khmer female migrants to sell home and farm products in Thailand's markets at higher prices, where the per capita GDP is 12 times that of Cambodia. Khmer women also engage in paid and formal employment as shop assistants, fruit sellers, and sweet sellers for mostly Thai employers. This largely circular and nonpermanent migration ranges from day migration to stays of two to three weeks at a time (UNIFEM 2005). Econometric evidence that combines a survey of Indonesian 
maids and factory workers in Malaysia with data from the Indonesia Family and Life Survey shows that these young female migrants may gain an additional US $\$ 80$ to US $\$ 130$ per month compared with their earnings if they stay in Indonesia. These income gains are as high as five times their income in Indonesia (Tan and Gibson 2010).

Migrants contribute to the economic development of their destination countries through their competencies and skills. Furthermore, they contribute to the economic development of the sending countries through remittances and increased experience and knowledge upon returning. Female migrants can improve the well-being of family members at home and potentially foster economic growth. In Indonesia, the proportion of households receiving remittances from female migrants between 2000 and 2007 far exceeded the proportion receiving remittances from male migrants. Their contribution to their family back home-in remittances as a percentage of per capita consumption among recipient households-also surpassed that of male migrants from 2000 to 2007 (Nguyen and Purnamasari 2011). ${ }^{11}$

In destination areas, women are particularly vulnerable to exploitation because of their status as migrants and because they are women. Women are more likely to be found in occupations where they are subject to labor exploitation and health risks, which can make migration detrimental to a woman's well-being. Furthermore, women's progress in empowerment may be negated upon returning to their home community.

Gender-based labor segregation channels migrant women into occupations that may subject them to physical and psychological abuse as well as labor exploitation and human rights violations (Yamanaka and Piper 2005). Many female migrants in the region, both documented and undocumented, work as live-in maids, caregivers, entertainers, sex workers, and other service employees (Yamanaka and Piper 2003). Labor legislation generally does not cover these occupations, leaving female migrants vulnerable to exploitation.
The largest segregated occupation, and one of the most isolating, is domestic work. Indonesian domestic workers employed in Malaysia typically work 16- to 18 -hour days, seven days a week, without holidays (Human Rights Watch 2004). In the Chiang Mai and Mae Sot provinces of Thailand, almost 98 percent of domestic workers worked for more than 12 hours a day (UNESCAP 2007). Over half of these domestic workers were subject to verbal abuse, 10 percent experienced physical abuse, and 14 percent stated that they experienced some form of sexual harassment (Punpuing et al. 2005). ${ }^{12}$ In addition to these abuses, domestic workers frequently had their freedom of movement and their communication with the outside world limited by their employers.

One of the greatest vulnerabilities women and girls face is trafficking for prostitution and forced labor. A highly profitable and growing industry, human trafficking is the third most lucrative illicit business in the world after arms and drug trafficking, and it is a substantial source of organized crime revenue (ILO 2008; UNFPA 2006). The International Labour Organization (ILO) estimates that at least 2.5 million trafficking victims are currently being exploited worldwide and that another 1.2 million are trafficked annually, both across and within national borders. Asia and the Pacific regions account for over half of these trafficked victims-an estimated 1.36 million (ILO 2008). ${ }^{13}$ Women often arrive in destination countries such as Malaysia through legal channels but without a job. These women become particularly vulnerable to trafficking because of financial hardship and limited information.

Male and female migrants often have jobs that subject them to health risks. The prevalence of female temporary migrants' work in the sex and entertainment industries increases their likelihood of acquiring HIV. In China, male migrants and nonmigrants have similar rates of casual and commercial sex; however, female temporary migrants have rates of casual and commercial sex 14 and 80 times the rates for 
female nonmigrants, respectively (Yang and Xia 2005). Male migrants, who dominate industries such as mining and construction, face increased health risks, including risk of death, partly as a result of lax occupational safety regulations. In China, between 2001 and 2005 , an average of 6,222 workers died in coal mining accidents each year; the majority of the workers were migrants (IOM 2009). Other effects of working in mines develop over time: pneumoconiosis, a lung disease caused by dust inhalation, accounts for 83 percent of all occupational disease recorded in China (Ministry of Health figures, Su 2005, as cited in IOM 2009).

Migrants' gains in female empowerment in the destination area may not have lasting impacts once women return to rural areas. Context matters in determining empowerment outcomes, as shown in many studies. Mason and Smith $(2003,2)$ compare autonomy measures across five Asian countries and argue that "community is a far stronger predictor of women's empowerment than are individual traits" (see the discussion in chapter 4). Evidence from China suggests that rural women migrants who return home experience a decrease in empowerment because of the existing community patriarchal inequality factors rather than individual characteristics (Connelly et al. 2010).

\section{The mixed impact of migration on those who stay behind}

Migrants' spouses, children, parents, and communities are also affected by their absence, and the evidence shows that the impact is mixed. Women and girls who are left behind may face more financial hardships, difficulties disciplining children, less access to food, as well as loneliness and isolation. Frequently, women who are left behind must engage more in income-generating activities to compensate for the income lost by the migrant relative if the latter does not send adequate remittances or remittances on a regular basis. Women left behind in rural China experience a substantial reallocation of traditional farm labor, with older women taking on most of the added hours in farm work. This additional obligation seems to be a persistent effect and comes at the cost of fewer hours in local off-farm work, with no signs of increased decision-making responsibilities over the household's farming activities. However, men who are left behind do not experience this reallocation ( $\mathrm{Mu}$ and van de Walle 2009).

Migration affects the employment of those left behind. In the Philippines, having a migrant in the household reduces the labor force participation and hours worked of nonmigrant relatives of both men and women, who substitute income for more leisure (Rodriguez and Tiongson 2001). In Indonesia, migration reduces the working hours of remaining household members by 33 hours per week if the migrant is male. This negative relationship is not observed for households with female migrants (Nguyen and Purnamasari 2011). Furthermore, in Indonesia, female migration may reduce the labor force participation of children ages $6-18$ by 17 percentage points (Nguyen and Purnamasari 2011). This impact is not seen with male migration. Anecdotal evidence from the Pacific Islands of Fiji, Samoa, and Tonga suggests a similar phenomenon. Regular remittances from female migrants such as nurses, teachers, domestic workers, and caregivers have induced those who receive remittances to increase their leisure time by resigning from their jobs or dropping out of school. This response can be a problem because it implies a total dependence on remittances (UNESCAP 2007).

The responsiveness of investment in education tends to vary according to the sex of the migrant. In Indonesia, migration may have a slightly positive impact on school enrollment among households with male migrants. By comparison, migration does not appear to have strong effects on children's schooling among households with female migrants, perhaps because the absence of mothers often makes it harder to monitor children's activities (Nguyen and Purnamasari 2011). 


\section{Implications for policy related to migration}

The number of female migrants in the East Asia and Pacific region is now estimated to have surpassed that of male migrants. Women have benefited from being more likely than men to be employed in growing export-oriented industries such as clothing, textile, toy, and electronics manufacturing, and they are more likely to provide services that are in demand, such as live-in maids or caregivers. By increasing a woman's economic opportunities and ability to generate income, migration can increase her empowerment, economic opportunities, knowledge, and skills, thus also improving the well-being of her family. It can also increase her participation as an active member of society and make her a role model for other women and girls. However, migrant women are more likely than men to work in occupations where they may be subject to labor exploitation and health risks, or, even worse, physical and psychological abuse. These occupations are generally not covered by labor legislation, leaving female migrants vulnerable to exploitation. The biggest danger women migrants face, especially those with no job and little money, is trafficking for prostitution and forced labor, a huge and growing illegal industry that exploits vulnerable women.

Improved laws, safety nets, and knowledge transfers can all help to mitigate the vulnerabilities experienced by migrant women. Some specific policy recommendations include improving the legal and social protections of female migrants, strengthening the monitoring and credibility of labor recruitment agencies, and developing and providing welfare and support services to assist female migrants. Governments in both sending and receiving countries should actively address the issue of human trafficking through prevention, protection, and prosecution. Gender-sensitive training for people involved in the migration process will increase their ability to identify and assist abused female migrants and those trafficked or at risk of being trafficked.

\section{Urbanization}

Urbanization has increased across the world and, for the first time in world history, the urban population accounts for more than 50 percent of the world's population globally (figure 5.5). At the global level, the Latin America and Caribbean region has the highest rate of urbanization in the world, which is expected to reach close to 90 percent by 2050. Since 1950, countries in the East Asia and Pacific region have experienced population shifts away from rural areas to urban centers. Individuals in developing countries, in search of better economic and social opportunities, are attracted to urban areas. With their concentration of population and economic activities, cities make a major contribution to countries' national incomes. As economic activity becomes concentrated, local welfare in urban areas may improve, although remote areas tend to lag behind until development proceeds and living standards converge (World Bank 2008).

Urbanization affects all aspects of life, from the family and community networks that people rely on to the economic activities conducted by men and women. Access

\section{FIGURE 5.5. The urban population now accounts for more than 50 percent of the world's population}

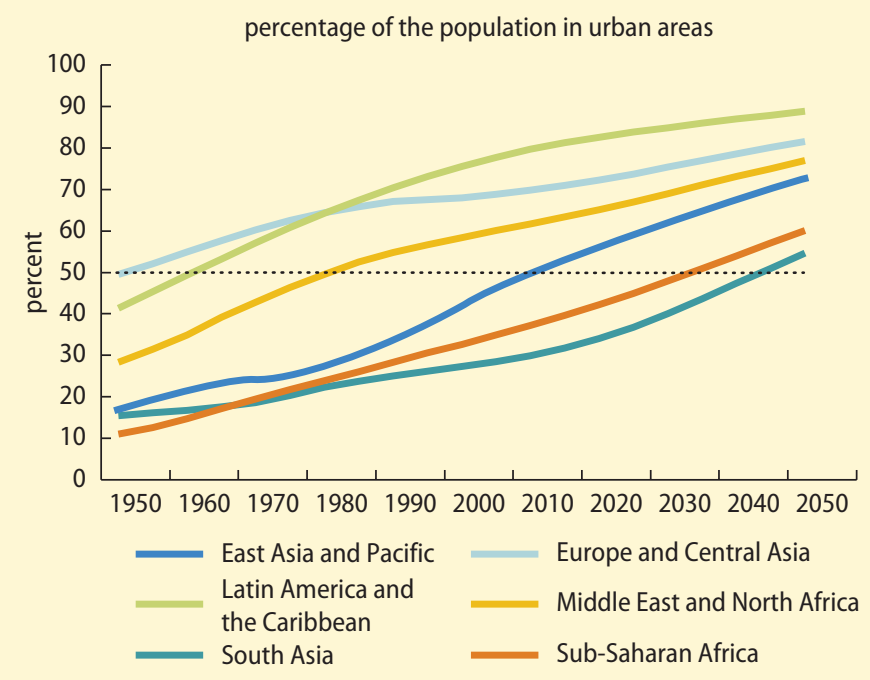

Source: UN DESA Population Division 2010. 


\section{FIGURE 5.6 Urbanization is expected to be rapid in East Asia}

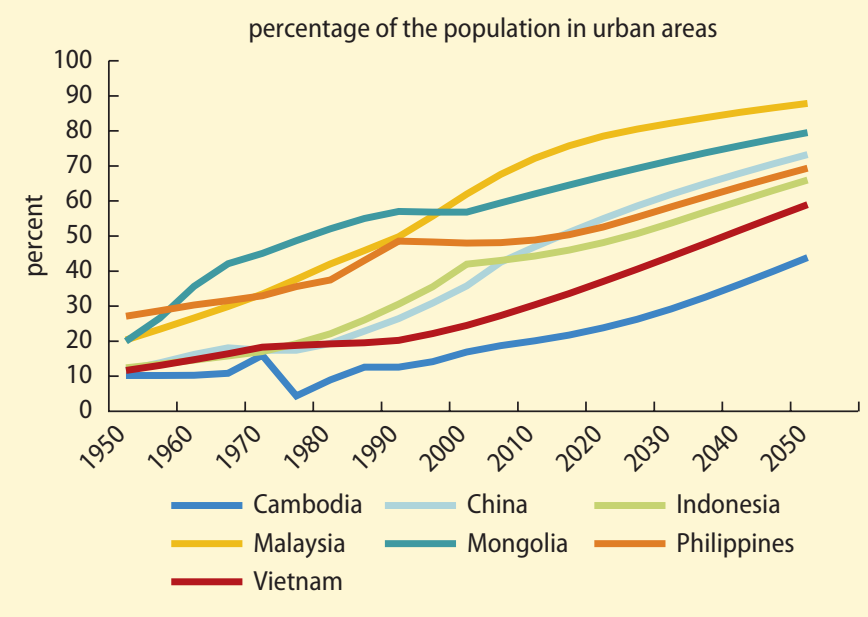

Source: UN DESA Population Division 2010.

FIGURE 5.7 The rates of urban growth are predicted to vary substantially across countries in the Pacific

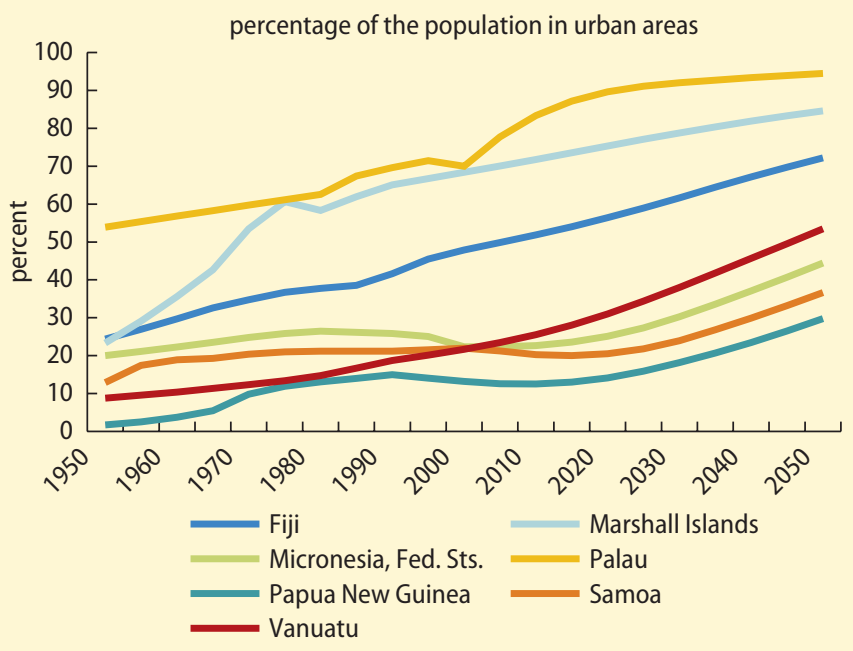

Source: UN DESA Population Division 2010.

to urban labor markets is likely to affect female participation in the formal labor market as well as the composition of productive work conducted (Moser 1993). Urbanization is also likely to alter the time use patterns of both men and women and, in particular, to reduce the time spent on housework for women. Gender differences in the time devoted to nonmarket activities are greater in rural areas, where more limited access to water, sanitation, and energy increases female time spent on basic life-sustaining activities, as discussed in chapter 3 .

This section analyzes urbanization patterns and how they affect men and women in the region. It then discusses the opportunities and challenges that men and women face in urban settings and highlights some policy priorities for tackling these challenges.

\section{Trends in urbanization in the East Asia and Pacific region}

Although the rate of urbanization differs across countries in the region, one observation remains clear: in all developing countries in the East Asia and Pacific region, the fraction of the population living in urban areas is expected to grow over the next half century. Figure 5.6 illustrates trends in the proportion of the population living in urban areas for East Asia. The growth of the urbanized population is substantial: in 1950, 12 percent of the Chinese population was living in urban areas, and by 2000 this number had risen to 36 percent and is estimated to increase to 73 percent by 2050. Urbanization in the Pacific varies substantially across countries (figure 5.7). In Palau, over 90 percent of the population is expected to be living in urban areas by 2050; in contrast, less than 30 percent are expected to do so in Papua New Guinea.

\section{Urbanization and gender}

Urban areas provide many opportunities for men and women: health care, education, and financial services are better developed and easier to access, and labor markets present a broader range of employment opportunities than in rural areas. This section discusses the opportunities and challenges of urbanization from a gender perspective in three dimensions: economic opportunities, service delivery, and agency.

\section{Economic opportunities}

Like their male counterparts, women have access to more economic opportunities in 
urban areas than in rural areas. Urban labor markets offer a wide variety of occupations, from manufacturing and services to clerical activities. $^{14}$

Limited access to child-care services may limit women's ability to take advantage of these opportunities, however. A study on gender differences in labor market behavior in Mongolia found that women spend about twice as much time on household duties as men, independent of whether they participate in the labor market, and that the number of young children decreases female labor market participation in urban areas (World Bank 2011a). The economic restructuring of the 1990s, in which Mongolia reduced statesponsored child-care provision, may partially explain the time burden on women. Although a set of policies was passed to increase children's enrollment in kindergarten, only about half of the children ages 2 to 6 were enrolled in a kindergarten in 2007, and urban areas face serious constraints in available schools (World Bank 2011a).

\section{Service delivery}

Public services are less expensive to provide in urban areas than in rural areas, because of population density and economies of scale (UNFPA 2007). Figures 5.8 and 5.9 show the percentage of the rural and urban populations with access to improved sanitation facilities and water sources. In rural areas in Cambodia, only 15 percent of the population had access to improved sanitation in 2005 , in contrast to urban areas, where 60 percent had access (figure 5.8). Similarly, in Mongolia, only 45 percent of the rural population had access to safe water sources, whereas 94 percent of the urban population did (figure 5.9).

Access to improved water and sanitation services is particularly important for women, who are often responsible for the collection, management, and use of the domestic water supply. Increasing access to improved water sources is likely to reduce women's time spent on domestic water management and to allow more time for other activities. Inadequate access to water may reduce women's
FIGURE 5.8 In most East Asian and Pacific countries, urban areas have better access to improved sanitation

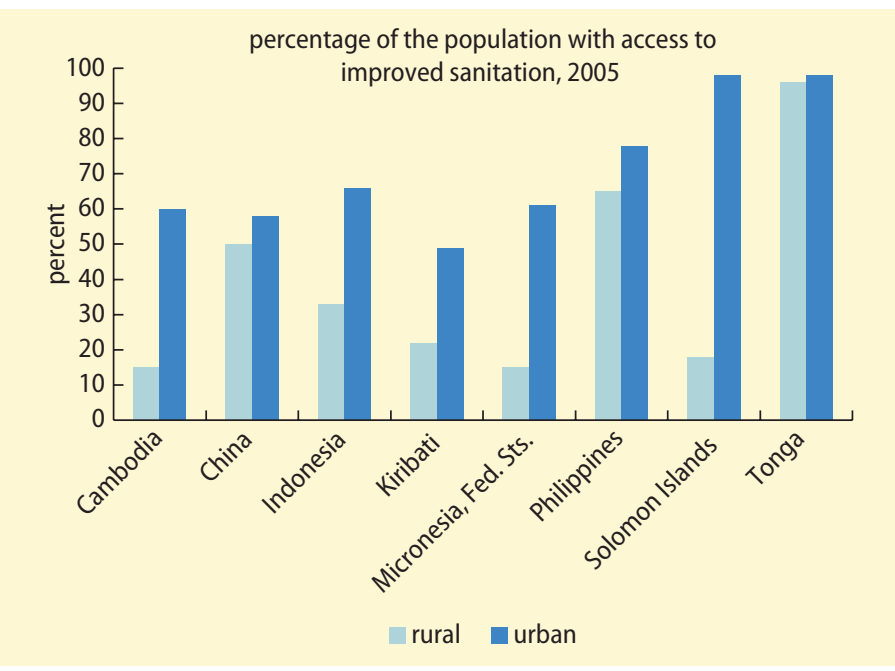

Source: World Development Indicators (WDI) database.

FIGURE 5.9 Rural areas have lower access to improved water sources than urban areas in the majority of countries in the region

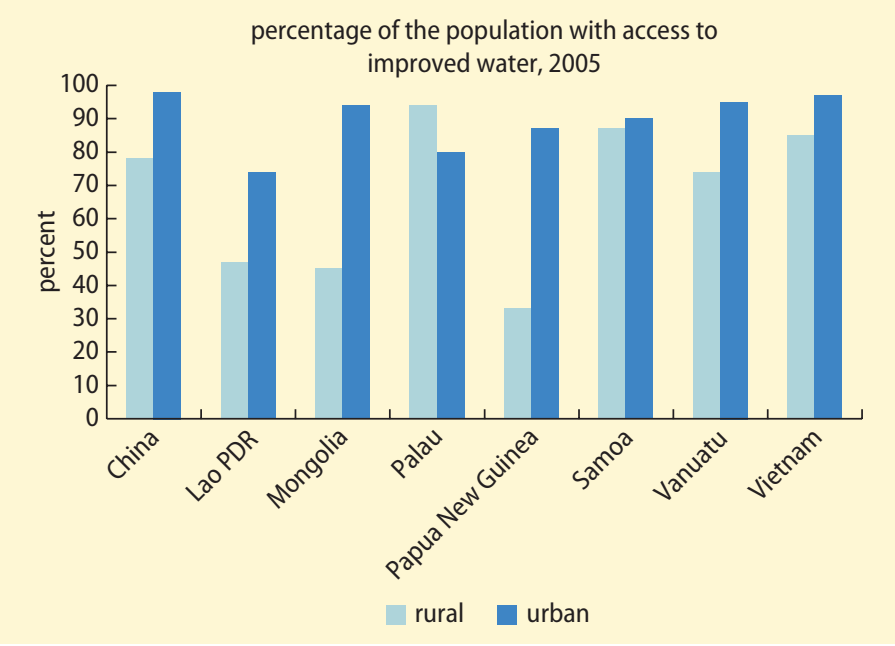

Source: WDI database.

economic opportunities by limiting access to home-based income-generating activities such as food production and sale, livestock raising, and other service-oriented business activities (Noel, Soussan, and Barron 2007). Poor sanitation can cause the spread of infectious diseases such as cholera, polio, or hepatitis. Finally, evidence from outside the region 
shows that improving water sources increases girls' school attendance (Koolwal and van de Walle, forthcoming).

Transportation is crucial for ensuring that urban populations are able to benefit from the social and economic potential of urban areas. Women and men have different transport needs and patterns. Women's transport needs and commuting patterns are associated with responsibilities in the household as well as income-generating activities. Studies show that women in urban areas travel frequently in off-peak times and conduct multiple stops on a single trip. In contrast, men tend to use transport at peak times for reaching work (World Bank 2010b). Women's commuting patterns also vary over their life cycle and according to their reproductive and domestic duties. ${ }^{15}$

In urban areas, transport systems may particularly benefit men since they are often focused on the major routes to and within the city (World Bank 2010b). Pricing structures during peak times are also likely to encourage longer trips relative to multiple short trips. Given the pricing structures of urban transport, and that men use transport for income-generating activities, transportation costs can constrain women's mobility if the intrahousehold distribution of transport expenditure is skewed toward financing trips for those earning incomes outside the household (World Bank 2010b).

Safety and cultural concerns may also limit women's access to certain modes of transport. Evidence from Cambodia suggests that female garment workers experience security concerns, principally from accidents, robberies, threats, and sexual assaults, during their commute to and from work (World Bank 2006a). Cultural concerns, such as men and women sharing a single crowded vehicle, may also constrain women's access to communal transport (World Bank 2010b).

\section{Agency}

Urbanization can contribute to changing norms and may alter women's roles within the society and households. Cities are a melting pot of people and ideas, which change traditional ways of life, structures, and norms. The density and diversity of the urban population can increase women's access to networks and to information (World Bank 2008). Evidence from Indonesia indicates that urban women are more likely to be the sole decision makers on a number of household matters than rural women (Rammohan and Johar 2009).

Some dimensions of women's agency may, however, be more restricted in urban areas. Violence in urban areas may be more pronounced because traditional and cultural norms are less likely to guide behavior and neighborhood networks are less developed (Blank 2008; UNFPA 2007). Exploitative occupations such as sex work are also more likely to be found in urban areas. For instance, in the capital of Papua New Guinea, a large fraction of unemployed young women engage in sex work to bolster their incomes (Blank 2008). Although urban children have better access to education in Cambodia, security concerns for daughters traveling to school were found to be higher among parents in urban areas than in rural areas (ADB 2004).

\section{Implications for policy related to urbanization}

Growing urbanization in the East Asia and Pacific region has presented women with increased economic opportunities and greater empowerment. However, evidence shows that women in urban areas continue to sort into sectors that yield lower incomes and that are more likely to be informal, despite the more extensive opportunities. The choices of women's economic activities are constrained in part by limited access to affordable child care. Cultural concerns in some countries in the region may also limit women's access to certain modes of transport, thus making it more difficult for them to commute. Women also face higher security risks than men do in urban areas, particularly from exploitation, sexual abuse, and assault. 
Whether women will be able to take full advantage of the wide range of opportunities available to them in urban areas will depend on whether the services and infrastructure exist in these cities to enable them to do so. Thus, policy makers need to ensure that their child care, education, infrastructure, transportation, and water and sanitation policies take into account women's specific social and cultural needs. They should also adopt rigorous laws and policies to protect women in urban areas from the risk of violence and exploitation, as discussed in the migration section above.

\section{Aging populations}

The world's population is aging. By 2045, the number of people age 60 years and older will exceed the number of those under the age of 15 for the first time in history (UN 2007). In Asia, this process is estimated to be even faster; the milestone of elderly people outnumbering children will be reached five years earlier, in 2040 (UN 2007). As a group, Asians age 64 and above are expected to more than triple, from 207 million in 2000 to 857 million in 2050. This demographic change is likely to have significant repercussions for economic development, the quality of life, and the role of public policy. In addition, population aging is likely to have a gender-differentiated effect among both older and younger cohorts. Several noteworthy challenges face the East Asia and Pacific region in managing these rapid demographic changes, notably how the aging population will maintain its standard of living, the types of formal and informal supports that are needed to do so, the impact on the working-age population, and the impact on health care and other services.

\section{Trends in population aging in the East Asia and Pacific region}

The high-income economies in East Asia are experiencing rapid population aging. Most emerging countries in the region have also begun this process; dependency ratios are already increasing in many middle income countries in East Asia and the Pacific. For example, fertility rates have dropped significantly in Mongolia and Vietnam, and dependency ratios have increased dramatically in middle-income countries, including China, Indonesia, and Thailand, and in countries in the Pacific, namely Fiji, Timor-Leste, and Tonga. ${ }^{16}$ Dependency ratios are expected to continue increasing and, given that women live longer than men, female dependency ratios will likely exceed male dependency ratios in the future (figures 5.10).

\section{Population aging and gender}

Life expectancy at birth has improved for both men and women since the 1990s. Reduced fertility and a decreased risk of maternal mortality have contributed to the improvements in life expectancy of women in many parts of the world (World Bank 2011b). Although the gender gap in life

\section{FIGURE 5.10 The old age dependency ratio is expected to increase for both men and women in the next two decades; the female ratio will exceed the male ratio in the future}

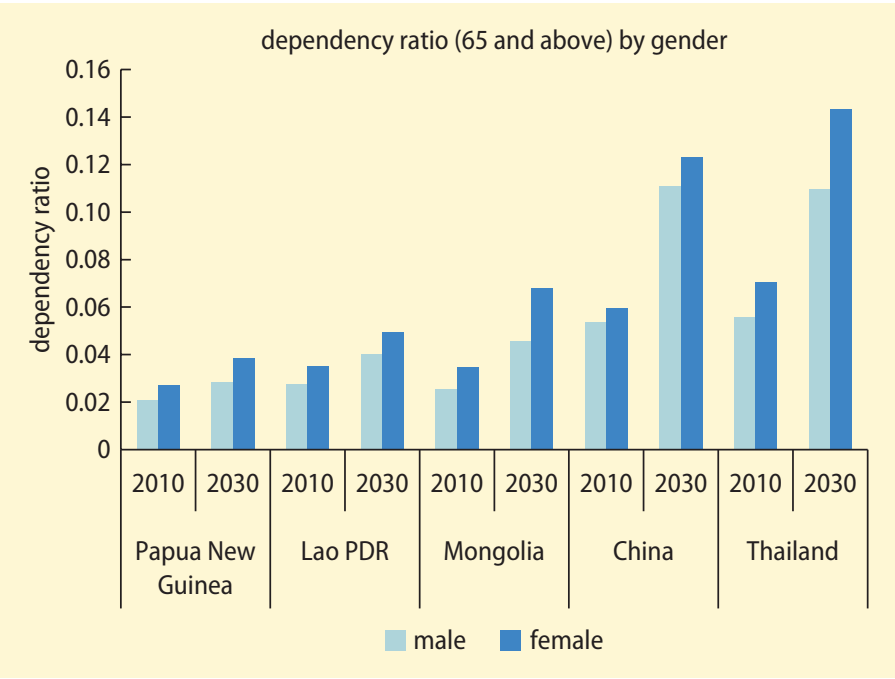

Source: HNPStats (Health Nutrition and Population Statistics) database, Population Projection, World Bank.

Note: Old age dependency ratio of males and females is defined as the ratio of the male and female population 65 years of age and above over the working-age population (15-64 years of age) of both genders. 

FIGURE 5.11 The gender gap in life expectancy at birth is lower in
the East Asia and Pacific region than in many other regions

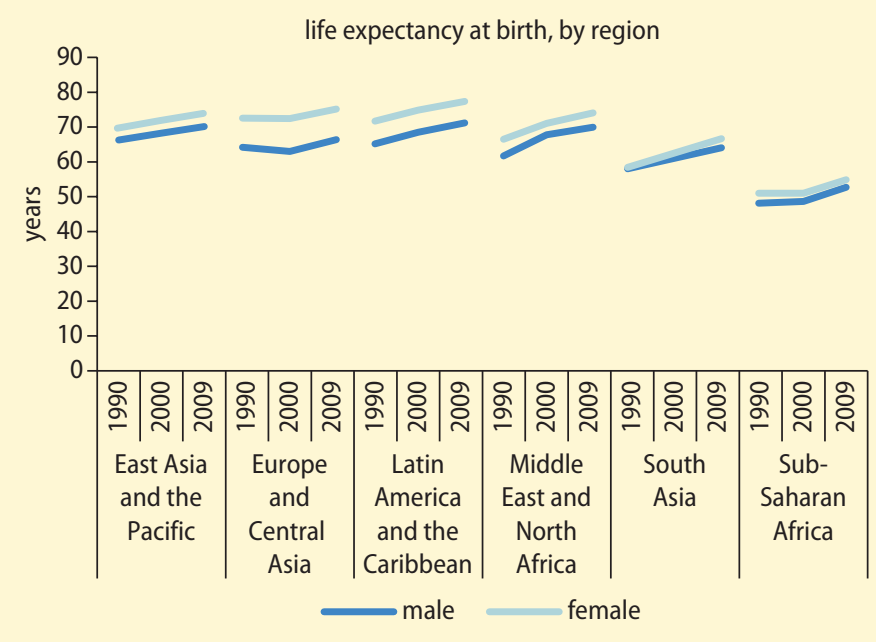

Source: WDI database.

FIGURE 5.12 Life expectancy at birth in the region has improved for both men and women since 1990, although gender gaps have widened in some countries

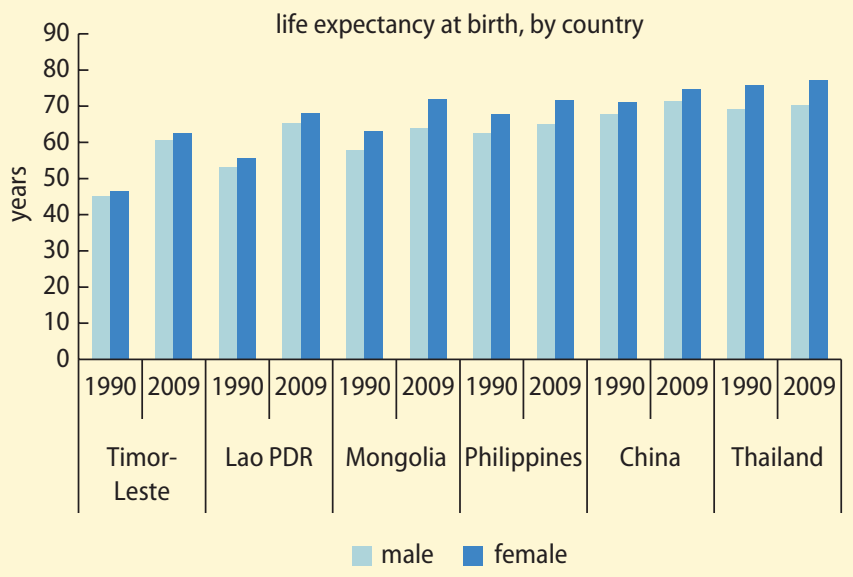

Source: WDI database.

expectancy is lower in the East Asia and Pacific region than in many other regions (figure 5.11), it has widened for many countries in the past two decades. In some countries, the widening gender gap in life expectancy is substantial, for example, in Mongolia (figure 5.12).

Older women have different access to resources than older men, in part because of their different life histories (Hooyman 1999; INSTRAW 1999). Even as gender gaps continue to close for today's youth, the gender gaps of the past are embodied in today's adults through less schooling, different work experiences, lower rates of pension coverage, and less control over assets, among other things. Women's social arrangements within the family and the community are different, and they tend to outlive their spouses. Therefore, a careful examination of the implications of an aging society must consider the perspectives of both women and men.

The debate is open as to whether men or women are more likely to suffer from being less vested in the labor market and in formal social security mechanisms such as pensions, since women are more likely to be vested in familial relations. Mothers' closer relationships with their children might lead to larger intrafamily transfers later in life (Aboderin 2004). Their abilities in home production might outlast men's abilities in the workforce, and psychologically they may be better able to handle old age, both because it poses a smaller disruption to their previous roles and because they tend to establish a broader and deeper array of friendships than men.

Gender differences in consumption poverty and housing quality are small among the elderly in many East Asian countries (table 5.1) (Friedman et al. 2003; Knodel 2009; Knodel and Chayovan 2008; Masud, Haron, and Gikonyo 2008). In countries where data at the individual level are available, elderly men systematically report higher levels of individual income than elderly women (Masud, Haron, and Gikonyo 2008; Ofstedal, Reidy, and Knodel 2004). This is consistent with women's lower participation in the workforce: women are less likely to earn income from work or to draw pensions during old age. However, differences in individual incomes do not appear to translate into significant differences in measures of material well-being at a household level; that is, elderly women are not more likely than elderly men to live in poor households.

Marital status, notably widowhood, tends to play a greater role than gender in 
TABLE 5.1 Evidence shows no systematic gender differences in consumption poverty among the elderly, regardless of family status

\begin{tabular}{|c|c|c|c|c|}
\hline \multicolumn{5}{|c|}{$\begin{array}{c}\text { Percentage of elderly individuals (65 and over) living } \\
\text { under US\$1.25 per day }\end{array}$} \\
\hline Country & $\begin{array}{l}\text { Marital } \\
\text { status }\end{array}$ & Male & Female & Total \\
\hline \multirow{2}{*}{ Indonesia } & Married & 29.3 & 33.0 & 30.4 \\
\hline & Widowed & 24.7 & 28.0 & 27.4 \\
\hline \multirow{2}{*}{ Cambodia } & Married & 8.2 & 8.5 & 8.3 \\
\hline & Widowed & 17.6 & 9.8 & 11.1 \\
\hline \multirow{2}{*}{ Lao PDR } & Married & 27.3 & 27.9 & 27.5 \\
\hline & Widowed & 26.4 & 28.8 & 28.3 \\
\hline \multirow{2}{*}{ Philippines } & Married & 13.9 & 13.2 & 13.6 \\
\hline & Widowed & 12.4 & 11.9 & 12.0 \\
\hline \multirow{2}{*}{ Thailand } & Married & 0.1 & 0.1 & 0.1 \\
\hline & Widowed & 0.1 & 0.2 & 0.2 \\
\hline \multirow{2}{*}{ Timor-Leste } & Married & 25.9 & 18.9 & 24.1 \\
\hline & Widowed & 27.9 & 23.1 & 24.6 \\
\hline \multirow{2}{*}{ Vietnam } & Married & 11.6 & 14.9 & 12.9 \\
\hline & Widowed & 8.6 & 14.9 & 13.8 \\
\hline
\end{tabular}

Source: World Bank estimates based on East Asia and Pacific household poverty monitoring database.

Note: Bolded numbers are statistically significant differences between male- and female-headed households and between widowed and married households at the 10 percent level.

determining the well-being of elderly men and women. Women are far more likely than men to be widows (figure 5.13). In Cambodia, the percentage of women who have lost a spouse is more than triple that of men, and women are also less likely to have living children than their male counterparts (Knodel 2009). In Thailand, 80 percent of elderly men are living with their spouses, compared to only about half of elderly women (Knodel and Chayovan 2008). In Indonesia, Cambodia and Timor Leste, the differences are dramatic. In Indonesia and Cambodia, approximately 65 percent of elderly women are widowed compared to approximately 20 percent of men; in Timor-Leste, 73 percent of elderly women are widowed compared to 30 percent of men.

Marital status is the most important correlate of household circumstances among the elderly. Across the region, unmarried elderly are more likely than married elderly to live with their children and receive support from their children, either directly through transfers or through their living arrangements (Friedman et al. 2003; Knodel and Chayovan

\section{FIGURE 5.13 Women ages 65 and above are far more likely to be widowed than men}

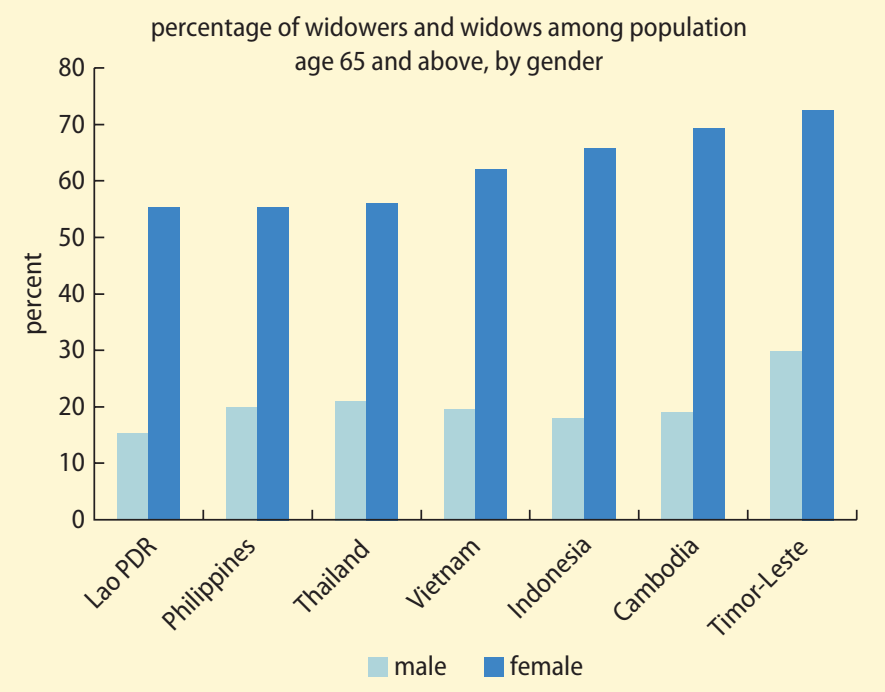

Source: World Bank staff estimates using CSES (NIS Cambodia), 2008 data; SUSENAS (BPS Indonesia), 2009 data; LECS (LSB Lao PDR), 2008 data; Mongolia LSMS (NSO Mongolia), 2007-08 data; Philippines Family Income and Expenditures Survey (NSCB Philippines), 2006 data; Thailand Household SocioEconomic Survey (NSO Thailand), 2009 data; Timor-Leste Survey of Living Standards (SLS) (NSD TimorLeste) 2007, data; and VHLSS (GSO Vietnam), 2008 data.

2008; Knodel and Zimmer 2009; Ofstedal, Reidy, and Knodel 2004). However, no systematic evidence shows that widows and widowers are consistently likely to be poorer than married elderly individuals (table 5.1), although they are more likely to perceive income inadequacy or lower rates of satisfaction with their economic status in many countries in the region, including Indonesia, Malaysia, Thailand, and Vietnam (Friedman et al. 2003; Knodel and Chayovan 2008; Masud, Haron, and Gikonyo 2008; Ofstedal, Reidy, and Knodel 2004).

Elderly women have access to fewer personal income sources and less-diversified income portfolios than elderly men. The lack of association between gender and poverty in the elderly population is partly because women, and in particular unmarried women, are more likely to receive money from children and other relatives than men and less likely to have their own sources of income (Masud, Haron, and Gikonyo 2008). Furthermore, men's income is more dispersed across a number of sources than women's 
income (Ofstedal, Reidy, and Knodel 2004). Women's greater reliance on transfers from informal support networks is likely to place them in a more tenuous position, both within their families and in society.

As migration and urbanization continue and fertility declines, there is concern that informal safety nets may decline and that transfers and care from children will erode (UNESCAP 2004; World NGO Forum on Ageing 2002). ${ }^{17}$ A decline in transfers is likely to have a gender-differentiated impact, since elderly women are more likely than elderly men to receive support from children and other family members. Evidence suggests that attitudes of respect and responsibility toward the elderly population may also be changing in parts of the region. Studies have reported that children from singlechild families in China are less committed to elder care in more recent generations than in previous ones (Wang 2010; Zhan 2004). People in the baby boom generation have been found to have more positive attitudes toward the elderly than those in more recent generations, regardless of gender (Xie, Xia, and Liu 2006). ${ }^{18}$

Older women are worse off than their male peers along a number of nonconsumption dimensions, many of which are associated with their age. They are less educated, have fewer assets, and are more likely to be illiterate (Knodel 2009; Long and Pfau 2008); they also have lower access to care (Knodel 2009; Long and Pfau 2008; Magnani and Rammohan 2009) and more health problems (Chen and Standing 2007). Some of these differences are likely to persist without targeted reform, whereas others are likely to narrow over time. For example, since education gender gaps have declined over time across birth cohorts, these differences are likely to be smaller among the future elderly population.

Because women live longer than men, the evidence suggests that they are also more likely to suffer from disabilities. The barriers to participating in social life for the elderly directly affect their quality of life, but such barriers also impose additional costs on their families. In Vietnam, one study showed that having a disabled household member increased the cost of living over 11 percent (Braithwaite and Mont 2009), and adjusting for these differences would raise the poverty rate of households with disabled members significantly. ${ }^{19}$ This is more likely to be an issue for women-the rate of disability in Vietnam is 8.5 percent for women compared to 6.6 percent for men, with the gap explained to a significant measure by the difference in longevity (Mont and Cuong 2011).

Finally, the elderly and, in particular, widows might be especially vulnerable to shocks. Men and women have different capacities to cope with economic shocks given differences in incomes and asset endowments. However, evidence from six provinces in Thailand and Vietnam suggests that rural households headed by widowed, divorced, or single women are not more likely to be affected by shocks than their male counterparts (Klasen, Lechtenfeld, and Povel 2011).

\section{Caregiving and its repercussions for working-age women}

Population aging may have a genderdifferentiated effect among the working-age population because the increasing dependency ratios, particularly when accompanied by falling fertility rates, will raise the burden of caregiving. Gender differences in the time spent caring for the elderly imply that women are more likely to accommodate the increased demand for nonmarket time. ${ }^{20}$

Within households, younger women are likely to bear a greater responsibility for caring for elderly parents than younger men, which may reduce the time they spend on income-generating activities. ${ }^{21}$ Data from the region suggests that although working age women spend more time on housework and caring than men, women residing with elderly members do not necessarily spend more time on these activities than women who do not reside with elderly members (figure 5.14). This may reflect a compensating grandparent effect in households with children: elderly household members contribute to caring for 
children, which thereby leaves the total time that younger women spend on housework and caring unchanged or diminished. For example, staff analysis of household data from TimorLeste finds that living with elderly members increases the time devoted to housework and caring activities by 40 minutes a day among women without young children (NSD TimorLeste 2007). In contrast, in households with young children the presence of elderly members reduces the time devoted by younger women to housekeeping and caring activities, who spend 30 fewer minutes on these activities than women with children who do not live with elderly members.

\section{Implications of aging populations for gender policy}

The population of the East Asia and Pacific region is aging rapidly, in many countries at a faster pace than that in the rest of the world. This demographic change will likely have significant repercussions for women since they live longer than men but have access to fewer economic assets and resources and are less vested in formal social security systems. Although women are more likely to have access to informal caregiving and support systems, traditional systems of caregiving are evolving and exposing more elderly individuals to lower levels of familial support. Because older women are less likely than men to be covered by insurance or to have accumulated assets, the burden of their care is still likely to fall on younger women.

Policy makers can address the burden of aging in several ways. Policies to close gender gaps in access to human and physical assets will affect both older and younger women, with implications for gender gaps among future generations of older women. Policies that focus on ensuring that health care and social security systems cover those most in need are likely to benefit both elderly men and women. The design of old-age security systems becomes particularly important in the context of the rapid demographic transition and cultural change occurring in many countries in the region. Old-age income security
FIGURE 5.14 Women's time devoted to housework and caregiving activities is not significantly greater in households with elderly members

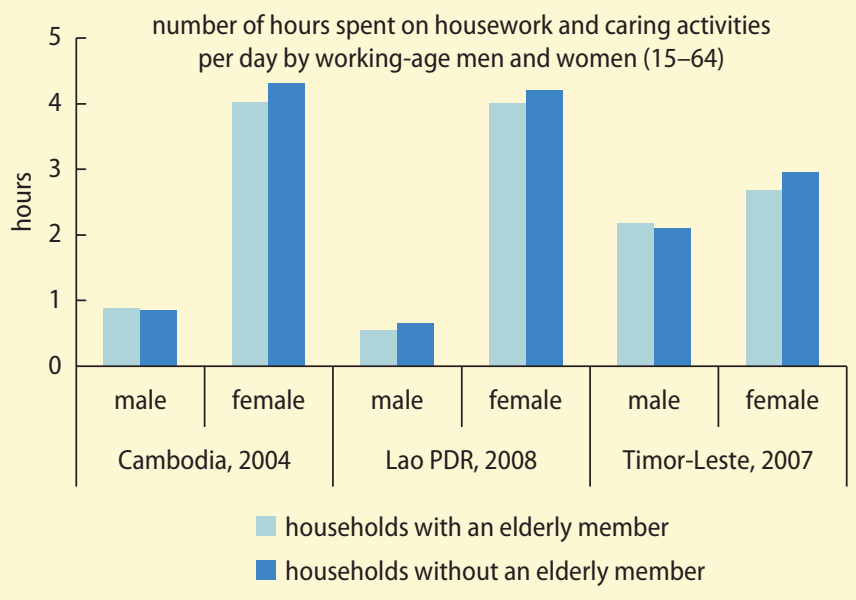

Source: World Bank staff estimates using CSES (NIS Cambodia), 2004 data; LECS (LSB Lao PDR), 2008 data; and Timor-Leste SLS (NSD Timor-Leste) 2007.

programs can protect women from destitution and reduce their reliance upon familial transfers. For example, joint annuities and survivor pensions are likely to be effective means to compensate and secure women's incomes in their old age. Finally, policy makers may consider ways to strengthen elder care to ensure that younger women do not face the disproportionate burden of care giving.

\section{Information and communication technologies}

The literature contains little evidence on how access to and use of ICTs vary by gender. Therefore, this section provides predominantly anecdotal or project-specific global evidence on the gender implications of the spread of ICTs.

The exponential growth of information and communication technologies in the developed and developing world is widely lauded as the defining economic and social force of the late 20th and early 21st centuries. ICTs encompass a plethora of technological advances, including radio, cell phones, computers, e-mail, social networking sites, and the Internet. Figures 5.15 and 5.16 show 
FIGURE 5.15 Internet use has increased substantially in the East Asia and Pacific region and around the developing world since 2000

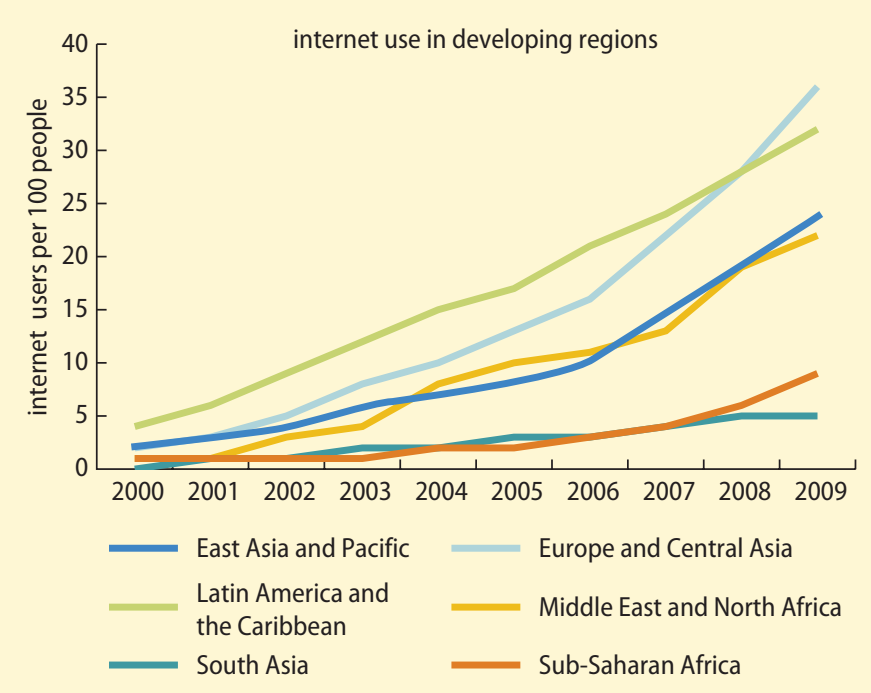

Source: WDI database.

FIGURE 5.16 The number of cell phone subscribers per 100 people in the East Asia and Pacific region has grown substantially since 2000

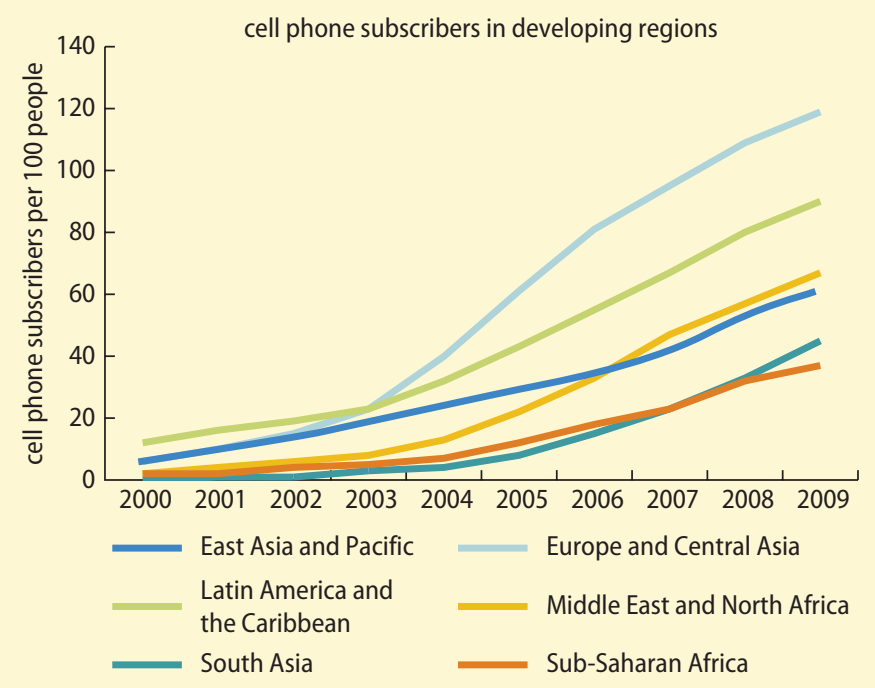

Source: WDI database.

the rapid expansion of access to the Internet and ownership of cell phones in developing countries around the world. The East Asia and Pacific region falls behind both Latin
America and the Caribbean and Europe and Central Asia in both of these indicators and ties with the Middle East and North Africa.

The spread of ICTs has increased access to information by enhancing knowledge sharing and gathering and by changing business practices and production structures. ICTs have affected many aspects of men's and women's lives, from economic opportunities and health outcomes to women's empowerment.

\section{ICTs and Gender}

The reach of technology, at the national level, has been growing in parts of the East Asia and Pacific region. In 2000, the majority of countries in the region had fewer than 2 Internet users per 100 people, with the exception of Malaysia, where there were already 20 Internet users per 100 people. Internet usage increased substantially in a number of countries over the 2000s. By 2009, Malaysia had approximately 58 Internet users per 100 people, and China had overtaken Thailand as the country with the second greatest number of Internet users-28 per 100 people-followed very closely by Vietnam, with 27 users per 100 people (figure 5.17). However, rapid growth of Internet use has not occurred in all countries. In Kiribati, Lao PDR, Papua New Guinea, and the Solomon Islands, Internet use is still close to its levels in 2000. Similar but starker patterns can be seen for cell phone use. In 2000, the level was fewer than 5 cell phones per 100 people in many countries in the region, and in the rest of the countries, with the exception of Malaysia and New Caledonia, it was fewer than 20 cell phones per 100 people (figure 5.18). By 2009, the number of cell phone subscribers had risen, along with disparities between countries. In Kiribati and the Marshall Islands, the number of cell phones per 100 people was still below 10, whereas in Samoa, which started from a base similar to the other Pacific countries, the number of cell phones per 100 people had risen to 84 .

Where gender-disaggregated data are available, they indicate gender differences in 
access to ICTs in the East Asia and Pacific region. Figure 5.19 displays the proportion of male and female subscribers to mobile phones in the population. Many regions across the world show a gender gap in cell phone subscriptions. Furthermore, gender differences in access to technology are greater among certain subgroups of the population. In other words, gender is likely to interact with socioeconomic characteristics such as income, education, location, and social and cultural constraints to determine access to technology (Huyer and Hafkin 2007).

In China, the number of Internet users has increased from approximately 20 million users in 2000 to over half a billion in 2011, a remarkable increase over time (CNNIC 2011). Although the fraction of female users has risen since 2000 , data suggest that men were more likely than women to be Internet users in China in the early to mid-2000s (figure 5.20). More recent data suggest that the gap between the number of men and the number of women using the internet in China has broadened as Internet use has risen: in 2011, 287 million men used the internet in China compared to 226 million women (CNNIC 2011). In percentage terms, however, the gender gap has narrowed: in 2011, women made up 44 percent of users, up from 30 percent of users in 2000 (CNNIC 2011).

ICTs can improve the welfare of both men and women in several different ways and can also have gender-differentiated effects by reducing constraints, such as time and transportation, that influence the decisions of women (Melhelm and Tandon 2009). First, ICTs can enhance women's economic opportunities by reducing the transaction costs of reaching markets. Second, the widespread dissemination of information on how men and women live their lives in other parts of the world may gradually change attitudes about gender norms and roles. Third, access to television, radio, and the Internet enables men and women to increase their knowledge and training through distance learning. Finally, rural populations can use ICTs to gain access to better health care through increased access to medical advice. These final two opportunities
FIGURE 5.17 Internet use has grown quickly in many countries in the region but has grown slowly in others

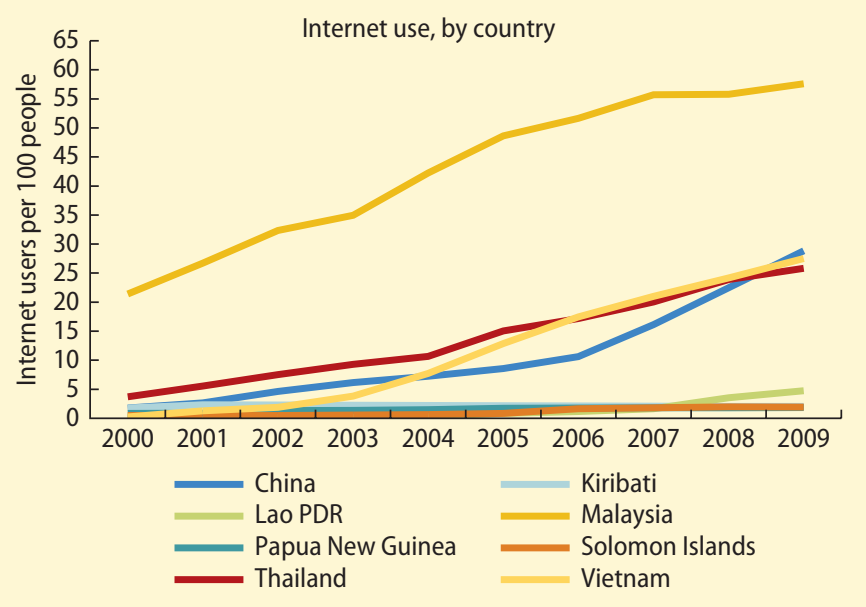

Source: WDI database.

FIGURE 5.18 The number of cell phone subscribers in the population has grown across most of East Asia but has remained limited in some Pacific countries

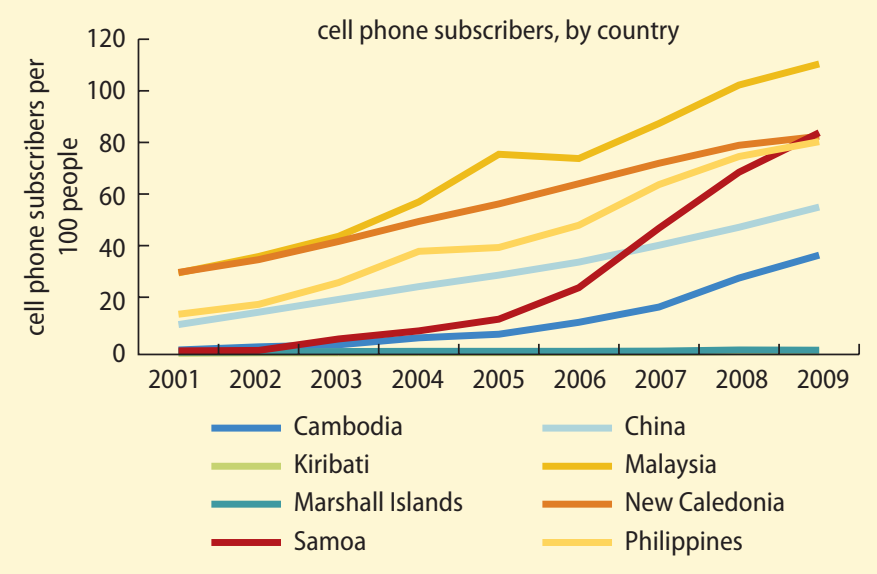

Source: WDI database.

Note: The data points for Kiribati are closely matched by those of the Marshall Islands and show as a single line.

may particularly benefit women, since evidence suggests that they face greater time and transportation constraints in accessing basic public services.

ICTs can enhance women's economic opportunities by increasing their access to markets through reduced information barriers and time and transportation constraints, 
FIGURE 5.19 Women in the region are less likely to be mobile phone subscribers than men

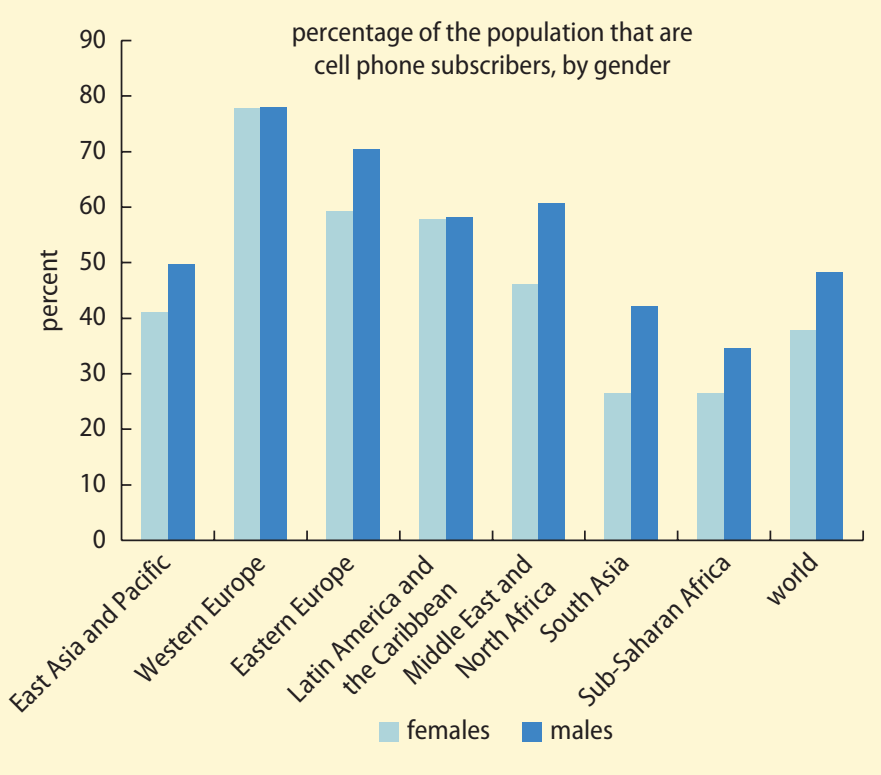

Source: World Bank estimates using GSMA Development Fund, the Cherie Blair Foundation, and Vital Wave Consulting, 2010.

FIGURE 5.20 Internet use has grown for both men and women in China, although a persistent gender gap in access remains

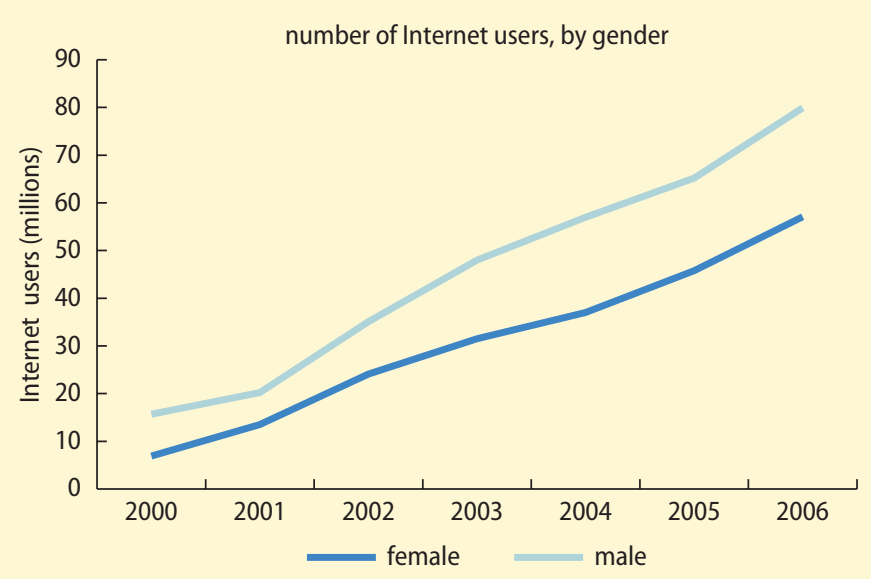

Source: CNNIC (China Internet Network Information Center) Internet Statistics.

in particular those in rural areas. For example, cell phones allow farmers to get better prices, by benefiting from market arbitrage opportunities (Aker 2010; Jensen 2007). ${ }^{22}$ Traditional technologies_-such as radio and television programs-have been used for decades in the developing world to provide advisory services to farmers in agricultural areas (Goyal 2010), and telecommunication centers and Internet kiosks allow farmers to access e-learning programs and search for agriculture-related information (Aker 2011). ${ }^{23}$ Although reducing information barriers and transaction costs is likely to affect the economic opportunities of both men and women, it is likely to have a greater effect on women, whose economic decisions are more likely to be constrained by transaction costs because of their multiple roles in households. For example, the e-Homemakers initiative in Malaysia reduces barriers for women entering the labor market; the initiative promotes home-based entrepreneurship and reduces time constraints by allowing women to work from home and to telework using ICTs.

Second, female empowerment and autonomy may be raised through the representation of lifestyles, autonomy, and gender roles in other parts of the world. ${ }^{24}$ One of the earliest examples of the power of entertainment-education to change behavior occurred in Mexico in 1977. The soap opera Acompaname promoted family planning, a socially sensitive topic at the time. The program is credited to have increased both awareness and use of birth control among Mexicans (Singhal and Rogers 1999). In another example, approximately 150 million individuals gained access to cable television service in India between 2001 and 2006 (National Readership Studies Council 2006, cited in Jensen and Oster 2009). This development had a large and swift effect on attitudes toward domestic violence and women's participation in household decision making (Jensen and Oster 2009). Studies have also found that exposure to cable television increased school enrollment for girls (but not for boys) and decreased fertility, an outcome that was associated with the increase in female autonomy (see chapter 4).

In societies in which social customs limit interactions between males and females, television may reduce stereotypes by increasing interaction or knowledge of others. For 
example, in Rwanda, a radio program aimed at discouraging blind obedience and promoting independent thought and collective action in problem solving was found to have increased listeners' willingness to express dissent and changed the ways in which communal problems were resolved (Paluck and Green 2009).

Technology can also be used to give women more control over their money and their actions. For example, in Bangladesh before mobile phones were common, a migrant husband's relatives had greater control over his remittances than his wife did; the advent of cell phones has allowed closer communication between husband and wife on how best to use the remittances (Schuler, Islam, and Rottach 2010).

Third, education programs conducted through ICTs can help to overcome the constraints faced by women in higher education by allowing them to pursue their education on a more flexible basis than normal programs allow. It also has the potential to increase access to higher education for women living in restrictive social situations, who may not be able to travel or live away from home to engage in higher education. ${ }^{25}$ Cell phones can also be used to increase adult literacy. Because sending text messages is cheaper than making voice calls, cell phone users have a financial incentive to send text messages and, thus, practice their reading and writing skills. ${ }^{26}$

Finally, ICTs can also be used to improve the provision and quality of health care services. In remote communities where access to high-quality medical care is limited, women often have less access to health care than men (see chapter 2). Therefore, increasing access to health care through ICTs may diminish existing health care disparities, but only if women are able to access ICTs to the same degree as men. For example, Sehat First provides health care and pharmaceutical services across Pakistan through telehealth centers where local clinic staff can seek advice from qualified physicians and specialists to whom they would not normally have had access (Sehat case study, cited in Melhem and Tandon 2009).

\section{Implications for policy related to ICTs}

ICTs can enhance the lives and economic opportunities of women in many ways. The widespread dissemination of information in the media on how men and women live their lives in other parts of the world may gradually change gender norms and roles, thus giving women in many countries the chance to live less restricted, more empowered lives. Technology can enhance women's economic opportunities as well as give them more control over their money. However, for this to happen, women must have access to these technologies, and the little evidence that is available shows that women are lagging behind men in their access to and use of ICTs. This gap implies that women may be less able to reap the direct benefits of having access to, for example, distance-learning opportunities and online agricultural extension services. More research is needed to explore whether and why women in the East Asia and Pacific region may be failing to benefit from these technologies to the same extent as men.

\section{Notes}

1. Exports as a proportion of GDP fell to 68 percent in Vietnam in 2009 due to the global financial crisis, and in Indonesia they rose to over 50 percent during the Asian crisis in the late 1990s.

2. According to neoclassical trade theory, trade liberalization should encourage countries to specialize in the production of goods in which they have a comparative advantage. Trade liberalization can lead to the expansion of employment in labor-intensive industries in developing economies. Since women are overrepresented in labor-intensive sectors, trade liberalization may benefit women by increasing demand for their skills more than those of men, thereby reducing pay differentials between men and women. International trade can also affect women's relative pay by reducing the power of producers to discriminate against female employees, which producers do by paying women less for the same work as men (Becker 1957; Berik, van der Meulen Rodgers, and Zveglich 2004; Schultz 2003). 
3. One cannot draw strong conclusions from the literature relating trade liberalization and wage gaps because gender-differentiated employment impacts after trade liberalization are also likely to directly affect productivity in the wage sector (Schultz 2003).

4. The results of the analysis by Bhalotra and Umana-Aponte (2010) indicate that, in Africa, women lose employment during recessions but, in South Asia, East Asia and the Pacific, and Latin America and the Caribbean, women's employment increases during recessions. This suggests that households use female employment as a financial coping strategy.

5. Evidence shows multiple examples of women working harder during crises in East Asian and Pacific countries. In Indonesia, the 199798 economic crisis increased employment among women, whereas male employment rates fell. These additional female workers were predominantly employed in the informal sector (Frankenberg, Smith, and Thomas 2003). During the 1997-98 East Asian crisis, the initial difference between the total number of hours worked by men and by women widened, meaning that women were increasingly overworked and men underworked in the Philippines (Lim 2000). Turk and Mason (2009) reported that, during the 2009 financial crisis, many women worked longer hours to maintain their household income. In Thailand and Vietnam, women searched for additional work to supplement their primary job, with child care sometimes being taken over by elderly household members or older children.

6. Mongolia is an exception. Women reported an improvement in their domestic relationships because men were working such long hours that they had little time left for fighting (Turk and Mason 2009).

7. For example, in Vietnam's apparel sector, better jobs with higher skill levels are largely held by male workers while sewing jobs are largely done by female workers (Kabeer and Tran 2003).

8. In internal rural to urban migration in China, differences in socioeconomic factors by gender do seem to exist. Migrant women tend to be less educated than rural migrant men, owing to their lower average age and to gender inequalities in educational attainment across rural China (Jacka 2009, cited in IOM 2009).
9. Within the growing export-based, largescale manufacturing and assembly activities in Asian cities, particularly in the garment sector, studies have suggested that employers prefer women because they accept lower wages, are considered more easily controlled, and are considered better able to undertake tasks that involve delicate and intricate finger work as well as repetitive tasks (Hugo 2003).

10. Female migration is complex and contextspecific, and studies show that the effect of migration on women's position is neither wholly positive nor wholly negative. Parrado, Flippen, and McQuiston (2005) argue that migration entails a large change in "structural context." Depending on the "context of reception, the degree of labor market segmentation and the extent to which migrants are isolated in the receiving society, migration may mitigate or reinforce patriarchal gender inequality" (Parrado et al. 2005, page 8).

11. This increase is in part due to the greater number of female migrants than male migrants from Indonesia. The difference in per capita consumption between households with male migrants and female migrants at the outset is not statistically significant, indicating that the difference is not because female migrants come from poorer households. No hard evidence suggests that female migrants earn more than male migrants; instead, female migrants from Indonesia likely earn more now than in the past because of high demand for their labor in the Gulf countries.

12. The numbers may actually be higher because respondents are often reluctant to report this form of abuse.

13. Human trafficking estimates may underrepresent actual numbers because of the elusiveness of the industry.

14. Work opportunities may, however, be lowskilled and precarious and may not be covered by formal labor market regulations. Many women in urban areas are self-employed in the informal sector and in activities that yield low incomes (UNFPA 2007).

15. In Indonesia, men and women ages 15-19 were commuting in equal numbers; beyond the age of 30 , however, the fraction of female commuters decreased (Rachmad, Adji, and Handiyatmo 2010). The change in commuting pattern implies that, during childbearing years, women's labor force participation concentrates in or around the home. 
16. Age dependency ratio is the ratio of elderly dependents (those older than 65) to the working-age population (ages 15-64).

17. However, some question this conclusion (Aboderin 2004; Hermalin 2003). Effects may differ across countries, depending on the interplay between culture, the economy, and the geography of development. A recent study in Thailand, for example, shows that as children migrate to the city, they do not abandon their rural elders (Knodel 2009). As noted earlier, some evidence from China suggests a generational shift in support may be occurring.

18. However, this divergence in views occured only in higher income groups. No generational differences existed among the lower income groups.

19. Qualitative evidence from Cambodia also illustrates how disability status increases vulnerability. In a 2008 World Bank participatory poverty and gender assessment in Siem Reap province, of the 107 households ranked in a participatory wealth ranking exercise by male and female villagers in Dour Dantrei village, 5 were identified as headed by disabled men, with 4 of the 5 ranked as "poor" or "very poor" - a poverty rate of 80 percent of disabled households, compared to a poverty rate of 50 percent for all households (Kuriakose and Kono, 2008).

20. Studies in the United States have consistently found that daughters play a central role in the more time-intensive day-to-day care of elderly parents, whereas sons take on a more managerial role (Dwyer and Coward 1992; Ofstedal, Knodel, and Chayovan 1999).

21. In China evidence shows that the effect of caring for elderly parents on women's labor market experience depended on whether the parents being cared for were the woman's parents (where the effect was insignificant) or her in-laws (where the effect was substantial), suggesting the important role of culture on family relations and obligations (Liu et al. 2008). Cultural differences also affect crossgenerational support across different regions in Indonesia and Vietnam (Friedman et al. 2003; Kreager and Schroder-Butterfill 2009).

22. For example, in Uganda, the Market Information Service Project collected data on the prices of the main agricultural commodities in major market centers and distributed this information to local radio stations to broadcast. Svensson and Yanagizawa (2009) found that better-informed farmers were able to bargain for higher farm-gate prices on their surplus production.

23. Within the region, three self-employment initiatives demonstrate how ICT access can enhance economic opportunities, particularly of women (Melhem and Tandon 2009). In the Philippines, the Sharing Computer Access Locally and Abroad project has set up computer livelihood centers to help give underprivileged young people access to employment opportunities. The project is reported to have resulted in increased Internet access and greater self-esteem and selfconfidence, and 60 percent of the beneficiaries were women. In Malaysia, the e-Homemakers initiative aimed to boost home entrepreneurship by increasing the self-esteem of mothers. In Fiji, the Foundation for Rural Integrated Enterprises and Development aims to increase economic empowerment in marginalized communities through three programs that focus on income generation, saving, and governance. The program uses the Internet to market products developed by the participants of the program, the majority of whom are women.

24. Exposure to television can also have less positive outcomes. For example, it can increase discontent within marriages, resulting in divorce. In Brazil, exposure to soap operas that feature modern values such as female empowerment and emancipation have increased rates of separation and divorce (Chong and La Ferrara 2009). In Indonesia, greater exposure to television and radio was found to reduce social capital, as measured by lower participation in social organizations and lower self-reported community-level trust (Olken 2009).

25. For example, in the United Kingdom, the Open University, which broadcasts lectures over the television and Internet, enables men and women to study on an individually determined schedule. In the United States, 60 percent of the students over age 25 who are engaged in distance learning are women (Kramarae 2001).

26. A cell phone-based literacy and numeracy program implemented in Niger was found to increase adults' math test scores, with the greatest increases being achieved by younger participants, who can acquire new skills using ICT more easily than older people (Aker, Ksoll, and Lybbert. 2010). 


\section{References}

Aboderin, Isabella. 2004. "Intergenerational Family Support and Old Age Economic Security in Sub-Saharan Africa: The Importance of Understanding Shifts, Processes and Expectations." In Living Longer: Ageing, Development and Social Protection, edited by Peter Lloyd-Sherlock. United Nations Research Institute for Social Development (UNRISD) and Zed Books.

ADB (Asian Development Bank). 2004. A Fair Share for Women: Cambodia Gender Assessment. Phnom Penh, Cambodia: United Nations Development Fund for Women (UNIFEM), World Bank, ADB, United Nations Development Programme (UNDP), and the U.K. Department for International Development (DFID).

Aker, Jenny. 2010. "Information from Markets Near and Far: Mobile Phones and Agricultural Markets in Niger." American Economic Journal: Applied Economics 2 (3): 46-59.

- 2011. "Mobile Phones and Economic Development in Africa." Journal of Economic Development 24 (3): 207-32.

Aker, Jenny, Christopher Ksoll, and Travis Lybbert. 2010. “ABC, 123: The Impact of a Mobile Phone Literacy Program on Educational Outcomes." Working Paper 223, Center for Global Development, Washington, DC.

Atkin, David. 2011. "Endogenous Skill Acquisition and Manufacturing in Mexico." Paper presented at the "3rd IZA Workshop: Child Labor in Developing Countries," Mexico City, June 1.

Becker, Gary S. 1957. Economics of Discrimination. Chicago: University of Chicago Press.

Berik, Gunseli. 2000. "Mature Export-Led Growth and Gender Wage Inequality in Taiwan." Feminist Economics 6 (3): 1-26.

- Forthcoming. "Gender Aspects of Trade." In Trade and Employment: From Myths to Facts, edited by M. Jansen, R. Peters, and J. M. Salazar-Xirinachs. Geneva: International Labour Organization-European Commission.

Berik, Gunseli, Yana van der Meulen Rodgers, and Joseph E. Zveglich. 2004. "International Trade and Gender Wage Discrimination: Evidence from East Asia." Review of Development Economics 8 (2): 237-54.

Bernanke, Ben S. 1983. "Nonmonetary Effects of the Financial Crisis in Propagation of the Great
Depression." American Economic Review 73 (3): 257-76.

Bhalotra, Sonia R., and Marcela Umana-Aponte. 2010. "The Dynamics of Women's Labour Supply in Developing Countries." IZA Discussion Paper 4879, Institute for the Study of Labor (IZA), Bonn, Germany.

Black, Sandra, and Elizabeth Brainerd. 2002. "Importing Equality? The Impact of Globalization on Gender Discrimination." Industrial and Labor Relations Review 57 (4): 540-59.

Blank, Lorraine. 2008. "Rapid Youth Assessment in Port Moresby, Papua New Guinea." September 4. http://siteresources.worldbank .org/INTEAPREGTOPSOCDEV/Resources/ 080904PNGUYEPPNGRapidYouthAssessm ent.pdf.

BPS (Badan Pusat Statistik). Indonesia National Labor Force Survey (SAKERNAS). Jakarta, Indonesia.

- Indonesia National Socioeconomic Survey (SUSENAS). Jakarta, Indonesia. ht t p://dds.bps.go.id/eng/aboutus . php?id_subyek=29\&tabel=1\&fl=3.

Braithwaite, Jeanine, and Daniel Mont. 2009. "Disability and Poverty: A Survey of World Bank Poverty Assessments and Implications." ALTER, European Journal of Disability Research 3: 219-32.

Bruni, Lucilla, Andrew Mason, Laura Pabon, and Carrie Turk. 2012. "Gender Impacts of the Global Financial Crisis in Cambodia." Photocopy, World Bank.

Cabegin, E., and M. Alba. 2011. "More or Less Consumption? The Effect of Remittances on Filipino Household Spending Behavior.” Unpublished manuscript, University of the Philippines, Manila.

CNNIC (China Internet Network Information Center) Internet Statistics. Beijing, China. http://www1.cnnic.cn/en/index/0O/index .htm.

- 2011. "Statistical Survey Report on the Internet Development in China. 29th Survey Report.” Beijing, China. http://www1.cnnic .cn/en/index/0O/index.htm.

Chen, Lanyan, and Hilary Standing. 2007. "Gender Equity in Transitional China's Healthcare Policy Reforms." Feminist Economics 13 (3-4): 189-212.

Chong, Alberto, and Eliana La Ferrara. 2009. "Television and Divorce: Evidence from Brazilian Novelas." Journal of the European Economic Association 7 (2-3): 458-68. 
Connelly, Rachel, Kenneth Robert, Zhenzhen Zheng, and Zhenming Xie. 2010. "The Impact of Migration on the Position of Women in Rural China." Feminist Economics 16 (1): 3-41.

Constable, Nicole. 2009. "Migrant Workers and the Many States of Protest in Hong Kong." Critical Asian Studies 41 (1): 143-64.

Davin, Delia. 2004. "The Impact of ExportOriented Manufacturing on the Welfare Entitlements of Chinese Women Workers." In Globalisation, Export-Oriented Employment and Social Policy: Gendered Connections, edited by Shahra Razavi, Ruth Pearson, and Caroline Danloy. London: Palgrave.

de Brauw, Alan, Jikun Huang, Scott Rozelle, Linxiu Zhang, and Yigang Zhang. 2002. "The Evolution of China's Rural Labor Markets During the Reforms." Journal of Comparative Economics 30 (2): 329-53.

Dercon, Stefan, and Pramila Krishnan. 2000. "In Sickness and in Health: Risk Sharing within Households in Rural Ethiopia." Journal of Political Economy 108 (4): 688-727.

Dumont, Jean-Christophe, John P. Martin, and Gilles Spielvogel. 2007. "Women on the Move: The Neglected Gender Dimension of the Brain Drain.” IZA discussion paper No. 2920. Institute for the Study of Labor, Bonn, Germany.

Dwyer, Jeffrey, and Raymond Coward. 1992. "Gender and Family Care of the Elderly: Research Gaps and Opportunities." In Gender, Families, and Elder Care, edited by Jeffrey W. Dwyer and Raymond T. Coward, 151-62. London: Sage.

Enterprise Surveys (database). World Bank, Washington, DC. http://data.worldbank.org/ data-catalog/enterprise-surveys.

Frankenberg, Elizabeth, Victoria Beard, and Mudu Saputra. 1999. "The Kindred Spirit: Ties Between Indonesian Children and Their Parents." Southeast Asian Journal of Social Sciences 27 (2): 65-86.

Frankenburg, Elizabeth, Jed Friedman, Thomas Gillespie, Nicholas Ingwersen, Robert Pynoos, Iip Umar Rifai, Bondan Sikoki, Alan Steinberg, Cecep Sumantri, Wayan Suriastini, and Duncan Thomas. 2008. "Mental Health in Sumatra after the Tsunami." American Journal of Public Health 98 (9): 1671-77.

Frankenberg, Elizabeth, James P. Smith, and Duncan Thomas. 2003. "Economic Shocks, Wealth, and Welfare." Journal of Human Resources 38 (2): 280-321.

Frederick, Stacey, and Cornelia Staritz. 2011. "Background Global Value Chain Country
Papers: Morocco." Background paper for Sewing Success? Employment and Wage Implications of the End of the Multifibre Arrangement, World Bank, Washington, DC.

Friedman, Jed, John Knodel, Bui The Cuong, and Truong Si Anh. 2003. "Gender Dimensions of Support for Elderly in Vietnam." Research on Aging 25 (6): 587-630.

Friedman, Jed, and Duncan Thomas. 2007. "Psychological Health before, during and after a Crisis: Results from Indonesia, 1993-2000." Policy Research Working Paper 4386, World Bank, Washington, DC.

Gaetano, Arianne, and Tamara Jacka, eds. 2004. On the Move: Women and Rural-to Urban Migration in Contemporary China. New York: Columbia University Press.

Gamberoni, Elisa, and José Guilherme Reis. 2011. "Gender-Informing Aid for Trade: Entry Points and Initial Lessons Learned from the World Bank." Economic Premise Note 62, World Bank, Washington, DC.

Goyal, Aparajita. 2010. "Information, Direct Access to Farmers, and Rural Market Performance in Central India." American Economic Journal: Applied Economics 2 (3). doi:10.1257/app.2.3.22.

GSMA Development Fund, the Cherie Blair Foundation, and Vital Wave Consulting. 2010. "Women \& Mobile: A Global Opportunity: A Study on the Mobile Phone Gender Gap in Low- and Middle-Income Countries." London, GSMA.

GSO Vietnam (General Statistics Office of Vietnam). Vietnam Household Living Standards Surveys. General Statistics Office, Hanoi, Vietnam. http://www.gso.gov.vn.

Guzmán, Juan Carlos. 2006. "Trends in International Migration: Is There a Feminization of Migration Flows?” Unpublished manuscript, Gender and Development Group, World Bank, Washington, DC.

Hermalin, Albert. 2003. "Theoretical Perspectives, Measurement Issues, and Related Research." In The Well-Being of the Elderly in Asia: A Four-Country Comparative Study, edited by Albert Hermalin, 101-41. Ann Arbor, MI: University of Michigan Press

HNPStats (Health Nutrition and Population Statistics) database, World Bank, Washington, DC. http://databank.worldbank.org.

Hooyman, Nancy. 1999. "Research on Older Women: Where Is Feminism?” Gerontologist 39 (1): 115-18. 
Hugo, Graeme. 2003. "Urbanisation in Asia: An Overview." Paper prepared for the "Conference on African Migration in Comparative Perspective," Johannesburg, South Africa, June 4-7.

- 2005. "Migration in the Asia-Pacific Region," paper prepared for the Policy Analysis and Research Programme of the Global Commission on International Migration, Geneva.

Human Rights Watch. 2004. "Help Wanted: Abuses against Female Migrant Domestic Workers in Indonesia and Malaysia." Human Rights Watch, New York.

Huyer, Sophia, and Nancy Hafkin. 2007. Engendering the Knowledge Society: Measuring Women's Participation. Montreal: Orbicom.

IFC (International Finance Corporation). 2008. "Special Economic Zones: Performance, Lessons Learned and Implications for Zone Development." IFC Financial and Private Sector Development, Washington, DC.

ILO (International Labour Organization). 2008. "Women's Entrepreneurship Development in Aceh: Impact Assessment." ILO, Jakarta, Indonesia.

INSTRAW (International Research and Training Institute for the Advancement of Women). 1999. Ageing in a Gendered World: Women's Issues and Identities. Santo Domingo, Dominican Republic: INSTRAW.

IOM (International Organization for Migration). 2009. Gender and Labour Migration in Asia. Geneva: IOM.

Jacka, Tamara. 2009. "The Impact of Gender on Rural-to-Urban Migration in China." In Gender and Labour Migration in Asia, edited by IOM, 263-292. Geneva: IOM.

Jampaklay, Aree, John Bryant and Rita Litwiller 2009. "Gender and migration from Cambodia, Laos and Myanmar to Thailand," in Gender and Labour Migration in Asia, edited by IOM, 193-216. Geneva: IOM.

Jensen, Robert. 2007. “The Digital Provide: Information (Technology), Market Performance and Welfare in the South Indian Fisheries Sector." Quarterly Journal of Economics 122 (3): 879-924.

Jensen, Robert, and Emily Oster. 2009. "The Power of TV: Cable Television and Women's Status in India." Quarterly Journal of Economics 124 (3): 1057-94.

Jones, Nicola, Rebecca Holmes, Hannah Marsden, Shreya Mitra, and David Walker. 2009. "Gender and Social Protection in
Asia: What Does the Crisis Change?” Paper presented at the Conference on the Impact of the Global Economic Slowdown on Poverty and Sustainable Development in Asia and the Pacific, Hanoi, Vietnam, September 28-29.

Kabeer, Naila, and Tran, T.V.A. 2003. "Global Production, Local markets: Gender, Poverty and Export Manufacture in Vietnam," Institute of Development Studies, Brighton.

Kang, E. 1999. "Economic Crisis and Trend of Female Labour Market Change." Trend and Prospect 40: 89-111 (in Korean).

Kim, Andrew, and Innwon Park. 2006. "Changing Trends of Work in South Korea: The Rapid Growth of Underemployment and Job Insecurity.” Asian Survey 46 (3): 437-56.

Kim, Haejin, and Paula Voos. 2007. "The Korean Economic Crisis and Working Women." Journal of Contemporary Asia 37 (2): 190-208.

Klasen, Stephan, Tobias Lechtenfeld, and Felix Povel. 2011. "What about the Women? Female Headship, Poverty and Vulnerability in Thailand and Vietnam." Discussion Paper 76, Courant Research Centre Poverty, Equity and Growth, Göttingen, Germany.

Knodel, John. 2009. "Is Intergenerational Solidarity Really on the Decline? Cautionary Evidence from Thailand." Seminar on "Family Support Networks and Population Ageing," Doha, Qatar, June 3-4.

Knodel, John, and Napaporn Chayovan. 2008. "Population Ageing and the Well-Being of Older Persons in Thailand." United Nations Population Fund (UNFPA), New York.

Knodel, John, and Zachary Zimmer. 2009. "Gender and Well-Being of Older Persons in Cambodia." Research Report 09-665, University of Michigan, Population Studies Center, Ann Arbor, MI.

Kong, Mee-Hae. 2007. "Rethinking Women's Status and Liberation in Korea." http://unpan1. un.org/intradoc/groups/public/documents/ APCITY/UNPAN0 07144.pdf, Retrieved September 9, 2011.

Kong, Mee-Hae. 2007. “Rethinking Women's Status and Liberation in Korea." Unpublished paper. http://unpan1.un.org/intradoc/groups/ public/documents/APCITY/UNPAN007144. pdf.

Koolwal, Gayatri, and Dominique van de Walle. Forthcoming. "Access to Water, Women's Work, and Child Outcomes." Economic Development and Cultural Change. (Published previously as Policy 
Research Working Paper 5302, World Bank, Washington, DC, 2010.)

Kramarae, Cheris. 2001. "The Third Shift: Women Learning Online." American Association of University Women Educational Foundation, Washington, DC.

Kreager, Philip, and Elisabeth Schroder-Butterfill. 2009. "Ageing and Gender Preferences in Rural Indonesia." CRA Discussion Paper 0905, University of Southampton Centre for Research on Ageing, England.

Kuriakose, Anne T., and Satoko Kono. 2008. "Empowerment of the Poor in Siem Reap EPSR), Cambodia: Preliminary Participatory Poverty and Gender Assessment (PPGA).” Draft report. World Bank, Washington, DC.

Kusago, Takayoshi, and Zafiris Tzannatos. 1998. "Export Processing Zones: A Review in Need of Update." Social Protection Discussion Paper 9802, World Bank, Washington, DC.

Lee, June. 2005. "Human Trafficking in East Asia: Current Trends, Data Collection, and Knowledge Gaps." International Migration 43: 165-201.

Lim, Joesph Y. 2000. "The Effects of the East Asia Crisis on the Employment of Women and Men: The Philippines Case." World Development 28 (7): 1285-1306.

Liu, Lan, Xiao-yuan Dong, and Xiaoying Zheng. 2010. "Parental Care and Married Women's Labor Supply in Urban China." Feminist Economics 16 (3): 169-192.

Long, Giang Thanh, and Wade D. Pfau. 2008. "The Vulnerability of the Elderly Households to Poverty: Determinants and Policy Implications for Vietnam." VDF Working Paper Series 87, Vietnam Development Forum, Hanoi.

LSB (Lao Statistics Bureau). Lao Expenditure and Consumption Survey. Vientane, Lao PDR. http://www.nsc.gov.la/index. php?option $=$ com_content $\&$ view $=$ article $\&$ id $=$ 50\&Itemid=73\&lang=.

Magnani, Elisabetta, and Anu Rammohan. 2009. "Ageing and the Family in Indonesia: An Exploration of the Effect of Elderly CareGiving on Female Labor Supply." Journal of Income Distribution 18 (3-4): 110-30.

Mason, Karen, and Herbert Smith. 2003. "Women's Empowerment and Social Context: Results from Five Asian Countries." Unpublished paper, World Bank, Washington, DC.

Masud, Jariah, Sharifah Azizah Haron, and Lucy Wamuyu Gikonyo. 2008. "Gender Differences in Income Sources of the Elderly in Peninsular
Malaysia." Journal of Family Economic Issues 29: 623-33.

McKay, Steven. 2006. "The Squeaky Wheel's Dilemma: New Forms of Labor Organizing in the Philippines" Labor Studies Journal 30 (4).

Melhem, Samia and Nidhi Tandon, with Claudia Morrell. 2009. Information and Communication Technologies for Women's Socio-Economic Empowerment. Washington, DC: World Bank.

Menon, Nidhiya, and Yana van der Meulen Rodgers. Forthcoming. "Impact of the 20082009 Twin Economic Crises on the Philippines Labor Market." World Development.

Mont, Daniel, and Nguyen Viet Cuong. 2011. "Disability and Poverty in Vietnam." World Bank Economic Review 25 (2): 323-59. doi: 10.1093/wber/lhr019.

Moser, C. 1993. Gender Planning and Development: Theory, Practice and Training. New York: Routledge.

$\mathrm{Mu}$, Ren, and Dominique van de Walle. 2009. "Left behind to Farm? Women's Labor Re-allocation in Rural China." Policy Research Working Paper 5107, World Bank, Washington, DC.

Munshi, Kaivan and Mark Rosenzweig. 2004. "Traditional Institutions Meet the Modern World: Caste, Gender, and Schooling Choice in a Globalizing Economy," American Economic Review 96 (4): 1225-52.

Murayama, Mayumi, and Nobuko Yokata. 2008. "Revisiting Labour and Gender Issues in Export Processing Zones: The Cases of South Korea, Bangladesh and India." IDE Discussion Paper 174, Institute of Developing Economies, Chiba, Japan.

Ngai, Pau. 2004. "Women Workers and Precarious Employment in Shenzhen Special Economic Zone, China." Gender and Development 12 (2): 29-36.

Nguyen, Trang, and Ririn. Purnamasari. 2011. "Impacts of International Migration and Remittances on Child Outcomes and Labor Supply in Indonesia: How Does Gender Matter?" Policy Research Working Paper 5591, World Bank, Washington, DC.

Noel, Stacey, John Soussan, and Jennie Barron. 2007. "Water and Poverty Linkages in Africa: Tanzania Case Study.” Stockholm Environment Institute, Stockholm.

NSCB (National Statistical Coordination Board) Philippines. 2006. Family Income and Expenditures Survey (FIES) 2006. National 
Statistical Coordination Board, Makati City, Philippines. http://www.nscb.gov.ph/fies/ default.asp.

NSD (National Statistics Directorate) TimorLeste. Timor-Leste Survey of Living Standards. Ministry of Planning and Finance, National Statistics Directorate, Dili, Timor-Leste. http:// dne.mof.gov.tl/TLSLS/AboutTLSLS/index.htm.

NSO Mongolia (National Statistical Office of Mongolia). Living Standards Measurement Survey (LSMS). National Statistical Office, Ulaanbaatar, Mongolia. http://www.nso.mn.

NSO Thailand (National Statistical Office Thailand). Thailand Socio-Economic Survey. Bangkok, Thailand: National Statistical Office. http://web.nso.go.th/tnso.htm.

Ofstedal, Mary Beth, John E. Knodel, and Napaporn Chayovan. 1999. "Intergenerational Support and Gender: A Comparison of Four Asian Countries." Southeast Asian Journal of Social Sciences 27 (2): 21-41.

Ofstedal, Mary Beth, Erin Reidy, and John E. Knodel. 2004. "Gender Differences in Economic Support and Well-Being of Older Asians." Journal of Cross-Cultural Gerontology 19: 165-201.

Olken, Benjamin. 2009. "Do TV and Radio Destroy Social Capital? Evidence from Indonesian Villages." American Economic Journal: Applied Economics 1 (4): 1-33.

Oostendorp, Remco. 2009. "Globalization and the Gender Wage Gap.” World Bank Economic Review 23 (1): 141-61.

Oster, Emily, and Bryce Millet. 2010. "Do Call Centers Promote School Enrollment? Evidence from India.” Working Paper Series 15922, National Bureau of Economics Research, Cambridge, MA.

Paluck, Betsy L., and Donald P. Green. 2009. "Deference, Dissent, and Dispute Resolution: An Experimental Intervention Using Mass Media to Change Norms and Behavior in Rwanda." American Political Science Review 103: 622-44.

Parrado, Emilio A., Chenoa Flippen, and Chris McQuiston. 2005. "Migration and Relationship Power among Mexican Women.” Demography 42 (2): 347-72.

Pierre, Gaelle. 2011. "Recent Labor Market Performance in Vietnam through a Gender Lens.” Policy Research Working Paper 6056, World Bank, Washington, DC.

Piper, Nicola 2009. "Overview." In Gender and Labour Migration in Asia, 21-42. Geneva: IOM.
Punpuing, Sureeporn. 2006. "Female Migration in Thailand: A Study of Migrant Domestic Workers." In Perspectives on Gender and Migration. Bangkok: United Nations Economic and Social Commission for Asia and the Pacific.

Punpuing, Sureeporn, Therese Caouette, Awatsaua Panam, and Khaing Mar Kyaw Zaw 2005. "Migrant Domestic Workers: From Burma to Thailand." Publication 286, Institute for Population and Social Research, Mahidol University, Thailand.

Rachmad, Sri H., Ardi Adji, and Dendi Handiyatmo. 2010. "Gendered Patterns of Urban Commuting with Better Connectivity in Jakarta Megapolitan Area." In Gender, Roads and Mobility in Asia, edited by Kyoko Kusakabe. Rugby, U.K.: Practical Action.

Rammohan, Anu, and Meliyanni Johar. 2009. "The Determinants of Married Women's Autonomy in Indonesia." Feminist Economics 15 (4): 31-55.

Rodriguez, E. R., and E. R. Tiongson. 2001. "Temporary Migration Overseas and Household Labor Supply: Evidence from Urban Philippines." International Migration Review 35 (3): 709-25.

Sabarwal, Shwetlena, Nistha Sinha, and Mayra Buvinic. 2010. "How Do Women Weather Economic Shocks? A Review of the Evidence." Policy Research Working Paper 5496, World Bank, Washington, DC.

Schuler, Sidney Ruth, Farzana Islam, and Elisabeth Rottach. 2010. "Women's Empowerment Revisited: A Case Study from Bangladesh." Development in Practice 20 (7): 840-54.

Schultz, T. Paul. 2003. "Does Globalization Advance Gender Equality?” Paper prepared for the conference "The Future of Globalization: Explorations in Light of Recent Turbulence," New Haven, CT, October 10-11.

Seguino, Stephanie. 1997. "Gender Wage Inequality and Export-Led Growth in South Korea." Journal of Development Studies 34 (2): 102-32.

- 2000. "The Effects of Structural Change and Economic Liberalisation on Gender Wage Differentials in South Korea and Taiwan.” Cambridge Journal of Economics 24 (4): 437-59.

Seguino, Stephanie, and Caren Grown. 2006. "Gender Equity and Globalization: Macroeconomic Policy for Developing Countries." Journal of International Development 18 (8): 1081-104. 
Shastry, Gauri Kartini. 2010. "Human Capital Response to Globalization: Education and Information Technology in India." Working paper, Wellesley College. http://www. wellesley.edu/Economics/gshastry/shastryITandEducation.pdf.

Singhal, Arvind, and Everett M. Rogers. 1999. Entertainment-Education: A Communication Strategy for Social Change. Mahwah, New Jersey: Lawrence Erlbaum.

Sørensen, Ninna Nyberg. 2005. "Migrant Remittances, Development and Gender." DIIS Brief, Dansk Institut for Internationale Studier, Copenhagen.

Standing, Guy. 1999. "Global Feminization Through Flexible Labor.” World Development 27 (3): 583-602.

Strauss, John, and Duncan Thomas. 2008. "Health over the Life Course." In Handbook of Development Economics, edited by T. Paul Schultz and John A. Strauss, Vol. 4. Amsterdam: North Holland.

Summerfield, Gale. 1995. "The Shadow Price of Labour in the Export-Processing Zones. A Discussion of the Social Value of Employing Women in Export Processing in Mexico and China." Review of Political Economy 7 (1): 28-42.

Svensson, Jakob, and David Yanagizawa. 2009. "Getting Prices Right: The Impact of the Market Information Service in Uganda." Journal of the European Economic Association 7 (2-3): 435-45.

Tan, Peck-Leong, and John Gibson. 2010. "The Impacts of Temporary Emigration of LowerSkilled Females on Sending Households in Indonesia." Paper presented at the Sixth Australasian Development Economics Conference.

Tejani, Shirin, and William Milberg. 2010. "Global Defeminization? Industrial Upgrading, Occupational Segmentation and Manufacturing Employment in MiddleIncome Countries." Working paper, Schwartz Center for Economic Policy Analysis, New York.

Thailand Household Socioeconomic Survey 2009, Thailand Household Socioeconomic Surveys, National Statistical Office of Thailand, http:// web.nso.go.th/tnso.htm

Thomas, Duncan, Kathleen Beegle, Elizabeth Frankenberg, Bondan Sikoki, John Strauss, and Graciela Teruel. 2004. "Education in a Crisis" Journal of Development economics 74: 53-85.
Turk, Carolyn, and Andrew Mason. 2009. "Impacts of the Economic Crisis in East Asia: Findings from Qualitative Monitoring in Five Countries." In Poverty and Sustainable Development in Asia: Impacts and Responses to the Global Crisis, edited by A. Bauer and M. Thant. Manila: Asian Development Bank.

UN (United Nations). 2007. "Population Estimates and Projections Section." Fact Sheet Series A. 7 March 2007. UN Department of Economic and Social Affairs (DESA) Population Division, New York.

UN DESA (UN Department of Economic and Social Affairs), Population Division. 2010. World Urbanization Prospects: The 2009 Revision. (CD-ROM). New York: UN.

UNESCAP (Economic and Social Commission for Asia and the Pacific). 2004. "Population Ageing, Focus of Regional Seminar in Macau." Population Headliners No. 302, UNESCAP, New York.

- 2007. "Perspectives on Gender and Migration, Economic and Social Commission for Asia and the Pacific." UNESCAP, New York.

UNFPA (United Nations Population Fund) 2006. State of the World Population 2006: A Passage to Hope-Women and International Migration. New York: UNFPA.

- 2007. State of the World Population 2007: Unleashing the Potential for Urban Growth. New York: UNFPA. http://www.unfpa.org/ swp/2007/.

UNIFEM (United Nations Development Fund for Women). 2005. "Good Practices to Protect Women Migrant Workers.” HighLevel Government Meeting of Countries of Employment, Co-Hosted by the Ministry of Labor, Royal Thai Government, and UNIFEM, East and South-East Asia, Bangkok.

UNPD (United Nations Population Division). 2008. Trends in Total Migration Stock, 2008 Revision (CD-ROM). http://www.un.org/ esa/population/publications/migration/ migration 2008.htm.

Wang, Danning. 2010. "Intergenerational Transmission of Family Property and Family Management in Urban China." China Quarterly 204: 960-79.

Wood, Adrian. 1991. "How Much Does Trade with the South Affect Workers in the North?" World Bank Research Observer 6 (1): 19-36.

World Bank. 2006a. "Cambodia: Women and Work in the Garment Industry." World Bank, Washington, DC. 
- 2006b. "Expanding Job Opportunities for Pacific Islanders through Labour Mobility: At Home and Away." World Bank, Washington, DC.

. 2006c. "Labor Migration in the Greater Mekong Sub-Region: Synthesis Report Phase I,” World Bank, Washington, DC.

- 2008. World Development Report 2009: Reshaping Economic Geography. Washington, DC: World Bank.

—. 2010b. "Mainstreaming Gender in Road Transport: Operational Guidance for World Bank Staff.” Transport Paper 28, World Bank, Washington, DC.

—_. 2011a. "Gender Disparities in Mongolian Labor Markets and Policy Suggestions.” World Bank, Washington, DC.

- 2011b. World Development Report 2012: Gender Equality and Development. Washington, DC: World Bank.

- Forthcoming. International Migration and Development in the East Asia and Pacific Region. Washington, DC: World Bank.

World Development Indicators (WDI) database. World DataBank, World Bank, Washington, DC. http://databank.worldbank.org.

World NGO Forum on Ageing. 2002. "Final Declaration and Recommendations of the World and GOP Forum on Aging." Global Action on Aging. http://www.globalaging .org.
Xie, Xiaolin, Yan Xia, and Xiaofan Liu. 2006. "Family Income and Attitudes Toward Older People in China: Comparison of Two Age Cohorts." Journal of Family Economic Issues 28: 171-82.

Yamanaka, Keiko, and Nicola Piper, eds. 2003. "Gender, Migration and Governance in Asia." Special issue, Asian and Pacific Migration Journal 12 (1-2).

Yamanaka, Keiko, and Nicola Piper. 2005. "Feminised Cross-Border Migration, Entitlements and Civil Action in East and Southeast Asia." Background paper for Gender Equality: Striving for Justice in an Equal World, Geneva: United Nations Research Institute for Social Development (UNRISD).

Yang, Xiushi, and Guomei Xia. 2005. "Risky Sexual Behavior among Female Entertainment Workers in China: Implications for HIV/STD Prevention Intervention." AIDS Education and Prevention 17 (2): 143-56.

Zhan, Heying Jenny. 2004. "Socialization or Social Structure: Investigating Predictors of Attitudes toward Filial Responsibility among Chinese Urban Youth from One and Multiple-Child Families." International Journal of Aging and Human Development 59 (2): 105-24.

Zhang, Heather. 1999. "Female Migration and Urban Labour Markets in Tianjin." Development and Change 30 (1): 21-41. 


\section{Promoting Gender Equality in East Asia and the Pacific: Directions for Policy}

he evidence presented in the preceding chapters has shown that growth and development cannot by themselves end gender disparities in all their dimensions. The evidence has also shown that persistent gender inequalities can exact costs on countries' productivity, income growth, and quality of development. Thus, public policy needs to play a role to reduce gender gaps. East Asian and Pacific countries will benefit from adopting appropriate policies to promote gender equality in endowments, in access to economic opportunities, and in agency. This chapter examines policy approaches to addressing the most serious, persistent, and costly gender disparities. In doing so, it attempts to answer the question: How can public policies and investments promote both gender equality and more effective development?

To show the types of policies and investments that can be most productive, this report has provided evidence on which dimensions of gender disparity tend to close with growth and development in East Asian and Pacific countries and which do not. Rapid growth and development in East Asian and Pacific countries have been accompanied by reduced gender inequalities in the areas of education, health, and female labor force participation, particularly among younger women. Progress toward gender equality in many domains is not automatic. Progress in education, health, and labor force participation has often been uneven, both within and across countries. Several East Asian and Pacific countries still experience the phenomenon of "missing" girls at birth. Women continue to work in less stable employment with lower rates of remuneration. They still possess weaker voice and influence than men. Women remain underrepresented in leadership positions in business and government. In a number of countries, gender-based violence remains prevalent.

The collection of evidence in this report suggests the following broad outlines of a regional strategy to promote gender equality and more effective development:

- Promoting human development remains a priority where gender gaps in education remain large or where health outcomes are poor. Investments in these areas are likely to yield high returns.

- Taking active measures to promote gender equality in economic opportunity can address the disparities that often persist with development. Such measures can 
often yield positive returns to economic productivity, though specific policy priorities depend on the structure of the economy and on which specific constraints are most binding.

- Initiating active measures to close gender gaps in agency across the region-and to protect women from discrimination and violence-will contribute to better developmental decision making and thus to development more broadly.

- Increasing economic integration, increased access to information and communication technologies (ICTs), migration, rapid urbanization, and population aging all bring with them new opportunities and new risks with respect to gender equality. An important role for public policy will be to foster the opportunities while managing the risks.

Interpretation of this proposed strategy should consider two points: that policies can simultaneously influence several domainsendowments, economic opportunity, and agency-and that policies should be contextspecific. First, policy approaches to promote better outcomes with respect to endowments, access to economic opportunities, and agency are likely to be mutually reinforcing. Individual outcomes in these areas are often interdependent. Basic human capital, for example, represents a critical factor in women's (and men's) access to economic opportunity and agency. Therefore, policies and investments that promote equality in education will also contribute to enhanced economic opportunity and agency. Similarly, measures to close gender gaps in voice and influence will enable women (and men) to be more effective agents on their own behalf, whether in pursuit of education, access to resources, or productive employment.

Second, the choice and design of policies should consider national and local realities. The great diversity of the East Asia and Pacific region with respect to gender inequalities will influence policy priorities. For example, even in countries where gender disparities in access to basic education and health services are no longer a dominant concern, special policies and programs may be warranted to address large and persistent gender gaps among specific subgroups of the population (for example, for poor, indigenous, or remote communities). Similarly, current policy priorities for promoting gender equality in economic opportunity will differ across countries, depending on the specific obstacles faced by women and on the structure of the economy (for example, the fraction of the population in agriculture or in the informal sector). Some aspects of women's agency improve with development in East Asian countries, but women in the Pacific Islands tend to experience a severe and persistent lack of agency. As a result, closing gender gaps in agency is a policy priority across the region, and effective measures will differ as a function of a number of factors, including local social norms regarding women's voice and influence, differences in countries' legal systems, societies' tolerance for violence, and so on.

This chapter examines each part of the proposed strategy in turn. To be most effective in reducing gender disparities, policy makers may need to address both systemic problems and gender-specific problems. To the extent possible, the discussion in this chapter will account for the potential costs as well as the benefits of policies. Such trade-offs can be particularly important in the context of labor market interventions. For example, although raising the minimum wage may close gender wage gaps among those employed in the formal sector, the numbers of women the sector can employ may decline. Similarly, affirmative action policies may help to promote female employment, but they can also raise questions about worker productivity and may be negatively perceived in the workplace. Although the evidence reviewed and generated for this report helps to answer many questions about gender and development in the East Asia and Pacific region, many knowledge gaps remain. To that end, the chapter concludes by highlighting a number of areas that deserve additional analytical work. 


\section{Promoting gender equality in human development}

East Asian and Pacific countries vary in the types of challenges they face with respect to gender equality in endowments, as analyzed in chapter 2. Where policies may be used and can have an impact also varies. Using that body of evidence as a basis, this section is organized around four themes: (a) closing persistent gender gaps in human development, (b) reducing gender streaming in education, (c) promoting balanced sex ratios at birth, and (d) addressing male-specific gender issues. Because basic human capital is an important factor for access to economic opportunity and agency, the discussion below will highlight examples where policies to promote equality in education also contribute to enhanced economic opportunity and agency.

\section{Closing persistent gender gaps in human development}

For the few East Asian and Pacific countries with overall low and unequal gender outcomes in education and health (for example, Cambodia, the Lao People's Democratic Republic, and Papua New Guinea), promoting human development remains a policy priority. Education and health outcomes are likely to improve as these countries become wealthier, with higher household income, better service delivery, and better expected employment opportunities. However, countries must act now, because human capital itself is an important engine for growth and can have long-term effects on well-being. For countries with localized gender disparities among certain ethnic groups or lowincome regions, growth in aggregate is not enough to improve outcomes for all subpopulations. Policy makers need to target interventions to these groups. For example, the efforts that have successfully improved human capital for both genders elsewhere in these countries can be replicated for these subpopulations, in combination with complementary interventions that address their specific constraints.
What can be done in this group of countries to provide equal access to education and reduce maternal mortality? Chapter 2 shows that demand-side and supply-side factors are responsible for these countries' poor human capital outcomes. Therefore, the set of education and health policies can range from improving service delivery (for example, through infrastructure, staffing, incentives, and use of information and communication technologies) to demand-side interventions (for example, cash transfers, information campaigns, and accountability). The exact constraints in each country context will influence the choice and sequencing of policies.

\section{Providing equal access to education}

A few countries in the East Asia and Pacific region still face overall low and genderunequal access to education, particularly starting at the secondary level. This problem requires solutions to increase the demand for schooling as well as the capacity and incentives of the education system. Policies to improve education outcomes in generalthat is, addressing systemic constraints-are expected to also improve gender equality as the enrollment gap between genders narrows.

Supply-side solutions can play an important role. Although primary schools are widely available in East Asian and Pacific countries, secondary school availability is a problem in a few countries, including Cambodia and Lao PDR. Those countries should consider building more schools and improve infrastructure in poor and remote areas where distance to school has been identified as a key constraint. These types of interventions, though usually with high up-front costs, can have significant impacts on increasing education and future earnings, as shown in an evaluation of Indonesia's school construction program in the 1970 s (Duflo 2000). Supply-side solutions need to be customized to address the context-specific constraints. Making special provisions for girls, such as private female latrines, may be necessary to ease parents' concern for girls' privacy and safety in school. Particular 
excluded groups such as ethnic minorities may need additional support. Teachers who speak the local language or who come from the relevant ethnic group can serve as role models and relate to the local social norms about educating children.

Innovative use of information and communication technologies (ICTs) in delivering services can enhance learning opportunities for girls and boys and improve the provision of education. The availability of distance learning, for example, can circumvent the constraints of travel for schooling and deliver education to youths who have no access to formal schooling or who have left the formal system. The Flexible Open and Distance Education (FODE) program in Papua New Guinea presents an interesting approach. It helps public distance learning centers provide upper primary- and secondary-level courses in English, mathematics, science, and social sciences. One key component of the project aims to provide FODE centers with appropriate information technology and to train staff members to effectively use that technology in administration, curriculum development, materials production, and teaching and learning activities.

Several demand-side solutions have been shown to work effectively. As discussed in chapter 2, parents in low-income families in Cambodia have difficulty covering the direct and indirect costs of schooling. One way to expand access is to provide financial incentives to attend school. In many developing countries worldwide, evaluation of the impacts of conditional and unconditional cash transfers indicates a significant gain in school enrollment (Fiszbein and Schady 2009). In Cambodia, a scholarship program targeted to girls and a related program targeted to boys and girls from low-income households led to an increase in school enrollment of at least 20 percentage points for both genders (Filmer and Schady 2008, 2009). Cash transfers and scholarship programs for school-age girls can also positively influence their long-term agency. For example, in Malawi and Pakistan, conditional cash transfers and school scholarship programs have been found to delay girls' age of marriage and increase their earning opportunities, which in turn strengthens women's bargaining power within the household (Baird et al. 2009; IEG 2011).

Aside from affordability, school enrollment may be discouraged by the weak incentives of service providers and lack of accountability of the school systems. The 2004 World Development Report called for improving accountability in service delivery, and follow-up work has demonstrated the positive impacts of various measures to encourage and enable parents to hold the school and teachers accountable for their childrens' schooling outcomes (World Bank 2003). Evidence on this aspect has been abundant in other developing countries but is much needed in the East Asia and Pacific region. ${ }^{1}$

\section{Reducing maternal mortality}

The slow improvements in maternal health outcomes in several East Asian and Pacific countries, including Cambodia, Lao PDR, parts of Indonesia, and Timor-Leste, suggest the importance of improving service delivery. Access to pre- and postnatal health facilitiesincluding sufficient infrastructure, especially in rural areas-and improved access to sanitation and potable water are fundamental to improving maternal mortality rates. Therefore, this report recommends continuing efforts to ensure the basic infrastructure and to provide access to safe water. The low rate of births attended by skilled professionals, especially in poor and rural areas in these countries, calls for interventions related to staffing. Impact evaluation evidence shows that performance-based contracting increases staff attendance and, consequently, the use of antenatal care, as shown in the case of Cambodia (see box 6.1). In addition, training and increased allocation of midwives to villages in Indonesia have increased women's body mass index (BMI) and children's birthweight and neonatal health (Frankenberg and Thomas 2001). However, just having more midwives is not enough to ensure and sustain service quality. Malaysia's experience in successfully reducing maternal mortality 


\section{BOX 6.1 Reducing maternal mortality rates through improved staffing and quality of service delivery}

Cambodia Basic Health Service Project. In the late 1990s, Cambodia initiated a performance-based contracting scheme with three service delivery forms: contracting-out, in which the whole service provision was allocated to the contractor; contracting-in, in which an external contractor was hired to improve the existing structure; and a comparison group in which no contracting took place (OECD 2009). Using the initial randomization of the program over 12 districts, Bloom et al. (2006) found that contracting-in significantly increased the likelihood of 24-hour service provision. Both contract forms increased the probability of staff attendance and the existence of supplies and equipment, management quality, and use of public providers. Among other positive health effects, antenatal health care increased by 36 percentage points for pregnant women in contracting-in districts, and both contract forms increased the use of health facilities for delivery (Bloom et al. 2006).

Indonesia Village Midwife Program. Initiated in 1989 , the program aimed at allocating more midwives to villages and exempted delivery fees for poor families (Makowiecka et al. 2008). Using panel data from 1993 and 1997, Frankenberg and Thomas (2001) found that the introduction of a midwife increased the BMI of women in reproductive age relative to the comparison groups. Also, the program has been found to increase birthweight (Frankenberg and Thomas 2001) and reduce neonatal mortality (Shrestha 2007). Although midwife coverage increased in Indonesia, along with the number of safe deliveries, progress in reducing maternal mortality rates has been argued to be below expectations (Dawson 2010). Using data on midwives in Serang and Pandeglang districts, Makowiecka et al. (2008) found that village-based midwives were more likely to have temporary contracts, were less experienced, and had less training than health center midwives. Also, midwives were found to be attracted to urban areas. In addition, Shankar et al. (2008) argued that the lack of practical experience and of training, supervision, and guidance have limited midwife retention and, more important, service quality.

Malaysia. With a reduction of maternal mortality from 1,500 per 100,000 live births in 1930 to less than 58 in 2005 (Dawson 2010), Malaysia constitutes one of the success stories of improving maternal health. Among other factors, the quality and the strict supervision of the midwives by certified nurses, support and guidelines, and training for emergency situations, such as improving the communication between the rural service and hospital staff (Dawson 2010), may explain this success. In addition, traditional birth attendants were also trained, registered, and given tools, and midwives were briefed on the integration with traditional practitioners (Dawson 2010).

Mongolia Maternal Mortality Reduction Strategy. Implemented between 2001 and 2010, this approach is a package of incentives, staffing, and demand-side information campaigns. The package included awareness-raising campaigns, such as radio and television programs about maternal health needs, that were broadcast multiple times a week (Yadamsuren et al. 2010). Initiatives such as the "mother-friendly governor" aimed to strengthen the commitment and rewards of improving maternal mortality-related indicators at the local government level. Several additional measures, such as the provision of attractive contracts to doctors for relocating into remote areas, maternal waiting homes, partial service and transportation cost coverage, and training of doctors and health practitioners, contributed to improving maternal health provision (Yadamsuren et al. 2010). suggests that rigorous training, supervision, and communication support for midwives are also essential factors for quality (Dawson 2010). Box 6.1 discusses these examples in further detail.

Service provision should also respond to noneconomic factors: maternal mortality may be reduced by making service delivery culturally sensitive. As described in chapter 2, norms about birthing practices play a role in birthing decisions and outcomes. Programs such as those in Malaysia and Tonga, which provide guidance to traditional birth attendants on hygiene practices, diagnosis of complicated cases, and the importance of prenatal care, are likely 
to be beneficial. In Malaysia, hospital services have adapted to allow naming rituals for Muslims (Hillier 2003). Studies in Cambodia and Lao PDR recommend building birth huts in the health center to allow privacy and to accommodate the presence of family and relatives (UNFPA 2005).

Financial assistance, such as subsidies or cash transfers, has been shown to improve the use of health services and reduce maternal mortality, given the financial barriers faced by poor women. The Cambodia Health Equity Fund (HEF) combined financial assistance to the poor and an incentive scheme for service providers. In 2007, the fund launched a voucher program to provide poor pregnant women with access to free prenatal and postnatal health care visits and delivery, as well as to cover the transportation costs. At the same time, the government implemented a nationwide incentive system that paid midwives and other health care staff an additional US $\$ 12.50$ and US\$15.00 per live birth in hospitals and health care centers, respectively (Ir et al. 2010). Using data from three health districts between 2006 and 2008, Ir et al. (2010) found that deliveries in health facilities increased by 196 percent for HEF voucher beneficiaries.

Policy interventions to improve accountability in service delivery can lead to increased use of maternal care services, as indicated by evidence from other parts of the world. In Uganda, community-based monitoring improved the quality and quantity of primary health care services (Björkman and Svensson 2009). In Peru, incentives to service providers, coupled with a mechanism giving citizens a voice to reach policy makers, proved useful: professional attendance for deliveries increased from 58 percent of births in 2000 to 71 percent in 2004 (Cotlear 2006).

\section{Reducing gender streaming in education}

For many East Asian and Pacific countries, most gender issues regarding basic access in education and health have abated with growth and development. If gender disparities in human capital persist in subgroups such as ethnic minorities or low-income regions, interventions such as those discussed earlier need to address the specific constraints faced by these subpopulations. However, visible gender streaming in education remains a direct barrier to gender equality in productive activities, voice, and participation.

Countries can make concerted efforts in education and labor market policies to tackle the current equilibrium of females sorting into lower-paying occupations and lower-productivity sectors, which is partly due to education streaming. The evidence presented in the preceding chapters shows that females shy away from certain fields of study, despite the high economic return, for reasons such as gender norms about school and work, stereotyping in school curricula, lack of role models, or lack of information. Although changing norms is very difficult, education systems can at least limit the perpetuating influence of gender-biased norms. What follows is a discussion about promising approaches, but future research needs to provide more rigorous evaluations of these policies.

One possible approach on this agenda is to reduce gender stereotyping in school curricula. Several countries in the region have begun to review and revise teaching materials from a gender perspective, though additional efforts are called for to ensure that the revisions introduced to promote gender-sensitive curricula are systematically applied (UNICEF 2009). For example, in Lao PDR, supplementary learning materials, new gender-sensitive primary education curricula, and textbooks were developed following a gender review and training of curriculum writers. In Vietnam, a review of the current curricula indicated that gender stereotyping was frequent, and isolated examples of good practice (including collaborative behavior between boys and girls) have been highlighted in teaching materials for replication. Piloting and evaluation are important since empirical evidence on the impacts of gender-sensitive curriculum reforms is very limited worldwide, let alone in the East Asia and Pacific region. ${ }^{2}$ 
Revising school and professional training curricula to include better female role models can enable greater agency in the household over time. The formal education system can educate young children on the basic principles of gender equality by integrating these principles into the curricula, introducing the value system early in children's lives, and challenging existing gender-related social norms that are learned outside the classroom. In Indonesia, a recent textbook evaluation shows strong gender bias starting in the sixth grade, with stereotypical gender roles that portray men as income earners and women as homemakers. The evaluation resulted in a recommendation that the government should promote the incorporation of gender equality into the curricula for primary and secondary school to address gender-based violence as well as other social norms that perpetuate gender inequality (Utomo et al. 2009).

Alternatively, policy interventions can actively promote entrance into nontraditional fields of study. Offering scholarships to girls and women to study fields such as engineering or law is one option. Not enough is known about the impact of such scholarships on breaking traditional patterns that are deeply rooted in norms, and small financial incentives may lead to changes only at the margin. Aside from financial incentives, other interesting approaches use female role models and encourage female pupils in nontraditional careers, though evidence of their impacts is usually not available either. ${ }^{3}$ In the United States, the Science Connections (SciCon) program offered monthly science workshops for girls plus a summer science weekend for the family to foster girls' interest in science. After the program, the retention rate from the first to the second workshop rose from only 10 percent to 25-50 percent for different cohorts. The program reportedly also increased girls' knowledge about nontraditional careers in science, self-confidence, interest in science, and motivation to increase their efforts in science-related courses. ${ }^{4}$ The Technical/Engineering Education Quality Improvement Project in India takes another approach to create a gender-friendly environment in science and engineering schools and department. The project expands access to training for female engineering faculty and includes refurbishments to enhance the ability of campuses to serve women students.

Activities to reduce traditional patterns of gender streaming in education are likely to become increasingly important as economies move up the value chain away from laborintensive production. In middle- and higherincome countries in the East Asia and Pacific region, movements up the value chain have typically been accompanied by reductions in the fraction of females working in Special Economic Zones (SEZs). For example, in Malaysia only 40 percent of workers in SEZs are now female, compared to 60 percent two decades ago (Simavi, Manuel, and Blackden 2010). Addressing the skill constraints of workers as countries make the transition up the value chain will require policies ranging from appropriate technical and vocational training among school-age girls and boys to training programs to help retrain workers whose skills are in lower demand.

\section{Promoting balanced sex ratios at birth}

A few countries-China and Vietnam, in particular-should continue their efforts to address the phenomenon of "missing girls" at birth. This problem does not have easy policy solutions since preference for sons is the underlying cause, and certain population policies or access to technology that comes with economic growth can exacerbate the problem. Countries can enact and enforce legal clauses against sex-selective abortion; however, those measures are extremely difficult to implement when societies have strong incentives to select the preferred gender and bypass the law. More promising policy approaches could alter the incentives themselves by enhancing the relative value of daughters as perceived by families.

Relying on economic growth to raise female education and participation in the labor market alone may not suffice, as the Republic of Korea's recent experience suggests. Chung and Das Gupta (2007) argued 
that the impacts of development in Korea since the 1950s influenced son preference through many factors: (a) higher earning prospects increased individuals' independence of family lineage, (b) retirement savings reduced financial dependence on children in old age, (c) urban life setting reduced the focus on traditional filial duty and promoted femaleinclusive social networks, (d) women's greater economic and physical mobility enhanced the value of daughters, and (e) urban life, with assets associated with nonfarm activities and less pressure from customary laws, facilitated gender equity in inheritance. The authors attributed the observed reduction in son preference in larger part to changing social norms (changes in son preference within all education and urban and rural population groups) and in smaller part to increased urbanization and education (changes due to movements between education groups and between urban and rural populations). Their findings suggest that interventions to influence social norms and facilitate the spread of new values work better than relying on raising female education and labor force participation alone. Therefore, policy makers should consider information campaigns, financial incentives, and improved social security for the elderly to reduce the imbalance in the sex ratio at birth.

China has been taking public actions to address the unbalanced sex ratio at birth with a package of approaches. Aside from regulations outlawing sex-selective abortion, the nationwide Care for Girls program in China is a well-known media campaign. It started with a pilot in Chaohu from 2000 to 2003 (Li 2007), which combined advocacy and training, along with punishment for discrimination in the form of sex-selective abortions and infanticide. The program achieved its main objectives: the sex ratios at birth in Chaohu fell from 125 boys per 100 girls in 1999 to 114 per 100 in 2002. Some of the program activities asked men to participate in the discussion as well, and encouraged them to help improve women's status in the home and in society (Li 2007). The National Population and Family Planning Commission then scaled up the Chaohu pilot through the national Care for Girls campaign in 24 counties of 24 provinces with severe gender imbalances. This campaign went beyond advocacy and media publicity alone. Direct financial incentives for parents to raise daughters have also been introduced as part of the Care for Girls campaign: families with elderly parents without sons receive an annual allowance of 600 yuan; daughter-only families receive preferential loans; daughters from these families also receive bonus points in college entrance exams. Although the exact attribution to the program's effects has not been evaluated, the sex ratios at birth in these 24 counties fell from 133.8 in 2000 to 119.6 in 2005 (Li 2007).

Improving social security for the elderly can also affect the sex ratio, since families might prefer to have sons in order to receive financial support in old age. Ebenstein and Leung (2010) assessed the impact of the introduction of a rural old-age pension program on sex ratios at birth in China. Using cross-sectional data, they found that the number of sons decreases the likelihood of participating in the pension program. Using a measure of availability of the program at the village level, the authors compared changes in the sex ratios at birth for cohorts born before and after the introduction of the program in 1991. They found that counties in which the pension program is available exhibit smaller increases in the sex ratio at birth.

\section{Addressing male-specific gender issues}

Male gender issues may also hamper countries' growth and development. First, in many parts of the East Asia and Pacific region (for example, China, Fiji, Malaysia, Mongolia, the Philippines, Samoa, and Thailand), countries need to monitor the initial signs of the reverse gender gap in education. Second, in many countries, being born male is the single greatest determinant for tobacco use and a main determinant for harmful alcohol use (WHO 2005, 2007). Such use is harmful for households and societies and warrants the attention of sound 
public policy, since the social costs are usually higher than private costs, which are externalized to other members of the society. Costs to economic growth can be even more severe when combined with the effects of an aging population.

Although this report does not exhaustively cover harmful tobacco and alcohol use, table 6.1 highlights several policy approaches to tackle the challenge inside and outside the region. These measures include policies to reduce the prevalence of alcohol and tobacco use and other policies to reduce the harmful impacts of such use. Taxation and restrictions on sales are usually not very effective in countries where alcohol and tobacco products are mostly sold through informal markets (WHO 2005, 2008).

Policies against tobacco use and excessive alcohol use should consider gender dimensions, gender norms, and cultural values. Gender-specific education and communication approaches may be used to more effectively target men (WHO 2007). Programs expected to decrease the prevalence of smoking include warnings about malespecific health risks of smoking (including reduced potency and fertility), messages about the harmful effects of passive smoking, and campaigns targeting men who are role models to boys, such as fathers, teachers, and peers (WHO 2007). Research from Cambodia, Malaysia, and Vietnam suggest the usefulness of messages that resonate with core social values of responsibility for family welfare, such as reminding the smoker that smoking harms children's health and stressing the role of setting a good example for children (Efroymson and Velasco 2007).

\section{Taking active measures to promote gender equality in economic opportunity}

Gender inequalities in economic opportunities, such as gender wage gaps and the concentration of women and female-led enterprises

\section{TABLE 6.1 Selected policy approaches to tackle excessive tobacco and alcohol use}

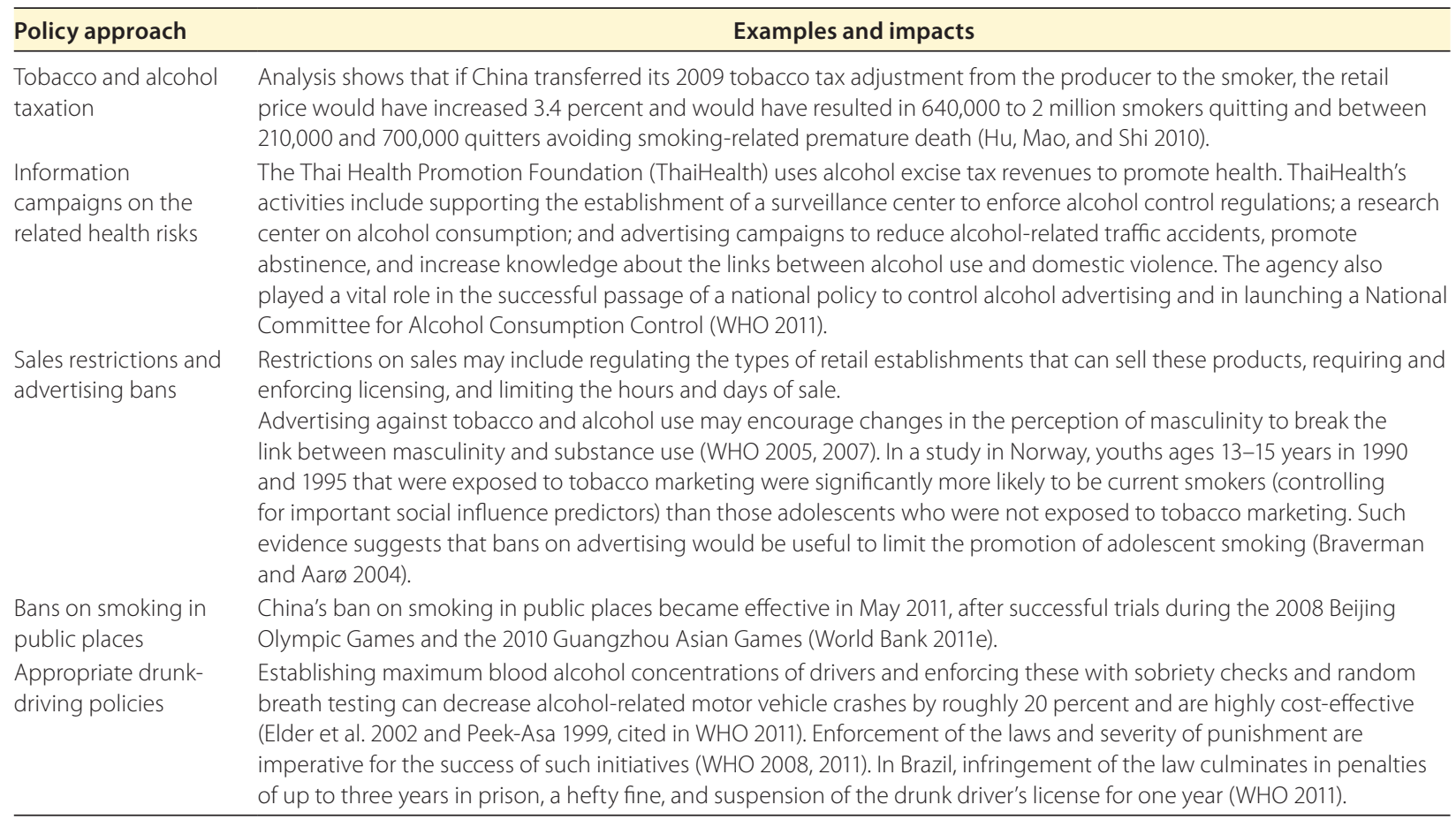


in less-remunerative jobs and sectors, exist in all countries in the region, although the gravity of inequalities and hence policy priorities vary by country. The focus of policies in all countries, however, has a common themeto provide an enabling environment in which women can balance their multiple roles and flourish in their income-generating activities. As discussed in chapter 3, the constraints that infringe on women's ability to flourish as economic actors occur in households, markets, and informal and formal institutions. This section highlights what policy makers can do in these three domains to improve gender equality in economic opportunity. The following sections focus on three primary areas: (a) reducing the time constraints associated with women's household roles, (b) increasing women's access to resources, and (c) establishing a level playing field by reforming institutions. Because the most serious constraints faced by women vary across economies according to economic structure (see chapter 3 ), this section ends with a brief discussion of countries' appropriate policy priorities.

\section{Reducing trade-offs between women's household and market roles}

This report finds that, in all countries, women's household roles affect their decisions as economic actors-for example, they affect the amount of time women are able to devote to market-orientated activities, the types of occupations that they enter into, and the types of enterprises they run. A key policy priority across countries is to reduce the impact of household roles on women's economic lives, a priority that will become increasingly important as aging continues and the demands of caring for elderly family members rise. Addressing women's dual roles is likely to be the most important in contexts where female labor force participation is severely affected by the competing demands for women's time (for example, in Malaysia, the Philippines, and Fiji, where female labor force participation rates drop particularly sharply when they have children).
Although governments cannot directly change the norms that influence gender divisions of domestic responsibilities, policies can work around existing customs and thereby reduce the impact that customs have on women's economic activities. Policies may also indirectly influence divisions of labor within households, for example, by instituting interventions that raise the value of women's market time. ${ }^{5}$

Although household responsibilities infringe upon women's economic activities across all countries, the policy recommendations in this area vary with a country's economic structure. In countries with predominantly rural populations and infrastructural constraints that limit women's access to markets and energy and water sources, policies targeted at improving existing infrastructure will likely have the greatest impact on women's time balance. In countries with a larger urban population, governments should consider policies that increase access to affordable child care, particularly where informal mechanisms for child care are more limited. In countries where the formal sector is increasingly important, addressing parental leave policies will help to level the playing field for men and women and may ameliorate gender divisions of labor within households.

\section{Investing in basic infrastructure and transportation}

In rural or urban areas with limited infrastructure, governments can reduce the time spent on domestic activities by investing in improved water, sanitation, and energy services. These services may release time that can be spent on market work or leisure and increase the income potential or well-being of women. Evidence from around the world suggests that water and electrification projects can reduce the time that women spend collecting water and fuel, and can increase productivity by increasing the length of the working day. ${ }^{6}$ In Lao PDR, evidence suggests that electricity extends the hours available for both productive and leisure activities, particularly for women and girls (World Bank 
2011d). In the Gansu and Inner Mongolia Poverty Reduction Project, the construction of drinking water facilities was found to reduce the workload for women (World Bank 2007b).

Government investment in transport infrastructure can improve access to markets by reducing travel time constraints. Although both women and men benefit from better access to markets, it likely affects the well-being of women more because they have less time to devote to market-oriented activities. In Papua New Guinea, evidence suggests that a road maintenance and rehabilitation program improved the quality of life of remote disadvantaged communities and improved access to markets, particularly for women, who were found to have increased the frequency of market visits and their own incomes generated from market activities (Jusi, Asigau and Laatunen 2007). Recent experience on infrastructure and transportation projects also suggests that the design of infrastructure projects can have important gender implications (box 6.2).

\section{Improving access to affordable child care}

Access to affordable and high-quality childcare options may reduce the amount of time that women spend on care-related activities, particularly among groups of women such as migrants, who have limited access to alternative child-care mechanisms. ${ }^{7}$ The evidence

\section{BOX 6.2 The design of infrastructure projects has important gender dimensions}

Consultations with both men and women can ensure that infrastructure projects meet the needs of both men and women, since use and access to infrastructure varies by gender. For example, many rural women lack access to motorized transport, tend to travel on feeder roads and tracks on foot, or use intermediate means of transport such as donkey carts and bicycles. Conventional rural transport planning has tended to focus on road networks and long-distance transport, which has led to the neglect of the needs of women in rural areas. In Peru, for example, women's participation in economic activities increased in response to a program that focused on upgrading nonmotorized tracks that are predominantly used by women and are not generally covered by traditional road-upgrading programs (Valdivia 2010).

In urban areas, integrating gender-specific needs into the design of urban transport systems can increase access for women. Women are more likely to travel during nonpeak hours and to conduct multiple short trips, which makes using public transport expensive. To make public transportation more accessible to women, fee structures may compensate gender differences in use by providing tickets that allow for multiple stops on a single trip, thereby reducing costs. The transportation system can also be improved to offset social and cultural factors that hinder women's access. For example, to accom- modate the needs of the Muslim majority, Malaysia introduced women-only trains in 2010. In a similar spirit, women-only buses during peak times were introduced to counteract sexual harassment and discomfort among female customers. Jakarta, Indonesia, introduced women-only train compartments on a busy commuter route to address sexual harassment complaints.

Because female-headed households may be subject to greater financial constraints than maleheaded households, gender-blind program design may have gender-differentiated effects. In Lao PDR, the rural electrification project did not reach poor female-headed households at the initial stage. An early assessment of the project suggested that approximately 40 percent of rural households could not afford the connection fees of approximately US $\$ 100$. These households were predominantly poor and were disproportionately headed by women. As a response, a pilot program targeted the poorest households, with a focus on female-headed households. A revolving loan fund provided these households with interest-free loans to cover 80 percent of their costs, and all female-headed households were eligible for support under this fund. Within a few years, electrification rates in pilot areas increased from 63 percent to 90 percent overall, and from 79 percent to 96 percent for female-headed households (Boatman and Chanthalinh 2009). 
presented in chapter 3 suggests that having children affects women's economic opportunities in all countries in the region, although the effects are greatest in urban areas where informal support networks are the most limited. ${ }^{8}$ A lack of child care can affect multiple dimensions of economic opportunities, including labor force participation, the type of job conducted, and gender wage gaps. For example, in Vietnam, a lack of child care has been found to be an important factor that pushes mothers from formal to informal employment (Heymann 2004). In China and Mongolia, reductions in the provision of subsidized child care led to a reduction in female labor force participation in urban areas (Chi and Li 2007; World Bank 2011a).

Policies to promote better access to affordable child care should target those women whose needs are the greatest and who have limited alternative access to child-care facilities. Community child-care centers, particularly those targeted at low-income neighborhoods, have been found to increase maternal employment in a number of countries across the world. Although evidence from the East Asia and Pacific region is limited, evidence from the Organisation for Economic Co-operation and Development (OECD) and the Latin America and Caribbean region suggests that the impact of increasing access to child care on female labor force participation and hours worked varies with, among other things, the availability of alternative caring arrangements and characteristics of families (Attanasio et al. 2004; Blau and Currie 2006; Lefebvre, Merrigan, and Verstraete 2009; Paes de Barros et al. 2010).

Targeting child care toward the needs of mothers is likely to increase its uptake. Programs that have identified and targeted groups with particular needs can increase women's labor force participation while addressing persistent inequalities. In Vietnam, the Community-Based Early Childhood Care and Development project aims to improve child outcomes, with a focus on ethnic minorities and migrant workers (ADB 2010). Migrant workers often have lower access to familial support and informal child-care arrangements, and hence have a substantial need for affordable child-care assistance. In Brazil, publicly provided child care lacked flexibility and had limited facility hours, which limited the impact of child care on women's earnings (Deutsch 1998).

Public policy may also need to tackle negative perceptions about the use of child care. Location-specific social norms may initially limit women's use of child-care services. Comparative analysis of women's labor force participation in Japan and Taiwan, China, noted that disapproval of mothers that rely on alternative child-care arrangements is frequent in Japan, with women being less reluctant to leave young children in the care of others (particularly relatives) in Taiwan, China. In Korea, a study suggested that three-quarters of men and women believe that a preschool-age child will suffer if his or her mother works (Yun-Suk and Ki-Soo 2005).

\section{Instituting parental leave policies}

Parental leave policies may improve gender parity in economic opportunities by enabling and promoting a more equitable division of child-rearing responsibilities between men and women and by allowing women to have the same opportunities as men for advancing their careers. The success of parental leave policies in achieving these goals depends on their design. Poorly designed or incomplete parental care policies can make hiring women, relative to men, more expensive for employers, leading to discrimination or reduced job opportunities for women, while exacerbating or emphasizing gender divisions of labor in the household. The factors that affect the success of parental leave include who pays for the leave-the employer, the employee, or the government; whether a country has provisions for both paternity leave and maternity leave, or covers only maternity leave; and what fraction of wages is received by beneficiaries.

Parental benefits in the region vary considerably by the number of days given, the 
percentage of leave that is paid, who pays for the leave, and whether paternity leave is provided for. Maternity leave is the most commonly found component of work-andfamily policies internationally and in the region. A study of 13 East Asian and Pacific countries found that provisions for maternity leave have been instituted in all the countries examined in the region (World Bank 2010b, 2011g). In the majority of countries studied, maternity leave is paid for by the employer; only in Mongolia, the Philippines, and Vietnam does the government fund maternity leave. Where paternity leave provisions are not in place, policies that grant only employer-paid maternity leave likely will reduce employers' incentives to hire female workers because of the additional costs of hiring women, particularly among younger age groups.

Within the region, only Cambodia, Indonesia, and the Philippines currently have policies for paternity leave. Besides introducing differential hiring costs by gender, the provision of maternity leave policies without similar paternity leave policies will likely reinforce gender differences in child-rearing responsibilities, because the asymmetries in the ability to take time off from work reinforces gender divisions of time. However, even in the presence of gender-neutral parental leave, evidence from the OECD suggests that progress has been slow in encouraging fathers to take any leave, let alone equal leave (Gornick and Hegewisch 2010). ${ }^{9}$ The majority of evidence suggests, however, that providing paternity leave alone is not sufficient to changing the current gender division of child-rearing responsibilities within households; rather, parental leave policy needs to be combined with other approaches to breaking down gender norms regarding household caregiving roles.

\section{Increasing women's access to resources}

Access to land and other productive resources in agriculture and other entrepreneurial sectors is important in all contexts. It becomes an even more salient and binding constraint in many East Asian and Pacific countries where women, despite accumulating sufficient human capital, still face barriers in access to productive assets.

\section{Promoting equal access to land}

Policies aimed at promoting equal access to land for women and men require careful thought because complex legal, social, and economic factors are at play. Although economic growth and income can help women acquire more land in some contexts, improving gender equality in access to land and land ownership does not automatically result from single interventions targeting economic factors. Access to land requires attention to formal property rights, customary systems, and the informal norms and practices that structure access to resources at household, community, and land agency levels. Access to land affects women's economic opportunities, since land is an important productive asset and form of collateral. As with education, access to land assets and income generated from land contribute to women's voice and influence. To that extent, policies promoting equal access to land also affect agency.

Leveling the legal playing field with respect to land ownership is essential. Gender-progressive legal review and reform should take place in all areas that legally infringe on land rights, including family code, inheritance rules, and civil legislation regarding women's rights to land, both within a marriage or consensual union and in cases of family dissolution or divorce (Giovarelli 2006). Explicit language ensuring equal property rights in the law helps avoid interpretation unfavorable to women. For example, Bolivia's 1996 land reform law specifies equity criteria in all land transactions, independent of the civil status of the party involved. The reference to civil status is important because it does not require that a woman be head of household or married to be eligible for land rights (World Bank 2010a).

In addition, countries are likely to benefit from adopting legal changes that actively promote better gender equality in access to 
land. For example, in 2003, Vietnam passed the Land Law, which requests certification of land under the name of both spouses if plots are used by both spouses. Qualitative analysis of impacts in Vietnam suggests that joint titling improves procedures and opportunities for women to access loans; empowers women in case of disputes, given the security of land use rights; and leads to higher mutual decision making (World Bank 2008). Using national survey data from 2004 to 2006, Trung (2008) found that joint land certification increased the working time and decreased the domestic labor burden for women belonging to the Kinh ethnic group. The study also found that joint land certification increased education expenses for daughters relative to sons in rural areas.

Experience from projects suggests several guiding principles to ensure that on-theground implementation of land titling and land administration does not put women at a disadvantage. These guidelines include gender- and socially inclusive land titling policy, procedures, and service delivery, and provision of complementary inputs to new landholders, particularly women (see World Bank 2010a for details). Important capacity building to increase women's legal literacy in relation to land may include sufficient campaigning and outreach to women and men regarding upcoming titling programs, the benefits and risks of land title, and procedures for redress (Harrington 2008). The adoption of these project guidelines in, for example, the Lao Land Titling Project (LTP1 and LTP2) yielded impressive results in improving women's access to land. The project had a special focus on women's awareness of land certificates and titling to women, including the involvement of the Lao Women's Union and a significant number of female staff in land titling agencies. The projects resulted in 38 percent of titles going to women, with a further 29 percent issued jointly to both spouses (Bell 2011). Project procedures should also ensure that women are represented in local titling and adjudication and community mapping processes, for example, through the use of female paralegals and parasurveyors
(World Bank 2010a). Training women in the use of new ICT resources can give them access to tools such as handheld global positioning system devices or mobile land registries for help in developing land cadastres and registering land transactions. The First Kyrgyz Land and Real Estate Registration Project put in place mobile registries for villages located 25 kilometers or more from the local registry office, and the registries traveled to the village either weekly or at the request of the village chief (Harrington 2008). Sufficient training of land agency and titling agency staff in women's and ethnic or other minorities' rights to land, as well as in local norms and practices, can help remove barriers faced by these groups in accessing titling services (World Bank 2010a).

Apart from securing land titles for women, policy makers planning for formal land allocation and designing interventions must understand and consider the gender implications of customary land tenure and use-rights regimes operating in specific communities. ${ }^{10}$ Land titling projects can support the issuance of titles to all rightful heirs to secure women's legal rights, which women can then transfer, gift, trade, or sell as desired (World Bank 2010a). Education regarding the benefits of land ownership is important for potential beneficiaries. Other target audiences for this kind of education include formal organizations-such as state institutions, labor organizations, legal aid organizations, women's organizations, and donors-and informal, customary institutions-such as councils of elders and neighborhood committees (World Bank 2010a).

Public policies should make specific efforts to support women's access to justice in formal and informal systems (including for individual and collective land rights), and to improve women's position in customary, as well as collective, land negotiations. The World Bank's Justice for the Poor program (J4P) aims to improve the delivery of justice services and to support inclusive and fair negotiation processes over customary land dealings, in which women usually are excluded from the decision-making process and receive fewer 
benefits (World Bank 2011c). In Vanuatu, for example, land leasing for tourism, agriculture, and extractive industries has excluded women during formal lease registration and overlooked women's customary access to garden plots or other productive uses. The J4P program used consultations and outreach, including through community drama, to bring the community together to discuss and debate sensitive land issues (Stefanova, Nixon, and Porter 2010). Evaluations of the impacts of such approaches are under way.

\section{Increasing women's access to other}

productive resources in agriculture

Improving female farmers' access to agricultural extension and other services that promote rural livelihoods will improve their income. In rural areas, women often play a leading role in agricultural activities when large numbers of men leave in search of employment in cities. Acquiring knowledge and skills in agriculture and other rural livelihoods can be extremely challenging, particularly when extension services are oriented around traditionally male activities or when training occurs outside of rural villages, limiting female participation. Recent projects have sought to address these issues (box 6.3).

Consultations with female farmers can help to identify gaps in existing service delivery. For example, the Integrated Agriculture Training Project in Papua New Guinea focused especially on gender concerns. The project expanded the number of female agricultural extension agents, incorporated women's needs in the design of the training, and included gender monitoring in the program (box 6.3). ${ }^{11}$

\section{BOX 6.3 Leveling the playing field in access to resources: Lessons from Papua New Guinea and Mongolia}

In Papua New Guinea, men and women have had differentiated access to agricultural extension services for multiple reasons. First, extension and training activities have traditionally focused on the formal commercial agriculture sector, dominated by men, rather than the subsistence and informal agricultural sectors that women are concentrated in (Cahn and Liu 2008). Second, contact between unrelated men and women is not culturally acceptable in Papua New Guinea, further reducing women's access to extension services, which are predominantly provided by men. Third, traveling to training courses can be difficult for women because of time limitations, financial constraints, and fears about safety, particularly for women in very remote villages, where limited transport options are available.

The Integrated Agriculture Training Program (IATP) provided targeted training and information services to men and women in rural areas. The program included a focus on women's needs. Participatory workshops aimed to ensure that women's voices were heard, and that the training needs highlighted by women were included in the selection of topics for training modules. The training content included livelihood, credit and savings, accounting, and management of poultry and commercial vegetables, which particularly reflected women's interests (Cahn and Liu 2008). The program trained both male and female trainers to deliver gender-sensitive modulesby 2005,30 percent of all trainers were female. This allowed course participants to be split into different groups when discussing topics on which men and women had different perspectives or when discussing more sensitive topics, and it also represented women as being capable of taking important roles in agriculture.

In Mongolia, a component of the Gansu and Inner Mongolia Poverty Reduction Project provided improved agricultural and livestock technology packages and upgraded agricultural and livestock support services (World Bank 2007b). Women were consulted during the development of different farm models to ensure that the gender divisions of labor were taken into account in the choice and development of activities. Approximately half of the total project beneficiaries were women, who benefited from women-specific project training and production activities such as cropping and livestock raising. 
ICTs have been successfully used to increase women's access to agricultural technologies. In Indonesia, Nokia Life Tools aims to bridge information gaps for farmers through a text message-based interface. The program works with local agricultural boards to distribute crop and market information and with meteorological departments to get climate and weather information to farmers. The Kenya Farmer Helpline, introduced in 2009 by Kencell, Kenya's largest call center, provides free advice to small-scale farmers. Call center operators provide expert advice in local languages on agricultural practices, from controlling pests, to raising livestock and poultry, to marketing products. Nearly half of the 30,000 farmers reached by the program are women, a substantially higher fraction than are reached through standard agricultural extension services (World Bank 2011f).

\section{Promoting equal access to finance and skills for entrepreneurs}

Distinguishing between systemic constraints to agricultural or entrepreneurial development and gender-specific constraints is crucial for identifying policies that can reduce gender disparities in economic opportunities. In chapter 3, the evidence from the formal sector suggested that broader constraints to business development, such as cumbersome registration procedures, affect both female- and male-led enterprises. Evidence from the informal sector is more limited but, again, suggests that gender differences in selfreported constraints are not necessarily as large as the systemic constraints facing enterprises. Because both the types of constraints facing enterprises and the gender differences in constraints vary substantially across countries, policy makers should focus on gaining a better understanding of the environment facing male- and female-run firms in both formal and informal sectors. ${ }^{12}$

Where gender-specific constraints to enterprise development are found, promoting gender equality in the control of productive assets-including land, financial capital, and information and technologycan help to enhance the productivity of female-led enterprises. Microfinance is the most pervasive approach to increasing access to finance among entrepreneurs, and it has been used extensively throughout the region to target female entrepreneurs.

Efforts to improve access to finance among female entrepreneurs should consider how to move their financial portfolios away from informal sources of credit and toward more formal credit institutions. Because women in many parts of the region have more limited assets that could serve as collateral and also often have more limited credit histories than men, they are more likely to be restricted in their sources of borrowing. For example, in the Pacific, family law and inheritance law have been identified as important constraints affecting women's ability to acquire and harness assets that may be used as collateral (Hedditch and Manuel 2010). Customary laws, in particular, introduce discriminatory practices against women with respect to access to land and property rights.

Beyond addressing financial constraints, governments could implement training programs to improve women's business skills and thereby address gender differences in entrepreneurial capital. For example, the results of a survey of 500 female enterprise owners in Vietnam suggest that female entrepreneurs feel the need to improve their business skills through training and education (IFC and MPDF 2006).

Although greater numbers of women are acquiring higher levels of education and business training, converting the skills acquired through these programs into productive outcomes has remained challenging. Therefore, training programs should address the appropriate skill gaps in target populations. For example, evidence shows that improving life skills had a greater impact on economic outcomes than improving vocational training skills in the Dominican Republic (Ibarrarán, Ripani, and Villa-Lora 2011). The evidence also suggests that the effects of training may vary across existing and aspiring entrepreneurs, and among existing entrepreneurs training may be needed in combination with other assistance to improve outcomes. For 
example, an impact evaluation of business training to female entrepreneurs in Sri Lanka suggests that business training alone may be insufficient to raise outcomes among existing female entrepreneurs, but may be more effective for new entrepreneurs (de Mel, McKenzie, and Woodruff, 2012). The study finds that combining business training with grants has a large impact on short-run business profitability among existing entrepreneurs, but no longer-term impact. Among new entrants, business training was found to increase profitability and improve business practices.

Programs that improve women's access to productive resources have been shown to increase women's self-confidence and empower them to be more actively engaged in society. In Cambodia, the Women's Empowerment Program provides poor women with literacy, leadership, and financial training. Apart from gains in endowments and economic opportunities, the program reports a positive impact on increasing women's voice and influence. For example, several participating women later joined leadership posts at the local level (Rosenbloom 2004). Similarly, an impact assessment of a women's entrepreneurship training program in Aceh, Indonesia, showed that business planning and management training helped to promote greater confidence among women trainees, create or strengthen new social networks, and identify ways to improve the business environment for women (ILO 2008). Other examples of programs that increase women's agency include community-driven development programs and self-help groups. In Indonesia, a community-driven development program named the Kecamantan Development Program contributed to developing the leadership skills of local women through its activities. The program helped develop the capacity of beneficiaries to plan, prioritize, and manage local community investments, as well as developed various livelihood skills to make them self-reliant (World Bank 2009). In India, self-help groups have increased women's assertiveness by offering support mechanisms and resources that develop women's confidence (Suguna 2006).

\section{Establishing an enabling environment for gender equality in the workplace}

Even though the formal sector in many East Asian and Pacific countries is small, governments have a role in strengthening the formal sector work environment to promote gender equality. Policy instruments available to the government include labor regulations, active labor market policies, and even affirmative action policies. Governments can work with the private sector using promising approaches that include improving business procedures or establishing firm certification for genderfriendly work environments.

\section{Promoting gender-equitable labor institutions and practices}

Labor regulations that result in asymmetries in the employability and costs of hiring male and female workers can be found throughout the region. In countries where gaps in discrimination legislation exist, closing those gaps should be made a priority. For example, although the Tongan constitution guarantees equality, it does not contain a specific prohibition on discrimination on the basis of gender (Hedditch and Manuel 2010). The lack of antidiscrimination legislation raises the possibility for women to be treated unfairly by employers.

Protective legislation, though well intentioned, can restrict the employability of women and should be tackled more directly. For example, restrictions on night work for women in the Philippines can reduce the attractiveness of hiring female employees. In addition, several countries in the region restrict the industries that women can work in as a means of protecting them from hazardous conditions. These protective measures can reduce the labor market opportunities of women.

Governments should give priority to tackling the motivating factors behind protective legislation more directly. Employment conditions and protections in industries continuously evolve, thus giving policy makers the opportunity to regularly revisit limitations on women's work in restricted industries in light 
of current safety standards and practices, while increasing protections for both male and female employees. Where the original concerns motivating these policies continue to be valid, for example, where transport safety issues restrict women's movement, governments can undertake measures such as providing safe and reliable transport infrastructure to ensure that women are able to overcome these concerns.

Gaps in the coverage of labor protections imply that certain groups may be at risk of exploitation. Addressing the lack of labor protections covering these groups can help to reduce these infringements. Female migrants in the region tend to be segregated into informal occupations such as domestic work, where they have few labor protections and are more at risk for becoming victims of exploitation. Improving the legal and social protections of female migrants working abroad will better protect those women in isolating and informal positions. Approaches to improve the well-being of migrants are discussed in greater detail later in this chapter.

\section{Establishing active labor market policies}

Active labor market policies can be used to overcome gender-based differences in access to job opportunities. For example, wage subsidies may allow individuals to signal their abilities to future employers and reduce employers' costs to hire female workers whom they may not otherwise have considered, albeit temporarily. This incentive for hiring gives employers the opportunity to reduce stereotypes by directly observing their female workers' skills, and also gives women valuable labor market experience. Promoting female participation in all sectors and in all jobs, at management level and below, is likely to increase information on the competencies of women as leaders within an organization, and may also be a way to establish environments that are more attuned to the issues faced by women. Skills training programs can be used to reduce occupational segregation by encouraging women and men to move into professions outside of gender stereotypes, particularly when paired with apprenticeship opportunities. Evidence within the East Asia and Pacific region on these programs remains limited; however, evidence from other regions suggests some promising lessons (box 6.4).

Efforts to promote female participation and gender equality in the private sector-by training women in leadership and giving them a space to be activists for gender equality-can also play an important role in strengthening women's voice. The Adolescent Girls Initiative (AGI) in countries worldwide is a public partnership with a core focus on leadership that helps young women transition from school to productive employment and active economic participation (World Bank 2011d). In Lao PDR, the AGI has led to the creation of career counseling offices where young women can get information on entering the labor force and long-term career planning.

\section{Using affirmative action policies}

Affirmative action policies, both voluntary and mandatory, can be used as a mechanism to increase the representation of women at all levels of the hierarchy, from entry-level to managerial positions. Evidence on affirmative action from developed countries suggests that voluntary programs may have limited effects on female employment and that, to be effective, programs need to be mandatory and have a credible enforcement mechanism (Holzer and Neumark 2000, World Bank 2011f). In Korea, affirmative action policies were introduced to expand women's employment and to reduce discriminatory practices in 2006 . They were initially implemented for public enterprises and private firms with more than a thousand employees, and was extended after a two year grace period to smaller private firms (Jung and Sung 2012). Firms who failed to meet the specified female employment or female manager ratio criteria were asked to submit an implementation plan, with the goal of raising female representation within the firm. An empirical evaluation of the program has found that it had no significant effect on female participation or on firm performance. The limited impact on female managerial or 


\section{BOX 6.4 The impact of active labor market policies on female employment: Evidence from across the world}

The evidence on the effectiveness of training programs in developing countries is mixed. However, the effects of training programs in developing countries are greater than those in developed countries, where benefits have been modest overall, albeit higher for female workers (Betcherman, Olivas, and Dar 2004; Card et al. 2011). For example, Jóvenes en Acción, a subsidized vocational training program, was found to have had a positive effect on paid employment and earnings, where the effects are principally driven by women (Attanasio, Kugler, and Meghir 2011). In contrast, the first phase of the Juventud y Empleo program in the Dominican Republic, which aimed to increase the employment probability of disadvantaged youth through basic skills training and vocational training, was found to have no effect on employment rates and hours of work (Card et al. 2011).

Broadening skills programs to include softer skills may have positive labor market effects. The Juventud y Empleo program in the Dominican Republic was modified in the second phase to include new life skills. A randomized evaluation of the modified program suggests that the life skills component of the program plays a central role in improving the employment outcomes of young women, who experienced a higher likelihood of having a job, higher wages, and higher job satisfaction approximately 12 to 18 months after the program. The program also had an important effect on reducing pregnancy in young women.

Programs that encourage both men and women to think outside of gender stereotypes are likely to increase the efficiency of allocating talent toward jobs. As discussed earlier in this chapter, just as policies in the education system can help change the traditional gender patterns of what to study and, consequently, what job to do, policies to address occupational segmentation directly in the labor market and in the business environment can also change outcomes for women. For example, a vocational and technical training voucher program in Kenya noted that men almost exclusively choose maledominated courses while females almost exclusively choose female-dominated courses such as hairdressing. To address misconceptions about the returns to vocational training, the program provided its female beneficiaries with information highlighting the large discrepancy between expected earnings from graduates in traditionally male-dominated trades (such as electricians) versus traditionally female-dominated trades (such as seamstresses). In addition, the intervention also used more subjective methods, including a presentation showing successful female car mechanics in Kenya, to encourage women to select training for more lucrative male-dominated trades. An impact evaluation of the program suggests that women given this information were almost 9 percentage points more likely to express interest in a male-dominated course (especially younger and more educated women) and 5 percentage points more likely to enroll in one (Hicks et al. 2011).

Reducing information barriers about female youth may also have a positive effect on labor market outcomes. In Jordan, young female graduates have a higher rate of unemployment than men, in part because of perceptions that women have lower levels of interpersonal and decision-making skills, that women are less productive than men, and that their commitment to the labor market is lower, potentially because of marriage and child rearing (Groh et al. 2012). The New Opportunities for Women pilot program puts forward two policies to overcome these perceived constraints: short-term wage subsidies, in the form of job vouchers equivalent to the minimum wage for six months, and employability skills training, which focuses on interpersonal and professional skills. The skills component focused on softer skills that had been identified as a constraint of young female workers, such as communication, team building, presentations, and business writing. An impact evaluation of the program finds that the soft-skills training had no impact on employment, but that the job vouchers had statistically significant and persistent positive effects on employment of graduates outside the capital, where it almost doubled the employment rates of graduates. In the capital, the wage subsidy was found to have a substantial employment effect in the short-term, but was unable to raise long-term employment prospects for unemployment female youth. 
female employee participation is partly attributed to the near voluntary nature of the program, which lacked an effective penalty for non-compliance and had a weak incentive system (Jung and Sung 2012).

In many countries, the public sector may take the lead in promoting gender-based quotas; this support can act as a signal to the private sector of women's productivity in underrepresented jobs. For example, in 2004 Malaysia introduced a public sector gender quota of 30 percent female representation across all decision-making levels, including positions such as department heads or secretary general (ASEAN 2008; Washington Post 2011). In 2006, 25 percent of women were holding top positions in the public sector; by 2010, this share had risen to 32 percent. The Malaysian government aims for 30 percent of key corporate board positions to be held by women by 2016 (Washington Post 2011).

Evidence suggests that affirmative action policies, particularly at a board level, involve trade-offs. Board diversity has been found to increase the attendance of both male and female board members in the United States, and female board members are more likely to participate as tougher monitors than men on corporate boards (Adams and Ferreira 2009). However, tougher monitoring does not necessarily translate into higher firm value. In the United States, board diversity has had a positive effect on firm value among firms with weaker governance, where greater monitoring may be beneficial, but has had a negative effect among firms with stronger governance.

The design of affirmative action can affect performance, particularly in circumstances where gender differences in the characteristics of the existing workforce imply that individuals with the appropriate skill set may not be available (Pande and Ford 2011). For example, in Norway, corporate board quotas of 40 percent were introduced in 2003 with a short implementation horizon. The Norwegian gender quota was found to decrease firm values, but this effect vanishes once board characteristics are accounted for, suggesting that the reduction in firm value is attributable to the comparatively young age and low job experience of women on Norwegian boards (Pande and Ford 2011). This finding suggests that policy makers may also want to keep the characteristics of the existing workforce in mind when designing affirmative action policies.

\section{Working with the private sector to foster gender equality}

Business formalization procedures that are gender blind may result in gender-differentiated outcomes. In these contexts, procedures should be modified to increase women's ability to operate their businesses on a formal basis. A number of factors, such as the need to juggle household and market roles, cultural restrictions on travel, and lower education levels, may imply that women are less able than men to maneuver complex formalization procedures and may therefore restrict their ability to register their businesses (Simavi, Manuel, and Blackden 2010). Simplifying and reducing the cost of business registration procedures, as well as introducing flexibility in application procedures to minimize the effects of time constraints, are likely to increase the ability of both male and female entrepreneurs to comply with business regulations and registration procedures, but such interventions are likely to have a greater impact on female entrepreneurs.

Encouraging companies to promote greater transparency in recruitment and promotion procedures can level the playing field for women and can help to achieve greater female representation, particularly at a managerial level. Proactive and supportive organizational policies can also help women acquire relevant competencies and move to managerial levels. For example, in 1996, Mongolia Telecom adopted a human resource development plan to reduce the crowding of women at lower levels. The two-pronged strategy included measures to help women cope better with their dual responsibilities at home and at work, and measures to enable the professional development and career growth of women. To help ease the work-family conflict on female 
employees, the company gave assistance to single mothers and financial aid for childbirth and education of children. As a result of these proactive steps, women now constitute over 20 percent of senior managers, compared with just 9 percent when the plan was introduced.

Firm certification has been used to promote gender equality in companies and organizations and to encourage women to reach their labor market potential. One firm certification tool, the Gender Equity Model (GEM), has proved to be successful in promoting equal opportunities for men and women and in overcoming cultural barriers in business practices. This public-private partnership, which was designed and implemented in Mexico, has been replicated in Argentina, Chile, Colombia, the Dominican Republic, and the Arab Republic of Egypt (World Bank 2011b). Firm certification validates and recognizes gender equity actions in private firms. An impartial and independent agency assesses firms' compliance in four areas: recruitment, career advancement, training, and sexual harassment. Findings from the GEM in Mexico show that participating firms have eliminated pregnancy discrimination from recruitment practices, and 90 percent of participating organizations report that workers' performance and productivity have increased (World Bank 2011b). Furthermore, organizations report that promotion of women to managerial positions has increased, although women at the top tier are still rare (World Bank 2011b). Certified firms also are more likely to have processes in place to deal effectively with harassment cases, although workers in certified firms also are more likely to have been victims of some form of harassment. This may also signal that they are more aware that some behaviors are forms of harassment that are inappropriate in the workplace (World Bank 2010c).

\section{Identifying policy priorities to foster equal economic opportunity}

This discussion lays out policy recommendations to address the major barriers constraining women and men in the region from fulfilling their potential in the economic sphere. Although all the policies presented here are important-reducing the trade-offs between women's household and market roles, addressing occupational segmentation, increasing women's access to resources and markets, and establishing an enabling environment for gender equality in the workplace-each country needs to consider its own appropriate policy priorities and policy mix. The guiding principles below recommend a way to prioritize policy actions, depending on the country's economic structure and, therefore, the types of major constraints faced by women.

- In predominantly agricultural economies, the suggested policy priorities are to focus on constraints that affect women in rural areas, such as (a) reducing gender disparities in access to productive resources in agriculture and (b) improving infrastructural services to increase women's access to markets.

- In economies with a heavier focus on manufacturing and services, policies should focus on reducing the constraints faced by women in urban areas and in the formal sector, such as the promotion of women-friendly work practices or affordable child care.

- In all economies, policies need to focus on reducing gender disparities in the constraints faced by enterprises, particularly those in the informal sector. A key priority is to identify constraints that are systemic and those that are genderspecific. Continuing to promote women's access to land will be important in all contexts because land serves as a productive resource, as a form of collateral, and as a status-enhancing asset. In addition, identifying and closing discriminatory labor market regulations and practices to make formal institutions more even handed should be a policy priority at all stages of structural transformation. 


\section{Taking measures to strengthen women's voice and influence}

The evidence presented in chapter 4 suggests that all countries in the East Asia and Pacific region can create opportunities to improve women's agency. In the Pacific Islands, policy priorities include increasing female voice and participation in the public sphere, and addressing pervasive gender-based violence. East Asia must address the increased vulnerabilities specific groups may face-including those who have been trafficked and those who are not protected by the law as a result of plural legal environments. Strengthening women's agency on multiple fronts is likely to have rewards, since increasing women's voice in one domain of agency is likely to have positive repercussions on others.

Measures to increase women's endowments and economic opportunity, such as those described previously, can strengthen their voice within the household and in society. Educated women in good health, with assets and income, are better able to act on their preferences and influence outcomes that affect themselves and others in society. In addition, several other policy approaches can directly promote women's agency and reduce gender-based violence. This section takes a more detailed look at the following areas of policy identified in chapter 4: (a) supporting initiatives to transform gender norms and practices, (b) strengthening the legal and institutional environment, (c) increasing women's access to justice, (d) enabling women's participation in politics and policy making, (e) pursuing a multipronged approach to reducing gender-based violence, and (f) creating space for women's collective agency.

\section{Supporting initiatives to transform gender norms and practices}

Socially constructed gender norms that limit women's ability to act and make choices for themselves are pervasive across the East Asia and Pacific region and affect women's lives through diverse channels-from influencing what they study and the occupations they choose to the societal acceptance of domestic violence and the negative perceptions of women leaders. Although socially constructed norms are difficult to transform directly, evidence from around the world suggests that they can be influenced in several ways, including public information campaigns and the promotion of role models. Policy makers in many East Asia and Pacific countries have an opportunity to promote the evolution of social norms where the societal transformations underpinning rapid urbanization and migration are likely to expose men and women to different models of gender relations.

Approaches that harness the social and structural change occurring in many countries in the region are likely to have a greater influence in changing social norms. Returning migrants are a source of new information and can be influential in changing practices and social gender norms. Returning rural migrants are often better placed than rural residents to question practices and norms that constrain people from exercising their voice and influence. Countries wishing to make positive change in rural areas, where gender stereotypes still predominate, can engage the help of returning migrants. For instance, women from Jiangxi province in China who have experienced migration to the city are more aware of their rights as people and are more knowledgeable about social and health practices, including access to services and modern health care. In Cambodia and China, a number of civil society organizations call upon the experiences and lessons of returning migrants to influence women's decision making on reproductive matters in rural areas.

Providing a forum for successful women to inspire other women and girls can help the evolution of gender perceptions. Women in leadership roles can serve as effective role models for other women and girls. Female teachers are among the first professional women that show girls that being active outside the home is socially acceptable. These women serve as agents of change in the communities they work in by educating and 
socializing children beyond gender stereotypes (Kirk 2006). In Papua New Guinea, for example, pastors are also involved in settling disputes between husbands and wives. They are viewed as role models for youth, while their wives, who typically engage in leadership positions, are viewed as role models for women (World Bank 2011c). Exposure to positive female role models from an early age can help break the cycle of gender inequalities across generations.

Policy makers can also support and encourage mass media outlets such as television, radio, and virtual outlets to promote positive messaging that will help change gender norms. Mass media outlets are used in countries like the Philippines and Vietnam to regularly disseminate messages raising awareness of women's contribution in society. These countries have adopted a more extreme approach of requiring mass media outlets to abide by gender equality principles. In the case of the Philippines, the requirement states that the media must regularly disseminate messages that raise awareness of women's contribution in society and avoid portraying negative female stereotypes. In Vietnam, the government, with the support of donors, is undertaking an information, education, and communication campaign to help curb gender-based violence by redefining male identity with respect to domestic violence. The message is: "Real men don't hit women."

Increasing access to information through new information technology can improve women's agency by increasing their knowledge base and exposing them to broader experiences and social practices. In Malaysia, women used information technology to create self-help cybercommunities to improve their networking opportunities in an environment that was more suitable to their lives and social gender norms. The Malaysian e-Homemakers project is one example of these self-help communities; through the e-Homemakers, women are able to share information on how to start and run a business, and are able to share their experiences in a safe space. In Japan, the government promotes self-help and external help through cybercommunity initiatives; the information provided to women through technology ranges from dealing with domestic violence to promoting women entrepreneurs in the agricultural and fishing industries (Farrell and Wachholz 2003).

\section{Strengthening the legal and institutional environment}

For a country to achieve gender equality in voice and influence, government and civil society must make concerted efforts across multiple fronts. A key element of this approach includes the institution and enforcement of legislation to create an enabling environment for equality of voice and influence regardless of one's gender. Countries should accede to and ratify international conventions that promote gender equality. Although most countries in the East Asia and Pacific region have acceded to and ratified the Convention on the Elimination of all Forms of Discrimination Against Women (CEDAW), Palau and Tonga have not (UNIFEM 2008).

Another important element is to ensure that domestic legislation and the institutions of implementation and enforcement are aligned with countries' commitments. For instance, despite the fact that CEDAW's international mandates are compulsory, many countries have laws that continue to discriminate against women by limiting their human rights. Some countries that have introduced legislation to reflect CEDAW mandates have made the language gender-neutral or exempted some types of violent acts, thus making laws inconsistent with international standards and leaving them open to broad interpretation. For example, legislation introduced in Cambodia and Thailand to address domestic violence contains subjective language that must be interpreted by the courts. In Thailand, a person must show that the perpetrator demonstrated "unethical dominance"; in Cambodia, a man can discipline his wife as long as it is done with compassion.

Another critical component of a multipronged strategy involves strengthening enforcement institutions to create an environment that enables both men and women to 
have voice and influence in the public sphere. Enforcement can be particularly challenging in plural legal environments, as seen in several East Asian and Pacific countries. Programs that increase women's knowledge of the law with respect to violence and human rights and the capacity of justice services to address women's issues contribute to greater safety and security among women in society. The Cambodian Women's Crisis Center (CWCC) began a community program that increases the society's awareness of violence against women and the rights of women, especially of the law on domestic violence and protection that was implemented in 2005. The program promotes initiatives to enforce the law by providing information and training to local authorities and developing community networks. The program has sponsored 63 community education sessions, serving a total of 1,638 participants; 6 training sessions for the police, which trained 150 officers; and 300 legal advice cases. The evaluation of the project shows that the program's targets were met or exceeded. Participants believed that, as a result of the program, the severity and rate of violence were reduced as a result of the education provided on the law, human rights, and the rights of women, and because information on the expected roles of men and women in their marriage were made clear (Weaner 2008).

\section{Increasing women's access to justice}

Programs that increase women's knowledge of the law help them to access the formal justice system and encourage them to exercise agency through formal mechanisms. In Indonesia, a civil society organization supporting women heads of household (PEKKA) helped shed light on the need to provide women with better access to justice services. Implemented by PEKKA and building on existing work by civil society, the Women's Legal Empowerment program encouraged the poor and marginalized (many of them women-headed households) to know and demand fulfillment of their rights while it worked on increasing the capacity of legal and justice institutions to respond. At the village level, the program was implemented by trained paralegals who educated people on the law, in particular, family law and laws on gender-based violence, and provided assistance and advocacy. The result of this effort has contributed to the opening up of spaces for women to voice their rights-not only within the home, but also in local communities-and to demand better justice services from their government. In the long term, the program is expected to improve women's livelihoods, and that of their families, through their increased agency (World Bank 2011c).

Programs can make the judicial system more accessible to women in a variety of ways. Technology can help women access the justice system. For example, mobile courts in rural areas of China and Indonesia provide a solution to the problem of accessibility and security for women who wish to exercise their rights in the legal system but lack transportation to the courts. Courts can also be viewed as financially inaccessible and, in Indonesia, the waiving of court fees for poor and marginalized groups has increased the ability of women to bring their cases to court (World Bank 2011c). The justice system can also adapt to better address the specific needs of women. Countries can institute gender-sensitive training for officials in the system, as well as increase the representation of women within all institutions charged with formulating, implementing, and enforcing the laws. For instance, in Papua New Guinea, female local magistrates have helped raise awareness among their male counterparts of the need to adopt gendersensitive approaches to the cases that come before them (World Bank 2011c). An example of a gender-sensitive consideration is that a female victim of gender-based violence may find it easier to approach a female police officer after an assault than a male police officer.

\section{Enabling women's participation in politics and policy making}

Implementation of political reservation systems has contributed to increasing women's participation in electoral politics in a number of countries. Gender-based political reservation systems seek to reduce obstacles in the 
recruitment process so that more women are attracted to participate in politics, thus adding strength to their collective voice. How these systems work varies across countries. Quotas-one form of reservation-take the form of constitutional changes to reserve a certain number of legislative as well as formal or informal political party posts for women. Such measures have been credited, at least in part, for the increased political and administrative participation of women seen across developing regions. For example, India has endorsed a constitutional amendment that women should constitute onethird of the heads of local governments. In East Asia and the Pacific, China, Indonesia, Korea, Papua New Guinea, Thailand, Vietnam, and, recently, the Cook Islands have all adopted formal or informal measures to promote political representation of women at the local level. For example, in Korea, the Grand National Party voluntarily supports quotas of 30 percent women candidates. At the national level, the law states that political parties must have a list with 50 percent women candidates, and at the local level, the party law of 2002 states that city council elections must aim to have gender parity (Quota Project 2010).

Countries can also consider using informal means of promoting women in politics through incentives instead of formal reservation systems. This route may be more effective in countries where formal reservation systems are likely to be contentious or elicit a political backlash. The argument in favor of formal reservation is that they open doors to women in politics and provide a relatively fast track for women to enter politics. In addition to enabling women to gain experience as office holders, such programs can help to change traditional views about women as political leaders. Evidence from India shows that public opinion about female political leaders improved with increased exposure (Beaman et al. 2009). Similarly, evidence from Italy finds that affirmative action in government has been effective in breaking down stereotypes against women (De Paola et al. 2009). However, active measures to promote women's political participation can prove controversial, as was the case in Timor-Leste, where quotas were not widely accepted. As with affirmative action in the labor market, the public has concerns about the pipeline of qualified candidates, along with possible perceptions about the qualifications of women elected through a reservation system (independent of their actual qualifications).

\section{Pursuing a multipronged approach to reducing gender-based violence}

Reducing discrimination against women and gender-based violence requires action on a number of fronts: efforts to increase women's voice within the household; enactment and enforcement of appropriate legislation and strengthening of women's access to justice; provision of adequate support services for victims of violence; and use of the media to provide information on women's rights, to increase social awareness, and to shift social norms with respect to violence.

Countries should enact and enforce laws that eliminate discrimination and violence against women. By taking a strong stance on gender-based violence legislation and enforcement, countries can make positive strides against gender-based violence in a short time. Cambodia saw a significant decrease in the incidence of domestic violence between 2000 and 2005. This decrease was largely attributed to strong efforts by the country's Ministry of Women's Affairs, which introduced the domestic violence legislation draft in 2001. The legislation was adopted by the National Assembly four years later, in October 2005. The new law criminalized acts of domestic violence, provided for the protection of victims, and allowed neighbors or local organizations to intervene if they witnessed domestic violence. As a complement to the law, women's organizations and other nongovernmental organizations carried out information and dissemination campaigns to help disseminate information on people's basic rights and responsibilities under the law.

Providing adequate access to services and support for victims of violence can include a range of services, from police and judiciary to health and social services. In Malaysia, the 
government established integrated one-stop crisis centers in hospitals that provide easy access to medical care, various social services, and the opportunity to report the crime with specially trained police officers (World Bank 2011f).

Reducing human trafficking also requires a multipronged approach of prevention, protection, and prosecution. Preventing human trafficking can include education, employment, and other services. ${ }^{13}$ People who are likely to be front-line responders in identifying victims of human trafficking should be trained to both identify and safely support victims of such abuse, as well as prepare victims to pass evidence on to investigators (UNIFEM 2005). Governments, with the help of relevant actors, should enact and enforce antitrafficking laws. ${ }^{14}$ Enforcement includes effective legislation and policies that hold traffickers accountable for their crimes to help constrict the industry. Countries' protection policies include providing immediate protection for potential or identified trafficked victims. Policies should address immediate needs such as shelter, medical, psychological, and psychosocial care; food and clothing; and longer-term care and reintegration of the victim. For example, in Taiwan, an antitrafficking law that went into effect in June 2009 provides trafficking victims with continued residency and temporary work permits. These measures enhanced victim treatment and improved victim cooperation in trafficking prosecutions (U.S. Department of State 2010).

\section{Creating space for women's collective agency}

Partnerships with women's business associations can provide a space for women to interact, learn, and advocate for gender equality. Women's business organizations help their members be better equipped to benefit from commercial opening to international markets by providing them with access to a global network of women's business associations, information, and advocacy on their behalf.
Specifically, these organizations can offer access to contacts for sources of credit, training in international trade issues, and mentors, as well as access to the more basic skills of operations management and marketing. As advocates for women's businesses, these organizations help raise awareness among broader international stakeholders about the importance of incorporating women into policy planning (for example, trade pacts). Also, their activism can help to spur laws that provide a level playing field for businesses owned by both genders (Jalbert 2000).

In Cambodia, the Government Private Sector Forum (G-PSF) was established in 1999 to improve the business environment in the country and promote investment. The G-PSF provides a forum for public sector and private sector collaboration in the country. Even though the majority of small businesses in Cambodia are run by women, until recently, women had little voice in the dialogue on small business policy, because female-owned businesses were barely represented in the G-PSF. In this context, the International Finance Corporation, together with Cambodia's Ministry of Women's Affairs, has sponsored an initiative to increase women's participation in the private sector's dialogue with government on how best to enable the growth and productivity of both male- and female-run enterprises. Soon after the gender composition of the G-PSF was changed, new policies addressing the needs of female entrepreneurs were incorporated in the agenda of the forum. As a result of women's participation in the G-PSF, import tariffs and taxes on silk yarn were cut for a period of three years, helping more than 20,000 silk weavers in the country (Simavi 2011).

\section{Fostering new opportunities, managing emerging risks}

A new and important challenge for policy makers will be to help foster emerging opportunities and, in particular, to manage emerging risks associated with increases in economic integration, increased access 
migration, rapid urbanization, population aging, and increased access to ICTs. Many of the emerging opportunities can be fostered through efforts to promote greater gender equality in endowments, economic opportunity, and agency. For example, where gender gaps in access to ICTs are emerging or growing, ensuring that women are able to benefit fully from these new technologies may require active measures similar to those discussed earlier to ensure equality of access to other types of productive resources. Managing emerging risks, however, may require additional policy approaches, such as those discussed in this section.

\section{Economic integration}

Greater economic integration will bring with it increased exposure to employment shocks, which will have gender-differentiated impacts. Addressing the risks associated with greater economic integration will require designing social protection programs that adequately account for the different risks faced by female and male workers. Building on the lessons from recent economic crises, several developing countries, including some within the East Asia and Pacific region, have begun to recognize the gender dimensions of risks and shocks when designing their programs. In Indonesia, for example, a conditional cash transfer program, Keluarga Harapan, targets households with members whose outcomes are particularly vulnerable during times of crisis, such as pregnant and lactating women.

Labor market programs and policies enacted to mitigate crises and their effects are likely to have gender-differentiated impacts. In Cambodia, the construction, garment, and tourism sectors were directly hit by the 2008 global financial crisis. In response, the government promoted short-term vocational training courses for 40,500 laid-off garment factory workers, who were almost entirely women. Furthermore, gender-blind policies in response to crises may not be gender-neutral in the longer term. Indonesia's economic crisis in 1997-98 awakened the pro-labor pressures that led to better enforcement of minimum wages (Narjoko and Hill 2007). Although the minimum wage policy helped narrow gender wage gaps, it decreased female employment, without affecting male employment (Suryahadi et al. 2003).

\section{Migration and trafficking}

Just as female migration throughout the region increases economic opportunities for women, it also creates new concerns about the welfare of female migrants. Protecting female migrants from exploitive situations, including from sex work, human trafficking, and inadequate labor protections, will require a gender-aware approach. Greater protection through improved laws, safety nets, and knowledge transfers will better address the vulnerabilities specific to women traveling abroad. Specific areas for action include improving the legal and social protections of female migrants, strengthening the monitoring and credibility of recruitment agencies, and developing and providing welfare and support services to assist female migrants. Well-developed welfare and support services can provide migrants with gender-specific assistance and safety nets. For example, the Philippines provides counseling, legal assistance, and liaison services to migrant workers in need of assistance. Resource centers with labor officers are established in countries with more than 20,000 Filipino migrant workers; they are open 24 hours a day, 365 days a year, and are staffed with a minimum of four officers. Offices in countries with many Filipina migrants are staffed with more female welfare officers and offer gender-specific assistance (Blokhus 2004). ${ }^{15}$

Governments in both labor-sending and labor-receiving countries should actively address the issue of human trafficking through prevention, protection, and prosecution. Female migrants are the most vulnerable group at risk of being trafficked for prostitution and forced labor. Policies aimed at prevention, protection, and prosecution, as discussed earlier in policies to minimize 
gender-based violence, can assist victims or those at risk of human trafficking.

\section{Rapid urbanization}

Growing urbanization in the East Asia and Pacific region has presented women with increased economic opportunities but also with challenges such as limited access to child care and higher security risks than men in urban areas. The types of policies needed in urban areas are similar to those discussed earlier to ensure equal access to economic opportunity and to reduce gender-based violence. Policy makers need to ensure that child care, education, infrastructure, transportation, and water and sanitation policies take into account women's specific social and cultural needs. Rigorous laws and policies to protect women in urban areas from the risk of violence and exploitation are also warranted.

\section{Population aging}

Rapid population aging in the region is likely to have important gender-differentiated effects because older women may increasingly find themselves living as widows. Along with risks from urbanization and the breakdown of extended family support networks, elderly women are likely to find themselves at increased economic risk, having accumulated relatively few assets and mostly lacking access to formal social security. Old-age income security programs can protect women from destitution. Joint annuities and survivor pensions have been argued to be effective means to compensate and secure women's incomes in old age (World Bank 2001). ${ }^{16}$ Also, equalizing the retirement age for men and women may increase pension coverage among those working in the formal sector. Simulations from Latin America suggest that equalizing retirement ages between men and women can increase pension benefits for women and decrease the male-female pension gap (James, Edwards, and Wong 2003). ${ }^{17}$ In addition, policy makers may consider ways to strengthen elder care to ensure that younger women do not bear an undue burden from caregiving.

\section{Filling knowledge gaps}

Although global and regional evidence on gender and development have provided useful lessons, much remains to be understood empirically to help inform effective public action. Continuing to close data and analytical gaps will be important to better understand policy priorities, the effects of specific interventions, and the costs and benefits of different policy options. Additional genderdisaggregated data and empirical analysis, both on long-standing gender issues and on the gender implications of emerging trends in the region, will enable policy makers to promote both gender equality and more effective development. The following discussion highlights a few priority areas.

First, collecting additional genderdisaggregated data, in many domains, is a key first step to fill knowledge gaps. This action can take place during data collection for administrative purposes or as part of projects, so that countries can monitor progress in gender equality at the national and project levels as well as take corrective actions and perform impact evaluations. Many topics warrant data collection by gender. For example, although land and credit have been identified as important factors affecting productivity and female empowerment, few sources of information are available on individual-level land ownership and access to credit in the region. Similarly, countries need more data on gender differences in access to other productive inputs and services in the agricultural sector. Collecting gender-disaggregated data within the household, including information on individual time use and consumption, would enable researchers to assess the impact of policies such as electrification programs or the provision of child-care services on the well-being and economic outcomes of men and women. Other areas for which countries in the region could collect information include why and to what extent performance of male- and female-owned enterprises differ, 
and how male and female access to technologies varies. Although household surveys provide information on household-level access to the Internet and mobile phones, very limited evidence is available to assess whether males and females have differences in access to ICTs. Further evidence is much needed on the enforcement of antidiscrimination legislation in the workplace and beyond, to monitor whether legislation translates into actions.

Second, additional empirical analysis should help policy makers to understand whether and why specific policy interventions work. The East Asia and Pacific region is behind the curve on conducting impact evaluations, and even further behind on conducting impact evaluations with gender dimensions. For example, rigorous evaluations of curriculum reforms to reduce gender stereotyping as well as evaluations of promising approaches to promote balanced sex ratios at birth would guide countries in such efforts. More rigorous evidence on the impact of extension services-including providing knowledge about new crop varieties and agricultural technologies-for men and women would inform policy makers of the extent to which such services can improve farmers' productivity. Other areas in which impact analysis could contribute to better understanding of policy effectiveness include the following: the long-run impact of gender quotas on firm performance and the impact women have on corporate boards; the effects of youth unemployment programs on girls' and boys' labor market outcomes; gender-differentiated impacts of community-driven development and public works programs in the region; and the effects of various approaches to increasing agency, such as political quotas, role models, and approaches designed to promote communication between spouses to reduce genderbased violence.

\section{Notes}

1. For examples of previous and ongoing research, see http://go.worldbank.org/78EK1G87M0.

2. In the mid-1970s, both the United Kingdom and the United States adopted antidiscrimi- nation legislation pertaining to education (Arnot, David, and Weiner 1999; Madigan 2009; Salisbury and Riddell 2000). Several states passed laws prohibiting the use of gender-stereotyped curricula, and companies producing textbooks developed guidelines to eliminate bias. Although the literature stresses that the review of teaching materials takes a central role in the process of promoting "equal opportunity education," the causal link between curriculum reforms and more gender-equitable education is not straightforward. In particular, curriculum reforms in the United Kingdom and the United States happened within the context of broader social change, in which greater numbers of women participating in the labor market challenged the notion of women's primary role being in the home.

3. For instance, the Finnish project TiNA included special day courses for girls ages 14-16 to provide information about nontraditional female occupations. The project also used female students as role models in the visits to schools (http://tina.tkk.fi/tina_2003/tina_2004_eng/). Another initiative that was launched in the late 1990s in Norway aimed at increasing the number of female students in computer science at the Norwegian University of Science and Technology. The initiative included an information campaign for girls at all high schools in the country. Girls who were interested in a career in computer science were invited to the university for the day, where they met students and professors and received information (http://www.ercim.eu/publication/ Ercim_News/enw38/gjestland.html).

4. OERL Under-Represented Populations Projects (http://oerl.sri.com/reports/up/reportUP_ es.html).

5. Evidence has shown that programs that raise the value of women's time in the workforce affect gender divisions of labor within the household and increase the amount of time women have available for market-oriented activities. In Ecuador, women's increased employment in the cut flower industry led to men's increased participation in housework (Newman 2002). In India, a project that increased the value of women's time by introducing new economic opportunities in agricultural procurement resulted in a decrease in their domestic workload, an increase in mobility, and enhanced decision-making powers within the household (World Bank 2007a). 
6. Quantitative evidence from South Africa suggests that the expansion of electrification raised female employment by nearly 10 percentage points and increased female earnings, but it had no effect on male employment (Dinkelman 2008). Furthemore, the evidence suggests that electrification increased women's market activities by releasing female time from cooking through altered cooking technologies (away from wood-based toward electricity-based cooking).

7. Child-care centers can also play a key role in reducing inequalities in access to nutritional support and mental stimulation among disadvantaged groups, including ethnic minorities and young girls.

8. Although child care services are found throughout the region in a variety of forms-from publicly provided child-care facilities such as the Early Childhood Development Centers in Thailand to child-care centers in factories in the southeast industrial zones in Vietnam (UNICEF 2004; ADB 2010)—-there is clearly a greater and unmet need for affordable child care in many countries.

9. For example, in Austria, France, and Germany, only 2 percent of men participate in leave compared to 90 percent of women (De Henau et al. 2007, cited in Gornick and Hegewisch 2010). Evidence has shown that men are more sensitive to levels of wage replacement than women, suggesting that policies that hope to encourage men's use of parental leave should consider higher wage replacement levels.

10. Individuals often "forum shop" in pressing their land cases, alternating between customary and formal systems, depending on which is expected to decide in their favor. For men, particular advantages can often be gained by using customary systems (Giovarelli 2006).

11. While acknowledging the overall positive effect of the program on women, Cahn and Liu (2008) highlighted several constraints that limited the effectiveness of the project's implementation with regard to gender parity. Except for the credit module, in which men and women participated equally, during 2002-05 female participation was below 20 percent in all other modules. This gap can be explained by the selection process of participants, which disadvantaged women. The selection of participants was made by ward councillors and district rural development officers, who had no gender training and discouraged female participation. Courses were not held in the home village and so involved travel and overnight stays, making women's participation particularly difficult. Finally, educational differences between men and women undermined women's motivation in the mixed learning groups of certain modules.

12. Self-reported constraints might not give the full picture, because firms are likely to report constraints only when they have tried to access a service. For example, firms that have not applied for a loan are unlikely to report the cost of finance as a constraint.

13. The Development and Education Programme for Daughters and Communities (DEPCD), a nongovernmental organization in Thailand, aims to prevent the trafficking of women and children into the sex industry and other exploitive labor situations. The organization targets at-risk youth and their families and educates them through seminars, research workshops, and awareness campaigns at community and local government levels. In addition to education, the organization offers employment alternatives through life skills and vocational skills training programs, in addition to sports activities for children (Smarasinghe and Burton 2007).

14. In the Philippines, the Visayan Foundation works in cooperation with the port authorities to set up institutions that provide protective services against trafficking in seaports of the archipelago. The foundation also promotes information in the seaports about trafficking and engages in local networking to encourage actions against trafficking.

15. To better ensure that women are migrating through legal channels, governments should strengthen the monitoring and credibility of recruitment agencies and overseas employment service providers. In Malaysia, the Private Employment Agency Act of 1981 requires employment agencies to abide by several terms in order for the government to better monitor the recruitment process. Such terms include providing the Labor Department with the details of the migrant domestic workers' and employers' employment contract, checking in on the migrant workers' welfare, and providing the migrant worker with the information of necessary contacts (the employment agency and the 
Labor Department) should employment conflicts or emergencies arise (UNIFEM 2005).

16. The effectiveness of the contributory pension system to increase the well-being of elderly women may be limited in the East Asia and Pacific region since the formal labor market is small and predominantly found in urban areas in many countries in the region. Therefore, gaps in pension coverage between rural and urban areas are likely to be as great as or even greater than gender gaps in coverage within rural and urban areas. For example, evidence from Zhejiang and Gansu provinces in China suggests that 79 percent and 54 percent of men and women, respectively, above age 60 have access to pensions in urban areas, whereas in rural areas only 5 percent and less than 1 percent of men and women, respectively, are covered by pensions (Giles, Wang, and Cai 2011).

17. Pensions can be crucial to safeguard incomes for the most vulnerable groups among the elderly, but they may cause adverse labor supply incentives. Flat non-contributory, minimum pensions and targeted benefits have been found to be particularly beneficial for women (James, Edwards and Wong 2003; Aguila, Attanasio, and Meghir 2011; World Bank 2001). However, minimum guaranteed pensions may reduce formal sector labor market participation (Aguila, Attanasio, and Meghir, 2010). Evidence from urban Zhejiang and Gansu provinces suggests that pension eligibility of urban men and women decreases their likelihood of working by 15.2 and 18.3 percent, respectively. In Indonesia, pension eligibility decreases the probability of working by 23.8 and 24.6 percent for urban men and women, and by 13.2 and 12.6 percent for rural men and women, respectively (Giles, Wang, and Cai 2011).

\section{References}

Adams, Renée, and Daniel Ferreira. 2009. "Women in the Boardroom and Their Impact on Governance and Performance." Journal of Financial Economics 94: 291-309.

ADB (Asian Development Bank). 2010. "Community-Based Early Childhood Care and Development in Viet Nam." Social Protection Project Brief, Asian Development Bank, Manila, Philippines.
Aguila, Emma, Orazio Attanasio, and Costas Meghir. 2011. "Changes in Consumption at Retirement: Evidence from Panel Data." Review of Economics and Statistics 93 (3): 1094-99.

Arnot, Madeleine, Miriam David, and Gaby Weiner. 1999. Closing the Gender Gap: Postwar Education and Social Change. Cambridge, U.K.: Polity Press.

ASEAN (Association of Southeast Asian Nations). 2008. "ASEAN Continues to Empower Women." ASEAN Bulletin. February. http://www.aseansec.org/BulletinFeb-08.htm\#Article-2.

Attanasio, Orazio, Luis Carlos Gomez, Ana Gomez Rojas, and Marcos Vera-Hernandez. 2004. "Child Health in Rural Colombia: Determinants and Policy Interventions." Economics and Human Biology 2 (3): 411-38.

Attanasio, Orazio, Adriana Kugler, and Costas Meghir. 2011. "Subsidizing Vocational Training for Disadvantaged Youth in Colombia: Evidence from a Randomized Trial." American Economic Journal: Applied Economics 3 (3): 188-220.

Baird, Sarah, Ephraim Chirwa, Craig McIntosh, and Berk Ozler. 2009. "The Short-Term Impacts of a Schooling Conditional Cash Transfer Program on the Sexual Behavior of Young Women.” Policy Research Working Paper 5089, World Bank, Washington, DC.

Beaman, Lori, Raghabendra Chattopadhyay, Esther Duflo, Rohini Pande, and Petia Topalova. 2009. "Powerful Women: Does Exposure Reduce Bias?" Quarterly Journal of Economics 124 (4): 1497-1540.

Bell, Keith. 2011. "Integrating Gender Issues into Bank Land Projects: The Experience of South East Asia." Presentation at the Annual World Bank Conference on Land and Poverty, Washington, DC, April 18-20.

Betcherman, Gordon, Karina Olivas, and Amit Dar. 2004. "Impacts of Active Labor Market Programs: New Evidence from Evaluations with Particular Attention to Developing and Transition Countries." Social Protection Discussion Paper 0402, World Bank, Washington, DC.

Björkman, Martina, and Jakob Svensson. 2009. "Power to the People: Evidence from a Randomized Field Experiment on CommunityBased Monitoring in Uganda." Quarterly Journal of Economics 124 (2): 735-69. 
Blau, David, and Janet Currie. 2006. "Preschool, Day Care, and Afterschool Care: Who's Minding the Kids?" In Handbook of the Economics of Education, Volume 2, edited by Eric A. Hanushek and Finis Welch. Amsterdam: North-Holland.

Blokhus, Ingrid. 2004. "Social Protection for Women Migrant Workers: A Comparative Study among Sending Countries." Paper prepared for the World Bank, Jakarta.

Bloom, Erik, Indu Bhushan, David Clingingsmith, Rathavuth Hong, Elizabeth King, Michael Kremer, Benjamin Loevinsohn, and J. Brad Schwartz. 2006. "Contracting for Health: Evidence from Cambodia." http://www.brookings.edu/views/papers/ kremer/20060720cambodia.pdf.

Boatman, Mette Rohr, and Vilaythong Chanthalinh. 2009. "Rapid Assessment of 'Power to the Poor' Pilot Project, Lao PDR Rural Electrification." Unpublished report prepared for the World Bank.

Braverman, Marc T., and Leif Edvard Aarø. 2004. "Adolescent Smoking and Exposure to Tobacco Marketing Under a Tobacco Advertising Ban: Findings From 2 Norwegian National Samples." American Journal of Public Health 94 (7): 1230-38. http://ajph .aphapublications.org/cgi/content/abstract/ 94/7/1230.

Cahn, Miranda, and Mathias Liu. 2008. "Women and Rural Livelihood Training: A Case Study from Papua New Guinea." Gender and Development 16 (1): 133-46.

Card, David, Pablo Ibarrarán, Ferdinando Regalia, David Rosas-Shady, and Yuri Soares. 2011. "The Labor Market Impacts of Youth Training in the Dominican Republic." Journal of Labor Economics 29 (2).

Chi, Wei, and Bo Li. 2007. "Glass Ceiling or Sticky Floor? Examining the Gender Pay Gap across the Wage Distribution in Urban China, 1987-2004.” MPRA Paper 3544, University Library of Munich, Germany.

Chung, W., and Monica. Das Gupta. 2007. "The Decline of Son Preference in South Korea: The Roles of Development and Public Policy.” Population and Development Review 33 (4): 757-83.

Cotlear, Daniel. 2006. A New Social Contract for Peru: An Agenda for Improving Education, Health Care, and the Social Safety Net. Washington, DC: World Bank.

Dawson, Angela. 2010. "Towards a Comprehensive Approach to Enhancing the
Performance of Health Workers In Maternal, Neonatal and Reproductive Health at Community Level: Learning from Experiences in the Asia and Pacific Regions." Discussion Paper 2, Human Resources for Health Knowledge Hub, University of New South Wales, Sydney.

de Mel, Suresh, David McKenzie, and Christopher Woodruff. "Business Training and Female Enterprise Start-up, Growth and Dynamics: Experimental Evidence from Sri Lanka." Policy Research Working Paper No. 6145, World Bank, Washington, DC.

De Paola, Maria, Roseeta Lombardo, and Vincenzo Scoppa 2009. "Can Gender Quotas Break Down Negative Stereotypes? Evidence from Changes in Electoral Rules.” Working Paper no. 10-2009. Department of Economics and Statistics, University of Calabria, Cosenza, Italy.

Deutsch, R. 1998. "Does Child Care Pay?: Labor Force Participation and Earnings Effects of Access to Child Care in the Favelas of Rio de Janeiro." IDB Working Paper 384, Inter-American Development Bank, Washington, DC.

Dinkelman, Taryn. 2008. "The Effects of Rural Electrification on Employment: New Evidence from South Africa.” PSC Report 08-653, University of Michigan, Population Studies Center, Ann Arbor.

Duflo, Esther. 2000. "Child Health and Household Resources in South Africa: Evidence from the Old Age Pension Program." American Economic Review 90(2): 393-98.

Ebenstein, Avraham, and Steven Leung. 2010. "Son Preferences and Access to Social Insurance: Evidence from China's Rural Pension Program." Population and Development Review 36 (1): 47-70.

Efroymson, Debra, and Menchi Velasco. 2007. Tobacco Use in Southeast Asia: Key Evidences for Policy Development. Bangkok, Thailand: Southeast Asia Tobacco Control Alliance (SEATCA).

Elder, R. W., R. A. Shults, D. A. Sleet, J. L. Nichols, S. Zaza, R. S. Thompson. 2002. "Effectiveness of Sobriety Checkpoints for Reducing Alcohol-Involved Crashes." Traffic Injury Prevention 3: 266-74.

Farrell, Glen, and Cédric Wachholz. 2003. Meta-survey on the Use of Technologies in Education in Asia and the Pacific 2003-2004. Bangkok, Thailand: UNESCO Asia and Pacific Regional Bureau for Education. 
Filmer, Deon, and Norbert Schady. 2008. Getting Girls into School: Evidence from a Scholarship Program in Cambodia, Economic Development and Cultural Change 56: 581-617.

-. 2009. "School Enrolment, Selection and Test Scores.” Policy Research Working Paper 4998, World Bank, Washington, DC.

Fiszbein, Ariel, and Norbert Schady. 2009. Conditional Cash Transfers: Reducing Present and Future Poverty. Policy Research Report Series. Washington, DC: World Bank.

Frankenberg, Elizabeth, and Duncan Thomas. 2001. "Women's Health and Pregnancy Outcomes: Do Services Make a Difference?" Demography 38 (2): 253-65.

Giles, John, Dewen Wang, and Wei Cai. 2011. "The Labor Supply and Retirement Behavior of China's Older Workers and Elderly in Comparative Perspective.” Policy Research Working Paper 5853, World Bank, Washington, DC.

Giovarelli, Renée. 2006. “Overcoming Gender Biases in Established and Transitional Property Rights Systems." In Land Law Reform: Achieving Development Policy Objectives, edited by John Bruce, 67-106. Washington, DC: World Bank.

Gornick, Janet, and Ariane Hegewisch. 2010. “The Impact of 'Family-Friendly Policies' on Women's Employment Outcomes and on the Costs and Benefits of Doing Business." Commissioned report, World Bank, Washington, DC.

Groh, Matthew, Nandini Krishnan, David McKenzie, and Tara Vishwanath "Soft Skills or Hard Cash? The Impact of Training and Wage Subsidy Programs on Female Youth Employment in Jordan." Policy Research Working Paper No. 6141, World Bank, Washington, DC.

Harrington, Andrew. 2008. "Women's Access to Land and Property Rights: A Review of the Literature. Justice for the Poor Kenya." Report 53001, World Bank, Washington, DC.

Hedditch, Sonali, and Clare Manuel. 2010. "Gender and Investment Climate Reform Assessment: Pacific Regional Executive Summary." International Finance Corporation, Washington, DC.

Heymann, Jody. 2004. "How Are Workers with Family Responsibilities Faring in the Workplace?" International Labour Organization, Geneva. http://ilo-mirror.library .cornell.edu/public/english/protection/ condtrav/pdf/wf-jh-04.pdf.
Hicks, Joan Hamory, Michael Kremer, Isaac Mbiti, and Edward Miguel. 2011. "Vocational Education Voucher Delivery and Labor Market Returns: A Randomized Evaluation Among Kenyan Youth.” Report for the Spanish Impact Evaluation Fund (SIEF) Phase II, World Bank, Washington, DC.

Hillier, Dawn. 2003. Childbirth in the Global Village: Implications for Midwifery Education and Practice. London: Routledge.

Holzer, Harry, and David Neumark. 2000. "What Does Affirmative Action Do?" Industrial and Labor Relations Review 53 (2): 240-71.

$\mathrm{Hu}$, Teh-wei, Zhengzhong Mao, and Jian Shi. 2010. "Recent Tobacco Tax Rate Adjustment and Its Potential Impact on Tobacco Control in China." Tobacco Control 19 (1): 80-82.

Ibarrarán, Pablo, Laura Ripani, and Juan Miguel Villa-Lora. 2011. "Youth Training in the Dominican Republic: New Evidence from a Randomized Evaluation Design.” Technical evaluation prepared for the Inter-American Development Bank, Washington, DC. http:// www.iza.org/conference_files/worldb2011/ ripani_16206.pdf.

IEG (Independent Evaluation Group). 2011. Do Conditional Cash Transfers Lead to Medium-Term Impacts? Evidence from a Female School Stipend Program in Pakistan. Washington, DC: World Bank.

IFC (International Finance Corporation) and MPDF (Mekong Private Sector Development Facility). 2006. "Women Business Owners in Vietnam: A National Survey.” IFC Gender Entrepreneurship Markets Initiative and MPDF, Washington, DC.

ILO (International Labour Organization). 2008. "Women's Entrepreneurship Development in Aceh: Impact Assessment." ILO, Jakarta, Indonesia.

IOM (International Organization for Migration). 2000. "Combating Trafficking in South-East Asia: A Review of Policy and Programme Responses." Migration Research Series 2/2000, IOM, Geneva.

Ir, Por, Dirk Horemans, Narin Souk, and Wim Van Damme. 2010. "Using Targeted Vouchers and Health Equity Funds to Improve Access to Skilled Birth Attendants for Poor Women: A Case Study in Three Rural Health Districts in Cambodia." BMC Pregnancy Childbirth 10: 1. doi:10.1186/1471-2393-10-1.

Jalbert, Susanne. 2000. "Women Entrepreneurs in the Global Economy." Center for International Private Enterprise, Washington, DC. 
James, Estelle, Alejandra Cox Edwards, and Rebeca Wong. 2003. "The Gender Impact of Pension Reform: A Cross-Country Analysis." Policy Research Working Paper 3074, World Bank, Washington, DC.

Jung, Jin Hwa, and Hyo-Yung Sung. 2012. "Affirmative Action in Korea: Its Impact on Women's Employment, Corporate Performance and Economic Growth.” Presented at the 2012 Annual Economic Association in Chicago, January 6-8, 2012.

Jusi, S. Asigau, W. and Laatunen N. 2007. "Social Impact Benefits of Road Rehabilitation Projects in Six Provinces in Papua New Guinea, South Pacific." Photocopy. Finnroad Ltd, in association with SMEC, Helsinki, Finland.

Kirk, Jackie. 2006. The Impact of Women Teachers on Girls' Education-Advocacy Brief. Bangkok: UNESCO Bangkok.

Lefebvre, Pierre, Philip Merrigan, and Matthieu Verstraete. 2009. "Dynamic Labour Supply Effects of Childcare Subsidies: Evidence from a Canadian Natural Experiment on Low-Fee Universal Child Care." Labour Economics 16 (5): 490-502.

Li, Shuzhuo. 2007. "Imbalanced Sex Ratio at Birth and Comprehensive Intervention in China."Paper presented at the " 4 th Asia Pacific Conference on Reproductive and Sexual Health and Rights," Hyderabad, India, October 29-31.

Madigan, Jennifer. 2009. “The Education of Girls and Women in the United States: A Historical Perspective." Advances in Gender and Education 1: 11-13.

Makowiecka, Krystyna, Endang Achadi, Yulia Izati, and Carine Ronsmans. 2008. "Midwifery Provision in Two Districts in Indonesia: How Well Are Rural Areas Served?" Health Policy and Planning 23: 67-75.

Narjoko, Dionisius, and Hal Hill. 2007. "Winners and Losers during a Deep Economic Crisis: Firm-Level Evidence from Indonesian Manufacturing." Asian Economic Journal 21 (4): 343-68.

Newman, Constance. 2002. "Gender, Time Use and Change: The Impact of the Cut Flower Industry in Ecuador." World Bank Economic Review 16 (3): 375-95.

OECD (Organisation for Economic Co-operation and Development). 2009. "Contracting Out Government Services and Functions." OECD Partnership for Democratic Governance, OECD, Paris.
Paes de Barros, R., P. Olinto, M. de Carvalho, T. Lunde, Norbert Schady, S. Santos, and A. Rosalem. 2010. "Impact of Free Childcare on Women's Labor Market Behavior: Evidence from Low-Income Neighborhoods in Rio de Janeiro." Presented at the GAP Workshop on "World Bank Regional Study on Gender Issues in Latin America and the Caribbean," Washington, DC, June 14.

Pande, Rohini, and D. Ford. 2011. "Gender Quotas and Female Leadership: A Review." Background paper for the World Development Report 2012, World Bank, Washington, DC.

Peek-Asa, Corinne. 1999. "The Effect of Random Alcohol Screening in Reducing Motor Vehicle Crash Injuries." American Journal of Preventive Medicine 199916 (1 Suppl): 57-67. http:// www.ncbi.nlm.nih.gov/pubmed/9921387.

Quota Project. 2010. "Republic of Korea Country Overview." Global Database of Quotas for Women. Institute for Democracy and Electoral Assistance (IDEA) and Stockholm University. http://www.quotaproject.org/uid/countryview .cfm?ul=en\&country=122.

Rosenbloom, Jackie. 2004. "Adult Literacy in Cambodia." Pact Cambodia, Phnom Penh. http://www.pactcambodia.org/Publications/ WORTH_Education/Adult_Literacy_in_ Cambodia.pdf.

Salisbury, Jane, and Sheila Riddell, eds. 2000. Gender, Policy and Educational Change: Shifting Agendas in the UK and Europe. London: Routledge.

Shankar, Anuraj, Susy Sebayang, Laura Guarenti, Budi Utomo, Monir Islam, Vincent Fauveau, and Fasli Jalal. 2008. "The Village-Based Midwife Programme in Indonesia." Lancet 371: 1226-28.

Shrestha, Ranjan. 2007. "The Village Midwife Program and the Reduction in Infant Mortality in Indonesia." Paper prepared for the 2007 Meeting of the Population Association of America, New York, March 29-31.

Simavi, Sevi. 2011. "Gender Dimensions of Investment Climate Reform: Operational Perspective." Presentation at the World Bank conference on "Female Entrepreneurship: What Do We Know? What Is Next?” World Bank, Washington, DC, April 6.

Simavi, Sevi, Clare Manuel, and Mark Blackden. 2010. Gender Dimensions of Investment Climate Reform: A Guide for Policy Makers and Practitioners. Washington, DC: World Bank. 
Smarasinghe, Vidyamali, and Barbara Burton. 2007. "Strategising Prevention: A Critical Review of Local Initiatives to Prevent Female Sex Trafficking." Development and Practice 17 (1): 51-64.

Stefanova, Milena, Rod Nixon, and Raewyn Porter. 2010. "Leasing in Vanuatu: Findings and Community Dissemination on Epi Island." Justice for the Poor Briefing Note 5 (4), World Bank, Washington, DC.

Suguna, B. 2006. Empowerent of Rural Women Through Self-Help Groups. Grand Rapids, MI: Discovery.

Suryahadi, Asep, Wenefrida Widyanti, Daniel Perwira, and Sudarno Sumarto. 2003. "Minimum Wage Policy and Its Impact on Employment in the Urban Formal Sector." Bulletin of Indonesian Economic Studies 39 (1): 29-50.

Trung, Le Dang. 2008. "Two-Name Land Use Certificates and Gender Inequality: An Empirical Investigation for Vietnam." DEPOCEN Working Paper 19, Development and Policies Research Center, Hanoi.

UNFPA (United Nations Population Fund). 2005. "Cultural Programming, Reproductive Health Challenges and Strategies in East and South East Asia." UNFPA Country Technical Services Team for East and South-East Asia, Bangkok, Thailand.

UNICEF (United Nations Children's Fund). 2004. "Regional Experience on Integrated Approach to Early Childhood: Six Case Studies in East Asia." UNICEF East Asia and Pacific Regional Office: Bangkok.

- 2009. "Gender Equality in Education, East Asia and the Pacific, Progress Note." UNICEF East Asia and Pacific Regional Office, Bangkok.

UNIFEM (United Nations Development Fund for Women). 2005. "Good Practices to Protect Women Migrant Workers.” Presented at the High-Level Government Meeting of Countries of Employment, co-hosted by the Ministry of Labor, Royal Thai Government, and UNIFEM East and South-East Asia, Bangkok.

- 2008. "A Life Free of Violence: Unleashing the Power of Women's Empowerment and Gender Equality Strategy 2008-2013.” United Nations Development Fund for Women, New York, NY. http://www.unifem .org/attachments/products/EVAWkit_03 _UNIFEMstrategy_en.pdf.
U.S. Department of State. 2010. Trafficking in Persons Report 2010. Washington, DC: U.S. Department of State.

Utomo, Iwu, Peter McDonald, Terence Hull, Ida Rosyidah, Tati Hattimah, Nurul Idrus, Saparinah Sadli, and Jamhari Makruj. 2009. "Gender Depiction in Indonesian School Text Books: Progress or Deterioration." Australian Demographic and Social Research Institute, Australian National University, Canberra.

Valdivia, Martin. 2010. "Contracting the Road to Development: Early Impacts of a Rural Roads Program.” PMMA Working Paper 18. http://ideas.repec.org/p/lvl/pmmacr/2010-18. html.

Washington Post. 2011. "Malaysia Says Women Must Hold 30 Percent of Top Corporate Posts by 2016 for Gender Equality.” June 27.

Weaner, J. 2008. "End of Violence against Women Project: Evaluation Report." UNIFEM, Cambodia Women's Crisis Center, Phnom Penh.

WHO (World Health Organization). 2005. "Gender Health and Alcohol Use." Gender and health information sheet, Department of Gender, Women and Health, WHO, Geneva.

- 2007. "Gender and Tobacco Control: A Policy Brief.” Department of Gender, Women and Health, WHO, Geneva.

- 2008. "Strategies to Reduce the Harmful Use of Alcohol, Report by the Secretariat." Sixty-first World Health Assembly, WHO, Geneva.

—. 2011. "Global Status Report on Alcohol and Health." http://www.who.int/substance_ abuse/publications/global_alcohol_report/ en/.

World Bank. 2001. Engendering Development: Through Gender Equality in Rights, Resources, and Voice. Washington, DC: World Bank.

- 2003. World Development Report 2004: Making Services Work for the Poor. Washington DC: World Bank.

- 2007a. World Development Report 2008: Agriculture for Development. Washington, DC: World Bank.

- 2007b. "Gansu and Inner Mongolia Poverty Reduction Project, Implementation Completion and Results Report.” World Bank, Washington, DC.

- 2008. "Analysis of the Impact of Land Tenure Certificates with Both the Names of 
Wife and Husband in Vietnam: Final Report." World Bank, Washington, DC.

- 2009. "Gender Equality in East Asia: Progress and the Challenges of Economic Growth and Political Change, East Asia Update." World Bank, Washington, DC.

— 2010a. "A Practical Guide for Addressing Gender Concerns in Land Titling Projects.” http://siteresources.worldbank.org/INTARD/ Resources/genderinlandguide.pdf .

- 2010b. Women, Business and the Law 2010: Measuring Legal Gender Parity for Entrepreneurs and Workers in 128 Economies. Washington, DC: World Bank.

- 2010c. Women's Economic Opportunities in the Formal Private Sector in Latin America and the Caribbean: A Focus on Entrepreneurship. Washington, DC: World Bank.

—. 2011a. "Gender Disparities in Mongolian Labor Markets and Policy Suggestions.” World Bank, Washington, DC.

—. 2011b. "Gender Equality as Smart Economics: A Work in Progress." GAP Booklet, World Bank, Washington, DC. - 2011c. Justice for the Poor. World Bank, Washington, DC. http://web.worldbank.org/ W B S I T E / E X T E R N A L / T O P I C S / EXTLAWJUSTICE/EXTJUSFORPOOR/ 0 , contentMDK:21172652 menuPK:3282 951 pagePK:210058 piPK:210062 theSite PK:3282787,00.html.

—. 2011d. "Lao PDR Country Gender Assessment.” World Bank, Washington, DC. - 2011e. Toward a Healthy and Harmonious Life in China: Stemming the Rising Tide of Non-Communicable Diseases. World Bank News \& Views July 26. http://www .worldbank.org/en/news/2011/07/26/ toward-health-harmonious-life-chinastemming-rising-tide-of-non-communicablediseases.

. 2011f. World Development Report 2012: Gender Equality and Development. Washington, DC: World Bank.

-. 2011g. "Women, Business and the Law in East Asia and Pacific Region." A background paper commissioned for Toward Gender Equality in East Asia and the Pacific: A Companion to the World Development Report. Washington, DC: World Bank.

Yadamsuren, Buyanjargal, Mario Merialdi, Ishnyam Davaadorj, Jennifer Harris Requejo, Ana Pilar Betrán, Asima Ahmad, Pagvajav Nymadawa, Tudevdorj Erkhembaatar, Delia Barcelona, Katherine Ba-thike, Robert J Hagan, Richard Prado, Wolf Wagner, Seded Khishgee, Tserendorj Sodnompil, Baatar Tsedmaa, Baldan Jav, Salik R. Govind, Genden Purevsuren, Baldan Tsevelmaa, Bayaraa Soyoltuya, Brooke R. Johnson, Peter Fajans, Paul F. A. Van Look, and Altankhuyag Otgonbold. 2010. “Tracking Maternal Mortality Declines in Mongolia between 1992 and 2007: The Importance of Collaboration." Bulletin of the World Health Organization 88: 192-98.

Yun-Suk, Lee, and Eun Ki-Soo. 2005. "Attitudes towards Married Women's Employment in Korea and Japan: Implications from Latent Class Analyses." Development and Society 34 (1): $125-45$. 



\section{ECO-AUDIT \\ Environmental Benefits Statement}

The World Bank is committed to preserving endangered forests and natural resources. The Office of the Publisher has chosen to print Toward Gender Equality in East Asia and the Pacific: A Companion to the World Development Report on recycled paper with 50 percent postconsumer fiber in accordance with the recommended standards for paper usage set by the Green Press Initiative, a nonprofit program supporting publishers in using fiber that is not sourced from endangered forests. For more information, visit www.greenpressinitiative.org.
Saved:

- 18 trees

- 9 million BTUs of total energy

- 1,608 pounds of net greenhouse gases

- 8,722 gallons of

waste water

- 583 pounds of solid waste 
ver the past few decades, the East Asia and Pacific region has been the most economically dynamic region in the world. Rapid growth, structural transformation, and poverty reduction have been accompanied by unprecedented progress in gender equality in education, health, and participation in the economy. Yet the experience of the region also illustrates that growth and economic development are not enough to attain gender equality in all its dimensions. Women still have less access than men to a range of productive assets and services; substantial employment segregation by gender remains. Women are less likely to work in formal-sector jobs and, despite closing of education gaps, continue to be paid less than men for similar work. Women in East Asia and the Pacific still have a weaker voice and less influence than men in both the private and public spheres. Moreover, women across the region remain vulnerable to gender-based violence, often at the hand of an intimate partner.

Toward Gender Equality in East Asia and the Pacific: A Companion to the World Development Report examines the relationship between gender equality and development, and outlines an agenda for public action to promote more effective and inclusive development in East Asian and Pacific countries. The report argues that gender equality is important in its own right. Promoting gender equality also enhances development. Indeed, the report finds that greater gender equality can enhance productivity and income growth and improve the quality of development decision making, and is an investment in the next generation. For these reasons, there is a critical role for public policy to play in promoting gender equality in the region.

The book contributes to the understanding of gender and development policy making in several important ways. It presents data and evidence drawing upon a newly created database of household surveys, thereby strengthening significantly the empirical basis for policy making. Moreover, the book's analysis focuses on issues particularly relevant to the region. For example, the report examines the gender dimensions of several global trends that are affecting the region's development-increasing economic integration, rising domestic and international migration flows, rapid urbanization, population aging, and rapid use of information and communication technologies. These trends have gender dimensions that are not commonly accounted for by policy makers but which will generate a distinct set of challenges for promoting gender equality going forward.

Drawing from this evidence base, the report identifies four priorities for public action:

- Promoting gender equality in human development where gender gaps in education are large or health outcomes are poor

- Taking active measures to close gender gaps in economic opportunity

- Taking measures to strengthen women's voice and influence-including protecting women from gender-based violence

- Using public policy to foster new opportunities and manage new risks associated with emerging global trends

This book is the second title in the East Asia and Pacific Regional Report Series, a series that presents analyses of issues relevant to the region, drawing on the global knowledge and experience of the World Bank and its partners. This series aims to inform public discussion, policy formulation, and development practitioners' actions, and thereby turn challenges into opportunities. 